\title{
Joachim Hösler
}

\section{Die sowjetische \\ Geschichtswissenschaft \\ 1953 bis 1991}

\section{Studien zur Methodologie- und Organisationsgeschichte}

Verlag Otto Sagner München · Berlin · Washington D.C.

Digitalisiert im Rahmen der Kooperation mit dem DFG-Projekt „Digi20“

der Bayerischen Staatsbibliothek, München. OCR-Bearbeitung und Erstellung des eBooks durch den Verlag Otto Sagner:

http://verlag.kubon-sagner.de

() bei Verlag Otto Sagner. Eine Verwertung oder Weitergabe der Texte und Abbildungen, insbesondere durch Vervielfältigung, ist ohne vorherige schriftliche Genehmigung des Verlages unzulässig. 
Osteuropastudien der Hochschulen des Landes Hessen

\author{
Reihe II
}

\title{
Marburger Abhandlungen zur Geschichte und Kultur Osteuropas
}

Im Auftrag der Philipps-Universität Marburg herausgegeben von

Hans-Bernd Harder und Hans Lemberg

\author{
Band 34
}

Verlag Otto Sagner

München 


\author{
Joachim Hösler
}

\title{
DIE SOWJETISCHE GESCHICHTSWISSENSCHAFT 1953 BIS 1991
}

STUDIEN ZUR METHODOLOGIE- UND

ORGANISATIONSGESCHICHTE

Verlag Otto Sagner $\cdot$ München

1995 
Diese Arbeit wurde mit dem Preis der Albert Osswald-Stiftung 1995 ausgezeichnet.

Bayortsche

8taatsbibliothok

Munction

D 4

ISBN 3-87690-575-3

Copyright by Verlag Otto Sagner, München 1995

Abteilung der Firma Kubon und Sagner, München

Druck: Weihert-Druck GmbH, Darmstadt

$96 P 87690$ Joachim Hösler - 9783954794454 
Meinen Eltern Liselotte und Alfred Hösler 


\section{Vorwort}

Vorliegende Arbeit wurde am 6. Januar 1995 vom Fachbereich Geschichtswissenschaften der Philipps-Universität Marburg als Dissertation angenommen. Herr Prof. Dr. Hans Lemberg hat die Arbeit betreut. Trotz anfänglicher, nicht ganz unberechtigter Bedenken hat er mich in meinem Vorhaben kontinuierlich unterstütz und wirkungsvoll gefördert. Dafür gilt ihm mein besonderer Dank.

Am 6. Januar 1990 war ich nach Moskau aufgebrochen, um auf der Grundlage der Graduiertenförderung des Landes Hessen und mit der Unterstützung des Deutschen Akademischen Austauschdienstes das Forschungsvorhaben zu realisieren. Dr. Robert Maier hat mir damals bei ersten Orientienungsproblemen geholfen und meine Gedanken in vielen freundschaftlichen Kontroversen angeregt. Daran denke ich gerne dankbar zurück. An der Staatlichen Lomonosov-Universität Moskau war mir Herr Dr. Jurij Moškov vom Lehrstuhl für Historiographie und Quellenkunde 1990 und 1992 als wissenschaftlicher Betreuer mit Rat und Tat zur Seite gestanden. Wie ihm so danke ich auch allen in der Einleitung genannten sowjetrussischen Gesprächspartnerinnen und -partnern, die aufgeschlossen und in großzügiger Weise hilfsbereit waren. Mein Dank schließt all die Bibliothekarinnen der Russischen Nationalbibliothek (damals noch Lenin-Bibliothek), der Bibliothek des Instituts zur wissenschaftichen Information für Gesellschaftswissenschaften der Akademie der Wissenschaften, der Gor'kij-Bibliothek, des Zentrums zur Aufbewahrung zeitgeschichtlicher Dokumente sowie der Marburger Bibliotheken ein, die nie müde wurden, jedes gewünschte Material zu beschaffen.

Prof. Dr. Karl Christ und Prof. Dr. Reinhard Kühnl haben während der schwierigen Anfangsphase der Arbeit ihre Unterstützung gewähr. Über viele Jahre hat Dr. Gert Meyer zahllose Anregungen gegeben. Dr. Matthias Willing hat mit bewundernswerter Ausdauer und Geduld die Hauptlast des Korrekturlesens getragen, schonungslos die wenig geglückten Formulienungen aufgedeckt und sich als konstruktiver Diskussionspartner erwiesen. Mit stoischer Ruhe hat Nico Biver die Formatierung übernommen. Im Marburger Seminar für osteuropäische Geschichte haben Franziska Lüdtke, Monica Wellmann, Ingo Eser, Eckart Günther und Andreas Park den camera ready-Ausdruck korrekturgelesen. Ihnen allen danke ich herzlich.

Ohne die verläßliche finanzielle wie ideelle Unterstützung, die mir meine Eltern und meine Großtante, Frau Josefa Schiffner (Forchheim), über Jahre hinweg gaben, hätte ich das Dissertationssprojekt wohl nicht verwirklichen können. Meiner Frau Heide-Marie Czapek und unserem Sohn Florian danke ich, daß sie meine Arbeit soweit wie möglich tolerierten und mich soweit wie nötig von ihr ablenkten.

Den Herausgebem der „Marburger Abhandlungen" danke ich schließlich für die Aufnahme der Arbeit in diese Reihe der Osteuropastudien der Hochschulen des Landes Hessen. 


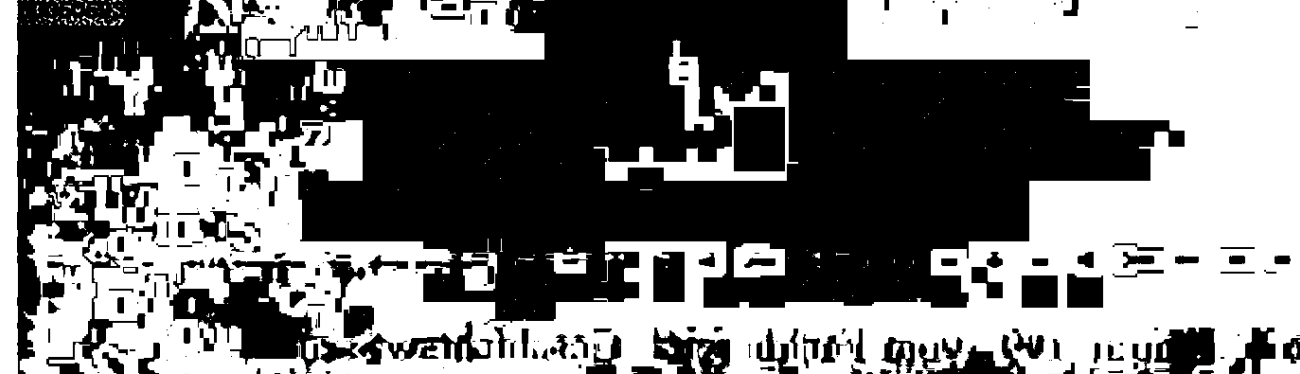

15

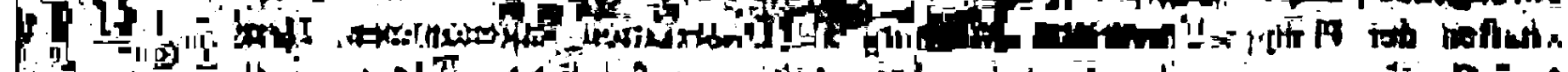

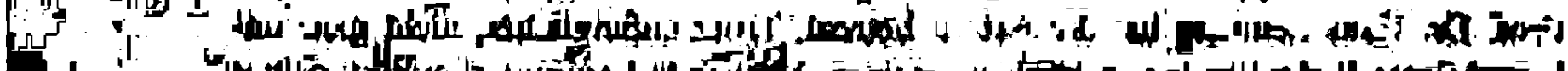

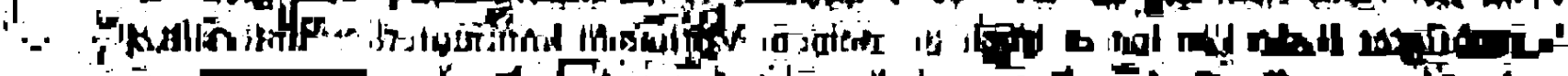
-

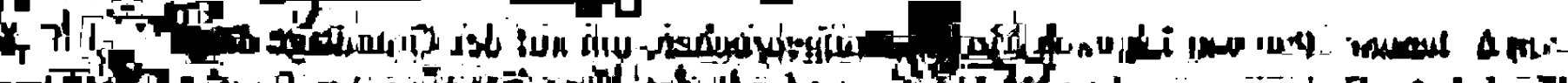

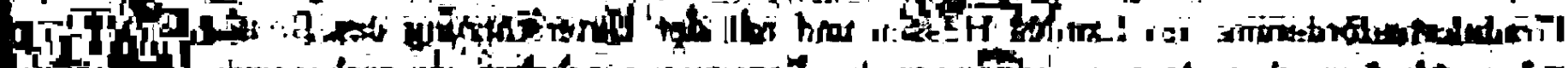
Hild

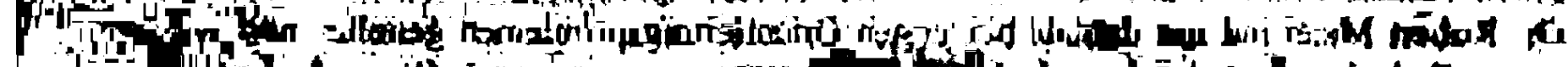

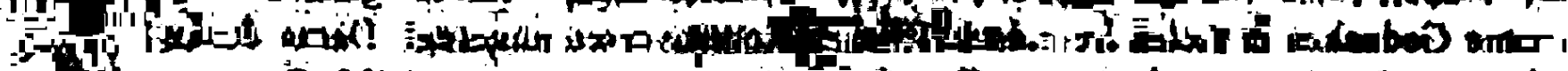

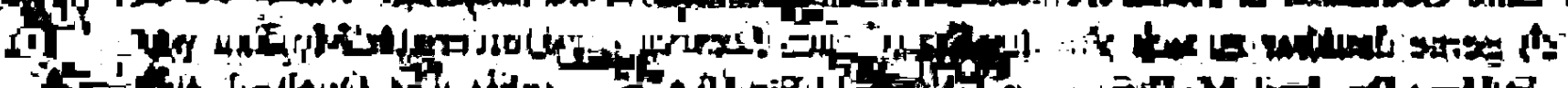

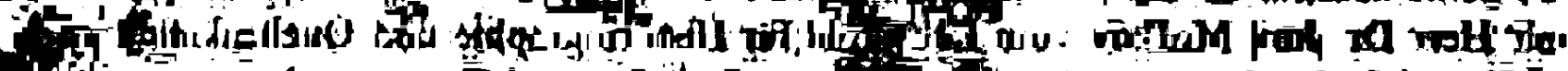
I1

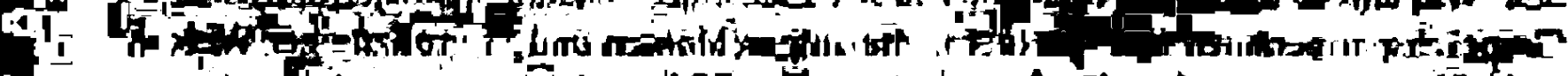

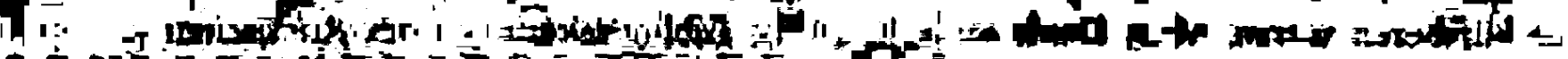

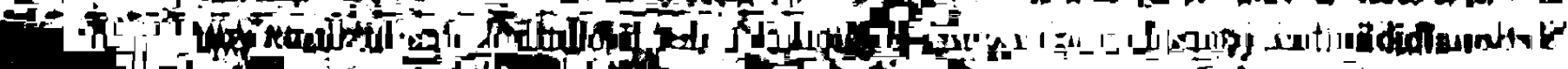

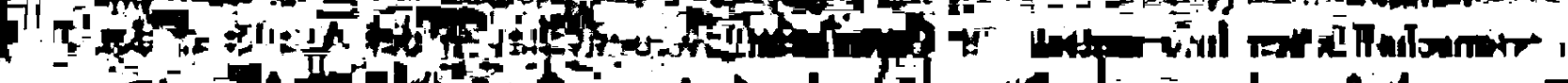

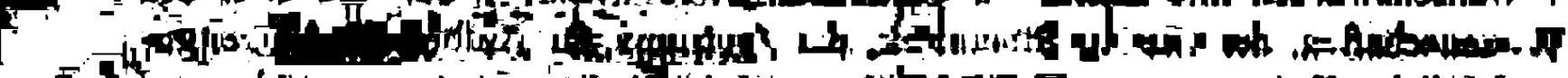

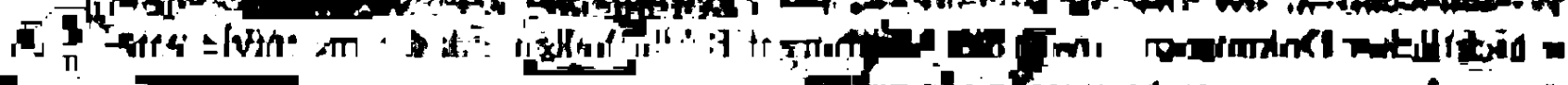
1 II

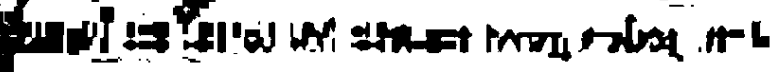

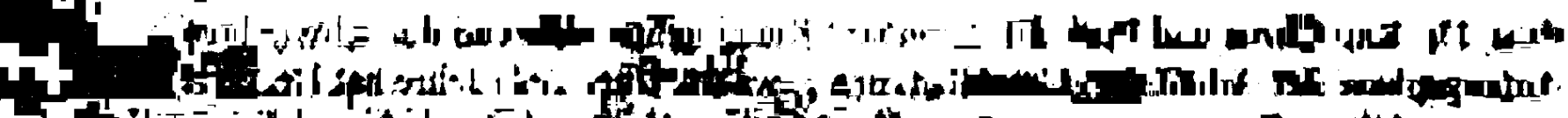

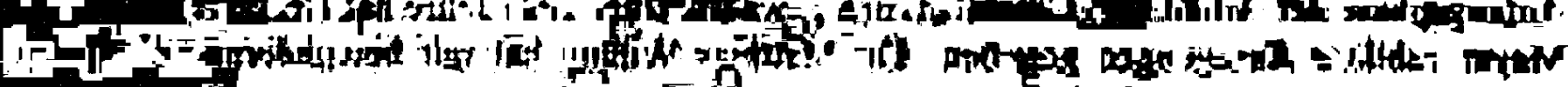

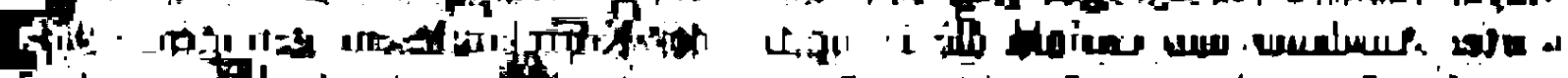

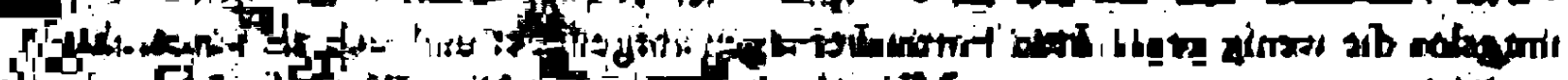

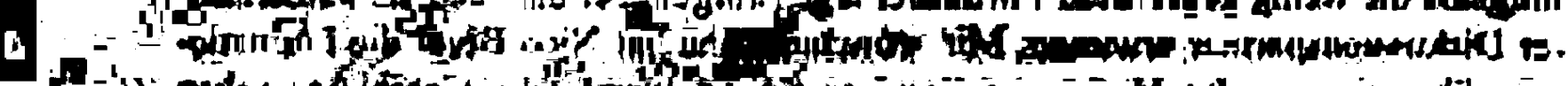

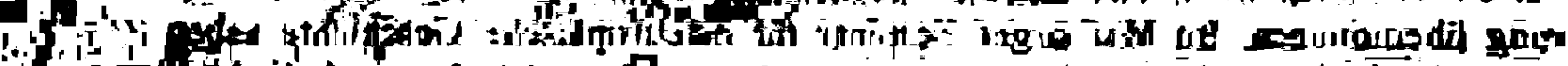

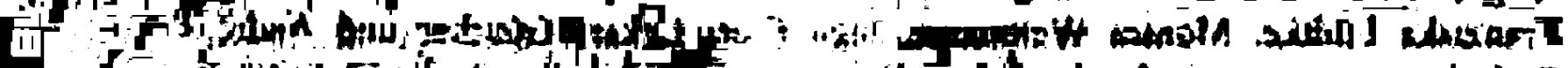

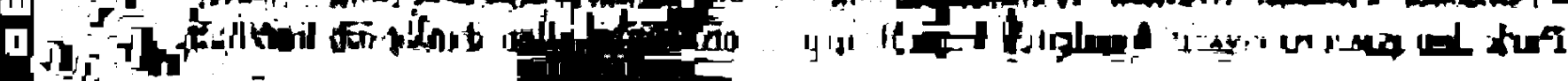

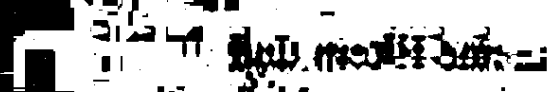
if

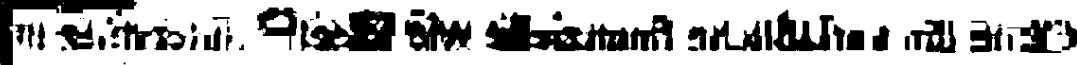

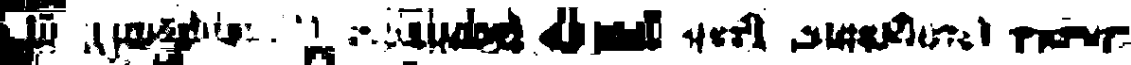

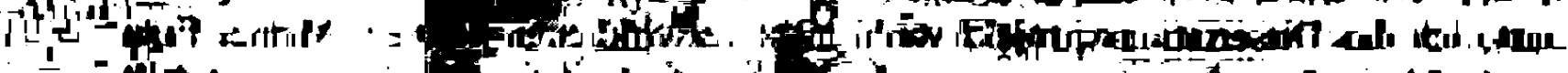

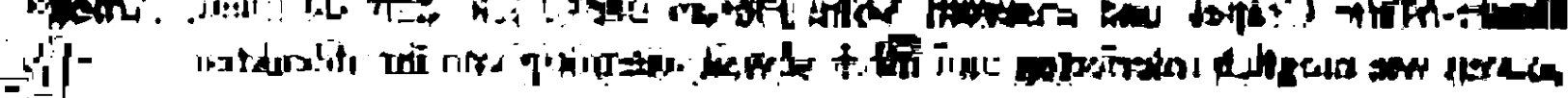
$\left(1+\frac{1}{10}\right.$

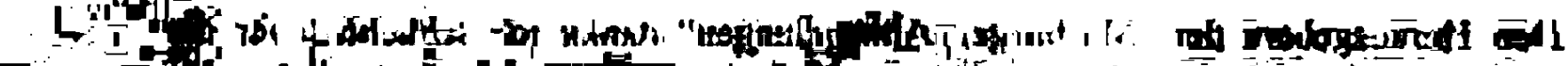

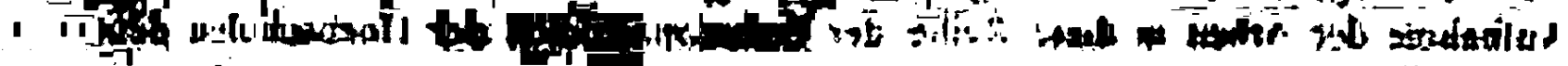

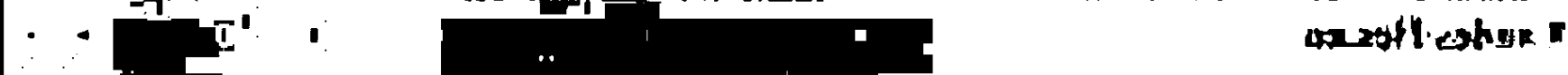
Al the 15. 1)

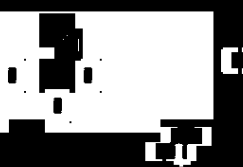

[I] 


\section{Inhaltsverzeichnis}

1. EINLEITUNG

2. ZUR PERIODISIERUNG UND STRUKTUR DER SOWJETISCHEN GESCHICHTSWISSENSCHAFT

3. DIE SOWJETISCHE GESCHICHTSWISSENSCHAFT 1953 BIS 1960: ENTSTALINISIERUNG UND ANTIREVISIONISMUS

3.1. DiE HISTORISCHE DISZIPLIN UNMITTELBAR NACH STALIN 1953 BIS 195717

3.1.1. Die Neuprofilierung der Voprosy istorii 18

3.1.2. Bemühungen um die Verständigung über den Forschungsstand und notwendige Revisionen

3.1.3. Zum Verhältmis von Einzehwissenschaft und Philosophie 37

3.2. DAS ANTIREVISIONISTISCHE GEGENSTEUERN 1955/57 BIS 1960

3.2.1. Der Ereignisverlauf von Anfang 1955 bis März 1957

3.2.2. Der Inhalt der antirevisionistischen Kritik 44

3.2.3. Die Antirevisionisten in Aktion $\quad 49$

3.2.4. Gegentendenzen 58

4. DIE SOWJETISCHE GESCHICHTSWISSENSCHAFT

IN DEN SECHZIGER JAHREN: PROFESSIONALISIERUNG UND DISSIDENZ

4.1. GeschichtSideologie. Die POLITISCHEN VoRgabeN ZUR HISTORISCHEN FORSCHUNG

4.2. DIE ALLGEMEINE ENTWICKLUNG DER HISTORISCHEN DISZIPLIN 91 4.2.1. Die Fachzeitschriften 91

4.2.2. Zur Geschichte der sowjetischen Gesellschaft 95

4.2.3. Zur Geschichte der sowjetischen Geschichtswissenschaft $\quad 102$

4.2.4. Zur Geschichtsmethodologie 111

4.3. GEGENSTANDSDISKUSSION. ZUM VERHÄLTNIS VON

PHILOSOPHIE UND EINZELWISSENSCHAFT

4.4. DiE GESCHICHTLICHE TATSACHE. FAKTEN UND IHRE INTERPRETATIONEN

4.5. GESETZMÄßIGKEIT UND ALTERNATIVITÄT IN DER GESCHICHTE 139

4.6. DISKUSSION DER FORSCHUNGSPRINZIPIEN 156

5. DIE SOWJETISCHE GESCHICHTSWISSENSCHAFT 1970 BIS 1986: ROUTINE UND RETARDATION 
5.1. Die KAMPAGNEN GEGEN DIE METHODOLOGIESEKTION UND DIE ,NEUE RICHTUNG“ DER OKTOBERREVOLUTIONSFORSCHUNG

5.2. DIE SOWJETISCHE GESCHICHTSWISSENSCHAFT IM ZEICHEN VON ROUTINE UND RETARDATION

5.3. DIE IDEOLOGIEDISKUSSION DER KPDSU 1983 UND DIE TRÄGHEIT DER HISTORISCHEN DISZIPLIN

5.4. DIE GESCHICHTSWISSENSCHAFT UND DER BESCHLEUNIGUNGSKURS 1985/86

\section{DIE LETZTE ETAPPE DER SOWJETISCHEN} GESCHICHTSWISSENSCHAFT 1987-1991:

6.1. Die UMGESTALTUNGSPOLITIK UND

DIE GESCHICHTSWISSENSCHAFT 1987 BIS 1991

6.1.1. Der Aufbruch während der "Perestrojka-Flitterwochen" 1987

6.1.2. Historie und Systemtransformation 1988/89

6.1.3. Die Geschichtswissenschaft während der gesellschaftlichen Agonie 1990/91

6.2. DIE LIQUIDATION DER ,WEIBEN FLECKEN“ 1986 BIS 1991

6.3. ZUR GEGENSTANDSBESTIMMUNG

6.4. NEUES ZUR DEFINITION HISTORISCHER FAKTEN

6.5. ALTERNATIVITÄT UND GESETZMĀBIGKEIT IN DER GESCHICHTE

ABKÜRZUNGSVERZEICHNIS 303

LITERATURVERZEICHNIS 305

VERZEICHNIS LETTENDER HISTORIKER 346

$\begin{array}{ll}\text { PERSONENINDEX } & 348\end{array}$ 
„Aber Geschichte hat nichts mit Uhrmacherei oder Kunsttischlerei zu tun. Sie ist ein Bemühen um bessere Kenntnis, folglich eine Angelegenheit, die ständig in Bewegung ist. Beschränkt man sich bei der Beschreibung einer Wissenschafi darauf, wie sie faktisch betrieben wird, vermag man ihr nie ganz gerecht zu werden. Wichtiger noch ist es, dovon zu sprechen, wie sie ein je besseres Gelingen ihres Anspruchs zu erreichen hoffi. "Il

\section{Einleitung}

Nach dem Putschversuch im August 1991 beschleunigte sich der Zerfall der Union der Sozialistischen Sowjetrepubliken. Die sowjetische Periode ging zu Ende, wenngleich über die weltgeschichtliche Zäsur hinaus mittel- und langfristige Kontinuitäten weiterwirken. Analog ist in der heutigen russischen Geschichtswissenschaft das Fortbestehen personeller Besetzungen, institutioneller Zusammenhänge und organisatorisch-struktureller Probleme zu beobachten. Doch die ökonomischen und politisch-ideologischen Rahmenbedingungen historischen Forschens haben sich ebenso entscheidend geändert wie die Materialgrundlage und die theoretischen Ansprüche der Historikerinnen und Historiker. Auch die Periode der sowjetischen Geschichtswissenschaft fand in der zweiten Jahreshälfte 1991 ihren Abschluß. Ziel der Dissertation ist es, die letzten Etappen dieser Periode unter methodologiegeschichtlichen Aspekten im zeitlichen Zusammenhang za analysieren. Da die Geschichte der sowjetischen Geschichtswissenschaft von der Oktoberrevolution bis Mitte der füfziger Jahre bereits deutlich besser erforscht ist, und weil die weitere Entwicklung nach 1953 durch die in wissenschaftlichen und sozialen Diskursen immer wiederkehrende Bezugnahme auf die „Folgen des Personenkults“ eine Einheit bildet, bot es sich an, den Berichtszeitraum auf die Jahre von 1953 bis 1991 festaulegen.

Trotz zahlreicher Veröffentlichungen kann die Entwicklung der sowjetischen Geschichtswissenschaft nach 1953 nicht als fundiert erforscht bezeichnet werden. Die frühen systematischen Arbeiten nach dem Zweiten Weltkrieg erfaßten naturgemäß nur noch die ersten Jahre der Entwicklung nach Stalins Tod. Dies trifft zum Beispiel auf die Untersuchung von Konstantin Shteppa und die unter dem Titel „Contemporary History in the Soviet Mirror“" zusammengefaßten Konferenzbeiträge von $1961 \mathrm{zu}^{2}$ Bei der Mehrzahl der späteren Publikationen handelt es sich um zeitgenössische Detailstudien, die zwar auch für den heutigen Beobachter viel Wissenswertes über einzelne Aspekte der Historiographie, über neue Trends und

\footnotetext{
1 Bloch, M: Apologie der Geschichte oder Der Benuf des Historikers (1949), hg. von L. Febvre, München 1985, $15 f$.

2 Shteppa, K.F.: Russian Historians and the Soviet State, New York 1962; Keep. J. (Ed.): Contemporary History in the Soviet Mirror, London 1964.
} 
Konflikte enthalten, aber doch nie die Entwicklung der historischen Disziplin in der UdSSR systematisch und über längere Zeitspannen verfolgten. ${ }^{3}$ Manche Autoren betrachteten weniger die historische Disziplin als vielmehr die sie hemmende und einschränkende Ideologie. ${ }^{4}$ Die nach 1985 erschienenen Aufsätze, Sammelwerke und Monographien zur Geschichtsdiskussion und Historiographie unter dem Einfluß der Umgestaltungspolitik widmeten der Entwicklung in den vorangegangenen vier Jahrzehnten nur wenig Aufmerksamkeit. ${ }^{5}$ Die sowjetische Historiographie der Geschichte der Geschichtswissenschaft kam trotz ihres mächtigen institutionellen Ausbaus und personellen Aufwandes über den Zeitraum bis Mitte der sechziger Jahre und die bloße Annotation und Kommentienung von Veröffentlichungen im

3 Ohne Anspruch auf Vollständigkeit seien genannt: Bonwetsch, B.: Oktoberrevolution. Legitimationsprobleme der sowjetischen Geschichtswissenschaft, in: Politische Vierteljahresschrift 1976, H. 2, 149-185; ders., Rußland, Oktober 1917: Hegemonie des Proletariats oder Volksrevo lution? Bemerkungen zur sowjetischen Historiographie seit Anfang der siebziger Jahre. in: OE 1987, H. 10, 733-747; Enteen, G.M.: A Recent Trend on the Historical Front, in: Survey 1974, H. 4, 122-131; Fedenko, P.: Khrushchev's New History of the Soviet Communist Party, München 1963; Geyer, D.: Gegenwartsfragen der sowjetischen Geschichtswissenschaf, in: Vierteljahreshefte für Zeitgeschichte 1967, H. 2, 109-120; ders., Klio in Moskau und die sowjetische Geschichte. Heidelberg 1985; Leitsch, W.: Die Veränderungen der historischen Bewertung, in: Boetticher, E./H.-J. Lieber/B. Meissner (Hg.): Bilanz der Ära Chruschtschow, Stuttgart-BerlinKöln-Mainz 1966, 258-277; Oberländer, E.: Zur Parteigeschichtsschreibung nach Stalin. Ein Vergleich der ersten und zweiten Auflage der neuen "Geschichte der KPdSU" von 1959 und 1962, in: Ost-Probleme 1963, 753-759; Piroschkow, V.: Sowjetische Geschichtswissenschaft im inneren Widerstreit, in: Saeculum 1960, H. 1/2, 180-198: Rogger. H.: Politics. Ideology and History in the USSR: The Search for Coexistence, in: Soviet Studies 1965, H. 3, 254-275; Urban, P.K.: The Re-Stalinization of the Soviet Historical Sciences, in. Bulletin. Institute for the Study of the USSR, Vol. V, January 1958, No. 1, 46-52; ders., Smena tendencij v sovetskoj istoriografii, München 1959.

4 Laqueur, W.: Mythos der Revolution. Deutungen und Fehldeutungen der Sowjetgeschichte Eine Studie, Frankfurt am Main 1967, 149ff; Marko, K.: Sowjethistoriker zwischen Ideologie und Wissenschaft. Aspekte der sowjetrussischen Wissenschaftspolitik seit Stalins Tod. 19531963, Köln 1964; ders., Evolution wider Willen. Die Sowjetideologie zwischen Orthodoxie und Revision, Graz-Wien-Köln, 1968; ders., Dogmatismus und Emanzipation in der Sowjetunion. Philosophie, Reformdenken, Opposition, Stuttgart-Berlin-Köln-Mainz 1971

s Um nur die Titel der umfassenden Untersuchungen zu nennen mit zahlreichen weiteren Literaturhinweisen, siehe Davies, R.W.: Perestroika und Geschichte. Die Wende in der sowjetischen Historiographie. München 1991; Geyer, D. (Hg.): Die Umwertung der sowjetischen Geschichte (= GuG Sonderheft 14), Göttingen 1991; Hagen. M. von: History and Politics under Gorbachev: Professional Autonomy and Democratization, in: The Harriman Institute Forum 1988, H. 11, 1-8; Ito, T. (Ed.): Facing Up to the Past. Soviet Historiography under Perestroika. Sapporo 1989; Liszkowski, U.: Die Revision der sowjetischen Geschichte im Zeichen der Perestrojka. Eine Zwischenbilanz, in: GWU 1990, H. 11, 653-674: Rejman. M.: Perestrojka i izučenie sovetskoj istorii, in: VI 1989, H. 12, 145-158; Sherlock. T.: Politics and History under Gorbachev, in: Problems of Communism 1988, H. 3-4, 16-42; Wheatcroft, S.: Unleashing the Energy of History, Mentioning the Unmentionable and Reconstructing Soviet Historical Awareness: Moscow 1987, in: ASEES 1987, H. 1, 85-132.; ders., Steadying the Energy of History and Probing the Limits of Glasnost': Moscow July to December 1987, in: ASEES 1987, H. 2, 57-114. 
wesentlichen nicht hinaus. ${ }^{6}$ Unter den zahlreichen Publikationen zur Entwicklung der sowjetischen Geschichtswissenschaft war die Monographie von Nancy Whittier Heer für den Autor besonders anregend. In ihrer Untersuchung der KPdSUGeschichtsschreibung zeigte Heer u.a., daß die Historie als ,politisches Subsystem" während der Dekade von 1956 bis 1966 nicht mehr nur auf die geschichtsideologischen und wissenschaftspolitischen Direktiven reagierte, sondern sich ein Dialog zwischen Historikern und Politikern entwickelt habe. ${ }^{7}$ Mit der hier vorgelegten historiographiegeschichtlichen Studie soll auch geprüft werden, wann und wie im einzelnen dieser Dialog begann und ob er über den Betrachtungszeitraum von Heer hinaus fortgesetzt wurde.

Die Historiographie der Geschichte der Geschichtswissenschaft kennt inzwischen mindestens elf unterschiedliche Typen, die gleichermaßen ihre Berechtigung haben, und die sich günstigenfalls ergänzen. ${ }^{8}$ Erstens: die Biographien und personenbezogenen Werk-Studien, in denen Leben und Gesamtwerk einzelner Vertreter des Faches gewürdigt und wissenschaftlich verortet werden. ${ }^{9}$ Zweitens: die Institutionsgeschichte, worin die Entwicklung des von den Historikern selbst geschaffenen, von der Wissenschaftspolitik geprägten, organisatorischen Rahmens historischer Forschungen - der Universitäten, Hochschulen und Akademien, der Konferenzen und wissenschaftlichen Periodika, des Wissenschaftsbetriebes auf nationaler und internationaler Ebene - untersucht wird. ${ }^{10}$ Drittens: Historiographie der Ideen- und Geistesgeschichte; sie verfolgt die großen Strömungen des Geschichtsdenkens und der -philosophie, ohne dabei die Praxis der Historiker, die Methoden, Gegenstandsbereiche und sozialen Funktionen der Geschichtswissenschaft zu analysie-

6. Vgl. etwa Neckina, M.V./E.N. Gorodeckij: Istoriograficeskie issledovanija v SSSR, in: Razvitie 1975, 79-100 (Übersetzung bei Donner, E./A. Anderle (Hg.): Studien zur Geschichte lund Theorie der Geschichtswissenschaf in der UdSSR. Halle 1981, 5-33); Ocerki istorii istoričeskoj nauki v SSSR, tom 5, M. 1985; Novoe v sovetskoj istorið̌eskoj nauke, M. 1988.

- Heer, N.W.: Politics and History in the Soviet Union, Cambridge (Massachusetts)-London 1971,58

* Diese Typologisierung erfolgt in Anlehung an und Ergänzung von Blanke. H.W.: Typen und Funktionen der Historiographiegeschichtsschreibung. Eine Bilanz und ein Forschungsprogramm, iın: Geschichtsdiskurs Band 1: Grundlagen und Methoden der Historiographiegeschichte, FrankfurtM. 1993, 191-211; Iggers, G.G.: Darstellungen der Geschichte der Geschichtswissenschaft Kategorien und Projekte, in: Wissenschaftliche Zeitschrif Karl Marx-Univ. Leipzig, Ges.- u. Sprachwiss. Reihe 1984, H. 4, 439-441; Küttler, W.: Historiographiegeschichte als Methodologiegeschichte. Zur Problemstellung einer Entwicklungsgeschichte der theoretischen und methocologischen Grundlagen der Geschichtswissenschaft, in: Historiographiegeschichte, 14-32.

9) So in der sowjetischen Historiographie z.B. Sokolov, O.D.: M.N. Pokrovskij i sovetskaja istorið̌eskaja nauka. M. 1970; Badja. L.V.: Akademik A.M. Pankratova - istorik rabočego klassa SSSR, M. 1979.

110 So z.B. Alatorceva, A.I.: Zuumal „Istorik-Marksist“ 1926-1941 gg., M. 1979; Erdmann, K.D.: Die Ökumene der Historiker. Geschichte der Internationalen Historikerkongresse und des (Comité International des Sciences Historiques (= Abhandlungen der Akademie der Wissenschaftten in Göttingen. Philologisch-historische Klasse. Dritte Folge, Nr. 158), Göttingen 1987. 
ren." Viertens: Historiographiegeschichte als Sozialgeschichte; diese noch ganz junge Richtung bemüht sich um die Freilegung der soziokulturellen Verflechtungen, um die Beantwortung der Fragen nach der Herkunft und den Karrieren der Wissenschaftler, nach den Produktionsbedingungen historischen Wissens und Bewußtseins, nach den Absichten und der Resonanz geschichtlicher Leitideen. ${ }^{12}$ Fünftens: Historiographiegeschichte als Werkgeschichte stellte früher die häufigste Form der Historiographie dar. Ohne den institutionellen und soziokulturellen Rahmen zu berücksichtigen, referieren solche Arbeiten die ,großen" Werke der Geschichtsschreibung. Geschichte wird hierbei weniger als Wissenschaft, sondem vielmehr als Literaturgattung betrachtet. ${ }^{13}$ Sechstens: Die Historiographie einzelner geschichtswissenschaftlicher Fachgebiete geht vom institutionsgeschichtlichen Ansatz aus, arbeitet mitunter personenbezogen, sozial- und werkgeschichtlich, ist aber vor allem problemorientiert und will Verlauf und Resultate der Forschung in einer bestimmten Teildisziplin analysieren. ${ }^{14}$ Siebtens: Die gleichsam klassische Historiographie der konkret-historischen Forschung konzentriert den Blick stärker als die fachspezifische Betrachtung auf ein bestimmtes Thema der Geschichte und die Frage, wie dieses in einer bestimmten Zeit von einem bestimmten Kreis von Historikem untersucht und bewertet worden ist. ${ }^{\text {Is }}$ Achtens: Historiographie als Methodengeschichte ist selten in monographischer Ausfuihrung anzutreffen, of kombiniert mit anderen Ansätzen und dennoch, allein schon aufgnund der Bedeutung einer gezielten Analyse der Methoden historischen Forschens, als eigenständiger Typus zu unterscheiden. ${ }^{16}$ Neuntens: Die Historiographie als Funktionsgeschichte thematisiert die grundsätzlichen gesellschaftlichen Funktionen der Geschichtswissenschaft, deren Veränderung und unterschiedliche Deutung in der Entwicklung, und erörtert das Spannungsverhältnis zwischen Gesellschaft und Historie als Wis-

"Zum Beispiel Meinecke, F.: Die Entstehung des Historismus (1936), 2. Auflage, München 1936; Kon, I.S.: Die Geschichtsphilosophie des 20. Jahrhunderts. Kritischer Abriß, 2 Bände, Berlin 1964.

12 Siehe beispielsweise Weber, W.: Priester der Klio. Historisch-sozialwissenschaftliche Studien zur Herkunft und Karriere deutscher Historiker und zur Geschichte der Geschichtswissenschaft 1800-1970, Frankfurt/Main 1985; Blanke, H.W.: Historiker als Beruf. Die Herausbildung des Karrieremusters "Geschichtswissenschaftler" an den deutschen Universitäten von der Aufklänung bis zum klassischen Historismus, in: Jeismann, K.-E.: Bildung, Staat, Gesellschaft im 19. Jahrhundert. Mobilisienung und Disziplinierung, Stuttgart 1989, 343-360. Vgl. auch Beyrau, D.: Die russische Intelligenz in der sowjetischen Gesellschaft, in: Geyer, Die Umwertung, 188-209.

13 Siehe etwa Fueter, E.: Geschichte der neueren Historiographie seit dem Humanismus, München-Berlin 1911; Ritter, M.: Die Entwicklung der Geschichtswissenschaft, an den führenden Werken betrachtet, München-Berlin 1919.

14 So z.B. die Untersuchung der KPdSU-Geschichtsschreibung bei Heer, Politics.

is So z.B. bei Schlarp. K.-H.: Ursachen und Entstehung des ersten Weltkrieges im Lichte der sowjetischen Geschichtsschreibung. Hamburg 1971; Nolte, H.-H.: „Drang nach Osten“. Sowjetische Geschichtsschreibung der deutschen Ostexpansion, Köln-Frankfurt a. Main 1976.

16 Beispiele stellen dar: Wach, J.: Das Verstehen. Grundzüge einer Geschichte der hermeneutischen Theorie im 19. Jahrhundert, 3 Bände, Tübingen 1926-1933; Koval'Zenko, I.D.: Metody istoričeskogo issledovanija, M. 1987. 
senschaft. ${ }^{17}$ Zehntens: Die Historiographie der Theorie- und Methodologiegeschichte thematisiert die „Entwicklung der methodologischen und theoretischen Grundlagen“, den „Begründungs- und Fundierungszusammenhang der Geschichte als Wissenschaft". Die Entwicklung der historischen Disziplin wird nicht umfassend dargelegt, sonderm

„(...) erforscht und erfaßt nach den Ansätzen, Formen und Phasen wie auch (...) nach den gegensätzlichen Grundrichtungen, in denen sich die theoretischen und methodologischen Grundlagen der Geschichte als einer wissenschaftlichen Disziplin ausgeprägt haben. “"18

Elftens: Die Historiographiegeschichte als Strukturgeschichte des historischen Denkens versucht, die genannten Typen zu einer Synthese zu bündeln, um die grundsätzlichen Strukturen historischen Denkens systematisch zu rekonstruieren und die Verändenungen in diesen Strukturen festzustellen. ${ }^{19}$

In der hier vorliegenden Studie wird Historiographiegeschichte dem 10. Typus entsprechend als Methodologiegeschichte verstanden und erstmals auf die sowjetische Geschichtswissenschaft angewandt. Meist lassen die Arbeiten dieses Typs die konkret-historische Einordnung der untersuchten Gegenstandsbereiche in die Gesellschafts- und Wissenschafts-Geschichte vermissen. Ist dies schon generell ein Defizit, so stellt es im Fall der hochpolitisierten sowjetischen Geschichtswissenschaft aufgrund des enormen Einwirkens der Kommunistischen Partei der Sowjetunion auf die Wissenschaftsentwicklung ein inakzeptables Versäumnis dar. Es wird deshalb in dieser Arbeit versucht, an Knotenpunkten der Entwicklung die soziopolitische Landschaft zu charakterisieren und zu beleuchten, in welcher Weise die KPdSU und ihr ZK-Apparat Einfluß ausübten. Partiell sollen auch historiographi-

17 Die Dissertation von Roger D. Markwick, die annähernd in der gleichen Zeit wie die vorliegende Untersuchung entstand, verbindet Typ 4 (Historiographie als Sozialgeschichte) und Typ 9 (Historiographie als Funktionsgeschichte) mit Ansätzen der kJassischen Historiographie konkrethistorischer Probleme (hier besonders der Geschichte des vorrevolutionären Rußlands). Vorrangig geht es Markwick darum, die politische Bedeutung der revisionistischen Geschichtsschreibung in der UdSSR während der sechziger Jahre herauszuarbeiten. Er erkennt diese vor allem darin, daß damit die Genesis einer neuen Generation von Intellektuellen respektive intelligenty im Sinne der revolutionär-demokratischen intelligencija der 1860er Jahre kausal verbunden gewesen sei. Siehe Markwick. R.D.: A Resurgent Intelligentsia: The Politics of Revisionist Historiography in the Soviet Union, 1956-74. Ph.D. thesis, Department of Government and Public Administration, University of Sydney 1994, 352ff. - Typische Beispiele fuir die Historiographie als Funktionsgeschichte: Ivanov, V.V.: Sootnosenie istorii i sovremennosti kak metodolo gičskaja problema, M. 1973; Dotterweich, V.: Heinrich von Sybel. Geschichtswissenschaft in politischer Absicht 1817-1861, Göttingen 1978.

18 Küttler, Historiographiegeschichte, 14ff. - Diesem Typus können die folgenden Arbeiten zugerechnet werden: Bollhagen, P.: Soziologie und Geschichte, Berlin 1966; Topolski, J.: Methodology of History, Warschau-Dordrecht-Boston 1976; Naumann, K.: Ökonomische Gesellschaftsformation und historische Formationsanalyse, Köln 1983.

19 Siehe hierzu Theorie der Geschichte. Beiträge zur Historik, 6 Bände, München 1977-1990; Rüsen, J.: Historische Vernunft. Grundzüge einer Historik I: Die Grundlagen der Geschichtswissenschaft. Göttingen 1983. 
sche Elemente des personenbezogenen Ansatzes und der Institutionsgeschichte realisiert werden, um zeigen zu können, wer sich unter welchen Umständen und warum engagierte, an dieser oder jener Diskussion beteiligte usw.

Gegenstand der theoretischen Analyse sind die sowjetischen Forschungen und Diskussionen über die methodologischen Grundlagen der Geschichtswissenschaft. Aus Gründen der Realisierbarkeit bleiben die speziellen Theoriediskussionen zur Allgemeinen und zur russischen Geschichte bis 1917 ausgeklammert; sie werden lediglich vermerkt. Das Interesse ist auf das methodologische Fundament der Erforschung der Geschichte der sowjetischen Gesellschaft und Geschichtswissenschaft gerichtet. In welcher Weise wurden diese Grundlagen von 1953 bis 1991 diskutiert und modifiziert? Welche Themen der Geschichtsmethodologie blieben all die Jahre virulent? Welche Zwischenlösungen wurden erzielt, welche Probleme weitergereicht? Welcher Art waren die Wechselbeziehungen zwischen Geschichtswissenschaft und historischem Materialismus? Welche Entwicklungsetappen und -phasen sind in der Methodologiegeschichte respektive der Geschichtswissenschaft zu unterscheiden? Wann, wie und warum griff die Kommunistische Partei in das Geschäft der historischen Zunft ein?

Zunächst werden im 2. Kapitel die der Untersuchung zugrundeliegenden Annahmen zur Periodisierung der sowjetischen Geschichtswissenschaft 1917 bis 1991 dargelegt und einige strukturelle Probleme erläutert. Das 3. Kapitel beleuchtet die Anfänge der Entstalinisierung in der sowjetischen Geschichtswissenschaft. Es sollen die Veränderungen der Arbeitsbedingungen für die historische Disziplin verdeutlicht sowie gezeigt werden, wie umkämpft diese waren, und wie einige Historikerinnen und Historiker sich einsetzten für eine Inventur ihres Faches. Das 4. Kapitel ist den Geschichtsdiskussionen in den sechziger Jahren gewidmet. Hier, wie auch im 6. Kapitel, in dem die letzte Etappe der sowjetischen Geschichtswissenschaft betrachtet wird, werden die gesellschaftlichen Rahmenbedingungen der historischen Disziplin, die politischen und geschichtsideologischen Vorgaben sowie die Arbeitsschwerpunkte der historischen Zunft im Spiegel der Fachzeitschriften skizziert, bevor die Auseinandersetzungen mit den jeweils aktuellen geschichtstheoretischen und -methodologischen Problemen analysiert werden. Es versteht sich, daß dabei nicht zwanghaft die ganze ,disziplinäre Matrix“ (Thomas S. Kuhn) der sowjetischen Geschichtswissenschaft, sondern nur die zentralen Auseinandersetzungen thematisiert werden. Das 5 . Kapitel ist den Kampagnen gegen die Teilnehmer an den Theorie- und Methodologiediskussionen sowie gegen die „Neue Richtung" der Oktoberrevolutionsforschung gewidmet. Ferner wird die historische Disziplin während der zweiten Halbzeit der Brežnev-Ära charakterisiert und untersucht, wie die führenden Historiker auf die sukzessiven Veränderungen im politischen Überbau der Gesellschaft reagierten, inwieweit Impulse angenommen oder gegeben wurden.

Das untersuchte Material ist in vier Quellengruppen einzuteilen: In erster Linie wurden die Kommunikationsorgane und Arbeitsergebnisse der historischen Zunft ausgewertet, also die wichtigsten Fachzeitschriften, die Monographien, Sammel- 
bände, Forschungsartikel, Konferenzprotokolle, Sitzungsberichte usw., die zum Thema veröffentlicht wurden. Bis 1957 war das Periodikum „Fragen der Geschichte" - Voprosy istorii - die einzige allgemeine zentrale Fachzeitschrift und steht deshalb für diesen Zeitabschnitt im Mittelpunkt der Aufmerksamkeit. Seit 1957 muß das zweimonatlich erscheinende Joumal „Geschichte der UdSSR“ - Istorija $S S S R$ - als veröffentlichte Quelle gleicher Bedeutung angesehen werden. Zweitens wurden schriftlich und mündlich übermittelte Einschätzungen von sowjetischen Historikerinnen und Historikern erschlossen. Zahlreiche wertvolle Informationen boten die Erinnerungen und schriftlichen Auskünfte von sowie die persönlichen Gespräche mit Jurij Moskov, Boris Mogil'nickij, Aaron Gurevič, Svetlana Neretina, Pavel Volobuev, Viktor Danilov, Michail Maškin, Aleksandr Nekric, Anatolij Černaev, Valentin Falin, Michail Gefter und Vladimir Egorov. Drittens wurden die unveröffentlichten Materialien von der Tätigkeit der Sektion für Geschichtsmethodologie (1964-69) unter der Ägide von Michail Gefter herangezogen, welche dankenswerterweise die Philosophin Dr. Svetlana Sergeevna Neretina, die damals an vielen Veranstaltungen teilgenommen und die Unterlagen von Michail Gefter erhalten hatte, für die Untersuchung zur Verfügung stellte. Bei diesem Material handelt es sich um unveröffentlichte Vortragsmanuskripte, Diskussionsbeiträge, Aufsatzentwürfe von Gefter und anderen Teilnehmern, Rechenschaftsberichte über die Arbeit der Sektion und die Korrespondenz, welche die Auseinandersetzungen Ende der sechziger und Anfang der siebziger Jahre dokumentieren. Viertens wertete der Autor in dem im März 1992 geöffneten Archiv des Zentralkomitees der Kommunistischen Partei der Sowjetunion (dem heutigen Centr chranenija sovremennoj dokumentacii - ,Zentrum zur Aufbewahrung zeitgeschichtlicher Dokumente") die von der Abteilung des Zentralkomitees der KPdSU für Wissenschaft und Kultur zusammengetragenen Papiere aus: ZK-inteme Recherchen, Bewertungen, Beschlußvorlagen, Briefe und Eingaben von Historikerinnen und Historikern an Funktionäre der Partei. Aus diesem Material ließen sich vor allem für die fünfziger und sechziger Jahre viele, wenngleich nicht lückenlose Hintergrundinformationen über die Konflikte zwischen der Geschichtswissenschaft und der Parteifuihnung sowie unter den Historikern gewinnen. 



\section{Zur Periodisierung und Struktur der sowjetischen Geschichtswissenschaft}

Jene ,zehn Tage, die die Welt erschütterten“,', stellten auch für die historische Disziplin in Rußland eine tiefgreifende Zäsur dar, mit der die Periode der sowjetischen Geschichtswissenschaft begann. Um deren Entwicklung in Etappen zu unterteilen, ist es notwendig, folgende Faktoren zu berücksichtigen: die politischen und soziokulturellen Bedingungen sowie die geschichtsideologischen und wissenschaftpolitischen Vorgaben für die Geschichtswissenschaft; ihre wichtigsten Konzeptionen, Forschungsschwerpunkte, Untersuchungsmethoden und Organisationsformen. Dies zugrunde gelegt, sind meines Erachtens grob folgende füf Etappen zu unterscheiden: 1. Aufbau und Kooperation, 2. Konfrontation und Stalinisierung, 3. Entstalinisienung, 4. Retardation, 5. Umbruch.

Die Führer der Russischen Sozialdemokratischen Arbeiter-Partei ${ }^{2}$, die im Oktober 1917 die politische Macht und Regierungsgewalt übernahmen, maßen einem Neubeginn der Geschichtsforschung, des Geschichtsunterrichts und der historischen Agitation und Propaganda große Bedeutung bei und implementierten daher umgehend den Aufbau neuer Institutionen fur das Archiv-, Bibliotheks- und Ausbildungswesen der Geschichtswissenschaft. Charakteristisch war dabei, da $B$ das bisherige System nicht gänzlich zerstört oder umgebaut, sondern kopiert und ergänzt wurde. So entstanden neben den traditionellen Universitäten ,Kommunistische Universitäten", parallel zu der seit 1725 existierenden Russischen Akademie der Wissenschaften eine Sozialistische (seit 1923: Kommunistische) Akademie für Gesellschaftswissenschaften mit vier sogenannten Instituten der Roten Professur zur schnellen Ausbildung marxistischer Nachwuchswissenschaftler, usw. ${ }^{3}$ Die Etappe des Aufbaus war zugleich eine Etappe der Kooperation zwischen den bereits im russischen Kaiserreich etablierten, nicht-marxistischen und den bolschewistischen, d.h. sich zur Oktoberrevolution und den bol' 'eviki bekennenden Historikern. Diese

So lautet der Titel von John Reeds Augenzeugenbericht über die Oktoberrevolution, den Lenin „den Arbeitern in aller Welt von ganzem Herzen“ empfahl. Stalin ließ das Buch in den dreißiger Jahren aus den Bibliotheken entfernen und Historiker, bei denen es gefunden wurde. verhaften. - Reed. J.: Zehn Tage, die die Welt erschütterten (1919), 18. Auflage, Berlin 1982, 5; Medwedew, R. (= Medvedev, R.A.): Das Urteil der Geschichte. Stalin und Stalinismus, 3 Bände, Berlin 1992, hier Band 1, 41 und 84

2 Bis zu ihrem 7. Kongreß bzw. Parteitag im Frühjahr 1918 trug die Partei diesen Namen, seit der 7. Allrussischen Konferenz im Frühjahr 1917, mit dem Zusatz bol 'Yeviki. Von März 1918 bis 1925 hieß die Partei ,Russische Kommunistische Partei (bol 'Yeviki)". vom Dezember 1925 bis 1952 „Allnussische Kommunistische Partei (bol 'Keviki)“. Seit dem 19. Parteitag im Oktober 1952 trug die Partei den Namen „Kommunistische Partei der Sowjetunion“. - Siehe Chrestomatija po istorii KPSS, 2 Bände. M. 1989.

3 Siehe dazu im einzelnen Heller, I.: Die Entstehung und Entwicklung der neuen geschichtswissenschaftichen Institutionen in der Sowjetunion (von 1917 bis zur Mitte der 30er Jahre). Halle 1986; BSE (III) 24, kniga II, M. 1977, 372f; vgl. auch Newski, W./S. Rawitsch: Arbeiterund Bauern-Universitäten in Sowjet-Rußland, zweite Auflage, Berlin 1920. 
Zusammenarbeit, die vor allem in dem Historischen Institut der 1924 gebildeten Russischen Assoziation wissenschaftlicher Forschungsinstitute der Gesellschaftswissenschaften (Rossijskaja associacija naurno-issledovatel'skich institutov obstestvennych nauk - RANION) vonstatten ging, zeigte sich 1928 während der „Russischen Historikerwoche“ in Berlin und während des VI. Internationalen Historikerkongresses in Oslo, und sie fand damals gleichsam ihren AbschluB. ${ }^{4}$ Denn im gleichen Jahr eröffnete der bedeutendste bolschewistische Historiker der zwanziger Jahre, Michail Nikolaevic Pokrovskij (1868-1932) ${ }^{5}$, die ,ideologische Offensive" gegen die Nicht-Marxisten, die 1929 erweitert wurde zur ,Attacke auf deren institutionelle Basis".

Ein umfassender Prozeß des Umbaus und der Disziplimierung kennzeichnet die zweite Etappe der sowjetischen Geschichtswissenschaft. Die Personalentwicklung war ebenso betroffen wie der institutionelle Aufbau, die schulischen und universitären Ausbildungs- sowie die akademischen Forschungsbereiche, einschließlich der Geschichtstheorie und -methodologie. Auf verbale Verdikte folgten seit 1929 Repressionen und Verhaftungen zunächst „bürgerlicher", seit der ersten, offen dirigistischen Einmischung Stalins in die Parteigeschichtsschreibung 1931, auch namhafter bolschewistischer Historiker der zwanziger Jahre. ${ }^{7}$ Die Institutionen wurden konzentriert, meist dergestalt, daß man die nach 1917 gegründeten, eigentlich sozialistischen auflöste bzw. in die traditionellen Einrichtungen hineinverlegte, die daraufhin von marxistischen Historikern majorisiert und vollständig auf den Kurs der Stalinschen Geschichtsideologie gebracht wurden; in dieser Weise ging zum Beispiel 1936 die Kommunistische Akademie in die traditionelle Akademie der

4 „Aber es ist nicht eine Werkstatt nur, in die wir blicken, sondern es sind zwei Lager, in der grundsätzlichen Auffassung aufs stärkste voneinander getrennt." - So die Beobachtung von Otto Hoetzsch 1928/29 in: Aus der historischen Wissenschaft der Sovet-Union. Vorträge ihrer Vertreter während der ,Russischen Historikerwoche“, veranstaltet in Berlin 1928 von der Deutschen Gesellschaft zum Studium Osteuropas, hg. von Otto Hoetzsch, Berlin-Königsberg 1929, X (Hervorhebung von Hoetzsch; J.H.). Vgl. Erdmann, Die Ökumene, 178ff; Shteppa, Russian Historians, 24ff; Heller, Die Entstehung, 152ff; Enteen, G.M.: The Soviet Scholar-Bureaucrat. M.N. Pokrovskii and the Society of Marxist Historians, London 1978, 64ff, Kalistratova, T.I.: Institut istorii FON MGU - RANION (1921-1929), Novgorod 1992.

5 Zur Rolle und Bedeutung Pokrovskijs siehe Friese, C.: M.N. Pokrowskij, der fuihrende sowjetrussische Historiker der zwanziger Jahre zwischen kritischer Wissenschaft, Geschichtstheorie und Parteidoktrin, in: Dietrich, R. (Hg): Historische Theorie und Geschichtsforschung der Gegenwart, Berlin 1964, 117-149; Eissenstat, B.W.: M.N. Pokrovsky and Soviet Historiography. Some Reconsiderations, in: SR 1969, H. 4, 604-618; Sokolov, M.N. Pokrovskij 1970; Durovic, S.: Marksistiðka istoriografska łkola Poksovskog. Beograd 1977; Enteen. The Soviet ScholarBureaucrat; Hecker, H.: Russische Universalgeschichtsschreibung Von den "Vierziger Jahren" des 19. Jahrhunderts bis zur sowjetischen "Weltgeschichte" (1955-1965), München-Wien 1983, 180-190; Cernobaev, A.A.: „Professor s pikoj“”, ili Tri žizni istorika M.N. Pokrovskogo, M. 1992.

6 Barber, J.: Soviet historians in crisis. 1928-1932, New York 1981, 38; vgl. Enteen. The Soviet Scholar-Bureaucrat, $79 f f$.

1 Siehe Medwedew (= Medvedev, R.A.), Das Urteil, Band 1, 300 und 318ff; Barber, J.: Stalin's letter to the editors of Proletarskaya revolyutsiya, in: Soviet Studies 1976, H. 1, 21-41; ders., Soviet historians, $126 \mathrm{ff}$. 
Wissenschaften ein, deren Präsidium zwei Jahre zuvor von Leningrad nach Moskau verlegt worden war. ${ }^{8}$ Der Geschichtsunterricht in den Schulen und die universitäre Ausbildung wurden nach direkten Anweisungen Stalins neu konzipiert, die Lehrbücher entsprechend umgeschrieben. Nach Pokrovskijs Tod wurden seine wissenschaftiche "Schule" und seine Geschichtskonzeption kritisiert und als ,antimarxistisch" sowie ,antileninistisch" verteufelt. Eine plumpe materialistische, empiristisch-narrative Geschichtsschreibung ersetzte Pokrovskijs sozialwissenschaftliches Herangehen. Eine sowjetpatriotische, russisch-nationale Sicht auf die "vaterländische Geschichte" rückte an die Stelle seiner antinationalen, dem proletarischen Internationalismus verpflichteten Darstellung der russischen Geschichte. ${ }^{9}$ Die Publikationen zur Liquidierung der Schule Pokrovskijs und der 1938 herausgegebene Kurze Lehrgang zur Geschichte der Kommunistischen Partei markierten die vollendete Stalinisierung und Dogmatisienung der historischen Disziplin. ${ }^{10} \mathrm{Ge}-$ wisse Fortschritte können ihr dennoch auch in dieser Etappe nicht abgesprochen werden: Stärker als zuvor wurde die Geschichtswissenschaft staatlich gefördert, die Entfaltung aller Teildisziplinen besser beachtet, das Themenspektrum wieder erweitert; dabei stützte man sich vielfach auf 1929 verhaftete, nun wieder rehabilitierte „bürgerliche" Historiker, die ihre Ausbildung noch vor 1917 erhatten hatten. " Doch angesichts der zahlreichen und vielfaltigen Repressionen gegen Historikerinnen und Historiker sowie der inhaltlichen Fälschungen und Verflachungen der Historiographie können diese Momente nichts an der notwendigerweise im wesentlichen negativen Gesamtbewertung dieser Etappe ändern, die nicht zuletzt aufgrund der antisemitischen Kampagne gegen den ,Kosmopolitismus in der Geschichtsschreibung" 1948/49, der neuen Repressionen und der andauernden Unterdrückung bis $1953 \mathrm{zu}$ datieren ist. ${ }^{12}$

8 Siehe Barber, Soviet historians, 39ff, Graham, L.R.: The Soviet Academy of Sciences and the Communist Party, 1927-1932, Princeton 1967; Kasack, W.: Die Akademie der Wissenschaften der UdSSR. Überblick über Geschichte und Struktur. Verzeichnis der Institute, dritte Auflage, Boppard 1978, $17 \mathrm{f}$.

9 Siehe dazu Oberländer, E.: Sowjetpatriotismus und Geschichte. Dokumentation, Köln 1967; Artizov, A.N.: Sud'by istorikov కkoly M.N. Pokrovskogo (seredina 1930-ch godov), in: VI 1994, H. 7, 34-48.

10 Shteppa, Soviet Historians, 146ff; Enteen, The Soviet Scholar-Bureaucrat, 187ff; Protiv istoriðeskoj koncepcii M.N. Pokrovskogo. Sbornik statej. Cast pervaja, M.-L. 1939; Istorija VKP(b). Kratkij kurs, M. 1938.

$"$ Siehe SDG 2, 943; Rauch, G.v.: Grundlinien der sowjetischen Geschichtsforschung im Zeichen des Stalinismus, in: Europa-Archiv 1950, 3383-3388; 3423-3432; 3489-3494, hier 3423ff.

12 Emphatisch bewertete noch 1988 Aleksandr Barsenkov die Entwicklung der Geschichtswissenschaft im ersten Nachkriegsjahrzehnt als Zeit eines ,großen Aufschwungs" und der "Vollendung der Geschichtsmethodologie“. - Barsenkov, A.S.: Sovetskaja istoriceskaja nauka v poslevoennye gody (1945-1955), M. 1988. Siehe dagegen Shteppa, Soviet Historians, 209ff passim; Rauch, Grundlinien, 3489ff, Oberländer, Sowjetpatriotismus, 28ff und 88ff passim; Stökl, G.: Zur Ždanov-Ära in der sowjetischen Geschichtswissenschaft. Die Rubiň̌tejn-Diskussion, in: Sowjetsystem und Ostrecht. Festschrift für Boris Meissner zum 70. Geburtstag. Berlin 1985, 197210; Ponomarev, A.M./A.M. Ankudinova: Stalinizm i istoriCeskaja nauka, Jaroslavl' 1991, 136ff. 
Von diesen beiden Etappen des Aufbaus und der Kooperation (1917 bis 1928) sowie der Konfrontation und Stalinisienung (1928 bis 1953) ausgehend, wird im folgenden Verlauf der Arbeit unter anderem versucht, die weitere Periodisierung der Geschichte der sowjetischen Geschichtswissenschaft zu konkretisieren und zu begründen.

$\mathrm{Zu}$ erinnern bleibt, daß der oben erwähnte, seit den sechziger Jahren in der sowjetischen Historiographie geläufige Begriff der „Vaterländischen Geschichte“ (ote`estvennaja istorija) ein Synonym für die „Geschichte der UdSSR“ (istorija SSSR) darstellt, und „die Geschichte aller Völker und Bevölkerungen, die je auf dem heutigen Territorium lebten", alle territorialen Erwerbungen von der Frühzeit bis in die Zeitgeschichte umfaßt. ${ }^{13}$ Die Abgrenzung zwischen Vaterländischer und Allgemeiner Geschichte (vseobstaja istorija), aus denen die Weltgeschichte (vsemirnaja istorija) zusammengesetzt wird, wurde bereits 1755 bei der Gründung der Staatsuniversität in Moskau, der heutigen Lomonosov-Universität, angelegt. ${ }^{14}$ In der UdSSR wurde die Geschichtswissenschaft dreigeteilt: Neben die Vaterländische und Allgemeine trat die Parteigeschichte mit eigenen Periodika und separaten Parteihochschulen, Lehrstühlen an der Akademie für Gesellschaftswissenschaften und dem Institut für Marxismus-Leninismus beim Zentralkomitee der KPdSU. Thre Repräsentanten untersuchten und propagierten die Geschichte der Kommunistischen Partei sowie die Entwicklung der revolutionären Bewegung in Rußland und der internationalen Arbeiterbewegung.

Die UdSSR-Geschichte im engeren Sinn, also die sowjetische Periode seit 1917, und ihre uns interessierende Historiographie- und Methodologiegeschichte wurden zentral verwaltet und erforscht von den Institutionen der Akademie der Wissenschaften der UdSSR. Erst nach Stalin erhielten die Geschichtswissenschaftler wieder eine "eigene" Abteilung in dieser Leitstelle der Forschung (vgl. Kapitel 3.1.3.). ${ }^{15}$ Diese Abteilung organisierte die Ordentlichen und Korrespondierenden Akademiemitglieder unter den (seit dem Ende der siebziger Jahre) über dreitausend wissenschaftlichen Mitarbeitern, dirigierte und überwachte die Aktivität der ihr zugeordneten Institute für Archäologie, Ethnographie, Orientalistik, Slawistik und Balkanistik sowie (seit 1968) für Allgemeine Geschichte einerseits und für Geschichte der UdSSR andererseits (siehe dazu Kapitel 4.1.). ${ }^{16}$ Innerhalb des zentralistischen Wissenschaftsbetriebes waren die Direktoren der Institute immer kontrolliert durch die ihnen zugeordneten Parteisekretäre und angeleitet durch das sogenannte Büro der Geschichtsabteilung. Diesem gehörten neben den Institutsdi-

\footnotetext{
13 Siehe Geyer, Klio, 7 f.

14 Es wurden damals separate Lehrstühle für die Rußländische und die Universal-Geschichte eingerichtet. - Letopis' Moskovskogo universiteta 1755-1979, M. 1979, 17

is Zusammen mit den drei Abteilungen für Philosophie und Recht, für Wirtschaftswissenschaften sowie für Literatur und Sprache bildete die Abteilung für Geschichtswissenschaften die Sektion der Gesellschaftswissenschaften in der AdW. - Kasack. Die Akademie, 29 und 54.

16 Ebd., 97ff.
} 
rektoren die Parteisekretäre und weitere, kooptierte (Ordentliche oder Korrespondierende) Akademiemitglieder an. Primus inter pares war der Akademische Sekretär (akademik-sekretar'), der qua Amt sowohl als oberster Historiker nach außen als auch als Vermittler der Parteidirektiven nach innen figurierte und wirkte, und der uns deshalb im weiteren Verlauf wiederholt begegnen wird. 


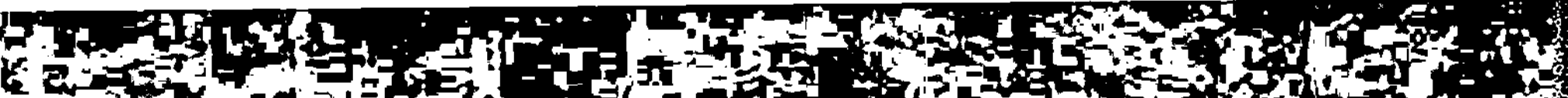

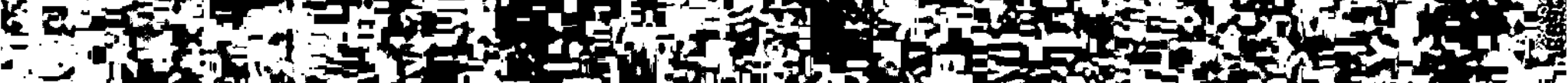

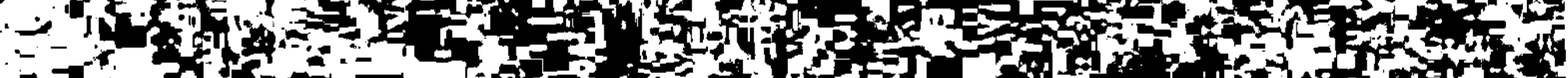

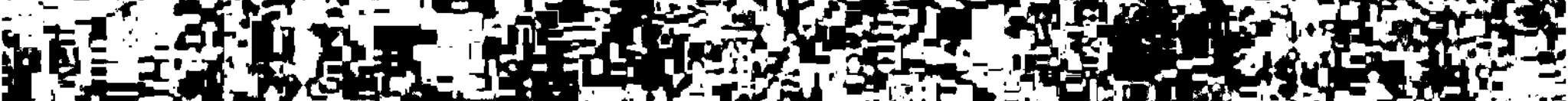

d

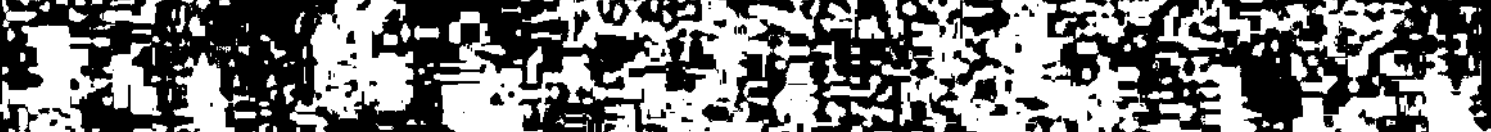

T

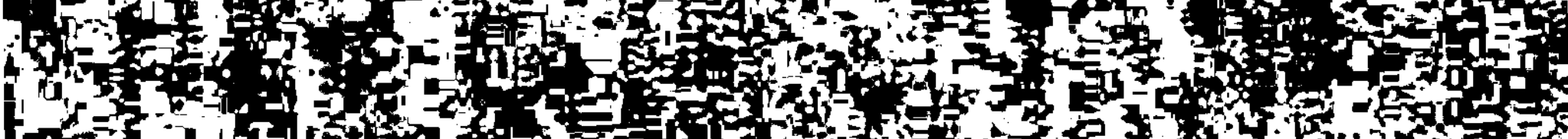

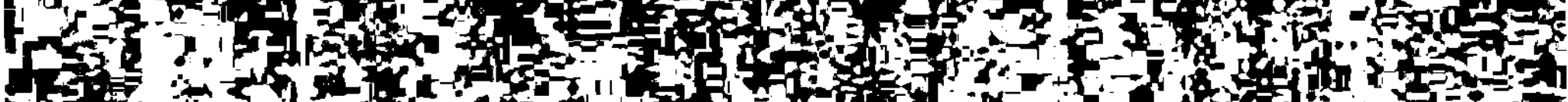

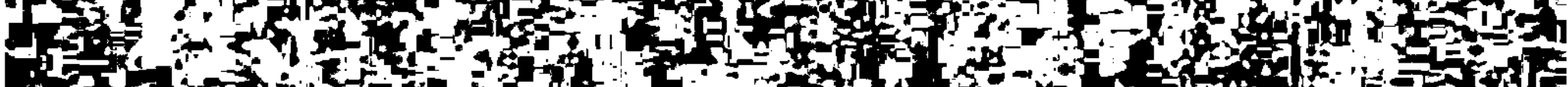

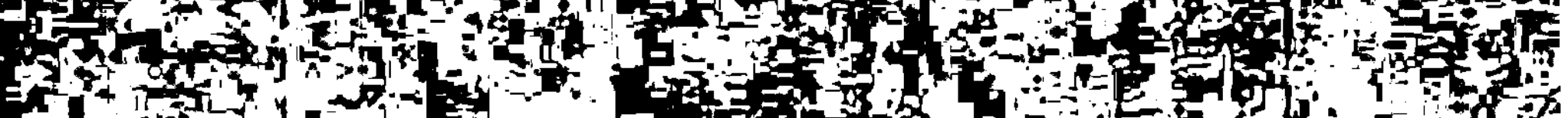

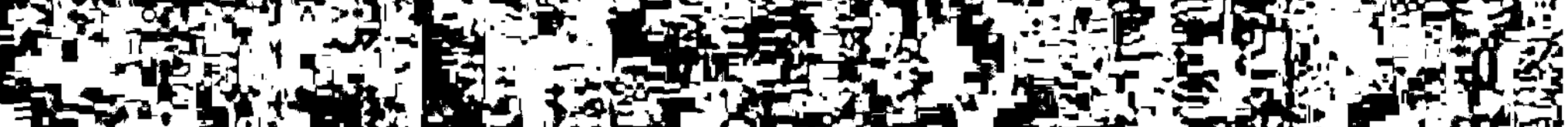
- S.

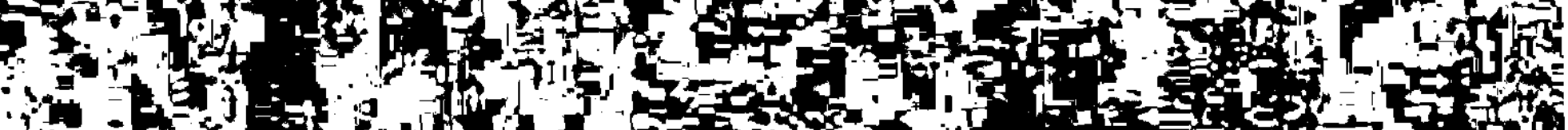

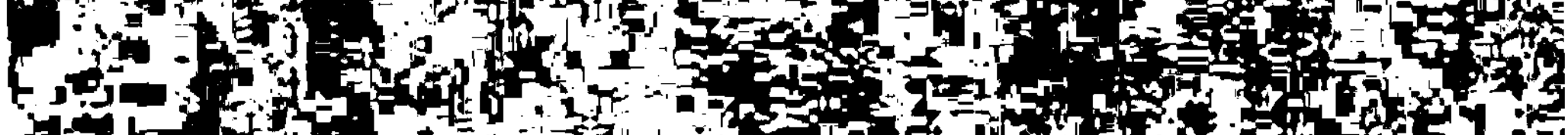

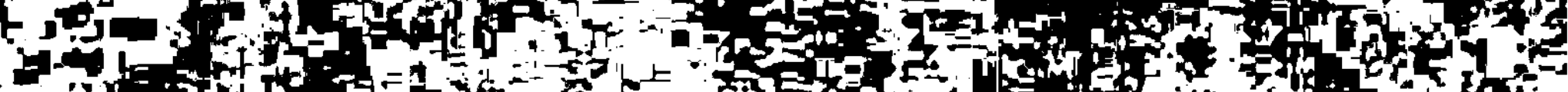

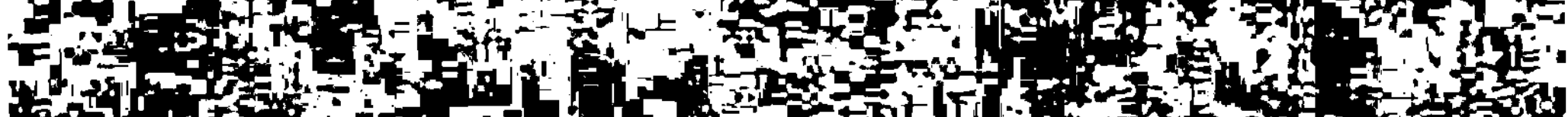

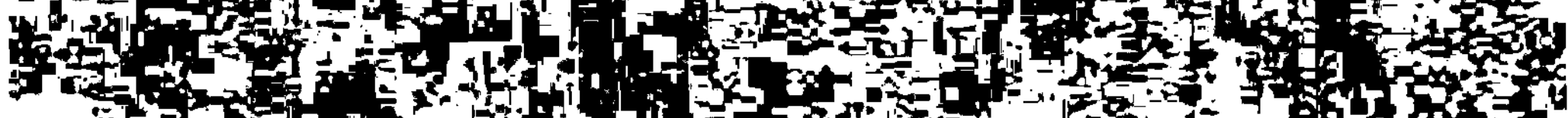
Fin

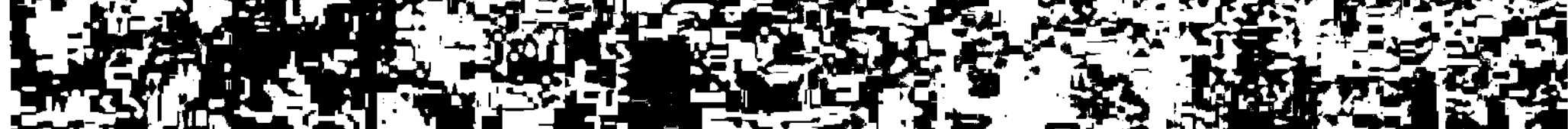

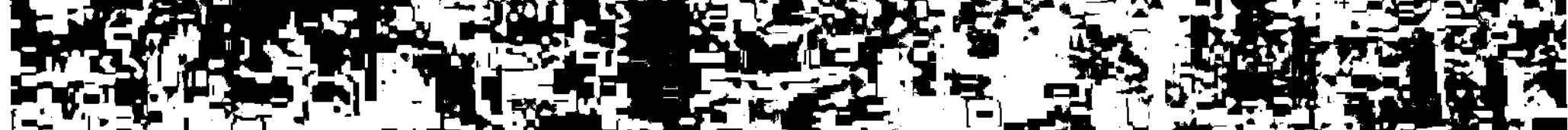

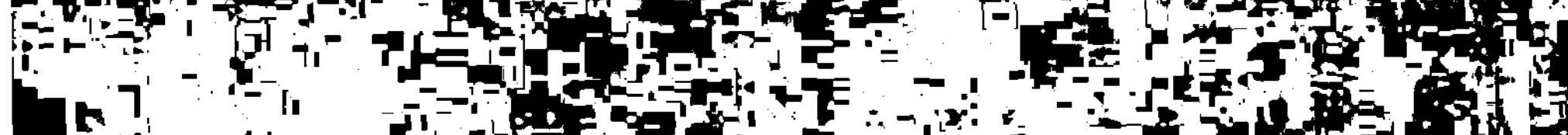

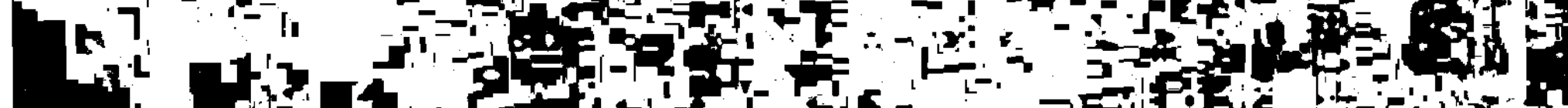

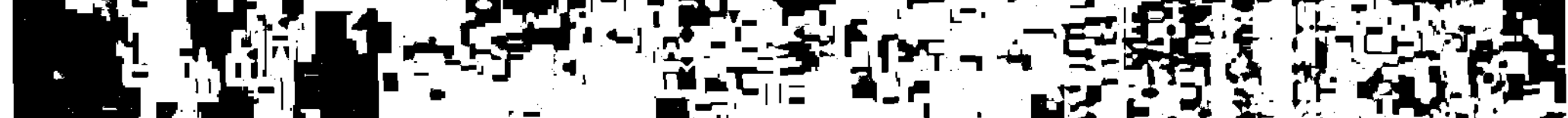

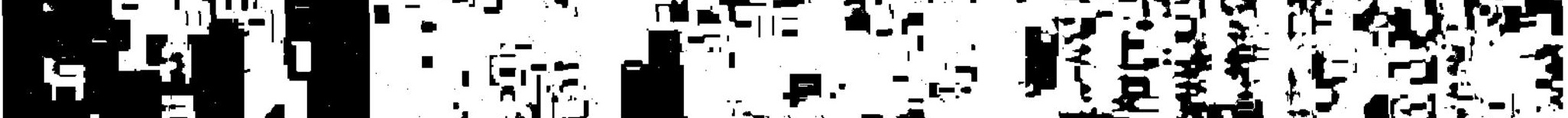

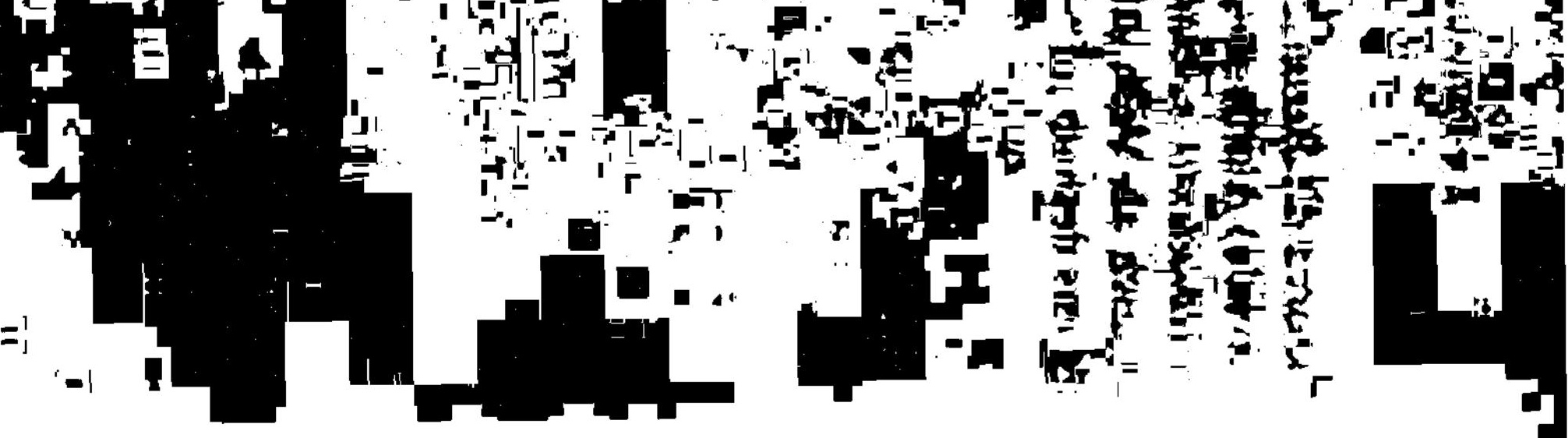




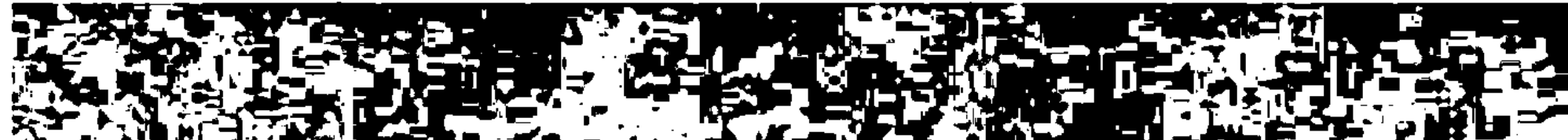

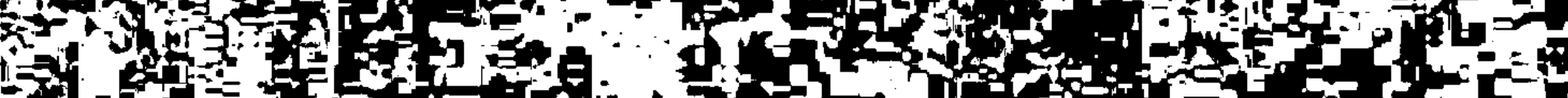

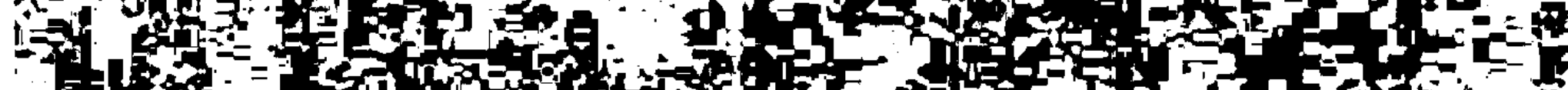

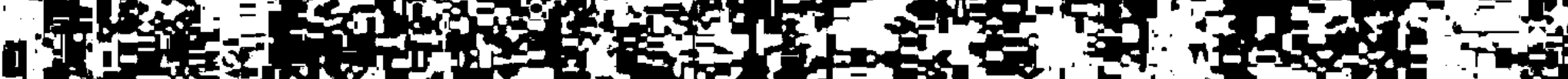

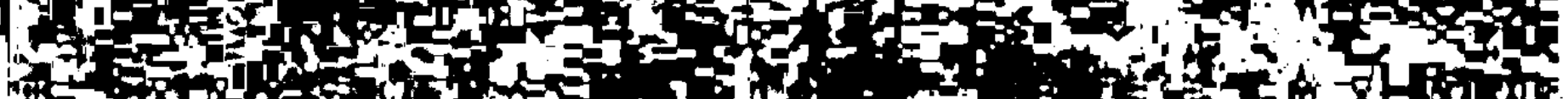

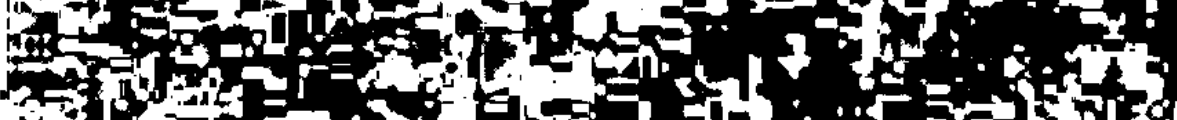
$\therefore$ a

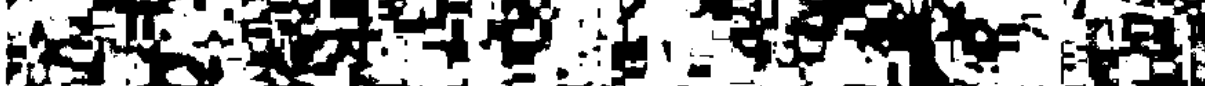

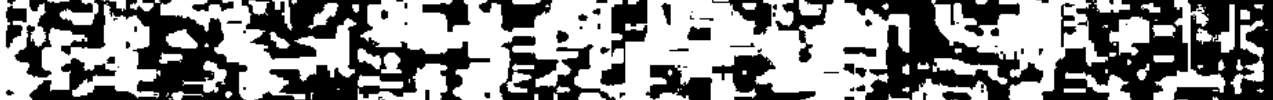
年

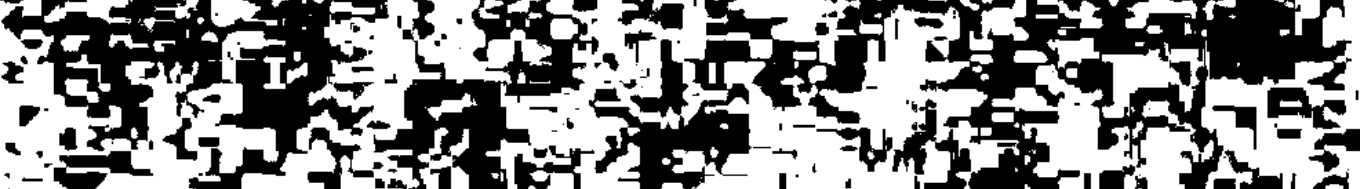

The

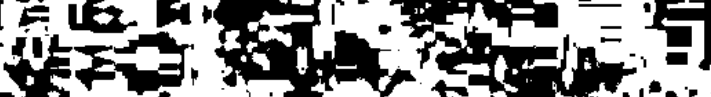
$2=-100 x$

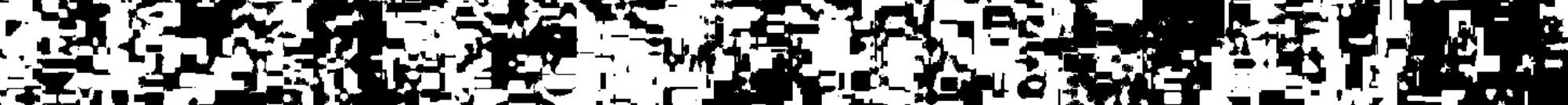

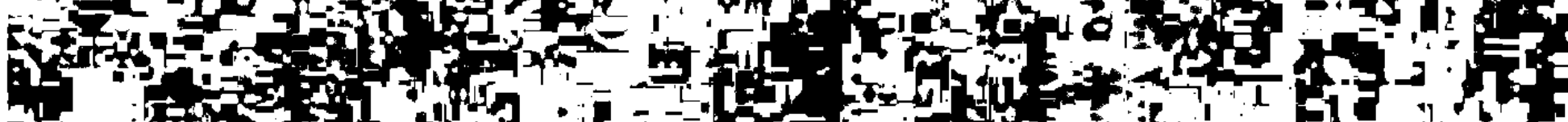

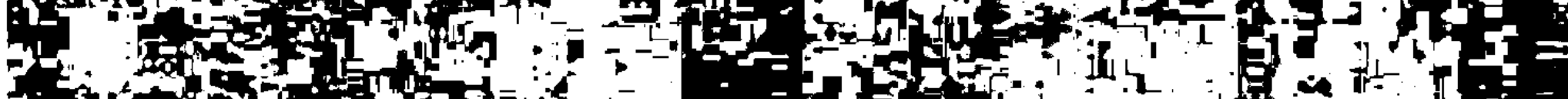
* 35

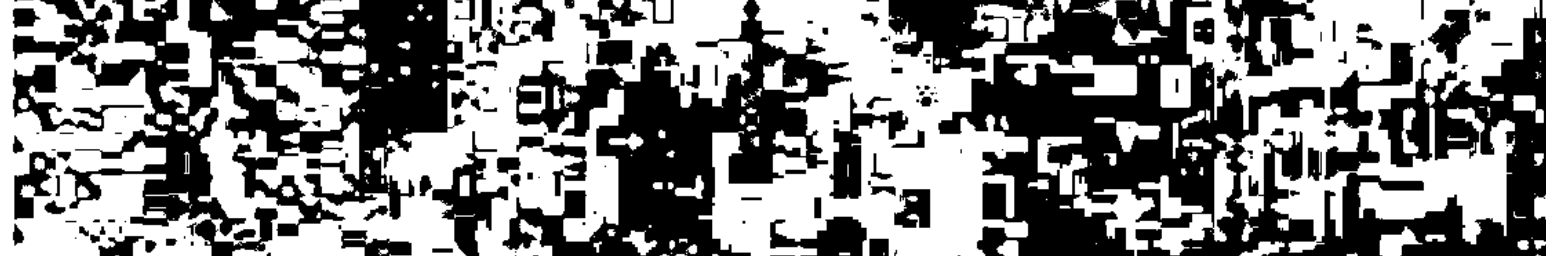
20.

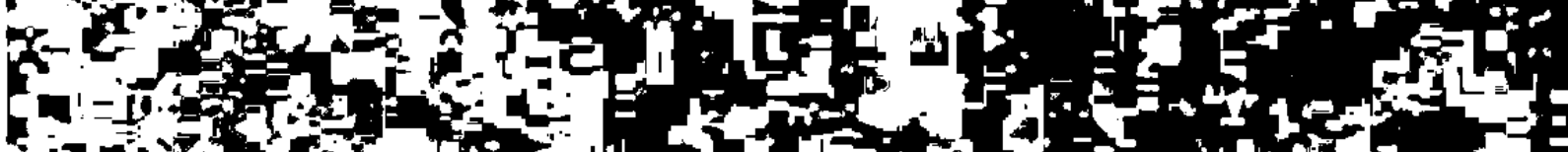

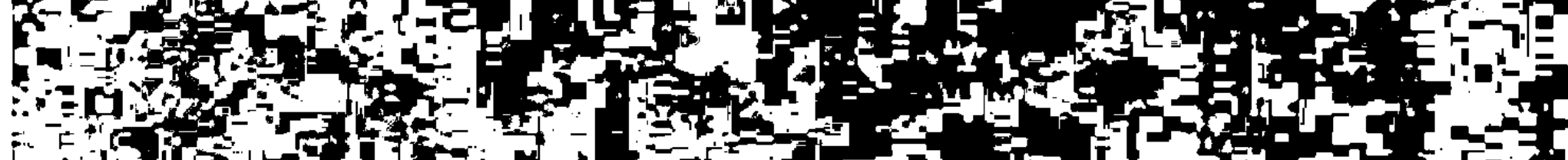

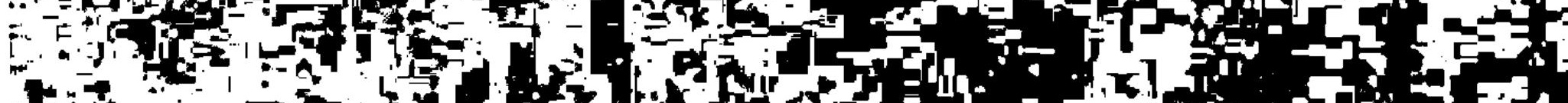

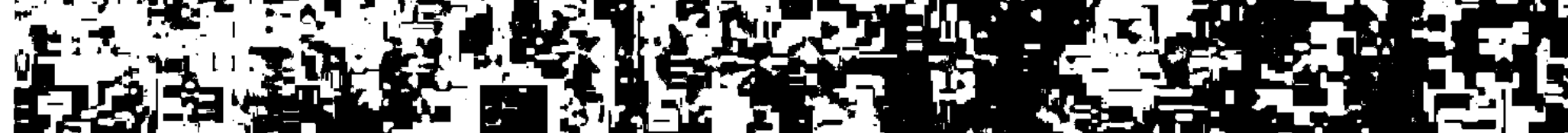
of (wither 340 .
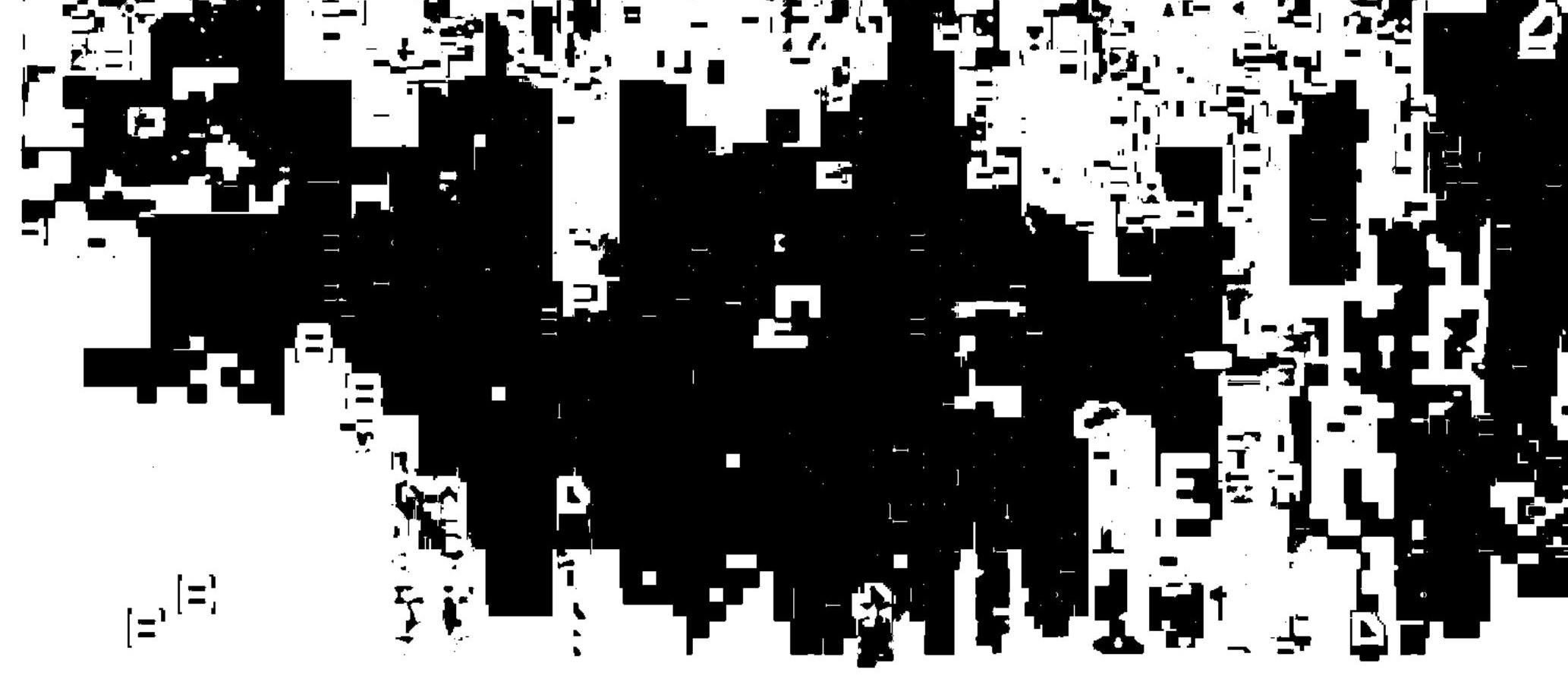


\section{Die sowjetische Geschichtswissenschaft 1953 bis 1960: Entstalinisierung und Antirevisionismus}

Das politische und kulturelle „Tauwetter" (ottepel') unter Chrušcev und die entsprechende Geschichtsdiskussion werden zuweilen immer noch datiert von 1956 bis 1964, von der berühmten "Geheimrede“ des Ersten Sekretärs im Anschluß an den 20. Parteitag der Kommunistischen Partei der Sowjetunion bis zu dessen Sturz im Oktober 1964, bestenfalls bis 1966 - dann seien alle Impulse der Ära Chruščev verbraucht gewesen. So schrieb Robert Davies 1989, daß nach dem 20. Parteitag

"the thaw among historians began almost immediately, and continued - with retreats and fresh starts - for ten years."

Martin Malia datierte noch 1994 in seiner Gesamtdarstellung der Geschichte der Sowjetgesellschaft "the beginnings of dissidence among the intellectuals" auf das Jahr 1956 und interpretierte diesen Beginn als direktes Produkt der ,secret speech". ${ }^{2}$

Bereits vor einem Vierteljahrhundert wies Wolfgang Leonhard auf die ,stille Entstalinisierung" in allen Bereichen von Staat und Gesellschaft unmittelbar nach Stalins Tod hin. ${ }^{3}$ Auch der durch vielerlei Repressionen und Schikanen 1976 zum Exil genötigte Historiker Aleksandr Nekrič erinnerte sich, daß die ,gesamte Atmosphäre des sowjetischen Lebens" sich ,sofort nach dem Tode Stalins" verändert habe. ${ }^{4}$

1 Davies, R.W.: Soviet History in the Gorbachev Revolution, Birmingham 1989, 1.

2 Malia, M.: The Soviet Tragedy. A History of Socialism in Russia 1917-1991, New YorkToronto 1994, 323.

3 „Die weitverbreitete Annahme, die Entstalinisierung, in der Praxis wie in der Ideologie, habe mit dem 20. Parteitag im Februar 1956 eingesetzt, ist unrichtig. Bereits in den ersten drei Jahren nach Stalins Tod vollzog sich eine 'stille Entstalinisienung', die die politische Atmosphäre der Sowjetunion beträchtlich veränderte." Leonhard begründete diese oft vergessene Feststellung mit den Veränderungen im Bereich der politischen Führung, bei der Leitung des Staatssicherheitsdienstes, der Wirtschafts-, Kultur-, Außen- und Wissenschaftspolitik. - Leonhard, W.: Die Dreispaltung des Marxismus. Ursprung und Entwicklung des Sowjetmarxismus, Maoismus und Reformkommunismus, Düsseldorf-Wien 1970, 187ff. Analog später auch Brandt, H.: Die soziale Revolution des Nikita Sergejewitsch Chruschtschow, in: Crusius, R.M. Wilke (Hg.): Entstalinisienung. Der XX. Parteitag der KPdSU und seine Folgen, FrankfurtM. 1977, 285-320, hier 297ff; Beyrau, D./I. Bock (Hg.): Das Tauwetter und die Folgen. Kultur und Politik in Osteuropa nach 1956, Bremen 1988, 8ff.

Nekrič, A.: Otrešis' ot stracha. Vospominanija istorika, London 1979, 119. - (Hier und im folgenden stütze ich mich auf diese russische Ausgabe, da die deutsche Übertragung - Nekritsch, A.: Entsage der Angst. Erinnerungen eines Historikers, Frankfurt/M. usw. 1983 - nicht vollständig ist.) 
Die Verhaftung Lavrentij Berijas,des gefürchteten Innenministers Stalins, am 26. Juni 1953 förderte diesen Wandel. ${ }^{s}$

In den folgenden Kapiteln wird diesen Hinweisen hinsichtlich der historischen Disziplin nachgegangen und untersucht, ob nicht auch auf diesem Plateau Entstalinisierungstendenzen vor dem 20. Parteitag feststellbar sind. Wie läßt sich die Entwicklung der Geschichtswissenschaft in den gesamtgesellschaftlichen Wandel einordnen? Verläuft jene deckungsgleich oder quer zu diesem? Um dies zu klären werden die Publikationen der Historikerschaft, vor allem die damals einzige unionsweite allgemeine Fachzeitschrift Voprosy istorii, und das im Archiv des Zentralkomitees der KPdSU aufbewahrte Material zum entsprechenden Zeitraum analysiert. Da die Redaktion der Voprosy istorii im Frühjahr 1957 bereits wieder eine neue Leitung erhielt, erscheint es angebracht, zunächst die Jahre unmittelbar nach Stalins Tod bis Anfang 1957 (Kapitel 3.1.) und danach die Zeitspanne 1957 bis $1959 / 60 \mathrm{zu}$ betrachten (Kapitel 3.2.).

\footnotetext{
3 „Berija wurde von Stalinisten mit stalinistischen Methoden gestürzt, aber sein Tod trieb die Entstalinisierung voran." - Arazi, D.: Ein Putsch im Kreml, in: Die Zeit v. 30.08.1991, 45f, hier 46. Vgl. Kolendic, A.: Machtkampf im Kreml. Vom Tode Stalins bis zur Hinrichtung Berijas, Bergisch-Gladbach 1983; Heller, M./A. Nekrich: Geschichte der Sowjetunion. Zweiter Band: 1940-1980, Königstein 1982, 209ff; Nekrasov, V.F. (Hg.): Berija: konec kar'ery, M. 1991; Knoll, V./L. Kölm (Hg.): Der Fall Berija. Protokoll einer Abrechnung. Das Plenum des ZK der KPdSU Juli 1953. Stenographischer Bericht, Berlin 1993.
} 


\subsection{Die historische Disziplin unmittelbar nach Stalin 1953 bis 1957}

Auf den ersten Blick scheinen die Leserinnen und Leser der Voprosy istorii von Stalins Tod am 5. März 1953 im voraus erfahren zu haben: Das Ableben des „Kampfgefährten und genialen Fortsetzers der Sache Lenins, des weisen Führers und Lehrers der Kommunistischen Partei und des sowjetischen Volkes" wurde „schon“ im Februar-Heft der damals einzigen zentralen Fachzeitschrift für Geschichtswissenschaft bekanntgegeben. ${ }^{1}$ Tatsächlich aber war es so, daß selbst die Januar-Ausgabe der Voprosy istorii erst am 31. März 1953 ausgeliefert wurde. ${ }^{2}$ Mit entsprechender Verspätung und dennoch ohne einschneidende Veränderungen erreichten auch die folgenden Hefte ihr Publikum. Als sei nichts geschehen, wurde beispielsweise in den März- und April-Ausgaben die Artikelserie fortgesetzt, mit der Stalins letzte Schrift über "Ökonomische Probleme des Sozialismus in der UdSSR" propagiert werden sollte.

Die ersten Anzeichen für Veränderungen gab es in der Mai-Ausgabe der Zeitschrift. Hier wurde berichtet von einer Sitzung des Präsidiums der Akademie der Wissenschaften im März 1953, höchstwahrscheinlich nach dem 5. 3., bei der in ungewohnter Offenheit die Tätigkeit des Geschichtsinstituts für unzulänglich erklärt wurde und entsprechende Maßnahmen beschlossen wurden. Im einzelnen wurde bemängelt, da $B$ im Institut Kritik und Selbstkritik nicht entwickelt seien, schöpferische Diskussionen nicht geführt würden, keine hinreichende Verbindung mit der ,wissenschaftlichen Öffentlichkeit" bestehe, die Anleitung und Kontrolle seitens der Institutsleitung schwach sei und die Institutspläne Jahr für Jahr nicht erfüllt würden. ${ }^{4}$ Die Tätigkeit müsse daher umgestaltet werden (dolšna byt' perestroena). Konkret wurde allerdings nur die Bildung füf neuer wissenschaftlicher

\footnotetext{
1 Siehe VI 1953, H. 2, 3

2 So die Mitteilung von Sidorov, A.L. am 31.03.1953 an M.A. Suslov und P.N. Pospelov, in: CChSD f. 5, op. 17 , d. 426,6 f.
}

3 Stalin, I.V.: Ekonomičeskie problemy socializma v SSSR. Učastnikam ekonomičeskoj diskussii. Zamečanija po ekonomičeskim voprosam, svjazannym s nojabr`skoj diskussiej 1951 goda (1952), in: StW 16, 188-245. - Vgl. Burdð̌alov, E.N.: Značenie truda I.V. Stalina 'Ekonomičeskie problemy socializma v SSSR' dlja izučenija istorii sovetskogo socialističeskogo obščestva. in: VI 1953, H. 3, 3-32; Gal'kin, I.S.: Značenie truda I.V. Stalina 'Ekonomičeskie problemy socializma v SSSR' dlja razrabotki voprosov novejšej istorii, in: VI 1953, H. 4, 3-17. Utechin bezeichnete diese Artikel wohl zu Recht als Teil der „(..) late-Stalinist campaign for eleminating 'subjectivism' and the 'remnants of Marrism' in history (...)", welche im Theorieorgan Bol 'sevik (ab 1953 Kommunist) 1952, H. 13 begonnen hatte. - Utechin, S.V.: Soviet Historiography after Stalin, in: Keep. Contemporary History, 117-129, hier 122: vgl. Openkin. L.A.: I.V. Stalin: poslednij prognoz buduščego ( $l z$ istorii napisanija raboty „Ekonomičeskie problemy socializma v SSSR“), in: VIKPSS 1991, H. 7, 113-128.

Siehe VI 1953, H. 5, 126. 
Gruppen (sektory) im Institut beschlossen, so daß von Mai 1953 zwölf davon arbeiteten. $^{s}$

Nach diesem eher dürttigen Umgestaltungsbeitrag häuften sich die Neuerungen. Drei von führenden Fachhistorikern ausgehende Bemühungen prägten die Entwicklung der Geschichtswissenschaft von Mitte 1953 bis Anfang 1957. Es ging erstens um die Neudefinition der Rolle und Bedeutung des zentralen Fachorgans Voprosy istorii, zweitens um die Verständigung über den Forschungsstand und notwendige inhaltliche Revisionen, drittens um die Neubestimmung des Verhältnisses von Einzelwissenschaft (Geschichtswissenschaft) und Philosophie (Historischer Materialismus).

\subsubsection{Die Neuprofilierung der Voprosy istorii}

Voprosy istorii, 1941 aus Istorik-marksist ${ }^{6}$ hervorgegangen, war 1953 noch die einzige unionsweit erscheinende allgemeine Fachzeitschrift für Geschichte. Sie war zuständig für die gesamte „Vaterländische Geschichte“ von den Anfängen bis zur Gegenwart, für die Allgemeine Geschichte, die Parteigeschichte und die historische Entwicklung der internationalen Arbeiterbewegung. Damit war die meist nur 130 Seiten umfassende Monatszeitschrift völlig überfordert, nicht zuletzt deswegen, weil die zahllosen ideologiegetränkten Leitartikel und Stalim-Exegesen kaum noch Platz für substantielle Aufsätze ließen. Die „Visitenkarte“ der sowjetischen Geschichtswissenschaft bot Anfang 1953 einen erbärmlichen Eindruck.

In seinem eingangs zitierten Schreiben an Suslov und Pospelov stellte der damalige Direktor des Geschichtsinstituts Sidorov' am 31. März 1953 ungeschminkt fest,

3 Neu waren die Gruppen ,für die Publikation von Quellen zur Geschichte der UdSSR“, ,zur Abfassung einer Geschichte der UdSSR und von Lehrbüchern", „für neue und neuere Geschichte der Länder Amerikas“, „für die Geschichte der Länder der Volksdemokratien“, zur Abfassung der "Weltgeschichte“; ebd., 127.

6 Siehe Alatorceva, Zurnal.

$1 \quad$ Arkadij Lavrovix Sidorov (27.01.1900-11.03.1966), Parteimitglied seit 1920, begann 1924 am Institut der Roten Professur zu studieren, gehörte zur Schule Pokrovskijs, war aber zunächst im Parteiauftrag propagandistisch tätig, erst seit Ende der dreißiger Jahre wissenschaftlichpädagogisch. Die Verzögenung in Sidorovs wissenschaftlicher Karriere führte Nekrið darauf zunick, daß der ansonsten, zweifellos fähige und dynamische Mensch“, der in der Regel ,gegen alle kämpfte, gegen die nach Meinung der Partei gekämpft werden mußte“, eine Zeitlang „jrgendwo die Trotzkisten unterstützte“. Er habilitierte sich 1943, war 1948 bis 1952 Prorektor der Staatlichen Lomonosov-Universität in Moskau, 1953 bis 1959 Direktor des Instituts für Geschichte an der AdW. Während der antisemitisch gefärbten Kampagne gegen den „Kosmopolitismus“ 1948 attackierte Sidorov besonders Akademiemitglied Minc, mit dem er, so vermutete Nekrix, ,alte Rechnungen offen hatte“. 1952 wurde auch der damals 32-jährige Nekrix von Sidorov ,methodologischer Fehler“ geziehen. Nekric zufolge organisierte Sidorov 1956 auch die stalinistischen Attacken gegen Anna Pankratova und Eduard Burdžalov bei einer öffentlichen Konferenz in der Historischen Bibliothek. Als Wissenschaftsfunktionär agierte Sidorov also mehrfach destruktiv. Als Wissenschaftler scheint er recht originell und konstruktiv gewesen zu sein. In den Nekrologen verwendeten Volobuev und Bovykin, beide stark beeinflußt von Sidorov 
daß sich an der Redaktionsarbeit der Voprosy istorii trotz schon 1952 geäußerter Kritik nichts gebessert habe. Im Gegenteil:

„Faktisch ist das Redaktionskollegium der Zeitschrift völlig auseinandergefallen." ${ }^{\text {“8 }}$

Für den notwendigen Neubeginn schlug Sidorov vor, Anna Michajlovna Pankratova, Korrespondierendes Akademiemitglied, zur Chefredakteurin, Eduard Nikolaevič Burdžalov und Ivan Ivanovič Udal'cov zur ihren Stellvertretern zu ernennen. Die folgenden Monate sollten zeigen, daß Sidorov nicht die schlechteste Wahl getroffen hatte. Unter der neuen Chefredakteurin ${ }^{10}$ und dem ,Motor" der Redaktion,

und zugleich von den fünfziger Jahren bis in die Gegenwart geradezu verbissene Kontrahenten, den Begriff der „Schule Sidorovs“; sie meinten damit das von ihm ,(...) organisierte und geleitete wissenschaftliche Kollektiv, das unter persönlicher Beteiligung Arkadij Sidorovs die gemeinsame Forschungsarbeit auf dem Gebiet der sozialökonomischen und politischen Geschichte des russischen Imperialismus verwirklichte." (Volobuev). Dazu zählten - und dies reflektiert Sidorovs Widersprüchlichkeit - sowohl Vertreter als auch Gegner der „Neuen Richtung“, u.a. A.M. Anfimov, A.Ja. Avrech, V.I. Bovykin, L.S. Gaponenko, M.Ja. Gefter, T.D. Krupina, K.N. Tarnovskij und P.V. Volobuev. - Bovykin, V.I.: Pamjati A.L. Sidorova, in: VMU Serija IX (Istorija) 1967, H. 2, 84-91; SIE 12, M. 1969, 857f: Tarnovskij, K.N.: Put' utenogo, in: IZ 80, M. 1967, 207244; Volobuev, P.V.: A.L. Sidorov kak universitetskij professor, in: OI 1993, H. 2, 121-127; Nekrič, Otrešis' ot stracha, 50f, $100 f, 146$.

8 Im einzelnen: A.D. Nikonov arbeite beim Theorieorgan Kommunist, A.D. Udal'cov sei lange krank gewesen, B.D. Grekov fehle seit langem wegen Krankheit, I.M. Volkov und S.F. Najda "kränkeln systematisch" (sistematiłeski bolejut). Gewöhnlich nähmen an den Redaktionssitzungen ein oder zwei Mitglieder teil. - Sidorov am 31.03.1953, 6.

9 Ebd., 6f. Sidorovs Vorschlag wurde von der Parteifuhrung begrüßt; Pankratova sollte 4.000, ihre Stellvertreter sollten 3.000 Rubel Monatslohn erhalten; siehe Pospelov, P.M. Suslov/A. Rumjancev/A. Nesmejanov am 15.05.1953 an N.S. Chrušcev, in: CChSD f. 5, op. 17, d. 426, 2830.

10 Anna Michajlovna Pankratova (08.02.1897-25.05.1957), die mit neun oder zehn Jahren ihren Vater verloren hatte, schloß 1917 ihr Geschichtsstudium ab, war seit 1919 Parteimitglied und studierte 1922-25 am legendären Institut der Roten Professur bei M.N. Pokrovskij weiter, zu dem sie eine Tochter-Vater-ähnliche Beziehung aufbaute und dessen namhafteste Schülerin sie in der zweiten Hälfte der zwanziger Jahre wurde. Sie profilierte sich unter seiner Anleitung durch Studien zur Geschichte der russischen Arbeiterklasse und hinterließ etwa zweihundert Veröffentlichungen. Wie bei ihrem Lehrer war ihre Forschungsarbeit stets von intensiver Organisationstätigkeit begleitet

An der 1934 begonnenen Liquidierung der Schule Pokrovskijs war Pankratova an vorderster Stelle beteiligt. Dieser ungeheure Tatbestand findet wohl in der ,intensiven 'Bearbeitung'“ (Artizov) eine Erklärung, der Anna Panksatova und ihr Freundeskreis in der zweiten Hälfte der dreißiger Jahre ausgesetzt waren: Die Redaktion der Zeitschrift „Geschichte des Proletariats der UdSSR", an der Pankratova mitarbeitete, wurde geschlossen. Am 26.08.1936 wurde Pankratova aus der Partei ausgeschlossen (der erste Schauprozeß gegen Zinov'ev und Kamenev fand vom 19. bis zum 24.08.1936 statt!). Vorgeworfen wurden ihr ihre Beziehung zu dem als "Trotzkist“ bezeichneten Historiker G. Jakovin und ihre freundschaftlichen Verbindungen mit „Konterrevolutionären" (genannt wurden Fridljand, Vanag, Zajdel', Bessonov), die sie der Partei gegenüber verteidigte. Darüber hinaus wurde Pankratova vorübergehend an die Universität Saratov abkommandiert. Am 10.08.1938 (02. bis 13.03.38 hatte der dritte Schauprozeß gegen Bucharin und Radek stattgefunden!) wurde sie wieder in die Partei aufgenommen. 1939 erschien der erste von 
Burdžalov", - Udal'cov trat nicht nennenswert in Erscheinung ${ }^{12}$ - wurde die Zeir schrift Subjekt und Objekt quantitativer und qualitativer Veränderungen: Das Rt daktionskollegium wurde fast vollständig erneuert ${ }^{13}$, die Auflage um fuinfunc-

zwei ,gegen die Geschichtskonzeption M.N. Pokrovskijs“ gerichteten Sammelbänden mit Pantratovas Kritik an erster Stelle.

Als Chefredakteurin der Voprosy istorii setzte sie sich ein für den parteilosen Historiker fir Neuere Geschichte. Prof. S.B. Kan (1896-1960), der Repressalien ausgesetzt war, weil er an 25.11.1917 als Petrograder Kadettenschüler das Winterpalais gegen die Bol'ševiki mitverteidị̆t hatte. Nach mehrjähriger Lehrtätigkeit entließ man ihn 1952 oder '53. Auch für V.V. Al'tmal. der als ehemals aktiver Trotzkist (1923-32) galt, aus der Partei ausgeschlossen, 1951 inhaftiet und 1953 amnestiert worden war, setzte sie sich ein; darüber hinaus für Astrov, früher den rechts-trotzkistischen Block zugerechnet, für Minc und Deborin u.a. Pankratova versuchte, diese u.a. bei der Arbeitssuche zu helfen, was schon im Herbst 1953, bei ihrer Kandidatur zum Volmitglied der AdW, und auch 1955ff gegen sie verwandt wurde. Trotz der Proteste einiger Stalnisten wurde Pankratova im Dezember 1953 Akademiemitglied. - Siehe CChSD f. 5, op. 17, 6. 425, 268; Volgin, V.P./A.M. Pankratova am 19.09.1953 an P.N. Pospelov, in: CChSD f. 5, ol. 17, d. 425, 244f; ebd., 252-268; Rumjancev, A. am 17.06.1955 an das ZK der KPdSU, i1: CChSD f. 5, op. 17, d. 520, 95-101, hier 96f; Pankratova, A.: Razvitie istoričeskich vzgljado M.N. Pokrosvkogo, in: Protiv istoričeskoj koncepcii, 5-69; Artizov, A.N.: Kritika M.N. Pskrovskogo i ego školy (K istorii voprosa), in: ISSSR 1991, H. 1, 102-120; MERSH 26, 224-22'; Badja, Akademik. (Badja wich, obwohl sie Zugang zu den Pankratova-Fonds im Archiv der AdV (f. 697), der Kommunistischen Akademie (f. 350), des Instituts fur Geschichte an der Kommınistischen Akademie (f. 359) hatte, den Brüchen und Widersprüchen im Leben und Werk d:r Historikerin aus. So entstand bloß ein geschöntes Bild. Die Biographie, die dem Menschen urd der Wissenschaftlerin Anna Pankratova gerecht wird, ist noch zu schreiben.)

11 Nekrič, Otrešis' ot stracha, 143, nannte Eduard Nikolaevic Burdzalov so. Dessen Lebłn (1906-1985) war kaum weniger widersprüchlich als das Pankratovas. Der langjährige Propagardist und leitende Mitarbeiter im ZK der KPdSU begann als stellvertretender Chefredakteur d:r Zeitschrift „Kul'tura i łizn “",abweichende“ Artikel uber den spontanten Charakter der Februarevolution $1917 \mathrm{zu}$ veröffentlichen, was ihm bereits vor seiner Tätigkeit bei Voprosy istoril Au:einandersetzungen mit etablierten Revolutions-Historikern einbrachte. - Siehe ebd., $143 \mathrm{ff}$.

12 Nekrič, der seine Dissertation am selben Tag (am 19.Mai 1949) wie Udal'cov verteidigt, berichtete, dieser habe sich von einem guten, entgegenkommenden .Jungen“ zu einem leiderschaftichen Stalinisten gewandelt. Abwechselnd hatte Udal'cov im Institut für Slawistik an der AdW und im ZK-Apparat gearbeitet, ehe er Botschaftsberater in Prag wurde. Dort soll er $1968 \mathrm{zu}$ denjenigen gezählt haben, „(...) welche die härtesten, entschlossentsten Maßnahmen gegen de unbotmäßigen Tschechen forderten." - Ebd., 67.

13 Weitere neue Redaktionsmitglieder waren: A.V. Arcichovskij, P.P. Epifanov, N.A. Smirno\%, M.N. Tichomirov, I.A. Fedosov, V.M. Chvostov. Von der alten Redaktion wurden lediglich de hochangesehenen B.D. Grekov und M.N. Družinin übernommen. Es schieden aus: I.M. Volkor, S.F. Najda, A.D. Nikonov, A.L. Sidorov und A.D. Udal'cov sowie der ehemalige Chefredakteur Petr Nikolaevic Tret'jakov, (30.10.1909-12.06.1976), Studienabschluß (Archäologie und G:schichte) an der Leningrader Staatsuniversität 1930, dort von 1934 bis 1941 auch Dozent. Parteimitglied seit 1940. Nach dem Krieg arbeitete er bis 1950 im ZK-Apparat in der Wissenschaftsabteilung der Leitung von Propaganda und Agitation und war zeitgleich Professor am Lehrstunl für UdSSR-Geschichte an der Akademie für Gesellschaftswissenschaften beim ZK der KPdSU. 1950 bis 1953 war er Chefredakteur bei Voprosy istorii, $1951-59$ Direktor des Instituts fur Slawistik, 1954 bis 1959 auch stellvertretender Akademischer Sekretär der Abteilung Geschichtswissenschaften der AdW. 1958 wurde er zum Korrespondierenden Akademiemitglied gewählt. 1966 bis 1970 war er nochmals Professor, diesmal an der Leningrader Staatsuniversität, von 
zwanzig Prozent erhöht ${ }^{14}$ und der Umfang der Hefte erweitert; die Zahl der Aufsätze und Rezensionen sowie der Autoren, vor allem auch aus der Peripherie, die vor 1953 unterrepräsentiert war, wurde gesteigert. ${ }^{15}$ Rubriken für Diskussionsbeiträge wurden eingerichtet und aufgewertet. ${ }^{16}$ Ein Novum war, daß die Redaktion sich der wissenschaftlichen Öffentlichkeit stellte, um über die Qualität und Funktion der Zeitschrift zu diskutieren. Referate und Diskussionen in den Sitzungen der Leitungsgremien konnten jetzt nachgelesen werden. ${ }^{17}$ Ebenso die in eigens organisierten ,Leserkonferenzen“ und Gesprächsrunden mit dem ,Autoren- und Leser-

1959 bis zu seinem Tode höherer wissenschaftlicher Mitarbeiter am Archäologie-Institut der AdW in Leningrad. - VI 1953, H. 5, 144; H. 6, 176; VI 1970, H. 5, 160-162; VI 1976, H. 10 , 217f: Biobibliografija učenych SSSR, Serija istorija. Vyp. 15, M. 1983, 3-6; BSE (III) 26, 191.

Bis Anfang 1957 gab es nur noch einzelne Veränderungen: Grekov starb am 09.09.1953; Chvostov schied Ende 1953 ohne Angabe von Gründen aus; Mitte 1954 verließ Arcichovskij die Redaktion, kehrte Ende des Jahres wieder zurück (das ZK warf Pankratova vor, sie habe Arcichovskij entlassen: Pankratova teilte mit, Arcichovskij sei „auf seine Bitte“ hin von den Pflichten befreit und als er von neuem mitarbeiten wollte, auf ihren Vorschlag hin wieder eingestellt worden); Mitte des Jahres 1954 kamen A.S. Erusalimskij, S.D. Skazkin und G.D. Običkin in die Redaktion; Anfang 1955 verließ I.I. Udal cov das Kollegium, für ihn kam I.A. Chrenov; Ende 1956 verließ Običkin wieder die Redaktion. weil er erster Chefredakteur der neuen Zeitschrift fur Parteigeschichte Voprosy istorii KPSS wurde. - VI 1953, H. 9, 164-167; H. 12, 192; VI 1954, H. 6, 192; H. 11, 192; Pankratova, A.M. im Mai 1955 an das ZK der KPdSU, in CChSD f. 5, op. 17, d. 520, 8-38, hier 38: VI 1954, H. 6, 192; VI 1955, H. I, 192; VI 1956, H. 1, 196; H. 2, 224.

14 Seit Anfang 1952 bis einschließlich Heft 8 des Jahres 1953 erschienen 40.000, ab Heft 9 S0.000 Exemplare.

is Darüber berichtete Pankratova am 25.06.1954 bei der erweiterten Sitzung des Wissenschaftlichen Rates des Akademieinstituts für Geschichte. Demnach wären unter der neuen Redaktion in zwölf Heften 256 Aufsätze und Rezensionen publiziert worden, in den vorangegangenen zwölf Ausgaben nur 167. Siehe Obsuždenie raboty żurnala „Voprosy istorii“, in: VI 1954, H. 9, 175177, hier 175.

1953 zählte die Redaktion 193 Autorinnen und Autoren, 1955: 442 (Nach: Konferencija citatelej žurnala „Voprosy istorii“, in: VI 1956, H. 2, 199-213, hier 200). In Pankratovas Rechenschaftsbericht an das ZK über das Jahr 1954 waren die Zahlen nicht ganz so hoch, drückten aber ebenfalls Steigerungen aus: Veröffentlichung von insgesamt 326 ,Materialien“ (fünf Leitartikel, 69 Aufsätze, 29 Mitteilungen, achtzehn Diskussionsbeiträge, fuinfzehn Briefe und Marginalien, 120 Rezensionen, 70 Kurzinformationen); beteiligt seien 287 Autorinnen und Autoren gewesen, darunter 101 sowjetische von außerhalb Moskaus. - Pankratova, A.M.: Otzet o rabote redakcii žurnala „Voprosy istorii“ za 1954 god (26.04.1955), in: CChSD f. 5, op. 17, d. 520, 81-94.

16 In der neu eröffneten Rubrik „Briefe und Marginalien“ (Pis'ma i zametki) erschienen 1954 in den Heften 8 bis 12 funfzehn Beiträge, im Jahrgang 1955: 29 Beiträge, 1956: 28. In der früher nur sporadisch genutzten Rubrik "Diskussionen und Besprechungen“ (Diskusssii i obsuzdenija) wurden 1955 insgesamt 31 Beiträge publiziert, 1956 waren es 28.

17 Soveš̌anie po koordinacii naǔ̌no-issledovatel'skoj raboty v Otdelenii istoričeskich nauk AN SSSR, in: VI 1954, H. 1, 179-180; Sidorov, A.L.: O rabote Instituta istorii Akademii nauk SSSR, in: VI 1954, H. 2, 177-180; V učenom sovete Instituta istorii AN SSSR, in: VI 1954, H. 2, 181-182; Bonbar', N.N.: Naučnaja sessija Otdelenij obక̌čestvennych nauk Akademii nauk SSSR i Akademij nauk zakavkazskich respublik, in: VI 1954, H. 6, 161-167; Bem, Ju.O.: Obšcee sobranie Ordelenija istoričeskich nauk AN SSSR, in: VI 1956, H. 6, 201-204. 
aktiv" vielfach vorgebrachte Kritik. ${ }^{18}$ Rasch wurde dabei deutlich, daß ganz unterschiedliche Erwartungen an die Redaktion herangetragen wurden. Auf der einen Seite wurde wiederholt gefordert, daß die Zeitschrift Diskussionsergebnisse zusammenfasse, bewerte und ihren Standpunkt zu kontroversen Fragen kundtue, ${ }^{19}$ $\mathrm{da} B$ sie mit eindeutigen Wertungen den Historikerinnen und Historikern direkt helfe, ,klarzukommen ${ }^{\text {'20 }}$ usw. Auf der anderen Seite wurde kritisiert, daß die Redaktion ihr Publikum noch immer bevormunde und sich der ,Direktivcharakter" der Leitartikel negativ auf Kontroversen auswirke. ${ }^{21}$ Die Redaktion lavierte und wies die Vorwürfe beider Seiten zurück: man könne ihr nicht vorwerfen, „Direktiven" zu verbreiten, denn sie müsse sich wichtigen Fragen stellen; ${ }^{22}$ es sei ihre Pflicht, „Abweichungen vom Historismus“, Erscheinungen der „Simplifizierung“, des „Schematismus“ und der „Vulgarisierung“ in der wissenschaftlichen Öffentlichkeit auszusprechen. ${ }^{23}$

Einigkeit unter den Diskutanten bestand darüber, daß eine Fachzeitschrift allein schon quantitativ längst nicht mehr allen Anforderungen gerecht und nicht jedes Thema adäquat berücksichtigt werden konnte. ${ }^{24}$ Dieses Problem war offenbar entscheidungsreif, als es 1956 öffentlich thematisiert wurde. Denn schon im JanuarHeft 1957 teilte Voprosy istorii den Lesern mit, daß künftig alle zwei Monate drei weitere Fachorgane unionsweit erscheinen werden: „Neue und Neueste Geschich$t^{125}$, „Fragen der Geschichte der KPdSU ${ }^{، 26}$ und ,Geschichte der UdSSR ${ }^{، 27}$.

18 Obsuždenie 1954; Konferencija 1956; Konferencija Citatelej žurnala „Voprosy istorii“ v Leningrade, in: VI 1956, H. 7, $184-190$ (künftig zitiert als Konferencija (Leningrad) 1956); Konferencija čitatelej žurnala „Voprosy istorii“ v Kieve, in: VI 1956, H. 8, 198-203 (künftig zitiert als Konferencija (Kiev) 1956).

19 So z.B. M.M. Smirin und A.L. Sidorov in der erweiterten Sitzung des Wissenschaftlichen Rates des Instituts für Geschichte an der AdW am 25.06.1954. - Obsuždenie 1954, 176.

20 So P.K. Fortupatov in der Beratung des Autoren- und Leser-Aktivs am 28.06.1954. - Ebd., 177.

21 So M.Ja. Gefter bei der Leserkonferenz Ende Januar 1956. - Konferencija 1956, 207

2 Burdžalov in seinem Schlußwort, ebd., 212.

23 So Pankratova, ebd., 213.

24 Konferencija (Leningrad) 1956, 185-187; Konferencija (Kiev) 1956, 199-202.

25 Novaja i novejsaja istorija, hg vom Institut für Geschichte an der AdW der UdSSR zur Behandlung der allgemeinen Geschichte der Neuzeit, der Weltgeschichte, der allgemeinen Zeitgeschichte und der internationalen Bedeutung der Oktoberrevolution. Erster Chefredakteur wurde A.A. Guber. - VI 1957, H. 1, 196-197.

26 Voprasy istorii KPSS, hg vom Institut für Marxismus-Leninismus beim ZK der KPdSU zur Erforschung und Propagierung der KPdSU-Geschichte, besonders nach 1917, der Geschichte der internationalen Arbeiterbewegung und anderer kommunistischer Parteien. Chefredakteur wurde G.D. Obickin. - VI 1957, H. 1, 196.

27 Istorija SSSR, hg. vom Institut für Geschichte an der AdW der UdSSR für folgende Schwerpunkte: Vaterländische Geschichte, besonders Geschichte der sowjetischen Gesellschaft, sozialökonomische, politische und kulturelle Geschichte der Völker der UdSSR, Geschichte der Kriege 
Die Arbeitsteilung war sicher längst überfällig und - mit Ausnahme der Separierung der Parteigeschichte - sinnvoll. Aufgrund des gewählten Zeitpunkts wirkte die Einrichtung neuer Periodika und die baldige Senkung der Auflagenstärke der Voprosy istorii allerdings wie eine Strafmaßnahme gegen die Traditionszeitschrift, deren Leitung Anfang 1957 unter heftigem Beschuß stand. Im Hinblick auf die "Fragen der Geschichte" wirkte die Schaffung der neuen Zeitschriften obendrein überstürzt. Diesen waren zwar deutlich inhaltliche Aufgaben zugeordnet, doch die künftige Rolle der bisher alleinigen Zeitschrift war dabei klärungsbedürftig geblieben. Sie war jetzt entlastet von der Geschichte kommunistischer Parteien und Bewegungen, von der Allgemeinen Geschichte, aber auch von der „Vaterländischen“. Was blieb? Anna Pankratova hatte mehrmals über die Aufgaben der Voprosy istorii als dem ,fuihrenden Organ der sowjetischen Geschichtswissenschaft" referiert und als inhaltliche Schwerpunkte die Geschichte der sowjetischen Gesellschaft, der Volksdemokratien und der Völker im asiatischen Teil der Sowjetunion genannt. ${ }^{28}$ Als diese Themenkomplexe Anfang 1957 den neuen Periodika zufielen, war die inhaltliche Selbstverständigungsdebatte bei Voprosy istorii zu keinen weiterreichenden Ergebnissen gekommen.

\subsubsection{Bemühungen um die Verständigung über den Forschungs- stand und notwendige Revisionen}

Schon am 21. März 1953 beklagten der Präsident der Akademie der Wissenschaften A.N. Nesmejanov und der wissenschaftliche Sekretär des Akademiepräsidiums A.V. Topciev in einem Schreiben an den für Ideologiefragen zuständigen ZKSekretär M.A. Suslov, daß das Institut für Geschichte an der AdW insgesamt sehr schlecht arbeite, ${ }^{29}$ aber vor allem die Geschichte der sowjetischen Gesellschaft vernachlässigt würde. ${ }^{30} \mathrm{Um}$ dem abzuhelfen schlugen sie vor, den Direktor des Instituts Sidorov von der Lehrstuhlleitung an der Lomonosov-Universität und den Redaktionsaufgaben bei der „Großen Sowjet-Enzyklopädie“ zu entbinden, damit er sich auf die Arbeit im Akademie-Institut konzentrieren könne; Gal'kin solle Sido-

und der Außenpolitik, Historiographie und Hilfswissenschaften. Erster Chefredakteur wurde M.P. Kim. - VI 1957, H. 1, 196.

28 Siehe Obsuždenie 1954, 175.

29 ,(...) ist zu betonen, daß die Mehrheit der Ordentlichen und Korrespondierenden Akademiemitglieder überhaupt nicht aktiv an der Arbeit des Instituts teilnimmt." - Nesmejanov, A.N./A.V. Topciev am 21.03.1953 an M.A. Suslov, in: CChSD f. 5, op. 17, d. 425, $5 f$.

30 Nesmejanov und Topxiev rechneten vor: Zusammen mit der Leningrader Abteilung gebe es 159 Geschichtswissenschaftler: sieben akademiki, also Vollmitglieder der AdW, vier Korrespondierende Akademiemitglieder, 43 Professoren (mit dem Grad des Doktor istoriteskich nauk) und 105 Promovierte (mit dem Grad des Kandidat istoriCeskich nauk). Von allen 159 Wissenschaftlern beschäftigten sich nur achtzehn mit der sowjetischen Periode, danunter keines der elf Akademiemitglieder! - Ebd., 5. 
rovs Stellvertreter werden; Nachwuchswissenschaftler für das Geschichtsinstitut sollten gezielt gefördert werden. ${ }^{31}$

Auch die neue Redaktion der Voprosy istorii lokalisierte den ,größten Defekt ${ }^{\text {‘32 }}$ der sowjetischen Geschichtswissenschaft auf dem Gebiet der ,,...) Erforschung der wichtigsten Periode der UdSSR-Geschichte - der Periode des Sozialismus (... “" ${ }^{33}$ Trotz schon im Dezember 1953 vom ZK der KPdSU geäußerter Kritik ${ }^{34}$ habe sich 1954 fast nichts geändert. In den vorliegenden Arbeiten würden die „Prinzipien der Wissenschaftlichkeit und des Historismus" oft verletzt und die "Schwierigkeiten“ der Staatswerdung der UdSSR, die man sich nicht als ,ebenmäßigen, direkten und leichten Weg, als ununterbrochenen siegreichen Triumphzug“ vorstellen dürfe, nicht gezeigt. ${ }^{35}$

„Die Historiker sind verpflichtet, die geschichtlichen Ereignisse so zu zeigen, wie sie in Wirklichkeit waren, und sie nicht zu beschönigen, nicht auszuschmücken. ${ }^{336}$

So formulierte die Redaktion ihre Erwartungshaltung gegenüber neuen wissenschaftlichen Arbeiten, notabene Mitte 1954, etwa achtzehn Monate vor dem 20. Parteitag der KPdSU! $!^{37}$

Wie berechtigt die Kritik und das Drängen auf einen Neuanfang waren, unterstrichen folgende Tatsachen, die 1954 von der Zeitschrift veröffentlicht wurden: Keine der zweiunddreißig 1953 publizierten Monographien befaßte sich mit der neuen „welthistorischen Epoche“, die nach dem Selbstverständnis der KPdSU, dem Auftraggeber der Historie, mit der Oktoberrevolution eröffnet worden war. ${ }^{38}$ Die Selbsterforschung der sowjetischen Gesellschaft war praktisch zum Erliegen gekommen. Daß dies der Tiefpunkt einer mehrjährigen Entwicklung war, zeigte der Ende 1954 veröffentlichte Bericht der ,Höchsten Attestationskommission ${ }^{\text {(39 }}$ über die Doktordissertationen zur Geschichte. Demnach war in den dreizehn Jahren von

\footnotetext{
31 Ebd. - Die Möglichkeit, die vorgeschlagenen personellen Veränderungen zu realisieren, wurde alsbald bestätigt. Die Umsetzung ging wohl doch schleppend. so daß der Instituts-Direktor wiederholt um verstärkte Unterstützung seitens des ZKs der KPdSU bat. - Rumjancev, A./V Kružkov/E. Gromov am 30.04.1953 an M. A. Suslov, in: CChSD f. 5, op. 17, d. 425, 7f. Sidorov. A.L. am 04.07.1953 an P.N. Pospelov, in: CChSD f. 5, op. 17, d. 425, 238-242.

32 O nekotorych važnejšich zadačach sovetskich istorikov, in: VI 1953, H. 6, 3-11, hier 4.

33 Za glubokoe i vsestoronnee issledovanie istorii sovetskogo obščestva, in: VI 1954, H. 9, 3-9, hier 3.

34 O sereznych nedostatkach v rabote Gosudarstvennogo izdatel'stva političeskoj literatury, in O partijnoj i sovetskoj pečati. Sbornik dokumentov, M. 1954, 662.

35 Za glubokoe $i$ vsestoronnee issledovanie, 5 .

36 Ebd

37 Vgl. auch Tichomirov, M.N.: O nekotorych voprosach naučno-issledovatel'skoj raboty v oblasti istorii, in: VI 1954, H. 3, 179-182, Pankratova, A.M.: Važnejšie zadači sovetskich istorikov, in: VI 1954, H. 6, 161-166.

38 Sidorov, O rabote.
} 
1940 bis 1952 228mal der Grad „Doktor der historischen Wissenschaften ${ }^{\text {c40 }}{ }^{4 e r l i e-}$ hen worden. ${ }^{41}$ Nur auf den ersten Blick schien die Geschichte der UdSSR gut vertreten zu sein, denn die meisten Arbeiten (110) waren diesem Gebiet zugeordnet. Davon entfielen allerdings 59 Arbeiten auf die Geschichte des Feudalismus (,,in der UdSSR"!), funfundzwanzig auf die Geschichte des Kapitalismus, sechs auf die Historiographie und Quellenkunde und nur zwanzig auf die Geschichte der sowjetischen Periode nach $1917 .^{42}$ Von diesen thematisierten sechzehn die Revolutionsund Bürgerkriegsphase (1917 bis Ende 1920), und nur vier Arbeiten befaßten sich mit der Entwicklung nach Bürgerkrieg und Kriegskommunismus. ${ }^{43}$ Hinzu kommt noch, daß bis 1954 lediglich fünf jener 20 Monographien zur Sowjetzeit publiziert, also 75 Prozent der Forschungsergebnisse der wissenschaftlichen Öffentlichkeit vorenthalten wurden. ${ }^{44}$

Dieser Offenlegung der sträflichen Vernachlässigung der zeitgeschichtlichen Selbsterforschung folgten - nicht sehr weit gehende - organisatorische und personelle Entscheidungen. Ende 1953 wurden vier neue Akademiemitglieder gewählt, welche die Aufwertung der zeitgeschichtlichen Forschung verkörperten. ${ }^{45}$ Am 10. August 1954 beschloß das Akademiepräsidium die Einrichtung einer Sektion „Geschichte der UdSSR in der Periode des Sozialismus ${ }^{\text {“46 }}$ im Institut für Geschichte. In drei gesonderten Gruppen dieser Sektion sollte fortan die Geschichte der Oktoberrevolution, des sozialistischen Aufbaus und des Großen Vaterländischen Krieges erforscht bzw. die Forschung koordiniert werden ${ }^{47}$ Die Gründung eines separaten Instituts für die „Vaterländische“ Geschichte wurde von Anna Pankratova während des 20. Parteitags und bald darauf von einem der konservativen Wortfiihrer, Boris Rybakov ${ }^{48}$, vorgeschlagen, ${ }^{49}$ aber (noch) nicht realisiert. ${ }^{50}$

\footnotetext{
40 Was formal der Habilitation in der Bundesrepublik Deutschland entspricht

41 O doktorskich dissertacijach po istorii, in: VI 1954, H. 12, 163-165.

42 Ebd., 163.

43 Za glubokoe i vsestoronnee issledovanie, 8.
}

4. In ihrer Ansprache beim 20. Parteitag der KPdSU (14.-25. Februar 1956) prangerte A.M. Pankratova offen die geringe Qualität der Dissertationen in den letzten zwanzig Jahren an und kritisierte, daß ,nicht mehr als zehn Prozent“ der Dissertationen aus den letzten funf Jahren publiziert worden seien. - Siehe Diskussionsreden auf dem XX. Parteitag der KPdSU. 14.-25. Februar 1956, Berlin 1956, hier 372f.

4s P.N. Pospelov für den Bereich „Geschichte der KPdSU“, N.M. Družinin, A.M. Pankratova und M.N. Tichomirov für den Bereich „Geschichte der UdSSR“", der Forschungsschwerpunkt aller vier neuen akademiki lag bei der Geschichte (Sowjet-)Rußlands am Ende des 19. und zu Beginn des 20.Jahrhunderts.

46 „Otdel istorii SSSR perioda socializma v Institute istorii AN SSSR“. - Za glubokoe i vsestoronnee issledovanie, 8.

47 Ebd.

48 Boris Aleksandrovic Rybakov, Jahrgang 1908, absolvierte 1930 die Historische Fakultät der Lomonosov-Universität, wo er seit 1943 als Professor tätig war und deren Dekan er 1950 wurde. 1951 trat er in die KPdSU ein. 1952 wurde er Prorektor der Universität, ein Jahr darauf Korrespondierendes Akademie-Mitglied. Seit 1956 leitete er das Institut für Archäologie an der 
Um die Verständigung der Historiker untereinander zu fördern, bedienten sich Pankratova und Burdžalov auch des Mittels der Leitartikel, das während der Stalin-Zeit eine solch negative Rolle in der Zeitschrift gespielt hatte. Unter Pankratova wurden sieben redaktionelle Leitartikel zur Historie publiziert. ${ }^{51}$ Dabei läßt sich eine gewisse Entwicklung erkennen: In den drei ersten überwog das Pochen auf die „Errungenschaften“ und „Erfolge“; den Lesern wurden die Partei- und Staatsdokumente sowie das klassische Werk von Marx, Engels, Lenin und Stalin empfohlen als „Waffe" der Erkenntnis. ${ }^{52}$ Der Tiefpunkt in der Reihe der Leitartikel war im Dezember 1954 mit demjenigen zum 75. Geburtstag Stalins erreicht - eine Hymne auf den ,großen Fortsetzer der Sache Lenins", in der Stalins Lebensweg, sein „Beitrag“ zur revolutionären Theorie und zur Entwicklung der marxistischlenimistischen Geschichtswissenschaft heroisch und völlig kritiklos nachgezeichnet wurden $^{\text {s3 }}$. Erst aus den drei letzten Artikeln waren vermehrt Denkanstöße herauszulesen. Dabei markierte die Zeitschrift folgende neue Positionen:

AdW der UdSSR. 1958, mit 50 Jahren, was von einer geradlinigen sowjetischen Karriere zeugt. wurde er Ordentliches Mitglied der Akademie der Wissenschaften. Seine wichtigsten Arbeitsgebiete waren die allgemeine Ethnogenese, die Ethnographie der slavischen Völker, die Geschichte des Heiden- und Christentums sowie die Entstehung des Staats.

Nekric bezeichnete Rybakov als überzeugten Antisemiten und großrussisch denkenden Chauvinisten. Über seine Arbeit schrieb er: „Von Jugend an ein befähigter Archäologe, wich Rybakov allmählich von der echten Wissenschaft ab und machte es zu seinem Lebensziel, die Überlegenheit alles Russischen nachzuweisen. Er war der Schöpfer der Mythen über die slavische Herkunft einer Reihe von Städten und Handwerken in der Rus." - Nekrič, Otrešis” ot stracha, 338 . Vgl. Rybakov, B.A./A.N. Sacharov: Akademik B.A. Rybakov otvečaet na voprosy žurnala „Voprosy istorii“, in: VI 1968, H. 9, 110-119; VI 1973, H. 9, 144 f.

49 Siehe Diskussionsreden, 374 und Obscee sobranie Otdelenija istoriceskich nauk AN SSSR. in: VI 1956, H. 6, 204.

so Erst im Zuge des Abbruchs der Theorie- und Methodologiediskussionen 1968 wurde das Geschichtsinstitut geteilt. Es entstanden das Institut für Allgemeine Geschichte und dasjenige für Geschichte der UdSSR. Erster Direktor des neuen Instituts fur Geschichte der UdSSR wurde ausgerechnet Rybakov! - Nekrix, Otrešis' ot stracha, 38; Neretina, S.S.: Istorija s metodologiej istorii, in: VF 1990, H. 9, 149-163.

31 „Über einige sehr wichtige Aufgaben der sowjetischen Historiker“: O nekotorych važnejłich zadaCach sovetskich istorikov, in: VI 1953, H. 6, 3-11; „Über die wissenschaftliche Ausarbeitung der Geschichte der Großen sozial istischen Oktoberrevolution": O naučnoj razrabotke istorii Velikoj Oktjabr'skoj socialističeskoj revoljucii, in: VI 1953, H. 11, 3-11; ,Für die tiefe und allseitige Erforschung der Geschichte der sowjetischen Gesellschaft": Za glubokoe i vsestoronnee issledovanie; „Großer Fortsetzer der Sache Lenins“: Velikij prodolžatel” dela Lenina, in: VI 1954, H. 12, 3-10; ,Für die weitere Festigung der wissenschaftlichen Kontakte zwischen Historikern aller Länder": Za dal'nejšee ukreplenie naux̃nych svjazej meždu istorikami vsech stran, in: VI 1955, H. 8, 3-10; „Über die Erforschung der Geschichte der Geschichtswissenschaft“: Ob izuð̌enii istorii istorixeskoj nauki, in: VI 1956, H. 1, 3-12, „Der 20.Parteitag der KPdSU und die Aufgaben bei der Erforschung der Parteigeschichte“: Dvadcatyj s-ezd KPSS i zadači issledovanija istorii partii, in: VI 1956, H. 3, 3-12.

52 O nekotorych važnejł̌ich zadačach, 4; O naučnoj razrabotke, 3; Za glubokoe i vsestoronnee issledovanie, 9.

33 Velikij prodolžatel'. 
- Sie unterstützte die Teilnahme einer sowjetischen Delegation am X. Internationalen Historikerkongre $B$ im September 1955 in Rom - nach zweiundzwanzig Jahren sowjetischer $\mathrm{Absenz}^{54}$, und sie plädierte in diesem Zusammenhang für die Ausweitung und Festigung wissenschaftlicher Kontakte gerade mit Fachkollegen aus nichtsozialistischen Ländern. ${ }^{\text {s5 }}$

- Sie stellte fest, es sei falsch, die jahrhundertelange Entwicklung der Geschichtswissenschaft (sic!) bis zur Entstehung des Marxismus als „vorwissenschaftliche Periode“ zu charakterisieren oder die „bourgeoise Geschichtswissenschaft" als ,pseudowissenschaftlich" $\mathrm{zu}$ disqualifizieren und vereinfachend über ihre ständige „Krise in der Epoche des Imperialismus" zu sprechen, ohne zu differenzieren und dies zu konkretisieren. Das wissenschaftliche Erbe dürfe nicht unterbewertet werden; ${ }^{36}$ es sei eine "wichtige Aufgabe“, die russische adlige und bürgerliche Historiographie $\mathrm{zu}$ untersuchen. ${ }^{57}$

- Die Entwicklung der historischen Disziplin in der Sowjetunion bezeichnete die Redaktion als ,nicht erforscht" ${ }^{\text {s8 }}$ Die Entwicklung der marxistischen Geschichtswissenschaft kurz vor der Revolution und in den ersten Jahren der Sowjetherrschaft müßten untersucht und der Platz von M.N. Pokrovskij in der sowjetischen Historiographie erst noch bestimmt werden. ${ }^{59}$ Damit war erstmals auf die Notwendigkeit hingewiesen, den bedeutendsten sowjetischen Historiker der zwanziger Jahre zu rehabilitieren. ${ }^{60}$

- Die Redaktion stellte sich vollständig hinter die Aussagen des 20. Parteitags der KPdSU (14.-25. Februar 1956), die auf Entstalinisierung himwiesen. ${ }^{61}$ In scharfer

s4 Zuletzt hatten sowjetische Vertreter 1933 in Warschau am VII. Internationalen Historikerkongreß teilgenommen. Nach dem Kongreß in Rom „,...) there was a spate of articles, mainly by professional historians who had been shocked by the continued refusal, or in some cases apparent inability, on the part of the Soviet historians to enter into a genuine intellectual encounter", schrieb Utechin mit Verweis auf die Berichte von Werner Hofer in: Deutsche Rundschau 1956, H. 6 und Karl Thieme in: GWU 1957, H. 10. - Utechin, Soviet Historiography, 117f; vgl. Doklady sovetskoj delegacii. Desjatyj kongress istoričeskich nauk v Rime, M. 1956; Erdmann, Die Ökumene, 190ff, 212ff, 316ff.

ss Za dal'nejšee ukreplenie, 9. - So auch Pankratova auf dem 20. Parteitag. vgl. Diskussionsreden, 374

s6 In diesem Zusammenhang erinnerte die Redaktion an unzureichend gewürdigte Historiker, an so unterschiedliche wie z.B. J.G. Herder (1744-1803), F.Ch. Dahlmann (1785-1860), B. Croce (1866-1952), G. Lefebvre (1874-1959), N.M. Karamzin (1766-1826), S.M. Solov'ev (18201879), V.O. KljuXevskij (1841-1911), N.P. Pavlov-Sil'vanskij (1869-1908) und A.E. Presnjakov (1870-1929). - Ob izuXenii, 7f.

\$7 "...) ihre progressive Bedeutung (...) (und die Frage; J.H.) worin ihre Krise bestand (...). Ebd., 11.

38 Ebd., 6.

39 Ebd.

60 Vgl. Shteppa, Russian Historians, 365f.

61 Zu den dort gefaßten Beschlüssen und den Besetzungen des ZK sowie der Zentralen Revisionskommission SPR 1, 7-97. 
Form hatte dort als erster A.I. Mikojan ${ }^{62}$ die Lage an der ,historischen Front“ kritisiert ${ }^{63}$ und offen zur Revision des bisherigen Geschichtsbildes aufgefordert. ${ }^{64}$ Nach der offiziellen Beendigung des Parteitags am Abend des 25. Februars hatte schließlich die Rede Chruščevs, über den Personenkult und seine Folgen ${ }^{\text {(65 }}$ die Delegierten geschockt. ${ }^{66}$ Anna Pankratova wies in ihrer Ansprache (die sie vor derjenigen des Ersten Sekretärs und ohne Absprache mit diesem hielt!) auf das „Zurückbleiben“ der historischen Disziplin bei der Revolutions- und Parteigeschichtsschreibung hin. ${ }^{67}$ Der „Personenkult“ bewirke noch immer ,Anti-

62 ,Erster Stellvertreter des Vorsitzenden des Ministerrats der UdSSR und Mitglied des Präsidiums des ZK der KPdSU". - Siehe Diskussionsreden, 88.

63 Vorher hatte Mikojan die neuen Standpunkte der KPdSU zur Außenpolitik (Konzept der friedlichen Koexistenz), zur Revolutionstheorie (Anerkennung national unterschiedlicher, auch friedlicher Wege zum Sozialismus) und zur Kriegsfrage (Vermeidbarkeit von Kriegen) erläutert. - Siehe Diskussionsreden, 88ff.

64 „Würden unsere Historiker die Tatsachen und Ereignisse der Geschichte unserer Partei in der sowjetischen Periode, auch solche, die im Kurzen Lehrgang beleuchtet sind, richtig und tief studieren, würden sie in den Archiven, in den historischen Dokumenten und nicht nur in den Zeitungsjahrgängen ordentlich wühlen, so könnten sie jetzt viele Tatsachen und Ereignisse, die im Kurzen Lehrgang dargelegt sind, vom Standpunkt des Leninismus aus besser beleuchten." „Was ist denn eine Wissenschaft ohne Schöpfertum? Das ist eher Scholastik, ein Lehrbuchexerzitium (...), denn Wissenschaft ist vor allem Schöpfertum, Schaffen von etwas Neuem, nicht aber Wiederholung des Alten." - Ebd., $120 \mathrm{ff}$.

6s Chrušcev, N.S.: Doklad na zakrytom zasedanii XX s-ezda KPSS „O kul'te ličnosti i ego posledstvijach“, M. 1959. - Die exakte Herkunf dieser authentischen Wiedergabe der Rede ist nach wie vor ungeklärt. Nach Auskunft des ersten sowjetischen Stalin-Biographen. Volkogonov, erfolgte die Erstveröffentlichung in der UdSSR erst 1989 in: ICK 1989, H. 3, 128-166; erstmalig in deutscher Sprache und vollem Umfang wurde die Rede nach der polnischen Fassung (in: Polityka 1988, H. 31) bei Judick, G./K. Steinhaus (Hg.): Stalin bewältigen. Sowjetische Dokumente der 50er, 60er und 80er Jahre, Düsseldorf 1989, 102-195, veröffentlicht. In der im wesentlichen authentischen, 1977 von Crusius und Wilke herausgegebenen Version fehlen einige Passagen, in denen Chrušcev betonte, daß die KPdSU am Sozialismus festhalten und sich positiv auf die Oktoberrevolution und Lenin beziehen wird. Zum Kontext siehe Hösler, J.: Ein Anfang. Bemerkungen zum gerade erschienenen Buch „Stalin bewältigen“, in: MB 1989, H. 5, 94-100. Vgl. Volkogonov, D.: Die interne Rede (Interview), in: Neue Zeit 1989, H. 16, 26-29; Crusius, R.M. Wilke (Hg.): Entstalinisienung. Der XX. Parteitag der KPdSU und seine Folgen. Frankfurt/M. 1977 , 487-537.

66 So mutig, sensationell und unzureichend Chruščevs Ausfuhrungen waren, so ambivalent wirkten sie sich unter den gegebenen politischen Kräfteverhältnissen auf die Geschichtswissenschaft aus: Sie gaben ,grünes Licht“" zu einer schärferen Stalin-Kritik, ermunterten zur (notabene weiteren) Revision des bisherigen Geschichtsbildes, riefen aber zugleich die sich weiterhin in Machtpositionen befindenden Vertreter des alten Denkens auf den Plan. Der langjährige Chrušcev-Berater, Fedor Burlackij, schilderte ein die Situation nach dem Parteitag trefflich illustrierendes Beispiel: In einem Akademieinstitut forderte die Parteiorganisation, nachdem ihr die Rede Chruščevs bekanntgegegeben worden war, die an Massenrepressalien Schuldigen zur Verantwortung zu ziehen. Die Parteiorganisation wurde, wohl auf Vorschlag Michail Suslovs hin. aufgelöst. - Burlazki, F. (= Burlackij, F.): Chruschtschow. Ein politisches Porträt. Düsseldorf 1990, 126; Crusius/Wilke, Entstalinisierung; Hösler, Ein Anfang, $96 \mathrm{f}$.

67 In der Parteigeschichtsschreibung zeige sich ,(...) besonders stark, wie die fortschrittliche Wissenschaft durch den Einfluß des Persönlichkeitskults behindert wird." - „Gewisse Historiker 
historismus“, Subjektivismus und Geschichtsbewertungen nach politischen Überzeugungen. Kriterien der Wissenschaft müßten wieder wichtiger werden als die der Parteipolitik. ${ }^{68}$

- Als erste wies Pankratova auch auf die Notwendigkeit hin, eine fünfte Ausgabe der Werke Lenins vorzubereiten, da die vierte bei weitem unvollständig sei. ${ }^{69}$

- Nach dem Parteitag vertrat die Zeitschrift erstmals die Haltung, daß die Beschlüsse, stenographischen Berichte und Protokolle von den Parteitagen und Konferenzen der KPdSU neben dem Presse-, Archiv- und statistischen Material als historische Quellen behandelt werden müßten, nicht wie bisher als von der „Weisheit der Partei“ diktierte historische Urteile. ${ }^{70}$

Diese neuen Wegzeichen, die Anna Pankratova mit dem Plädoyer verband, ,(...) einen noch energischeren Kampf für einen streitbaren schöpferischen Marxismus zu entfalten ${ }^{\text {c71 }}$, fanden Widerhall in vier Diskussionen, die alle vor dem 20. Parteitag begannen und ein bis zwei Jahre andauerten:

Erstens: Im Anschluß an einen noch ganz der Stalinschen Dogmatik verhafteten Artikel von Boris Poršnev über ,das ökonomische Grundgesetz des Feudalismus ${ }^{\text {(72 }}$ und eine im Oktober 1953 abgehaltene Konferenz über die Entwicklung der Warenproduktion im feudalistischen Rußland, bei der Anna Pankratova ein äquivokes Eingangsreferat hielt ${ }^{73}$, kam es seit Anfang 1954 zu einer, großen“ Aussprache

frisieren die geschichtlichen Ereignisse, simplifizieren sie, behandeln sie einseitig und infolgedessen unrichtig. Sie stellen den Weg, den die Partei zurückgelegt hat, als einen einzigen Triumphzug dar (...). “- Diskussionsreden, 367ff.

68 .Leider führen wir keinen konsequenten und entschiedenen Kampf (...) gegen alle Elemente des Antihistorismus und der Simplifikation, gegen eine subjektivistische Einstellung zur Geschichte, gegen die Modernisierung der Geschichte und eine der jeweiligen Situation angepaßte. konjunkturhafte Geschichtsbetrachtung.“ - „Das Fehlen einer Analyse der sozialen Grundlagen dieser oder jener historischen Ereignisse und die subjektivistische Art, alle unsere Mißerfolge allein mit schädlichen Aktionen der Feinde oder der Menschen, die als solche herausgestellt werden, (...) zu erklären - das läßt auf einen ziemlich weit verbreiteten Überrest des Persönlichkeitskults schließen, mit dem Schluß gemacht werden muß.“ - In der Organisation der wissenschaftlichen Arbeit gebe es ,(...) viele Resolutionen, viele Sitzungen, aber wenig wissenschaftliche Arbeit (...) Es ist erforderlich, die Wissenschafter kühner zur Bearbeitung aktueller Probleme heranzuziehen, ihnen Aufträge zu erteilen und den Kampf gegen Elemente der Rückversicherung und der wissenschaftlichen Ängstlichkeit zu verstärken. Wissenschaftliche Fragen können nicht durch Befehle oder Abstimmungen entschieden werden." - Ebd., 370ff.

69 Ebd., $367 f$.

70 Dvadcatyj s-ezd, 1956, 11; vgl. Heer, Politics, 80ff.

1 Konferencija 1956, 201.

?2 Poršnev, B.F.: K voprosu ob osnovom ekonomičeskom zakone feodalizma, in: VI 1953, H. 6, 52-67.

3 Pankratova, A.M.: O roli tovarnogo proizvodstva pri perechode ot feodalizma k kapitalizmu, in: VI 1953, H. 9, 59-77. Zur Konferenz vgl. Koval'cenko, I.D.: Naucnaja konferencija po voprosu o razvitii tovarnogo proizvodstva v Rossii v period imperializma (Bericht), in: VI 1953, H. 10, 144-148. 
über das ,ökonomische Grundgesetz“ des Feudalismus, zu der bis Anfang 1955 füfzehn Beiträge veröffentlicht wurden, ehe die Redaktion die Diskussionsergebnisse zusammenfaßte. ${ }^{74}$

Zweitens: Von Herbst 1954 bis Mitte 1956 wurde über die Periodisienung der Geschichte der Sowjetgesellschaft gestritten. ${ }^{75}$ Es fällt auf, daß dies - abgesehen von Auseinandersetzungen über die KPdSU-Geschichte, die uns hier nicht interessieren sollen ${ }^{76}$ - der einzige die Sowjetperiode betreffende Problemkomplex war, der damals andiskutiert wurde. In ihrem die Debatte eröffnenden Artikel kritisierten Berchin und Kim als erste etablierte sowjetische Historiker offen einige Ergebnisse der Stalinschen Geschichtsklitterung. Sie begründeten die Notwendigkeit der Periodisierungsdiskussion (hinsichtlich der sowjetischen Periode!) damit, daß dieses Problem immer wieder vernachlässigt worden sei und daß die im ,Kurzen Lehrgang" von $1938^{77}$ festgelegte Einteilung ,an wesentlichen Unzulänglichkeiten" leide. ${ }^{78}$ Dies liege vor allem an der von Stalin gewollten Kongruenz der Periodisierung der Parteigeschichte mit derjenigen der sowjetischen Gesellschaft. ${ }^{79}$ Eine ,völlige

74 Mejman, M.N./S.D. Skazkin: Ob osnovnom ekonomiðeskom zakone feodal'noj formacii, in: VI 1954, H. 2, 71-91; Ob osnovnom ekonomizeskom zakone feodal'noj formacii, in: VI 1954, H. 7, 117-129 (Einzelbeiträge von M.Ja. Sjuzjumov, G.M. Danilova, M.S. Telepenin, K.A. Antonova); $K$ voprosu ob osnovnom ekonomixeskom zakone feodal'noj formacii, in: VI 1954, H. 8, 6578 (Einzelbeiträge von E.V. Gutnova, S.A. Siderenko); Kolganov, M.V.: Ob osnovnom ekonomičeskom zakone feodalizma, in: VI 1954, H. 9, 73-80; Poljanskij, F.Ja.: Problema osnovnogo ekonomičeskogo zakona feodalizma, in: VI 1954, H. 10, 79-85; Snesarevskij, P.V.: O dejstvii osnovnogo ekonomičeskogo zakona feodalizma, ebd., 85-89; Minkov, T.: Ob osnovnom ekonomiceskom zakone feodal'noj formacii, in: VI 1954, H. 11, 77-81; Chromov, R.P.: Ob osnovnom zakone feodalizma, ebd., 82-85; Kratkij obzor statej ob osnovnom ekonomiCeskom zakone feodalizma, in: VI 1955, H. 2, 76-90; O dvuch osnovnych stadijach razvitja feodal 'noj formacii, in: VI 1955, H. 3, 181-184; Obsuždenie voprosa ob osnovnom ekonomǐeskom zakone feodalizma, in: VI 1955, H. 4, 86-97; Ob osnovnom ekonomi ̌eskom zakone feodal'noj formacii (k itogam diskussii), in: VI 1955, H. 5, 79-85.

7s Berchin, I.B.M.P. Kim: O periodizacii istorii sovetskogo obš̌estva, in: VI 1954, H. 10, $72-$ 78; Kuckin, A.P.: K voprosu o periodizacii istorii sovetskogo obšcestva, in: VI 1955, H. 3, 71-75; Orlov, B.P.: K voprosu o periodizacii istorii sovetskogo obšcestva, ebd., 75-77; Panfilova, A.M./A.M. Anfimov: K voprosu o periodizacii istorii sovetskogo obšcestva, ebd., 77f, Vilenskij, B.V.: K voprosu o periodizacii istorii sovetskogo obšcestva, ebd., 78f; O periodizacii istorii sovetskogo obscestva, in: VI 1955, H. 4, 81-86; Seleznev, M.S./F.V. Nikolaev: O periodizacii istorii sovetskogo obscestva, in: VI 1955, H. 9, 55-58; Michajlov, V.N./F.S. Sabanov: O periodizacii istorii sovetskogo obšestva, ebd., 59-61; O periodizacii istorii sovetskogo obšcestva, ebd., 61f; O periodizacii istorii sovetskogo obscestva, in: VI 1956, H. 6, 58-62.

${ }^{76}$ Einen Überblick dazu geben Wolfe, B.D.: Party Histories from Lenin to Khrushchev, in: Keep. Contemporary History, 43-61; Schapiro, L.: Continuity and Change in the New History of the CPSU, ebd., 69-82 und die jeweiligen Diskussionen dieser Beiträge, ebd., 61-68 und 82-91; Heer, Politics, 80ff und 186ff.

7 Istorija 1938.

78 Berchin/Kim, O periodizacii, 72.

79 Ebd. Berchin/Kim verwiesen auf Stalin, I.: Ob učebnike istorii VKP(b). Pis'mo sostaviteljam učebnika istorii VKP(b), in: K izučeniju istorii, M. 1937, 28-31, hier 28, wo Stalin genau genommen keine Kongruenz von Partei- und Gesellschaftsgeschichte forderte, sondern schrieb, die 
Übereinstimmung" könne es jedoch nicht geben, weil Partei- und Gesellschaftsgeschichte unterschiedlichen Gesetzmäßigkeiten gehorchten. ${ }^{80}$ Auffallend an der vorgeschlagenen Periodisierung ${ }^{81}$ war - neben der sehr ungenauen Terminologie ${ }^{82}$ die These, daß Oktoberrevolution und Bürgerkrieg einen geschichtlichen Abschnitt bildeten. ${ }^{83}$ Lenin hatte Anfang Dezember 1919 in einer kämpferischen Rede den Bürgerkrieg als ,Fortsetzung der Politik der Revolution“ bezeichnet ${ }^{84}$, und so bestanden auch die Autoren darauf:

„Beginn des Bürgerkriegs in Rußland war die Große sozialistische Oktoberrevolution. "8s

Nur zwei Historiker erklärten jede Revisionsbemühung für überflüssig, weil die im „Kurzen Lehrgang“ dargelegte „Periodisienung der Geschichte der sowjetischen Gesellschaft richtig" sei. ${ }^{86}$ Lediglich die Präzisierung der Nachkriegsjahre sei erforderlich. ${ }^{87}$ Alle anderen Diskutanten befürworteten die Aussprache, weil die bisherige Periodisierung ,ungenau" sei, mechanistisch angewandt werde und von subjektivistischen Fehlern gekennzeichnet sei; weil die Geschichtswissenschaft sich weiterentwickelt und neues Material zutage gefordert habe oder ganz einfach, weil die alte Periodisierung 1937 ende. ${ }^{88}$

Die von Berchin und Kim geforderte Trennung der Periodisienung von Partei- und Gesellschaftgeschichte fand unter den Kollegen einhellig keine Zustimmung. Dagegen wurde der untrennbare Zusammenhang der beiden Sujets betont. ${ }^{89}$ Auch die

Geschichte der Partei dürfe nicht ohne Verbindung mit der Geschichte des Landes dargelegt werden, was ja zutreffend ist. Etwas anderes ist freilich die Reduktion der Gesellschaftsgeschichte auf die Geschichte der Partei, die bei Stalin, wenn nicht explizit, so implizit anzutreffen war.

80 Die Geschichte der KPdSU müsse periodisiert werden nach den „Hauptgliedern“ in der Kette politischer Aufgaben der Partei. Die Geschichte der sowjetischen Gesellschaft hingegen gemäß den ,im wesentlichen abgeschlossenen Entwicklungsetappen der Produktionsweise“. Berchin/Kim, O periodizacii, 73.

81 Sie war unterteilt in die „Übergangsepoche von Kapitalismus zu Sozialismus (1917-1936)“ und die „Epoche des Sozialismus und des schrittweisen Übergangs zum Kommunismus (1937 und nachfolgende Jahre)". - Ebd., 78.

82 Die Begriffe „Epoche“, „Periode“, „Etappe“ wurden weder definiert noch eindeutig angewandt. - Ebd., 75-78.

83 Ein in der westlichen nichtmarxistischen Forschung üblicher Zugang, wenn politische Kriterien hervorgehoben werden. Vgl. etwa Service, R.: The Russian Revolution 1900-1927, London 1986; Hildermeier, M.: Die russische Revolution 1905-1921, Frankfurt a.M. 1989.

84 Lenin, V.1.: VII Vserossijskij s-ezd sovetov 5-9 dekabrja 1919 g. Doklad, in: LPSS 39, $387-$ 414, hier 406

85 Berchin/Kim, O periodizacii, 76.

86 V.M. Gotlober nach O periodizacii 1955, 61; Kučkin, K voprosu, 71.

87 Ebd

${ }^{88}$ Orlov, K voprosu; 1.I. Minc nach O periodizacii 1955, 85; E.B. Genkina, ebd., 81.

89 Kučkin, K voprosu, 71; Michajlov/Sabanov, O periodizacii, 59; N.V. Efremenkov nach O periodizacii $1955,62$. 
Redaktion stellte in ihrem zusammenfassenden Artikel fest, die Kommunistische Partei sei zwar ein „eigenständiger Organismus“ mit ,inneren Gesetzmäßigkeiten“ und einer internen Geschichte, doch im wesentlichen sei die Parteigeschichte ,ein organischer Teil" der Geschichte der sowjetischen Gesellschaft. ${ }^{90}$ Was Berchin und Kim als eine der Hauptursachen ,wesentlicher Unzulänglichkeiten" betrachteten die Identifizierung von Partei- und Gesellschaftsgeschichte - blieb also erhalten. Dies stand in einem offensichtlichen Widerspruch zu der Separienung einer KPdSU-Geschichtsschreibung mit eigenen Instituten und eigener Zeitschrift, wie sie 1957 erfolgte.

Hinsichtlich des Periodisierungskriteriums kritisierten alle Teilnehmer der Diskussion, „Entwicklungsetappen der Produktionsweise“ (Berchin/Kim) sei zu eng, sei ökonomistisch. Der Jurist Vilenskij verwies auf die Staatsentwicklung, die mitberücksichtigt werden müsse; ${ }^{91}$ Jurij Poljakov hob die einschneidende Bedeutung von Kriegen hervor und machte den neuen Vorschlag, die Entwicklung seit 1917 nur durch den Großen Vaterländischen Krieg zu unterteilen. ${ }^{92}$ Der Spezialist für Agrargeschichte, V.P. Danilov, gab Berchin und Kim grundsätzlich recht, die chronologische Gliederung der sowjetischen Geschichte nach der Entfaltung der sozialistischen Produktionsweise vorzunehmen. Allerdings müßten politische, kulturelle und nationale Faktoren mit den ökonomischen in Beziehung gesetzt werden. ${ }^{93}$ Die Redaktion faßte diese Einwände dahingehend zusammen, daß nicht nur Entwicklungen mit „Basis-“, sondern auch mit „Überbau-Charakter" berücksichtigt werden müßten. Dies erfordere vor allem die ,grundsätzliche Besonderheit" des sozialistischen Aufbaus, die darin bestehe,

„(...) daß die Formierung ihrer (der sozialistischen Gesellschaft, J.H.) ökonomischen Basis erst beginnt nach dem Sturz der Herrschaft der Bourgeoisie und der Errichtung der Diktatur des Proletariats (...).“"

90 Denn „(...) die Kommunistische Partei ist die Vorausabteilung der Werktätigen der UdSSR die fuhrende Kraft der sowjetischen Gesellschaft, die regierende Partei in der UdSSR." Daher würden seit der Oktoberrevolution das ,innerparteiliche Leben“ und die gesamte Parteientwicklung bestimmt von den Aufgaben des sozialistischen Aufbaus und den Entwicklungsetappen der sozialistischen Gesellschaftsformation. - O periodizacii 1956, 59.

91 Vilenskij, K voprosu, 79.

92 "(...) die ganze Geschichte der sowjetischen Gesellschaft in drei große geschichtliche Perioden einzuteilen: die erste - von der Oktoberrevolution bis zum Beginn des Vaterländischen Krieges, die zweite - die Periode des Vaterländischen Krieges und die dritte - die Jahre des Aufbaus nach dem Krieg." - O periodizacii 1955, 81.

93 Ebd., 83f.

94 O periodizacii 1956, 58f. - Bei der sozialistischen Revolution müsse die politische Umwälzung der ökonomischen vorausgehen; mit jener beginne, mit dieser ende die „Übergangsepoche“ zwischen Kapitalismus und Sozialismus. Mit dieser Haltung wurde furwahr der Bock zum Gärtner gemacht: Eine wesentliche Ursache des späten Scheiterns der Oktoberrevolution wurde zum Prinzip erklärt, nämlich die Tatsache, daß die Oktoberrevolution vor allem eine politische Revolution war, der die ökonomische Grundlage und damit der "Sperrklinkeneffekt" fehlte. Ein Pro- 
Der Periodisienungvorschlag der Redaktion blieb unvollständig. Neu war, daß die Übergangsepoche mit der „Periode des Hinüberwachsens der bürgerlichdemokratischen in die sozialistische Revolution" von März bis Oktober 1917 begann. ${ }^{95}$ Die von Berchin und Kim vorgeschlagene Zusammenziehung von Oktoberrevolution und Bürgerkrieg wies die Redaktion nach den zahlreichen entrüsteten Widerworten ${ }^{96}$ ebenfalls zurück. Die kurze „Atempause“ (Lenin $\left.{ }^{97}\right)$ im Frühjahr 1918 dürfe nicht übersehen, der Bürgerkrieg nicht als gesetzmäßige Folge oder unmittelbare Fortsetzung der sozialistischen Revolution betrachtet werden. Die bisher übliche Hervorhebung des ,großen Umschwungs“ 1929, die Danilov erhalten sehen wollte, negierte die Redaktion. Neue Eckdaten sollten 1926 und 1932 sein, womit die Periode des ,Aufbaus des Fundaments der sozialistischen Ökonomik" im Zuge der „,beschleunigten Industrialisierung" und „,kompakten Kollektivierung" abgesteckt werden sollte. ${ }^{98}$ Für die Nachkriegsentwicklung stelle das Jahr 1953 eine „wichtige Grenze“ dar,

„(..) als die Kommunistische Partei und die Sowjetmacht ernsthafte Fehler in der Leitung der Landwirtschaft, Verletzungen der sowjetischen Gesetzlichkeit und der Leninschen Normen des innerparteilichen Lebens, gewaltige Mängel in einer Reihe von Bereichen des staatlichen, ökonomischen und kulturellen Aufbaus aufdeckten."

Damit hatte die Redaktion lediglich an einigen Schnittstellen der Debatte Zwischenbilanz gezogen. Nach wie vor hielt sie die Revision der bisherigen Periodisierung der sowjetischen Geschichte seit 1917 für notwendig. ${ }^{100}$

Drittens: In einer weiteren Diskussionsrunde wurde über die Wirkungsweise ökonomischer Gesetzmäßigkeiten in antagonistischen Gesellschaftsformationen gestritten. Dies stellte einen - noch stark von der Stalinzeit geprägten - Vorlauf der späteren Diskussionen über Gesetzmäßigkeit und Alternativität in der Geschichte dar. Gegenstand der Debatte 1954 bis 1956 waren Stalins Bemerkungen zum Gesetzesbegriff. die im Zusammenhang mit der damaligen ökonomischen Diskussion am 3. und 4. Oktober 1952 in der Pravda veröffentlicht worden waren. Damals hatte Stalin ,(...) gegen gewisse subjektivistische Interpretationen der Entwicklung der Ökonomik der sozialistischen Gesellschaft (...) ${ }^{\text {c101 }}$ den „objektiven Charakter“ wis-

blem, welches in der UdSSR jahrzehntelang tabuisiert wurde. - Vgl. Fülberth, G.: Sieben Anstrengungen, den vorläufigen Endsieg des Kapitalismus zu begreifen, Hamburg 1991, 121

9s O periodizacii 1956, 60.

96 Kučkin, K voprosu, 72; Orlov, K voprosu, 76; Ju.A. Poljakov und P.G. Sofinov nach O periodizacii 1955, 81; Seleznev/Nikolaev, O periodizacii. 56.

9" Lenin, V.I.: Rex' $\vee$ Moskovskom sovete rabočich, krest ’janskich i krasnoarmejskich deputatov 12 marta $1918 \mathrm{~g}$, in: LPSS 36, 83-88. Eine Auseinandersetzung mit dem von Berchin und Kim zitierten Lenin-Wort fand nicht statt.

98 O periodizacii $1956,61 \mathrm{f}$.

99 Ebd., 62

100 Ebd

101 Bollhagen, P.: Gesetzmäßigkeit und Gesellschaft. Zur Theorie gesellschaftlicher Gesetze, Berlin 1967, 19 
senschaftlicher Gesetze allgemein, und „besonders der Gesetze der politischen Ökonomie im Sozialismus “ ${ }^{102}$ akzentuiert. Stalins Marxismus-Verständnis zufolge wirkten alle „Gesetze der Wissenschaft" unabhängig vom Willen der Menschen ${ }^{103}$ und konnten in allen Gesellschaftsformationen gleichermaßen ,genutz", aber nicht in irgendeiner Weise beeinflußt werden. ${ }^{104}$

Dementsprechend kreiste die Diskussion 1954 bis 1956 um die Fragen nach der Wirkungsweise gesellschafticher und ökonomischer Gesetze und den Möglichkeiten ihrer ,Ausnutzung“". Der Sozialwissenschaftler Igor Semenovic Kon ${ }^{105}$ hatte die Auseinandersetzung provoziert mit seinen sich zum Teil widersprechenden Thesen: In vorsozialistischen Formationen dominiere das Spontane in der gesellschaftlichen Entwicklung wegen des Privateigentums an den Produktionsmitteln. Ökonomische Gesetze könnten nur bei einer, ,aktiven, schöpferischen Rolle des Überbaus“ genutzt werden. Dabei repräsentierten allerdings verschiedene soziale Klassen immer unterschiedliche ökonomische Tendenzen oder Gesetze: die jeweils konservativreaktionäre Klasse verkörpere in ihrer Politik die spezifischen Funktions- und Entwicklungsgesetze der bestehenden Formation, die revolutionäre Klasse die auf Systemtransformation zielenden allgemeinsoziologischen Gesetze. ${ }^{106}$

Kons These von der Dominanz des Spontanen in nichtsozialistischen Gesellschaftssystemen akzeptierten seine Kritiker nur, soweit nicht die Handlungsfähigkeit der Arbeiterklasse als revolutionärem Subjekt im Kapitalismus in Frage gestellt wurde. Die klassenmäßige Zuordnung der unterschiedlichen Gesetzestypen fand keine

\footnotetext{
102 Stalin, Ekonomiceskie problemy, in: StW 16, 189.

103 „Die Menschen können diese Gesetze entdecken, sie erkennen, sie erforschen, sie in ihren Handlungen berücksichtigen, sie für Interessen der Gesellschaft nutzen, aber sie können sie nicht verändern oder aufheben (...) ganz gleich, ob die Rede ist von der Periode des Kapitalismus oder von der Periode des Sozialismus." - Ebd., 190ff.
}

104 „Die Nutzung ökonomischer Prozesse, ökonomischer Gesetze im Interesse der Gesellschaft erfolgt in dem einen oder anderen Maß nicht nur im Sozialismus und Kommunismus, sondern auch in anderen Formationen". - Stalin, l.: Otvet t-šcu Notkinu, Aleksandru Il'icu (1952), in: StW 16, 246-257, hier 248. Analog dazu Glezerman, G.E.: I.V. Stalin ob ob-ektivnom charaktere zakonov obšcestvennogo razvitija i ich soznatel'nom ispol'zovanii ljud'mi, M. 1953; Ovander, N.E.: Ob ob-ektivnom charaktere zakonov razvitija sovetskogo socialisticeskogo obscestva, in: VF 1953, H. 4, 40-49.

105 International bekannt wurde Kon durch seine große Arbeit zur zeitgenössischen Geschichtsphilosophie: Filosofskij idealizm i krizis buržuaznoj istoriðeskoj mysli. Kriticeskie ozerki filosofii istorii epochi imperializma, M. 1959. In der deutschen Übertragung überarbeitet und ergänzt: Die Geschichtsphilosophie des 20. Jahrhunderts. Kritischer Abriß. 2 Bände, Berlin 1964. Später wandte er sich sozialpsychologischen Themen zu und machte sich auch als Sexologe einen Namen. Vgl. Kon, I.S.: Soziologie der Persönlichkeit, Berlin 1971.

106 Kon, I.S.: O dejstvii ekonomiðeskich zakonov $v$ antagonistiðeskich formacijach, in: VI 1954, H. 5, 111-127. 
Zustimmung. Das Proletariat ,nutze“, so hieß es in den Repliken, selbstverständlich die spezifischen Entwicklungsgesetze des Kapitalismus bewußt! ${ }^{107}$

Mitte 1956 brach die Redaktion der Voprosy istorii die fruchtlose Auseinandersetzung ab, weil diese, wie sie richtig feststellte, ,scholastischen, buchstabengelehrten Charakter" hatte. Zitate, nicht aber konkret-historisches Material seien die Argumentationsgrundlagen der Opponenten gewesen. Theoretische Fragen wie die der Gesetzmäßigkeiten sollten auch weiterhin in der Zeitschrift erörtert werden, allerdings ,schöpferisch“ und „basierend auf konkret-historischem Material“. ${ }^{108}$

Bemerkenswert an der redaktionellen Intervention war, daß eine grundlegende geschichtstheoretische These Stalins mit der ganzen Autorität der tonangebenden Fachzeitschrift explizit für falsch erklärt wurde, hier die Aussage Stalins über die „Nutzung“ der Gesetzmäßigkeiten. ${ }^{109}$ Das eigentliche Problem - Stalins Objektivismus - akzentuierte die Redaktion allerdings weder in geschichtstheoretischer noch -methodologischer Hinsicht. Im Anschluß an Friedrich Engels und unter Berufung auf W. Petty, A. Smith und D. Ricardo bekräftigte sie die Aussage über den spontanen, objektiven Charakter in ,kapitalistischen " Gesellschaften. ${ }^{10}$ Erst mit dem Übergang zu sozialistischen Produktionsverhältnissen werde der spontane Charakter überwunden, würden wirtschaftliche und gesellschaftliche Entwicklungen plan- und gestaltbar. ${ }^{111}$ Damit wurden hinsichtlich vorsozialistischer Formationen die objektivistischen Fehler Stalins, hinsichtlich der sozialistischen Gesellschaft die voluntaristischen wiederholt. Die bei Stalin vollzogene, geschichtsmethodologisch relevante

„(...) Ausdehnung des Aspekts der Bewußtseinsunabhängigkeit von objektiven Gesetzen auf die Beantwortung der Frage nach der Spezifik gesellschaftlicher Gesetze $(\ldots)^{\text {c112 }}$

wurde von den Diskutanten nicht problematisiert. So blieb unausgesprochen, daß gerade dadurch die Geschichte

107 Persov, M.S.: O sootnošenii obšcesociologičeskich i specificeskich zakonov formacii, in: VI 1955, H. 1, 84-86; Zamjatnin, V.N.M.I. Kanuzina: K voprosu o dejstvii ekonomičeskich zakonov $\checkmark$ antagonističeskich obšcestvach, in: VI 1955, H. 5, 86-91; Orleanskij, A.I.: K voprosu o zakonomernostjach obscestvennogo razvitija, in: VI 1955, H. 10, 67-73; Grot, L.Ju.: K voprosu o dejstvii ekonomičeskich zakonov $v$ antagonističeskich obł̌estvach, in: VI 1956, H. 1, 81-86.

108 Po povodu diskussii o dejstvii ekonomičeskich zakonov $v$ antagonisticeskich formacijach, in: VI 1956, H. 7, 66-67.

109 „Diese Streitigkeiten brachten der Wissenschaft keinen Vorteil, da die Ausgangsthese I.V. Stalins über die Nutzung (...) nicht richtig ist." - Ebd., 66.

110 „In einer Gesellschaft, die auf Privateigentum an Produktionsmitteln basiert, tragen die Wirkungen ökonomischer Gesetze unausweichlich spontanen Charakter; weder einzelne Personen noch bürgerliche Staaten insgesamt können auf die Wirkung ökonomischer Gesetze irgendeinen ernsthaften Einfluß ausüben." - Ebd., 67.

11 Ebd.

112 Naumann, Ökonomische Gesellschaftsformation, 13. 
„(...) nicht mehr als Resultat des - wie auch immer bewußten - Handelns der Subjekte begriffen werden, sondern allein als Exekution der (oder Verstoß gegen die) objektiven Gesetze, unter den sich auf mysteriöse Weise wandelnden 'ökonomischen Bedingungen' " "113

Viertens: Wenig Erfolg hatten Pankratova und Burdžalov auch mit der letzten Beitragsserie (1956/57), mit der versucht wurde, die aus den letzten Jahren der Stalinzeit stammenden, rein negativen Wertungen nationaler Befreiungsbestrebungen gegen Rußland zu revidieren. Die seit 1950 gültige Agentendoktrin über den Führer der dagestanischen und tschetschenischen Befreiungsbewegung, Samil $(1797-1871),{ }^{114}$ rückte dabei wegen der heftigen Kritik von A.M. Pikman ins Zentrum der Aufmerksamkeit. ${ }^{115}$ Anna Pankratova äußerte sich wiederholt zur Kontroverse, wies vorschnelle Urteile zurück und forderte ein

„(..) aufmerksameres, tieferes und konkreteres Studium der Gesamtheit aller inneren und äußeren Bedingungen, unter denen diese Bewegungen entstanden sind und sich entfaltet haben". ${ }^{116}$

Nach dem Ausscheiden Pankratovas und Burdžalovs aus der Redaktion der Voprosy istorii wurde der Austausch sachlicher Argumente rasch beendet und die Auseinandersetzung administrativ entschieden. ${ }^{17}$ Nicht Pikman und seine gleichgesinnten Kollegen behielten das letzte Wort, sondern die Repräsentanten dogmatischer und großrussischer Positionen. Auch weiterhin galt die Angliederung (prisoedl-

\footnotetext{
113 Ebd., 14.

114 Formuliert bei Bagirov: K voprosu o charaktere dviženija mjurodizma i Samilija, in: Bol '̌evik 1950, H. 13. Vgl. auch den Artikel über Samil in der zweiten Auflage der "Großen Sowjetischen Enzyklopädie" von 1952, Band 13, 278 (nussisch); deutsch in: Oberländer, E.: Sowjetpatriotismus und Geschichte. Dokumentation. Köln 1967, $233 \mathrm{f}$.

11s Siehe Konferencija 1956, 204; Pikman. A.M.: O bor be kavkazskich gorcev s carskim kolonizatorami, in: VI 1956, H. 3, 75-84; Danijalov, G.D.: O dviženii gorcev pod rukovodstvom Samilija, in: VI 1956, H. 7, 67-72; Bušuev, S.K.: O kavkazskom mjuridizme, in: VI 1956, H. 12, 72-79, Obsuždenie voprosa o charaktere dviženij gorskich narodov Severnogo Kavkaza v 2050-ch godach XIX veka, in: VI 1956, H. 12, 188-191; Soveščanie istorikov po voprosu o charaktere dviženija gorskich narodov Severnogo Kavkaza v pervoj polovine XIX veka, in: VI 1956, H. 12, 191-198; K diskussii o charaktere dviženija gorcev Dagestana pod rukovodstvom Samilja. in: VI 1957, H. 1, 195-196; Pokrovskij, M.V.: O charaktere dviženija gorcev Zapadnogo Kavkaza v 40-60-ch godach XIX veka (Bericht), in: VI 1957, H. 2, 62-74.

116 Konferencija 1956, 213. - In ihrer Rede beim 20. Parteitag sagte sie: „Der Zarismus unterjochte die Völker grausam (...). Es ist bekannt, daß Lenin das zaristische Rußland als 'Völkergefängnis' bezeichnete. (...) Die Geschichte der nationalen Bewegungen in Rußland sollte gründlicher studiert werden. Man muß konkret-historisch an sie herangehen (...) und den Kampf an zwei Fronten fortsetzen - gegen den Großmachtchauvinismus und gegen den lokalen Nationalismus, denn das sind zwei Seiten derselben Medaille." - Diskussionsreden, $371 \mathrm{f}$.
}

117 Pikman, A.M.: Polemiki prosto ne bylo, in: VI 1990, H. 2, 187-189 
nenie) kaukasischer und mittelasiatischer Völker an das Russische Reich als .objektiv progressiv“. ${ }^{118}$

\subsubsection{Zum Verhältnis von Einzelwissenschaft und Philosophie}

Seit 1938 waren die Geschichtswissenschaft und die Philosophie in der Akademie der Wissenschaften der UdSSR in einer Abteilung zusammengefaßt. ${ }^{119}$ Diese an sich nicht zu überschätzende organisatorische Regelung hatte sich verhängnisvoll auf die Geschichtsforschung ausgewirkt, da sie korrespondierte mit der unter Stalin gültigen Identitätsthese über die beiden Disziplinen. Diese besagte, daß die Geschichtsschreibung faktenorientiert zu betreiben sei und lediglich

„(...) das (ökonomisch restringierte) Begriffsinstrumentarium des historischen Materialismus 'anzuwenden'" und zu illustrieren habe. ${ }^{120}$

Bereits im Sommer 1953 beschloß das Akademiepräsidium die Gründung einer eigenständigen Abteilung der Geschichtswissenschaften ${ }^{121}$ und beseitigte damit die organisatorische Seite dieser Herabsetzung. Die neue Redaktion der Voprosy istorii vertrat fortan - wenn auch vielfach nur deklamatorisch - die Position, daß auch die Geschichtswissenschaft theoretisches Wissen liefern könne und müsse, und $\mathrm{da} B$ geschichtstheoretische und -methodologische Probleme zuvorderst von Historikern, gegebenenfalls in Zusammenarbeit mit Philosophen bearbeitet werden müßten. ${ }^{122}$

Um diesem Anliegen Nachdruck zu leihen, veranstaltete die Redaktion immer häufiger Konferenzen mit Autoren und Lesern. Erst relativ spät, im Lauf des Jahres 1956, stieg die Beteiligung an diesen Diskussionsveranstaltungen der Zeitschrift

118 Erwin Oberländer vermittelt an dieser Stelle in seiner ansonsten sehr aufschlußreichen Dokumentation ein unvollständiges Bild. Pikmans Artikel von 1956 markierte nicht den neuen gültigen Standpunkt, wie die Zusammenstellung der Texte bei Oberländer glauben macht, sondern nur den Versuch zur Umwertung, der jedoch zurückgewiesen wurde. Noch als die Diskutanten auf Konferenzen unterschiedliche Positionen austauschten, wurde in internen Papieren der Partei der offizielle Standpunkt fixiert: Der Kampf nichtrussischer Völker gegen den Zarismus habe ,antikolonialen“ Charakter getragen, sei aber von den „herrschenden Kreisen“ der Türkei und Englands (hier im Falle der Kaukasusvölker) mit der Beihilfe einiger Vertreter der nichtrussischen Völker ausgenutzt worden. „In der Ideologie der Bewegung und der Politik ihrer Führer gab es reaktionäre Züge." - Kuznecova, K./A. Cernjaev/D. Kukin am 01.03.1958 an das ZK der KPdSU, in: CChSD f. 5, op. 35, d. 77, 36f; vgl. Oberländer, Sowjetpatriotismus, 231-236; Strogo sobljudat' leninskij princip partijnosti $v$ istoričeskoj nauke, in: K 1957, H. 4, 17-29, hier $25 f$.

119 Und zwar in der „Otdelenie istorii i filosofii AN SSSR“; siehe SIE 1, 297.

120 Naumann, Ökonomische Gesellschaftsformation, 9.

121 "Otdelenie istoričeskich nauk AN SSSR“; siehe VI 1953, H. 10, 158.

122 Siehe O nekotorych važnejšich zadačach sovetskich istorikov, in: VI 1953, H. 6, 3-11, hier 10. 
erheblich. ${ }^{123}$ Es waren die ersten Versuche, die „Altlasten“ der Stalinschen Dogmatik abzutragen. Dabei offenbarte sich eine große ,methodologische Hilflosigkeit“, wie I.V. Kuznecov bei der Leserkonferenz im Januar 1956 es formulierte. ${ }^{124}$ Immerhin gab es einzelne neue Vorschläge, die in Voprosy istorii weiterverbreitet wurden: Grundsätzlich solle methododologischen Fragen aufmerksamer nachgegangen werden ${ }^{125}$ und vor allem die, Arbeitsmethoden ausländischer Wissenschaftler" soltten endlich studiert werden. ${ }^{126}$ Der bislang praktizierte subjektivistische Zugang, die Fakten den Konzeptionen unterzuordnen, müsse überwunden werden. ${ }^{127}$ A.A. Vvedenskij unterbreitete der Redaktion den geradezu ketzerischen Vorschlag, eine Aussprache einzuleiten

„(...) über verschiedene wissenschaftliche Schulen, die bei uns bestehen können auf der Basis einheitlicher marxistisch-leninistischer Methodologie. “128

123 Ende Januar 1956 nahmen mehr als sechshundert Wissenschafler und Lehrer in Moskau teil, in Leningrad am 19. und 20. Mai sowie in Kiev im Juni waren es etwa funfhundert Menschen. - Konferencija 1956, 199; Konferencija (Leningrad), 1956, 184; Konferencija (Kiev). 1956, 198.

124 Konferencija 1956, hier 207.

125 So U.A. Suster ebd., 189; M.A. Rubač nach Konferencija (Kiev) 1956, 200

126 So S.S. Volk nach Konferencija (Leningrad) 1956, 185.

129 So V.N. Bernadskij nach Konferencija (Leningrad) 1956, 186. Bernadskij führte allerdings diese Untugend auf die "sogenannte Schule Pokrovskijs“" zunück.

128 Siehe Konferencija (Kiev) 1956, 200. - Allein der Begriff „wissenschaftliche Schule" war seit der Totalkritik an Pokrovskij tabuisiert. 


\subsection{Das antirevisionistische Gegensteuern $1955 / 57$ bis 1960}

In dem Maß, in dem sich die Bemühungen Pankratovas und Burdžalovs um die Entstalinisierung der Geschichtswissenschaft materialisierten, nahmen auch das Mißtrauen seitens konservativer Fachkollegen und Parteifunktionäre sowie der Druck, der vom Parteiapparat ausging, zu. Anhand der im Archiv des Zentralkomitees der KPdSU aufbewahrten Materialien, die im März 1992 der Öffentlichkeit zugänglich wurden, lassen sich die entsprechenden Ereignisse chronologisch rekonstruieren (Kapitel 3.2.1.). Die einerseits öffentlich vorgetragene und die andererseits nur intern im Parteiapparat diskutierte und fixierte Kritik an der Redaktionsleitung der Voprosy istorii vergleichend, soll im Anschluß daran der Inhalt der antirevisionistischen Kritik dargelegt werden (3.3.2.). Das Kapitel zur Entwicklung in den füfziger Jahren schließt mit der Untersuchung der Auswirkungen (3.2.3.) und der Grenzen (3.2.4.) des Antirevisionismus ab.

\subsubsection{Der Ereignisverlauf von Anfang 1955 bis März 1957}

Anfang 1955 schon gingen Gerüchte um, im Apparat des Zentralkomitees der KPdSU würde kritisches Material über die Redaktion von Voprosy istorii und vor allem über Anna Pankratova zusammengestellt. Tatsächlich erhielt die damals von A.M. Rumjancev geleitete ZK-Abteilung für Wissenschaft und Kultur im Januar und Mai 1955 zumindest aus Kiev sogenannte „Bemerkungen und Vorschläge“ verschiedener Absender, die recht stereotyp Lob und vor allem Tadel über Voprosy istorii aufzählten. 'Pankratova bat wiederholt ohne Erfolg um ein Treffen mit Vertretern der ZK-Abteilung. ${ }^{2}$ Am 26. April 1955 schickte sie ihren Rechenschaftsbericht (1954) an das Zentralkomitee. ${ }^{3}$ Für den 29. des Monats wurde sie ins ZK zum Informationsaustausch eingeladen. Am Abend vorher teitte ihr eine Mitarbeiterin des Zentralkomitees, K.S. Kuznecova, mit, daß in der Wissenschaftsabteilung des ZK von P.V. Volobuev ${ }^{4}$ unterschriebene Aufzeichnungen (zapiski) vorlägen, in

1 CChSD f. 5, op. 17, d. 520, 56ff.

2 Im Mai 1955 schrieb Pankratova, sie habe zwei Jahre lang nichts gehört von Rumjancev und Licholat, die im ZK für die Anleitung der Zeitschrift zuständig seien; die Redaktion wünsche ständigen Kontakt, sie persönlich habe mehrfach um die Möglichkeit gebeten zu referieren. Pankratova, A. im Mai 1955 an N.S. Chrušcev, M.A. Suslov, P.N. Pospelov und A.M. Rumjancev, in: CChSD f. 5, op. 17, d. 520, 2-7, hier 2.

3 Pankratova, A.M.: Otčet o rabote redakcii žurnala "Voprosy istorii“ za 1954 god (26.04.1955), in: CChSD f. 5, op. 17, d. 520, 81-94.

4 Pavel Vasil'evic Volobuev, geboren am 01.01.1923, Altersgenosse von Ju.A. Poljakov und I.D. Koval'čnko, KPdSU-Mitglied seit 1944, absolvierte 1950 die Historische Fakultät der Moskauer Staats-Universität, wo A.L. Sidorov sein wichtigster Lehrer war. Er war nach eigenen Angaben von Oktober 1953 bis Oktober 1955 in der Wissenschaftsabteilung des ZK unter anderem für die "Anleitung" der Voprasy istorii zuständig. Im Gespräch mit dem Autor am 08.04.1993 stand er zu seiner damaligen Aktivität und sagte sinngemäß: „Ja, ich arbeitete gegen Pankratova 
denen die Redaktionsleitung scharf kritisiert würde. ${ }^{5}$ Am Morgen des 29. April sah Pankratova die Unterlagen ein und verließ sofort wieder das ZK-Gebäude, ohne an dem geplanten Treffen teilgenommen $\mathrm{zu}_{\text {haben. }}{ }^{6}$ Tags darauf berief sie eine Redaktionssitzung ein, in der sie das Kollegium über den Inhalt der zapiski informierte und sich die Unterstützung (zumindest der Mehrheit, aber darüber liegen keine Quellen vor) der Redaktion versichem ließ. ${ }^{7}$

Am 17. Mai 1955 gingen beim Zentralkomitee ein Protestbrief und ein 30-seitiges Schreiben Pankratovas ein, in dem die Chefredakteurin die Vorwürfe zu widerlegen suchte. ${ }^{8}$ In internen Papieren des Zentralkomitees vom 17. Juni und 28. Juli wurde die Kritik an der Arbeit Pankratovas und Burdžalovs dennoch bekräftigt. ${ }^{9}$ Eine weitere Zusammenstellung mit Datum vom 11. August 1955 läßt Meinungsverschiedenheiten im ZK und Signale zu einer positiveren Einschätzung der Re-

und Burdžalov. Wenn ich mich heute daran erinnere, was wir schrieben, denke ich, was waren wir für Dummköpfe!" - Anschließend kam er als wissenschaftlicher Mitarbeiter an das Geschichtsinstitut der AdW der UdSSR, dessen Direktor inzwischen Sidorov geworden war. Er zählte bald zur "Neuen Richtung“ in der Oktoberrevolutionsforschung. Von 1966 an leitete er die Arbeitsgruppe zur Veröffentlichung der mehrbändigen "Geschichte der UdSSR“. Wegen seiner 1953/55 erworbenen „Verdienste“ wurde er 1970 vom Parteiapparat, der ihn für „unseren Mann“ hielt, auserkoren, als Direktor das Institut für Geschichte der UdSSR auf Parteilinie zu bringen. Im gleichen Jahr bestätigte ihn die Vollversammlung der Akademie der Wissenschaften als ihr Korrespondierendes Mitglied. Nachdem er jedoch die Neuerer und die Teilnehmer an den abweichenden Theoriediskussionen in Schutz genommen hatte. mußte er am 4. März 1974 das Geschichtsinstitut verlassen. Er wurde als einfacher wissenschafticher Mitarbeiter abkommandiert in das Institut für Geschichte der Naturwissenschaft und Technik an der AdW. Erst in den Tagen der perestrojka, nach der Veröffentlichung seiner Monographie über die Wahl des geschichtlichen Weges, kehrte er an ,sein“ Institut zurück, wurde im Dezember 1990 zum Vollmitglied der Akademie gewählt und löste schließlich sogar Isaak Minc als Vorsitzenden des Wissenschaflichen Rates zur Erforschung der Oktoberrevolution ab. - Nekric, Orrešis ot stracha, 339ff; Lewytzkyj, B. (Hg.): Who's Who in the Soviet Union. A Biographical Encyclopedia of 5,000 Leading Personalities in the Soviet Union, München etc. 1984, 356; VI 1971, H. 1, 144; Trubinova, T.S.: V otdelenii istorii AN SSSR, in: ISSSR 1991, H. 3, 232-234, hier 232; Hildermeier, $M$. Revolution und Revolutionsgeschichte, in: Geyer, Die Umwertung, 32-53, hier 46f.

5 Pankratova, A.M. im Mai 1955 an N.S. Chrušcev, M.A. Suslov, P.N. Pospelov und A.M. Rumjancev, in: CChSD f. 5, op. 17, d. 520, 4. Pankratova fugte an dieser Stelle hinzu, daß niemand bei ihr, Burď̌alov oder der Parteiorganisation der Zeitschrift gewesen sei und - nach ihrem Wissen - keinerlei Überprüfung stattgefunden habe.

6 „(...) unter dem Vorwand schlechten Gesundheitszustands (...", schrieb ihr damaliger Kontrahent Rumjancev, A.M. am 17.06.1955 an das ZK der KPdSU, in: CChSD f. 5, op. 17, d. 520, 95-101, hier 95

7

Ebd., 96.

8 Pankratova im Mai 1955 an Chruščev u.a., 2-7; dies., Spravka v zvjazi s zapiskoj Otdela nauki i kul'tury o soderžanii žurnala „Voprosy istorii“" za 1953-1954 gg., in: CChSD f. 5, op. 17, d. 520, 8-38.

9 Rumjancev am 17.06.1955; Rumjancev, A.K. Kuznecova/A. Licholat/A. Cernjaev am 28. 07.1955 an das ZK der KPdSU, in: CChSD f. 5, op. 17, d. 520, 42-55. 
daktionsarbeit erkennen. ${ }^{10}$ Trotzdem stellten ein halbes Jahr später - nach der Leserkonferenz der Voprosy istorii Ende Januar 1956 in Moskau - V.A. Kirillin, der neue Leiter der ZK-Abteilung, und Kuznecova einen Bericht darüber zusammen, in dem sie der positiven Einschätzung der Veranstalter in Moskau widersprachen. Besonders wegen Burdžalovs Ausführungen hätten viele Teilnehmer ihr ,Befremden und ihre Empörung" der Partei gegenüber ausgedrückt."

Nach dem 20. Parteitag der KPdSU aber, am 2. April 1956, teilte Kirillin kurz und knapp mit, das 1955 im Zentralkomitee gesammelte Material über Voprosy istorii habe seine Bedeutung verloren: die Umgestaltungsarbeit der Redaktion habe erst begonnen, Beratung und Urteil seien verfrüht. ${ }^{12}$ Es scheint, als hätten der Druck auf die Redaktion und die unmittelbare Gefahr des administrativen Eingreifens kurze Zeit nachgelassen. Doch es mangelte der neuen Redaktionsleitung an echter Unterstützung. Am 30. Mai 1956 appellierte Burdžalov eindringlich an den damaligen ZK-Sekretär D.T. Sepilov, die kollektive Aufarbeitung emsthafter Fragen in der Geschichtswissenschaft zu fördern. ${ }^{13}$ Am 24. März, 4. Mai und 24. September 1956 wandte sich Anna Pankratova schriftich an Suslov mit der Bitte, A.M. Gavrilova, die der Redaktion als Mitarbeiterin zugeteilt worden war, aber für die vorgesehenen Aufgaben nicht qualifiziert sei, von ihren Pflichten entbinden zu dürfen. ${ }^{14}$ Am 27. Juni d.J. richtete wiederum Gavrilova ein 12-seitiges Schreiben an das ZK, in dem sie Pankratova und Burdžalov denunzierte. ${ }^{15}$ Ebenfalls in den Sommermonaten erhielt das ZK zwei Berichte, die der Sekretär des Leningrader Stadtkomitees der KPdSU, I. Zamčevskij, und der Direktor des Instituts für

10 Rumjancev, A. am 11.08.1955 an das ZK der KPdSU, in: CChSD f. 5, op. 17, d. 520, $102-$ 108. Erstmals heißt es, daß die Autoren der zapiski, Volobuev und Cernjaev, zahlreiche Artikel in "VI" nicht objektiv bewertet und unbegründete Schlußfolgerungen gezogen hätten. In der überarbeiteten Beurteilung (vom 20.05.1955) habe Volobuev seine Wertungen sogar „(...) noch mehr zugespitzt (...)", anstatt sie zu korrigieren, schrieb Rumjancev, der sich vorher eisern mit Volobuev und Cemjaev solidarisiert hatte; hier $102 \mathrm{f}$.

"Kirillin, V.A./K.S. Kuznecova am 07.02.1956 an das ZK der KPdSU, in: CChSD f. 5, op. 35, d. $23,20-25$.

12 Kirillin, V.A. am 02.04.1956 an das ZK der KPdSU, in: CChSD f. 5, op. 17, d. 520, 112

13 „Nach dem 20. Parteitag", schrieb Burdžalov, „denkt jeder darüber nach, wie die Geschichtswissenschaft zu verbessern sei, jeder hat Ideen, Überlegungen, Vorschläge. (...) Warum hat man die Historiker nicht zusammengerufen, nicht mit ihnen gesprochen, sich nicht mit ihnen beraten?" - Burdžalov, E.N. am 30.05.1956 an D.T. Sepilov, in: CChSD f. 5, op. 35, d. 39, 8894, hier $93 f$.

14 Pankratova hatte um eine Kraft gebeten, die sich mit der Geschichte der sogenannten volksdemokratischen Länder befassen sollte; Gavrilova, schrieb Pankratova, habe sich nie mit diesem Gebiet beschäftigt und beherrsche auch keine der dafür erforderlichen Sprachen. Siehe Pankratova, M.A. am 24.03.1956 an M.A. Suslov, in: CChSD f. 5, op. 35, d. 39, 1; dies. am 04.05.1956 an M.A. Suslov, ebd., 2; dies. am 24.09.1956 an M.A. Suslov, ebd., 15.

is Hauptvorwurf: Burdžalov interpretiere den 20. Parteitag als Umwälzung (perevorot) und zwinge die Zeitschrift auf einen revisionistischen Kurs, wobei er von Pankratova unterstützt werde. - Gavrilova, A.M. an 27.06.1956 an das ZK der KPdSU, in: CChSD f. 5, op. 35, d. 39, 95107. 
Parteigeschichte beim Leningrader Gebietskomitee der KPdSU, Knjazev, über das Auftreten Burdžalovs ,im Geiste bourgeoisen Objektivismus'“ (Knjazev) bei den dortigen Leserkonferenzen der Zeitschrift verfaßt hatten. ${ }^{16}$ Burdžalov nahm am 14. Juli in der ZK-Abteilung Einsicht in das Schreiben von Zamčevskij und wandte sich daraufhin am 17. Juli direkt an Chruščev: Die Leserkonferenz habe im Zeichen des Kampfes für die Erfüllung der Beschlüsse des 20. Parteitags stattgefunden; Zamčevskij und andere, die bei der Konferenz geschwiegen hätten, hätten danach eine regelrechte Kampagne gegen die Zeitschrift begonnen. Thre Kritik basiere ,auf Fälschungen" und zeige lediglich ihr Bestreben, die Entwicklung der Geschichtswissenschaft in die vom 20. Parteitag gewiesene Richtung zu stören. ${ }^{17}$

Doch es gab auch Solidaritätserklärungen für Pankratova und Burdžalov. Am 17. und 18. August bekamen sie Post aus Leningrad: Zwei Historiker, die anders als ihre Vorgesetzten die Leserkonferenz und das Auftreten Burdžalovs positiv bewerteten, berichteten über den Druck, der nun auf sie ausgeübt würde, und baten um Unterstützung. ${ }^{18}$ Mit solidarischen Erklänungen gegenüber Burdžalov wandten sich Anfang September 1956 siebzehn Leningrader Historiker an das ZK und die Leningradskaja Pravda ${ }^{19}$, sieben wissenschaftliche Mitarbeiter der Staatlichen Bibliothek Saltykov-Scedrin schrieben direkt an Chruščev und baten inn (vergebens), die Veröffentlichung ihrer Replik gegen Aleksandrov ${ }^{20}$ zu unterstützen. In ihrem Schreiben an den Ersten Sekretär bezeichneten sie Aleksandrovs Artikel in der Leningrader Parteizeitung als "typisches Rezidiv unhaltbarer Überbleibsel der Blütezeit des Persönlichkeitskults“."21

Aus der Sicht Pankratovas und Burdžalovs trat jedoch keine Besserung ein, im Gegenteil! Am 23. August schrieb Pankratova an Suslov, um die Zeitschrift sei eine ,ungesunde Lage“ entstanden, die nicht dazu beitrage, die gestellten Aufgaben im Sinne des 20. Parteitags zu erfüllen. Pankratova wies auf die gegen Voprosy

16 Zamcevskij, I.: O vystuplenii tov. Burdžalova - zam. glavnogo redaktora žurnala „Voprosy istorii“" v g. Leningrade (28.06.1956), in: CChSD f. 5, op. 35, d. 39, 52-55; Knjazev: Spravka o vystuplenii tov. Burdžalova E.N. v Leningrade na konferencii čitatelej žurnala „Voprosy istorii“ (02.07.1956), in: CChSD f. 5, op. 35, d. 39, 57-59.

17 Burdžalov, E.N. am 17.07.1956 an N.S. Chrušxev, in: CChSD f. 5, op. 35, d. 39, 80-87. Mitte September erreichte auch aus Kiev ein Denunziationsschreiben das ZK. In diesem Falle prangerten zwei „einfache“ Historiker Burdžalovs Ausführungen bei der Leserkonferenz am 28. und 29. Juni in Kiev an. Siehe Belous/Korostarenko am 18.09.1956 an Chrušcev, in: CChSD f. 5, op. 35, d. 39, 74 .

18 Dal'skij, A.N. am 18.08.1956 an A.M. Pankratova und E.N. Burdžalov, in: CChSD f. 5, op. 35, d. 39, 108-110; Michrin, P. am 17.08.1956 an E.N. Burdžalov, ebd., 121-124.

19 Vjatkin, M.P. u.a am 01.09.1956 an Kirillin, Bogdanov und Kurtynin, in: CChSD f. 5, op. 35, d. 39, 135-142; sorgfältig zeigten diese Autoren durch eine Synopse der Texte, wie Aleksandrov die Aussagen Burdžalovs verfalischt hatte.

$20 \mathrm{Vgl}$. unten Fußnote 24.

21 Al'šcic, D.N. u.a. am 05.09.1956 an Chruščev, in: CChSD f. 5, op. 35, d. 39, 143-152, hier 143. 
istorii gerichteten Veröffentlichungen in Kommunist ${ }^{22}$, in Partijnaja zizn $^{123}$ und in der Leningradskaja Pravda ${ }^{24} \mathrm{hin}$, die unhaltbare Vorwürfe und Verleumdungen enthielten; es könne kein Zufall sein, daß diese drei Artikel fast gleichzeitig erschienen seien. ${ }^{25}$ Am 21. September wandte sich Burdžalov mit der dringenden Bitte an Suslov, in die Angelegenheit einzugreifen. All seine, Burdžalovs, Protestversuche seien unterdrückt, Leserbriefe nicht veröffentlicht und nicht beantwortet worden. ${ }^{26}$ Offenbar reagierte Suslov nicht, wie Burdžalov gehofft hatte, denn am 11. Dezember 1956 richtete er einen Brief analogen Inhalts an Sepilov, den er bat, ihn, wenn auch kurz, zu empfangen oder jemanden zu beauftragen, die strittigen Fragen auf objektive Weise zu klären. ${ }^{27}$ Am 8. Februar 1957 schrieb Burdžalov nochmals ausfuihrlich an Pospelov, Kirillin und den Leiter der ZK-Abteilung für Propaganda und Agitation, F.V. Konstantinov. Burdžalov sah sich von den Parteiinstanzen auf verhängnisvolle Weise im Stich gelassen: Er wies auf interne Papiere hin, in denen die Anschuldigungen Aleksandrovs eindeutig zurückgewiesen würden. Weil dies nicht veröffentlicht worden sei, bestehe in der Öffentlichkeit jedoch weiter der Eindruck, die Vorwürfe seien berechtigt und die Partei teile sie. Entsprechend seien Ende 1956 diverse Versammlungen in Parteiorganisationen und wissenschaftlichen Instituten verlaufen: ${ }^{28}$

„In letzter Zeit hat die verleumderische Kampagne gegen die Redaktion (...) große Ausmaße angenommen. “29

Von den „Genossen“, an die er, Burdžalov, sich gewandt hatte, habe er in den letzten sechs Monaten keine Antwort erhalten. Nun bat er, die Leningradskaja

22 Za tvorčeskuju razrabotku istorii KPSS, in: K 1956, H. 10, 14-26. - Diesem Artikel folgten noch (ebenso gegen „VI“ gerichtet) Golikov, G.: K razrabotke istorii Oktjabr'skoj revoljucii, in: K 1956, H. 15, 44-58; Velikoe edinstvo socialističeskich stran nerusimo, in: K 1956, H. 16, 3-13; Vinogradov, V./. Maevskij: Protiv izvraščenija istorii obrazovanija socialističeskogo sposoba proizvodstva v SSSR, ebd., 122-128 (dies speziell gegen Nasyrin, V.P.: O nekotorych voprosach socialističeskogo preobrazovanija promyšlennosti v SSSR, in: VI 1956, H. 5, 90-99).

23 Bugaev, E.: Kogda utrax̌ivaetsja naučnyj podchod, in: PŽ 1956, H. 14, 62-72. Darauf: O stat'e tov. E. Bugaeva, in: VI 1956, H. 7, 215-222; O zurnale „Voprosy istorii“, in: PZZ 1956, H. 23, 71-77.

24 Aleksandrov, A.: Za podlinno-naučnyj podchod $k$ voprosam istorii, in: Leningradskaja Pravda, 05.08.1956.

25 Pankratova, A.M. am 23.08.1956 an M.A. Suslov, in: CChSD f. 5, op. 35, d. 39, 61-63.

26 Burdłalov, E.N. am 21.09.1956 an Suslov, in: CChSD f. 5, op. 35, d. 39, $78 f$.

27 Burdy̌alov, E.N. am 11.12.1956 an Sepilov, in: CChSD f. 5, op. 35, d. 39, $153 f$.

28 Burdłalov, E.N. am 08.02.1957 an Pospelov, Kirillin und Konstantinov, in: CChSD f. 5, op. 35, d. 39, 157-162; Burdžalov bezog sich auf eine Sitzung der Lehrstühle für Parteigeschichte und Geschichte der Sowjetgesellschaft an der Moskauer Staatlichen Lomonosov-Universität im November 1956 und eine Versammlung der Parteiorganisation an der dortigen Historischen Fakultät am 10.01.1957

29 Ebd., 158. - Vgl. auch Heer, Politics, 88f: „Thus in late November the regime once more escalated the conflict with the revisionists." 
Pravda anzuweisen, seine Antwort auf Aleksandrovs Artikel zu drucken. ${ }^{30}$ Am 25. Februar 1957 unterzeichnete der Leiter der ZK-Abteilung für Wissenschaft, Hochschulen und Schulen, Kirillin, seine Vorlage für das Zentralkomitee der Partei: Aleksandrovs Artikel in der Leningradskaja Pravda sei in grobem Ton geschrieben und verfälsche stellenweise Burdžalovs Aussagen bei der Leserkonferenz. Dies müsse dem Redakteur der Zeitung gesagt werden. Jedoch: eine Widerlegung o.ä. zu publizieren, sei ,nicht zweckmäßig“. Auch die Attacken des Dozenten Savinčenko und des Professors Bušuev während der Parteiversammlung der Historischen Fakultät an der Lomonosov-Universität bezeichnete Kirillin als ,grobe persönliche Angriffe", „unbegründete politische Anschuldigungen“ und "demagogisch" “ ${ }^{31}$ Der Sekretär der Parteiorganisation, Saprykin, sei in der ZK-Abteilung für sein Schweigen gerügt und beauftragt worden,

„(..) ein Gespräch mit den Gen. Savincenko und Bušuev zu führen und bei der nächsten Parteiversammlung (...) auf die unrichtigen Momente in ihren Auftritten hinzuweisen. "32

Sie, wie Buržalov gefordert hatte, in der Partei zur Verantwortung zu ziehen, bezeichnete Kirillin als ,nicht richtig““ ${ }^{33}$ Dieses Dokument bestätigt also Burdžalovs Vorwurf an die Partei, intern zwar die Kritik an ihm und Pankratova nicht zu teilen, sie aber öffentlich nicht zurückzuweisen. Damit waren die Revisionisten ihren Gegner ausgeliefert, war - auf mehr oder weniger elegante Weise - das Urteil gegen Burdžalov und Pankratova gesprochen: Burdy̌alovs Kontrahenten erhielten lediglich Rügen; vor das Parteigericht kam der Geschädigte selbst. Daran änderte auch der letzte Appell Burdžalovs an Sepilov nichts mehr, der die Materialsammlung zu dieser Kampagne im ZK-Archiv abschließt:

"Lieber Dmitnij Trovimovic! Anna Michajlonna Pankratova wollte mit Ihnen über unsere Zeitschrift sprechen, aber gestem brachte man sie ins Krankenhaus. Sie versprachen, mich zu empfangen (...). Ich bitte Sie sehr, dies vor der Annahme des endgültigen Beschlusses über die Zeitschrift (...) zu tun. Auch möchte ich Thnen mitteilen, da $B$ einige Anschuldigungen gegen mich auf den privaten Brief, der von mir im Sommer letzten Jahres an Ihren Namen gerichtet war, (...) basieren. Noch einmal bitte ich Sie inständig, mich zu empfangen. ${ }^{34}$

\subsubsection{Der Inhalt der antirevisionistischen Kritik}

In der Sache lautete der wiederholt vorgebrachte Hauptvorwurf gegen Pankratova und Burdžalov, sie würden aufgnund ihrer irrigen Interpretation der Parteibeschlüs-

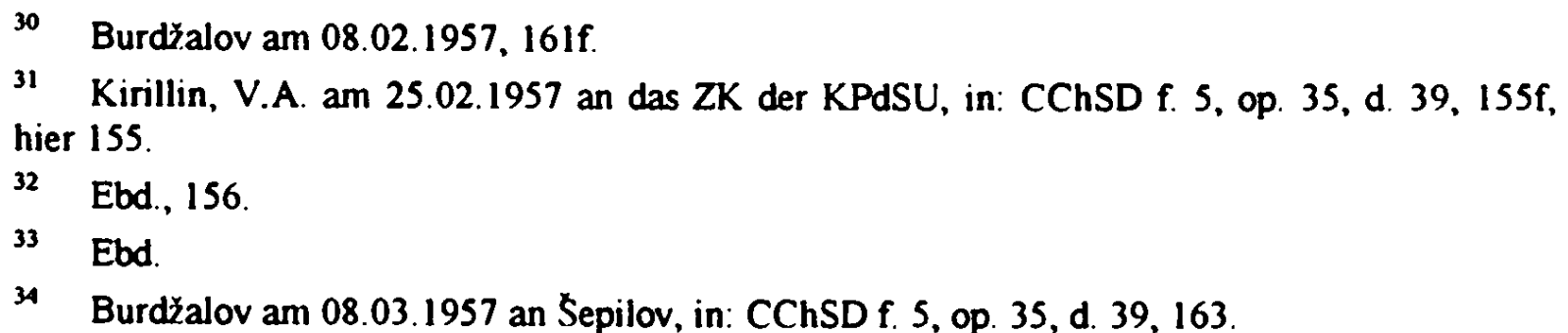


se die berechtigte Kritik am „Personenkult um Stalin“ ausweiten und gänzlich dem ideologischen Gegner nachgeben. Treibende Kraft sei Burdžalov, dessen Fehler sich erklärten

„(..) durch die Preisgabe der marxistisch-leninistischen dialektischen Forschungsmethode und des Prinzips der Parteilichkeit in der Geschichtswissenschaft. In seinen Artikeln verflechtet sich Objektivismus eng mit Subjektivismus und Dogmatismus. ${ }^{\text {a3s }}$

Pankratova, die ihn als „konsequenten Marxisten“ ansehe, unterstütze ihn mit all ihrer Autorität als Akademie- und ZK-Mitglied ${ }^{36}$ Inhaltlich wurde dies vor allem mit folgenden Revisionsansätzen begründet, die unter Pankratova und Burdžalov gestartet wurden:

- Neubewertung der Rolle der Men'Ševiki in der ersten russischen Revolution 1905/07 und der Bol'ševiki in der zweiten im Februar 1917: Burdžalov und andere Autoren in Voprosy istorii hätten die grundsätzlichen Unterschiede zwischen Bol'seviki und Men'seviki verwischt. Burdžalov habe die Bol'seviki als von den Massen isolierte Kräfte gezeichnet und anstatt ihrer Taktik bloß die Fehler Stalins und Zinov'evs dargelegt. ${ }^{37}$

- Neubewertung einzelner Persönlichkeiten: Burdžalov sei offen für die Verteidigung und Rehabilitierung von Feinden der Revolution, Feinden des Volks eingetreten und habe empfohlen, ihre Schriften als geschichtliche Quellen zu nutzen. ${ }^{38}$

35 Strogo sobljudat' leninskij princip. 21.

36 Gavrilova am 27.06.1956, 103. Die so manifestierte Zugehörigkeit Pankratovas zur sowjetischen Elite verhinderte zweifelsohne eine frühere Entlassung. konnte ihr letztlich aber nicht helfen. Die Denunziation Gavrilovas zeigt, daß gerade unter dem Hinweis auf die hohen Funktionen die Vorwürfe gegen Pankratova sogar verstärkt wurden.

37 So besonders in Strogo sobljudat' leninskij princip, wo auch die entsprechenden ,anrüchigen" Artikel. die in „VI" veröffentlicht wurden, genannt sind. Analog bei Kirillin/Kuznecova am 07.02.1956, 21; siehe auch Bugaev, Kogda utračivaetsja naučnyj podchod, 69f; O zurnale 1956, 73; Za tvorčeskuju razrabotku, 24; Golikov, K razrabotke, 52. - De facto plädierte Burdłalov dafur, bei der geschichtlichen Analyse politischer Kräfte (ob Men`ßeviki oder Bol 'seviki) konkret-historisch einzelne Linien, Strömungen, Etappen usw. zu unterscheiden und ahistorische, politisch motivierte Pauschalurteile zu überwinden. Siehe Burdžalov, E.N.: O taktike bol'sevikov $v$ marte-aprele 1917 goda, in: VI 1956, H. 4, 38-56; ders.: Esče raz o taktike bol'Kevikov v marte-aprele 1917 goda, in: VI 1956, H. 7, 109-114; O stat'e 1956, 216ff; Vjatkin u.a. am $01.09 .1956,139$.

38 So Zamčevskij, O vystuplenii, 53; Knjazev, Spravka, 57; Belous/Korostarenko am 18.09.1956, 74; Gavrilova am 27.06.1956, 99. - Burdžalov hatte in diesem Zusammenhang die Namen von L.D. Trockij, G.V. Zinov'ev, L.B. Kamenev, A.G. Sljapnikov, F.F. Raskol'nikov und M.N. Tuchačevskij genannt, die er vom Stigma „Volksfeind“ befreit und deren Aktivität er unvoreingenommen erforscht sehen wollte; G.V. Plechanov und die z.T. verfemten Parteihistoriker V.G. Knorin, A.S. Bubnov, N. Popov, V.I. Nevskij und E.M. Jaroslavskij müßten endlich in der Historiographie registrient und in die Forschung einbezogen werden; vgl. Burdžalov, O taktike; ders., Ešče raz o taktike: O stat’e 1956, 216. 
- Kritik Stalinscher Dogmen: Mit seiner Forderung, die Staatsauffassung Stalins (und andere „Beiträge“ zur marxistisch-leninistischen Theorie) zu überwinden, sei Burdžalov weit über die notwendige Kritik des Personenkults hinausgegegangen; dies treffe auch auf Burdžalovs Empfehlung zu, künftig die politischen Erfahrungen anderer sozialistischer Länder (z. B. Jugoslawiens!) positiv zu nutzen. ${ }^{39}$

- Selbständiges professionelles Arbeiten: die führende Rolle der KPdSU sei in Frage gestellt, wenn Burdžalov behaupte, der 20. Parteitag habe die allgemeine Richtung vorgegeben und weitere Direktiven seien weder zu erwarten noch notwendig, da Voprosy istorii die einzelnen Fragen selbständig bearbeite. ${ }^{40}$

- Versachlichung des Umgangs mit der nichtmarxistischen Historiographie: die Aufrufe in Voprosy istorii zum Kampf gegen die bürgerliche Geschichtsschreibung fielen abstrakt und unglaubwürdig aus, in Wirklichkeit nehme die Redaktion ein ,neutrales Verhältnis gegenüber dem Marxismus feindlichen Ansichten“ ein. ${ }^{41}$

Diese Kritikpunkte waren bis Anfang 1956 vom Parteiapparat notiert und zusammengetragen worden, schienen aber nach dem 20. Parteitag unbedeutend geworden zu sein. Innenpolitisch gab es m.E. keine Gründe für die politische Führung, daran etwas zu ändern. Es waren außenpolitische Faktoren, nämlich die Krisen in Polen und Ungarn im Sommer und Herbst $1956^{42}$, welche die Führung um Chruščev zu einem Teilrückzug bewegten: Die Entstalinisierung wurde zeitweise zurückgenommen. ${ }^{43}$ Den Beginn dieses politischen Kurswechsels markierte der

39 Gavrilova am 27.06.1956, 101. In der Antwort auf Bugaev stellte sich die Redaktion der „VI" auf den für Konservative beunruhigenden Standpunkt, daß hierbei selbstverständlich ,erst der Anfang einer großen Arbeit getan" sei; O stat'e 1956, 216.

40 Knjazev, Spravka, 57; Aleksandrov, Za podlinno-naučnyj podchod. - Darin sah Burdžalov das entscheidende Neue nach dem 20. Parteitag: vorher seien die Historiker es gewohnt gewesen. von oben Direktiven und Antworten auf alle Fragen zu erhalten. „Durch den 20. Parteitag ist uns eine vollkommen klare und deutliche Linie gegeben, ist uns, den Historikern gesagt, daß wir uns selbst in unseren Fragen klarwerden müssen, nicht sofort, nicht in einem Zug, nicht auf dem Weg irgendeiner routinemäßigen Kampagne, sondern gedankenvoll, ernsthaft, und daß wir damit unverzüglich beginnen sollen (...).“ Zitiert nach Vjatkin u.a. am 01.09.1956, 137; vgl. auch Al'šxic u.a., $146 \mathrm{f}$.

41 O žurnale 1956, 74. - Die Redaktion der „V“" betonte immer wieder, gegen die „reaktionäre bürgerliche Geschichtswissenschaft“ zu kämpfen. Aber die Kritik ,(...) muß man mit wahrhaftigen, wirklich marxistischen wissenschaftlichen Positionen führen und nicht mit Hilfe beleidigender Epitheta.“ Dabei sei endlich differenziert vorzugehen, die Gegenüberstellung von „Marxisten" und „Reaktionären" hemme die Auseinandersetzung mehr, als sie zu fördern. Siehe $O$ stat'e 1956, 222.

42 Siehe die Dokumentation bei Crusius/Wilke, Entstalinisierung, 82ff, vgl. Heller/Nekrich, Geschichte, 223ff. Zur Wechselwirkung zwischen dem 20. Parteitag in der UdSSR und der Krise in der Tschechoslowakei vgl. Kaplan, K.: Die politische Krise in der Tschechoslowakei 1956, in: Beyrau/Bock, Das Tauwetter, 72-84.

43 Siehe Leonhard, W.: Kreml ohne Stalin, Köln 1959, 303ff; ders., Die Dreispaltung, 194ff; Heller/Nekrich, Geschichte, 240ff. 
ZK-Beschluß vom 30. Juni $1956^{44}$, der auch fur die Historie, ,(...) the turning point toward a policy of retrenchment ${ }^{\text {cas }}$ darstellte. Der Beschlu $B$ war allerdings über den Herbst 1956 hinaus bedeutsam, denn die zentralen Kompromißformeln blieben jahrzehntelang gültig. ${ }^{46}$ Dies betraf:

- die Ursachen des „Personenkults um Stalin“: Der ZK-Beschluß führte hier das Erklärungsschema ein, wonach ,(...) man sowohl die objektiven, konkreten historischen Bedingungen, in denen der Aufbau des Sozialismus in der UdSSR vor sich ging, als auch gewisse subjektive Faktoren, die mit den persönlichen Eigenschaften Stalins zusammenhängen, in Betracht ziehen" muß, nicht aber die Ursache in der Theorie und Praxis des Sozialismus selbst suchen darf. ${ }^{47}$

- die Bewertung Stalins: Das Stigma des „Verbrechers“ ordnete der ZK-Beschluß Berija zu; Stalin hob sich davon als ehrlicher Parteisoldat, dem emsthafte Fehler unterliefen, ab. Er habe Seite an Seite mit den Genossen um die „Verwirklichung des Leninschen Vermächtnisses" gekämpft. ${ }^{48}$ Die "Sowjetmenschen", so hieß es, hätten Stalin ,als einen Menschen" gekannt, ,(...) der stets für den Schutz der UdSSR vor den Anschlägen der Feinde eintritt und für die Sache des Sozialismus kämpft. Er wandte zuweilen (...) unwürdige Methoden an (...). Darin bestand die Tragödie Stalins. ${ }^{\text {(49 }}$

- die Folgen des Personenkults: auch gegen radikale Fragen nach den Auswirkungen der Stalin-Ära setzte der ZK-Beschluß Grenzmarken. Es könne nicht behaup-

44 O preodolenii kul'ta ličnosti i ego posledstvij. Postanovlenie CK KPSS 30 ijunja 1956 goda. in: SPR 1, 321-338; deutsch in: Judick/Steinhaus, Stalin, 196-228.

45 Heer, Politics, 86.

$46 \mathrm{Vgl}$. auch Heller/Nekrich, Geschichte, 220: „Die Resolution vom 30. Juni 1956 hob die Beschlüsse des XX. Parteitags praktisch auf und wurde von nun an zur ideologischen Basıs des nachstalinistischen Konformismus." - Nicht zufälig wurde daher der ZK-Beschluß - anders als die tabuisierte "Geheimrede" Chrušcevs - in der kommunistischen Presse wiederholt publiziert; in deutscher Sprache in: Neues Deutschland v. 03.07.1956; in: Wissen und Tat 1956, H. 7; in: MB 1977, H. 3; er blieb auch in den einschlägigen sowjetrussischen Dokumentenbänden zugänglich.

47 Zu den objektiven Faktoren wurde gezählt, daß es sich (1.) um den ersten Versuch gehandelt habe, eine sozialistische Gesellschaft zu errichten, daß (2.) das Sowjetland ein Vierteljahrhundert lang isoliert geblieben sei, daß (3.) nach 1933 die Kriegsgefahr eminent gestiegen sei, daß (4.) die Feinde in der Partei nach Lenins Tod aktiver geworden seien und (5.) in kürzester Frist eine jahrhundertelange Rückständigkeit hätte überwunden werden müssen. - Siehe Judick/Steinhaus, Stalin, 204ff.

Zu den subjektiven Faktoren zählten (1.), gewisse persönliche Eigenschaften " Stalins, auf die schon Lenin hingewiesen hatte, (2.) Stalins falsche Formel vom sich notwendig verschärfenden Klassenkampf und (3.) die Aktivität der "verbrecherischen Bande Berias“. - Ebd., 208ff.

48 „Er war dem Marxismus-Leninismus ergeben und leitete als Theoretiker und bedeutender Organisator den Kampf der Partei gegen die Trotzkisten, die rechten Opportunisten und die bürgerlichen Nationalisten sowie gegen die Machenschaften der kapitalistischen Einkreisung. " Ebd., 208.

49 Ebd., 212. 
tet werden, der „Personenkult“ habe das Gesellschaftssystem verändert: „Trotz allem Schaden, (...) konnte er die Natur unserer Gesellschaftsordnung nicht ändern und hat sie auch nicht geändert. ${ }^{\text {so }}$ Die Folgen wurden lediglich in den „ernsten“ Fehlern bei der Leitung der Landwirtschaft, der Kriegsvorbereitung und der Jugoslawien-Politik gesehen. ${ }^{51}$

Die wachsende Nervosität der Führung um Chruščev angesichts der Ereignisse in Polen und Ungarn im Herbst 1956 nutzten die Gegner der weitergehenden Infragestellung gesichert scheinender Erkenntnisse und der für sie beunruhigenden Methodologiediskussionen, um die "Anklage“ gegen Burdžalov und Pankratova zu enweitern. Nicht nur in der Historie, sondern auch bei der politischen Bewertung der jüngsten Ereignisse, vor allem in Ungarn, hätten sie das Prinzip der Parteilichkeit verletzt. ${ }^{52}$ Diese Verschärfung der Vorwürfe stellte schließlich den politischen Todesstoß gegen die revisionistischen Historikerinnen und Historiker dar. Anfang 1957, als der temporäre Rückzug Chruščevs am weitesten erfolgt war ${ }^{53}$, war der Druck gegen sie so angewachsen, daß sie von der Führung um Chruß̌čev politisch nicht mehr zu halten waren - oder: nur noch zu halten gewesen wären um den Preis einer Konfrontation mit den ,Anti-Revisionisten“, die Chruščev aber scheute. Am 9. März 1957 faßte das Zentralkomitee der KPdSU den Beschluß, der den vorläufigen - Punkt unter das Ringen zwischen Revisionisten und Konservativen setzte. $^{54}$ Bezüglich inhaltlicher Fehler wurde der Redaktion vorgeworfen, prinzipielle Differenzen zwischen Men'Seviki und Bol'ševiki, die wirkliche Taktik der Bol'Seviki im Frühjahr 1917, den illegalen Kampf der Trotzkisten und rechten Opportunisten und die Notwendigkeit, den Kampf gegen die bürgerliche Ideologie zu verschärfen, verschwiegen zu haben. Diese theoretischen und methodologischen Fehler hätten die Tendenz enthalten, von den Leninschen Prinzipien der Parteilichkeit abzuweichen. Offiziell sanktioniert wurden Pankratova und Burdžalov jedoch. weil sie zu lange jede Kritik zurückgewiesen hätten, und weil Burdžalov in der Redaktionsarbeit die Prinzipien der kollektiven Führung grob verletzt habe. Beschlossen wurde, Burdy̌alov aus der Redaktion zu entlassen. Pankratova sollte auf

so .Zu glauben, daß eine einzelne Persönlichkeit, selbst eine so bedeutende wie Stalin, unsere gesellschaftliche und politische Ordnung ändern konnte, bedeutet, (...) in Idealismus zu verfallen. (...) Bekanntlich wird die Natur der gesellschaftlichen und politischen Ordnung dadurch bestimmt, wie die Produktionsweise ist (...). Die ganze Welt weiß, daß in unserem Lande (...) eine sozialistische Produktionsweise entstanden ist (...)." - Ebd., $214 f$.

si Ebd., 215

32 Die Zeitschrift ,(..) hat die revolutionären Traditionen des ungarischen Volkes nicht durch die Aufdeckung der geschichtlichen und politischen Verbindungen der faschistischen Meuterer des Jahres 1956 und der blutigen Würger der Revolution in Ungarn im Jahr 1919 verteidigt." Strogo sobljudat' leninskij princip, 28

33 Leonhard fixierte den Tiefpunkt exakt im Januar 1957, als Chruščev bei einem Empfang der Chinesischen Botschaft seine Lobrede Stalins mit den Worten schloß: „Gebe Gott, wie man so sagt, daß jeder Kommunist so kämpft, wie Stalin gekämpft hat." (Erstveröffentlichung in: Pravda v. 19.01.1957) - Hier zitiert nach Leonhard, Die Dreispaltung. 213.

s4 O žurnale „Voprosy istorii“. Postanovlenie CK KPSS 9 marta 1957 goda, in: SPR 1, $381 \mathrm{f}$. 
ihre Fehler hingewiesen und belehrt werden, sie hätte aber, was scheinbar eine Respektsbezeugung gegenüber dem Akademiemitglied war, weiterhin Chefredakteurin bleiben dürfen. ${ }^{\varsigma 5}$ Die damals Sechzigjährige war aber offenbar zu müde und resigniert ob der Kämpfe und Demütigungen. „Ihre“ Zeitschrift teilte bald das Ableben Anna Pankratovas am 25. Mai 1957 mit. $^{56}$ Genau ein Jahr nach dem 20. Parteitag und der internen Rede Chruščevs, in der oberflächlich oft als Beginn der Entstalinisienung bezeichneten Zeit, erlitten die Kritiker des Stalinismus ${ }^{97}$ in der historischen Disziplin eine deutliche Niederlage, welche die Revisionsversuche auf diesem Plateau der Gesellschaft vorerst „einfror“.

\subsubsection{Die Antirevisionisten in Aktion}

Auf den Tag genau fün Jahre nach Stalins Tod meldeten die Genossen Vollzug: erfolgreich seien die "subjektivistischen" Fehler und die „voluntaristische" Auslegung der ,Kritik des Personenkults", die von Anna Pankratova und Eduard Burdžalov in Voprosy istorii zugelassen und gefördert worden seien, korrigiert worden. Dies berichteten die neuen leitenden Redaktionsmitglieder Matjuškin, Borisov und Fedotov (der auch Sekretär, also Vorsitzender der Parteiorganisation bei der Zeitschrift war) dem ZK-Sekretär Suslov. ${ }^{58}$ In ihrem Schreiben wiesen die drei Autoren aber auch auf weiterbestehende Probleme hin: Einige Redaktionsmitglieder arbeiteten mangelhaft; ${ }^{59}$ das Büro der Geschichtsabteilung in der Akademie der

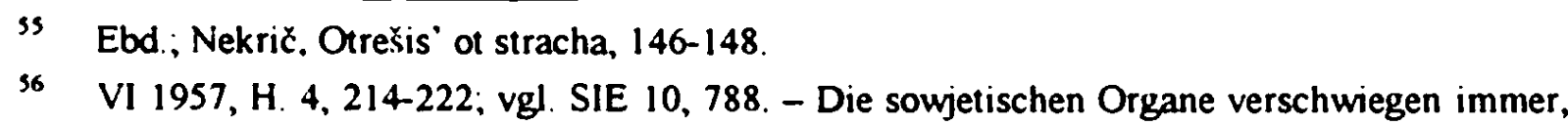
daß Anna Pankratova Suizid beging. Der bekannte Wirtschafts- und Sozialwissenschafler Jürgen Kuczynski schrieb am 21. März 1994 in einem Brief an den Autor: „Die Bestätigung des Selbstmords meiner guten Freundin Pankratowa erhielt ich durch gemeinsame Freunde (unter anderem von Tulpanow), die aber alle inzwischen verstorben sind.“- Vgl. Kuczynski, J.: „Ein linientreuer Dissident". Memoiren 1945-1989, Berlin und Weimar, 2. Auflage 1992, 105f; ders., Frost nach dem Tauwetter. Mein Historikerstreit, Berlin 1993, 43.

s" Den Begriff „Stalinismus“ verwende ich im Anschluß an Werner Hofmann, der darunter „(...) eine exzessiv machtorientierte Ordnung der Innen- und Außenbeziehungen einer Gesellschaft des erklärten Übergangs zum Sozialismus“" verstand. „Als Stalinismus soll (...) jener Exzeß der Macht verstanden werden, der nicht in den Aufgaben einer 'Erziehungsdiktatur' gründete, der nicht objektiv 'notwendig' war. Der Stalinismus resümiert sich in der Entscheidung aller Fragen unter dem Gesichtspunkt der Macht, der Durchsetzbarkeit des Gewollten. Stalinismus ist ein spezifischer Opportunismus der Macht, auf der allgemeinen Grundlage der proletarischen Gesellschaft. Seine soziale Bedingung ist die zeitweilige relative Verselbständigung der Führer von ihrer vorerst noch schwach entwickelten gesellschaflichen Basis. Die erklärte Diktatur des Proletariats hat so fur lange Zeit den Charakter einer stellvertretenden Diktatur angenommen. worin die Staatsgewalt ihren eigentlichen gesellschaftlichen Trägern entfremdet gegenübertrat." - Hofmann, W.: Was ist Stalinismus? (Erstveröffentlichung 1967). Heilbronn 1984, 29, 48f.

58 Matjuškin, N.1.Ju. V. Borisov/P.I. Fedotov am 05.03.1958 an M.A. Suslov, in: CChSD f. 5 , op. $35, d .77,38-46$, hier $38 f$.

\$9 Offenkundig schwärzten hier die jüngeren Konservativen die älteren an. Genannt wurden Pankratovas Vorgänger als Chefredakteur, der Archäologe P.N. Tret'jakov (1909-1976), der 1958 Korrespondierendes Akademiemitglied geworden war; L.V. Cerepnin, ein Historiker 
Wissenschaften unterstütze die neue Redaktion nicht, der Stellvertreter des Akademischen Sekretärs Žukov, P.N. Tret'jakov, und der Mitarbeiter S.I. Praslov verletzten gar „Grundprinzipien der parteilichen Leitung der Presse ${ }^{c 6,60}$ ein gewisser Černjaev, der schon früher Erusalimskij ${ }^{61}$ und Burdžalov mehrfach vor Kritik geschützt habe und auch 1958 noch ein "Sprachrohr rückständiger Auffassungen“ sei, arbeite gegen die Redaktion, die er im Auftrag des Zentralkomitees der Partei anleiten sollte; faktisch behindere er die Erfüllung der Parteibeschlüsse! ${ }^{62}$ Solcherart sahen Matjuskin, Borisov und Fedotov den Erfolg der anti-revisionistischen Maßnahmen, welche die Partei im März 1957 ergriffen hatte, geschmälert.

Um auszuleuchten, inwiefern eine neuerliche „Wende zu stalinschen Dogmen ${ }^{\text {c63 }}$ die Geschichtswissenschaft erfaßte, werden zunächst die Veränderungen bei Voprosy istorii und der seit 1957 erscheinenden Fachzeitschrift Istorija SSSR untersucht, bevor das neue Alte inhaltlich betrachtet wird.

Im ZK-Beschluß über Voprosy istorii war hinsichtlich personeller Umbesetzungen zwar nur davon die Rede, daß Burdžalov entlassen werden und Matjuškin an seine Stelle rücken soltte, ${ }^{64}$ aber tatsächlich wurde ein großes Revirement bewirkt: Nach dem Tode Anna Pankratovas blieben von der alten Redaktion nur noch Skazkin, Smirnov und Chrenov im Kollegium. Durch elf neue Männer, ${ }^{65}$ unter ihnen der

.großen Kalibers" (Nekrið), der in der antisemitischen „Kampagne gegen Kosmopolitismus in der Geschichtsschreibung“" 1948/49 mit zu den Kritikern N.L. Rubinకtejns gehörte und sich auch Anfang der sechziger Jahre in neuen Auseinandersetzungen auf der Seite der Dogmatiker befand: I. A. Orbeli (1887-1961), Orientalist, seit 1935 Akademiemitglied; schließlich R.P. Dadykin, der irgendwann zwischen 1953 und 1957 von seinem Vorgesetzten A.P Kuckkin, der damals Leiter des Sektors für Geschichte der sowjetischen Gesellschaft am Historischen Institut der Akademie war, nach Odessa geschickt worden war, um belastendes Material gegen Anna Pankratova zu suchen. Kuckkin war überzeugt. Pankratova sei dort als Sozialrevolutionärin aktiv gewesen. Dadykin fand zwar nichts, wurde aber mit einer leitenden Stelle belohnt. - Biobibliografija učenych SSSR. Serija istorii, vyp. 15, M. 1983, 3ff; Nekrix, Orešis' ot stracha, 54, 146, 169; VI 1961, H. 2, 224.

60 Matjuškin/Borisov/Fedolov am 05.03.1956, 38.

61 Arkadij Samsonovic Erusalimskij, (1901-30.11.1965). Parteimitglied seit 1938, zählte zur ersten Generation der sowjetischen Historiker, war Schüler Pokrovskijs und 1939 einer dessen pflichtschuldigen Kritiker. Trotz seiner steilen Karriere unter Stalin konnte er den Makel des ehemaligen Pokrovskij-Schülers nicht gut ablegen. - VI 1966, H. 2, 219; MERSH 10, 231-233.

62 Matjuškin/Borisov/Fedotov am 05.03.1956, 44.

63 Urban. Smena, 33. Analog ders., The Re-Stalinization, 46-52; Piroschkow, Sowjetische Geschichtswissenschaft, 198; Dallin, A.: The Soviet Social Sciences After Stalin, in: Winger, H.W. (Ed.): Iron Curtons and Scholarship. The Exchange of Knowledge in an Divided World, Chicago 1958, 82-95, hier 95; Shteppa, Russian Historians, 374.

64 Vgl. O zurnale 1957, 382.

65 Ju.V. Borisov, R.P. Dadykin, L.M. Ivanov, N.I. Matjułkin, A.L. Naroðnickij, I.A. Orbeli, G.N. Sevost'janov, P.N. Sobolev, P.N. Tret'jakov, P.I. Fedotov, L.V. Cerepnin. - VI 1957, H. 3, 224. 
ehemalige Chefredakteur unter Stalin, Tret'jakov, stieg die Mitgliederzahl der Redaktion auf vierzehn. ${ }^{66}$

Die Zähmung der führenden Fachzeitschrift und die seit 1957 bestehende Konkurrenz mit neuen Periodika spiegelten sich auch in der stetig sinkenden Auflagehöhe, die sich binnen zweier Jahre um mehr als die Hälfte verringerte. ${ }^{67}$ Zurück ging auch die Zahl der in der Diskussionsrubrik veröffentlichten Beiträge; ${ }^{68}$ einschneidender als der quantitative Rückgang war freilich der Verlust des Streitbaren und die wieder einkehrende Vernachlässigung der sowjetischen Periode: Seit Mitte 1957 gab es hierzu keinen ,Diskussionsbeitrag“ mehr.

Über das Jahr 1957 hinaus galt Voprosy istorii als die fuihrende Fachzeitschrift, welche die zentralen Aufgaben der historischen Zunft gemäß den Parteibeschlüssen zu formulieren hatte. Allerdings bekam sie seit diesem Jahr Unterstützung respektive Konkurrenz. ${ }^{69}$ Die wichtigste der neu erscheinenden Zeitschriften war die Istorija SSSR. Deren anfangs geringe Auflage wurde rasch erhöht und bei zwölftausend Exemplaren stabilisiert. ${ }^{70}$ Anders als bei Voprosy istorii saßen bei Istorija SSSR mehrere namhafte Gelehrte im Redaktionskollegium, die offensichtlich für die ,richtige Linie" Gewähr bieten und die Autorität des Journals stärken soltten." Im ersten Heft bezeichnete der Redaktionsartikel das neue Periodikum anspruchsvoll als ,wissenschaftliche Forschungszeitschrift, welche die Geschichte aller Völker der UdSSR“ und ,alle Perioden der Vaterländischen Geschichte“, vor allem

66 Bis Ende 1958 oblag die Redaktionsleitung Matjuškin, ehe S.F. Najda für die Dauer von eineinhalb Jahren Chefredakteur wurde. Matjuskkin blieb Redaktionsmitglied. Zur nächsten groBen personellen Auswechselung Mitte 1960 siehe Kapitelende. - VI 1959, H. 1, 224.

67 Bis Ende 1957 erschienen noch 50.000 Exemplare, ab 1958 um die siebenunddreißigtausend. 1959 wurde erstmals die Grenze von 30.000 Exemplaren unterschritten (29.700); ab 1960 nur noch um die 22.000. Mit dem September-Heft 1961 erstmals unter 20.000: 19.950 Exemplare. - VI 1957, H. 12; 1958, H. 1; 1959, H. 1; 1960, H. 1; 1961, H. 9, immer Seite 224.

68 1957: elf Beiträge in der Rubrik „Diskussionen und Erörtenungen“, 1958: zwölf, 1959: sieben, 1960: vier.

69 Seit 1957 erschienen funf historische Fachzeitschriften neu: zur Geschichte der Weltkultur der Vestnik istorii mirovoj kul'tury (bis 1961), zur KPdSU-Geschichte Voprasy istorii KPSS, zur allgemeinen neuen und neuesten Geschichte Novaja i novejsaja istorija, für die Archäologie Sovetskaja archeologija und zur gesamten UdSSR-Geschichte von den Anfängen bis zur Gegenwart sowie zu der Geschichte aller zur UdSSR gehörenden Nationalitäten die Istorija SSSR "Geschichte der UdSSR“.

Kurzlebig waren die „Wissenschaftlichen Referate der Hochschule“ zu den historischen Wissenschaften Naucnye doklady vyssej skoly. Istoriceskie nauki (1958-61) und das Fachorgan für China-Forschung Sovetskoe kitaevedenie (1958-59). Besser erging es der Zeitschrift für Militärgeschichte Voenno-istoriłeskij zurnal, die seit 1959 erscheint und auch die UdSSR überlebte. Orerki 1985, 106f.

10 Der Start erfolgte mit 5.000 Exemplaren; Steigerung bis maximal 14.100, seit Anfang 1959 12.200. - ISSSR 1957, H. 1, 271; 1958, H. 2, 237; 1959, H. 1, 271.

"Chefredakteur: M.P. Kim, sein Stellvertreter: S.O. Smidt; dem Kollegium gehörten an: L.S. Gaponenko, I.A. Guržij, P.A. Žilin, B.M. Kočakov, 1.1. Minc, M.V. Nečkina, Ju.A. Poljakov, M.N. Tichomirov, A.V. Fadeev, L.V. Cerepnin, V.K. Jacunskij. - ISSSR 1957, H. 1, 271. 
aber die „Geschichte der sowjetischen Gesellschaft" behandeln wolle. ${ }^{72}$ Hoffnungsvoll klang die Absichtserklärung, „schöpferische Diskussionen“ über besonders aktuelle und komplizierte Fragen führen zu wollen, weil die

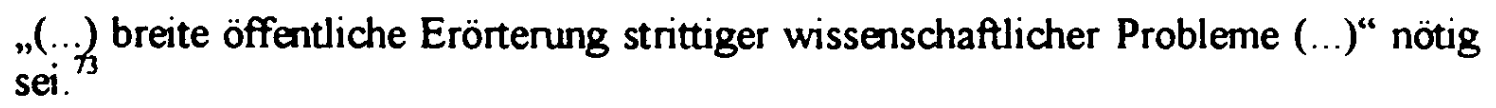

Zwar lag das redaktionelle Programm ganz auf der Linie der Partei, wenn die Beachtung des Parteilichkeitsprinzips als notwendige Bedingung der richtigen Erklärung geschichtlicher Fakten und Ereignisse bezeichnet wurde. Doch auffallend zurückhaltend äußerte sich der Leitartikel zu den Vergehen der Kollegen bei Voprosy. istorii, deren Bekämpfung sich ja gerade auf dem Höhepunkt befand: Nur ,einzelne" Historiker hätten den Kurs des 20. Parteitags falsch, als eine „Abschwächung“ des ideologischen Kampfes verstanden. ${ }^{74}$ Deutete sich damit eine offenere Linie bei Istorija SSSR an?

Die Leitartikel in Voprosy istorii, die unter Pankratova und Burdžalov anregende Diskussionspapiere geworden waren, wurden wieder hemmungslos politisch instrumentalisiert. Sie dienten zunächst dazu, die Kritik an der Zeitschrift mit Selbstkritik zu beantworten, dann wurden sie immer stärker als politische Schulungsartikel mißbraucht. Von den zwölf Leitartikeln, die in den 39 Heften unter Matjuškin und Najda veröffentlicht wurden, befaßten sich nur füf mit der Historiographie, ${ }^{75}$ wobei es vor allem um die sogenannte Selbstkritik ging. ${ }^{76}$ Die restlichen sieben Leitartikel dienten der Vor- und Nachbereitung des Juni-Plenums (1957) des Zen-

\footnotetext{
72 Ot redakcii, in: ISSSR 1957, $\mathrm{H}$ 1, 3-6 hier 5

13 Ebd., $5 f$.

34 Ebd., 4.
}

73 "Für die Leninsche Parteilichkeit in der Geschichtswissenschaft!“: Za leninskuju partijnost' $v$ istoriceskoj nauke! In: VI 1957, H. 3, 3-19; ,Für das schöpferische Studium der Geschichte der Großen Sozialistischen Oktoberrevolution": Za tvořeskoe izuCenie istorii Velikoj Oktjabr'skoj socialističeskoj revoljucii, in: VI 1957, H. 7, 3-16; „Unter dem Banner des Großen Oktober": Pod znamenem Velikogo Oktjabrja, in: VI 1957, H. 10, 3-22; „Für die schöpferische Untersuchung der Geschichte der sowjetischen Streitkräfte“: Za tvorčeskoe izučenie istorii Sovetskich Voonužennych Sil, in: VI 1958, H. 2, 3-19; „V.I. Lenin über Parteilichkeit in der Geschichtswissenschaft": V.I. Lenin o partijnosti v istoričeskoj nauke, in: VI 1958, H. 4, 3-22.

76 Die den Historikern vom 20. Parteitag gestellte Hauptaufgabe - Überwindung des Personenkults - sei von der ehemaligen Redaktion falsch verstanden und auf "liberale“ Weise interpretiert worden. Daher ließ sie „ernsthafte methodologische Fehler“" zu und verletzte die „Prinzipien der marxistisch-leninistischen Parteilichkeit". Die neue Redaktion stimmte der Kritik zu, die in der Pravda, in Partijnaja Yizn' und in der Theoriezeitschrift Kommunist geübt worden war: Sie wolle die zugelassenen Fehler in der Historiographie der Geschichte der KPdSU und des Sowjetstaats, der Vaterländischen und der Allgemeinen Geschichte „liquidieren“. Weil auch das Geschichtsinstitut an der Akademie die fehlerhafte Position der ehemaligen Redaktion nicht korrigiert habe, sei die Zeitschrift ab sofort unmittelbar der Abteilung der Geschichtswissenschaften an der Akademie untergeordnet. - Za leninskuju partijnost', 6 und 17f; Za tvorceskoe izučenie 1957, 7; Pod znamenem, 13. 
tralkomitees und des 21. (außerordentlichen) Parteitags der KPdSU, der vom 27. Januar bis 5. Februar 1959 tagte. $^{77}$

Jenes ZK-Plenum im Juni 1957, bei dem es Chrušcev gelang, innerparteiliche Widersacher, die Stalinisten Molotov, Kaganovix, Malenkov, Vorošilov, Bulganin, Pervuchin, Saburov, Sepilov u.a. zu ächten und aus der Führung zu entfermen ${ }^{78}$, sandte keine eindeutigen Signale an die Geschichtswissenschaft. Einerseits wurden die revisionistischen Historiker in dunkler Androhung mit den sogenannten ,parteifeindlichen Fraktionsmachern" in Verbindung gebracht. ${ }^{79}$ Andererseits war doch evident. daß Chruščev hier konservative Kräfte ausgeschaltet und den Kurs auf (wenn auch von der Parteispitze kontrollierte) Entstalinisierung wieder eingeschlagen hatte. Die Delegierten des 21. Parteitags befaßten sich fast ausschließlich mit volkswirtschaftlichen Fragen und beschlossen den "Siebenjahrplan" 1959 bis $1965^{80} \mathrm{Da}$ dennoch ganze fünf Leitartikel in Voprosy istorii diesem Ereignis gewidmet waren, lag an dem Parteitagsbeschluß, daß die Sowjetunion mit dem „vollständigen und endgültigen Sieg“ des Sozialismus in eine neue Periode ihrer Entwicklung eintrete. ${ }^{81}$ Diese ,überaus wichtige Schlußfolgerung ${ }^{\text {(82 }}$ des Parteitags wurde für die Geschichtswissenschaft zum zentralen Axiom, aus dem ab sofort die neuen Aufgaben abzuleiten waren. ${ }^{83}$

$"$.Die Leninsche Einheit der Partei ist unzerstörbar!“: Leninskoe edinstvo partii nesokrušimo!, in: VI 1957, H. 5, 3-16; „Geschlossenheit und Einheit der internationalen kommunistischen Bewegung": Spločennost’ i edinstvo meł.dunarodnogo kommunističeskogo dvið̌enija. in: VI 1958, H. 1, 3-21;"Unverbrüchliche Einheit von Partei und Volk": Nerusimoe edinstvo partii i naroda, in: VI 1958, H. 12, 3-26; „Große Ergebnisse und Perspektiven“: Velikje itogi i velikie perspektivy, in: VI 1959, H. 1, 3-21; ,Die großen Vorzüge des Sozialismus in Aktion“: Velikie preimuščestva socializma v dejstvii, in: VI 1959, H. 2, 3-20;, Der 21. Parteitag der KPdSU - ein historisches Ereignis im Leben von Partei und Volk“: Dvadcat' pervyj s-ezd KPSS - istoriceskoe sobytie v žizni partii i naroda, in: VI 1959, H. 3, 3-28, „Der 21. Parteitag und die weitere Festigung des sozialistischen Weltsystems": Dvadcat' pervyj s-ezd i dal'nejక̌ee upročenie mirovoj socialističeskoj sistemy, in: VI 1959, H. 5, 3-21.

78 Siehe Pethybridge, R.: A Key to Soviet Politics. The Crisis of the Anti-Party Group, New York 1962; Leonhard, Kreml, 348ff, Judick/Steinhaus, Stalin, 234ff.

9 So in Leninskoe edinstvo, 12. Vgl. Heer, Politics, 97f.

so Siehe Vneokerednoj dvadcat' pervyj s-ezd KPSS, in: KPSS $v$ rezoljucijach i rešenijach s-ezdov, konferencij i plenumov CK, Teil 4, 7. Auflage, M. 1960, 380-500. Vgl. Ritvo, H.: Twenty-First Party Congress - Before and After, in: ASEER 1961, H. 2, 203-219 und H. 3, 436453: Samsonow, A.M. (= Samsonov, A.M.) u.a.: Geschichte der UdSSR in drei Teilen (aus dem Russischen), Teil 3, M. 1979, 142ff; Istorija SSSR s drevnejక̌ich vremen do našich dnej $v$ dvuch serijach $v$ dvenadcati tomach, tom 11, M. 1980, 610ff.

81 So in der Resolution zum Hauptreferat Chruščevs ,über die Kontrollziffern der volkswirtschaftlichen Entwicklung der UdSSR 1959-1965“, in: KPSS v rezoljucijach, 381-407, hier 395.

82 Samsonow u.a., Geschichte, 142.

83 Es sollte allerdings nicht übersehen werden, daß diese These vom „endgültigen Sieg“, die besagte, daß es keinerlei Kräfte mehr gebe, die den Kapitalismus in der UdSSR wiederherstellen könnten, eine innenpolitische Entspannung implizierte: Der Suche nach immer neuen „Agenten 
Das oberste Gebot, das zu predigen die Ideologen nicht müde wurden, war das der Parteilichkeit. ${ }^{84}$ Drei Autoritäten wurden nun bemüht, um die Zunft auf dieses Prinzip einzuschwören: die Partei, Lenin und der Erste Sekretär der KPdSU, Chrušcev. Der Anleitung durch die Partei verdanke die sowjetische Geschichtswissenschaft die „erfolgreiche, schöpferische Entwicklung" ${ }^{85}$ Mit dem Beschluß vom 9. März 1957 über Voprosy istorii stehe die Partei ganz in der Tradition des Kampfes Lenins gegen „bürgerlichen Objektivismus“. ${ }^{86}$ Unter Berufung auf $\mathrm{ChruŠCev}^{87}$ hieß es weiter, das Wichtigste bestehe darin, daß das Prinzip der Parteilichkeit „organisch verknüpft“ sei mit „Volksverbundenheit". Die Einheit von Parteilichkeit und Volksverbundenheit erfordere

erstens die gründliche Erforschung „(..) der entscheidenden Rolle der werktätigen Massen auf allen Stufen der gesellschaftlichen Entwicklung, (...) des revolutionären Kampfes der Arbeiter und Bauem, (...) der weltweiten kommunistischen und Arbeiterbewegung, des Kampfes der Völker für ihre soziale und nationale Befreiung."

Zweitens gebiete sie, gesellschaftliche Ereignisse „(...) von der Position des Klassenkampfes, der Position der Unausweichlichkeit der proletarischen Revolution und der Diktatur des Proletariats (...)" zu bewerten und „(...) die sozialökonomischen Ursachen gesellschaftlicher Phänomene aufzudecken, an sie heranzugehen vom Standpunkt der Interessen der Arbeiterklasse und aller Werktätigen.“

Drittens verlange sie von den Wissenschaftlem, „(..) aktive Kämpfer für die Verwirklichung der Politik der KPdSU zu sein.“ Denn: „Die Politik der Partei basiert

des Imperialismus" im eigenen Lager war damit die „theoretische“ Grundlage (Stalins These vom notwendig sich verschärfenden innenpolitischen Klassenkampf) entzogen.

84 .Für die Leninsche Parteilichkeit in der Geschichtswissenschaft“ lautete das - alte - Credo der neuen „VI“-Redaktion im Frühjahr 1957. Nach Ablauf eines weiteren Jahres erinnerte erneut ein Leitartikel an die Verletzungen des Parteilichkeitsprinzips durch E.N. Burdžalov, S.A. Pokrovskij, S.V. Paparigopulo und V.A. Smirnov. - Vgl. Za leninskuju partijnost', 5; Za tvorčeskoe izučenie 1957, 7; Pod znamenem, 12; V.I. Lenin o partijnosti $v$ istoričeskoj nauke, in: VI 1958, H. 4, 3-22, hier $9 f$ und $20 f$.

8s V.l. Lenin o partijnosti, 9.

86 Aus mehreren Schriften und beispielhaften ,parteilichen“ Wertungen des Staatsgründers hob der Leitartikel zwei Aussagen Lenins hervor: Materialismus schließe Parteilichkeit ein, verpflichte zu offener Bewertung aller Ereignisse vom Standpunkt einer bestimmten gesellschaftlichen Gruppe aus. Und: Der Marxismus stelle sich die Aufgabe, alle Formen des Antagonismus und der Ausbeutung sowie deren vergänglichen Charakter und die Notwendigkeit ihrer Umwandlung aufzudecken und somit dem Proletariat zu dienen. „Marxistisch-leninistische Parteilichkeit“, so faßte der Leitartikel die Ausführungen Lenins zusammen, vereine in sich ,(..) Wissenschaftlichkeit im strengsten Wortsinn, echte Objektivität, Unduldsamkeit gegenüber ideologischen Gegnern mit revolutionärer Praxis, selbstlosem Dienen für die Arbeiterklasse und die werktätigen Massen. “- Ebd., $3 \mathrm{f}$ und 6.

87 „Wer mit dem Volk sein will, der wird immer mit der Partei sein. Wer fest auf den Positio nen der Partei steht, der wird immer mit dem Volk sein." - Chruščev, N.S.: Za tesnuju svjaz' literatury i iskusstva s żizn'ju naroda, M. 1957, 24. Zitiert nach V.I. Lenin o partijnosti, 6. Hier zeigte sich Chrušcevs Bemühen, den Personenkult um Stalin und dessen Alleinherrschaft zu venurteilen und das System neu zu legitimieren durch die propagierte Einheit von Partei und Volk. Vgl. Burlazki (=Burlackij, F.), Chruschtschow, 214ff. 
auf der marxistisch-leninistischen Theorie. Sie ist zutiefst wissenschaftich. Gerade daher sind für uns Parteilichkeit und echte Wissenschaftlichkeit untrennbar. Gerade deshalb können die Wissenschaftler die Forschungsarbeit nur dann erfolgreich betreiben, wenn sie sich in ihrer ganzen Tätigkeit leiten lassen von der Ideologie der Partei und deren Ansichten und politische Linie vollständig teilen."

Der zweite Imperativ, der nun für die Geschichtswissenschaft gelten sollte, lautete: Kampf gegen die bürgerliche Ideologie. Die Anhänger dieses Kampfes fanden allerdings nur sukzessive zu einer wohlgefälligen Begründung. Anfangs hieß es noch unentschlossen, marxistische Geschichtswissenschaft habe sich immer

„(..) im scharfen Kampf gegen die bürgerliche und kJeinbürgerliche Historiographie (...)" entwickelt. ${ }^{89}$

Dann bemühte ein Leitartikel in Voprosy istorii das Parteilichkeitsprinzip, welches den konsequenten Kampf gegen die bürgerliche Ideologie erfordere. ${ }^{90}$ In der Sitzung des Büros der Geschichtsabteilung in der Akademie im Dezember 1957 begründete Truchanovskij, damals stellvertretender Direktor des Geschichtsinstituts, den zu verschärfenden Kampf mit der ,liberalen Interpretation der KPdSU-Politik“ durch die Revisionisten 1956/57..$^{91}$ Schließlich besann man sich auf das berühmte Lenin-Zitat, wonach es außer bürgerlicher und sozialistischer Ideologie nichts Drittes gebe und jede Schwächung der letzteren notwendig zur Stärkung der ersteren führe. ${ }^{92}$ Warum aber sollte der Kampf gerade jetzt verstärkt werden? Auch hier half Lenin weiter, und Truchanovskijs Argumentation, daß die Korrektur der revisionistischen Fehler den verstärkten Kampf erforderten, wurde in ihr Gegenteil verkehrt: Die Siege der sozialistischen Bewegung zwängen die „bürgerlichen Ideologen“ zu immer „verfeinerter Verfälschung des Marxismus“, was mit der Ausweitung des Kampfes gegen die bürgerliche Geschichtsschreibung beantwortet werden müsse -

„(...) von Problemen der Methodologie bis zu konkreten Fragen der Geschichte verschiedener Völker.“93

\footnotetext{
88 Alle Zitate aus dem Leitartikel V.I. Lenin o partijnosti, 6f: Hervorhebung im letzten Absatz von mir, J.H.

89 Za tvoř̌eskoe izučenie 1957, 7.

9 Pod znamenem, 12.

91 Dadykin, R.P.: Rabota Instituta istorii AN SSSR v 1957 godu (Bericht), in: VI 1958, H. 3, 199-204, hier 199.

92 V.I. Lenin o partijnosti. 8.

93 Ebd., 10. Das methodologische „Sündenregister“ der bürgerlichen Historie war üppig: "Idealismus im Verständnis des gesellschaftlichen Lebens, Negation der Existenz objektiver Gesetzmäßigkeiten der gesellschaftichen Entwicklung. Voluntarismus, Subjektivismus, das Bestreben, gesellschaftliche Prozesse vom Standpunkt ideologischer Beweggründe der Menschen zu betrachten, die Negation der entscheidenden Rolle der Volksmassen in der Geschichte. Die fehlende Anerkennung der objektiven Wahrhaftigkeit geschichtlicher Kenntnisse, ihrer Zuverlässigkeit: Agnostizismus und Skeptizismus, Relativismus, Versuche, die Wissenschaft der Religion unterzuordnen (...)." - Ebd., $10 f$.
} 
In größere politische Zusammenhänge wollte Ponomarev, der schon damals für die Verbindungen zu kommunistischen und sozialdemokratischen Parteien zuständig war $^{94}$, die neue Direktive einordnen: es gehe darum, die „Hauptgefahr" für die kommunistische Bewegung, den ,Revisionismus ${ }^{\text {ses }}$ zu bekämpfen. Drohend führte Ponomarev aus, die Revisionisten, die alle Bestandteile des Marxismus-Leninismus verfalschen wollten, agierten nicht nur im Ausland, sondern auch in den sozialistischen Ländern - wieder eine deutliche Warnung an Burdžalov u.a. Deshalb sei der ,antirevisionistische Kampf" seit der Zusammenkunft der Vertreter Kommunistischer und Arbeiter-Parteien im November 1957 in Moskau ,auf noch breiterer Front entwickelt" worden. ${ }^{96}$ Doch erst mit der Auswertung des 21. Parteitags fand Žukov, der damalige Akademische Sekretär, die - zumindest für die Chruščev-Ära - gültige Formel: Von allen Gesellschaftswissenschaftlern sei jetzt die ,aktive Beteiligung am Aufbau des Kommunismus" verlangt. Die drei entscheidenden Felder, auf denen die Geschichtswissenschaft dazu beitragen müsse, seien die kommunistische Erziehung der Jugend, der Kampf gegen feindliche Ideologien und die Untersuchung der Gesetzmäßigkeiten des Übergangs vom Sozialismus zum Kommunismus (welcher vom 21. Parteitag zur politischen Tagesaufgabe erklärt worden war). Diesen Aufgaben, so Zuukov, sei „die ganze Arbeit der Institutionen der Abteilung der Geschichtswissenschaften" unterzuordnen. ${ }^{97}$ Kurze Zeit später bezeichnete Akademiemitglied Nečkina ${ }^{98}$ den

94 Boris Nikolaevic Ponomarev, Jahrgang 1905, wurde 1961 ZK-Sekretär, war 1972-86 Politburromitglied, blieb bis zum 27. Parteitag der KPdSU 1986 Leiter der Internationalen Abteilung des Zentralkomitees, somit zuständig für die Kontakte mit kommunistischen, sozialistischen und sozialdemokratischen Parteien. "Ich habe mein ganzes Leben dem Studium des MarxismusLeninismus, der Propagierung dieser Lehre und ihrer praktischen Verwirklichung gewidmet", schrieb er 1984. - Ponomarjow, B.N.: Der Kommunismus in der sich verändernden Welt, FrankfurtM. 1984, 13. Vgl. die Rezension von R. Steigerwald, in: UZ v. 17.02.1984; Adam. W. Im Kreml für Volksfronten zuständig. Ponomarjow auch mit 80 noch aktiv, in: FAZ v 17.01.1985.

95 In der offiziellen Sprachregelung bezeichnete „Revisionismus“ eine ,ideologisch-politische Strömung, die gerichtet ist auf die Revision grundlegender Aussagen des revolutionären Marxismus unter dem Vorwand seiner Modernisierung“. - Kratkij slovar’ po naučnomu kommunizmu. M. 1989, 324f.

96 Siehe Balašov, V.N.: Sessija otdelenij obščestvennych nauk AN SSSR po bor be s sovremennym revizionizmom (Bericht), in: VI 1958, H. 7, 171-190, hier über das Referat Ponomarevs, 171 ff.

97 Siehe Assaturova, M.I.: Ob̌̌ce sobranie otdelenija istoričeskich nauk (Bericht), in: VI 1959, H. 6, 157-163, hier 157. - Auch in einem Leitartikel der Istorija SSSR wurde die Bekämpfung der bürgerlichen Historiographie damit begnündet, daß das Sowjetland eingetreten sei in die „Periode des umfassenden Aufbaus der kommunistischen Gesellschaft", siehe Novyj istoričeskij etap v razvitii sovetskogo obščestva, in: ISSSR 1959, H. 1, 3-9, hier 3.

98 Milica Vasil'evna Neckina, 25.02.1901-16.05.1985, hatte in Kazan' 1917-21 Geschichte studiert und bis 1923 gelehrt. 1924-27 war sie Gasthörerin am Historischen Institut der Roten Professur bei Pokrovskij, seit 1924/25 arbeitete sie in der Forschungs- und Lehrtätigkeit in der Russischen Assoziation Wissenschaftlicher Forschungsinstitute für Gesellschaftswissenschaften (RANION, wo bis Ende der zwanziger Jahre noch bolschewistische und nichtmarxistische Histo- 
„(...) Kampf gegen die bürgerliche Verfälschung der Geschichte und den Revisionismus, für die Reinheit des Marxismus-Leninismus (...) in der gegenwärtigen Etappe als Hauptaufgabe der Arbeiter unserer ideologischen Front." "99

Damit hatte die wissenschaftspolitische Intention, die Geschichtswissenschaft noch stärker zur gesellschaftlichen Arbeit zu verpflichten, ihren offiziellen Ausdruck gefunden. Beispiele ihrer Umsetzung ließen nicht lange auf sich warten. ${ }^{100}$

Quantität vor Qualität - so kann ein weiteres Argument für die RestalinisierungsThese begrifflich gefaßt werden. Es schien, als solle die „Tonnenideologie" in der Geschichtswissenschaft Einzug halten. Bei jeder sich bietenden Gelegenheit wurde die jüngste erfolgreiche Entwicklung der Geschichtswissenschaft vor allem mit der gestiegenen Zahl an Publikationen begründet. Stolz präsentierte die Bibliothek für Gesellschaftswissenschaften an der Akademie im April 1958 sechshundert Neuerscheinungen zur Oktoberrevolution. ${ }^{101}$ Eine 1959 erschienene Bibliographie nannte gar 5.334 Titel, die 1957/58 zur Geschichte der Revolution und des Bürgerkriegs (1917-21) publiziert worden seien. ${ }^{102} \mathrm{DaB}$ in kurzer Zeit ganz widersprüchliche Angaben veröffentlicht wurden, zeigt, daß in einem offensichtlichen ,Zählrausch“ auf Genauigkeit wenig Wert gelegt wurde. ${ }^{103}$ Die Tatsache der sich fortsetzenden

riker zusammenarbeiteten) und der Moskauer Universität. 1930-85 war sie wissenschaftliche Mitarbeiterin an der Kommunistischen Akademie (seit 1936: Akademie der Wissenschaften), seit 1935 Professorin an der Historischen Fakultät der Lomonosov-Universität (MGU). 1936 Doktor istoriceskich nauk (Habilitation); 1953 Korrespondierendes Akademiemitglied, 1958 Vollmitglied der AdW; seit 1958 auch Hauptverantwortliche für die historiographischen Forschungen in der UdSSR, u.a. als Chefredakteurin der Orerki istorii istoriceskoj nauki v SSSR (1960-85) und der Jahrbücher Istorịa $i$ istoriki (1972-85). Neckinas Karriere verzögente sich in den vierziger Jahren bis zum Tode Stalins, weil sie $1947 \mathrm{ff}$,fehlerhafte", d.h. differenzierte Positionen in den Diskussionen über Müridismus und den Anschluß nichtrussischer Territorien und Völker ans Zarenreich vertrat. - Biobibliografija učenych SSSR. Serija istorii, vyp. 17, M. 1987; Nekric, Otrešis" ot stracha, 85ff.

99 Siehe Smirnova, L.I.: Protiv buržuaznoj fal sifikacii istorii SSSR (Bericht), in: VI 1959, H.7, 166-175, hier 166

100 Protiv fal'sifikacii istorii vtoroj mirovoj vojny, M. 1959; Eremenko, A.I.: Protiv fal'sifikacii istorii vtoroj mirovoj vojny, M.-L. 1959; Žilin, P.A.: Buržuaznye fal'sifikatory istorii vtoroj mirovoj vojny, M. 1959; Salov, V.l.: O fal'sifikacii taktiki bol'ševikov v marte-aprele 1917 goda zapadnagermanskoj buržuaznoj istoriografiej, in: VI 1959, H. 8, 120-129; Barg. M.A.: O tak nazyvaemom 'krizise feodalizma' $\vee$ XIV-XV veka (k istoriografii voprosa), in: VI 1960, H. 8, 94 113.

101 Siehe Pavlov, M.N./V.E. Poletaev: Obsuždenie itogov nauěno-izdatel'skoj dejatel'nosti v svjazi s 40-letiem Oktjabr'skoj revoljucii (Bericht), in: VI 1958, H. 7, 190-203, hier 190.

102 Siehe die Rezension von P.I. Roščevskij in: VI 1960, H. 2, 206-208.

103 „Fast 2.000“ Titel zum 40. Jahrestag der Oktoberrevolution zählte Rusljakova, V.G.: Razrabotka istorii Oktjabr'skoj revoljucii posle XX s-ezda KPSS, in: VI 1960, H. 5, 85-102, hier 87. Nur „ungefähr 2.000 Titel" in vier Jahren (1956-59) zur "Geschichte der sowjetischen Gesellschaft" meldete Borisov, Ju.S.: Naučnaja sessija po istoriografii socialističeskogo i kommunističeskogo stroitel'stva (Bericht), in: VI 1960, H. 8, 124-132, hier 124. Die Staatliche Bücherkammer der UdSSR gab bekannt, 1956 bis 01.10 .1958 seien „mehr als 5.500 Bücher und Broschüren zu Fragen der Geschichte der Völker der UdSSR" erschienen, davon zur sowjetischen 
Publikationsflut an sich ist m.E. jedoch positiv zu bewerten. Daß überhaupt wieder mehr Fachliteratur zur Geschichte veröffentlicht wurde war unmittelbar nach Stalims Tod ein Fortschritt; dieser positive Trend setzte sich 1957 bis 1960 fort. ${ }^{104}$ Die Neigung aber, den Zustand der Disziplin nach quantitativen Kriterien zu beurteilen, stieß mehrfach auf Kritik. ${ }^{105}$

Über diese vier skizzierten Phänome hinaus, die zur Begründung einer Restalinisierungs-These heranzuziehen wären - Instrumentalisierung der Leitartikel, Parteilichkeitsprinzip, Kampf gegen bürgerliche Historiographie und Dominanz quantitativer Bewertungskriterien -, sind allerdings auch andere Trends zu finden, die auf das fortgesetzte Bemühen um Entstalinisierung hindeuten.

\subsubsection{Gegentendenzen}

Nach dem linientreuen Leitartikel in Istorija SSSR zum 21. Parteitag und den sich daraus ergebenden neuen Aufgaben für die Geschichtswissenschaft ${ }^{106}$ widmete sich der Chefredakteur der Zeitschrift, M.P. Kim, nochmals diesem Thema. Kim hielt sich zwar an die offizielle Terminologie ${ }^{107}$, aber das Parteilichkeitsprinzip erwähnte er mit keinem Wort! Statt dessen erinnerte er an den geschichtlichen Charakter der marxistisch-leninistischen Theorie, die sich stets auf der Grundlage der ausgewerteten historischen Erfahrung weiterentwickeln müsse, ${ }^{108}$ und rückte den Historismus als wesentliches Erkenntnisprinzip im Marxismus in den Vordergrund. ${ }^{109}$ Nach dem 20. Parteitag hätten die Historiker zwar fehlerhafte Ansichten aus der Stalin-Zeit

Geschichte im engeren Sinn 1.122 Bücher; siehe Izdanie v Sovetskom Sojuze knig i brošjur po istorii SSSR za 1956-1958 gg., in: ISSSR 1959, H. 1, 264.

$104 \mathrm{Vgl}$. Utechin, Soviet Historiography, 120; Heer, Politics, 76.

105 Siehe Dadykin, Rabota, 204 und Sedov, K. I.: Obscee sobranie otdelenija istoričeskich nauk AN SSSR (Bericht), in: VI 1958, H. 5, 179-185, hier 183.

106 Novyj istoriðeskij etap.

107 Weil die UdSSR in die neue ,Periode des umfassenden Aufbaus der kommunistischen Gesellschaff" eintrete, wachse die Bedeutung der Geschichtswissenschaft, deren ,erste Pflicht" es sei, die Gesetzmäßigkeiten dieser Entwicklung auszuarbeiten; es gelte, wachsam gegenüber den Feinden des Leninismus und der Partei zu sein und sich den Marxismus-Leninismus besser anzueignen; die Partei habe alle notwendigen Bedingungen geschaffen, nun sei es an den Historikern, ,zur gemeinsamen Sache des kommunistischen Aufbaus ihr würdiges Scherflein beizutragen." - Kim, M.P.: O nekotorych zadaXach istorixeskoj nauki v svete resenij XXI s-ezda KPSS, in: ISSSR 1959, H. 2, 3-23.

108 „Der historische Zugang zur Behandlung von Fragen der Theorie und Politik stellt einen der Grundsteine der Methodologie des Marxismus-Leninismus dar.“ - Ebd., 5.

109 Er erinnerte an die Formulienung Lenins aus einem Brief an Inessa Armand aus dem Jahr 1916, die in der Folgezeit häufig zitiert wurde: „Der ganze Sinn des Marxismus, sein ganzes System erfordert, jede Annahme (položenie) nur $(\alpha)$ historisch; $(\beta)$ nur in Verbindung mit anderen; $(\chi)$ nur in Verbindung mit der konkreten Erfahrung der Geschichte zu betrachten." - Ebd., 6. Vgl. Lenin, V.I.: (Brief an) I.F. Armand (am 30.11.1916), in: LPSS 49, 328-334, hier 329; vgl. LW 35, 227ff. 
revidiert und begonnen, dem Leninschen Historismus gemäß schöpferisch an die ungelösten Probleme der Geschichte heranzugehen. Doch immer noch gebe es

„(...) nicht wenige Leute, die, obgleich sie mit Worten für den schöpferischen Marxismus eintreten, in der Sache doch halsstarrige Dogmatiker bleiben. " 110

Um den Dogmatismus zu überwinden sei dreierlei vonnöten: die Historiker müßten sich bewußt werden, daß dem Marxismus-Leninismus der „Geist schöpferischer Entwicklung" eigen sei und die Interessen des kommunistischen Aufbaus besonders dringlich kühnes Suchen in der Wissenschaft erforderten; sie müßten im Einklang mit den Tatsachen der Geschichte verfahren; entschlossen müßten sie sich dem gegenwärtigen Leben zuwenden. ${ }^{11}$ Nicht den "Subjektivismus“ Burdžalovs und anderer, sondern den Dogmatismus derer, die nicht konsequent die ,Folgen des Personenkults" beseitigen wollten (Namen nannte Kim freilich nicht), betrachtete Kim als größtes Übel. Er empfahl keine entmündigende Parteilichkeit, sondern „konkret-historisches Herangehen“, und setzte damit zum ideologischen Korsett der Anti-Revisionisten alternative Akzente, die über den Tag hinaus gültig blieben, gerade weil er nicht im Stile Burdžalovs ,rebellierte“, sondern sich tarnte mit der offiziellen Terminologie.

Gegentendenzen zur Restalinisierung zeigten sich auch bei der systematischen historiographischen Arbeit, die nicht zuletzt aufgrund der anhaltenden Publikationsflut ${ }^{112}$ von vielen Historikern für notwendig erachtet wurde. ${ }^{113} 1958$ wurde der "Wissenschaftliche Problemrat für Geschichte der Geschichtswissenschaft" gegründet, der unter Leitung des Akademiemitglieds Nečkina die historiographischen Forschungen unionsweit fordern und koordinieren sollte. Erklärter Schwerpunkt war die Herausbildung und Weiterentwicklung der marxistisch-leninistischen Geschichtswissenschaft in der UdSSR. ${ }^{114}$ Die bereits seit 1946 bestehende Kommissi-

110 Kim. O nekotorych zadačach. 12.

11 Dort, wo der Historiker mit dem Leben verbunden sei, könne es keinen Dogmatismus geben, schrieb Kim unter Berufung auf Lenin. - Ebd.

$112 \mathrm{Vgl}$. die umfangreiche Bibliographie der Neuerscheinungen 1956 bis 1961 zur Geschichte der UdSSR in: Sovetskaja istoriceskaja nauka of XX k XXII s-ezda KPSS. Istorija SSSR. Sbornik statej, M. 1962, 557-626.

113 Historiographische Themen würden bloß zufälig berücksichtigt, klagte z.B. Tret'jakov; l'oprosy istorii vernachlässigten besonders die sowjetische Historiographie, sagte der lettische Historiker A.A. Drizul bei einer Leserkonferenz in Riga am 26.10.1958; bei einer weiteren Diskussion von Lesern forderte I.I. Kitaev mehr historiographische Informationen. - VI 1957, H. 3, 205; Biron, A.K.: Konferencija Citatelej Zurnala „Voprosy istorii“ (Bericht), in: VI 1959, H. 2, 209f, Grigor'ev, F.G.: Konferencija citatelej zurnala "Voprosy istorii“ v voenno-politiceskoj akademii imeni V.I.Lenina (Bericht), in: VI 1959, H. 8, 190-193, hier 191. Vgl. auch den Bericht in ISSSR 1959, H. 2, 244-247, hier 246, wonach V.E. Illerickij empfahl, sich vor allem mit dem Werk von B.D. Grekov, A.M. Pankratova, Ju.V. Got'e, V.I. Piðeto und S.V. Bachrušin zu beschäftigen.

114 Siehe Dunaevskij, V.A.: Der Wissenschaftliche Problemrat „Geschichte der Geschichtswissenschaft" bei der Abteilung Geschichte der AdW der UdSSR, in: JbG (Nr. 28), Berlin 1983, 265-274; ders., Der Wissenschaftliche Problemrat "Geschichte der Geschichtswissenschaft" an 
on zur Geschichte der Geschichtswissenschaft, die anfangs von V.P. Volgin. seit 1949 von M.N. Tichomirov und seit Dezember 1958 ebenfalls von Nečkina geleitete wurde, sollte dadurch entlastet werden und sich intensiver um die Fertigstellung der auf vier Bände angelegten „Studien zur Geschichte der Geschichtswissenschaft" bemühen. ${ }^{115}$ Auch bei der Erörterung des - analog zur volkswirtschaftlichen Planung - für sieben Jahre projektierten Forschungsplans der Zeitschrift Voprosy istorii drückte sich die Aufwertung der historiographischen Arbeit aus. ${ }^{116}$

Schon die ersten historiographischen Beiträge zeigten einerseits, wie stark der Druck von der stalinistisch-antirevisionistischen Seite war, die Verurteilung Stalins zurückzunehmen, andererseits aber auch, daß die von diesen Kräften gewünschte Restalinisierung nicht durchzuhalten war. In der streng formalisierten marxistischleninistischen Terminologie ist dies en detail abzulesen. In zwei Leitartikeln in den Voprosy istorii zur Oktoberrevolutionsforschung verminderte sich binnen kurzer Zeit der Status Stalins: In Heft 7 (1957) hieß es, Lenin habe die Grundlagen zur sowjetischen Geschichtswissenschaft gelegt, seine „Mitarbeiter und Schüler“ hätten diese Arbeit fortgesetzt. Hervorgehoben wurde „die große Bedeutung“ der Arbeiten Stalins, ehe weitere Parteigrößen, die zur Geschichte publizierten, aufgezählt wurden. ${ }^{117}$ In Heft 10 folgten dem ,grundlegenden“ Lenin die „Schüler und Mitstreiter"،118 - einschließlich des nicht mehr hervorgehobenen Stalin. Im gleichen Heft pries M.E. Najdenov aber wieder die Verdienste Stalins: sein Brief an die Zeitschrift „Proletarische Revolution “ ${ }^{\text {(19 }}$ habe sich nicht nur auf der ganzen ideo-

der Fachabteilung Geschichte der Akademie der Wissenschaften der UdSSR und seine Forschungs- und Lehrtätigkeit auf dem Gebiet der Historiographie, in: Wissenschaftliche Zeitschrift der Karl Marx-Universität Leipzig. Ges.- und Sprachwiss. Reihe 1984, H 4, 413-421

11s Siehe Koroleva, N.A.: V komissii po istorii istoričeskoj naukı pri Instıtute istorii AN SSSR (Bericht), in: VI 1959, H. 9. 202-207.

116 Im Planentwurf, der im August 1959 veröffentlicht wurde, war Historiographie neben Quellenkunde, Bibliographie und Ethnographie noch ein untergeordneter Punkt. Kurze Zeit später erkläte Najda, der damalige Chefredakteur der loprosy istorii, die Historiographie der Geschichtswissenschaft zu einer der drei Hauptaufgaben der Zeitschrift. - Vgl. Proekt plana raboty Zurnala „Voprosy istorii“" na 1959-1965 gody, in: VI 1959, H. 8, 207-213, Borisov, L.P.: Obsư̌.denie perspektivnogo plana raboty redakcii žurnala „Voprosy istorii“ na 1959-1965 gody (Bericht), in: VI 1959, H. 11, 182-185, hier 182

117 Za tvorčeskoe izučenie 1957, 4.

118 In der Reihenfolge des kyrillischen Alphabets wurden genannt: Vorošilov, Dzeržinskij, Kalinin, Kirov, Ordžonikidze, Sverdlov, Stalin, Frunze und Chruš̌̌ev. - Pod znamenem, 13.

119 Stalin, J.: Über einige Fragen der Geschichte des Bolschewismus. Brief an die Redaktion der Zeitschrift .Proletarskaja Rewoluzija“ (1931), in: ders., Fragen des Leninismus, Berlin 1955, 489-503. Vgl. Barber, Stalin's Letter. - De facto begann die Dogmatisierung im wesentlichen schon 1929, wie oben in Kapitel 2 ausgefuihn wurde. Stalins Brief war nicht der Wendepunkt. sondern Ergebnis und Ausdruck des vorangegangenen Umschwungs. Siehe dazu zuletzt Entin, Dž. (Enteen, G.M.): Intellektual'nye predposylki utverždenija stalinizma v sovetskoj istoriografii, in: VI 1995, H. 5-6, 149-155. - Im internationalen Zusammenhang betrachtete Babičenko die Wirkungen von Stalins Brief, ohne dessen innenpolitische Vorgeschichte adäquat zu beleuchten: er untersuchte „den Prozess der Ablösung des Marxismus-Leninismus, der Idee des Sozialismus in unserem Land und teilweise in den ausländischen kommunistischen Parteien durch den Stali- 
logischen Front, sondern auch in der Geschichtswissenschaft positiv (!) ausgewirkt: ${ }^{120}$ Die Klassiker seien intensiver studiert, das theoretische Niveau erhöht, Pokrovskij scharf kritisiert und die leninistische Geschichtskonzeption gefestigt worden, was im „Kurzen Lehrgang“ zur Parteigeschichte von 1938 Früchte getragen habe. Das Phänomen der umfassenden Dogmatisierung der Historie unter Stalin reduzierte Najdenov zum Mißverständnis „einiger“" Historiker, welche die von Stalin angeblich verteidigten, genialen leninschen Aussagen" nicht richtig genutzt, sondern bloß mechanisch wiederholt hätten. ${ }^{121}$ Nur wenn das Parteilichkeitsprinzip beachtet werde, könnten die Folgen dieser Kanonisierung überwunden werden. ${ }^{122}$

Im Kontext der antirevisionistischen Reaktion sind auch die Aussagen zu Stalin und dessen Machtordnung in der neuen Parteigeschichte von 1959 und weiteren Zeitschriftenaufsätzen zu sehen. ${ }^{123}$ Hier spiegelte sich das Dilemma der Ideologen der Macht wider: Ein Rückfall hinter die wesentlichen Thesen der Rede Chrušcevs beim 20. Parteitag oder nur hinter das Kompromißpapier des Zentralkomitees vom Juni 1956 war bereits weder politisch noch wissenschaftlich ohne Konflikte möglich. ${ }^{124}$ Die freie Sicht auf die Quellen ließen die Antirevisionisten aber auch nicht

nismus (...)“. Siehe Babičenko, L.G.: Pis’mo Stalina v „Proletarskuju Revoljuciju“ i ego posledstvija, in: VIKPSS 1990, H. 6, 94-108, hier 95.

120 Najdenov fand eine Reihe von Leistungen Stalins erwähnenswert: das „Gefühl bolschewistischer Parteilichkeit“, die „Unduldsamkeit gegenüber jeder Abweichung vom Leninismus“ und das .Interesse an der marxistisch-leninistischen Theorie" habe Stalin bei den Historikern gestärkt. - Najdenov, M.E.: Velikaja Oktjabr'skaja socialističeskaja revoljucija v sovetskoj istoriografi1, in: VI 1957, H. 10, 167-180, hier 173ff

121 ..Im Resultat entwickelte sich bei einigen Historikern die Tendenz zum Dogmatismus und zur Buchstabengelehrtheit, es bildete sich eine besondere Methode der Zitatanhäufung heraus, die mit Wissenschaft nichts gemein hat."- Ebd., 180.

122 Ebd

123 Istorija Kommunističeskoj Partii Sovetskogo Sojuza, M. 1959 (Deutsche Übersetzung: Geschichte der Kommunistischen Partei der Sowjetunion. Berlin 1960). Zeitgenössische Rezensenten der Parteigeschichte von 1959 hielten diese fälschlicherweise für ein ,....) Ergebnis jener (...) Revisionsbemühungen, die seit dem Frühjahr 1956 die sowjetkommunistische Parteigeschichte betroffen haben " (Dietrich Geyer in: JbbGO 1962, 144ff, hier 144). Alfred G. Meyer stellte fest: „(...) eine gründliche Revision der Parteilinie über ihre eigene Geschichte enthält der neue Lehrgang nicht." (OE 1960, H. 4, 266ff, hier 266). Wie auch?! Schließlich war das Nachfolgewerk des „Kurzen Lehrgangs“ gerade nicht das Ergebnis von Revisionsbemühungen, sondern im Gegenteil die Antwort konservativer Ideologen (wie z.B. Ponomarev) und Historiker (wie z.B. Kučkin) darauf. So muß die Frage an diese Parteigeschichte 1959 nicht lauten: Wie weit ist die Revision gekommen? Sondern: Wie weit zurück sind die Antirevisionisten gegangen? - Ponomarev und Kučkin waren übrigens auch schon an der schriflichen Niederlegung des „Kurzen Lehrgangs“ 1938 beteiligt. Siehe Istoriografija istorii SSSR. Epocha socializma, M. 1982, 96.

124 In diesem Zusammenhang sind auch die Hinweise von Heer wichtig: erstens auf die „serious

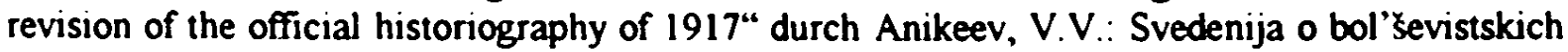
organizacijach s marta po dekabr 1917, in: VIKPSS 1958, H. 2, 126-193 und zweitens auf die schwindende Unterstützung, welche die Sektionsleiterin für KPdSU-Geschichte am Institut für Marxismus-Leninismus, M.D. Stučebnikova, für ihre stalinistischen Ausfuihrungen 1956/58 erhielt: Heer, Politics, 101. 
zu. Daher entstand bei der Neufassung keine streitbare Darstellung der KPdSUGeschichte, sondern eine blutleerer Katechismus, der sich vom „Kurzen Lehrgang“" vor allem, in der Fortfuihrung bis 1959 und in den Nuancen "“125 unterschied. ${ }^{126}$ Umgeben waren die Konzessionen von grenzziehenden Thesen, um deren Gültigkeit und Beachtung es den Autoren vor allem ging und deren drei ${ }^{127}$ im Anschluß an eine sowjetische Rezeption zitiert werden sollen: ${ }^{128}$ Demnach haben die Autoren des Lehrbuchs ,einleuchtend“ gezeigt,

"(...) da $B$ die Zerschlagung der Trotzkisten, Bucharin- und Zinov'ev-Anhänger, der Anarcho-Syndikalisten und bürgerlichen Nationalisten die notwendige objektive Voraussetzung des Erfolgs des sozialistischen Aufbaus unter solchen Bedingungen darstellt, wenn nichtsozialistische Klassen existieren. “129

Zweitens: „Die Tätigkeit Stalins trug historisch widersprüchlichen Charakter. Einerseits hat Stalin große Verdienste im Kampf um die Festigung der Partei und des Sowjetstaats, beim Aufbau des Sozialismus, bei der Entwicklung und Bereicherung der marxistisch-leninistischen Theorie. (...) Andererseits ließ Stalin vor allem in seinen letzten Lebensjahren in seiner Arbeit eine Reihe grober Fehler und Verzernungen zu, die der Sache der Partei, der Sache des Volkes emsthaften Schaden zufügten und die Entwicklung der sowjetischen Gesellschaft bremsten. “130

Drittens: „(...) die Fehler und Unzulänglichkeiten (...) konnten nicht ändern und änderten nicht den tief demokratischen, wahrhaft volksnahen Charakter des sowjettschen Systems. Die von der Partei betriebene Politik war richtig, sie reflektierte die Interessen des Volkes “.131

Das waren die „Pflöcke“, die zu setzen und zu verankern Ziel der neuen Parteigeschichte war. ${ }^{132}$ Solche Lehren wurden $1957 / 58$ jedoch nicht mehr widerspruchslos

\section{Alfred G. Meyer in der Rezension in: OE 1960, H. 4, 226}

126 Die Nuancen betrafen z.B. Lenin, der wieder zur alleinigen zentralen Figur der Oktoberrevolution stilisiert wurde, die Feststellung (vorübergehender) Fehleinschätzungen Stalins im Febnuar und März 1917, die erstmalige Erwähnung des politischen Testaments Lenins, in dem dieser vor bedenklichen Charakterzügen Stalins gewarnt hatte: auch auf ernsthafte Fehler Stalins in der politischen Führung nach 1934 und zu Beginn des „Großen Vaterländischen Krieges” wurde hingewiesen. - Siehe Geschichte 1960, 265ff, 477ff, 637ff, 679ff, vgl. Heer, Politics, 105ff.

12: Diejenigen Thesen, die sich auf die Tätigkeit Stalins beziehen.

128 Problemy razvitija istoričeskoj nauki (V svjazi c vychodom v svet „Istorii KPSS“), in: VF 1960, H. 5, 15-25.

129 Ebd., $17 \mathrm{f}$.

130 Ebd., 22.

131 Ebd.

132 Zu Stalins 80. Geburtstag brachten die Fachzeitschriften V'oprosy istorii und Istorija SSSR keinerlei Hinweis auf den Jubilar: Entstalinisierung fand im wörtlichen Sinn statt! Im Theorieorgan der KPdSU Kommunist wagte man sich mit dem Geburtstagsartikel nicht mehr auf die erste Seite. In der Heftmitte war der ungezeichnete Artikel versteckt, in dem Stalin - wieder - als tragische Figur charakterisiert wurde. Nancy Heer irne sich, als sie schrieb, diese Charakterisierung weiche essentiell von Chruščevs Rede ab, in der Stalin dargestellt worden sei ,as actively evil in his sickness, motivated by considerations of personal power even to the detriment of the interests of communism." Auch Chrušcev hob am Ende seiner Rede auf die „Tragik" ab: „Man 
hingenommen. Nečkina wollte die historiographische Arbeit offenkundig auf ein solides Fundament stellen. Thr ging es darum, Historiographie als eigenständige Disziplin zu etablieren. Thr Definitionsversuch blieb etliche Jahre grundlegend für alle weiteren Diskussionen:

„Unter Historiographie verstehen wir die Geschichte der Geschichtswissenschaft, in diesem Fall die (...) der UdSSR, und wir betrachten diese Disziplin nicht als Hilfswissenschaft, sondern als selbständiges Fach der Geschichte, welches seinen eindeutigen Gegenstand besitzt - die Geschichte der Geschichtswissenschaft, seinen vollständig festgelegten Kreis von Primärquellen - die Arbeiten der Historiker, die einander abwechseln, die sich verflechten, die verschiedene Seiten des geschichtlichen Prozesses erörtern, die selbständige Phänomene darstellen, und schließlich als Fach, welches nicht nur genau festgesetzte Gegenstände und den Kreis von Primärquellen hat, sondern eine bestimmte Methodologie." $"$ 133

Anfang 1960 eröffnete Nečkina in Istorija SSSR die erste Diskussion über die Entwicklung der sowjetischen Geschichtswissenschaft. ${ }^{134}$ In vielem blieb sie traditionell. Von 1917 bis 1956 unterschied sie drei Abschnitte, und bewertete dabei die Stalin-Zeit grundsätzlich positiv. ${ }^{135}$ In den Jahren 1953 bis 1956 habe die vierte Periode begonnen, die gekennzeichnet sei von der Überwindung der durch den Personenkult entstandenen Fehler. Neckina belegte die Kernphase der stalinistischen Dogmatisienung seit den Regierungsbeschlüssen von 1934 ebenfalls mit positiven Titeln, würdigte sogar den ,Kurzen Lehrgang“ von 1938. ${ }^{136}$ Anders als Najdenov hob sie allerdings die Fehler im Zusammenhang mit dem Personenkult hervor, führte sie auf diesen zurück und verniedlichte sie nicht zu Mißverständnissen einiger Historiker: So machte sie Stalin implizit dafür verantwortlich, daß die Erforschung der sowjetischen Gesellschaft vernachlässigt, die geschichtliche Rolle der Volksmassen reduziert, die einzelner Persönlichkeiten überbewertet, willkürlich geschichtliche Themen tabuisiert, bestimmte Fragen, wie z.B. die Bewertung Samils falsch dargestellt und das vorrevolutionäre Rußland idealisiert worden sei. ${ }^{137}$ En passant rehabilitierte Nečkina Plechanov, an dessen Schrift zur monisti-

kann nicht sagen, daß die Taten Stalins die eines gedankenlosen Despoten waren. Er meinte, daß man im Interesse der Partei, der werktätigen Massen, um der Verteidigung der revolutionären Errungenschaften willen, so handeln müßte. Darin liegt die wirkliche Tragödie!" Zitiert nach Judick/Steinhaus, Stalin, 191f. Vgl. Heer, Politics, 111; K 1959, H. 18, 47-56.

133 Siehe Koroleva. V komissii, 203.

134 Nečkina, M.V.: O periodizacii istorii sovetskoj istoričeskoj nauki, in: ISSSR 1960, H. 1. Hier nach der deutschen Übertragung Netschkina, M.W.: Zur Periodisierung der Entwicklungsetappen der sowjetischen Geschichtswissenschaft, in: SW 1960, H. 7, 778-796.

135 1917 bis 1923: Entstehung der sowjetischen Geschichtswissenschaft, Kampf gegen die adelig-bürgerliche Historie, Formulierung der marxistischen Geschichtskonzeption u.a.; bis 1934/36: Verschärfung des Kampfs gegen antimarxistische Strömungen und Sieg über diese; 1934 bis 1956: „Periode der bedeutenden Stärkung der marxistisch-leninistischen Geschichtswissenschaft"! - Netschkina, Zur Periodisienung, 786ff.

136 Netschkina, Zur Periodisierung, 786-794.

$13^{-}$

Ebd., 795 
schen Geschichtsauffassung von $1895^{138} \mathrm{zu}$ gutem Recht „eine ganze Generation russischer Marxisten erzogen" worden seien. ${ }^{139}$

An Pokrovskij, dem wichtigsten sowjetischen Historiker der zwanziger Jahre, der unter Stalin als ,Anti-Leninist" gegolten hatte, ${ }^{140}$ war in der historiographischen Diskussion nicht vorbeizukommen. Die bekannten Vorwürfe wurden zunächst wiederholt, aber allmählich abgeschwächt. Nach Auffassung des Juli-Leitartikels in Voprosy istorii 1957 entwickelte sich nach 1934 ein „Kampf gegen die antilenimistische Konzeption M.N. Pokrovskijs“" ${ }^{141}$ In Heft 10 handelte es sich nur noch um einen „Kampf mit nichtmarxistischen Ansichten" “42 , was in der sowjetischen Terminologie einen weit schwächeren Vorwurf ausdrückte. Akademik Rybakov hielt es im März 1959 dennoch für notwendig, daß noch immer existierende „Erscheinungsformen der 'Schule' Pokrovskijs" vollständig überwunden würden. ${ }^{143}$ Und als der Beschluß des Zentralkomitees der Partei und der Sowjetischen Regierung über die Vermittlung der Staatsgeschichte (graะdanskoj istorii) in den Schulen sich zum füfundzwanzigsten Mal jährte, ließ die Redaktion der Voprosy istorii es sich nicht nehmen, in einer mehrteiligen Serie über die angeblich so gute Entwicklung der historischen Fakultäten seit 1934 zu berichten und in der Einleitung dazu die wichtige Rolle zu betonen, die jener Beschluß vom 16. Mai 1934 ,im Kampf gegen die antiwissenschaftliche Schule Pokrovskijs" gespielt haben soll. ${ }^{144}$ Auch in den Diskussionen über die Inkorporation des Kaukasus und Mittelasiens ins Zarenreich, die organisiert waren, um die Revisionsversuche Pikmans und anderer abzuwehren, waren erneut aus den dreißiger Jahren wohlbekannte Vorhaltungen gegen Pokrovskij zu vernehmen, der den Anschluß dieser Regionen an Rußland als ,absolutes Übel" bezeichnet hatte. ${ }^{145}$ Nečkina wog in ihrem oben bereits

138 Plechanov, G.V. (N. Beltov): K voprosu o razvitii momstıceskogo vzgljada na istorıju, S. Peterburg 1895.

139 Netschkina, Zur Periodisierung. 784

140 Siehe Nezkina, M.V.: Vopros o M.N. Pokrovskom v postanovlenijach partii i pravitel'stva 1934-1938 gg o prepodavanii istorii $i$ istoričeskoj nauke ( $\mathrm{K}$ istočnikovedðeskoj storone temy), in:

IZ 118, M. 1990, 232-246 (Mitte der sechziger Jahre geschrieben, 1966 zur Veröffentlichung abgelehnt!); Artizov, A.N.: Kritika M.N. Pokrovskogo i ego školy (K istorii voprosa), in: ISSSR 1991, H. 1, 102-120.

141 Das war der schärfste unter Stalin gegen Pokrovskij erhobene Vorwurf. - Vgl Za tvorčeskoe izuČenie 1957. 5. (Hervorhebung von mir, J.H.); Protiv istoričeskoj koncepcii M.N. Pokroskogo. Sbornik statej. Cast pervaja, M.-L. 1939, darin besonders den Beitrag von Anna Pankratova über die Entwicklung von Pokrovskijs geschichtlichen Auffassungen. 5-69.

142 Pod znamenem, 13. Hervorhebung von mir, J.H.

143 Siehe Assaturova, Obščee sobranie, 161.

144 O rabote istoriceskich fakul'tetov gosudarstvennych universitetov (K 25-letiju postanovlenija CK VKP(b) i Sovnarkoma SSSR „O prepodavanii gră̌danskoj istorii v školach SSSR“), in: VI 1959, H. 7, 182-201, hier 182. Fortsetzung in: Vl 1959, H. 10, 192-194; H. 11, 185-190; H. 12 , 185-187. Der Beschluß, erstveröffentlicht in der Provda am 16.05.1934, ist in deutscher Sprache wiedergegeben bei Oberländer, Sowjetpatriotismus, $125 \mathrm{f}$.

14s Siehe Pjaskovskij, A.V.: K voprosu o progressivnom značenii prisoedinenija srednej Azii $\mathbf{k}$ Rossii, in: VI 1959, H. 8, 21-46; Bał̌ova, A.P.: Ob-edinennaja naučnaja sessija, posvjaščennaja 
zitierten Aufsatz Positives und Negatives im Werk Pokrovskijs ab, ohne sich von den Stalinschen Verdikten zu lösen. Mit dem Namen des Historikers, der

„(..) damals die gesamte geschichtswissenschaftliche Tätigkeit und die führenden Organe und Institutionen der Geschichtswissenschaft leitete", ${ }^{146}$

verband sie alle Erfolge und Fehler jener Zeit von 1924 bis 1936. Der „Hauptfehler“ Pokrovskijs, der bekanntlich 1932 starb, sei dessen ungenügende Kenntnis der Werke Lenins gewesen; ${ }^{147}$ die Parteibeschlüsse von 1934/36 hätten eine ,nutzbringende Wendung" bewirkt. ${ }^{148}$ Ungeachtet dessen wurde zur gleichen Zeit die Rehabilitierung Pokrovskijs und die sachliche Auseinandersetzung mit seinem Werk eingeleitet. Sokolov erinnerte 1970 daran, daß im August 1958 eine Tagung anläßlich des 90 . Geburtstags Pokrovskijs im Revolutionsmuseum stattgefunden habe. Dort habe der ehemalige Dekan der Historischen Fakultät an der Leningrader Universität, der 1937 inhaftierte ,Altmeister der sowjetischen Agrargeschichte" und Historiograph, Sergej Mitrovanovič Dubrovskij ${ }^{149},-$ als erster - über die Notwendigkeit gesprochen, die einseitige Bewertung der wissenschaftlichen Ansichten und gesellschaftspolitischen Tätigkeit Pokrovskijs zu revidieren ${ }^{150}$ Ende des gleichen Jahres wandte sich Sidorov, damals noch Direktor des Geschichtsinstituts an der Akademie, an den Ideologie-Sekretär des Zentralkomitees der Partei, Suslov, mit der Bitte, die Veröffentlichung ausgewählter Werke Pokrovskijs in zwölf Bänden zu gestatten. ${ }^{151}$ Sidorov suchte Suslov zu gewinnen, indem er beteuerte, dies solle keinesfalls eine Rehabilitienung Pokrovskijs bedeuten, im Gegenteil: seine Fehler könnten dann besser kritisiert werden. Freilich wußten Absender und Adressat, daß es um mehr als nur darum ging, wenn man,

„(..) den wirklichen Platz des großen Historikers und Aktivisten der Kultur in der sowjetischen Geschichtswissenschaft (...) bestimmen" wollte. ${ }^{132}$

Grundsätzlich unterstützten Wissenschafts- und Propaganda-Abteilung des Zentralkomitees den Vorschlag Sidorovs, hielten aber eine zwölfbändige Ausgabe für ,unzweckmäßig“. ${ }^{153}$

progressivnomu značeniju prisoedinenija srednej Azii k Rossii (Bericht), ebd., 173-183; Azabaev, F.A./B.V. Lunin: Ob-edinennaja naučnaja sessija, posvjaščennaja progressivnomu značeniju prisoedinenija srednej Azii k Rossii (Bericht), in: ISSSR 1959, H. 5, 214-218

146 Netschkina, Zur Periodisienung, 790.

14* Ebd., 792. Welch zunückhaltender Vorwurf im Vergleich zu früher, da Pokrovskij bewußte Fälschung der Thesen Lenins unterstellt wurde!

148 Netschkina, Zur Periodisienung. 793.

149 Nekrič schrieb, Dubrovskij sei ungefähr zwanzig Jahre im Lager gewesen. - Nekrič, Otreł̌is' ot stracha. 178; siehe Geyer, D. (Hg.): Wirtschaft und Gesellschaft im vorrevolutionären Rußland. Köln 1975, 303: Dubrovskij, S.M.: Die russische Bauernbewegung 1907-1914, in: ebd., 347-367; vgl. Artizov, Kritika, 108.

1 so Sokolov, M.N.Pokrovskij, 26, hier Fußnote 48

151 Sidorov, A.L. am 13.12.1958 an M.A. Suslov, CChSD, f. 5, op. 35, d. 77, 274-276.

152 So Sidorov ebd., 275. 
Erstmals bilanzierte der für die „Geschichte des sozialistischen und kommunistischen Aufbaus" zuständige Wissenschaftliche Rat im März 1960 unionsweit die Historiographie der sowjetischen Gesellschaft. Der Leiter des Rates, M.P. Kim. stellte dort offen selbstkritisch fest, daß es noch immer keine theoretischen Arbeiten gebe,

"(...) in denen tiefgreifende wissenschaftliche Verallgemeinerungen und umfassende Schlußfolgenungen aus der geschichtlichen Erfahrung des sozialistischen Aufbaus in der UdSSR gezogen würden." 134

Kim forderte die Versammelten auf, endlich, gestützt auf die ,geschichtliche Wirklichkeit“, deren „tiefliegenden Prozesse" zu erforschen und den Dogmatismus und Empirismus der Stalinzeit zu überwinden. ${ }^{\text {ss }}$

Schien es 1957 noch so, als sollten Altstalinisten die wichtigste Fachzeitschrift vollends und dauerhaft kontrollieren, so endete deren Dominanz in der Redaktion der Voprosy istorii im Sommer 1960. Außer Matjuškin, Najda, Borisov und Tret'jakov verließen sechs weitere „1957er“ die Redaktion. ${ }^{156}$ Zehn neue Mitglieder kamen hinzu, ${ }^{157}$ Truchanovskij wurde Chefredakteur - und blieb ganze 27 Jahre in dieser Position. ${ }^{158}$ Die neue Mannschaft ${ }^{159}$ stellte sich zwar mit einem $z u-$ nächst traditionell dogmatisch wirkenden Leitartikel ${ }^{160}$ vor, setzte aber Akzente,

193 Von 1965 an erschienen vier Bände ausgewählter Werke. Pokrovskij, M.N.: Izbrannye proizvedenija v cetyrech knigach, kniga 1, M. 1966, kniga 2, M. 1965, kniga 3-4, M. 1967. Kukin, D./V. Snastin am 05.03.1959 an das ZK der KPdSU, in: CChSD f. 5, op. 35, d. 77, 277.

154 Kim. M.P.: O sostojanii razrabotki istorii socialisticeskogo i kommunisticeskogo stroitel'stva i zadacach sovetskoj istoriðeskoj nauki, in: Istoriografija socialističeskogo i kommunistið̌eskogo stroitel'stva v SSSR. Sbornik statej po materialam sessii naučnogo soveta, M. 1962, 5-29, hier 14. 135 Ebd

156 Es waren dies: Dadykin, Ivanov, Sevost janov, Sobolev, Fedotov und Cerepnin. Von den 1957 Hinzugekommenen blieben bloß: Naročnickij und Orbeli. - Siehe VI 1960, H. 6, 224 und H. 7, 224. Orbeli starb am 02.02.1961; VI 1961, H. 2, 224.

15- L.S. Gaponenko, G.N. Golikov, V.M. Donskoj, Ja.Ja. Zutis, V.M. Kulikov, P.N. Lavrov, A.I. Levkovskij, N.V. Matkovskij, V.I. Sunkov und V.G. Truchanovskij. Donskoj und Matkovskij verließen 1961 die Redaktion wieder. Zutis (16.08.1893-28.06.1962) schied Anfang 1962 aus, während F.D. Ryžzenko, E.I. Trjapicyn, I.A. Fedosov und S.A. Judačev dazukamen. - VI 1960, H. 7, 224; VI 1961, H. 4, 224; VI 1962, H. 1, 224.

158 Vladimir Grigor'evix Truchanovskij, geboren am 15.07.1914, absolvierte neben der historischen eine pädagogische und diplomatische Ausbildung. er war seit 1939 Parteimitglied, seit 1964 Korrespondierendes Akademiemitglied. Am Institut für Geschichte der AdW war er 1953 bis 1957 höherer wissenschaftlicher Mitarbeiter, 1957 bis 1960 stellvertretender Direktor, danach von 1960 bis Juni 1987 Chefredakteur der Voprasy istorii. - BSE (III) 26, 275; VI 1987, H. 6 , 192.

159 Wenn die Namen nicht täuschen, war die Redaktion bereits seit dem Ausscheiden von Anna Pankratova im März 1957 und nun auch über den Sommer 1960 hinaus hundertprozentig in Männerhand.

160 Die ewig dienende Rolle der Geschichtswissenschaft wurde beschworen, ebenso die Notwendigkeit, sich den Marxismus-Leninismus anzueignen. Kommunistische Parteilichkeit falle - 
um die zentrale Fachzeitschrif strukturell und inhaltlich neu zu profilieren sowie die wissenschaftliche Forschung und Diskussion zu beleben: Künftige Autoren der Fachzeitschrift wurden ermahnt, sich - Lenins Maxime entsprechend - bei ihren Aussagen und Wertungen nicht auf

„(..) einzelne Fakten, sondem die ganze Gesamtheit der zu der betrachteten Frage gehörenden Fakten, ohne eine einzige Ausnahme, (...) ${ }^{\text {"161 }}$

zu stützen. Der ,Kampf gegen die bürgerliche Historiographie“ wurde beschworen, zugleich aber betont, daß diese differenziert beurteilt werden müsse ${ }^{162}$ und die internationalen Beziehungen nicht nur mit marxistischen, sondern verstärkt mit ,gewissenhaften bürgerlichen Historikern" ausgebaut werden müßten. ${ }^{163}$ Bei der Auflistung künftiger Arbeitsschwerpunkte wurde erstmals die „Erforschung methodologischer Fragen" hervorgehoben. Deren Vertiefung sei eine wichtige Aufgabe der Historiker und erfordere die fachlich-berufliche Zusammenarbeit mit Philosophen, Ökonomen, Rechts- und Literaturwissenschaftlern. ${ }^{164}$ Der Leitartikel verwies hierzu auf die neuen Periodika, die erheblich erweiterte Diskussionsräume hätten entstehen lassen ${ }^{165}$, sowie auf fünf der sechs unionsweiten Wissenschaftlichen Räte ${ }^{166}$, die acht Forschungsgruppen ${ }^{167}$ und zwei Kommissionen ${ }^{168}$ im Ge-

automatisch - mit ,höchster wissenschaftlicher Objektivität" zusammen. - Sovetskaja istoričeskaja nauka na novom etape razvitija, in: VI 1960, H. 8, 3-18, hier 3f und 6.

161 Lenin. V.I.: Statistika i sociologija, in: ders., Sočinenija. Izdanie cetvertoe, M. 1941ff, t. 23 , 265-271, hier $266 f$.

162 Sovetskaja istoričeskaja nauka 1960, 7 und $5 f$.

163 Ebd., $5 f$.

164 Ebd., $9 f$.

165 Zusätzlich zu den oben bereits genannten Periodika zählte der Leitartikel neunzehn neue Zeitschriften auf: speziell zur Ukrainischen Geschichte: Ukrainskij istoriteskyj zurnal, zum Archinwesen: Istoriceskij archiv (1955-62), zur sowjetischen „Ostforschung“: Sovremennyj vostok, die allgemeinen „Historischen Schriften“ - Istoriłeskie zapiski (die schon 1937-41 erschienen waren, seit 1945 wieder publiziert wurden), die Fachzeitschriften für Mediävistik. Srednie veka (seit 1942), für Byzantinistik, Vizantijskij vremennik (seit 1947), für Quellenkunde, Problemy istocnikovedenija, für Religionsgeschichte V'oprasy istorii religii i ateizma, die Quellenbände zur UdSSR-Geschichte Materialy po istorii SSSR und zur sowjetischen Agrargeschichte Materialy po istorii zemledelija i sel 'skogo chozjajstva v SSSR, das Jahrbuch des Museums fur Religions- und Atheismusgeschichte Ezegodnik muzeja istorii religii i ateizma, das Jahrbuch der Archäographie Archeograficeskij ezegodnik, das Periodikum zur nordosteuropäischen Geschichte Skandinavskij sbornik.

Hinzu kamen noch zahlreiche von Hochschulen und Forschungsinstituten herausgegebene Schriften. sogenannte Trudy und Utenye zapiski; ebd., 12. Vgl. Orerki, 1985, 105ff.

166 Diesen Räten gehörten Vertreter von Akademie- und Partei-Instituten, Hochschulen, Universitäten und Schulen der RSFSR und anderer Sowjetrepubliken an. Mit ihrer Hilfe sollten die Forschungen in den jeweiligen Themenbereichen unionsweit abgestimmt werden. Es handelte sich um die wissenschatlichen Räte zur Geschichte des sozialistischen und kommunistischen Aufbaus in der UdSSR, Nautnyj sovet po istorii socialistiCeskogo i kommunistiCeskogo stroitel 'stva v SSSR (Leiter: M.P. Kim), zur Geschichte des nationalen Befreiungskampfes der Völker gegen den Kolonialismus und zur Entwicklungsgeschichte der unabhängig werdenden östlichen Länder, ...po istorii nacional 'no-asvoboditel noj bor'by narodov protiv kolonializma $i$ istorii 
schichtsinstitut der Akademie, die keine administrativen. sondern ,schöpferische gesellschaftliche Organisationen" seien. Mittels dieser Institutionen sollte die Forschungsarbeit besser koordiniert, sollten schöpferische wissenschaftliche Diskussionen ausgeweitet werden. ${ }^{169}$

In einem separaten Beitrag ${ }^{170}$ informierte die Abteilung der Geschichtswissenschaften an der Akademie, welcher seit März 1957 die Zeitschrift Voprosy istorii direkt unterstellt war, über Profil und Struktur der Fachzeitschrift, die weiterhin das ,zentrale allgemeingeschichtliche Journal sowjetischer Historiker" sein solle. Bei der Aufzählung der Grundprobleme, die künftig systematisch erörtert werden sollten, war - wie schon früher - kein besonderes Profil zu erkennen. Nicht durch andere Themen, sondern durch eine andere Art der Behandlung sollte die Zeitschrift sich von den zahlreichen übrigen Periodika unterscheiden, sie müsse versuchen. ,(...) vor allem theoretische, große problemorientierte und historiographische Aufsätze zu publizieren. “171 Systematisch müsse die Zeitschrift „Diskussionsmaterialien zu großen Problemen der Geschichtswissenschaft" veröffentlichen und regelmäßig über die Lage der Geschichtswissenschaft in der UdSSR, aber auch im Ausland informieren. ${ }^{172}$

razvitija stran l'astoka, starsich na put' nezanisimosti (B.G. Gafurov), zur Geschichte der Oktoberrevolution, ...po istorii Velikoj Oktjabr 'skoj socialisticeskoj revoljucii (I.I. Minc), zu den geschichtlichen Voraussetzungen der Revolution, ...po izuCeniju istoriceskich predposylok $l^{\text {eeli- }}$ koj Oktjabr'skoj socialisti eskoj revoljucii (A.L. Sidorov), zur Genesis des Kapitalismus, ...po genezisu kapitalizma (S.D. Skazkin). Vergessen wurde im Leitartikel der Wissenschaftliche Problemrat zur Geschichte der Geschichtswissenschaft. - Sovetskaja istoričeskaja nauka 1960, 13.

16. Zur Erforschung der Vaterländischen Geschichte und der Geschichte einzelner Länder des Westens, im einzelnen: zur Geschichte der Bauern und der Landwinschaft in der UdSSR. Tvor' eskaja gruppa po izuC eniju istorii krest janstva i sel 'skogo chozjajst'a v SSSR (Leiter: V.P Danilov), zur revolutionären Situation in Rußland in den $50 \mathrm{er}$ und $60 \mathrm{er}$ Jahren des 19.Jahrhunderts, ...po issledovaniju revoljucionnoj situacii $v$ Rossii v 50-60-x godach $\mathrm{XIX} v$. (M.V. Nečkina), zur sozialistischen Ideengeschichte, ...po izuðeniju istorii socialisticeskich ide! (B.F. Poršnev), zur Geschichte Frankreichs, ...po istorii Francii (V.P. Volgin), zur Geschichte Spaniens und Englands (Leiter beider Gruppen: I.M. Majskij), zur Geschichte Italiens (S.D. Skazkin), und zur Geschichte Deutschlands (A.S. Erusalimskij). - Ebd

168 Die Kommission zur Geschichte der Geschichtswissenschaft Komissija po istorii istori nauki, geleitet von M.V. Nečkina und diejenige zur russischen Agrar- und Bauerngeschichte. .po istorii sel 'skogo chozjajstva i krest janstva Rassii (N.M. Druzinin). - Ebd., $13 \mathrm{f}$.

169 Ebd., 14.

170 O profile i strukture žurnala „Voprosy istorii“, in: VI I960, H. 8, 19-21.

17 Wenn mittels enger Kontakte zu anderen Redaktionen eine Doppelung vermieden würde, dann könne die Veröffentlichung thematisch ähnlicher Materialien nur dazu beitragen. der Wissenschaft abträgliche Monopolstellungen zu verhindern. - Ebd., 19.

172 Dementsprechend baute sich Voprosy istoril ab Heft 8 des Jahres 1960 in folgender Weise auf: Den Forschungsaufsätzen folgten die Rubriken „Geschichtswissenschaft in der UdSSR“, „Geschichtswissenschaft im Ausland” sowie „Briefe und Marginalien“. - Ebd., $20 f$. 
Im gleichen Heft waren die zusammengefaßten Redebeiträge mehrerer Akademiemitglieder ${ }^{173} \mathrm{zu}$ lesen, die am 30. Juni 1960 über die Zeitschrift beraten hatten. Mit einer nie zuvor angetroffenen Frische forderten die Diskussionsteilnehmer mehr fundierte Kritiken und analytische, objektive Rezensionen in der Zeitschrift, mehr Informationen über das wissenschaftliche Leben im In- und Ausland, vor allem über die aktuellen Kontroversen ${ }^{174}$ "Weiße Flecken“ der Geschichtswissenschaft wollte Efimov behandelt sehen. ${ }^{175}$ Und Neckina begeisterte sich:

"Jetzt brodelt das schöpferische Leben in vielen Städten unserer Heimat. Dieses pulsierende Leben der sowjetischen Geschichtswissenschaftler muß die Zeitschrift auf ihren Seiten reflektieren. “176

Mehr Artikel mit historiographischem, bibliographischem und Diskussions-Charakter müsse es geben. ${ }^{177}$ Kim ermunterte die Redaktion zu einer betont extrovertierten Haltung: Voprosy istorii dürfe nicht auf von selbst eintreffende Aufsätze warten, sondern müsse mit den neuen Aufgaben auf die Historiker zugehen, wobei Fragen der Methodologie und Theorie von zentraler Bedeutung seien. ${ }^{178}$ Alle Redebeiträge waren von dem starken Optimismus geprägt, mit den neuen Impulsen und künftigen regelmäßigen Treffen der Akademiemitglieder notwendige und hinreichende Bedingungen zu schaffen für einen echten Aufschwung, nicht nur in der Arbeit der zentralen Fachzeitschrift, sondern unionsweit in der geschichtlichen Disziplin.

Festzuhalten ist also, daß der 1957 vehement gestartete Antirevisionismus schon bald auf Gegentendenzen stieß: die sich fortsetzende Ausweitung der Forschung und Publikationswelle, die Verfechtung des Historismus als Korrektiv zum starren Parteilichkeitsprinzip, die intensivere systematische Erforschung der Entwicklung der sowjetischen Geschichtswissenschaft, die Einleitung der faktischen Rehabilitierung Pokrovskijs. Dies führte zu einer Koexistenz progressiver, auf weitere Destalinisierung gerichteter und regressiver, auf Restalinisienung zielender Kräfte. Das Nebeneinander bestand im wörtlichen Sinne: In derselben Parteiorganisation, Redaktion, ja in derselben Ausgabe der Voprosy istorii oder anderer Fachzeitschriften

\footnotetext{
1:3 Es handelte sich um die akademiki M.V. Nečkina. I.I. Minc. S.D. Skazkin und I.M. Majskij sowie um die Korrespondierenden Mitglieder der Akademie A.V. Efimov, S.V. Kiselev und M.P. Kim. Gastgeber der Beratung war der ,frischgebackene“ Chefredakteur der „V", V.G. Truchanovskij. - Sovešcanie akademikov i členov-korrespondentov AN SSSR v redakcii žurnala "Voprosy istorii', in: VI 1960, H. 8, 132-136.

1\%4 So äußerten sich Efimov, Neckina, Minc, Kim und Majskij. - Ebd

1"s Ebd., 133.

1'6 Ebd. Entsprechende Artikel in „V" sollten keine trockenen stenografischen Berichte sein, sondern zeigen, "(...) welche Fragen die Historiker bewegen, wie diese Fragen gestellt und beantwortet, welche Auseinandersetzungen über sie gefuihn werden." - Ebd., $133 f$.

179 So v.a. Kiselev und Majskij. - Ebd., $134 f$ f.

178 Ebd., 135.
} 
waren entsprechend entgegengesetzte Aussagen und Wertungen zu finden. ${ }^{179} \mathrm{Zu}$ treffend hat Heer diesen Tatbestand als „bifurcation" bezeichnet: Zunehmend mehr Vertreter der Geschichtswissenschaft - nicht wie Heer, in diesem Punkt sich selbst widersprechend, schrieb, die Historiographie als Ganzes ${ }^{180}$ - begannen, vom vorgegebenen Weg abzuweichen und professionell zu arbeiten, was in diesem Fall bedeutetete: weniger von politischen Vorgaben und Erwartungshorizonten bestimmt, weniger politisch ambitioniert, sondern stärker an Quellen orientiert und sachlich entscheidend. Es entwickelte sich diejenige „Dualität des Wissenschaftlichen und des Politischen ${ }^{\text {(181 }}$, die seitdem die sowjetische Geschichtswissenschaft maßgeblich prägte. Die personelle Umsetzung in der Redaktion der Voprosy istorii zuungunsten der Antirevisionisten und die neue Offenheit und Selbstkritik der etablierten Historikerinnen und Historiker Mitte des Jahres 1960 markieren meines Erachtens den Übergang zu der Diskussionsphase der sechziger Jahre im Rahmen der von 1953 bis Anfang der siebziger Jahre sich erstreckenden Etappe der Entstalinisierung.

1.9 Heer, Politics, 117 schilderte den Fall zweier Artikel zum gleichen Thema - der Moglichkeit einer friedlichen Revolution nach dem Putschversuch des Generals Kornilov im September 1917 - in Voprosy istorii KPSS 1960, H. 3: Der Artikel A.M. Sovokins .....) is a thoughtful exploration of a new periodization of 1917, which would designate the two and a half weeks immediately following the Kornilov episode as a second period of possible peaceful revolution." Der Artikel von S.L. Titarenko hingegen , (...) is, in striking contrast, essentially a propaganda tract hammering away at the theme of party unity: historical experience appears as a device to show that only eradication of revisionism and opportunism could have achieved socialism in the USSR."

180 Heer, Politics, 116

181 Ebd. 


\section{Die sowjetische Geschichtswissenschaft in den sechziger Jahren: Professionalisierung und Dissidenz}

Die beiden nächsten Kapitel dienen dazu, den Rahmen zu verdeutlichen, in dem die geschichtsmethodologischen Diskussionen in den sechziger Jahren stattfanden. Die die Entwicklung der sowjetischen Geschichtswissenschaft in hohem Maß prägende Einflußnahme der Kommunistischen Partei der Sowjetunion erfordert zunächst die Analyse der politischen Vorgaben seitens der Partei- und Staatsfuihrung an die historische Disziplin (4.1.). Danach wird herausgearbeitet, was die Arbeit der führenden Fachzeitschriften, Voprosy istorii und Istorija SSSR, kennzeichnete und inwieweit sie von der politisch vorgegebenen Geschichtsideologie dirigiert wurde. Hierzu werden ferner die Forschungs- und Diskussionsschwerpunkte im Bereich der Geschichte der sowjetischen Gesellschaft, der Historiographie der Geschichtswissenschaft und der Geschichtsmethodologie im Allgemeinen skizziert (4.2.). Daran schließt sich die Untersuchung der in den sechziger Jahren im Zentrum der geschichtstheoretischen und -methodologischen Diskussionen stehenden Probleme: der Gegenstandsbestimmung (4.3.), der Fakteninterpretation (4.4.), der Gesetzesdefinition (4.5.) und der Debatte über Forschungsprinzipien (4.6.). 


\subsection{Geschichtsideologie. Die politischen Vorgaben zur historischen Forschung}

Mit dem 22. Parteitag der KPdSU, der von 17. bis 31. Oktober 1961 abgehalten wurde, tat Chruščev den zweiten großen politischen Schritt weg von seinem Vorgänger. Folgt man Medvedev, dann ist das nicht personalistisch formuliert: Seinen Recherchen zufolge war im Präsidium des Zentralkomitees vereinbart worden. während des Parteitags weder die Stalinfrage noch die der ,antiparteilichen“ Gruppe um Malenkov anzusprechen. ${ }^{1}$ Chruščev überraschte also nicht nur die Delegierten, sondern auch den engsten Führungskreis, als er in seiner Eröffnungsrede die jüngere Vergangenheit thematisierte. Die ihm folgenden Redner überarbeiteten ihre vorbereiteten Texte entsprechend - der 22. Parteitag entwickelte sich zum eigentlichen Entstalinisierungs-Parteitag: Noch ehe er endete, war Stalins Leichnam aus dem Mausoleum am Roten Platz entfernt und an der Kremlmauer beigesetzt worden. $^{2}$

1 Siehe Medwedew, R.: Vom XX. zum XXII. Parteitag der KPdSU. Ein kurzer historischer Überblick, in: Crusius/Wilke, Entstalinisierung, 23-49, hier $44 f$.

2 Ebd., 45f. - Nun wurden auch Städte, Plätze, Straßen usw., die noch Stalins Namen getragen hatten, umbenannt. Der 22. Parteitag war deshalb besonders wirkungsvoll, weil - anders als 1956 - alle Redetexte umgehend in den Zeitungen publiziert und von einem schon sensibilisierten Publikum aufgesogen uurden. Medvedev weiß auch davon zu berichten, daß der Chefideologe der Partei, Suslov, in den Sitzungspausen des Parteitags seinen Zorn über Chruščevs Überraschungsmanöver artikulierte; zwei andere, in der Regel zuverlässige Chronisten. Michail Heller und Aleksandr Nekrič, vermuten, daß gerade damals, in jenen Sitzungspausen des 22. Parteitags „(...) der Grundstein zu der Verschwörung gegen Chruschtschow gelegt (...)" wurde. ..Seele der Verschwörung war M.A. Suslow. Praktisch begann damit die Sabotage der Maßnahmen zur Entstalinisierung “ - Heller/Nekrich, Geschichte, 287f. Bestätigt wird die Hauptrolle Suslovs beim Sturz Chruščevs auch von Sacharow, A.: Mein Leben. München-Zürich 1991, 278f.

Michail Andreevic Suslov, 1902-1982, war die Ausnahmefigur unter den führenden Parteikadern: Er gehörte als einziger sowohl unter Stalin, als auch unter Chrušcev und Brežnev dem engsten Führungskreis an. Seit 1921 Parteimitglied, absolvierte er 1924 die Arbeiterfakultät in Moskau, 1928 das „Georgij-Plechanov"-Institut für Volkswirtschaft und anschließend das Ökonomische Institut der Roten Professur; seit den dreißiger Jahren war er in diversen leitenden Funktionen verantwortlich für zahlreiche Repressionen, seit 1941 ZK-Mitglied, von 1947 bis zu seinem Tode am 25.01.1982 ZK-Sekretär und verantwortlich für die Ideologie. Die Mitgliedschaft im Präsidium (später Politbüro) der Partei seit 1950 wurde nach Stalins Tod nur kurz unterbrochen, wohingegen er ständig ZK-Sekretär blieb. Chrušxev veranlaßte 1955 die Wiederwahl Suslovs ins Präsidium als Hauptverantwortlichen für ideologische Anleitung, wohl aus taktischen Erwägungen. Spätestens unter Brežnev der zweite Mann in der Parteihierarchie, saß Suslov allen. die auch nur punktuell von der Parteilinie abwichen, im Nacken, mitunter auch dem Außenminister A.A. Gromyko. - Siehe Lewytzkyj. B./Ju. Stroynowski (Hg.): Who's Who in the Socialist Countries. A biographical encyclopedia of 10,000 leading personalities in 16 communist countries, first edition New York-München 1978, 600; Medvedev, R.A.: Oni okružali Stalina, M. 1990, 314ff: Burlazki (= Burlackij, F.). Chruschtschow, 204ff. Falin. V.: Politische Erinnerungen, München 1993, 5 Iff passim; vgl. unten die Fußnote zu Il'iZev. 
Dieser überraschende Verlauf des Parteitags warf auch vor den Historikem ,(...) eine große Zahl vielfaltiger und wichtiger Probleme (...)" auf, wie der damalige Akademische Sekretär Evgenij Zukov ${ }^{3}$ unfreiwillig zutreffend formulierte. ${ }^{4}$ Monatelang berieten Partei-Ideologen und Historiker über die Bedeutung des Parteitags fur die Geschichtswissenschaft. ${ }^{5}$ Anders als der konservative Historiker Najdenov sich das im Vorfeld des Parteitags gedacht hatte, ${ }^{6}$ waren dabei die ,Auswirkungen des Personenkults um Stalin auf die Geschichtswissenschaft" ein sehr wichtiges Thema. In dem Leitartikel der Voprosy istorii zum „Parteitag der Erbauer des Kommunismus ${ }^{67}$ wurden nur drei solcher Auswirkungen in allgemeiner Form erwähnt: die Werke der Klassiker seien subjektivistisch, willkürlich interpretiert worden; Theorie und Wissenschaft hätten sich von der Praxis gelöst; engstirniger Dogmatismus und Buchstabengelehrtheit sowie Unduldsamkeit gegenüber allem Neuen seien aufgeblüht. ${ }^{8}$

3 Evgenij Michajlovið Zukov (23.10.1907-09.03.1980) war seit 1929 als Dozent an verschiedenen Hochschulen in Leningrad tätig, nach Erwerb des Doktortitels 1941 (der Habilitation vergleichbar) als Professor. 1941 trat Zukov in die KPdSU ein. Von 1946 an - im gleichen Jahr wurde er Korrespondierendes Akademiemitglied - besetzte er einen Lehrstuhl an der Akademie für Gesellschaftswissenschaften beim ZK der KPdSU in Moskau. 1958 wurde er Ordentliches Mitglied der AdW. Von 1957 bis 1971 leitete er das Büro der Geschichtsabteilung an der AdW der UdSSR, war also 14 Jahre lang der - formell - bedeutendste Historiker unter den Akademiemitgliedern. 1968 wurde er der erste Direktor des neu gebildeten Instituts für Allgemeine Geschichte und 1971 Vorsitzender des Nationalen Komitees der Historiker der Sowjetunion. Im November 1975 wurde er - was keinem anderen Akademiemitglied gelang - zum zweiten Mal Akademischer Sekretär. Diese drei Funktionen hatte er bis zu seinem Ableben inne. Zukov war als "Chefredakteur" auch hauptverantwortlich für die Herausgabe der "Weltgeschichte in zehn Bänden“ (M. 1955-1965) und der "Sowjetischen Geschichtsenzyklopädie“ (M. 1961-1976). Zukov war Japanologe, beschäftigte sich aber auch viel mit internationalen Beziehungen in der Neuzeit, der Geschichte des Kolonialismus und der Periodisienung der Weltgeschichte. - SIE 5, 566; BSE (III) 9, 239; Tiłkov, V.A.: Godičnoe obšcee sobranie, in: VI 1980, H. 5, 123ff; VI 1980, H. $6,188 \mathrm{f}$.

4 Zukov, E.M.: XXII s-ezd KPSS i zadaci sovetskich istorikov, in: VI 1961, H. 12, 3-13, 3.

9 Siehe die Leitartikel in der Zeitschrift Istorija SSSR: Izučenie istorii SSSR meždu XX i XXII s-ezdami KPSS, in: ISSSR 1961, H. 5, 3-31; S-ezd stroitelej kommunističeskogo obščcestva, in: ISSSR 1961, H. 6, 3-12; K novomu tvorčeskomu pod-emu! In: ISSSR 1962, H. 1, 3-15; Dvadcat' vtoroj s-ezd KPSS i podgotovka specialistov po istorii SSSR, in: ISSSR 1962, H. 5, 3-16.

6 Die Erwähnung des „Personenkults“ diente Najdenov lediglich dazu, nochmals die Richtigkeit der antirevisionistischen Beschlüsse von 1956/57 gegen Voprosy istorii zu betonen. In aller Breite dagegen bilanzierte er hölzern und fast ausschließlich nach rein quantitativen Kriterien ,(...) den Aufschwung der Geschichtswissenschaft nach dem 20. Parteitag der KPdSU (...), eine der gedeihlichsten Perioden in ihrer Entwicklung." - Najdenov, M.E.: Sovetskaja istoriceskaja nauka nakanune XXII s-ezda KPSS, in: VI 1961, H. 10, 3-24, hier 6 und 23.

7 So die übliche Umschreibung des 22. Parteitags, siehe Dvadcat' vtoroj s-ezd Kommunističeskoj partii Sovetskogo Sojuza - s-ezd stroitelej kommunizma, in: VI 1961, H. 11, 3-8; S-ezd stroitelej.

8 Ebd., 6. 
Die Diskutanten der allgemeinen Versammlung der Abteilung Geschichtswissenschaften an der Akademie der Wissenschaften am 17. und 18. November 1961 wurden konkreter. Deborin' sprach über den Zusammenhang der Verfallschung der marxistischen Klassiker einerseits und der Überhöhung der Stalinschen Arbeiten andererseits. Diese reklamierten zwar für sich, eine „Enzyklopädie des MarxismusLeninismus" darzustellen, hätten aber z.B. die Dialektik falsch dargelegt und das Gesetz der Negation der Negation unterschlagen. ${ }^{10}$ Nečkina erinnerte, daß unter Stalin wissenschaftliche Diskussionen ,manchmal" mittels "Überarbeitung" regelrecht ausgetauscht wurden." Chvostov beiklagte, die in der Stalin-Zeit entstandene „Khuft zwischen der Analyse des konkreten Materials und der Ausarbeitung theoretischer Fragen" führe bis in die Gegenwart dazu, daß viele Arbeiten an bloßem Faktenwissen, reiner Deskription und dem Mangel an neuen Schlußfolgerungen litten. ${ }^{12}$ Arcichovskij sprach über „unrichtige Vorstellungen über ganze Perioden“ der sowjetrussischen Geschichte. Prägnant und alarmierend war sein Hinweis, da B einige Folgen des „Personenkults“ in der Historiographie, ,noch vollständig unbewußt" seien. ${ }^{13} \mathrm{Am}$ ausführlichsten widmete sich M.P. Kim bei dieser Beratung und in einem Artikel für die Voprosy istorii diesem Thema. Kim verdeutlichte dabei, $\mathrm{da} B$ die Geschichtswissenschaft umfassend, von der Theorie und Methodologie. den Methoden und der Quellenannalyse, bis hin zur Behandlung einzelner Themen und der ,erzieherischen Rolle“ in der Gesellschaft beschädigt und dadurch ihre Autorität in hohem Maße untergraben worden sei. ${ }^{14}$ Im Unterschied $\mathrm{zu}$ anderen

9 Abram Moiseevic Deborin (Joffe) (1881-08.03.1963), in der Emigration Absolvent der Universität Bern, Parteimitglied seit 1928, Akademiemitglied seit 1929, spielte in der Philosophie der zwanziger Jahre eine zentrale Rolle, vergleichbar mit derjenigen Pokrovskijs in der Geschichtswissenschaft. In der polemischen Auseinandersetzung mit G. Lukács und gegen die sogenannten „Mechanizisten“ formulierte er die Grundsätze des dialektischen Materialismus, die später unter Stalin obligatorisch wurden. Gleichwohl wurden die „Deborinisten“ seit Mitte 1930 des ,menschewistischen Idealismus“ beschuldigt und repressier. Erst nach dem 20. Parteitag uurden Deborin wieder Aubeitsmöglichkeiten an der AdW gewährt. - VI 1963, H. 4, 218; Ahlberg, R.: „Dialektische Philosophie“ und Gesellschaft in der Sowjetunion, Berlin 1960; Deborin, A. N . Bucharin: Kontroversen über dialektischen und mechanistischen Materialismus. Einleitung von Oskar Negt, hg. von H. Blumenberg. J. Habermas. D. Henrich und J. Taubes. FrankfurtMain 1969; Schleifstein, J.: Zu Negts Kritik der Leninschen Widerspiegelungstheorie, in: Zur stalinistischen Philosophie. Mit Beiträgen von O. Negt, J. Schleifstein, E.Th. Mohl, A. Schmid, Hamburg 1970, 43-51; Kolakowski. L.: Die Hauptströmungen des Marxismus. Entstehung. Entwicklung. Zerfall. Dritter Band, München-Zürich, 2. Auflage 1981, 77ff; Labica, G.: Der MarxismusLeninismus. Elemente einer Kritik (erstmals französisch, Paris 1984), West-Berlin 1986, $30 \mathrm{ff}$.

10 Siehe Sovetskie istoriki obsužzajut zadači nauki v svete resenij XXII s-ezda KPSS, in: VI 1962, H. 1, 3-13, hier 9.

11 Ebd.

12 Ebd., 10.

13 Ebd., $9 f$.

14 Ebd., 8f. Siehe auch Kim, M.P.: O zadačach izučenija istoriceskogo opyta socialisticeskogo stroitel'stva v SSSR v svete rešenij XXII s-ezda KPSS, in: VI 1962, H. 2, 3-19, hier 14ff: Der "Personenkult" ${ }^{\prime}(. .$.$) engte das schöpferische Denken der Historiker stark ein, hemmte ihre In-$ itiative bei der Formulierung und Lösung neuer theoretischer Probleme der Geschichtswissen- 
Autoren erinnerte Kim auch daran, da $B$ die Entstalinisienung bereits 1953 begonnen hatte. ${ }^{15}$ Jetzt müsse die ,streng objektive, wahrhaftige Beleuchtung " geschichtlicher Tatsachen und Ereignisse die Hauptrichtung im Kampf der sowjetischen Geschichtswissenschaft gegen die „Folgen des Personenkults“ darstellen. ${ }^{16}$

Selbst wenn sich auch bei Kim im weiteren pflichtschuldige, dogmatische Formulierungen fanden, ${ }^{17}$ hatte er mit dieser Orientierung doch wieder, wie schon 1959, andere Akzente gesetzt als die Konservativen. Denn der kurz gehahtene Leitartikel in Voprosy istorii zum 22. Parteitag betonte zwar, daß dieser den Kurs des 20. auf „vollständige Liquidienung der Auswirkungen des Personenkults" fortsetzte, versuchte aber, die Historiker auf ideologische und propagandistische Aufgaben, vor allem den Kampf gegen die „,bürgerliche Ideologie“" zu orientieren. ${ }^{18}$ Für die gleiche Ausgabe der Zeitschrift verfaßte Golikov einen regelrechten Einberufungsbefehl für die Historiker: Wie jeder "Sowjetmensch", so hätten auch die Historiker ihren Platz in der ,Armee der Erbauer des Kommunismus"; die Historiker der sowjetischen Gesellschaft befänden sich, an der Hauptkampflinie der geschichtlichen Front. “19 Auch der Akademische Sekretär Žukov gehörte zu denjenigen, die nicht müde wurden, vor der ,ideologischen Amnestie“ der Feinde in den eigenen Reihen zu mahnen. ${ }^{20}$

„Wenn wir den Kampf mit dem Dogmatismus führen, (...) können wir nicht eine Minute vergessen, daß der Revisionismus die Hauptgefahr in der gegenwärtigen kommunistischen Bewegung bleibt. ${ }^{\text {"21 }}$

schaft. (...) monopolisierte faktisch das Recht. die Wahrheit aufzudecken, das 'letzte' Wort in der Wissenschaf zu sagen, (...) die Aufgaben der Gesellschaftswissenschaften wurden im wesentlichen darauf reduzien, die 'Eröffnungen' Stalins zu kommentieren, seine 'Weisheit' und 'Genialität' zu zeigen.“ Der .Personenkult" „....) schloß jeden Gedanken an die Möglichkeit theoretischer und methodologischer Fehler seitens Stalins, den man in einen 'Theorie-Gott' verwandelte, aus. (...) Viele fähige und verdiente Historiker wurden einer ungerechten Aburteilung unterzogen, als angeblich ideologisch dem Marxismus feindlich Gesonnene (...)", z.B. der "hervorragende marxistische Historiker M.N. Pokrovskij”.

is Kim. O zadačach, 12.

16 Ebd., 14.

17 Kim schloß mit den Worten: „Die Arbeiter an der ideologischen Front, unter ihnen auch die Historiker, verfügen über alle notwendigen Bedingungen für die erfolgreiche Lösung der verantwortungsvollen und wichtigen Aufgaben, die ihnen durch die Kommunistische Partei und durch das Volk auferlegt sind. Die Pflicht der Historiker ist es, alle schöpferischen Kräfte aufzubieten und einen würdigen Obolus zu der gemeinsamen Sache des kommunistischen Aufbaus beizutragen." - Ebd., 19.

18 Dvadcat' vtoroj s-ezd 1961, 7.

19 Golikov, G.N.: Na perednem krae istoričeskoj nauki, in: VI 1961, H. 11, 18-42, hier 18 und 40 .

20 Zu diesen zählte Zukov im November 1961 die Trotzkisten, rechten Opportunisten und nationalistische Abweichler; siehe Sovetskie istoriki, 8.

21 Zukov, XXII s-ezd 1961, 5. 
Der Chefideologe der Partei, Suslov, gab im Januar 1962 den Gesellschaftswissenschaftlem Empfehlungen mit auf den Weg, welche die von ihm selbst geforderte Überwindung des Dogmatismus behindern mußten: Anstatt zu ruhiger und gründlicher Analyse verfälschter Einzelfragen zu ermuntern, forderte Suslov auf, jetzt. d.h. also mit allem dogmatischen Ballast, stärker als bisher in die Breite zu gehen. propagandistisch den zunehmenden (sic) ${ }^{22}$ Angriffen des Klassenfeindes entgegenzuwirken. Erforscht werden sollten vor allem die Geschichte der KPdSU und der sowjetischen Gesellschaft, weniger historische Probleme, die „weit von der Gegenwart entfernt sind. ${ }^{23}$ Die aggressive Linie bestätigte bei der Vollversammlung der Akademie der Wissenschaften im November 1962 auch der neue Vorsitzende der Ideologischen Kommission des Zentralkomitees, der ZK-Sekretär I'’ǐev ${ }^{24}$, der sich $\mathrm{zu}$ dieser Zeit besonders in der Kampagne gegen avantgardistische und abstrakte Künstler hervortat. ${ }^{25}$ Alle Gesellschaftswissenschaften seien gefordert, die neuen theoretischen Fragen des kommunistischen Aufbaus zu erforschen, und die Geschichtswissenschaft müsse stärker als bisher die historischen Erfahrungen der Kommunistischen Partei und des Sowjetvolkes vermitteln. ${ }^{26}$ Die geschichtliche Wahrheit müsse in vollem Umfang wiederhergestellt werden. Was aber den „Personenkult“ angehe, so sei vor allem anderen zu zeigen, daß dieser

„(...) die fortschreitende Entwicklung der sowjetischen Gesellschaft nicht aufhaiten. die Natur der sozialistischen Ordnung nicht verändem, die organisatorischen, politischen und theoretischen Grundlagen der vom großen Lenin gegründeten Partei nicht ins Wanken bringen konnte. ${ }^{\text {“27 }}$

2 Das erinnert an die fatale These Stalins vom sich gesetzmäßig verschärfenden Klassenkampf nach der sozialistischen Revolution.

23 Suslov, M.A.: XXII s-ezd KPSS i zadači kafedr obščestvennych nauk, in: K 1962, H. 3; hier nach der deutschen Übertragung Suslow, M.A.: Der XXII. Parteitag der KPdSU und die Aufgaben der gesellschaftswissenschaftlichen Lehrstühle, in: SW 1962, H. 6, 569-604, hier 591f.

24 Leonid Fedorovic Il'ixev, geboren 1906, Parteimitglied seit 1924, Absolvent des Instituts der Roten Professur fur Philosophie 1937; $1953-58$ arbeitete er im Außenministerium, anschlieBend leitete er bis 1961 die ZK-Abteilung fur Propaganda und Agitation; 1961-65 ZK-Sekretär und 1962-65 Vorsitzender der Ideologischen Kommission beim ZK der KPdSU. Zwischen inm und Suslov gab es dauerhafte Kontroversen und Rivalität. Chruščev berief Il'ǐ̌ev, um Suslovs Monopol in Ideologiefragen zu brechen; nach Chrušcevs Ablösung mußte auch Il'izev weichen: von 1965 an war er stellvertretender Außenminister. - Prominent Personalities in the USSR. A Biographic Directory Containing 6,015 Biographies of Prominent Personalities in the Soviet Union. Compiled by the Institute for the Study of the USSR (Munich), New Jersey 1968, 213; Lewytzkyj/Stroynowski, Who's Who, 237; MERSH 38, 72-75.

25 Siehe Medvedev, R.: Ličnost' i epocha. Politiceskij portret L.I. Brežneva. Kniga 1, M. 1991, 104.

26 Il'ǐ̌ev, L.F.: Naučnaja osnova rukovodstva obščestva. Nekotorye problemy razvitija obšcestvennych nauk, in: K 1962, H. 16; hier nach Iljitschow, L.: Die wissenschaftliche Grundlage der Leitung der gesellschaftlichen Entwicklung. Einige Probleme der Entwicklung der Gesellschaftswissenschaften, in: SW 1963, H. 2, 113-140, hier 121-130.

27 Vgl. ebd., 131; hier zitiert nach Stroitel'stvo kommunizma i obščestvennye nauki, in: VI 1962, H. 11, 3-8, hier 5. 
Damit befand sich Il'ičev im Gleichklang mit dem ZK-Beschluß vom Juni 1956, mit dem die Konservativen um Chruščev die Wirkung von dessen sogenannter Geheimrede beim 20. Parteitag abgeschwächt hatten.

Vom 18. bis zum 21. Dezember 1962 fand nach der noch von Pokrovskij geleiteten ersten gesamtsowjetischen Historikerkonferenz $1928 / 29^{28}$ die zweite unionsweite Beratung statt. Bereits die Art der Berichterstattung war bezeichnend: in Voprosy istorii erschienen mit relativ hoher Auflage (18.100) recht oberflächliche Berich$\mathrm{te}^{29}$; erst 1964 wurde der Protokollband mit einer Auflage von nur 5.000 Exemplaren veröffentlicht. ${ }^{30}$ Auch die von der Beratung selbst ausgehenden Signale waren widersprüchlich, sie reflektierten, wie Heer es formulierte,

„a growing split among historians based upon their varying concepts of the craft, their self-identification as historians within the Soviet system, and their approaches to methodology. ${ }^{\text {c31 }}$

In seinem Eingangsreferat faßte Ponomarev die „Folgen des Personenkults“ für die Geschichtswissenschaft in drei Hauptmomenten zusammen: erstens die Herabsetzung Lenins, der Massen und der Partei einerseits, die Verherrlichung der Rolle Stalins andererseits; zweitens der unmanxistische Forschungszugang; hier nannte Ponomarev Subjektivismus und Willkür bei der Bewertung geschichtlicher Ereignisse und Persönlichkeiten; drittens die Atmosphäre des Administrierens und der unlauteren Kritik. $^{32}$ Dabei sei auch den philosophischen und methodologischen Grundlagen der Geschichtswissenschaft geschadet worden. Dies hänge damit zusammen, daß das Prinzip der Parteilichkeit dem der Objektivität „vulgär" entgegengestellt worden sei, daß der Dogmatismus zur ,Loslösung vom Leben“ geführt und so die erkenntnistheoretischen Möglichkeiten der Disziplin eingeengt habe. ${ }^{33}$ Bemerkenswert ist, daß Ponomarev den verhängnisvollen Einfluß auf die Geschichtswissenschaft, er sprach hier allerdings nur von der Parteigeschichte, schon 1931 mit Stalins Brief an die Zeitschrift „Proletarische Revolution“ beginnen sah. ${ }^{34}$ In der Anfang der sechziger Jahre stattfindenden, ansonsten recht kontroversen historiographischen Diskussion wurde dieses Datum von allen anderen übergangen und der Beginn des Dogmatismus erst mit den Bemerkungen Stalins, Ždanovs und

28 Dokumentient in Trudy Pervoj Vsesojuznoj konferencii Istorikov-marksistov. 28/XII 19284/I 1929. 2 Bände, M. 1930.

29 Vsesojuznoe Soveščanie istorikov, in: VI 1963, H. 2, 3-75.

30 Vsesojuznoe Soveščanie o merach ulučšnija podgotovki naučno-pedagogičeskich kadrov po istoričeskim naukam, 18-21 dekabrja 1962 g., M. 1964.

31 Ebd. Heer, Politics, $147 f$.

32 Ponomarev, B.N.: Istoričeskuju nauku i obrazovanie - na uroven' zadač kommunističeskogo stroitel'stva, in: K 1963, H. 1; hier nach Ponomarjow, B.: Der kommunistische Aufbau und die Aufgaben der Historiker, in: SW 1963, H. 4, 333-361, hier 338. Ebenso in Vsesojuznoe Soveščanie 1964, 19.

33 Ponomarjow, Der kommunistische Aufbau, 338; vgl. Vsesojuznoe Soveščanie 1964, 19.

31 Ponomarjow, Der kommunistische Aufbau, 339; vgl. Vsesojuznoe Sove ̌̌canie 1964, 19. Vgl. Stalin, Über einige Fragen. 
Kirovs zu den Lehrbuchentwürfen im Jahre 1934 verbunden. ${ }^{35}$ Ponomarev stellte nun dagegen fest, daß Stalin schon 1931 die Kontrolle über die KPdSU-Geschichtswissenschaft übernommen habe. ${ }^{36}$ Wer im einzelnen Stalin dabei assistierte, wer ,unduldbare Sitten" kultivierte, Fachkollegen grob beschimpfte und verleumdete, unbequeme Menschen vertrieb und ,auch physisch beseitigten" ließ, wagte Ponomarev nicht $\mathbf{z u}$ sagen; statt dessen flüchtete er sich in unpersönliche Formulierungen ${ }^{37}$ Namen nannte Ponomarev im Zusammenhang des noch immer virulenten „Widerstands gegen den Geist der Beschlüsse des 20. Parteitags“: P.B. Žibarev und M.D. Stucebnikova ${ }^{35}$, M.V. Natmeladze und N.I. Sturua ${ }^{39}$, V.F. Ionkin una A.G. Cernych ${ }^{40}$ mußten sich diesen Vorwurf gefallen lassen. Bei der Skizzienung der weiteren Aufgaben der Geschichtswissenschaft im Sinne des neuen Parteiprogramms hob Ponomarev hervor, daß der Geschichtsmethodologie und -philosophie mehr Aufmerksamkeit als bisher geschenkt werden müsse. Aufgrund der langjährigen Reduktion geschichtstheoretischer und -methodologischer Fragen auf den historischen Materialismus war der Zusatz interessant, wonach der historische Materialismus theoretische Grundlage aller Gesellschaftswissenschaften sei, daß

"(...) aber jede, auch die Geschichtswissenschaft, (...) auch ihre eigenen theoretischen Fragen" habe."

Ponomarev hatte mit seinen Worten augenscheinlich einige konservative Historiker ermutigt, sich offener als bislang zu äußern. So sprach \%ukov im Plenum über ein ,psychologisches Trauma“, welches den Kadern der historischen Disziplin durch den „Personenkult“ zugefügt worden sei. Systematisch sei den Menschen einge-

35 Siehe etwa Netschkina, Zur Periodisienung: Najdenov, M.E.: Problemy periodizacii sovetskoj istorižeskoj nauki, in: VI 1961, H. 1, 81-96; Sovetskaja istoričeskaja nauka 1962. Stalins Einflußnahme 1934 dokumentierte Oberländer, Sowjetpatriotismus, hier v.a. $125 f$.

36 Ponomarjow, Der kommunistische Aufbau, 339. Zum gleichen Ergebnis kam übrigens Barber, Soviet historians, 142: „Stalin's letter to Proletarskaya revolyutsiya marked the beginning of a new epoch in Soviet historical sholarship. The violent public controversies that had characterised the preceeding years ceased, orthodox interpretations of historical questions were established, and a new institutional structure for the historical profession was created." - Wie bereits oben ausgefuihrt, vertritt der Autor der vorliegenden Studie die Auffassung, daß die Etappe der Disziplinienung und Stalinisierung der sowjetischen Geschichtswissenschaft 1929 begann. Vgl. Kapitel 2 und 3.2.4.

37 Ponomarjow, Der kommunistische Aufbau, 339f, vgl. den russischen Text in Vsesojuznoe Sovešcanie 1964, 20.

38 Žibarev, P.B/M.D. Stučebnikova: Obzor istoðnikov istorii KPSS. Kurs lekcij, M. 1961

39 Natmeladze, M.V.N.I. Sturua: Iz istorii rabočego klassa Gruzii (1921-1958 gg.), Tbilisi 1961.

40 Ionkin, V.F./A.G. Cernych: O pervom etape razvitija sovetskoj istoričeskoj nauki, in ISSSR 1960, H. 5, 75-81.

41 Ponomarjow, Der kommunistische Aufbau, 343. Hervorhebung im Original. Als Beispiele solch ,theoretischer Fragen“ nannte Ponomarev die Klassenkampftheorie, die These von der schöpferischen Rolle der Volksmassen in der Geschichte und das Problem der Periodisienung der Geschichte. - Ebd. 
schärft worden, daß einzig Stalin vollwertige marxistische Arbeiten verfassen könne. ${ }^{42}$ Daher rühre die für die Wissenschaft so verderbliche Zaghaftigkeit des Denkens. Um das Niveau zu heben, sei es deshalb notwendig, das Primat der Theorie in geschichtlichen Forschungen wieder herzustellen. ${ }^{43}$ Isaak Minc ${ }^{44}$ ereiferte sich über die dogmatischen Publikationen, die Ponomarev schon kritisiert hatte, weil in ihnen über die Folgen von Stalins Eingreifen in das Leben der Wissenschaftler hinweggegangen würde:
„Auch Sie wissen - nicht nur wir, die Vertreter der älteren Generation, wissen dies - da $B$ nach der Veröffentlichung des Briefs von Stalin die Vernichtung der Kader unter den Historikem begann. Viele Historiker wurden diffamiert, dann repressiert; viele hat man gezwungen, 'Fehler' zuzugeben. (...) Und diese Periode der Vemichtung von Kadern wird ausgegeben als Periode des Kampfs für die Reinheit des Marxis- mus-Leninismus! $!^{\text {44s }}$

Nečkina ergänzte die Ausführungen über die Stalinzeit mit dem Hinweis auf die schreckliche Atmosphäre, die damals (auch) unter Historikern entstanden sei. Jeder sei vom nächsten isoliert gewesen, habe mit der Angst gelebt, der Freund, mit dem man strittige Fragen erörterte, könne in Schwierigkeiten kommen. ${ }^{46}$ Mit den Worten von Marx und Dante wünschte Nečkina sich und dem Auditorium die Geschichtswissenschaft als eine Disziplin, in der die "Seele stark" sei und die Angst keinen Rat erteilen könne. ${ }^{47}$ Denn zu sehr sei die Forschung beeinträchtigt worden.

42 ,Fast zwanzig Jahre lang - die Periode der Bewußtseinsbildung einer ganzen Generation unserer Menschen - wurde das selbständige Denken im Bereich der Theorie bei "einfachen Sterblichen' in Zweifel gezogen. Selbständig zu denken wurde den Menschen aberzogen." Siehe Vsesojuznoe Soveš̌anie 1964, 56.

43 Ebd

44 Izaak Izrail'evic Minc, 03.02.1896-05.04.1991, Parteimitglied seit 1917. Teilnehmer der Revolution und des Bürgerkriegs 1917/18, deren Erforschung er sich sein Leben lang widmete. 1926 Absolvent des Historischen Instituts der Roten Professur, Schüler M.N. Pokrovskijs. Seit 1946 Akademiemitglied hatte er gleichwohl während der antisemitischen Kampagne gegen „Kosmopolitismus“ 1948/49 etliche Angriffe und Emiedrigungen zu überstehen. Von 1954 an mit dem Grad eines „Höheren wissenschaftlichen Mitarbeiters“ im Institut für Geschichte an der Akademie der Wissenschaften; seit 1962 Vorsitzender des Problemrates zur Erforschung der Oktoberrevolution. Für seine dreibändige „Geschichte des Großen Oktobers“ (M. 1967-73) erhielt er 1974 den Lenin-Preis. Der Lenin-Orden war ihm bereits zur Vollendung des siebten Lebensjahrzehnts im Jahr 1966 verliehen worden. - SIE 9, 475f; ISSSR 1966, H. 2, 238; BSE (III) 16, 301f: Nekriz, Otrešis' ot stracha, 50ff.

\footnotetext{
4s Vsesojuznoe Soveštanie 1964, 75.
}

46 Ebd., 89. - Anschauliche Schilderung dieser Atmosphäre bei Leonhard. W.: Die Revolution entläßt ihre Kinder, Köln-Berlin 1955. Wie prägend dies war, wird evident bei Leonhards gemischten Gefuihlen, mit denen er im Juli 1987 erstmals nach 42 Jahren wieder in die Sowjetunion flog. Gefühle, die einem unbelasteten UdSSR-Reisenden $1985 \mathrm{ff}$ völlig fremd waren. Siehe Leonhard, W.: Spurensuche. Vierzig Jahre nach „Die Revolution entläßt ihre Kinder“, Köln 1992, $21 \mathrm{ff}$.

47 Siehe Vsesojuznoe Sovešcanie 1964, 92. 
Die Historiker seien von der Methodologie und der Geschichte ihres eigenen Faches getrennt worden. Dies gelte es jetzt zu überwinden. ${ }^{48}$

Vom Juni-Plenum des Zentralkomitees der Partei im Jahre 1963, welches sich hauptsächlich mit ideologischen Fragen beschäftigte ${ }^{49}$, gingen recht drohende Signale aus. In erster Linie waren diese Teil der Kampagne gegen unbotmäßige Künstler und Literaten, sie richteten sich aber auch gegen die Geschichtsdisziplin. Die allgemeinen „Hauptrichtungen der ideologischen Arbeit ${ }^{400}$, hieß es in Voprosy isturi, würden alich die Aufgaben der Geschichtswissenschaft. bestimmen. Chruš $\check{c}_{\text {ev }}$ hatte beim Plenum diejenigen Literaten, die alle möglichen „Gemeinheiten“ über das Land herauskramen würden, als ,Agenten der bürgerlichen Ideologie in der sowjetischen Welt" bezeichnet und keinen Zweifel darüber gelassen, daß diese mit allen Mitteln bekämpft würden. Daß dies vollständig auch für die Geschichtswissenschaft zutreffe, teilte Voprosy istorii den Lesem des Leitartikels mit. ${ }^{51}$ Die Fehler eines Historikers waren expressis verbis nicht mehr ein nur wissenschaftliches, sondern vielmehr ein hochbrisantes politisches Problem: Wer die ,majestätische, heroische Vergangenheit" nicht ausreichend hervorhebe oder Arbeiten beschreibenden, faktografischen Charakters verfasse, negiere nicht nur prinzipielle methodologische Positionen, sondern auch den Kampf gegen die ideologischen Gegner, an dem teilzunehmen jeder Historiker verpflichtet sei. ${ }^{52}$

48 Ebd, 89f: - „Offensichtlich ist es sehr wichtig, die Historiker mit der Methodologie zu vereinen, ihnen alle Rechte und Möglichkeiten zu geben, marxistische Soziologie zu studieren und sich auf dem Gebiet der marxistischen Geschichtsphilosophie zu äußern. (...) Sehr wichtig ist, daß diese neue Disziplin (die Historiographie der Geschichte der Geschichtswissenschaft: J.H.) von der Jugend studiert wird, damit der zurückgelegte Weg der Geschichtswissenschaft mehr und mehr zum Eigentum unserer Gesellschaft wird."

49 SPR 5, M. 1964, 7-25.

so ,Dies sind: die Formierung der kommunistischen Weltanschauung bei den Werktätigen, die Überwindung der Überreste des Vergangenen im Bewußtsein und Verhalten der Sowjetmenschen, die Erziehung der aktiven und bewußten Erbauer des Kommunismus im Arbeitsprozeß, die Erhöhung des Bildungs- und des kulturellen Niveaus des Volkes, die Erziehung des Volkes im Geiste des sowjetischen Patriotismus und des sozialistischen Internationalismus, der entschlossene Kampf gegen Antikommunismus und alle Formen der bürgerlichen Ideologie." Zadači istoričeskoj nauki v svete rešenij ijun'skogo Plenuma CK KPSS, in: VI 1963, H. 8, 3-18, hier 7.

s1 Ebd., 9. - Entschlossen, mit analogen ,ungesunden Erscheinungen“ in der eigenen Disziplin Schluß zu machen, präsentierte sich auch der Leitartikel in Istorija SSSR; siehe Povysit' rol' istoričeskoj nauki $v$ ideologiceskoj rabote, in: ISSSR 1963, H. 4, 3-9, hier 9.

52 Zadači 1963, 9 und 13. - Nicht anders Poljakov, Ju.A.: Kommunističeskoe vospitanie i istorija, in: VI 1963, H. 7, 3-18, hier besonders 6: „Ja, wir müssen die Wahrheit schreiben, müssen über Schwierigkeiten, Fehler, Unzulänglichkeiten schreiben. Aber notwendig ist die wahrhaftig wissenschafliche, von parteilichen Positionen geleitete Kritik, und keine Krittelei, die auf billige Sensation aus ist. Das Wesentliche darf nicht vergessen werden: zu sehen, daß das Heroische die Seele unserer Geschichte ist." Ausfiihrliche Darlegung und Kritik des Inhalts von Poljakovs Artikel bei Marko, Sowjethistoriker 1964, 49-55. Markos Fazit: „Wissenschaft im eigentlichen Sinne, Wissenschaft um der Erkenntnis und der Wahrheit willen, ist außerhalb dieses Horizonts.“- Ebd., 54. 
Kennzeichnend für die frühen sechziger Jahre war jedoch, daß die historische Zunft mit politischen Drohungen nicht mehr einfach ruhigzustellen war. Die wissenschaftspolitische Obrigkeit mußte den virulenten Problemen Raum geben. Das erste Signal zur gleichsam offiziellen Anerkennung der wachsenden Bedeutung methodologischer Fragen von Natur- und Gesellschaftswissenschaften gab die erweiterte Präsidiumssitzung der Akademie der Wissenschaften am 18. Oktober 1963..$^{53}$ Il'ičev leitete dort in seinem mehrstündigen Vortrag die Wichtigkeit dieser Thematik aus vier Ursachengruppen ab: der ,stürmischen“ Entwicklung der Wissenschaft selbst, gemeint war die wissenschaftlich-technische Revolution; den Bedürfnissen der Praxis, also den Erkenntnis- und vor allem Legitimationsinteressen der kommunistischen Führung des Staates; der Entwicklung der marxistischen Philosophie; schließlich aus der Notwendigkeit des ideologischen Kampfes heraus. ${ }^{54}$ Anders als bis dahin in der Historiographie üblich, führte Il'ičev die Vernachlässigung der Geschichtsmethodologie auf das ,Auftreten“ gegen Pokrovskij zunück; eben seitdem seien geschichtsmethodologische Fragen ganz aus dem Gesichtsfeld der Historiker verschwunden. ${ }^{\text {ss }}$ Die daraus erwachsene Kluft zwischen allgemeiner Theorie, Geschichtsmethodologie und empirischem Material gelte es jetzt zu überwinden. ${ }^{56}$ Erklärtes Anliegen der Referenten dieser Sitzung, Fedoseev, Francev, Zukov, Minc, Il'ičev u.a., war, einen Impuls zu geben für die Bearbeitung der methodologischen Fragen in den Einzelwissenschaften. ${ }^{57}$

Diesem Ziel diente die erweiterte Sitzung der direkt dem Akademiepräsidium angegliederten Sektion Gesellschaftswissenschaften in den ersten Januartagen $1964 .^{58}$ Die beiden Akademiemitglieder P.N. Fedoseev und Ju.P. Francev waren jedenfalls bemüht, diese Diskussion in doppelter Hinsicht zu ,führen": Lang unterdrückte Probleme - Gegenstand der Geschichtswissenschaft, geschichtliche Gesetzmäßig-

Das ZK-Plenum und der Artikel Poljakovs sind Ausdruck dessen, daß die KPdSU-Führung unter Chrušcev seit 1960/61 den bei Stalin - in Negation des Geschichtbildes Pokrovskijs - gepflegten Sowjetpatriotismus wiederbelebten. Oberländer brachte dies in Zusammenhang mit dem neuen Parteiprogramm von 1961, dem Generationenwechsel, dem Versuch, die Jugend und jüngere Erwachsene stärker ideologisch zu binden sowie mit dem Konflikt mit China; vgl. Oberländer, Sowjetpatriotismus. 9 und 35f.

53 Metodologičeskie problemy nauki. Materialy zasedanija Prezidiuma AN SSSR, M. 1964; Methodologische Probleme der Naturwissenschaften und Gesellschaftswissenschaften. Sitzung des Präsidiums der Akademie der Wissenschaften der UdSSR vom 18. Oktober 1963, in: SW 1964, H. 2, 197-206 (Übersetzung des Berichts in: K 1963, H. 16).

34 Il'ǐev, L.F.: Metodologižeskie problemy estestvoznanija i obščestvennych nauk, in: Vestnik Akademii nauk SSSR 1963, H. 11, hier nach der deutschen Übersetzung - lljitschow, L.F.: Methodologische Probleme der Naturwissenschaften und der Gesellschaftswissenschaften, in: SW 1964, H. 3, 217-268, hier $218 \mathrm{ff}$.

ss Ebd., 267.

s6 Ebd. - Vgl. Methodologische Probleme, 200.

37 Siehe Methodologische Probleme

58 Istorija i sociologija. M. 1964. Der Protokollband enthält auch die nur schriftlich eingereichten Stellungnahmen, insgesamt 35 Beiträge von dreiundzwanzig Historikern, acht Philosophen und vier weiteren Gesellschaftswissenschaftlern. 
keiten, Objektivität und Parteilichkeit, Formationstheorie und Epochenbestimmung, die Verbindung von Geschichtswissenschaft und gesellschafticher Praxis packten sie nun wirklich an, und sie ermutigten gerade die Generation, die bei Pokrovskij gelernt hatte, selbst initiativ zu werden. Sie gaben allerdings auch schon deutlich die Richtung der Lösungsansätze vor. Die „Entlarvung der Fehler“ Pokrovskijs wollten sie nicht länger als ,wichtigen Markstein" in der Entwicklung der sowjetischen Geschichtswissenschaft im positiven Sinne verstanden wissen. Vielmehr sei inzwischen allen ,absolut klar", daß Pokrovskij ein ,hervorragender sowjetischer Historiker" gewesen sei. ${ }^{59}$ In der notwendigen Kritik des „Personenkults" dürften die Errungenschaften der Geschichtswissenschaft nicht negiert werden. Niemand könne sich aber umgekehrt mit diesen zufrieden geben und die noch bestehenden „Hindernisse und Ablagenungen“ ignorieren. Interdisziplinär sei an die unaufschiebbare Aufgabe heranzugehen,

„(...) allseitig, unter der Bedingung schöpferischer wissenschaftlicher Diskussionen die gesamte Forschungsarbeit dem Leben anzunähern und die methodologischen Probleme der Geschichtswissenschaft tiefgreifend zu bearbeiten. “60

Dementsprechend forderte der am Ende des ersten Beratungstages gefaßte Beschluß alle Forschungsinstitutionen auf, sich mehr als bisher auf geschichtstheoretische und -methodologische Probleme zu konzentrieren ${ }^{61}$ Die Eigeninitiative von Historikern in methodologischen Seminaren wurde ausdrücklich begrüßt und ihre Unterstützung seitens der Institutsleitungen angemahnt. ${ }^{62}$

Noch im gleichen Jahr wurde Chruščev entmachtet und von L.I. Brežnev an der Parteispitze und A.N. Kosygin in der Staatsführung ersetzt. Aufgrund der Fehler Chruščevs und des Drucks, den seine konservativen und stalinistischen Gegner unter deren Ausnutzung umso leichter auf ihn ausüben konnten ${ }^{63}$, war im Herbst

\footnotetext{
39 Siehe Istorija 1964, 7f.

60 Ebd., 8.
}

61 Die folgenden Themen wurden genannt: die Wechselbeziehung des Historischen und Soziologischen. die Korrelation allgemeiner Gesetzmäßigigkeiten des welthistorischen Prozesses und der Besonderheiten einzelner Länder, die Periodisienung der Geschichte, der Wirkungsbereich spezifischer Gesetzmäßigkeiten, die Rolle der Klassen und des Klassenkampfs in der Menschheitsentwicklung, die Rolle der Volksmassen und der Persönlichkeit in der Geschichte, die Wechselbeziehung des Bewußten und Spontanen. Gesetzmäßigkeiten der Entwicklung gesellschaftichen Denkens, die Kritik idealistischer, subjektivistischer Konzeptionen in der Geschichtsmethodologie. - Istorija 1964, 338.

62 Ebd., 339.

63 Siehe dazu Heller/Nekrich, Geschichte, 288ff; Burlazki (= Burlackij, F.), Chruschtschow, 272ff; Barsukov, N.: Kak byl smeščen N.S. Chnušcev, in: Trudnye voprosy istorii. Poiski, razmyšlenija, novyj vzgljad na sobytija i fakty, M. 1991, 222-239.

Ein weiteres, möglicherweise mitentscheidendes Motiv der Verschwörer nannte der frühere stellvertretende Außenminister der DDR Peter Florin im Juli 1991 im Gespräch mit seinem ehemaligen Schulfreund Wolfgang Leonhard: „Beim Sturz Chruschtschows haben die DDR und die Deutschland-Frage eine wichtige Rolle gespielt. Chruschtschow sollte ja im November 1964 zu einem Besuch in die Bundesrepublik Deutschland kommen. In der DDR-Führung wurde damals 
1964 der Boden dafür ,psychologisch ${ }^{604}$, d.h. hinsichtlich der Massenstimmung bestens vorbereitet. ${ }^{65} \mathrm{Ob}$ damit wirklich das, gute Jahrzehnt" in der Geschichte der sowjetischen Gesellschaft schon beendet war, soll hier dahingestellt bleiben. ${ }^{66}$ Für die geschichtswissenschaftliche Disziplin jedenfalls gilt die Feststellung von Heer:

„The amazing fact was that very little happened in historiography. “67

Doch es ist zu differenzieren: Öffentlich und in den Seminaren wurde auf spannende Weise weiter diskutiert, Kontroverses noch publiziert - dazu später. In den Führungsetagen der Partei und den wissenschaftichen Institutionen wurden allerdings, man kann sagen, in aller Ruhe, personelle Verändenungen vorgenommen ${ }^{68}$ sowie inhaltliche Konzepte vorbereitet, die nicht sofort, sondern mittel- und langfristig die Geschichtswissenschaft von neuem beeinflußten und beeinträchtigten. Die inhaltliche Umorientierung betrieb allen voran der neue Instrukteur der Historie, Trapeznikov. ${ }^{69}$ Unmittelbar nach seiner Amtsübernahme drängte er führende Gesellschaftswissenschaftler, unter ihnen die Historiker Žukov, Sacharov, Kim, Gal'kin, Rybakov, Chvostov, Gaponenko, Nečkina, Poljakov u.a. zur Mitarbeit in vier Kommissionen, in denen innerhalb von zwei Monaten ein Dokument vorbereitet werden sollte über den planmäßigen Bedeutungszuwachs der gesellschaftswissenschaftichen Disziplinen. ${ }^{10}$ Eine in diesem Kontext am 23. Juni 1965 abgehaltene Historiker-Beratung deutete den neuen alten Trend an: Zurück ins Jahr 1934 sehnten sich einige der Redner, denn alles in den damaligen Regierungsbeschlüssen

befürchtet. er könnte gegenüber der Bundesrepublik weitgehende Konzessionen machen und damit die Existenz der DDR gefährden (...)." - Leonhard. Spurensuche, $301 f$.

ot So Heller/Nekrich, Geschichte. 290.

6s Einer der Berater Chruš̌evs erinnert sich: „Chruschtschow, so dachte nicht nur ich damals, hat alles furr seinen Sturz getan.“- Burlazki (= Burlackij, F.), Chruschtschow, 271.

66 „Die Jahre der Hoffnung auf eine Demokratisierung (...) waren vorüber. Damit endeten auch die Jahre der Verwirnung auf seiten des Staates. Nun brach die Epoche des sowjetischen Konformismus an. " - Heller/Nekrich, Geschichte, 290.

67 Heer, Politics, 131

68 So z.B. die Verbannung Il'ið̌evs aus dem ZK-Sekretariat ins Außenministerium. Seine Stelle nahm Trapeznikov ein; vgl. die folgende Fußnote.

69 Sergej Pavlovix Trapeznikov, geboren 1912, Parteimitglied seit 1931, wurde beim 23. Parteitag 1966 ZK-Mitglied. Er galt als Gefolgsmann Brežnevs, mit dem er Anfang der 30er Jahre politisch zusammenwirkte und einen Autounfall hatte, an dessen Folgen Trapeznikov zeitlebens litt. Der mehrjährige Krankenhausaufenthalt rettete ihn allerdings vor Repressionen. Unter Brežnev wurde er 1965 Leiter der ZK-Abteilung für Wissenschaft und Lehranstalten, 1966 (bis 1970) war er Vorsitzender der Kommission für Erziehung. Wissenschaft und Kultur im Unionsrat des Obersten Sowjet der UdSSR. In diesen Funktionen prägte er auch die Entwicklung der Geschichtswissenschaft maßgeblich und sehr negativ mit. Akademische Ehren wurden ihm lange verwehrt: 1966 erreichte er bei der Wahl der Korrespondierenden Mitglieder der Akademie nicht die erforderliche Zwei-Drittel-Mehrheit; dies gelang ihm erst 1976. - Lewytzkyj/Stroynowski, Who's Who, 632; Medvedev, Lixnost', 104f, 126, 143ff; Sacharow, Mein Leben, $340 \mathrm{ff}$

70

Siehe CChSD f. 5, op. 35, d. 212, 86 und 152-154. 
Gesagte sei „sehr richtig, genau, wahr" gewesen." Andere forderten ganz offen die ,scharfe Wende“. Heimat - rodina - müsse von der Geschichtswissenschaft wieder als erster wesentlicher Wert vermittelt werden. ${ }^{72}$ Als einziger stellte sich Kim gegen den Strom, freilich ohne den Rahmen des Marxismus-Leninismus zu verlassen. Kim sprach von einer ,kritischen Zeit“, welche die Geschichtswissenschaft durchlebe, und er nannte dafür vier Ursachen: die „Fadheit der Sprache“, (vor allem) Subjektivismus und kon-junkturstina, ungenügender Zugang zu Dokumenten und "Geschichte ohne Historismus“. ${ }^{73}$ Offen sprach Kim aus, daß aus politischen Gründen oft die Wahrheit nicht geschrieben würde ,(...) oaer wir berichtigen sie 'ein klein wenig' “ ${ }^{74}$ Nach dieser Beratung im Kreise der Historiker traf man sich im größeren Rahmen, zusammen mit Philosophen und Ökonomen, wieder Mitte November 1965. Der Ausruf des Mitverfassers des „Kurzen Lehrgangs“, Kuckin, kann als Fazit dieser Sitzung übernommen werden:

„Man muß ein Ende machen mit der Fehlersuche bei Stalin. “7s

Im Widerspruch zu den seit 1953 sukzessive entwickelten Positionen sah nun Trapeznikov „das ganze Elend“ der Gesellschafts- und Geschichtswissenschaften wieder darin, daß unter dem Deckmantel der Stalin-Kritik ganze Etappen der Geschichte revidiert worden seien. ${ }^{76}$ Aufmerksame Zeitgenossen registrierten den Kurswechsel. So etwa Michail Gefter ${ }^{77}$, der bei der Parteiversammlung im Ge-

1 So A.M. Sacharov, der bedauerte, daß jene Beschlüsse nicht erfullt worden seien und neuerdings Pokrovskijs Fehler wieder vergessen würden. Analog äußerte sich I.S. Gal'kin. Siehe Stenogramma sovešcanija po voprosam istorii SSSR i vseobł̌cej istorii (23.Juni 1965), in: CChSD f. 5, op. 35, d. 212, 86-151, hier $94 \mathrm{ff}$ und $101 \mathrm{ff}$.

12 So P.A. Zilin und K.K. Dubina: letztere rechtfertigte in einem bösen Seitenhieb auf die sowjetischen Kriegsgefangenen die nach deren Rückkehr aus Deutschland gegen sie verübten Repressionen. Für die ,Liebe zur Heimat" müßten alle bis zum Letzten einstehen; „Hauptsache Überleben" - das dürfe nicht die Botschaft sein. Siehe ebd., $112 \mathrm{ff}$.

73 Ebd., 98ff.

94 Ebd., 100.

15 Siehe Stenogramma zasedanija Ideologičeskoj komissii pri CK KPSS po voprosu razvitija obšxestvennych nauk. 15-18 nojabrja 1965 g., in: CChSD f. 5, op. 35, d. 210, 3-346, hier 178

9 Mit der gleichen Intention auch Trapeznikov, S.P.: Marksizm-leninizm - nezyblemaja osno va razvitija ob̌̌čestvennych nauk, in: Pravda v. 08.10.1965; vgl. Neretina, Istorija, 155f. - Es entsprach einer offenen Solidarisierung mit den Stalinisten, wenn Trapeznikov und Pospelov Chrušcev wegen seines taktischen Verhaltens zu dem ZK-Beschluß vom Juni 1956 „Über die Überwindung des Personenkults und seiner Folgen" kritisierten; ebd., $89 f$ und 205.

77 Michail Jakovlevic Gefter, geboren am 24.08.1918, ein ,sehr origineller Historiker, Schüler von A.L. Sidorov (...), den einige im Spaß, aber vielleicht auch ernsthaf 'Ideengenerator' nannten. Als Mensch war er kompliziert, und sein Weg war nicht einfach." So erinnert sich Nekric an Gefter. Als wissenschaftlicher Mitarbeiter am Institut für Geschichte an der AdW der UdSSR leitete er 1964 bis 1968/69 die „Sektion zur Bearbeitung methodologischer Probleme der Geschichte“ (dazu unten mehr). In dieser Zeit „(...) erwies er sich nicht nur als fähiger Historiker, sondern auch als Mensch, der sehr klare antistalinistische Positionen bezog" (Nekrič). Svetlana Neretina, die ihn durch die Zusammenarbeit in dieser Sektion gut kennt, schilderte ihn als „Revolutionär" und „politischen Aktivisten“, und sagte: „In der Sektion bei uns wußten einfach 
schichtsinstitut am 30. Oktober 1965 eine mutige Rede gegen Trapeznikovs Wendeerklärung hielt. Gefter griff den schon zum Allgemeinplatz verkommenen Ruf nach ,schöpferischen“ Diskussionen auf, konkretisierte aber, daß solche Diskussionen gleichberechtigt und frei geführt werden müßten, was bedeute, daß es keine Unterschiede geben dürfe, in Dienstgraden und Titeln", und daß Resultate weder vorherbestimmt noch den Diskutanten aufgezwungen werden dürften. ${ }^{78}$ Gefter plädierte dafür, von neuem die Entwicklung des marxistischen Denkens, das Erbe Lenins, dessen wissenschaftliche Arbeitsmethoden und vor allem die Probleme des Voluntarismus und der Demokratie in dieser Wissenschaftsgeschichte zu untersuchen, denn gerade dies seien keine bloß theoretischen Fragen, sondern ,reale Phänomene in der Geschichtswissenschaft". Gerade um der Vorwärtsentwicklung der Geschichtswissenschaft willen müsse Demokratie zum Forschungsthema werden. ${ }^{79}$

Als zu Beginn des Jahres 1966 in Voprosy istorii ein Leitartikel zum 40-jährigen Bestehen der Zeitschrift veröffentlicht wurde, schien die Welt im Sinne der Reformer wieder in Ordnung zu sein. In abwägender Manier wurde hier über Pokrovskij und die Revisionisten um Burdžalov geschrieben, die Vernachlässigung der Geschichtsmethodologie beklagt und gefordert, sich an Aktualität, Parteilichkeit, Schöpfertum und Professionalität zu orientieren. ${ }^{80}$ Auf Trapeznikov muß der Leitartikel renitent gewirkt haben, denn Parteiprogramm und Parteigrößen wurden nicht bemüht. Statt dessen beriefen sich die "Leitartikler" auf Friedrich Engels. Ausfuihrlich wurde Engels' Erläuterung des Wesens des Geschichtsprozesses unter dem Gesichtspunkt der Vielfalt von Einzelwillen zitiert, was eine schlau verpackte, aber deutliche Aufforderung an die Historiker war, nicht nur die große Linie des Geschichtsverlaufs, dessen Endresultat und die Wirkung der vermeintlichen oder tatsächlichen Haupttriebkräfte zu beachten, sondern die ,....) unendliche Gruppe von Kräfteparallelogrammen (...)“ zu analysieren und dabei zu berücksichtigen, daß

alle, wer unter uns 'Lenin' ist. Das war Michail Jakovlevic.“ Zehn Jahre nach der Zerschlagung der Methodologie-Sektion fiel Gefter wieder in Ungnade, als einige Mitarbeiter der von ihm mitgeleiteten Zeitschrift Poiski verhaftet wurden. In Folge dieser Auseinandersetzungen trat Gefter 1981 aus der KPdSU aus. Seine hauptsächlichen Arbeitsgebiete waren: Geschichte des russischen Imperialismus, marxistische Geschichtstheorie, Geschichtsmethodologie. - Nekric. Orešis' ot stracha, 243 und 342f; Neretina, S.S.: Interv'ju s Neretinoj Svetlanoj Sergeevnoj (am 08.04.1992 mit Roger Markwick und dem Autor), Typoskript (25 Seiten), hier, 14f; Gefter, M.Ja.: Iz tech i etich let, M. 1991, 184ff; Pantin, I.K.: Rossija v mire: istoričeskoe samouznavanie (Razmyšlenija v svjazi s knigoj M.Ja. Geftera „Iz tech i etich let“), in: VF 1993, H. 1, 20-30.

78 Gefter, M.Ja.: Vystuplenie na partsobranii Instituta istorii po dokladu A.M. Rumjanceva ob itogach Oktjabr'skogo Plenuma CK KPSS 1965 goda. 30.10.1965, Typoskript (13 S.) in: NA 2, 5f. - Zur Bedeutung der Parteiorganisation im Geschichtsinstitut der AdW in den sechziger Jahren während des Vorsitzes von V.P. Danilov, siehe Markwick, A Resurgent Intelligentsia, 290ff.

79 Gefter, 4f. Am Ende seiner Rede rief Gefter dazu auf, ein „demokratischeres und flexibleres System verschiedener Zugänge zu theoretischen Fragen" zu schaffen. - Ebd., 12f.

80 Zurnal i istoričeskaja nauka, in: Vl 1966, H. 1, 3-14. 
- in einem je zu bestimmenden niedrigen oder hohen Maße - jeder der Einzelwillen zur Resultante beiträgt und ,(...) insofern in ihr einbegriffen " ist. ${ }^{81}$

Die Auswertung des wahrscheinlich langweiligsten Parteitags der KPdSU $1966^{82}$ in Voprosy istorii und Istorija SSSR war allerdings wieder geprägt von der Zeitenwende. Die Pensionierung des Initiators der Entstalinisierung und die geschmeidige Gegenoffensive von Suslov und Trapeznikov forderten ihren Tribut. Niemand konnte sich den Veränderungen gegenüber neutral und gleichgültig verhalten. In Voprosy is:orii warde dem Druck im wesentlichen narhgegeben: Kein Wort war nun mehr zu finden über Stalin, den „Personenkult" und seine Folgen. ${ }^{83}$ Die Historiker wurden aufgerufen, populäre Lehrbücher zu schreiben, soziologische Analysen des kommunistischen Aufbaus zu betreiben und dauerhaft Revisionismus und Dogmatismus zu bekämpfen. Als wesentliche Schlußfolgerung des 23. Parteitags wurde das Prinzip der Parteilichkeit, des klassenmäßigen Herangehens an die Geschichte bezeichnet. ${ }^{84}$ Im Unterschied dazu wurde in Istorija SSSR zu Beginn des Leitartikels nicht nur an das Oktober-Plenum des Zentralkomitees von 1964, sondern auch an die Parteitage 1956 bis 1961 erinnert. ${ }^{85}$ Jede einseitige Geschichtsinterpretation wurde abgelehnt. Als Gegengift des ausdrücklich kritisierten „Personenkults" empfahl dieser Leitartikel nicht das Parteilichkeitsprinzip, sondern vielmehr ,schöpferische Diskussionen, genossenschaftliche Kritik und Selbstkritik“.

„Wissenschaft kann sich ohne Meinungskampf nicht entwickeln, und das heißt, auch nicht ohne Polemik. (...) Ohne Polemik ist eine auf hohem wissenschaftlichen Niveau stehende Historiographie und Bibliographie undenkbar. Die historische Monographie und der wissenschaftliche Aufsatz können ebenfalls nicht ohne Polemik auskommen." ${ }^{\text {s6 }}$

Ähnliches wiederholte sich 1967 anläßlich des 50. Jahrestags der Oktoberrevolution. Bei Istorija SSSR wurde das vor allem in den sechziger Jahren Geleistete nüchtern bilanziert, ohne Forschungsdefizite zu verschweigen und ohne die Wis-

81 Engels, F.: an Joseph Bloch. 21./22. September 1890, in: MEW 37, 462-465, hier 464. Engels' hier zu findende Warnung vor einem ökonomistischen Verständnis der materialistischen Geschichtsauffassung, auf die Fedoseev und Francev im Januar 1964 noch hingewiesen hatten, wurde im Leitartikel nicht berücksichtigt; vgl. ebd., 463 und 465; Zurnal 1966, 10; Istorija 1964. 10.

82 So Roy Medvedev über den 23. Parteitag der KPdSU, der vom 29. März bis 08. April 1966 stattfand, und mit dem Brežnev seine Position behaupten und ausbauen konnte. - Medvedev, Lixnost', 109ff und 125ff.

83 Bol '̌ie zadaxi, in: VI 1966, H. 6, 3-8.

84 Ebd., besonders 5 und 8.

8s Nakaz XXIII s-ezda KPSS, in: ISSSR 1966, H. 3, 3-9, hier 3.

86 Ebd., 8. - Das unzulängliche Niveau der Polemiken und der beleidigende Ton in den Diskussionen wurden beklagt. Mir scheint evident zu sein, daß sich dies nicht gegen kritische, zu Revisionen bereite Historiker richtete. $\mathrm{Vgl}$. ebd., $7 f$. 
senschaftler allzu sehr zu gängeln. ${ }^{87}$ Der ,schädliche Einfluß des Personenkults auf die Historiker" wurde nicht verschwiegen, und jeder Wissenschaftler sah sich ermahnt, daß es von seiner theoretischen Qualifikation, Parteilichkeit und seinem professionellen Können abhänge, die noch bestehenden Hindernisse zu überwinden. ${ }^{88}$ Anders der Leitartikel in Voprosy istorii. Wie man sich die weitere Entwicklung der Geschichtswissenschaft hier vorstellte, wurde deutlich gemacht durch die positive Bewertung der Richtungsentscheidungen in den dreißiger Jahren, die hinter schon Erreichtes wieder zunückfiel. ${ }^{89}$ Wie schon in dem Leitartikel der Voprosy istorii zum 23. Parteitag wurden die verhängnisvollen Auswirkungen der Stalinschen Machtausübung auf die Historie auch hier minimalisiert. Statt dessen wurde eine neue Geschichtsklittenung geboren: Die ,subjektivistischen“ Fehler Burdžalovs u.a. seien in Folge des ZK-Plenums im Oktober 1964 beseitigt worden! Die administrative Intervention von 1957 gegen die revisionistischen Anstrengungen sollte vergessen gemacht werden. ${ }^{90}$

Aus ihren Fachzeitschriften erfuhren die Vertreter der historischen Zunft von den Wegweisungen der Geschichtsideologen. Keinen geringeren Eindruck als diese Papiere dürfte der konfrontative Kurs der politischen Fühnung gegen Dissidenten hinterlassen haben, der seit 1966 Konflikte in neuer Qualität nach sich zog. Zu erwähnen sind die politischen Prozesse gegen die Schriftsteller Sinjavskij und Daniel im Februar 1966 sowie gegen den Dichter Galanskov und den Bürgerrechtler Ginzburg zwei Jahre später. Bekanntlich waren dies nur die prominenten Fälle. ${ }^{91}$ Seit Mitte der sechziger Jahre gab es, vor allem in den großen Städten, eine breit-

87 S0-letie Oktjabrja i izučenie otecestvennoj istorii, in: ISSSR 1967, H. 2, 3-10; Otečestvennaja istorija v SSSR za 50 let, in: ISSSR 1967, H. 6, 3-15.

${ }_{88}$ Oecestvennaja istorija $1967,14$.

89 ,Bewertet man die sowjetische Historiographie in der ersten Hältte der 30er Jahre, ohne die - sehr bedeutenden - Schattenseiten ihrer Entwicklung zu verhehlen, (...) muß man klar sehen, daß der Umschwung, der von den Historikern unter Führung der Partei zu Beginn der 30er Jahre verwirklicht worden ist, eine zutiefst progressive Sache für die Geschichtswissenschaft. für die Erforschung unserer vaterländischen Geschichte war." - Izucenie otecestvennoj istorii za 50 let Sovetskoj vlasti, in: VI 1967, H. 11, 3-18, hier, 12.

9 Ebd., 17.

91 Andrej Donatovix Sinjavskij emigrierte nach mehreren Jahren der Haft 1973; Julij Markovið Daniel, Jahrgang 1925, starb 1988; Jurij Galanskov, Jahrgang 1939, starb 1972 in einem sowjetischen Arbeitslager; Aleksandr Ginzburg wurde 1979 aus der UdSSR abgeschoben. - Zu diesen Fällen und zum Gesamtzusammenhang siehe Lewytzkyj, B.: Politische Opposition in der Sowjetunion 1960-1972. Analyse und Dokumentation, München 1972; Gerstenmaier, C.: Die Stimme der Stummen. Die demokratische Bewegung in der Sowjetunion, Stuttgart 1971, 83ff; Beyrau, D.: Sowjetische Intelligenz und Dissens, in: Beyrau, D./W. Eichwede (Hg.): Auf der Suche nach Autonomie. Kultur und Gesellschaft in Osteuropa. Bremen 1987, 21-52; ders., Anderes Denken, Dissens und Opposition 1956 bis 1986, in: Ferenczi, C./B. Löhr $(\mathrm{Hg}$ ): Aufbruch mit Gorbatschow? Entwicklungsprobleme der Sowjetgesellschaf, Frankfurt/Main 1987, 196-224; ders., Die russische Intelligenz in der sowjetischen Gesellschaf, in: Geyer, Die Umwertung, 188-209; Eichwede, W.: Abweichendes Denken in der Sowjetunion, in: GuG 1987, H. 1, 39-62; Nekrix, Otrešis' ot stracha; Sacharow, Mein Leben, 289ff. 
gefächerte Aktivität kritischer Einzelpersönlichkeiten, kleiner oppositioneller Gruppen, von Selbstverlagen ${ }^{22}$ u.a., die nicht die „Erobenung der Macht" anstreb-

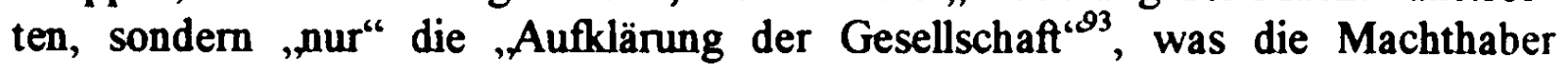
gleichwohl als Bedrohung ihrer Existenz wahrnahmen. Nichts schien gefährlicher zu sein als zu denken. ${ }^{94}$ So war es kein Zufall, daß der Historiker Aleksandr Nekrič nach der Veröffentlichung seiner fundierten Monographie ,22. Juni 1941“ im Jahr 1965, in der er sich kritisch zur Stalinschen Außen- und Kriegsfuihrungspolitik äuBerte, auch in den Sog der Repressionen geriet. ${ }^{95}$ Trapeznikov, der im Auftrag des Zentralkomitees der Parte1 über die Entwicklung des Geschichtsinstituts zu wachen hatte, erkannte in der ,Affäre Nekric“ zum zweiten Mal die Unbotmäßigkeit vieler Historiker an eben diesem Institut. 1966 schon waren Trapeznikovs Ambitionen, Korrespondierendes Akademiemitglied zu werden, nicht von der erforderlichen Mehrheit unterstützt worden. Im Fall von Nekrič hinderte die von den Repräsen-

92 Instruktiv zur Bedeutung der Samizdat-Zeugnisse für die sozialwissenschaftiche Theoriebildung: Schlögel, K.: Literatur der Dissidenz als Ansatz einer Theoriebildung zur sowjetischen Gesellschaft. Ein Diskussionsbeitrag, Köln 1982 (=: Berichte des BOIS 31-1982); vgl. Tökes, R.L. (Hg.): Dissent in the USSR. Politics, ideology, and people, Baltimore-London 1975, 233-325.

93 So Eichwede, Abweichendes Denken, 44ff, besonders 49.

94 Der parteilose, seit den fünfziger Jahre stets kritisch sich artikulierende Mediävist Aaron Jakovlevið Gurevix erfuhr nach einer Parteiversammlung im Geschichtsinstitut Ende der sechziger Jahre, in der auch von ihm die Rede war, von einem Vertrauten, der daran teilgenommen hatte, warum der dort anwesende ZK-Vertreter ihn, Gurevič, für ,gefährlich" halte: „Er denkt", hatte der Mann aus dem ZK-Apparat geantwortet. Davon erzählte A.Ja. Gurevic dem Autor am 17.12.1990 in Moskau. Bereits in jungen Jahren solidarisierte sich der Schüler des bekannten Mediävisten Neusychin mit Isaak Minc, als dieser 1948/49 in der antisemitischen Kampagne gegen "Kosmopolitismus" angegriffen wurde. Wegen seiner jüdischen Abkunft und seiner $\mathrm{Zi}$ vilcourage wurden ihm trotz zahlreicher, auch international anerkannter Veröffentlichungen die hohen akademischen Ehren verweigert. - Nekrix, Otrexis' ot stracha, 52f; FAZ Magazin vom 29.04.1993, Heft 687, 21.

95 Aleksandr Moiseevic Nekrix (1920-31.08.1993), arbeitete von 1950 bis 1976 am Institut für Geschichte (seit 1968: für Algemeine Geschichte). Er habilitierte sich 1963. Nach monatelangen Auseinandersetzungen, in deren Verlauf Nekrix viele Anfeindungen, aber auch Solidarität von Kollegen erfahren hatte, forcierte das Komitee für Staatssicherheit schließlich nach einem Artikel in „Der Spiegel“ vom 18. März 1967 den Druck gegen Nekric, der dann im Juni 1967 aus der Partei ausgeschlossen wurde. Danach hatte Nekrið jahrelang unter Beschränkungen bei Publikationsvorhaben, dem Entzug der Reiseerlaubnis, Teilnahmeverbot an internationalen Historikerveranstaltungen in der Sowjetunion und anderen Schikanen zu leiden. Nach der Emigration im Juni 1976 arbeitete er im Russischen Forschungszentrum der Universität Harvard. Welch großen Eindruck diese Auseinandersetzung bei allen Beteiligten hinterlassen haben mag, läßt eine Episode aus dem Jahr 1987 erahnen: Als der Historiker Dašicev seine Überlegungen zu einer neuen außenpolitischen Konzeption-der UdSSR vorstellte, wurde ihm die "Wiederbelebung von Nekritschewismus" vorgeworfen. - Nekric, Otreక̌is" ot stracha, $211 \mathrm{ff}, 300 \mathrm{ff}$; vgl. seine zusammen mit Michail Heller verfaßte „Geschichte der Sowjetunion“, 1981; Daschitschew, W.: Aus den Anfängen der Revision der sowjetischen Deutschlandpolitik. Ein Dokument zur Deutschen Frage aus dem Jahre 1987, in: Aus Politik und Zeitgeschichte. Beilage zur Wochenzeitung Das Parlament, B 14/94 v. 08.04.1994, 36-46, 38; „Delo A.M. Nekriða“ (Iz istorii gonenij na sovetskuju intelligenciju), in: Kentavr 1994, H. 4, 94-114. 
tanten der ,Neuen Richtung ${ }^{\circ 6}$, von den Teilnehmern der Sektion zur Geschichtsmethodologie unter der Leitung von Michail Gefter ${ }^{97}$ und von anderen kritischen Historikem (auch im Parteikomitee!) maßgeblich mitgeprägte Stimmung Trapeznikov an dem harten Durchgreifen, das er sich zweifelsohne wünschte. Daher ist es nicht übertrieben, hinsichtlich der Teilung des Geschichtsinstituts 1967/68 von der persönlichen Rache Trapeznikovs zu sprechen. Seit 1956 war wiederholt über die Reorganisation des Geschichtsinstituts nachgedacht worden. Im Zusammenhang mit der „Affäre Nekrix“" konnte nun Trapeznikov das Zentralkomitee davon überzeugen, daß das Historische Institut ,unverwaltbar" geworden sei und geteilt werden müsse. Es entstanden die Institute für Allgemeine Geschichte und für die Geschichte der UdSSR ${ }^{98}$ Die von Michail Gefter geleitete Methodologiesektion, das wichtigste Diskussionsforum für Gesellschaftswissenschaftler in der zweiten Hälfte der sechziger Jahre und ein „Katalysator vieler geschichtswissenschaftlicher Richtungen", wurde in das Institut für Allgemeine Geschichte integriert. ${ }^{100}$ Der Tatbestand, daß die Problematik ,marxistisch-leninistische Methodologie der Geschichtswissenschaft" dem Institut für Allgemeine Geschichte und nicht demjenigen für Geschichte der UdSSR zugeordnet wurde, zeigte ein weiteres Mal das geringe Interesse der politischen Führung an der Entwicklung einer Theorie und Methodologie zur Geschichte der sowjetischen Gesellschaft. ${ }^{101}$

Die Reorganisation, die vortrefflich genutzt werden konnte, um kritische Arbeitskollektive zu trennen, war in vollem Gange, als im Frühjahr 1968 die Ereignisse in der Tschechoslowakei die Gemüter zu bewegen begannen. Ob die im Juni 1968 im Selbstverlag verbreiteten „Gedanken über Fortschritt, friedliche Koexistenz und geistige Freiheit" von dem Physiker Andrej Sacharov, ${ }^{102}$ die weltweites Aufsehen erregten, ${ }^{103}$ auch in der Historikerzunft kursierten und Hoffnungen auf wirkliche Reformen verstärkten? Falls ja, dann währte das Hoffen allenfalls kurz: Mit den militärischen Aktionen in der Tschechoslowakei im August $1968^{104}$ negierte die sowjetische Führung nicht nur den realen gesellschaftlichen Versuch Dubceks und den Utopieentwurf Sacharovs, sondern auch alle alternativen Gedanken in der so-

96 Siehe Kapitel 4.2.2.
97 Siehe Kapitel 4.2.4.
$98 \quad$ Siehe Nekrič, OtreY̌is' of stracha, 318 und 337f, V Central'nom Komitete KPSS, in: VI 1969, H. 4, 3f.

99 So Neretina, Istorija, 150.

100 Siehe ebd., 149ff und 155ff, V Central'nom Komitete, 3f. Zur weiteren Kampagne in den frühen siebziger Jahren siehe Kapitel 5.1.

$101 \mathrm{Vgl}$. V Central'nom Komitete, 3f.

102 Sacharow, A.D.: Gedanken über Fortschritt, friedliche Koexistenz und geistige Freiheit, FrankfurtMain 1968; vgl. Sacharov, Mein Leben, 307ff.

103 So Eichwede, Abweichendes Denken, 46.

104 Nekrix, OtreX̌is' ot stracha, 308ff; Heller/Nekrich, Geschichte, 312ff, Hoensch, J.K.: Geschichte der Tschechoslowakei, 3. Auflage, Stuttgart 1992, $165 f f$. 
wjetischen Geschichtswissenschaft. $1968^{105}$ bekräftigte die sowjetische Führung ihre Entscheidung gegen Alternativen und Meinungspluralität im Sozialismus. Die neue Lage nutzte Trapeznikov umgehend zu einem noch härteren Kurs: Die Methodologiesektion wurde 1969 doch noch aufgelöst. Weitere mißliebige Wissenschaftlerinnen und Wissenschaftler wurden in zum Teil fachfremde Bereiche oder vorzeitig in den Ruhestand versetzt, um die als potentiell systembedrohend wahrgenommenen Theorie- und Methodologiediskussionen zu beenden und um die Kollektive auseinanderzureißen. ${ }^{106}$

Die Auseinandersetzungen waren lange noch nicht vorüber, als ein Leitartikel in Voprosy istorii bereits Normalität und Wohlgefallen suggerierte: Die Schaffung der beiden neuen Akademieinstitute wurde als ,noch ein Beweis der Sorge“ der KPdSU um die Geschichtswissenschaft bezeichnet. ${ }^{107}$ Die ausfuihrliche Darlegung der weiteren Forschungsaufgaben stand bereits ganz im Zeichen der herannahenden 100. Wiederkehr des Geburtstags Lenins. ${ }^{108}$ So wurde auch die anvisierte „Ausarbeitung einer marxistisch-leninistischen Konzeption der vaterländischen Geschichte" schon in der Projektion auf eine neue Stufe in der ausufernden LeninExegese, der sogenannten „Leniniana“, reduziert. ${ }^{109}$ Angesichts der Umstände, in denen dieser Leitartikel erschien, und der Perspektiven, die er „eröffnete“, hatte es einen tieferen, düsteren Sinn, daß der in der Überschrift des Leitartikels gewählte russische Ausdruck, ,neue Ufer" (novye rube $̌ i$ ) wörtlich ,neue Grenzen" bedeutet.

105 Zur Bedeutung der Ereignisse in diesem Jahr für die europäische und weltweite Entwicklung vgl. den Diskussionsbeitrag von Wallerstein, I.: Die posthegemoniale Ära, in: Taz v. 24.12.1990, 8-10.

106 Neretina, Istorija, 155ff; Nekrič, Otrešis' ot stracha, $318 \mathrm{f}$.

107 Novye nubeži sovetskich istorikov, in: VI 1969, H. 8, 3-16, hier 5.

108 Siehe auch Navstrexu istoričeskoj date, in: ISSSR 1969, H. 1, 3-7.

109 Novye rubeži, $7 \mathrm{f}$. 


\subsection{Die allgemeine Entwicklung der historischen Disziplin}

Was machten die Historikerinnen und Historiker aus dem, was ihnen die Parteiund Staatsführung vorgab? Inwieweit konnte sich die historische Zunft von den politischen Forderungen lösen, um stärker den Ansprüchen der Wissenschaft zu genügen? Um dies zu klären, werden im folgenden die quantitative und qualitative Entwicklung der zentralen Fachzeitschriften, vor allem der Voprosy istorii und der Istorija SSSR, dargelegt sowie die Historiographie der Geschichte der sowjetischen Gesellschaft, der Geschichte der sowjetischen Geschichtswissenschaft und der Geschichtsmethodologie untersucht.

\subsubsection{Die Fachzeitschriften}

Generell ist zu sagen, daß die sowjetische Geschichtswissenschaft in den sechziger Jahren einen enormen Ausbau in quantitativer Hinsicht erfuhr, mit dem einige vergleichbare Fortschritte der füfziger Jahre fortgesetzt und erweitert wurden. ${ }^{1}$ Ausdruck dessen waren u.a. die zahlreichen neuen Periodika, die seit Ende der fünfziger Jahre die Informationsgrundlage der historischen Zunft verbesserten. ${ }^{2}$ Hinweise auf die schnell wachsenden Zahlen von Studierenden und Forschenden finden wir beispielsweise im Rahmen einer in Istorija SSSR ausgetragenen Diskussion über die Nutzung von Archivmaterial. Demnach kamen Mitte der sechziger Jahre jährlich mehr als füfmal so viele Benutzer in die Lesesäle der staatlichen Archive als vor 1955. ${ }^{3}$ Das Problem, dem die Fachzeitschrift einige Artikel widmete, wurde darin gesehen, daß viele der Leserinnen und Leser zum ersten Mal Archivmaterial benutzten und darin ganz unerfahren seien. So würden die Archivalien oft über-

1 Der Aufschwung der historischen Disziplin war freilich eingebettet in den quantitativen Ausbau des gesamten Wissenschaftsbetriebes, vor allem der Akademie-Institutionen. Das drükken beispielsweise die wachsenden Zahlen der Korrespondierenden und der Ordentlichen Akademiemitglieder aus: Die Zahl der Korrespondierenden Mitglieder nahm von 1950 bis 1960 um funfzig, von 1960 bis 1970 um zwanzig Prozent zu. Die Zahl der akademiki nahm in den füfziger Jahren um siebzehn Prozent, in den sechziger Jahren aber um $51 \%$ zu. - Petrovskij, A.B.I L.K. Semenov/V.S. Malov: Kadry Akademii. Sostav, struktura, dinamika, in: Vestnik AN SSSR 1990, H.11, 37-49, hier 39f.

2 Hervorzuheben sind darunter die Fachzeitschrift für Militärgeschichte, Voenno-istori eskij zurnal (1959ff), das Blatt für Parteigeschichte, Voprasy istorii KPSS (1957ff), das Periodikum für neuzeitliche Geschichte, Novaja i novejsaja istorija (1957ff), das Journal fur Slawisten, Sovetskoe slavjanovedenie (1965f) und die Mitteilungen der Staatlichen Archivverwaltung, Sovetskie archivy (1966ff). - Ocerki 1985, 104-109.

3 Etwa dreißigtausend Leserinnen und Leser sollen in der ersten Hälfte der sechziger Jahre jährlich die Staatsarchive besucht haben. - Gindin, I.F./L.E. Sepelev: Protiv nekritiCeskogo i proizvol'nogo ispol'zovanija archivnych dokumentov, in: ISSSR 1964, H. 5, 74-91, hier 74f. 
schät $Z$, ohne da $B$ in ausreichendem $M a ß$ auf deren Inhalte, auf andere Quellen und die Fachliteratur geachtet würde. ${ }^{4}$

Die beiden Redaktionen von Voprosy istorii und Istorija SSSR mußten sich den offiziellen Angaben zufolge in quantitativer Hinsicht bescheiden geben. Dem gestiegenen Diskussionsbedürfnis der Fachhistoriker und dem wachsenden öffentlichen Interesse an den Geschichtsdiskussionen entsprach nur die Auflagenentwicklung bei Voprasy istorii nach 1964 einigermaßen: Die angegebene Zahl der Exemplare sank bis 1964 stetig, bevor sie in der zweiten Hälfte der sechziger Jahre wieder ordentlich anstieg und sich bei etwa dreißigtausend Exemplaren einpendelte. ${ }^{s}$ Istorija SSSR konnte die Spitzenwerte aus den füfziger Jahren nicht halten; die Auflagenhöhe schwankte das ganze Jahrzehnt hindurch zwischen sieben- und zehntausend. ${ }^{6}$

Das Redaktionskollegium der Voprosy istorii hatte mit dem Chefredakteur Truchanovskij einen ruhenden Pol gefunden. Unter seiner Leitung kam es in den sechziger Jahren nur zu kleineren personellen Verändenungen, meist aus Alters- und Gesundheitsgründen. ${ }^{7}$ Bei Istorija SSSR ging es unruhiger zu: Zwei Chefredakteure folgten dem - wie oben mehrfach deutlich wurde - verhältnismäßig aufgeschlossenen M.P. Kim, und zweimal änderte sich die Zusammensetzung der Redaktion in größeren Maßstäben. Dabei kamen 1967 auch einige Vertreter der ,Neuen Richtung" der Oktoberrevolutionsforschung ${ }^{8}$ und andere moderat-revisionistisch eingestellte Historiker zum Zuge.

4 Siehe ebd.; vgl. Grunt, A.Ja.: V podderžku predloženij I.F. Gindina i L.E. Sepeleva, in ISSSR 1965, H. 1, 229-232; Kuznecov, 1.I.: O proizvol'nom obrašcenii s archivnymi dokumentami, in: ISSSR 1966, H. 3, 229-231.

3 Ende 1961 sank die Auflagenzahi erstmals unter 20.000, rutschte Anfang 1964 weiter auf 13.700 ab. Die Auflage uurde erstmals wieder beim Oktoberheft 1964, also nach der Entmachtung Chruščevs, angehoben. Anfang 1967 und 1969 wurden die höchsten Auflagenstärken angegeben, 30.000 bzw. 31.150. - Siehe VI 1961, H. 9, 224; 1964, H. 1, 224; H. 10, 224: 1967, H. I, $224 ; 1969$, H. 1, 224.

6 Siehe ISSSR 1961, H. 1, 2; 1962, H. 1, 2; 1964, H. 1, 2; 1967, H. 1, 240; 1969, H. 1, 224

, Die größte Veränderung fand Mitte 1965 ohne erkennbaren politischen Grund statt: sechs Mitglieder, Lavrov, Levkovskij, Naroxnickij, Ryženko, Smirnov und Selestov verließen die Redaktion, fünf Historiker kamen neu hinzu: R.T. Achramovic, I.V. Dudinskij, M.P. Kim, A.S. Cernjaev und L.K. Skarenkov (als stellvertretender Chefredakteur). - Im November 1967 starb Viktor Ivanovic Sunkov (Nekrolog in: VI 1967, H. 12, 210-212); Anfang 1968 schied Skarenkov wieder aus. I.D. Koval'čenko kam bald darauf ins Kollegium; Mitte 1969 wurde E.M. "/ukov Redaktionsmitglied. Nach dem Ausscheiden von Trjapicyn und Vsevolod Michajlovič Kulakov (Nekrolog in: VI 1969, H. 10, 217f) hatte die Redaktion Ende der sechziger Jahre dreizehn Mitglieder. - Siehe VI 1965, H. 7, 224; 1968, H. 1, 224; 1968, H. 2, 224; 1969, H. 5, 224; 1969, H. $6,224$.

Zur „Neuen Richtung“ der Oktoberrevolutionsforschung siehe unten Kapitel 4.2.2.

9 Anfang 1961 löste Vasilij Dmitrievi飞 Moxalov, der noch unter Stalin Vorsitzender der Parteiorganisation des Geschichtsinstituts gewesen war, Kim als Chefredakteur ab. - Močalov warnte 1948 Nekric andeutungsweise vor der „antikosmopolitischen Kampagne“ und mahnte 
Unter Truchanovskij wurden in Voprosy istorii in den sechziger Jahren zwanzig Leitartikel veröffentlicht. Elf davon hatten rein politischen Charakter, waren aus politischem Anla $B$ geschrieben und hatten fast ausschließlich politischen Inhalt. ${ }^{10}$ Die übrigen neun Leitartikel dienten der wissenschaftspolitischen Einweisung und dem historiographischen Überblick. Sie thematisierten entweder die Arbeit und das Profil der Zeitschrift selbst ${ }^{11}$ oder suchten neue Forschungsschwerpunkte zu begründen. ${ }^{12}$ So forderte Mitte 1962 (sic!) ein Leitartikel mehr Aufmerksamkeit für die Geschichte der sowjetrussischen Arbeiterklasse. ${ }^{13}$ Ein nennenswertes historiographisches Erbe aus vorrevolutionärer Zeit gab es auf diesem Gebiet nicht. Vor allem Pankratova hatte, angeregt von ihrem Lehrer Pokrovskij, sozialgeschichtliche Untersuchungen der russischen und sowjetischen Arbeiterklasse etabliert. ${ }^{14}$ Erst mit Beginn der sechziger Jahre kam es bei diesem Forschungsthema zu einem wirklichen Aufschwung, der von einer größeren Anzahl nachrückender Spezialisten

ihn, „im Hintergrund zu bleiben“. Während der Parteiversammlung des Geschichtsinstituts, die dem 20. Parteitag der KPdSU 1956 gewidmet war, wurde Mocalov als eifriger „kul'tist“, Anhänger des Stalinkults, und als einer der Autoren der offiziellen Stalinbiographie angegriffen. Mit Močalov kamen S.S. Dmitriev, V.V. Mavrodin, A.A. Preobrał̌enskij und P.G. Ryndzjunskij ins Kollegium. Ein Jahr später verstärkten L.K. Skarenkov, der Mitte 1965 bis Anfang 1968 auch in der „VI"-Redaktion war, und V.N. Jakovcevskij das Redaktionskollegium. - Im Frühjahr 1966 erklomm Jurij Aleksandrovic Poljakov den Chefsessel, den er bis Ende des Jahrzehnts innehatte. Poljakov gehört, wie etwa Pavel Volobuev und Ivan Koval'čenko, zu der Historikergeneration, die nach der Oktoberrevolution, aber vor dem .großen Umschwung" 1928 geboren und in der Zelt schärfster Repressionen, der Vorkriegsphase und während des Krieges ausgebildet wurden. Ihre Lehrer waren in der Regel die Schüler Pokrovskijs, z.B. Minc, Pankratova, Neckkina. Poljakov wurde am 18.10.1921 in Tałkent geboren, absolvierte 1945 die Historische Fakultät der Staatlichen Lomonosov-Universität in Moskau und trat im gleichen Jahr in die KPdSU ein. Er spezialisierte sich auf die Geschichte der Oktoberrevolution, des Bürgerkriegs, des Wiederaufbaus und der Bauernschaft 1959 wurde er Leiter der 1954 gebildeten Abteilung für die Geschichte der sowjetischen Gesellschaft am Geschichtsinstitut der AdW. Er habilitierte sich 1965, wurde 1966 Korrespondierendes Akademiemitglied und im gleichen Jahr Chefredakteur der Istorija SSSR. Im Jahr 1970 übernahm er eine Professur an der Akademie für Gesellschaftswissenschaften beim ZK der KPdSU. - L.V. Milov wurde Poljakovs Stellvertreter bei Istorija SSSR. 1967 verließen Mavrodin, Moxalov, Ryndzjunskij, Skarenkov und Jakovcevskij die Redaktion und acht neue Mitglieder kamen hinzu: Ju. V. Vorob’ev, V.E. Poletaev, G.A. Cypkin, V.Z. Drobižev, zwei Repräsentanten der "Neuen Richtung“ der Oktoberrevolutionsforschung. P.V. Volobuev und A.Ja. Grunt, sowie der auch international anerkannte Spezialist für die Geschichte des Zweiten Weltkriegs. A M. Samsonov. - Nekrið̌, Otrexis ot stracha, 37, 73f, 142; SIE 11, 392; BSE (III) 20, 327: VI 1971, H. 12, 116-118; ISSSR 1961, H. 1, 2; 1962, H. 1, 2; 1966, H. 4, 2; 1967, H. 1, 240; 1967, H. 6, 2.

10 Zu diesen Artikeln siehe Kapitel 4.1.

"Siehe oben in Kapitel 3.2. und in 4.1

12 K XXV Meždunarodnomu kongressu vostokovedov, in: VI 1960, H. 7, 3-12 informierte über den 25. Internationalen Kongreß der Orientalisten.

13 Bol'̧̧ie vnimanija izučeniju istorii rabočego klassa SSSR, in: V1 1962, H. 6, 3-16.

1. Siehe Ignatenko, T.A.: Izučenie istorii rabocego klassa SSSR v Institute istorii Kommunističeskoj akademii pri CIK SSSR (1929-1935 gg.), in: Istorija i istoriki. Istoriograficeskij ex̌egodnik 1973, M. 1975, 5-32, 11 und 25f: Ozerki istorii istorizeskoj nauki v SSSR, tom 4, M. 1966, 398ff; Ocerki 1985, 246. 
getragen wurde, und in dessen Zusammenhang jener Leitartikel zu lesen ist. ${ }^{15} \mathrm{Im}$ Herbst des gleichen Jahres informierte der redaktionelle Beitrag über die Arbeit an der sechsbändigen „Geschichte des Großen Vaterländischen Krieges der Sowjetunion". ${ }^{16}$ Auch hier waren gewaltige Forschungsdefizite zu überwinden, denn bis Ende der fünfziger Jahre war der Kriegsredner Stalin der einzige „Historiker" des Krieges geblieben. ${ }^{17}$ Ende 1964 war ein Leitartikel über die historische Forschung an den Hochschulen zu lesen. Darin kam zum Ausdruck, daB die tradierte Arbeitsteilung zwischen den Akademien als reinen Forschungsstätten und den Hochschulen als Lehr- und Ausbildungszentren korrigiert wurde. ${ }^{18}$ Zwar blieben die Geschichtsinstitute der Akademie der Wissenschaften bis zum Ende der UdSSR Forschungseinrichtungen ohne Lehraktivität, aber die Hochschulen und Universitäten respektive deren Professoren und Dozenten profilierten sich doch zunehmend auch als publizierende Geschichtsforscher. ${ }^{19}$

In Istorija SSSR erschienen in neun Jahren, von Anfang 1961 bis Ende 1969 vierzehn Leitartikel. ${ }^{20}$ Das waren bis auf eine Ausnahme Artikel, in denen Parteitage,

is Vgl. Ivanov, L.M.: Sostojanie i zadači izučenija istorii proletariata Rossii, in: VI 1960, H. 3 , 50-74; Matjugin, A.A.: Nekotorye voprosy izučenija istorii sovetskogo rabočego klassa in: VI 1960, H. 6, 102-116; Skaratan, O.I.: Metodologiとeskie aspekty izučenija istorii sovetskogo raboxego klassa, in: VI 1966, H. 4, 3-15; Bataeva, T.V.: Istoriograficeskie raboty o sovetskom raboxem klasse, in: VI 1969, H. 4, 153-160; Senjawski, S.L. (= Senjavskij, S.L.)/W.B. Telpuchowski (= Telpuchovskij, V.B.): Die Arbeiterklasse der UdSSR, Berlin 1974 (zuerst russisch 1971), 26ff; Dittrich, G.: Sowjetische Publikationen zur Geschichte der Arbeiterklasse der UdSSR, in: BzG 1973, H. 6, 1026-1040; ders., Die sowjetische Historiographie zur Geschichte der Arbeiterklasse der UdSSR in der Übergangsperiode 1917-39. Entwicklungen und Ergebnisse, theoretisch-methodologische Positionen und Probleme, in: JbG 17, Berlin 1977, 267-315; Meyer, Gert: Industrialisierung. Arbeiterklasse und Stalinherrschaft in der UdSSR, in: Das Argument 106, Berlin 1977, 844-859, hier 854.

16 Osnovnye problemy tret'ego toma „Istorii Velikoj Otě̌estvennoj vojny Sovetskogo Sojuza“, in: VI 1962, H. 10, 3-20.

17 Siehe Bonwetsch, B.: Der „Große Vaterländische Krieg“ und seine Geschichte, in: Geyer, Die Umwertung, 167-187, hier 168: „Eine wirkliche Beschäftigung mit dem Krieg setzte erst unter Chruščev ein, vor allem seit dem eigentlichen Entstalinisierungsparteitag von 1961. Die Kriegsgeschichte wurde zu einem integralen Bestandteil der Entstalinisierung. “ Das sechsbändige Werk aus der Chrušxevzeit, 1962-68 auch in Deutsch erschienen, blieb Bonwetsch zufolge bis zum Ende der UdSSR „die anspruchsvollste sowjetische Darstellung" des Zweiten Weltkrieges aus sowjetischer Sicht. - Ebd.

18 Naučno-issledovatel'skaja rabota po istorii v vyš̌ej łkole, in: VI 1964, H. 11, 3-12.

19 Spiegel dessen sind u.a. die Vestniki - Informationsblätter - der Universitäten. z.B. der Vestnik der Moskauer Staatsuniversität, „Reihe Geschichte“, oder auch die in Buchform vorgelegten Arbeitsberichte von Hochschulen, z.B. die TMGIAI, Moskau, und MIVIN, Tomsk. - Vgl. auch Fedosov, I.A.: Istoriceskaja nauka v Moskovskom universitete (1956-1965 gg.), in: VI 1966. H. 10, 134-144.

20 Wenn man berücksichtigt, daß VI monatlich, ISSSR nur zweimonatlich erschien, wird erkenntlich, daß in ISSSR bezogen auf die Zahl der Ausgaben (VI: 120 Hefte in zehn Jahren: ISSSR: 54 Hefte in neun Jahren) deutlich mehr Leitartikel standen als in VI. Nur in jeder sechsten Ausgabe der VI stand ein Leitartikel (16,6\% aller Hefte), aber in jeder vierten der ISSSR $(25,9 \%$ aller Hefte). 
Jahrestage und Historikerkonferenzen zum Anlaß für die politische Unterrichtung der Historikerinnen und Historiker genommen wurden. ${ }^{21}$ Der einzige Leitartikel historiographischen Charakters rief dazu auf, die Geschichte der Partisanenbewegung im „Großen Vaterländischen Krieg“ zu schreiben. ${ }^{22}$ Wie bei der allgemeinen Geschichte des Krieges ging es auch hier um ein Desiderat der Forschung, zu dem im weiteren Verlauf der sechziger Jahre tatsächlich eine Reihe von Publikationen vorgelegt wurden ${ }^{23}$ Inhaltlich wurde allerdings die aus Stalins Tagen stammende „Fiktion eines spontanen Volkskampfes ${ }^{\text {(24 }}$ von neuem kolportiert. ${ }^{25}$

\subsubsection{Zur Geschichte der sowjetischen Gesellschaft}

Die Fachzeitschriften, Forschungsberichte und historiographischen Studien geben ein beredtes Zeugnis davon, daß die Entwicklung der sowjetischen Geschichtswissenschaft in den sechziger Jahren besonders durch die verstärkte Hinwendung zur Geschichte der sowjetischen Gesellschaft gekennzeichnet war. Diese Wende wurde bereits 1953 eingeleitet ${ }^{26}$ und trug in den sechziger Jahren Früchte. ${ }^{27}$ Dabei wurde die Prioritätenänderung derart konsequent realisiert, daß V.P. Danilov sich 1966 als Vorsitzender der Parteiorganisation am Geschichtsinstitut der AdW bemüßigt sah, vor einer weiteren Vernachlässigung der vorrevolutionären Perioden und einer ganz ungleichmäßigen Entwicklung der sowjetischen Geschichtswissenschaft zu

\footnotetext{
21 Siehe Kapitel 4.1.

22 Sozdadim istoriju narodnogo partizanskogo dviženija 1941-1945 gg., in: ISSSR 1961, H. 2, 3-9.
}

23 Siehe Mitasova, L.: Partizanskoe dviženie na Pskovšxine v gody Velikoj Otečestvennoj vojny 1941-1945 gg. Rekomendatel'nyj ukazatel' literatury, Pskov 1964; Kurnosov, A.A./E.S. Lagutin: $K$ voprosu ob effektivnosti partizanskogo dvizenija na territorii Sovetskogo Sojuza, in: Protiv fal'sifikacii istorii Velikoj mirovoj vojny, Sbornik statej, M. 1964, 266-305 (verantwortlicher Redakteur diese Sammelbandes war A.M. Nekriz!). Vgl. Armstrong, J.A. (Ed.): Soviet Partisans in World War II, Madison 1964; Bonwetsch, B.: Sowjetische Partisanen 1941-1944. Legende und Wirklichkeit des ,allgemeinen Volkskrieges“, in: Schulz, G. (Hg.): Partisanen und Volkskrieg. Zur Revolutionienung des Krieges im 20. Jahrhundert, Göttingen 1985, 92-124.

24 So Bonwetsch, Der „Große Vaterländische Krieg“, 175.

2s Schon der damalige Präsidiumsvorsitzende des Obersten Sowjets M.I. Kalinin habe 1942 die Partisanenbewegung im "Großen Vaterländischen Krieg“" zu Recht als „Volksbewegung" bezeichnet. Durch ihren „wirklich umfassenden Volkscharakter" unterscheide sich diese wesentlich von den gegen Napoleons Armee 1812 und gegen die „Weißen“ im Bürgerkrieg 1918/20 gerichteten Kämpfen. - Sozdadim istoriju, 4ff; vgl. auch Bonwetsch, Sowjetische Partisanen, 92ff.

26 Siehe Kapitel 3.1.

27 Vor dem 20. Parteitag der KPdSU behandelten etwa zwanzig Prozent der Fachliteratur die Geschichte der sowjetischen Gesellschaft seit 1917; danach und bis Anfang der sechziger Jahre waren es ungefähr 50\%. - Izučenie istorii SSSR meždu XX i XXII s-ezdami KPSS, in: ISSSR 1961 , H. 5, 3-31, hier 18.

Im Geschichtsinstitut der AdW waren $195829 \%$ aller wissenschaftlichen Arbeiten der sowjetischen Geschichte nach 1917 gewidmet; 1963 sollten es planmäßig 61\% sein. - ISSSR 1964, H. 1, 214. 
warnen. Vor allem die Alte und Mittelalterliche Geschichte kämen bei der Zuteilung von Fachhistorikern und Mitteln zu kurz. ${ }^{28}$ Wie berechtigt Danilovs Sorge war, drückt auch die Themenverteilung bei den Promotionsarbeiten aus. Demnach verlagerten sich die Gewichte nicht nur in den Bereich der sowjetischen Periode, sondern mehr noch auf die Geschichte der KPdSU. 1957 bis 1962 befaßten sich 116 mehr Promovenden mit der Parteigeschichte als mit Themen aus der ganzen „Vaterländischen Geschichte" von den Anfängen der Rus' bis in die Gegenwart, aus den Gebieten der Archäologie, Ethnographie und Hilfswissenschaften zusammen! $!^{29}$ Richtungsweisend bei der Festlegung der Forschungsschwerpunkte war das Legitimationsbedürfnis des Staates und der regierenden Partei: Hinsichtlich der Geschichte der sowjetischen Gesellschaft galt es, aus Sicht der Sieger die Geschichte der Siege zu schreiben; im Oktober 1917, ${ }^{30}$ im Bürgerkrieg 1918/20, ${ }^{31}$ beim Wiederaufbau des Landes und der Verwirklichung der Neuen Ökonomischen

28 Auf Danilovs Initiative hin wurde angeordnet, in den Jahren 1967 bis 1970 siebzig Aspiranten (Doktoranden) für die Fachgebiete Alte Geschichte, Mediävistik, Byzantinistik, Neuzeit und Feudalismus (in der UdSSR-Geschichte) zuzulassen. - Danilov, V.P.: O trevožnom položenii v nekotorych otrasljach istorizeskoj nauki (an den Sekretär des ZK der KPdSU P.N. Demixev), in: CChSD f. 5, op. 59, d. 41, 21-27; Rumjancev, A.M. (27.06.1967) E.M. Cecharinu, in: CChSD f. 5, op. 59, d. 41, 28; Cecharin, E.M.: Spravka (07.07.1967) v CK KPSS, ebd., 29.

29 Die Bibliographie Niniznaja letopis hatte für die Zeitspanne von 1957 bis Juni 19621.520 Dissertationsschriften verzeichnet. Davon 688 aus dem Bereich der Parteigeschichte (45,3\%!), 445 aus dem der Geschichte der UdSSR, einschließlich der ganzen vorrevolutionären Geschichte aller "Völker der UdSSR von den Anfängen bis in die Gegenwart" (29.3\%), 260 Arbeiten aus dem Bereich der Algemeinen (Welt-) Geschichte (17,1\%), 127 aus den Gebieten Archäologie. Ethnographie und Hilfswissenschaften $(\mathbf{8 , 4} \%)$ - Dunaevskij, V.A./A.M. Sacharov/S.L. Senjavskij: Naǔxnaja rabota molodych istorikov, in: VI 1963, H. 1, 36-49, hier $37 f$.

30 Gerade die Oktoberrevolutionsforschung erfuhr mit dem Nahen des 50. Jahrestags der Revolution den größten Aufschwung in quantitativer Hinsicht. In den Fachzeitschriften dominierte 1967 der Rote Oktober. Ausschlaggebend war hier die Legitimationsfunktion: Platz für Innovationen und Alternativen in der historischen Erforschung wurde im Rahmen des Jubiläums nicht gelassen. In Istorija SSSR ging es vergleichsweise ruhig zu. Einen besonderen Beitrag zum Revolutionsjubiläum leistete ISSSR mit der Rubrik „Historiker - Teilnehmer der Oktoberrevolution“, in der an bolschewistische Historiker der ersten Stunde, darunter einige Repressierte, erinnert wurde. - Siehe in VI die Hefte 1 bis II des Jahrgangs 1967 sowie Jubilejnaja sessija Obšcego sobranii Akademii nauk SSSR, posvjǎ̌čennaja 50-letiju Velikoj Oktjabr'skoj socialističeskoj revoljucii, in: VI 1968, H. 1, 3-6; Rumjancev, A.M.: Istoriceskij opyt Velikogo Oktjabrja, ebd., 717: Jubilejnoe Obščee sobranie Otdelenija istorii Akademii nauk SSSR, posvjaščennoe 50-letiju Velikoj Oktjabr'skoj socialističeskoj revoljucii, ebd., 18; Zukov, E.M.: Pjat desjat let sovetskoj istoriceskoj nauki, ebd., 18-28. Vgl. Rusljakova, V.G.: Razrabotka istorii Oktjabr'skoj revoljucii posle XX s-ezda KPSS, in: VI 1960, H. 5, 85-102; Golikov, G.N.: K izučeniju istorii Velikogo Oktjabrja, in: VI 1962, H. 11, 33-53; Gorodeckij, E.N.: Nekotorye Certy sovremennoj Sovetskoj istoriografii Oktjabr'skoj revoljucii, in: ISSSR 1967, H. 5, 7-28: Ocerki 1985, 405-420; S veršiny pjatidesjatiletija, in: ISSSR 1967, H. 5, 3-7.

Vgl. Gimpel'son, E.G.: O politike „Voennogo Kommunizma“ (1918-1920 gg.), in: VI 1963. H. 5, 36-50; Selestov, D.K.: Sovetskaja istoriografija graždanskoj vojny i voennoj intervencii v SSSR, in: VI 1964, H. 2, 22-48; Serman, I.L.: Sovetskaja istoriografija grał̌danskoj vojny v SSSR (1920-1931), Charkov 1964; Ozerki po istoriografii sovetskogo obǐcestva. M. 1965, 137-219, besonders 195ff; Orerki 1985, 440-447. 
Politik, ${ }^{32}$ bei der Industrialisierung, ${ }^{33}$ der Kollektivierung der Landwirtschaft, ${ }^{34}$ der Kulturrevolution, ${ }^{35}$ im ,Großen Vaterländischen Krieg ${ }^{36}$ und beim erneuten Wiederaufbau des Landes nach $1945 .{ }^{37}$ Die Summe der Einzelforschungen sollte dann in die vielbändige „Geschichte der UdSSR“ einfließen. ${ }^{38} \mathrm{Im}$ Rahmen dieser Projekte blieb für streitbare Diskussionen und alternative Vorschläge kaum Platz. Nur eine Ausnahme gab es: die sogenannte ,Neue Richtung“ in der Oktoberrevolutionsforschung, ${ }^{39}$ deren wichtigste Vertreter A.M. Anfimov, M.Ja. Gefter, I.F. Gin-

$32 \mathrm{Vgl}$. Berchin, I.B.: Nekotorye voprosy istoriografii novoj ekonomiceskoj politiki v SSSR, in: VI 1961, H. 3, 28-44; Poljakov, Ju. A.: Stimul, mera, temp. Nekotorye problemy novoj ekonomičeskoj politiki, in: VI 1964, H. 7, 21-32; ders., Načalo vosstanovlenija sel'skogo chozjajstva sovetskoj strany (1921-1922 gg.), in: ISSSR 1964, H. 4, 29-52; Ocerki 1985, 459ff. - In der Fachzeitschrift für Parteigeschichte, Voprosy istorii KPSS, wurde 1966/67 eine Diskussion über die Geschichte der Neuen Ökonomischen Politik ausgetragen.

${ }^{33}$ Vgl. Očerki 1965, 280-340; Lel’čuk, V.S.: Istoriografija socialističeskoj industrializacii nacional'nych respublik SSSR, in: ISSSR 1966, H. 2, 81-102; Socialističeskaja industrializacija SSSR. Ukazatel' sovetskoj literatury, M. 1972; Lel'čuk, V.S.: Socialističeskaja industrializacija SSSR i ee osvešcenie v sovetskoj istoriografii, M. 1975; Orerki 1985, 478ff.

34 Vgl. Danilov, V.P.: $\mathrm{K}$ itogam izučenija istorii sovetskogo krest janstva i kolchoznogo stroitel'stva v SSSR, in: VI 1960, H. 8, 34-64; Bogdenko, M.L.: K istorii načal'nogo etapa splošnoj kollektivizacii sel'skogo chozjajstva SSSR, in: VI 1963, H. 5, 19-35; Orerki 1965, 341-382: Vylcan, M.A.A.A. Ivnickij/Ju.A. Poljakov: Nekotorye problemy istorii kollektivizacii v SSSR. In: VI 1965, H. 3, 3-25; Bogdenko, M.L./I.E. Zelenin: Istorija kollektivizacii sel'skogo chozjajstva $\vee$ sovremennoj sovetskoj istoriko-ekonomičeskoj literature, in: ISSSR 1962, H. 4, 133-151: Ocerki 1985, 492ff.

35 Vgl. Fadeev, A. V.: Razmyšlenija ob izučenii istorii kul'tury, in: VI 1964, H. 1, 27-43; Zak, L.M.: Istorija kul'turnogo stroitel'stva SSSR $\mathrm{v}$ sovetskoj istoriografii (1956-1963 gg.), in: VI 1964, H. 2, 3-21; Ozerki 1965, 549-598; Ozerki 1985, 573-587.

$36 \mathrm{Vgl}$. Deborin, G.A.: Osnovnye problemy pervogo toma „Istorija Velikoj Oterestvennoj vojny Sovetskogo Sojuza“, in: VI 1961, H. 1, 18-41; Očerki 1965, 383-421; Očerki 1985, 534-552.

3* Hier gab es relativ spät nennenswerte gedruckte Ergebnisse. Siehe etwa Razvitie socialističeskoj ekonomiki SSSR v poslevoennyj period, M. 1965; Volkov, I.M.: Razvitie sel'skogo chozjajstva SSSR v poslevoennye gody (1946-1970), M. 1972: Sovetskaja derevnja v pervye poslevoennye gody. 1946-1950, M. 1978. - Der die Nachkriegszeit behandelnde 11. Band der "Geschichte der UdSSR“" erschien erst 1980: Istorija SSSR s drevnejక̌ich vremen do našich dnej v dvuch serijach $v$ dvenadcati tomach. Vtoraja serija toma VII-XII ot Velikoj Oktjabr'skoj socialističeskoj revoljucii do našich dnej. Tom XI: Sovetskij Sojuz na puti k razvitomu socializmu 19451961 gg., M. 1980.

38 Das Werk (genaue Angabe in der vorangegangenen Fußnote) war ursprünglich auf elf, dann auf zwölf Bände angelegt; erschienen sind letztlich doch nur elf. Die erste Serie, Band 1-6, die die vorrevolutionäre Geschichte der UdSSR behandelt, wurde 1966 bis 1968 publiziert. Die Veröffentlichung der zweiten Serie, Band 7-11, zur Geschichte der Sowjetzeit, verzögerte sich erheblich. In den sechziger und siebziger Jahren erschienen jeweils nur zwei Bände! 1967 Band 7, geleitet von I.I. Minc (Oktoberrevolution, Bürgerkrieg), sowe Band 8, geleitet von Ju. A. Poljakov (Aufbau des Fundaments des Sozialismus 1921-32). Band 9, verantwortet von A.P. Kučkin (1933-41), erschien 1971; Band 10, verantwonet von A.V. Karasev (1941-45) erschien 1973, Band 11, den I.B. Berchin betreute (1945-61) erst 1980.

39 Dazu sind nach wie vor unübertroffen instruktiv die beiden Studien von Bonwetsch. Okto berrevolution, 49-185 und ders., Rußland, 733-747, auf die wir uns im folgenden stützen können.

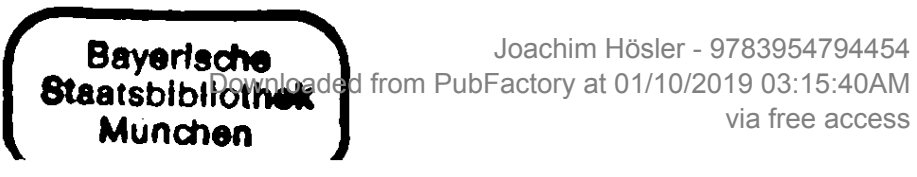


din, A.Ja. Grunt, K.N. Tarnovskij und P.V. Volobuev waren. Diese und andere Autoren hatten sich seit Mitte der fünfziger Jahre daran gemacht, die Stalinsche Interpretation der Ursachen und des Verlaufs der Oktoberrevolution zu korrigieren. Von zentraler Bedeutung waren folgende zwei Punkte:

Erstens versuchte die „Neue Richtung“ zwischen Stalins These von der unterentwickelten „Halbkolonie Rußland“ und der poststalinschen Übertreibung des Entwicklungsniveaus eine Position zu begründen, die auf sozialökonomischen Analysen der Entwicklung Rußlands am Ende des 19. und zu Beginn des 20. Jahrhunderts basierte und an zahlreiche Aussagen Lenins anknüpfte. Das leisteten - noch angeregt von dem im März 1966 gestorhenen Arkadij Sidorov ${ }^{40}$, aber inhaltlich weit über ihn hinausgehend - die auf die Wirtschaftsgeschichte Rußlands vor den Revolutionen 1917 spezialisierten Historiker Anfimov, Gindin, Tarnovskij, Volobuev u.a. ${ }^{41}$ Demnach sei Rußland vor 1917 nicht im gleichen Maße wie die Verei-

Bei Bonwetsch, Rußland, handelt es sich um die überarbeitete Fassung eines Vortrages, den Bernd Bonwetsch im Mai 1987 bei einer Konferenz der "Internationalen Kommission zur Geschichte der Oktoberrevolution in Rußland" in Odessa hielt. Die Schildenung seiner Eindrücke von diesem Aufenthalt zeugt von der damaligen perestrojka-Stimmung und Diskussionsfreude sowjetischer Historiker; siehe Bonwetsch, B.: Die Blickwinkel wechseln. Geschichtswissenschaft in der "Umgestaltung“. Persönliche Erfahrungen mit einer Konferenz in Odessa, in: Das Parlament, 05./12.09. 1987, 8f. - Zur Charakteristik und Wiederbelebung der "Neuen Richtung“ während der perestrojka siehe Hildermeier, $M$ : Revolution und Revolutionsgeschichte, in: Geyer, Die Umwertung, 32-53, besonders 46ff.

40 Siehe Sidorov, A.L: Ekonomi eskie predposylki socialisticeskoj revoljucii v Rossii, in: ISSSR 1957, H. 4, 9-39; ders., Finansovoe položenie Rossii $v$ gody pervoj mirovoj vojny, $M$. 1960; ders., Nekotorye problemy razvitija rossijskogo kapitalizma v sovetskoj istorizeskoj nauke. in: VI 1961, H. 12, 26-62; ders., Issledovanija po istorii imperializma v Rossii, in: VI 1963, H. 4, 121-126; ISSSR 1966, H. 3, 234f, Bovykin, Pamjati, 90. Vgl. die Fußnote zu Sidorov in Kapitel 3.1.1.

41 Vgl. dazu etwa Volobuev, P.V.: Monopolisticeskij kapitalizm v Rossii i ego osobennosti, M. 1956; Tarnovskij, K.N.: Formirovanie gosudarstvenno-monopolističeskogo kapitalizma v Rossii v gody pervoj mirovoj vojny, M. 1958; Volobuev, V.P.: O gosudarstvenno-monopolističeskom kapitalizme v Rossii v 1917 g. (mart-oktjabrja), in: VI 1959, H. 9, 44-63; Bovykin, V.I.: Banki i voennaja promyšlennost' Rossii nakanune pervoj mirovoj vojny, in: IZ 64, M. 1959, 82-135; Anfimov, A.M.: K voprosu o charaktere agrarnogo stroja Evropejskoj Rossii v načale XX v., in: IZ 65, M. 1959, 119-162; Bovykin, V.I./.F. Gindin/K.N. Tarnovskij: Gosudarstvenno-monopolistiČeskij kapitalizm $\vee$ Rossii (k voprosu o predposylkach socialisticeskoj revoljucii), in: ISSSR 1959. H. 3, 83-117; dazu: Solov'eva, A.M.: Obsuždenie doklada V.1. Bovykina, I.F. Gindina i K.N. Tarnovskogo „Gosudarstvenno-monopolističeskij kapitalizm v Rossii“, ebd., 231-235; ferner: Laveryそev, V.Ja.: Process monopolizacii chlopłatobumał̌noj promył̌lennosti Rossii (19001914 gody), in: VI 1960, H. 2, 137-151; Anfimov, A.M.: V.I. Lenin o charaktere agrarnych otnošenij v Rossii v načale XX veka, in: VI 1960, H. 4, 140-153; Volobuev, P. V.: Ob obščch zakonomernostjach i nacional no-istoričeskich uslovijach pobedy socialističeskoj revoljucij $\vee$ Rossii, in: VI 1960, H. 11, 19-39; Tarnovskij, K.N.: Problema rossijskogo gosudarstvenno-monopolistiČeskogo kapitalizma perioda pervoj mirovoj vojny v sovetskoj istoriografii, in: VI 1961, H. 7 , 33-53; Anan'ix̌, B.V./R.S. Ganelin: Naučnaja sessija po probleme „Osnovnye zakonomernosti i osobennosti razvitija Rossii $v$ epochu imperializma“, in: VI 1962, H. 3, 118-123; Ob osobennostjach imperializma v Rossii, M. 1963 (Der Sammelband enthält Materialien der vierten Konferenz der um Sidorov gruppierten Arbeitsgruppe im September 1961; Rezension von Horst 
nigten Staaten, England oder Deutschland durchkapitalisiert gewesen. Neben den höchsten Stufen der kapitalistischen Produktionsweise - Finanzkapital, Industrieund Bankmonopol - existierten in Rußland weiterhin auf dem Lande die halbfeudalistische Abarbeit auf Gutsherrengütern sowie die Natural- und kleine Warenwirtschaft, im industriellen Bereich die Manufaktur und das Kleingewerbe. Die sozialökonomischen Verhältnisse in Rußland hätten also einen ,mehrbasigen Charakter" (Ivanov/Tarnovskij) gehabt, und das Besondere sei gewesen, daß diese Mehrbasigkeit erstens vielschichtiger gewesen sei als in anderen Ländern und zweitens kein Durchgangs-, sondern das „Endstadium“ der sozialökonomischen Entwicklung dargestellt habe. Die besonders $\mathrm{kra} B$ ausgeprägte Heterogenität habe die ,konfliktbeladene, antagonistische sozialökonomische Struktur“ (Ivanov/Tarnovskij) entstehen lassen, die zur Bedingung der sozialistischen Revolution geworden sei. ${ }^{42}$

Zweitens war von zentraler Bedeutung, daß die „Neue Richtung“ die auf Stalin zurückgehende, immer wieder aufgelegte Behauptung mehr oder weniger direkt korrigierte, die revolutionären Bewegungen 1917 seien allesamt von der bolschewistischen Partei initiierte, gelenkte und von den Massen bewußt durchgefuihrte Aktionen gewesen. Dies ergab sich für einige Autoren zwingend aus den Ergebnissen der sozialökonomischen Analysen: Die Einsicht in die Heterogenität der Produktions- und Lebensverhältnisse der Massen führte zu der Annahme, daß nicht eine politische Partei alle wichtigen Massenaktionen lenken und leiten, und nicht eine gesellschaftliche Klasse allein - das Proletariat - als progressive Kraft auftreten konnte, sondern daß am revolutionären Prozeß den sozialökonomischen Verhältnissen entsprechend verschiedene Klassen und Schichten - unter der (nur zeitweiligen!) Hegemonie des Proletariats - entscheidend mitwirken mußten. ${ }^{43}$

Giertz, in: JbGUV 10, Berlin 1967, 392-395); Laveryčev, V.Ja.: O gosudarstvennom regulirovanii ekonomika Rossii, in: VI 1963, H. 4, 50-62; Gindin, I.F.: Gosudarstvennyj kapitalizm v Rossii domonopolističeskogo perioda, in: VI 1964, H. 9, 72-95; Ryndzjunskij, P.G.: Voprosy izučenija melkotovarnogo uklada v Rossii XIX v., in: ISSSR 1963, H. 4, 95-117; Tarnovskij, K.N.: Sovetskaja istoriografija rossijskogo imperializma (1917-1962 gg.), M. 1964 (siehe dazu die informative Rezension von Joachim Mai in: JbGUV 10, Berlin 1967, 388-391); Gindin, I.F.: O nekotorych osobennostjach ekonomiceskoj i social'noj struktury rossijskogo kapitalizma $v$ načale XX v., in: ISSSR 1966, H. 2, 48-66; Anfimov, A.M.: Krupnoe pomešciče chozjajstvo Evropejskoj Rossii, M. 1969; Problemy social'no-ekonomičeskoj istorii Rossii, M. 1971; Voprosy istorii kapitalističeskoj Rossii. Problema mnogoukladnosti, Sverdlovsk 1972.

42 Siehe Anfimov, K voprosu, 119 ff und 162; Volobuev, Ob obsčich zakonomernostjach, 22ff passim; Gindin, Gosudarstvennyj kapitalizm, 72ff; ders., O nekororych osobennostjach, 48ff, ders., Social'no-ekonomičeskie itogi razvitija rossijskogo kapitalizma i predposylki revoljucii v našej strane, in: Sverženie samoderžavija. Sbornik statej, M. 1970, 39-88, besonders 39ff und 80ff; Ivanov, L./K. Tarnovskij: Die sozialökonomische Struktur Rußlands. Das Problem der Mehrbasigkeit, in: JbfW 1973, H. 4, 165-173, hier 165 und 173.

43 Siehe Grunt, A.Ja.: O charaktere i mechanizme razvitija revoljucionnogo tvorcestva mass (Iz opyta Oktjabr'skoj revoljucii $1917 \mathrm{~g}$ ), in: Istori nosti. Stat'i i obsuł.denija, M. 1969, 45-62; vgl. Kukin, D.M.: Partija bol'łevikov v Fevral'skoj buržuazno-demokratǐ̌eskoj revoljucii, in: Sverženie 1970, 7-23; Volobuev, P.V.: Charakter i 
Die wichtigsten Thesen, die sich daran anschlossen, sagten folgendes aus: Da vorher keine bürgerlich-demokratische Revolution in Rußland bis zum Ende gebracht worden sei, habe die Oktoberrevolution die Fortsetzung der Februarrevolution dargestellt und gleichsam deren demokratische Aufgaben übernommen, die sich mit den sozialistischen verschränkten; das Bündnis von Proletariat und Bauernschaft, die treibende Kraft der Februarrevolution, sei nicht auseinandergefallen, sondern habe sich in der sozialistischen Revolution gefestigt; erst seit 1918 sei es zur Klassendifferenzierung unter den Bauern gekommen; Bauern und Kleinbürger hätten bis 1918 ein größeres politisches Gewicht für den gesellschaftlichen Fortschritt gehabt als bislang angenommen; die Februarrevolution sei wesentlich „eine spontane revolutionäre Explosion" (Volobuev) gewesen, und auch im Hinüberwachsen zur sozialistischen Revolution habe die Spontaneität der Massen die entscheidende Grundlage revolutionärer Aktion dargestellt; das erkläre das weit verbreitete kleinbürgerliche Denken und relativiere die Führungsrolle der Bol'Seviki. ${ }^{44}$

Das alles war, wie Bonwetsch nachgewiesen hat, in der sowjetischen Oktoberrevolutionsforschung in den sechziger Jahren weitgehend anerkannt und dominierend und floß noch in offizielle Darstellungen, die im Zusammenhang mit dem Revolutionsjubiläum 1967 veröffentlicht worden sind, ein. ${ }^{45}$ Ende der sechziger und zu Beginn der siebziger Jahre waren es dann weniger wissenschaftliche, sondern vielmehr politische Überlegungen, die die Parteifuhrung veranlaßten, die „Neue Richtung" ihren Kritikem preiszugeben und zerschlagen zu lassen. ${ }^{46}$ Das wurde während der Kampagnen in den siebziger Jahren ${ }^{47}$ und im Zuge der perestrojka deutlich, als die ehedem „Neue Richtung“ wieder rehabilitiert wurde: Als der alte Streit neu entbrannte, bestätigte Bovykin, damals und heute ein scharfer Kontrahent der

osobennosti Fevral'skoj revoljucii, ebd., 24-38; Lejberov, I.P.: Vtoroj den' Fevral'skoj revoljucii (sobytija 24 fevralja 1917 g. v Petrograde), ebd., 100-119; Znamenskij, O.N.: Sovetskie istoriki o sootnošenii stichijnosti i organizovannosti v Fevral'skoj revoljucii, ebd., 283-295; Rossijskij proletariat: oblik, bor'ba, gegemonija, M. 1970.

44 Das alles findet sich besonders bei Anfimov, Gefter, Gindin, Grunt, Tarnovskij und Volobuev in ihren oben genannten Arbeiten, besonders deutlich bei Volobuev, Ob obščich zakonomernostjach, 22-30 und 33-38; ders., Charakter, 24-38; vgl. Bonwetsch, Oktoberrevolution. 152ff; ders., Rußland, 734ff.

4s „Was später so souverän als falsch deklariert wurde, war $1969 \mathrm{zu}$ dem geworden, was sowjetische Historiker als offiziell sanktionierte Revolutionsdarstellung verstehen mußten." - Bonwetsch, Oktoberrevolution, 167. Vgl. Geyer, D.: Die russische Revolution. Neuerscheinungen im Jubiläumsjahr 1967, in: JbbGO 1968, 531-548, hier 531-539.

46 Bonwetsch erinnerte an die Neue Linke, an den Einfluß der Schriften von C. Wright Mills und Herbert Marcuse, an den „Schock des Pariser Mai 1968“, die März-Ereignisse in Polen und den "Prager Frühling“. Erst durch die Offenheit in den Zeiten der perestrojka wurde bekannt. daß der Wende im Jahr des „Prager Frühlings“ auch die „erste und bisher einzige sowjetische Hitlerbiographie" zum Opfer fiel. Geschrieben von Daniel Melamid alias Melnikov und Ljudmilla Cernaja, wurde sie 1991 mit beträchtlichen Erweiterungen veröffentlicht. - Bonwetsch. Oktoberrevolution, 159ff; Holm, K.: Verbrecher Nummer eins. Die erste und bisher einzige sowjetische Hitlerbiographie, in: FAZ v. 11.12.1991, N3.

47 Siehe dazu Kapitel 5.1. 
Neuerer, daß nicht die Heterogenitäts-These der Stein des Anstoßes gewesen sei. ${ }^{48}$ Den Neuerern wurden die daran geknüpften Thesen zum Verhängnis, mit denen sie aus orthodoxer Sicht die Februarrevolution und die spontanen Massenbewegungen auf-, die Oktoberrevolution, den Reifegrad der russischen Arbeiterklasse und die Rolle der Bol'Seviki abgewertet hatten. ${ }^{49}$

Andere Abweichungen vom offiziell gewünschten Geschichtsbild wurden in den sechziger Jahren nicht zugelassen. Die Geschichte der UdSSR war als gesetzmäßiger Proze $B$ zu beschreiben, der notwendigerweise auf die Oktoberrevolution als dem Beginn der weltweiten Ablösung des Kapitalismus durch den Sozialismus zulief. Die russische Geschichte und die Entwicklungen der nichtrussischen Nationalitäten gingen in der Geschichte der UdSSR, der „Vaterländischen Geschichte" auf. Die Befreiung der Nationalitäten aus dem russischen „Völkergefängnis“ und das Aufblühen ihrer Kulturen sollten den krönenden Abschluß im Zusammenfließen (slijanie) aller zu einer gemeinsamen sowjetischen Kultur finden. ${ }^{50}$ Gegen die tradierte, nach 1917 fortgesetzte Trennung von „Vaterländischer“ und Allgemeiner Geschichte an Hochschulen und Schulen sprach sich Michail Gefter 1964 in der Tageszeitung Izvestija in einem Artikel über den Geschichtsunterricht in der Schule aus. Gefter bezeichnete das ganze System des Geschichtsunterrichts als ,strittig ${ }^{\text {sl }}$ und vor allem die Absonderung der Russischen von der Allgemeinen Geschichte als

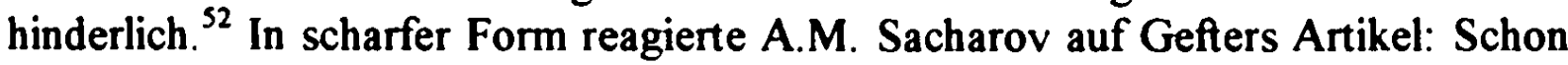
1923 hätten V.P. Viktorov und M.N. Pokrovskij versucht, die hergebrachte Struktur der schulischen und universitären Geschichtsausbildung zu verändern, was glücklicherweise (!) von der Partei 1931 und 1934 korrigiert worden sei. Sacharov bezog sich hier uneingeschränkt positiv auf die konkreten Schritte der Stalinisierung und ,kritisierte“ völlig abstrakt den „Personenkult““ ${ }^{53}$ Das Konzept der

Die sozialökonomische Heterogenität Rußlands vor der Revolution sei ja nicht zu bestreiten
und damals auch gar nicht kritisiert worden. - Bovykin, V.I.: Problemy perestrojki istoriðeskoj
nauki i vopros o „,novom napravlenii“ v izučenii social'no-ekonomiðeskich predposylok Velikoj Oktjabr'skoj socialističeskoj revoljucii, in: ISSSR 1988, H. 5, 67-100, hier 72.

49 Zur Kritik im einzelnen siehe Bonwetsch, Oktoberrevolution, 154ff und ders., Rußland, 737.

so Siehe Kretov, F.D.: K voprosu o sozdanii mnogotomnoj istorii SSSR, in: VI 1961, H. 2, 54 66, besonders 64 ff.

s1 Man bräuchte „(...) Monate, ja vielleicht Jahre des Suchens, der Experimente, der Nachprüfung aus Erfahrung; die Kooperation von Wissenschaftlern, Pädagogen, Schriftstellern, Menschen aller Berufe - Enthusiasten der Schule; eine schöpferische Diskussion, den offenen und gleichbereichtigten Widerstreit der Standpunkte." - Gefter, M.: Uroki žisni, in: Izvestija v. 20.11.1964, 3 .

\$2 Gefter schlug vier Unterrichtsabschnitte vor: Erstens einen Kurs „Unsere Heimat“ zur Vermittlung der Grundkenntnisse über Natur, Naturvorräte, Bevölkerung. Wirtschaft und Gesellschaftssystem der UdSSR; zweitens einen Kurs, der die Geschichte Rußlands mit der allgemeinen Geschichte bis 1917 verbindet; drittens einen Kurs zur Geschichte der sowjetischen Gesellschaft und zur Zeitgeschichte des Auslands; viertens einen synthetisierenden Kurs zur Geschichte der materiellen und geistigen Kultur. Siehe ebd.

33 Dank dieser Verrenkung konnte er den merkwürdigen Satz formulieren: „Unter den Bedingungen des Personenkults konnte der Beschluß vom 16. Mai 1934, wie auch viele andere, nicht 
„Vaterländischen Geschichte" und deren isolierte Vermittlung und Erforschung in der Schule, in den Universitäten und Akademie-Institutionen wurde ein weiteres Mal von ganz ,oben“ bestätigt.

\subsubsection{Zur Geschichte der sowjetischen Geschichtswissenschaft}

Mit der intensiveren Erforschung der jüngsten Vergangenheit seit der Oktoberrevolution ging die bessere Pflege der Historiographie einher. Seit dem Ende der fünfziger Jahre sprach man in der Sowjetunion von der Historiographie als einem eigenen Zweig (otrasl') der historischen Disziplin. ${ }^{54}$ In dem entsprechenden Artikel in der "Sowjetischen Geschichtsenzyklopädie“" schrieb A.I. Danilov" ${ }^{\text {S5 }}$ 1965, die Historiographie erforsche hauptsächlich sechs Aspekte der Historie als Wissenschaft: die sozialen Grundlagen historischer Erkenntnis, die theoretisch-methodologischen Prinzipien, die Quellenbasis, die Forschungsproblematik, die Geschichtskonzeptionen (Theorien) sowie die Organisation und Formen der Forschungsarbeit. ${ }^{56}$ Vorrangig ging es darum, auf der Grundlage dieser Untersuchungen die Geschichte der sowjetischen Geschichtswissenschaft zu schreiben. Die Fundamente zur Selbstreflexion in der historischen Disziplin wurden, wie oben schon gezeigt worden ist, Ende der fünfziger Jahre gelegt. Am Anfang der sechziger Jahre waren ,nur die ersten Schritte" getan. ${ }^{37}$ Die Periodisierungsdiskussion zur Entwicklung der sowjetischen Geschichtswissenschaft, die Milica Neckina 1960 initiiert hatte, ${ }^{58}$ und die

bis zum Ende verwirklicht werden." - Sacharov, A.M.. O značenii otečestvennoj istoril, in: ISSSR 1965, H. 4, 3-12, hier 7; vgl. den Beschluß in: Oberländer, Sowjetpatriotismus, $125 f$.

s4 Siehe Selestov, D.K.: Važnye problemy istoriografii sovetskogo obł̌čestva, in: VI 1966, H. 4, 130-133, hier 130.

ss Aleksandr Ivanovic Danilov (08.03.1916-27.11.1980), war wie A.Ja. Gureviz ein Schüler des namhaften Mediävisten A.I. Neusychin (1898-22.10.1969). Danilov, seit 1943 Mitglied der KPdSU, habilitierte sich 1958, war von 1958 bis 1961 Professor an der Universität Kazan', von 1961 bis 1967 Professor für Alte und Mittelalterliche Geschichte sowie Rektor der Universität Tomsk. 1967 wurde er Ordentliches Akademiemitglied und Bildungsminister der RSFSR. Ende der sechziger Jahre war er auch für eine Legislaturperiode Deputierter des Obersten Sowjets der UdSSR. Die Schwerpunkte seiner Veröffentlichungen lagen in der Agrargeschichte des deutschen Frühmittelalters, der deutschen und russischen Historiographie des 19. und 20. Jahrhunderts und der Geschichtsmethodologie. Er war in den sechziger Jahren der führende Kopf der historiographischen Forschungen in Tomsk und begründete 1963 den Sammelband „Methodologische und historiographische Fragen der Geschichtswissenschaft" (Metodologiceskie i istoriograficeskie voprosy istoriceskoj nauki, MIVIN). - Siehe BSE (III) 7, M. 1972, 528; Mogil'nickij, B.G.: Naučno-pedagogičeskaja dejatel'nost' A.I. Danilova in: MIVIN 15, T. 1982, 3-20; Pamjati Aleksandra Ivanoviča Danilova, ebd., 178-181; Mogil'nickij, B.G.: Das Tomsker Zentrum für historiographiegeschichtliche und methodologische Forschungen, in: JbG, Nr. 28, Berlin 1983, 275294; die Verzeichnisse der Veröffentlichungen A.I. Danilovs in: SV 46, 270-274 und MIVIN 18, T. 1986, 173-175.

36 Danilov, A.I.: Istoriografija kak naučnaja disciplina, izučajušcaja istoriju istoričeskoj nauki. in: SIE 6, M. 1965, 510-514, hier 511 .

37 Golikov, Na perednem krae, 26.

s8 Siehé oben Kapitel 3.2.4. 
bis Anfang 1962 andauerte, führte - wie Nexkina selbst berechtigterweise bilanzierte - dazu,

"(..) die Forschung anzuregen, einige neue Themen aufzuwerfen, die vorhandenen Kräfte zu erkennen, die nächsten Aufgaben zu umreißen und die unterschiedlichen Meinungen klarzustellen. Eine einheitliche Ansicht zu allen Fragen ist durchaus nicht notwendig - besonders nicht am Beginn der Arbeit. Ohne individuelle Forschungen und unterschiedliche Hypothesen ist eine schöpferische Arbeit undenkbar." "\$\%

In der Diskussion kristallisierten sich die unterschiedlichen Meinungen an drei Knotenpunkten heraus. Umstritten waren a) die Definition und das Selbstverständnis der Historiographie der sowjetischen Geschichtswissenschaft, b) die Periodisienungskriterien der Geschichte der historischen Disziplin und c) die Periodisierung selbst und die Bewertung einzelner Etappen.

Ad a) Hierüber gab es drei unterschiedliche Auffassungen: Nečkina woltte die Historiographie als eigenständige Disziplin verstanden wissen, welche die Geschichte der marxistisch-leninistischen Geschichtswissenschaft erforsche. ${ }^{60}$ Sigurd Smidt erinnerte an das Erbe der vorrevolutionären Geschichtsschreibung und daran, da $B$ es auch nach 1917 bis in die dreißiger Jahre hinein eine ,bürgerliche und eine kleinbürgerliche Geschichtswissenschaft" gegeben habe. Deren Repräsentanten würden, wenn die Historiographie im Sinne des Vorschlags von Nexkina verstanden würde, vergessen oder ausgeblendet bleiben. Unbestreitbar hätten aber auch sie zur Entwicklung der Disziplin beigetragen, was bislang nicht adäquat berücksichtigt worden sei. ${ }^{61}$ Viktor Danilov markierte die dritte Position; er wandte sich dagegen, aus der Geschichte der Geschichtswissenschaft eine selbständige Disziplin zu machen. Sie bleibe weiterhin eine „Hilfswissenschaft", deren vorrangige Aufgabe darin bestehe, zur Lösung der Forschungsprobleme der historischen Disziplin in jeder erdenklichen Weise beizutragen. ${ }^{62}$

Ad b) Hinsichtlich der Periodisierungskriterien gab es zwei konkurrierende Standpunkte: Nečkina und Smidt ergänzten sich in dieser Frage dahingehend, daß sie dafür plädierten, die Verändenungen im gesellschaftlichen Überbau, also die Ideo-

39 Netschkina, M.W.: Ergebnisse der Diskussion über die Periodisierung der Geschichte der sowjetischen Geschichtswissenschaft, in: SW 1962, H. 12, 1369-1386, hier 1369 (leicht gekürzte Überseztung und Wiedergabe aus ISSSR 1962, H. 2).

60 „Die Geschichte der sowjetischen Geschichtswissenschaft ist die Geschichte einer marxistisch-leninistischen Wissenschaft. - Und ,(...) wir betrachten diese Disziplin nicht als Hilfswissenschaft (...).“ - Netschkina, Zur Periodisienung, 784; zweites Zitat nach Koroleva, V komissii, 203.

61 Schmidt, S.O.: Über den Gegenstand der sowjetischen Geschichtsschreibung und einige Prinzipien ihrer Periodisierung, in: SW 1962, H. 6, 669-683, hier 672f (Übersetzung aus: ISSSR 1962, H. 1). Smidt erinnerte an M.K. Ljubavskij, V.V. Bartold, S.V. Bachrułin, S.B. Veselovskij, E.V. Gautier, D.M. Petrušsevskij, E.V. Tarle und besonders an A.E. Presnjakov.

62 Siehe den Sitzungsbericht von Alekseeva, G.D.: Pervaja ,istoriograficeskaja sreda“, in: VI 1961, H. 6, 147-150, hier 149. 
logieentwicklung in der Gesellschaft, zur Unterscheidung der großen Perioden und mehrere immanente Faktoren der Disziplin selbst zur Binnendifferenzierung in kleinere Etappen heranzuziehen. Was die großen Perioden angehe, falle die historiographische Entwicklung im wesentlichen mit der gesellschaftlichen zusammen. ${ }^{63}$ Neckina nannte sechs immanente Faktoren: die vorherrschende allgemeine Konzeption geschichtlicher Entwicklung, die Forschungsproblematik, neue Untersuchungsmethoden, die Einbeziehung neuer Quellen, die Forschungsergebnisse ${ }^{64}$ und neue Organisationsformen des wissenschaftichen Arbeitens. ${ }^{65}$ Najdenov, der wiederholt als konservativer Kritiker Nečkinas hervortrat, bezog hier eine Gegenposition, die sich zu Stalins Zeiten wohl bewährt hätte: Nečkinas Periodisienungskriterien - so Najdenov - ignorierten den Kampf der Ideologien, in dessen Rahmen die Geschichtswissenschaft sich entwickle. Anstatt, wie Nečkina, mehrere Faktoren zu berücksichtigen, sollten die „Fakten des Aufkommens neuer ideologischer Gegner der sowjetischen Historiographie" zur Periodisierung genügen, da durch sie die Geschichtswissenschaft am deutlichsten geprägt werde.

Ad c) Infolgedessen fielen auch die Periodisierungsvorschläge und besonders die Bewertungen der einzelnen Perioden unterschiedlich aus. Ohne die verschiedenen Schemata auszubreiten, kommt es hier darauf an, die kontroversen Sichtweisen auf die Geschichtswissenschaft in den zwanziger und dreißiger Jahren sowie in der Nachkriegszeit zu umreißen. Wieder war es vor allem Najdenov, der sich zum Hauptvertreter konservativer oder, um es deutlicher zu sagen, stalinistischer Wertungen machte.

Hinsichtlich der zwanziger Jahre hoben alle Diskussionsteilnehmer die Auseinandersetzung zwischen vorrevolutionären und revolutionären Geschichtskonzeptionen hervor. Neckina unterschied in einer ersten Periode (1917-1934) nur zwei Etappen: eine Anfangsetappe, die bis 1923 reiche, und ,das große dynamische Jahrzehnt" von 1924 bis 1934, in dem sich das marxistische Denken durchgesetzt habe. $^{67} 1917$ sei die in den neunziger Jahren des 19. Jahrhunderts begonnene „Leninsche Etappe“ der Geschichtswissenschaft auf höherem Niveau - weil staatlich sanktioniert - fortgesetzt worden. ${ }^{68}$ Najdenov wollte - ohne daß er das expressis verbis sagte - die Periodisienung stärker an den „Kurzen Lehrgang“, Stalins

\footnotetext{
63 Netschkina, Zur Periodisierung, 783; Schmidt, Über den Gegenstand, $675 f$.

64 Netschkina, Zur Periodisierung, 783.
}

65 Dieser letzte Punkt sei nach der Diskussion hinzuzufugen. schrieb Netschkina. Ergebnisse, 1373.

66 Najdenov, M.E.: Problemy periodizacii sovetskoj istoriðeskoj nauki, in: ISSSR 1961, H. 1, 81-96, hier 83; in dieser Frage analog: Luckij, E.A.: Osnovnye principy periodizacii razvitija sovetskoj istoriceskoj nauki, in: ISSSR 1961, H. 2, 102-115, hier 107.

67 Netschkina, Ergebnisse, $1381 \mathrm{f}$.

68 Vgl. ebd., 1377ff; Nečkina, M.V./Ju.A. Poljakov/L.V. Cerepnin: O projdennom puti, in: Sovetskaja istoriðeskaja nauka ot XX k XXII s-ezda KPSS. Istorija SSSR. Sbornik statej, M. 1962, 5-36, hier 15; Dunaevskij, V.A./A.M. Stanislavskaja: Obsuždenie IV toma „Ozerkov istorii istoričeskoj nauki v SSSR“, in: VI 1965, H. 3, 154-158, hier 155. 
Geschichtslehrbuch, angleichen; denn er hob für die erste Etappe nicht nur wie alle anderen Diskussionsteilnehmer den Kampf gegen (klein-) bürgerliche Geschichtskonzeptionen hervor, sondern fügte hinzu, daß in dieser ersten Etappe die Vertreter der jungen Disziplin sich die Geschichtskonzeption Pokrovskijs angeeignet hätten, die sich wesentlich von derjenigen Lenins unterscheide und dieser gegenüber einen Rückschritt dargestellt habe. ${ }^{69}$ Die zweite Etappe soltte nur bis 1927 reichen; als wichtigste Momente, die ihren Hauptinhalt bezeichneten, nannte Najdenov: der „Kampf gegen die trotzkistischen Geschichtsfälscher, die Konsolidierung marxistischer Historiker, die Entstehung der 'Schule' M.N. Pokrovskijs, der ideologische und politische Zusammenbruch des Trotzkismus, der Sturm auf die Erschließung des historiographischen Erbes V.I. Lenins “. ${ }^{70} 1928$ habe die dritte Etappe begonnen, in der aus Najdenovs Sicht der „Kampf gegen die Geschichtsauffassungen rechter Kapitulanten und bourgeoiser Nationalisten vom Typus' Javorskijs in der Ukraine u.a. "im Vordergnund stand. ${ }^{11}$

Über die Zeit nach 1934 hieß es in der Diskussion allenthalben, dies sei die zweite Periode, die der "bedeutenden Stärkung der marxistisch-leninistischen Geschichtswissenschaft" gewesen ${ }^{72}$ was, wenn man den Marxismus-Leninismus als Rechtfertigungsideologie der Stalinschen Macht begreifen würde, durchaus sinnvoll wäre. ${ }^{/ 3}$ Besonders bei den Texten von Nečkina und \$midt bekommt der Leser

69 Najdenov, Problemy, 90. - Ferner schrieb Najdenov folgenden Unsinn: „Man muß betonen, daß M.N. Pokrovskij dem Leninismus und insbesondere dessen Geschichtskonzeption gegenüber nicht feindlich eingestellt war. Er kannte sie einfach nicht, und war vielleicht sogar ahnungslos über ihre Existenz." Später korrigierte sich Najdenov dahingehend, daß er von der Leninschen Etappe im weiteren (seit 1890) und engeren Sinn (seit 1927) sprach. - Ebd., 92; vgl. Najdenov, M.E.: O leninskom etape $v$ istoričeskoj nauke, in: VI 1966, H. 2, 21-37; kritisch dagegen: Vajnštejn, O.L.: Stanovlenie sovetskoj istoričeskoj nauki (20-e gody), in: VI 1966, H. 7, 32-47; Sarbej, V.G.: Ešče raz o leninskom etape $v$ istoričeskoj nauke (po povodu stat'i M.E. Najdenova), in: VI 1966, H. 9, 15-26. Vgl. auch Sokolov, O.D.: V.I. Lenin i formirovanie bol'sevistskich vzgljadov M.N. Pokrovskogo, in: VI 1963, H. 8, 30-41; ders., M.N. Pokrovskij 1970, 5 sowie ebd. im 2. und 4. Kapitel passim: Behrendt, L.-D.: Die Entwicklung der Ansichten M.N. Pokrovskijs über den russischen Imperialismus. Zur Durchsetzung des Leninismus in der ersten Periode der sowjetischen Geschichtswissenschaft, in: ZfG 1971, H. 3, 382-392.

70 Najdenov, Problemy, 90.

"Ebd., 91. - Najdenov meinte hier den ukrainischen Historiker Matvej Ivanovił Javorskij, dem in der Auseinandersetzung im Mai 1929 eine ,antibolschewistische“ Geschichtskonzeption vorgeworfen wurde. Javorskij mußte im gleichen Jahr die Leitung in der historischen Abteilung des Instituts für Marxismus in Kiev verlassen und wurde 1930 aus der Kommunistischen Partei, der er seit 1920 angehör hatte, ausgeschlossen. Vgl. die Eintragung in BSE (I) 65, M. 1931, 328 (in der 2. und 3. Ausgabe der „Großen Sowjetenzyklopädie“ blieb M.I. Javorskij ungenannt).

12 So Netschkina, Zur Periodisierung, 794; Schmidt, Über den Gegenstand, 680, sprach „(...) von einer Konsolidierung der sowjetischen Geschichtswissenschaft als marxistischer Wissenschaft (...)“. Analog auch Luckij. Osnovnye principy 1961, 114; Neckkina/Poljakov/Cerepnin, O projdennom puti, $17 f$.

${ }_{33} \mathrm{Vgl}$. die Analyse von Labica, Der Marxismus-Leninismus, 25, wo es heißt: „Insgesamt ist klar, daß der offizielle Geburtsakt des Marxismus-Leninismus nichts anderes ist als die theoretische Weihe der Stalinschen Politik." - (Kursiv bei Labica). 
den Eindruck, eine übergeordnete Instanz hätte darauf bestanden, dieses Etikett anzubringen. Des weiteren bemühten sich beide um eine differenzierte Bilanz der von Stalin dominierten Zeit. So hoben sie neben den ,Errungenschaften“ - Zusammenschluß der Historiker zur Ausarbeitung der marxistisch-leninistischen Geschichtskonzeption, Wiedereinrichtung historischer Fakultäten, Überwindung der Fehler Pokrovskijs, die Erarbeitung des ersten allgemeinen Geschichtslehrbuchs. des „,Kurzen Lehrgangs“, umfassendes Lenin-Studium, allgemeiner historiographischer Aufschwung ${ }^{74}$ - besonders die ,im Zusammenhang mit dem Personenkult begangenen Fehler" hervor: die Behinderung der Erforschung der Sowjetgesellschaft, die Unterschätzung der historischen Rolle der Volksmassen, das übertriebene Interesse für Einzelpersönlichkeiten, vor allem die Überzeichnung der Bedeutung Stalins, die Tabuisierung einzelner Themen, Idealisierung der vorrevolutionären Zeit, Geschichtsfälschungen (Neckina nannte die negative Bewertung Šamils), die übliche Überarbeitung und Angleichung der Texte an allgemeine Dogmen, die Zitiersucht, die Methode des ,Illustrierens“, das fast völlige Vergessen der Historiographie, ${ }^{75}$ die Disqualifizierung Pokrovskijs als , antimarxistisch", die Schließung von Forschungsinstituten und Auflösung von Periodika sowie die geringere Partizipation Werktätiger an der historischen Forschung. ${ }^{76}$ Und Nečkina fügte hinzu:

"Der Tod vieler Historiker in den Jahren des Personenkults fügte der sowjetischen Geschichtswissenschaft einen nicht wieder gutzumachenden Verlust zu. "7

In concreto ließen Nečkina und Smidt also keinen Zweifel daran aufkommen, daß sie in den dreißiger Jahren in ihrer Disziplin mehr Schatten als Licht sahen. Najdenov wollte von all dem nichts wissen. Folgende ,negativen Züge“ machte er in dieser Periode aus:

„In den Jahren des Großen Vaterländischen Krieges und kurz danach gab es Rückfälle zur bourgeois-nationalistischen Ideologie; in einzelnen historischen Forschungsarbeiten wurden Elemente bürgerlichen Objektivismus' bemerkt, Fälle des Eindringens des bürgerlichen Kosmopolitismus in die Geschichtsliteratur wurden beobachtet. In den Arbeiten einiger Historiker gab es Elemente des Dogmatismus, des Subjektivismus und des Voluntarismus. Negativen Einfluß auf die Entwicklung der sowjetischen Geschichtswissenschaft übte der Personenkult aus. "78

Nennenswerte Fehler vermochte Najdenov also immer nur bei denen zu erkennen, die von Stalins Generallinie abwichen. Folgerichtig fiel seine Einschätzung von der

14 So Netschkina, Zur Periodisierung, 794 und dies., Ergebnisse, 1384; vgl. auch Schmidt, Über den Gegenstand, 681.

13 Soweit die Fehlerliste von Nexkina, Zur Periodisierung. 795; dies., Ergebnisse, 1384 und Nexkina/Poljakov/Čerepnin, O projdennom puti, 24.

76 Dies bezeichnete Schmidt, Über den Gegenstand, 681, als Ausdruck des verderblichen Einflusses des Personenkults. Vorsichtig setzte er hinzu: „Es gab Anzeichen für eine Reglementierung des Denkens und eine Standardisierung des Stils historischer Darstellungen.“

11 Netschkina, Ergebnisse, 1384.

18 Najdenov, Problemy, 93. - Der hier von mir hervorgehobene Satz war das einzige, was Najdenov zum Thema Geschichtswissenschaft und Stalinismus zu sagen wußte! 
Entwicklung der Geschichtswissenschaft in der Nachkriegszeit höchst positiv aus; der Krieg war schließlich gewonnen, die ideologischen Gegner im Innern - Nationalisten, Kosmopoliten - wurden niedergenungen usw. Ohne das im einzelnen belegen zu können, behauptete Najdenov, nach 1945 seien bei der Erforschung der sowjetischen Geschichtsperiode die größten Fortschritte gemacht worden. Das Jahrzehnt von 1946 bis 1956 sei das, fruchtbarste" in der Geschichte der sowjetischen Geschichtswissenschaft gewesen, obwohl die negative Wirkung des „Personenkults“ nun am größten gewesen sei. ${ }^{79}$ In den Jahren 1953 und 1956 erkannte er keine nennenswerten Einschnitte in der Entwicklung der Geschichtswissenschaft. Der 20. Parteitag der KPdSU habe lediglich die vierte Etappe der zweiten Periode des fortwährenden Aufschwungs der historischen Disziplin eingeläutet. $^{80}$

Zu einem anderen Ergebnis kamen Neðkina und Smidt. Sie sahen die Arbeit der Historikerinnen und Historiker auch in der Nachkriegszeit nachhaltig von den „Folgen des Personenkults“ behindert. 1953 habe die „Umgestaltung der Parteiarbeit" und die Überwindung der Fehler begonnen; von der fruchtbarsten Zeit könne also erst danach gesprochen werden. ${ }^{81}$ In ihrer Diskussionsbilanz schrieb Neckina, daß die „Einheit vieler Besonderheiten“ jene zwei Jahrzehnte ${ }^{82}$,, $u$ einem Ganzen“, das heißt zu einer Periode verbinde.

„Mit dem Jahre 1956 beginnen die Historiker der Geschichtswissenschaft richtig und einmütig eine neue, die zeitgenössische Periode. “\$3

Im Gegensatz zu Najdenov, der mit seinen Antworten eine Apologetik der stalinisierten Geschichtswissenschaft vorlegte, präsentierten Neckina und Smidt also durchaus kritische und selbstkritische Thesen. Daß hier zwei konträre Ansätze konkurrierten, zeigte sich auch an der unterschiedlichen Erwartungshaltung gegenüber der Diskussion: Najdenov warf Nečkina Erkenntnisskeptizismus vor; sie gehe eindeutigen Antworten aus dem Wege. ${ }^{84}$ Nečkina hielt es für notwendig, fragend und offen für abweichende Meinungen die historiographische Arbeit zu beginnen. ${ }^{85}$

so Ebd., 95 f.

81 Schmidt, Über den Gegenstand, 681ff; vgl. Netschkina, Zur Periodisienung, 795; Neckinal Poljakov/Cerepnin, O projdennom puti, $25 \mathrm{f}$.

82 Sie fügte hinzu: „(1934-1953, wenn man von den ersten Beschlüssen 1934 ausgeht, oder 1937-1956, wenn man die allgemeinhistorische Periodisierung und den eine Periode abschlieBenden XX. Parteitag der KPdSU als Grenzdaten annimmt).“- Netschkina, Ergebnisse, 1385.

83 Ebd

84 Najdenov, Problemy, $81 \mathrm{f}$.

85 Auch in der Zusanımenfassung der Ergebnisse hielt sie daran fest: „Der Hauptsinn der Arbeit besteht darin, daß wir Schritt für Schritt den zurückgelegten Weg betrachten, uns der einen Fakten erinnern und andere entdecken und sie auf der Grundlage der entscheidenden sozialen Prozesse der sich entwickelnden Sowjetgesellschaft historisch einordnen. Wir 'inventarisieren' sozusagen die Hauptfakten des historiographischen Prozesses (...).“ - Netschkina, Ergebnisse, 1386. 
An den fünfbändigen „Studien zur Geschichte der sowjetischen Geschichtswissenschaft" zeigt sich, da $B$ in abgeschwächter Form vor allem die Positionen von Nečkina „offiziell“" wurden und daß dennoch die eben skizzierten Probleme über Jahre hinweg umstritten blieben. Seit 1958 leitete Milica Nečkina die Arbeit zu den „Studien“" ${ }^{86}$ In der Einleitung zum vierten Band schrieb sie, daß die Geschichte der sowjetischen Geschichtswissenschaft „vor allem die Geschichte einer marxistischleninistischen Wissenschaft" sei, sie jedoch auch nichtmarxistische und antimarxistische Arbeiten berühre, ${ }^{87}$ Nečkina fügte hier also ihrer Definition der Historiographie die Ergänzungen von Smidt hinzu. Was die Periodisierungskriterien angeht, so hieß es auch hier, daß mehrere Faktoren berücksichtigt werden müßten. ${ }^{88}$ Die großen Entwicklungsperioden der sowjetischen Gesellschaft und der $\mathrm{Ge}$ schichtswissenschaft seien deckungsgleich. ${ }^{89}$ Auch hinsichtlich der Binnenperiodisierung wurde Nečkinas Vorschlag orientierend: Der vierte Band der "Studien“, der die Entwicklung von 1917 bis Mitte der dreißiger Jahre behandelte, war entsprechend der oben dargelegten Periodisienung von Neckina strukturiert. ${ }^{90}$ Stalin wurde nicht verschwiegen, was ja oft die poststalinsche Art der „Entstalinisierung“ war, sondern insgesamt $89 \mathrm{mal}$ erwähnt, $21 \mathrm{mal}$ positiv, ${ }^{91}$ 68mal negativ. Recht gründlich setzten sich die Historiographen mit Stalins Einlassungen auseinander und wiesen nach, mit welcher AnmaBung sich der Generalsekretär in die verschiedensten Fachdiskussionen eingemischt hatte, egal ob es um die Bewertung von Mahatma Gandhi oder um die Erforschung der Geschichte Chinas ging. ${ }^{92}$ Nečkina formulierte ihre Beurteilung von Stalins Einfluß auf die Geschichtswissenschaft zwar etwas moderater als in der vorangegangenen Periodisierungsdiskussion, in der Sache aber blieb sie eindeutig bei ihrer Position. ${ }^{93}$ Die Fertigstellung des funf-

86 Bis dahin war - 1955 - nur der erste Band erschienen; die Hauptverantwortung dafur hatte M.N. Tichomirov

7 Siehe Oxerki 1966, 12

88 Diesmal nannte Nečkina funf Kriterien: Geschıchtskonzeption, Forschungsproblematik, Methoden, Quellen und Organisationsformen der Arbeit; siehe ebd.

89 Von Oktober 1917 bis Mitte der dreißiger Jahre reiche die erste, bis Mitte der funfziger Jahre die zweite große Periode; ebd., 11.

90 Siehe ebd, 14ff; vgl. die Rezension in: VI 1967, H. 5, 144-153

91 Vor allem als Kritiker des Trotzkismus und als Propagandist der Neuen Ökonomischen Politik; vgl. Ocerki 1966, 486.

92 Ebd., 785, 809.

93 ,Die fortschreitende Entwicklung der sowjetischen Geschichtswissenschaft wurde Ende der 20er, Anfang der 30er Jahre verlangsamt und erschwert durch das Aufkommen des Personenkultes um Stalin, welcher der sowjetischen Wissenschaft einen schweren Schaden zufuigte. Stalin beging große Fehler und Machtmißbrauch, der auch für die Historiker schwerwiegende Folgen hatte. Nach dem Brief Stalins an die Redaktion der Zeitschrift 'Proletarische Revolution' im Jahr 1931 wurden der Dogmatismus und die Buchstabengelehrsamkeit, die Ablösung der Forschung durch Zitate und das Anpassen des Materials an vorgefaßte Schlußfolgerungen verschärf. Das kennzeichnete nicht alle Arbeiten der Historiker und nicht in einheitlichem Maße, die Forschung wurde nicht unterbrochen und sammelte Resultate, aber der Entwicklungsprozeß der Wissenschaft wurde unverkennbar gehemmt." - Orerkj 1966, 18. 
ten Bandes - über die Entwicklung der sowjetischen Geschichtswissenschaft von der Mitte der dreißiger bis Ende der sechziger Jahre - wurde fast zwei Jahrzehnte lang behindert und verschleppt. ${ }^{94}$ Er erschien erst 1985 (!), kurz vor dem Tode Nečkinas, und war um 249 Seiten schmaler als der vorangegangene, obwohl er eine um etwa fünfzehn Jahre längere Zeitspanne behandelte als dieser. ${ }^{95}$

Wie schwer man sich tat, die Entwicklung der historischen Disziplin selbstkritisch zu reflektieren, zeigte sich auch beim Umgang mit einzelnen namhaften Vertretern. Die Rehabilitierung Pokrovskijs, in den fünfziger Jahren schon begonnen, ${ }^{96}$ blieb lange umstritten. ${ }^{97}$ A.I. Gukovskij, A.M. Dubrovskij, A.A. Govorkov, V.G. Sarbej, V.I. Astachov und F.P. Sevcenko wandten sich gegen die ,übertriebene Kritik der schwachen Seiten" von Pokrovskijs Geschichtskonzeption im Manuskript des vierten Bandes der „Studien“: Lenins Würdigung Pokrovskijs fehle ebenso wie die Rolle Stalins bei der Herausbildung der negativen Auffassungen über den führenden Historiker der zwanziger Jahre; die Bedeutung der „Schule“ Pokrovskijs für die sowjetische Geschichtswissenschaft werde nicht gewürdigt; statt dessen werde der Begriff weiterhin als abwertendes Etikett verwendet. L.V. Cerepnin, der Autor des kritisierten Kapitels, verteidigte seine Arbeit, die er als ,prägnante Charakteristik" bezeichnete, und gab dem Sitzungsbericht zufolge keine Bereitschaft zur Überarbeitung zu erkennen. ${ }^{98}$ Auch in der veröffentlichten Fassung vermied es Cerepnin, die von seinen Kritikern angesprochenen Punkte einzuarbeiten, bemühte sich aber um eine ausgewogene Lebensbilanz des „bolschewistischen Historikers“.99 Die offiziellen Epitheta Pokrovskijs blieben widersprüchlich, ${ }^{100}$ doch

94 Nekrix schrieb 1979: „Der Band ist so auch bis heute nicht erschienen, obwohl er bereits einige Male im Entwurf vorgelegt, erörtert und zum Druck freigegeben worden war." - Nekrič, Otrešis' ot stracha, 339.

95 Ocerki 1985

96 Siehe Kapitel 3.2.4.

97 Vgl die Kontroverse: Dubrovskij, S.M.: Akademik M.N. Pokrovskij i ego rol' v razvitii sovetskoj istorið̌eskoj nauki, in: VI 1962, H. 3, 3-31; Obsuždenie stat'i S.M. Dubrovskogo "Akademik M.N. Pokrovskij i ego rol' v razvitii sovetskoj istoriðeskoj nauki“", ebd., 31-40; Sokolov, O.: Ob istoričeskich vzgljadach M.N. Pokrovskogo, in: K 1962, H. 4, 69-79; Najdenov, M.E.: M.N. Pokrovskij i ego mesto v sovetskoj istoriografii, in: ISSSR 1962, H. 3, 48-71; Luckij, E. A.: Razvitie istoričeskoj koncepcii M.N. Pokrovskogo, in: Istorija i istoriki, M. 1965, 334-370.

98 Siehe Dunaevskij/Stanislavskaja, Obsuł̌denie, 156.

99 Ozerki 1966, 180-198, hier 197.

100 In dem Leitartikel, der Anfang 1966 anläßlich des 40-jährigen Bestehens der Zeitschrift in Voprasy istorii erschien, wurde Pokrovskij als ,großer Wissenschaftler" und ,herausragender gesellschaftlicher Aktivist" bezeichnet, der all sein Wissen und seine ganze Kraft in die Entwicklung der sowjetischen Geschichtswissenschaft investiert habe. - Im Leitartikel der VI zum 50. Jahrestag der Oktoberrevolution galt Pokrovskij erneut als „bedeutender sowjetischer Gelehrter“, "marxistischer Wissenschaftler" und „bolschewistischer Propagandist", der allerdings „vulgären Soziologismus“" und ein angeblich ,nihilistisches Geschichtsverständnis“" verbreitet habe. Als Beispiele für Pokrovskijs inhaltliche Fehler dienten bezeichnenderweise ausschließlich Verstöße gegen das Gebot des „vaterländischen“ Denkens: die von Rußland geführten Kriege habe er als "Eroberungskriege“ bewertet, den Begriff „Vaterländischer Krieg“ als nationalistisch bezeichnet, 
scheint mit der Veröffentlichung des vierten Bandes der "Studien" ein Damm gebrochen. Was von 1966 an über Pokrovskij zu lesen war, bewegte sich auf einem ordentlichen Niveau; Denunziationen kamen nicht mehr vor. 1967 waren auch die ,Ausgewählte(n) Werke in vier Büchern" vollzählig. ${ }^{101}$ Erinnerungen von Historikern, die noch bei Pokrovskij studiert hatten, trugen mit dazu bei, ein lebendiges Bild von ihm zu vermitteln. ${ }^{102}$ Gukovskij schilderte anläßlich der 100 . Wiederkehr des Geburtstags Pokrovskijs das Entstehen dessen wichtigsten Werkes, der russischen „Geschichte seit den alten Zeiten“ ${ }^{103}$ Sokolov legte 1966 bis 1970 ausführlich seine Untersuchungsergebnisse vor, was den Höhepunkt der tatsächlichen inhattlichen Rehabilitienung Pokrovskijs darstellte. ${ }^{104}$

Nicht einfacher war es mit Pokrovskijs bedeutenster Schülerin und Kritikerin, Anna Pankratova. Das mußte 1967 auch eine Gruppe von Historikern - „Schüler und Freunde der bekannten sowjetischen Geschichtswissenschaftlerin" - erkennen, die sich an den ZK-Sekretär Suslov mit der Bitte wandten, die 70. Wiederkehr des Geburtstags und den 10. Jahrestag ihres Todes in würdiger Weise zu begehen. Minc, Gorodeckij und Gefter gehörten zu den Bittstellern, die meinten, daß Menschen wie Pankratova im Gedächtnis des Volkes weiterleben sollten und aufgrund ihres Lebensweges ein ,glänzendes Beispiel für die junge Generation“ böten. Sie schlugen vor, das doppelte Jubiläum in der Presse entsprechend hervorzuheben, feierliche Sitzungen in der Akademie der Wissenschaften anzusetzen, sowie eine

die Normannen als Organisatoren des Altussischen Staats anerkannt, die Inkorporation nichtrussischer Völker nur als Folge der "Kolonialpolitik des Zarismus“ interpretiert usw. Das alles traf ins Mark des Stalinschen Sowjetpatriotismus. - Zurnal 1966, 4; Izučenie otečestvennoj istorii za 50 let Sovetskoj vlasti, in: VI 1967, H. 11, 3-18, hier 7f.

1011965 erschien Band 2, 1966 Band 1, 1967 Band 3 und 4.

102 Arkadij Sidorov beispielsweise berichtete von den eindrucksvollen Vorlesungen Pokrovskijs; A.I. Gukovskij erzählte von der kameradschaftlichen Atmosphäre in den Seminaren Pokrovskijs, der nicht als "Professor" angesprochen werden wollte, sondern als "Genosse"; Isaac Minc riet den Nachwuchswissenschaftlern, so lebendig wie Kljuðevskij und Pokrovskij zu schreiben. Diese und andere Erinnerungen von Historikern erschienen in der Rubrik "Die Arbeitserfahrung sowjetischer Historiker". Siehe Sidorov, A.L.: Nekotorye razmyšlenija o trude i opyte istorika, in: ISSSR 1964, H. 3, 118-138, hier 120ff; Gukovskij, A.I.: Kak ja stal istorikom, in: ISSSR 1965, H. 6, 7699, hier 88; Minc, I.I./A.B. Mel'nikov: Akademik I.I. Minc otvečaet na voprosy zurnala "Voprosy istorii", in: VI 1968, H. 8, 182-189, hier 184. Vgl. dazu Marko, K.: Sowjethistoriker über sich, in: Gedenkschrift Martin Göhring. Studien zur europäischen Geschichte, Wiesbaden $1968,413-430$.

${ }^{103}$ Gukovskij, A.I.: Kak sozdavalas' ,Russkaja istorija s drevnejšich vremen“ M.N. Pokrovskogo (K 100-letiju so dnja roždenija M.N. Pokrovskogo), in: VI 1968, H. 8, 122-132 und H. 9, 130142.

104 Siehe Sokolov, O.D.: Razvitie istoriceskich vzgljadov M.N. Pokrovskogo, in: Pokrovskij, M.N.: Izbrannye proizvedenija, tom 1, M. 1966, 5-71; Sokolov, O.D.: Michail Nikolaevič Pokrovskij, in: ISSSR 1967, H. 1, 117-122; ders., M.N. Pokrovskij - vydajuščijsja organizator naučno-issledovatel'skoj raboty v SSSR, in: VI !969, H. 6, 30-45; ders., Bor'ba M.N. Pokrovskogo protiv dvorjansko-buržuaznoj istoriografii, in: ISSSR 1969, H. 5, 33-47; ders., M.N. Pokrovskij 1970. 
Straße, eine Bibliothek und eine Schule nach Pankratova zu benennen. ${ }^{105}$ Der Vizepräsident der Akademie, Fedoseev, schlug daraufhin dem Zentralkomitee der Partei vor, am 13. April 1967 eine ,besondere Sitzung" des Wissenschaftlichen Rates im Geschichtsinstitut abzuhalten und eine Straße Moskaus nach der Historikerin zu benennen. ${ }^{106}$ Das wurde seitens des Parteiapparats als ausreichend betrachtet. ${ }^{107}$ Eine historiographische Auseinandersetzung - vergleichbar derjenigen über Pokrovskij - mit der führenden Historikerin der vierziger und füfziger Jahre in der UdSSR fand nicht statt. Erst 1979 wurde eine Untersuchung ihres Werkes, vor allem ihrer Arbeiten zur Geschichte der Arbeiterklasse, vorgelegt. ${ }^{108}$

\subsubsection{Zur Geschichtsmethodologie}

In den sechziger Jahren waren in der UdSSR alle Natur- und Gesellschaftswissenschaften stark geprägt von der intensiveren Beschäftigung mit methodologischen und theoretischen Problemen. ${ }^{109}$ Darin stellte die Geschichtswissenschaft keine Ausnahme dar. Bei allen Konferenzen, die Anfang der sechziger Jahre zur Beratung politischer, ideologischer und historiographischer Fragen mit Historikem abgehalten wurden, erging die Mahnung an die Vertreter der historischen Disziplin, mehr als bislang geschichtstheoretische und -methodologische Probleme zu thematisieren. ${ }^{110}$ Die jährlichen Rechenschaftsberichte, die der Vorsitzende der Geschichtsabteilung der Akademie - von 1956 bis 1971 war das E.M. Zukov -, in Moskau vorzutragen hatte, zeugen von der entsprechenden Schwerpunktsetzung. Ende 1964 bezeichnete der Akademische Sekretär

„(..) eine gewisse Erhöhung der Aufmerksamkeit für die methodologische und allgemeinphilosophische Seite der historischen Forschungen (...)“ als „Hauptergebnis“

10s Minc. I.I./E. Gorodeckij/S. Jakubovskaja u.a. am 27.02.1967 an den ZK-Sekretär M.A. Suslov, in: CChSD f. 5, op. 59, d. 41, 61-63.

106 Fedoseev, P.N., Vizepräsident der AdW der UdSSR, am 11.04.1967 an das ZK und die Abteilung für Wissenschaft, ebd., 64. - Bei der Straße handelt es sich um die Verbindung zwischen der Ringstraße (Sadovaja-Spasskaja ulica) und der in das Zentrum Moskaus führenden Sretenka ulica.

107 Scerbakov, S., stellvertretender Leiter der Wissenschaftsabteilung des ZK der KPdSU, am 20.04.1967 an das ZK, ebd., 65.

108 Badja, Akademik. Siehe dazu die Fußnote 10 in Kapitel 3.1.1.

$109 \mathrm{Vgl}$ dazu Metodologiðeskie problemy nauki 1964: Metodologiðeskie problemy sovremennoj nauki. Sbornik statej, M. 1964 (= I. Buch) und (mit demselben Titel) M. 1970 (=2. Buch).

110 Siehe oben Kapitel 4.1. Vgl. Bejlina, E.E.: Istoriograficeskaja konferencija $\vee$ MGU, in: ISSSR 1963, H. 4, 217-220; Sul'gin, V.S.: Istoriograficeskaja konferencija v Moskovskom universitete, in: VI 1963, H. 7, 117-119; Kumanev, V.A.: Ob osnovnych napravlenijach razvitija issledovanij $\vee$ oblasti istorii $v$ Leningrade, in: VI 1965, H. 2, 122-125; Razgovor s citateljami našego ð̌urnala, in: ISSSR, H. 5, 228f; Zurnal 1966, 8; Levin, G.R./A.A. Sviridov: Čitatel'skaja konferencija $v$ Leningrade, in: VI 1966, H. 6, 170 f. 
des zu Ende gehenden Jahres; noch befinde sich aber der notwendige Umschwung in seinem Anfangsstadium. ${ }^{111}$ Der Chefredakteur der Voprosy istorii, Truchanovskij, hob in seinem Redebeitrag bei dieser Jahreshauptversammlung der führenden Historiker ebenfalls die ,methodologische Problematik“ an erster Stelle hervor. ${ }^{112}$ Funktionsträger wie Zukov und Truchanovski hielten die geschichtstheoretischen und -methodologischen Forschungen vor allem aus politischen Gründen für erforderlich; sie seien - so sagte Žukov in seinem Bericht über die Arbeit im Jahr 1966 - ,unbedingt notwendig für die erfolgreiche Führung des ideologischen Kampfs. " ${ }^{113}$ Ganz ähnlich begründete auch A.I. Danilov sein Plädoyer für die intensivere Ausarbeitung theoretisch-methodologischer Probleme, das Anfang 1961 in Voprosy istorii veröffentlicht wurde. ${ }^{114}$ Danilov bekannte sich zu dem, granitenen Fundament der marxistisch-leninistischen Lehre" und bezog sich positiv und unkritisch auf Parteibeschlüsse zur ideologischen Agitation und Propaganda. ${ }^{115}$ Folgende Probleme nannte Danilov: die Spezifik des Widerspiegelungsprozesses in der Geschichtswissenschaft, die Natur historischer Begriffe, die Spezifik ihrer Bildung, die Anwendung philosophischer, ökonomischer und juristischer Kategorien in der Geschichtsforschung, die Dialektik des Allgemeinen, Einmaligen und Besonderen in der historischen Erkenntnis, der Verallgemeinerungsprozeß, die methodologischen Grundlagen verschiedener Wege (Methoden) historischer Forschung, die theoretischen Prinzipien der Auswahl, Analyse und Bewertung von Geschichtsquellen unterschiedlichen Typs, das Leninsche Prinzip der Parteilichkeit und schließlich das Prinzip des Historismus. ${ }^{116}$ Dazu sollten Philosophen und Historiker verschiedener Forschungszweige interdisziplinär zusammenarbeiten, am besten in einer Arbeitsgruppe im Geschichtsinstitut der Akademie oder in einem dem Büro der Geschichtsabteilung zugeordneten Wissenschaftlichen Rat. In jedem Fall aber müsse, darauf legte Danilov Wert, die Arbeit einer solchen Gruppe den Interessen der allgemeinen Forschung untergeordnet und in den "offensiven Kampf gegen die gegenwärtige bürgerliche Historiographie" integriert sein. ${ }^{117}$

Danilovs prägnanter Beitrag hatte die Funktion eines Hinweis- und Aushängeschilds, mit dem ein fuihrender Historiker und politischer Funktionär die Richtung für die beginnenden Theorie- und Methodologiediskussionen vorgeben wollte. Aus Tomsk, wo Danilov bald darauf den Lehrstuhl furr Alte und Mittelalterliche Geschichte übernahm, kamen auch in den folgenden Jahren weitere Impulse für die

111 Siehe den Bericht von Bromlej, Ju.V./V.I. Neupokoev: Godičnoe Obš̌̌ee sobranie Otdelenija istorii AN SSSR, in: VI 1965, H. 6, 140-151, hier 140.

112 Ebd., 150.

113 Siehe den Bericht von Assaturova, M.I.: Obšcee godičnoe sobranie Otdelenija istorii, in: VI 1967 , H. 6, 155-162, hier 155 .

114 Danilov, A.I.: O nekotorych voprosach dal'nejšego izučenija teoretiko-metodologičeskich problem istoričeskoj nauki, in: VI 1961, H. 3, $216 f$.

115 Ebd., 216.

116 Ebd., 217.

117 Ebd., 217. 
Geschichtsdiskussionen. Danilov begründete und leitete dort ein Seminar für methodologische Fragen der Geschichtswissenschaft. ${ }^{118}$ Forschungsergebnisse und Diskussionsbeiträge der Beteiligten flossen in den Sammelband ,Methodologische und historiographische Fragen der Geschichtswissenschaft" ein, der erstmals 1963 erschien, und von dem 1990 die neunzehnte Ausgabe veröffentlicht wurde. Die 1963 bis 1969 publizierten sechs Ausgaben des Sammelbandes enthielten insgesamt 61 Aufsätze. In erster Linie befaßten sich die Tomsker Historiographen mit der deutschen, respektive bundesdeutschen Geschichtsschreibung und -philosophie. ${ }^{119}$ Wenngleich diese Artikel nicht völlig in dem Stil „Kampf gegen...“ geschrieben waren, ging es auch hier in erster Linie um die Entlarvung „bürgerlicher Falsifizierer" und darum, nach innen, den eigenen Kollegen zu signalisieren, was opportun war. ${ }^{120}$ Zweiter Schwerpunkt der Tomsker Sammelbände waren die Probleme der marxistisch-leninistischen Geschichtstheorie und -methodologie, wozu in den sechziger Jahren siebzehn Artikel publiziert wurden. ${ }^{121}$ Wie in den folgenden Kapiteln zu sehen sein wird, waren darunter auch manche konstruktive Diskussionsbeiträge. Die übrigen vierundzwanzig Aufsätze verteilten sich auf Themen der angloamerikanischen, französischen, vorrevolutionären russischen, der ostdeutschen und der sowjetischen Historiographie. ${ }^{122}$

Eine gegenüber Aleksandr Danilovs Programm alternative Orientierung formulierte Michail Gefter. Er begründete die geschichtstheoretischen und -methodologischen Diskussionen (nicht ausschließlich, aber vorrangig) wissenschaftich und nicht poli-

118 Boris Georgievič Mogil'nickij, der Lehrstuhlnachfolger Danilovs, schrieb an den Autor: „Gewiß, in Tomsk gab es niemals ein spezielles Zentrum, ähnlich der Sektion für Geschichtsmethodologie am Institut für Geschichte der AdW der UdSSR. In gewissem Maße erfullten (und erfüllen) jedoch der 1962 von A.I. Danilov gegrindete Lehrstuhl für die Geschichte der Alten Welt und des Mittelalters und auch das von inm gegnündete methodologische Seminar, welches bis in die Gegenwart weiterarbeitet, die Funktionen eines solchen Zentrums. (...) Gerade in diesem Rahmen werden die geschichtsmethodologischen Forschungen und die methodologischen Diskussionen zu aktuellen Problemen der geschichtlichen Erkenntnis gefüht.“ - Mogil'nickij, B.G. am 14.06.1991 an J.H.

11 Dazu erschienen zwanzig Beiträge, die der Rezeption von Otto von Freising. Leopold von Ranke. Heinrich von Sybel, Karl Lamprecht, Georg von Below, Karl Mannheim, Friedrich Meinecke u.a. gewidmet waren. Die Auflage betrug meist 500, nie mehr als 700 Exemplare.

120 Bei der internationalen Konferenz, „Rußland im 20. Jahrhundert: Schicksale der Geschichtswissenschaft", die vom 06. bis 09. April 1993 tagte, referierte G.Z. loffe, der jahrzehntelang „Falsifizierungsliteratur“ geschrieben hatte, über den „Kampf gegen die ausländische Geschichtsschreibung“. Er berichtete, daß es gar nicht darum ging, die ausländischen Autoren zu kritisieren und dieser Kampf nicht so sehr nach außen gerichtet war, sondern nach innen. - Eigene Mitschrift des Verfassers.

121 27,9 Prozent aller Aufsätze.

122 Elf dieser Artikel befaßten sich mit anglo-amerikanischer und französischer Geschichtsschreibung $(18,3 \%)$, sieben mit der vorrevolutionären russischen Historiographie $(11,7 \%)$, vier mit der Geschichtswissenschaft in der DDR $(6,7 \%)$, nur einer mit der sowjetischen Historiographie, konkret mit der Geschichte des Kapitalismus in Sibirien $(1,7 \%)$. 
tisch. Die „Methodologie der Geschichte“ definierte Gefter in der „Sowjetischen Geschichtsenzyklopädie“ 1966 als

„Theorie historischer Erkenntnis. Die Methodologie der Geschichte erarbeitet Prinzipien und Mittel zur Beschaffung von Wissen über die Vergangenheit, zur Systematisierung und Interpretation der erhaltenen Daten mit dem Ziel, das Wesen des historischen Prozesses aufzuklären sowie ihn in aller Konkretheit und Ganzheit zu rekonstruieren. “123

$\mathrm{Zu}$ den Grundproblemen der Geschichtsmethodologie gehörten: der Gegenstand und die Grenzen der Geschichtswissenschaft, die Wechselbeziehung der historischen Disziplin zu anderen wissenschaftlichen Disziplinen, die soziale Funktion und Wirksamkeit der Geschichtswissenschaft, die Erkennbarkeit und das objektive Kriterium der Wahrheit bei der Erforschung des Vergangenen, Begriffe als hauptsächliches Erkenntnismittel und als unmittelbarer Untersuchungsgegenstand, die historische Tatsache und ihr Platz bei der Rekonstruktion des Vergangenen, die Spezifik der Geschichtsforschung, die Aufeinanderfolge und Wechselbeziehung ihrer Schritte und Formen ${ }^{124}$ Gefter hielt es fur notwendig, diese Probleme in neuen organisatorischen Zusammenhängen interdisziplinär zu behandeln, ohne durch akademischen Bürokratismus und die Erfolgsorientierung des etablierten Forschungsbetriebs behindert zu werden. So verteidigte Gefter in der Jahreshauptversammlung der Geschichtsabteilung Anfang 1967 die Tätigkeit der Arbeitsgruppen und

„(..) sprach über die Bedeutung der schöpferischen Diskussionen unabhängig davon, ob sie zu einem endgültigen Resultat führen. Er betonte, daß die Konzentration der Aufmerksamkeit eines großen Forscherkreises auf die Lösung strittiger Probleme sowie das Aufdecken neuer Standpunkte und widersprüchlicher Meinungen im Diskussionsverlauf schon an sich ein bedeutender Beitrag zur Wissenschaft sei. Es sei sehr wichtig (...), daß die Ergebnisse der schöpferischen Diskussionen operativ dem weiten Kreis der wissenschaftlichen Gemeinschaft vermittelt werden, was bei uns noch nicht immer gemacht wird. “"125

Tatsächlich entstanden seit Anfang der sechziger Jahre zahllose größere und kleinere Gruppen, Seminare und Zirkel, in denen Historiker und Vertreter anderer Wissenschaften, Studierende, Dozenten und Professoren an den Hochschulen, Universitäten und Akademie-Institutionen des Landes geschichtstheoretische und methodologische Fragen erörterten. ${ }^{126}$ Die in Moskau und für die Entwicklung der historischen Disziplin im ganzen Land wichtigste Einrichtung war zweifelsohne die von Michail Gefter geleitete „Sektion zur Bearbeitung methodologischer Probleme

123 Gefter, M.Ja: Metodologija istorii, in: SIE 9. M. 1966, 387-401, hier 387.

124 Ebd., 388; vgl. ebd., $391 f$.

125 So berichtete Assaturova, Obšxee godičnoe sobranie, 162.

126 Jurij Aleksandrovic Moškov, der Dozent an der Historischen Fakultä der LomonasovUniversität, der den Verfasser bei seinen Moskauaufenthalten 1990 und 1992 wissenschaftlich betreute, erzählte, daß die Zahl der Gruppen tatsächlich unüberschaubar und ihre Aktivitäten vielfältig gewesen seien. 
der Geschichte“ am Geschichtsinstitut der Akademie der Wissenschaften der UdSSR $^{127}$ Als die Sektion im Januar 1964 ihre Arbeit aufnahm, nannte Gefter folgende Schwerpunktthemen:

„Marxismus und historisches Denken im 19. und 20. Jahrhundert; die Korrelation der Methodologie des historischen Materialismus und konkret-historischer Forschungen; die Korrelation allgemeiner Gesetze der Geschichte und konkreter Formen des welthistorischen Prozesses. “128

Vielleicht werden weitere Untersuchungen dies korrigieren, aber den derzeit vorliegenden Quellen und Aussagen Beteiligter zufolge, prägten Gefters Vorstellungen die Arbeit der Sektion in entscheidendem Maße. Gefter ging es vor allem darum, die zentralen Gedanken von Marx, Engels und Lenin zur Geschichts- und Gesellschaftstheorie zu überprüfen. Er wollte die Frage beantworten, ob mit diesen Voraussetzungen die Geschichte Rußlands und der Sowjetunion erforscht und erklärt werden könne. Hier stießen sowjetische Historiker ja immer dann, wenn es um die Geschichte der Sowjetgesellschaft ging, auf vorgefertigte Antworten und auf verschlossene Archive und Bücherschränke. Ohne kritische Forschungsfragen und ohne Quellen war Gefters Problem aber nicht zu lösen. Deshalb - so berichtete Svetlana Neretina - versammelte Gefter in ,seiner" Sektion bewußt Spezialisten verschiedener Länder und Perioden; Fachhistoriker, die auf besserer Quellen- und Literaturbasis arbeiten konnten als die otecestvenniki, die auf die russische und sowjetrussische Geschichte spezialisierten „Vaterlands“-Historiker. Dank der Mitarbeit jener sollte geprüft werden, ob die Marxsche oder Leninsche Geschichtskonzeption bei der Erforschung etwa Westeuropas, Amerikas, Byzanz', des Mittelalters, der Antike usw, ,arbeitet" (rabotaet). So wollte Gefter herausfinden, wie die theoretischen und methodologischen Grundlagen der historischen Forschung in der Tradition von Marx und Lenin weiterentwickeht werden könnten; daß dies notwendig und möglich sei, davon war er überzeugt. ${ }^{129}$ Das absolvierte Arbeitspro-

\footnotetext{
127 Den Beschluß zur Gründung dieser Arbeitsgruppe faßte das Präsidium der AdW 1963 auf Initiative der diesem Präsidium direkt angegliederten Sektion Gesellschaftswissenschaften. Nicht zu vergessen ist also, daß die später als dissidentisch eingestufte Methodologiesektion ursprünglich eine offizielle AdW-Institution war. Siehe ISSSR 1964, H. 1, 216; Markvik, R.: Doklad po teme: „Katalizator istoričeskoj nauki i ideologii: sektor metodologii Instituta istorii AN SSSR, 1964-1968 gg." (1992); Markwick, R.D.: Catalyst of Historiography, Marxism and Dissidence: The Sector of Methodology of the Institute of History, Soviet Academy of Sciences, 1964-68, in: Europe-Asia Studies 1994, H. 4, 579-596, hier 580; vgl. Neretina, Istorija. - Ich danke Roger Markwick (Sydney) für die Überlassung des Typoskripts seines Vortrags aus dem Jahr 1992.

128 Siehe Cernova, L.N.: Chronika (der Sektionsarbeit 1964-1968), Typoskript (6 Seiten) in: NA 1,1

129 Vgl. Neretina, Interv'ju, 15-19. Nekric schrieb: „Gefter war ein uberzeugter, ernsthafter und gründlicher Marxist. Er war bestrebt, Lenin neu zu entdecken, den Leninismus oder wenigstens die methodologischen Grundlagen des Geschichtsverständnisses von vulgarisierenden Ablagerungen und Mythen zu reinigen. Gefter und einige andere Gesellschaftswissenschaftler, die sein Seminar besuchten, wollten aufrichtig den Marxismus verbessern, dessen richtiges Verständnis erreichen und die Ausarbeitung des Leninismus zur Anwendung auf unsere Zeit fortsetzen." -
} 
gramm reflektierte Gefters Intentionen, die aber sicherlich nicht nur von ihm vertreten wurden; ansonsten hätte die Sektion nicht einen derartigen Zulauf gehabt. Der von Cernova angefertigten Chronik ${ }^{130}$ zufolge referierte beispielsweise 1964 Ja.S. Drabkin über die Erforschung sozialer Revolutionen; ${ }^{131} 1965$ berichtete V.Ja. Zevin über die füfte Ausgabe der Werke Lenins; 1966 sprachen A.L. Mongajt über ,archäologische Kulturen" und ethnische Einheiten, ${ }^{132}$ M.A. Barg und E.N. Černjak über die Typologisienung von Gesellschaftsformationen, ${ }^{133}$ I.V. Bestužev über die Analyse und Bewertung von Außenpolitik und Kriegen, ${ }^{134}$ N.N. Maslov über die Entwicklung der Parteigeschichtsschreibung 1931 bis 1955, M.G. Pankratova und V.L. Mal'kov über die amerikanische, ${ }^{135}$ N.P. Komolova über die italienische Geschichtswissenschaft; ${ }^{136} 1967$ diskutierten Ju.I. Semenov über die Formationstheorie und den weltgeschichtlichen ProzeB, ${ }^{137}$ E.N. Gorodeckij über die Erforschung der Oktoberrevolution, ${ }^{138}$ I.V. Grigor'ev über geschichtsmethodologische Probleme im Werk von Antonio Gramsci; ${ }^{139} 1968$ referierte E.M. Staerman über die Frage: „Antike - Gesetzmäßigkeit oder Ausnahme?“ ${ }^{140}$ A.A. Zinov'ev über Logik und historische Forschung, I.V. Blauberg und E.G. Judina über Möglichkeiten und Probleme des Systemzugangs bei Sozialforschungen, G.S. Pomeranc über die Rolle der Maßstäbe von Zeit und Raum bei der Modellierung des Geschichtsprozesses. Lebhafte und kontroverse Diskussionen nach den Referaten waren die

Nekrič, Otrełis' of stracha, 243; vgl. auch Gefters Aufsatz Rassija i Marks von 1977, wiederabgedruckt in: Gefter, Iz tech i etich let, 37-63

130 Cernova. Chronika (o.J.), 1-3.

$131 \mathrm{Vgl}$. Drabkin, Ja.S.: Nerełennye problemy izučenija social'nych revoljucij, in: Istoričeskaja nauka 1969, 209ff (mit Diskussionsbeiträgen).

132 Vortrag und Diskussion wurden veröffentlicht in der Zeitschrift Narody Azii i Afriki 1967 , H. 1.

133 Vgl. Barg. M.A.: Ponjatie vsemirno-istoričeskogo kak poznavatel'nyj princip istoričeskoj nauki, M. 1973 (35 Seiten; die deutsche Übersetzung - Barg, M.: Die Kategorie des Welthistorischen als Erkenntnisprinzip der marxistischen Geschichtswissenschaft. in: Engelberg, E./W. Küttler $(\mathrm{Hg}$ ): Probleme der geschichtswissenschaftlichen Erkenntnis, Berlin 1977, 39ff).

134 Bestužev, I.V.: K analizu charaktera vnešnej politiki i vojn. Kriterii progressivnosti i spravedimosti, in: Istoričeskaja nauka 1969, 394ff (mit Diskussionsbeiträgen).

$135 \mathrm{Mal}$ 'kov, V.L.: K sravnitel'no-istoričeskomu izučeniju radikal'nych social'nych dviženij v SSA, in: Istoričeskaja nauka 1969, 126-158; Pankratova, M.G.: Problematika russkoj revoljucii v amerikanskoj rusistike, ebd., 192-208.

136 Komolova, N.P.: Obščstvenno-političeskaja bor'ba i osobennosti razvitija poslevoennskoj ital'janskoj istoriografii, in: Istoričeskaja nauka 1969, 159-176.

$137 \mathrm{Vgl}$. den späten Wiederabdruck in deutscher Sprache - Semjonov, Ju.I.: Ökonomische Gesellschaftsformationen und Weltgeschichte, in: Ökonomische Gesellschaftsformationen. Theorie und Geschichte. hg. vom IMSF, Frankfurt am Main 1981, 32-43.

138 Gorodeckij, Nekotorye certy.

139 Vgl. Grigor'ev, I.V.: Istoriðeskie vzgljady Antonio Gramši, M. 1978.

$140 \mathrm{Vgl}$. dazu Staerman, E.M.: Antičnoe obščestvo. Modernizacija istorii $i$ istoričeskie analogii, in: Problemy istorii dokapitalisticeskich obłčestv. Kniga 1, M. 1968, 638-671. 
Regel. ${ }^{141}$ Der ZK-Apparat beobachtete die Arbeit der Sektion, deren Existenz stets gefährdet war, von Anfang an mißtrauisch. ${ }^{142}$ Erst 1968 - im Zusammenhang mit der ,Affäre Nekrič“ - begann die offene Attacke gegen die Sektion; die Auseinandersetzung zog sich hin bis $1974 .{ }^{143}$ In der ersten Phase, 1968/69, in der die Sektion aufgelöst wurde, konnten noch die ersten (und letzten) Arbeitsergebnisse publiziert werden. Dabei handelte es sich um folgende Sammelbände: „Probleme der Geschichte vorkapitalistischer Gesellschaften. Buch 1" 144 "Quellenkunde. Theoretische und methodische Probleme“, ${ }^{145}$ "Geschichtswissenschaft und einige Probleme der Gegenwart"146 und „Philosophische Probleme der Geschichtswissenschaft“. ${ }^{147}$ Ein Sammelband anläßlich der 100. Wiederkehr des Geburtstags Lenins $^{148}$ ging zwar noch zum Druck, wurde aber auf Drängen der Institutsleitung nicht mehr publiziert. ${ }^{149}$ Zwei weitere Sammelbände waren in Vorbereitung, konnten aber ebenfalls nicht mehr fertiggestellt werden. ${ }^{150}$

Besonders in der Einleitung zu den Aufsätzen und Diskussionsbeiträgen über "Geschichtswissenschaft und einige Probleme der Gegenwart" wurden die Absichten und die Herangehensweise der Autoren - und stellvertretend aller an der Arbeit der Methodologiesektion Beteiligten - prägnant formuliert: Die seit dem 20. Parteitag der KPdSU zu beobachtende intensivere Bearbeitung geschichtsmethodologischer Fragen sei zu begrüßen, denn auf diesem Gebiet müßten Empirie und Theorie vereint und über die Weiterentwicklung der Disziplin entschieden werden. Dazu sei die Aneignung des marxistischen, leninistischen Erbes erforderlich. Allerdings nicht durch die „Mobilisienung von 'Zitaten'“, sondern durch eine ,neue Lesart" (novym proxteniem) der Geschichtskonzeption von Marx. Engels und Lenin. ${ }^{\text {st }}$ Die Entwicklung dieses Geschichtsdenkens müsse mit besonderer Betonung der Methode und der Dialektik der Widersprüche analysiert werden. ${ }^{152}$ Inzwischen sei auch klar, daß die Geschichtsmethodologie nicht außerhalb der historischen Dis-

\footnotetext{
$141 \mathrm{Vgl}$. Neretina, Istorija, 151-155.

142 Siehe ebd., 155ff.

143 Siehe Kapitel 4.1. und 5.1.

144 Problemy istorii 1968 (691 Seiten Umfang. 2.000 Exemplare); diesem Buch sollten in der Reihe „Gesetze der Geschichte und konkrete Formen des welthistorischen Prozesses“ weitere Sammelbände folgen.

145 Istočnikovedenie. Teoretičeskie i metodičeskie problemy, M. 1969 (511 Seiten Umfang. 2.800 Exemplare).

146 Istoričskaja nauka 1969 (430 Seiten Umfang, 4.600 Exemplare).

147 Filosofskie problemy istorizeskoj nauki, M. 1969 (318 Seiten Umfang, 5.600 Exemplare).

148 Vorgesehener Titel: "Lenin i problemy istorii klassov i klassovoj bor by“.

149 Siehe Neretina, Istorija, 157.

1so Die geplanten Titel lauteten: „Probleme der Strukturanalyse in der Geschichtsforschung“ und ,Logik des kulturellen Wandels"; siehe ebd., 157.

151 Istoriceskaja nauka 1969,6.

152 Ebd., 6f.
} 
ziplin erarbeitet werden könne. ${ }^{153}$ Ausgehend von ihren Forschungsergebnissen müßten die Fachhistoriker selbst nach Auswegen in der Geschichts- und Erkenntnistheorie suchen. Dabei beanspruche niemand, endgültige Lösungen zu präsentieren: der Sammelband habe Diskussionscharakter, biete verschiedene Standpunkte und Hypothesen an. ${ }^{154}$ Die Autoren der Einleitung bezeichneten es als „offenkundig", daß solche schöpferische Diskussionen der Sache der Marxisten nicht schadeten, sondern ,unsere dialektisch-materialistische Methode" bereicherten und die Voraussetzung seien für einen erfolgreichen Kampf gegen Antikommunismus und fur die Gewinnung derjenigen nichtmarxistischen Kollegen im Ausland, die in objektiver Weise historische Forschung betrieben. ${ }^{\text {1ss }}$

So lautete - kurz gefaßt - die Forschungsprogrammatik der unter Michail Gefters Leitung arbeitenden Methodologiesektion. Die einzelnen Beiträge zu den „Problemen der Geschichte vorkapitalistischer Gesellschaften" und zu „Geschichtswissenschaft und einige Probleme der Gegenwart" liegen außerhalb des hier interessierenden Themenkreises und werden nicht weiter benücksichtigt. Ein großer Teil der Aufsätze zur „Quellenkunde“ und über „Philosophische Probleme der Geschichtswissenschaft" ergänzt die Materialgrundlage der Untersuchungen in den folgenden Kapiteln. In diesen sollen bei weitem nicht alle Probleme der Geschichtsmethodologie behandelt werden, sondern nur diejenigen, die von fundamentaler Bedeutung waren und sind, und die Gegenstand besonders lebhafter Kontroversen wurden. Das trifft auf folgende Themen zu: das Verhältnis von Philosophie und Einzelwissenschaft, von historischem Materialismus und Geschichtswissenschaft; die historische Tatsache als geschichtsmethodologisches Problem; Gesetzmäßigkeit und Alternativität in der Geschichte; Parteilichkeit, Objektivität und Historismus als Prinzipien historischer Forschung.

\footnotetext{
153 Ebd., 7.

154 Ebd., $9 f$.

15s Ebd., 10.
} 


\subsection{Gegenstandsdiskussion. Zum Verhältnis von Philosophie und Einzelwissenschaft}

Als die 1957 erstickte Methodologiediskussion wieder begann, war es kein Zufall, $\mathrm{da} B$ die Gegenstandsproblematik das erste zentrale Thema war und die ganze Diskussionsphase hindurch blieb. Denn, hierin ist dem zu Zeiten der DDR führenden Historiker Ernst Engelberg grundsätzlich beizupflichten, die Bestimmung des Gegenstands der marxistischen Geschichtswissenschaft stellt „das erste der Grundprobleme ihrer Methodologie" dar. ${ }^{\prime}$ In der Sowjetunion waren die Fragen nach der Korrelation von Geschichte und Philosophie einerseits, von Geschichte und weiteren Einzelwissenschaften andererseits in den sechziger Jahren aus zwei weiteren Gründen pressant. Erstens verlangte die Weiterentwicklung der marxistischen Soziologie und des sogenannten Wissenschaftlichen Kommunismus eine neue Definition des Platzes der Historie im System der Gesellschaftswissenschaften. ${ }^{2}$ Zweitens behinderte die unter Stalin durchgesetzte ,Identitätsthese ${ }^{\text {‘3 }}$ bezüglich des historischen Materialismus und der Geschichtswissenschaft die von Historikerinnen und Historikern immer deutlicher verlangte eigenständige Entwicklung der historischen Disziplin. Der offiziell gültigen sowjetischen Auffassung zufolge erforschte der historische Materialismus, aufgefaßt als Ausdehnung des dialektischen Materialismus auf die Untersuchung der Gesellschaft, nicht eine bestimmte Seite, sondern die Wechselbeziehung aller Seiten, die allgemeinen Gesetze des gesellschaftlichen Lebens. ${ }^{4}$ Wenn die "Besonderheit" der Geschichtswissenschaft darin bestehen sollte, daß sie

„(...) den Entwicklungsprozeß der Gesellschaft insgesamt, die ganze Gesamtheit der Phänomene des gesellschaftlichen Lebens, alle seine Seiten in ihrer Wechselwirkung und wechselseitigen Bedingtheit" erforscht",

wodurch könnte sich dann die historische Disziplin noch auszeichnen gegenüber dem historischen Materialismus und dem Wissenschaftichen Kommunismus? In den fünfziger Jahren antwortete der polnische Philosoph Adam Schaff auf das Dilemma, historischer Materialismus und Geschichtswissenschaft hätten tatsächlich den gleichen Erkenntnisgegenstand (Entwicklung und Entwicklungsgesetzte der

1 Engelberg. E.: Über Gegenstand und Ziel der marxistisch-leninistischen Geschichtswissenschaft, in: Marxismus Digest 1971, H. 2, 3-29, hier 3 (Erstveröffentlichung in: ZfG 1968, H. 9); vgl. auch Großer, G.: Der Gegenstand des wissenschaftlichen Kommunismus. Methodologische Probleme seiner Bestimmung, Berlin 1981, 82

2 Kachk, Ju.: Nužna li novaja istoričeskaja nauka? In: VI 1969, H. 3, 41-54, hier 50.

3 Naumann, Ökonomische Gesellschaftsformation, 22f. Siehe auch Kapitel 3.1.3.

4 Zugleich galt der historische Materialismus als verbindliche Methode und gemeinsame Theorie aller sowjetischen Gesellschaftswissenschaften. - Fedorova, A.T.: K voprosu o predmete istoriceskogo materializma, in: VF 1957, H. 3, 49-60, hier 49, 54, $58 \mathrm{f}$.

s Grekov, B.D.: Istorija, in: BSE (II), 19, 24-33, hier 28. Diese fur die Stalinzeit maßgebende Bestimmung floß auch noch in den ersten Band der "Studien zur Geschichte der Geschichtswissenschaft in der UdSSR“ ein, siehe Oxerki istorii istoricesko nauki v SSSR, tom 1, M. 1955, 7. 
Gesellschaft), sie unterschieden sich voneinander nur in der Anwendung verschiedener Methoden, der logischen und der historischen. ${ }^{6}$ In der Auseinandersetzung damit suchten sowjetische Philosophen eine terminologische Lösung dergestalt, $\mathrm{da} B$ historischer Materialismus und Geschichtswissenschaft sich zwar mit dem gleichen „Objekt“ der Gesellschaft, aber mit verschiedenen Gegenständen (predmet) befaßten. Auf dieser Grundlage blieb die Präzisierung des Gegenstands der Geschichtswissenschaft kontrovers. Vier Definitionsversuche konkurrierten in den sechziger Jahren, wobei die erste Position den Gesetzesbegriff für die Geschichtswissenschaft negierte, während die übrigen Auffassungen ihn - in der einen oder anderen Weise - für die Geschichtswissenschaft reklamierten.

Erstens: Der Leningrader Historiker und Philosoph Rožin war ein entschiedener Befürworter eines dezidiert empiristischen Gegenstandsverständnisses. Er schlug eine klare Arbeitsteilung zwischen beiden Diszplinen vor: die manxistische Soziologie, das heißt: der historische Materialismus, solle die „soziologischen Gesetze der Entwicklung und der Funktionsweise ökonomischer Gesellschaftsformationen" aufdecken. Die Geschichtswissenschaft habe den ,konkreten Gang der geschichtlichen Entwicklung“ und die ,geschichtlichen Ereignisse in ihrer inneren Verbindung“ zu beschreiben sowie den „Prozeß der Verwirklichung gesellschaftlicher Gesetze" zu erforschen. In dem $\mathrm{MaB}$, in welchem Geschichtswissenschaft selbst Gesetze entdecke und formuliere, wiederhole sie bloß die Arbeit der Soziologie und erfülle die eigentlichen Funktionen der Beschreibung und Verallgemeinerung nicht. ${ }^{8}$

Zweitens: Dazu ganz im Gegensatz plädierten der Sozialwissenschaftler Igor Kon ${ }^{9}$ und der Philosoph Boris Grušin dafür, die modemen nichtmarxistischen Gesell-

6 Saff, A: Ob-ektivnyj charakter zakonov istorii (polnische Erstveröffentlichung 1955), M. 1959, 375ff; analog auch Ivanov, G.M.: K voprosu o svoeobrazii istoriðeskogo poznanija, in: MIVIN, vypusk 1, T. 1963, 3-26.

1 So Pripiznov, V.I.: O sootnošenii istoričeskogo materializma i istoriðeskoj nauki, in: VF 1961, H. 1, 103-113, hier 105; Rožin, V.P.: Vvedenie v marksistskuju sociologiju, L. 1962, 36f: Verbin, A.I./G.D. Karelova: $K$ istoriografii voprosa o sootnołenii predmetov istoričeskogo materializma $i$ istoričeskoj nauki, in: TMGIAI, tom 18: Voprosy istorii sovetskogo obščestva, novoj i novejక̌ej istorii, M. 1963, 21-33; Gulyga, A.V.: O predmete istoričeskoj nauki, in: VI 1964, H. 4, 20-31; Verbin, A./A. Furman: Mesto istoričeskogo materializma v sisteme nauk, M. 1965, 88ff.

8 Rožin, Vvedenie, 36ff; Marksistsko-leninskaja filosofija. Učebnoe posobie. M. 1964, 294f. Rožin zählte zu den verantwortlichen Redakteuren und Autoren dieses Lehrbuchs. Vgl auch RoŽin, V.P.: Istoričeskij materializm - vseobక̌caja metodologija obščestvennych nauk, in: Metodologixeskie voprosy obscestvennych nauk. Vyp. 1, L. 1968, 5-18, hier besonders 16.

9 Er hatte bereits 1951, noch ganz dem Lobgesang auf „die genialen Arbeiten des Genossen Stalin“ verpflichtet, versucht, die Spezifik der Geschichtswissenschaft zu verdeutlichen: Auf der Grundlage der vom historischen Materialismus formulierten allgemeinen Gesetze erforsche die Geschichtswissenschaft „Teilgesetze“ einzelner Perioden, Epochen und Formationen und stelle die ,konkreten Formen des historischen Prozesses in ihrer ganzen Fülle und Vielfalt" dar. - Kon, I.S.: K voprosu o specifike i zadačach istoričeskoj nauki, in: VI 1951, H. 6, 48-64, hier nach der deutschen Übertragung: Zur Frage der spezifischen Besonderheiten und der Aufgaben der Ge- 
schaftswissenschaften kritisch zu rezipieren und in Anlehnung an sie den Theoriegehalt der sowjetischen Geschichtswissenschaft deutlich zu erhöhen. ${ }^{10}$ Den ihres Erachtens in die "Sackgasse“ geratenen nichtmarxistischen Strömungen setzten Kon und Grušin ihre zwar getrennt vorgestellten, aber analogen materialistischdialektischen Konzepte entgegen, mit denen Theorie und Empirie versöhnt, die Spezifik und die Wissenschaftlichkeit der historischen Disziplin sowie deren Platz im System der (Gesellschafts-) Wissenschaften bestimmt werden sollten. Die moderne marxistische Geschichtswissenschaft müsse das Ziel verfolgen, den geschichtlichen Entwicklungsprozeß, das heißt, das Untersuchungsobjekt als System in Entwicklung zu reproduzieren, was ohne theoretische Voraussetzung und Ver-

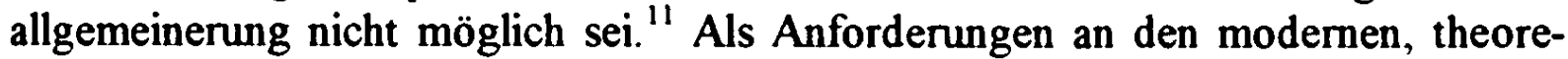
tisch versierten marxistischen Historiker befanden die beiden Autoren:

- bei der Reproduktion von den empirischen Daten, Tatsachen und Verbindungen auszugehen, ${ }^{12}$

- alle an der Oberfläche des geschichtlichen Verlaufs zu beobachtenden Fakten nur als äußere Erscheinungsform des objektiven, naturgeschichtlich-gesetzmäßigen

schichtswissenschaft, in: SW 1951, H. 2, 230-250, hier 230 und 236, kritisch dazu Naumann. Ökonomische Gesellschaftsformationen, $11 f$.

10 Kon setzte sich dabei mit positivistischen (A. Comte, Spencer, J.S. Mill, M. Schlick, O. Neurath. R. Carnap), neokantianischen (W. Dilthey, B. Croce. R.D. Collingwood. W. Windelband, H. Rickert) und neopositivistischen (K. Popper, C. Hempel, P. Gardiner, W. Dray) Positionen auseinander. - Kon, I.S.: Buržuaznaja filosofija istorii v tupike, in: VI 1960, H. 12, 30-54: ders., Neopozitivizm i voprosy logiki istoričeskoj nauki, in: VI 1963, H. 9, 45-65; ders., K sporam o logike istoričeskogo ob-jasnenija (schema Poppera-Gempelja i ee kritiki), in: Filosofskie problemy istoričeskoj nauki, M. 1969, 263-295. - Grušin „beackerte“ die dialektische Logik historischer Forschung auf der Grundlage eines (m.E. zu) weit gefaßten Begriffs der .,modernen historischen Wissenschaften“, zu denen er die "historisierenden“" Bereiche geradezu aller Wissenschaften zählte, z.B. evolutionäre Biologie. Wissenschaftsgeschichte. Sprachwissenschaft. Geomorphologie, Kosmogonie, Anthropologie, Politökonomie usw., weshalb seine Ausfuihrungen entsprechend multidisziplinär, abstrakt und für die Geschichtswissenschaft wenig ergiebig gerieten. Vgl. Grušin, B.A.: Marks i sovremennye metody istoričeskogo issledovanija, in: VF 1958, H. 3, 11-25; ders., Očerki logiki istoričeskogo issledovanija (process razvitija i problemy ego naučnogo vosproizvedenija), M. 1961, besonders 3ff; $17 \mathrm{ff}$.

"Grušin unterschied die Geschichtstheorie, die Entwicklungsprozesse als Systemtheorie reproduziere, von der „theoretischen Geschichte“ als Wissenschaft, die Systemgeschichte oder die "Geschichte des Systems" reproduziere. Der Theoretiker reproduziere den strukturellen Zustand des Systems als dessen Entwicklungsresultat; die Struktur des sich entwickelnden Systems sei sein Untersuchungsgegenstand (predmet). Der Historiker hingegen müsse die geschichtlichen und strukturellen Verbindungen zwischen den genetisch gegebenen Formen des Systems und die empirische Geschichte des Systems als äußere Erscheinungsform seines Entwicklungsprozesses reproduzieren. - Grušin, Marks i sovremennye metody, $11 \mathrm{ff}$, vgl. Kon, Neopozitivizm, 6lf, ders., K sporam, $289 f$.

12 Der Historiker müsse „(...) nicht die einen oder anderen empirischen Fakten und Ereignisse (...) und nicht die einen oder anderen einzelnen inneren Formen (...), sondern eine Menge, Masse solcher innerer Formen (Elemente, Verbindungen) (...)" berücksichtigen. - Hervorhebungen von Grušin, Marks i sovremennye metody, 22. 
Prozesses zu betrachten, zu deren Erklärung dieser zugrundegelegt werden müs$\mathrm{se}^{13}$

- das Objekt als ganzes, einheitliches System, in und mit der ihm eigenen Struktur $2 u$ reproduzieren, nicht nur in einigen Bestandteilen; ${ }^{14}$

- den Prozeß zu reproduzieren, das heißt, die Gesamtheit der geschichtlichen Zusammenhänge zwischen den zeitlich aufeinanderfolgenden und äußerlich nicht miteinander verbundenen Bestandteilen des Objekts;

- nicht einfach die Veränderung des Objekts in der Zeit, sondern den Prozeß qualitativer Veränderungen, also Veränderungen in der Struktur des Systems zu reproduzieren;

- schließlich auch die Gesetze des Übergangs von einem (qualitativen) geschichtlichen Zustand in einen anderen aufzudecken und zu reproduzieren. ${ }^{15}$

Wenn die geschichtlich-gesellschaftliche Entwicklung ein gesetzmäßiger Prozeß sei, könne der Historiker sie nicht reproduzieren, ohne selbst die Gesetze dieser Entwicklung aufzudecken. So führe

"(...) die Geschichte notwendig zur Theorie, und die genetische Erklärung zur Erklärung durch das Gesetz oder die Gesamtheit von Gesetzen." "16

Drittens: Der Hegel-Biograph Gulyga ${ }^{17}$ formulierte die Position derer, die allgemeine oder gesellschaftliche Gesetzmäßigkeiten zum Gegenstand der Geschichtsforschung erklärten:

"Gegenstand der Geschichte ist die Untersuchung der Gesetze der gesellschaftlichen Entwicklung in ihren konkreten Erscheinungformen. " 18

\footnotetext{
13 Ebd., 24.

14 Kon, Neopozitivizm, 62; ders., K sporam, 290; ebenso auch Grušin, Marks i sovremennye metody, 24.

15 Kon und Grušin, ebd.

16 Kon, Neopozitivizm, 63; ders., K sporam, 291.

17 Gulyga, A:: G.W.F. Hegel, Leipzig 1974.

18 Gulyga, A.W.: Über den Charakter des historischen Wissens, in: SW 1963, H. 1, 38-51, hier 43 (Erstveröffentlichung: $O$ charaktere istoričeskogo znanija, in: VF 1962, H. 9, 28-38). Siehe auch: Gulyga, A.V.: O predmete istoriceskoj nauki, in: VI 1964, H. 4, 20-31 (deutsch in: SW 1964, H. 12, 1282-1296); ders., Istorija kak nauka, in: Filosofskie problemy istoričeskoj nauki, M. 1969, 7-50, besonders 19f. - Analog äußerten sich Žukov, E.M.: Istorið̌eskie nauki i obš̌aja metodologija in: Metodologizeskie problemy nauki. Materialy, M. 1964, 221-223 und Iwanow, G.M.: Die Spezifik der Widerspiegelung der Wirklichkeit in der Geschichtswissenschaft, in: SW 1963, H. 6, 615-635 (Erstveröffentlichung in VI 1962, H. 12, 18ff), hier 617f: Während historischer Materialismus das Wesen des gesellschaftlichen Entwicklungsprozesses erforsche, müsse Geschichtswissenschaft in ,(...) jeder Erscheinung deren Wesen, im einmaligen Ereignis das Allgemeine, im Zufäligen das Notwendige (...) aufdecken." Geschichtswissenschaft analysiere Gesetzmäßigkeiten nicht unter theoretischem Aspekt, sondern in ihrer konkreten Erscheinungsform.
} 
Geschichtswissenschaft müsse die historische Wirklichkeit als „Einheit von Notwendigem und Zufälligem" widergeben. Der Historiker habe allgemeinsoziologische „Gesetze und gleichermaßen auch die Fakten" zu erforschen. In diesem Sinne sah Gulyga in der Geschichtswissenschaft Idiographie und Verallgemeinerung verschmelzen. ${ }^{19}$ Der von Rožin angewandte Begriff des konkreten Entwicklungsgangs wurde hier aufgegriffen und verbunden mit der Forderung, "unter den konkreten Bedingungen" die „Wirkung“(Verbin/Karelova), ,in der Kette konkreter Ereignisse“ die „Erscheinungsform“ (Borisov) gesellschaftlicher Entwicklungsgesetze $\mathrm{zu}$ zeigen. ${ }^{20}$

Im Rahmen dieser Position unterschied Tarnovskij - soweit feststellbar - als einziger zwischen Gegenstand (Qualität) und Inhalt (Quantität) der Einzelwissenschaft: Letzterer verändere sich, werde umfassender und bereichert. Der Gegenstand der Disziplin drücke jedoch deren Spezifik aus und sei in diesem Sinn ,gleichbleibend und unveränderlich". ${ }^{21}$

Viertens: Um die „Kluft“ zwischen Theorie und Empirie (Fedoseev/Francev) zu schließen, plädierte eine Gruppe von Historikem und Philosophen dafür, den Gegenstand der Geschichtswissenschaft mit dem Begriff der ,spezifischen konkrethistorischen Gesetzmäßigkeit" zu beschreiben ${ }^{22}$ Die Akademiemitglieder Fedoseev und Francev wandten sich in ihrem einleitenden Grundsatzreferat bei der Historikerkonferenz Anfang Januar 1964 gegen die empiristische Auffassung, Geschichtswissenschaft solle bloß allgemein-soziologische Gesetze illustrieren. Sie müsse vielmehr die „Besonderheiten“ und den „Wirkungsmechanismus" dieser Ge-

\footnotetext{
19 Vgl. Gulyga, Über den Charakter, 43 und ders., O charaktere, $32 f$.

20 Verbin/Karelova, K istoriografii, 24; zu Ju.S. Borisov siehe Istorija i sociologija, M. 1964, 319 .
}

21 Siehe Istorija 1964, $312 \mathrm{f}$.

22 Aus der Sicht des dialektischen Materialismus diskutierte bereits 1957 der Philosoph Bikkenin die Korrelation allgemeiner und spezifischer Entwicklungsgesetze. Glezerman unterschied zwischen den ,allgemeinen Gesetzen", welche die Existenzbedingungen jeder menschlichen Gesellschaft beschrieben, und den "spezifischen Gesetzen“, welche die Existenzbedingungen einzelner Gesellschaftsformationen bezeichneten. Aber nicht diese Gesetze, sondern der ,konkrete Entwicklungsgang der Gesellschaft" sei der eigentliche Untersuchungsgegenstand der Geschichtswissenschaft. Pripiznov wandte sich in seinem Aufsatz 1961 dagegen, daß „(...) der historische Materialismus die allgemeinsten Gesetze und die Geschichte spezifische GesetzmäBigkeiten einzelner geschichtlicher Perioden (...)" erforschen solle, wie es „einige Autoren“, die er nicht nannte, vorgeschlagen hätten. - Bikkenin, N.B.: K probleme sootnošenija obšcich i specificeskich zakonov razvitija, in: Vestnik Maskovskogo universiteta. Serija Ekonomika. Filosofija, Prava 1957, H. 3, 103-120; Glezerman, G.E.: K voprosu o predmete istoriceskogo materializma, in: VF 1960, H. 3, 8-22, hier 13 (deutsch in: SW 1960, H. 7, 727-746), hier 14f; ders., O zakonach obščestvennogo razvitija. M. 1960, 125f; Gleserman, G.J.: Der historische Materialismus und die Entwicklung der sozialistischen Gesellschaft (Russisch M. 1967), 2., überarbeitete Auflage, Berlin 1973; Pripiznov, O sootnosenii, 104. 
setze unter konkreten Bedingungen erklären. ${ }^{23}$ Darin erschöpfe sich aber nicht die theoretische Anstrengung in der Historie:

„Die Erforschung des Wirkungsmechanismus' soziologischer Gesetze führt unmittelbar zur Aufdeckung, zur Enthüllung spezifischer historischer Gesetzmäßigkeiten. ${ }^{\prime 24}$

Diese vierte Auffassung wurde dominant, die Analyse spezifischer, konkrethistorischer Gesetzmäßigkeiten wurde standardmäßig als wichtigste Forschungsaufgabe formuliert. ${ }^{25}$

Die sogenannte Gegenstandsdiskussion fand eine Ergänzung in dem Nachdenken über die Spezifik der Geschichtswissenschaft. Der Hinweis auf die Retrospektivität reichte den wenigsten Historikern Anfang der sechziger Jahre aus, da gerade damals betont wurde, da $B$ auch andere Disziplinen historisch arbeiten, wie zum Beispiel die Literaturwissenschaften, Biologie, Kosmogonie, oder auch der historische Materialismus und die marxistische Soziologie. ${ }^{26}$ Die Mehrzahl der Diskutanten versuchte die Spezifik der Geschichtswissenschaft über ihre Methode zu erschlieBen. So bestand furr Tarnovskij, \%ukov, Glezerman u.a. die Besonderheit der historischen Disziplin darin, daß sie - anders als der historische Materialismus - die Formationsentwicklung und -abfolge bzw. die Erscheinungen allgemeiner Gesetzmäßigkeiten mittels der historischen Methode ,möglichst konkret" erforsche und darstelle. $^{27}$

23 Fedoseev, P.N./Ju.P. Francev: O razrabotke metodologičeskich voprosov istorii, in: Istorija 1964, 5-38, hier $14 f$.

24 Ebd., 16. - Vor allem Glezerman, Gurevič und Gefter bemühten sich um die Präzisierung dieses Begriffs. Siehe Istorija 1964, 130; sowie Gurevič, A.Ja.: Nekotorye aspekty izučenija social'noj istorii (obšcestvenno-istoriceskaja psichologija), in: VI 1964, H. 10, 51-68, (deutsch in SW 1965, H. 3, 323-336), hier 54; ders., $K$ voprosu ob osobennostjach istorii kak nauki, in: TMGIAI, tom 25: Voprosy metodologii istoričeskoj nauki, M. 1967, 178-198, besonders 181; ders., Obšcij zakon i konkretnaja zakonomernost' v istorii, in: VI 1965, H. 8, 14-30; ders., Ob istoriceskoj zakonomernosti, in: Filosofskie problemy istoriceskoj nauki, M. 1969, 51-79. Zur Präzisierung und zur Diskussion des Gesetzesbegriffs siehe Kapitel 4.5.

2s Dazu und zur Diskussion des Gesetzesbegriffs siehe Kapitel 4.5.

26 Lavrovskij etwa beharrte unter Berufung auf Cagin, Gorodeckij und Barg darauf, daß Soziologie und Geschichte sich nur auf der Zeitebene unterschieden, nicht hinsichtlich Logik und Methode. Er verfolgte damit, wie Kon und Grušin, das Ziel, die Historie als struktur- und systemanalytische Sozial wissenschaft zu definieren. - Lavrovskij; V.M.: K voprosu o predmete i metode istorii kak nauki, in: VI 1966, H. 4, 72-77, hier 74; vgl. Cagin, B.A.: Analiz V.1. Leninym roli sub-ektivnogo faktora v obščestvennoj ł̌izni, in: VF 1963, H. 4; Gorodeckij, E.N.: Voprosy metodologii istoričeskogo issledovanija v posleoktjabr skich trudach V.I. Lenina, in: VI 1963, H. 6, 16-34: Barg. M.A.: Die Strukturanalyse in der historischen Forschung, in: SW 1966, H. 2, 194 205 (zuerst in: VF 1964, H. 10).

27 Geschichtswissenschaft und historischer Materialismus, schrieb Glezerman, verhalten sich zueinander wie z.B. Literaturgeschichte und -theorie, Rechtsgeschichte und -theorie etc. - Glezerman, K voprosu, 16; Zu Tarnovskij siehe Istorija 1964, 312; Zukov, Istoričeskie nauki, 221. 
Auch Verbin und seine Co-Autoren argumentierten in diese Richtung: die Forschungsgegenstände, Methoden und Funktionen beider Disziplinen würden sich zueinander verhalten wie Allgemeines und Besonderes. ${ }^{28}$ Zwar erforsche der historische Materialismus auch das Besondere, die Geschichtswissenschaft auch das Allgemeine, den geschichtlich-gesellschaftlichen Entwicklungsprozeß als Ganzes und insgesamt. ${ }^{29}$ Während aber die philosophische Disziplin die gesellschaftlichen Entwicklungsgesetze und das Allgemeine betrachte, konzentriere sich die historische Forschung auf das Singuläre, gehe vom Konkreten aus, ziele auf die Erkenntnis der konkret-geschichtlichen Entwicklung, die für den historischen Materialismus lediglich die Erscheinungsform und Illustration des Allgemeinen darstelle. ${ }^{30}$

„Die Erforschung des Besonderen, des Konkret-Wesentlichen im gesellschaftlichen Leben der Vergangenheit - das ist das Wesen, die Spezifik der Geschichtswissenschaft. ."31

Gurevič brachte zwei bereichernde Gedanken in die Diskussion ein: Erstens problematisierte er in der Debatte der sechziger Jahre als erster die Besonderheiten der Geschichtsmethodologie, um die Spezifik der Geschichtswissenschaft zu verdeutlichen. Bis dahin war in diesem Kontext bestenfalls von der ,historischen Methode“ die Rede gewesen. Gurevið ließ sich auf den Streit über die Seriosität der Geschichtswissenschaft nicht ein. Kategorisch stellte er fest:

„Geschichte ist eine Wissenschaft. Aber: erstens ist sie nicht nur Wissenschaft. zweitens ist sie eine besondere Wissenschaft. ${ }^{.32}$

Die Besonderheit bestehe darin, da $B$ die Methodologie der Disziplin drei Bestandteile besitze, .,drei Aspekte historischer Erkenntnis" berücksichtigen müsse. ${ }^{33}$ Dies

28 Verbin, A.I./A.P. Sercova. Istoričeskij materializm i nekotorye metodologičeskie voprosy istoričeskoj nauki, in: Metodologičeskie voprosy obłcestvennych nauk (Sbornik statej). Vyp. 1 , M. 1966, 331-350, hier 334f: Verbin/Karelova, $K$ istoriografii, 24; Verbin/Furman, Mesto, $90 f$. $\mathrm{Vgl}$. Pripiznov, O sootnosenii, 106ff.

29 Daher seien die bei Kalašnikova, Fedorova, Sosonkin, Sulimov und Tulenov verwendeten Kategorien „Ganzes" und „Teil" nicht geeignet, um historischen Materialismus und Geschichtswissenschaf voneinander zu unterscheiden. - Verbin/Furman, Mesto $88 \mathrm{ff}$ kritisieren im einzelnen Kalašnikova, V.C.: Istoričeskij materializm kak nauka, M. 1954, 5; Fedorova, K voprosu 1957, 54, Sosonkin, I.: Istoriceskij materializm kak nauka, in: Kommunist Turkmenistana 1956, H. 2. 30ff, Sulimov, E.F.: IstoriCeskij materializm kak nauka, M. 1960, 25f, Tulenov, Ż.: Istoričeskij materializm kak nauka i zakony razvitija obšcestva, Alma-Ata 1962, 3.

30 Das Allgemeine diene der Geschichtswissenschaft nur als Mittel, das Konkrete zu verstehen. - Verbin/Furman, Mesto, 91f: Verbin, A.I./P.M. Egides: Istoričeskij materializm - metodologičeskaja osnova istoričeskoj nauki, in: TMGIAl, tom 25: Voprosy metodologii istoričeskoj nauki, M. 1967, 5-31, hier 29f: Verbin/Karelova, K istoriografii, 25; Verbin/Sercova, Istoričeskij materializm, 335.

31 Verbin/Egides, Istoričeskij materializm, 16. Retrospektivität, Faktenorientierung und die Reproduktion des Vergangenen in der Entwicklung bezeichneten Verbin, Egides und Sercova als weitere „Besonderheiten“ der Geschichtswissenschaft. Vgl. ebd., 19ff und Verbin/Sercova, Istoričeskij materializm, 341

32 Gurevič, K voprosu, 198. 
komme daher, daß sich die Disziplin mit vielfältigen Phänomenen des gesellschaftlichen Lebens zu befassen habe, gleichermaßen mit sich wiederholenden Tendenzen und einmaligen Fakten. Gurevic bezeichnete sein Fach als Wissenschaft über das Wesentliche und über konkrete Phänomene, über ,den konkreten Gang der Geschichte, in dem das Allgemeine sich zeigt “ ${ }^{34}$ Nicht das ,reine Gesetz" sei zu entdecken, sondern die „Abweichungen von der Norm", die in der Geschichte die Norm darstelten. ${ }^{35}$ Um ein erkenntniswissenschaftlich fundiertes und zugleich sinnlich-konkretes Abbild zu erhalten, würden Methoden der wissenschaftlichen Analyse und Synthese benutzt. Spezifisch für die Geschichtswissenschaft sei dabei. $\mathrm{da} B$ über das wissenschaftliche Moment (empirische und theoretische Erkenntnis) hinaus zwei weitere Aspekte, der philosophisch-axiologische und der künstlerischästhetische, relevant würden. ${ }^{36}$ Denn die Geschichtsforschung stelle einen Prozeß dar, in dem die Gesellschaft sich selbst ergnünde. Leidenschaftsloses Arbeiten sei eine Illusion, weil die Wertungen in hohem Maß abhängig seien von ideologischen und weltanschaulichen Positionen. Die axiologische Problematik, dies suchte Gurevič zu verdeutlichen, ohne $\mathrm{da} B$ er schon Lösungen bieten konnte, begleite den Historiker in allen Stadien seiner Arbeit: bei der Aufgabenstellung und Problemformulierung angefangen, bei der Sammiung und Auswahl des Materials ebenso wie bei der Analyse, Synthese und Bewertung. Gurevič mahnte, sich dessen stets bewußt zu sein, entsprechend vorsichtig zu "werten" und nicht der Illusion aufzusitzen, mit Hilfe statistischer oder strukturwissenschaftlicher, also „streng“ wissenschaftlicher Methoden sei das Problem zu umgehen; die philosophisch-axiologische Seite der Geschichtsmethodologie müsse vielmehr selbst zum Gegenstand der Disziplin gemacht werden. ${ }^{37}$

Schließlich spielten „künstlerische Intuition und schöpferische Phantasie“ eine wichtige Rolle, wenngleich sie Analyse und Synthese nicht ersetzen könnten. Zur Erklärung geschichtlicher Phänomene und Ereignisse gelange der Historiker in der Regel auf dem Wege der Ableitung von der Folge auf die Ursache, weil unmittelbares Wissen, eine ausreichende Dichte von Quellen fehle.

„(...) die Erklärung der Ursachen geschichtlicher Phänomene wird vom Wissenschaftler auf der Grundlage der vorhandenen Daten konstruiert, die er seinem Verständnis von der Logik der Entwicklung entsprechend, das heißt letztlich, in Übereinstimmung mit seiner Geschichtsphilosophie, gruppiert. “38

Vor allem bei der Klärung der Handlungsmotive einzelner Persönlichkeiten sei dies der Fall. Ausgehend von allem, was über den betreffenden ,Helden“ bekannt sei, so Gurevič,

$\begin{array}{ll}\text { 33 } & \text { Ebd. } \\ \text { 34 } & \text { Ebd., } 184 \text { und } 182 . \\ \text { 3s } & \text { Ebd., 184. } \\ \text { 36 } & \text { Ebd., 183ff. } \\ \text { 37 } & \text { Ebd., 185-192. } \\ \text { 38 } & \text { Ebd., 194. }\end{array}$


„(...) rekonstruiert der Historiker mit Hilfe seiner Phantasie seinen (des Helden; J.H.) ganzen Charakter, erarbeitet eine eigene Vorstellung darüber, welche Gedanken er (der Held; J.H.) haben mußte, welche Gefühle er unter bestimmten Bedingungen und in bestimmten Situationen oder bei der Vollziehung bestimmter Handlungen empfand. “39

Erweise sich das Modell als tragfähig, dann gehe es ein in den „Stoff der historischen Erzählung“" ${ }^{40}$ Mit literarischem Schaffen sei dieses Vorgehen des Historikers dennoch nicht gleichzusetzen. Schriftsteller und Historiker gingen entgegengesetzte Wege: dieser versuche vom geschichtlich feststellbaren Verhalten (povedenie) auf das Charakterbild und auf die Motive des Helden (obraz) zu schließen; jener gehe vom Abbild des Helden aus zu dessen Verhalten. ${ }^{41}$ Gegenüber Kritikern, die meinten, Geschichtswissenschaft verlöre auf solche Weise ihren streng wissenschaftlichen Charakter, argumentierte Gurevič unter Berufung auf Gulyga ${ }^{42}$ und westliche Historiker ${ }^{43}$, „Elemente der künstlerischen Methode“ könnten durchaus organischer Teil geschichtlicher Erkenntnis werden, wenn sie immer wieder sorgfältig kontrolliert und überprüft würden. ${ }^{44}$

Zweitens folgerte Gurevix aus der Gegenstandsbestimmung, wonach Geschichtswissenschaft nicht allgemeine, sondern konkret-historische Gesetzmäßigkeiten erforsche, daß die Sozialpsychologie bzw. die ,gesellschaftlich-geschichtliche Psychologie" ein wichtiger Aspekt historischer Forschung in der UdSSR werden sollte. Sozialpsychologie dürfe nicht länger in der Ideologie und der Erforschung gesellschaftlich-politischer Ideen und Interessen aufgehen, sondern solle entwickelt und genutzt werden, um die (relativ stabilen) Mentalitäten und (relativ instabilen) Stimmungen in Gesellschaften zu erfassen. ${ }^{45}$ So sei Sozialpsychologie geeignet, den inhaltlichen Reichtum einer konkreten geschichtlichen Wirklichkeit besser erkennbar werden zu lassen, Kausalitäten in der Geschichte aufzuklären und über die Makrostruktur einer Gesellschaft hinaus auch deren Mikrostruktur zu analysieren. Wenn sozialpsychologische Forschung als Teil der Sozialgeschichte (wie etwa bei Levebvre, Soboul, Rude u.a.) oder im Rahmen der Kulturgeschichte (so bei Hui-

\footnotetext{
39 Ebd., 195.

10 Ebd

41 Ebd., $195 f$.

42 Gulyga, A.V.: Ponjatie i obraz v istoričeskoj nauke, in: VI 1965, H. 9, 3-14.

43 In diesem Zusammenhang rezipierte Gurevic L. Gershoy, I. Berlin, L. Gottschalk, E. Cassirer; vgl. Gurevič, K voprosu, 194-197.

4. Ebd., 197.

45 Erste positive Ansätze in der UdSSR sah Gurevið lediglich bei Batkin, Romanov und Staerman. Neue Horizonte zeigte der Mediävist der historischen Zunf im Lande durch die Rezeption vor allem der französischen Historiographie (G. Levebvre, R. Baehrel, A. Soboul, G. Rude, L. Febvre, R. Mandrou, M. Bloch, J. Huizinga). - Vgl. Batkin, L.M.: Etjud o Džovanni Morelli (k voprosu o social'nych kornjach ital'janskogo Vozroždenija), in: VI 1962, H.12; Ro manov, B.A.: Ljudi i nravy drevnej Rusi, L. 1947; Staerman, E.M.: Moral' i religija ugnetennych klassov Rimskoj imperii, M. 1962. Siehe Gurevic, Nekotorye aspekty, $61 \mathrm{ff}$.
} 
zinga und in der ,Neuen Geschichtswissenschaft" bei Febvre und Bloch), gepflegt werden würde, dann könnte, so hoffte Gurevič, die sowjetische Geschichtswissenschaft z.B. die Wechselwirkung objektiver und subjektiver Faktoren besser klären. könnte zeigen, wie objektive, unabhängig vom menschlichen Bewußtsein bestehende Bedingungen nicht automatisch, sondern mittels der bewußtseinsmäßigen, emotionalen Wahrnehmung und Erfassung zu wirklichen Ursachen, Hintergründen von Geschichte, das heißt von menschlicher gesellschaftlicher Tätigkeit werden. ${ }^{46}$ Auch die nur Holzschnittartiges produzierende marxistisch-leninistische Klassenstrukturanalyse glaubte Gurevič - durchaus auf materialistischer Grundlage - verfeinern zu können. Mit der Sozialpsychologie sei auch die Mikrostruktur etwa der mittelalterlichen Gesellschaft zu erfassen, seien also die ,primären gesellschaftlichen Zellen oder Gruppen des organischen Bestandes ${ }^{\text {(447 }}$, aus denen sich Klassen zusammensetzten, zu analysieren. Erst durch die Erforschung des sozialpsychologischen Klimas und der Gefühls- und Erlebniswelt in den „Molekülen“ einer Gesellschaft könnten deren Struktur, die Wirkung moralischer Normen, die Aktivität und Passivität der Gesellschaftsmitglieder, mögliche gesellschaftlich-politische Konflikte usw. konkretisiert werden. ${ }^{48}$

Ohne Berücksichtigung der Sozialpsychologie einer Gesellschaft hielt Gurevič den „Übergang von der Analyse der sozialökonomischen Struktur, der Basis der Gesellschaft zur Erklärung und Erläuterung ihrer Ideologie" für unmöglich. ${ }^{49}$ Gurevič begründete die historische Sozialpsychologie nicht nur theoretisch, sondern realisierte sie auch selbst. ${ }^{50}$ Er vermochte damit mehr zu tun, als nur die bekannten Plädoyers gegen Determinismus und ökonomistischen Materialismus zu wiederholen: Er forderte eine Forschungsrichtung von erheblichem Erkenntniswert und leistete damit auch einen Beitrag zur Profilierung der historischen Disziplin gegenüber dem historischen Materialismus, der konkreten marxistischen Soziologie und gegenüber den anderen Gesellschaftswissenschaften. Infolge der administrativen Sanktionierung Ende der sechziger und zu Beginn der siebziger Jahre blieben diese Anregungen allerdings auf den Kreis der wissenschaftlichen Schüler von Gurevič beschränkt.

Am Ausgangspunkt der Diskussion über Gegenstand und Spezifik der sowjetischen Geschichtswissenschaft wurden Soziologie und Geschichte, Allgemeines und Besonderes, Theorie und Empirie schroff gegenübergestellt (Rožin, Pripiznov, Schaff)

\footnotetext{
46 Gurevič, Nekotorye aspekty, 55f.

4" Familie, ländliche, dörfliche Gemeinschaft, Stadt usw. Vgl. ebd., 57f.

48 Ebd., 56ff.

49 Ebd., 59 und 68

so Siehe sein grenzüberschreitendes Buch „Das Weltbild des mittelalterlichen Menschen“ (zuerst Russisch, M. 1972, danach Dresden 1978), welches zum Standardwerk des Geschichtsstudiums in der UdSSR, in der DDR und in der BRD wurde. Vgl. Gurjewitsch, A.J.: Mittelalterliche Volkskultur, München 1987: Gurevič, A.Ja.: Istoričeskaja nauka i istoričeskaja antropologija, in: VF 1988, H. I, 56-70; ders., Social'naja istorija i istoričeskaja nauka, in: VF 1990, H. 4, 23-35.
} 
und damit ,faktisch die idiographische Geschichtskonzeption" reproduziert. ${ }^{51}$ Mit den oben dargelegten neuen Positionen wurde die Einheit von Idiographie und Verallgemeinerung beschworen (Gulyga), ohne deren innere Relation zu thematisieren, oder es wurde der Theoretizität der Geschichtswissenschaft (Kon, GruY̌in) das Wort geredet, ohne auf deren Grenzen hinzuweisen. Die nur angedeutete innere Relation der Beziehung von Soziologie und Geschichte zu erschließen, blieb eine noch $z u$ erledigende, weiterfürende geschichtsmethodologische Aufgabe.

s1 Allerdings ,(...) mit dem Unterschied, daß die Theorie der Gesellschaft, die Soziologie, nicht zur Hilfswissenschaft der Geschichte degradient wird, sondern ein objektives wissenschaftliches Bild der gesetzmäßigen Einheit des geschichtlichen Entwicklungsprozesses vermitteln soll (...). Dieser Unterschied ist durchaus nicht unwesentlich, aber er ist eben (...) primär weltanschaulicher und nicht methodologischer Natur. Das methodologische Problem bleibt offen, und die offen gebliebene Lücke wird nur scheinbar durch die weltanschauliche Stellungnahme ausgefültt "- Bollhagen, Soziologie, 7. 


\subsection{Die geschichtliche Tatsache. Fakten und ihre Interpretationen}

Der Geschichtsphilosoph Peter Bollhagen (DDR) hat mit Recht darauf hingewiesen, $\mathrm{da} B$ methodologische Probleme der Geschichtswissenschaft sich nur dann analysieren und lösen lassen, wenn die logische Struktur der historischen Aussagen und Erkenntnis in ihrem inneren Wesen untersucht wird. Und dies - so Bollhagen weiter - beginne nicht erst mit den Fragen der Begriffsbildung, des Charakters historischer Gesetze und der Möglichkeit, sie zu formulieren, sondern

"(...) bereits bei der Untersuchung der historischen Tatsache, die kein einfaches, ungegliedertes und deshalb ausschließlich singuläres Ganzes ist, sondem eine komplizierte logische Struktur besitzt."'

Diese grundlegende Bedeutung des Themas wurde in der sowjetischen Geschichtswissenschaft trotz der allgemein recht lebhaften Theoriediskussion ${ }^{2}$ lange nicht erkannt, und erst in der zweiten Hälfte der sechziger Jahre, nicht vor 1966, wandten sich ihm einige Historiker zu. $\mathrm{Zu}$ einem echten Austausch von Gedanken und Argumenten kam es allerdings auch dann nicht. Dorosenko, Gurevic, Bibler, Gulyga, Ivanov u.a., die sich dazu 1968/69 äußerten, näherten sich lediglich in ersten Schritten dem Problem. Und die Publikationen lagen fur einen Dialog wohl auch zeitlich zu eng beieinander. ${ }^{3}$ Auffallend ist, daß nicht nur die „bürgerliche“, sonderm auch die manxistische Literatur im Ausland zu dieser Frage kaum rezipiert wurde. ${ }^{4}$

Gurevič legte die ,radikale Evolution“ der Begriffsdeutung der historischen Tatsache (istoriCeskij fakt) seit Leopold von Ranke dar und zeigte anhand dessen, daß sich hinter scheinbar selbstverständlichen Vorstellungen über geschichtliche Tatsachen

\footnotetext{
1 Bollhagen, Soziologie, 139.
}

2 In der philosophischen Literatur ist das Problem früher und intensiver behandelt worden als in der historischen Diskussion. Vgl. Problemy logiki naučnogo poznanija, M. 1964; Problemy myక̌lenija $v$ sovremennoj nauke, M. 1964; Kopnin, P.V.: Logika naucnogo issledovanija i ee osnovnye ponjatija, in: VF 1964, H. 3, 59-68; Logika naučnogo issledovanija, M. 1965; Studien zur Logik der wissenschaftlichen Erkenntnis. Aus dem Russischen von G. Richter, Berlin 1967; Teorija poznanija i sovremennaja nauka, M. 1967; Problemy logiki i teorii poznanija, M. 1968; Problemy metodologii social'nogo issledovanija, L. 1970.

3 Dorošenko, N.M.: O sootnołenii ob-ektivnych i sub-ektivnych storon $\mathrm{v}$ istoričeskom fakte, in: VLU Serija 5, 1968, H. 1, 85-92; ders., Problema fakta v istoričeskom poznanii. Avtoreferat dissertacii na soiskanie učenoj stepeni kandidata filosofskich nauk, L. 1968; Gurevič, A.Ja.: Cto takoe istoričeskij fakt? In: Istočnikovedenie. TeoretiČeskie i metodičeskie problemy, M. 1969, 5988; Bibler, V.S.: Istoriceskij fakt kak fragment dejstvitel'nosti (Logið̌eskie zametki), ebenda, 89101; Gulyga, Istorija; Ivanov, G.M.: K voprosu o ponjatii ,istoričeskij fakt“, in: MIVIN, vyp. 6, T. 1969, 17-34.

1 Lediglich Gurevič und - mit Abstrichen - Ivanov zeigten, daß sie mit dem Forschungsstand vertraut waren. 
„(...) ein ganzer Komplex, bei weitem nicht immer klarer und gelöster, wesentlicher Probleme (...)" verbirgt."

Aus seiner Skizze des Wandlungsprozesses von der Fetischisierung zur Mystifizierung historischer Tatsachen ${ }^{6}$ zog Gurevic die Schlußfolgenung, daß es unproduktiv sei, eine endgültige Lösung anzustreben, weil jede Bestimmung stets nur für die aktuelle Entwicklungsetappe der historischen Disziplin selbst gültig sein könne. ${ }^{7}$ Daher plädierte er für das, immer wieder neue gründliche Durchdenken der Kategorien “. ${ }^{8}$ Dieses zielte Ende der sechziger Jahre darauf, den Begriff der historischen Fakten ontologisch - als Element der geschichtlichen Wirklichkeit ${ }^{9}$ - und gnoseologisch - als Element geschichtlichen Wissens ${ }^{10}-\mathrm{zu}$ definieren, die beiden Aspekte abzugrenzen und in Beziehung zueinander zu setzen.

Als einziger vertrat Bibler die Auffassung, es handle sich bei einem Element der vergangenen Wirklichkeit um das kleinste, nicht mehr teilbare, das ,einfachste Fragment" der Realität." "Über die innere Struktur der historischen Tatsache machte sich Bibler keine weiteren Gedanken. Er verdrängte so eine Reihe objekti-

5 Gurevix, Cto takoe istoričeskij fakt, 59.

6 Gurevič unterschied fünf Schritte dieser Entwicklung: 1. um die Mitte des 19. Jahrhunderts. besonders bei Ranke ein vergleichsweise naiver Optimismus, der Historiker müsse einfach nur genügend Fakten sammeln; 2. die Positivisten (wie etwa Comte, Mill, Fustel de Coulanges), die Fakten als Produkt des Denkens aus der Textinterpretation zu gewinnen trachteten; 3. um die Jahrhundertwende die ,kritische Geschichtswissenschaft" (als Vorläufer: Langlois und Seignobos, als typischer Vertreter: Maitland), die erstmals die eindeutige Bestimmtheit von Fakten anzweifelte und die Subjektivität des Erkenntnisprozesses thematisierte; 4. die neokantianische Antwort darauf (bei Dilthey, Windelband, Rickert), die den idiographischen, individualisierenden Geisteswissenschaften einen niedrigeren oder zumindest anderen Status zuordnete als den nomothetischen, generalisierenden Naturwissenschaften: 5. Präsentismus bei Autoren, die mit subjektivistischen, relativistischen und agnostizistischen Positionen den wissenschaftichen Status der Historie vollends negierten. - Gurevic, Cto takoe istori Präsentismus in der bürgerlichen Historiographie der USA, in: ZfG 1966, H. 7, 1069-1091.

7 Gurevič, Cto takoe istoričeskij fakt, 77f.

8 Ebd., 78.

9 Am präzisesten definierte Ivanov den ,historischen Fakt“: istoriteskij fakt diene „(...) als Bezeichnung jedes sozial bedeutsamen Phänomens der geschichtlichen Wirklichkeit oder des gesellschaftlichen Bewußtseins, eines Phänomens, das es in der Vergangenheit wirklich gab, welches real war und jetzt, dank seiner Widerspiegelung in historischen Quellen Forschungsobjekt der Geschichtswissenschaft wurde." - Ivanov, K voprosu 1969, 34. Bei der ontologischen Seite ist es wichtig, daran zu denken, daß nicht nur Materielles, Gegenständliches, sondern auch Wissen, Bewußtsein, Religion, Ideologie usw. Elemente geschichtlicher Wirklichkeit sind. Bei Dorošenko wird dies zum Beispiel nicht deutlich, wenn er sagt, ontologisch werde ,historischer Fakt als objektives Phänomen, als reales historisches Ereignis“ betrachtet. - Dorosenko, $\mathrm{O}$ sootnošenii, 86; vgl. Dorošenko, Problema, 5f.

10 In gnoseologischer Hinsicht diene der Begriff „,...) als Bezeichnung einer dem geschichtlichen Phänomen adäquaten wissenschaftlichen Rekonstruktion der Vergangenheit, die vom Historiker geschaffen wird und gesichertes Wissen darstellt, welches (...) das erforschte Ereignis konstatiert und beschreibt." - Ivanov, K voprosu 1969, 34

11 Kursiv bei Bibler, Istoričeskij fakt, 90. 
ver gnoseologischer Probleme und warf eine Frage auf, die in den Bereich der spekulativen Geschichtsphilosophie gehört: Er fragte nach der Möglichkeit, historische "Fakten zu wissen" und nicht nur Wissen über Fakten zu erlangen. ${ }^{12}$ Nur so könne die Kluft zwischen der „Welt gemäß der Wahrheit" und der „Welt gemäß der Ansicht" aufgehoben werden. Berechtigte Einwände ${ }^{13}$ meinte Bibler entkräften zu können. Mit der Formulierung seines Erkenntnisgegenstands (Erkenntnisproblems) könne der Historiker das zu untersuchende Fragment der Wirklichkeit eingrenzen. Dann habe der Historiker festzustellen, ob das in der Quelle Überlieferte tatsächlich stattgefunden habe. Schließlich erweitere er das Fragment der vergangenen Wirklichkeit ,real", das heißt: er stelle das entsprechende Stück Vergangenheit in seiner Gegenwart wieder her! ${ }^{14}$ Die Konstruktion und Rekonstruktion der Vergangenheit hielt Bibler für möglich und notwendig, um das Problem der Realität im Gegensatz zum Schein zu lösen. ${ }^{15}$

Die anderen Autoren hatten hierzu mehrheitlich ablehnende, untereinander aber nicht gänzlich übereinstimmende Positionen. ${ }^{16}$ Während Gulygas Formulierung es offen ließ, ob er meinte, der Historiker rekonstruiere geschichtliche Fakten als Element vergangener Wirklichkeit oder als Bestandteil des Wissen $s^{17}$, betonte Ivanov dagegen explizit, daß auch bei der sorgfältigsten „Rekonstruktion der objektiven Realität eines geschichtlichen Ereignisses" nicht das Ereignis selbst (nicht "die Tatsache der geschichtlichen Wirklichkeit"), sondern ,nur" sein Abbild (,wissenschaftliche historische Fakten") geschaffen würde. ${ }^{18}$ Dieses sei der Form nach subjektiv, dem Inhalt nach objektiv. ${ }^{19}$ Gurevič widersprach dem agnostizistischen Aspekt in Biblers extrem erkenntnisoptimistischer Auffassung, das wissenschaftli-

\footnotetext{
12 Kursiv bei Bibler, Istoričeskij fakt, 91.
}

13 Er selbst fragte rhetorisch: ,(..) ob man annehmen kann, daß (...) nicht einfach neues Wissen über die Wirklichkeit das Resultat der rekonstruktiven Arbeit des Historikers ist, sondern ein wiederhergestelltes Fragment der Wirklichkeit selbst (...)." - Und wenn ja, auf welcher Grundlage? Und ,.... wie kann es sich ergeben, daß ein Fakı vergangener Wirklichkeit Resultat dieser Arbeit (...) sein wird?" - (Hervorhebung von Bibler) Ebd., 97.

14 Ebd., 99.

is Ebd., 89ff.

16 Es sei nochmals daran erinnert, daß die Beiträge in so kurzen Zeitabständen erschienen, daß die Autoren kaum in der Lage gewesen sein dürtten, aufeinander zu reagieren. Nur bei Bibler und Gurevič kann von der gegenseitigen Kenntnis der Positionen ausgegangen werden: die beiden beteiligten sich an den Diskussionen in der Sektion fur Geschichtsmethodologie unter der Leitung M.Ja. Gefters.

17 Der Historiker , (...) hat keinen unmittelbaren Kontakt mit den Tatsachen, er hat zu tun mit den Quellen. Von diesen ausgehend, rekonstruiert er die Fakten, stellt sie wieder her.“- Gulyga. Istorija, 13.

18 Ivanov, K voprosu 1969, 26f. - Analog auch Podosetnik, V.M.: Gnoseologičeskoe značenie faktov v poznanii obక̌čestvennych javlenij, in: Teorija 1967, 207-230, hier 208.

19 .Das Denken des Historikers schaff nicht willkürlich geschichtliche Tatsachen, sondern fixiert, deckt bloß in Form der wissenschaftichen Tatsache das auf, was in der geschichtlichen Wirklichkeit real war."- Ivanov, K voprosu 1969, 27. 
che Resultat sei weniger objektiv als die Realität. Das Gegenteil sei der Fall! ${ }^{20}$ Eine historische Tatsache - so Gurevič weiter - sei zwar in all den konkreten Verbindungen, in denen sie existierte, unwiederholbar, aber diese Individualität sei nicht absolut; das einmalige Ereignis, der einmalige Proze $\beta$ wiesen auch stets etwas Typisches auf. ${ }^{21}$ Eine geschichtswissenschaftliche Tatsache müsse daher eine ,Einheit von Abstraktion und Vorstellung über das konkrete sinnliche Objekt", eine Einheit von Allgemeinem (Gesetzmäßigem) und Individuellem (Unwiederholbarem) darstellen. ${ }^{22}$ Auch die historische Tatsache sei kein ,Ziegel", kein „Atom", sondern stelle selbst eine Beziehung zwischen vielen Fakten dar. ${ }^{23}$ Deshalb sei es nicht ausreichend, Fakten zu konstatieren, sondern notwendig, sie zu analysieren und zu interpretieren; in diesem Sinne ,schaffe" der Historiker geschichtliche Tatsachen. ${ }^{24}$ $\mathrm{DaB}$ dies in der Geschichte der Geschichtswissenschaft mit unterschiedlichen Abstraktionsniveaus und unter verschiedenen Aspekten geschah und geschieht, weise hin auf die Dynamik der Tatsachen. ${ }^{25}$

„Zwischen dem realen Ereignis der Vergangenheit und der Tatsache, über die der Historiker schreibt. liegt ein langer und schwieriger Weg “. ${ }^{26}$

Auf diesem Weg beeinflußten weltanschauliche und axiologische Momente, Theorie und das aktive Denken des Historikers seine Arbeit in allen Stadien. ${ }^{27}$ Daraus sei aber nicht auf , (...) die Unmöglichkeit einer wissenschaftlich-objektiven Konstruktion in der Geschichte (...) zu schließen. ${ }^{28}$ Der wertende Aspekt könne von einem objektiven ausgeglichen werden. Denn der geschichtliche Kontext, in dem Tatsachen zu sehen und zu interpretieren seien, sei kein Modell, kein Produkt des Denkens, sondern existiere unabhängig vom Historiker und könne von ihm rekonstruiert werden. Die ,innere Logik der Tatsachen“, die objektiv existierenden Beziehungen zwischen den Tatsachen ermöglichten die Objektivierung der Erkennt-

20 .Indem deren Chaos und Unordnung (das der Realität; J.H.) überwunden werden, durch welche die Realität dem 'Alltagsbewußtsein' der Menschen entgegensteht, (...) deckt die wissenschaftliche Vorstellung allein die objektiven Verbindungen der Phänomene auf, zeigt die wahre Natur der Fakten der Geschichte." - Gurevič, Cto takœe istoričeskij fakt, 81

21 Ebd., 82.

22 Ebd., 82f. Das „Unglück“ der historischen Tatsache bestehe darin, daß in der Fachliteratur mal die eine, mal die andere Seite verabsolutiert werde.

23 Ebd., 87. Die Komplexität der historischen Tatsache verdeutlichte auch Ivanov, der mit seinem Klassifizierungsvorschlag zugleich begriffliche Klarheit schaffte. Er unterschied dem Inhalt nach politische, ökonomische und ideologische Tatsachen, der Struktur nach einfache (elementare) und komplizierte Tatsachen, und der Bedeutung nach wesentliche und unwesentliche Tatsachen. - Ivanov, K voprosu 1969, $28 \mathrm{ff}$

24 Gurevič, C.to takoe istoriceskij fakt, $81 \mathrm{ff}$.

2s Ebd., 85f.

26 Ebd., 83.

27 Ebd., 78ff.

28 Ebd., 87. 
nis. ${ }^{29}$ So kam Gurevič zu dem Schluß, daß Geschichte objektiv erkennbar sei. Diese These, so mahnte er, sollte jedoch Resultat "qualifizierten methodologischen Nachdenkens" sein und kein axiomatisches Postulat. ${ }^{30}$

Den (eindeutig) objektiven Charakter des Wissens bestritt wiederum Dorošenko. Anders als Bibler betrachtete er das nicht als Dilemma, sondern als einen Wesenszug geschichtswissenschaftlicher Erkenntnis, der akzeptiert werden müsse: Geschichtliche Quellen seien in doppelter Hinsicht objektiv und in einer Hinsicht subjektiv ${ }^{31}$ beim Abbild der Wirklichkeit sei das Verhältnis umgekehrt: der Autor der Quelle und der Historiker drückten ihm ihren Stempel auf. ${ }^{32}$ Objektiv sei das Abbild in dem $\mathrm{Ma} B$, in welchem es die Merkmale des Untersuchungsobjekts, und nicht die psychologischen Zustände des Erkenntnissubjekts reflektiere. ${ }^{33}$ Die aus der Subjekt-Objekt-Beziehung resultierenden subjektiven Elemente seien - so Dorošenko - der Tatsache als geschichtswissenschaftlichem Wissen notwendigermaBen eigen. Nicht die Subjektivität sei das Problem, sondern, daß diese in der sowjetischen Fachliteratur ignoriert oder negativ bewertet werde. ${ }^{34}$

Kontrovers wurde auch der Stellenwert geschichtswissenschafticher Tatsachen beurteilt: Während Gurevic - wie oben dargelegt - die Notwendigkeit des Interpretierens etc. hervorhob, betonte Gulyga den besonderen, eigenständigen Wert der Fakten in der Geschichtswissenschaft. ${ }^{35}$ Geschichtswissenschaftliche Tatsachen

29 „In der historischen Forschung existieren zwei Aspekte: ein wertender, durch die Weltanschauung des Historikers bedingter, und ein objektiver, ein von theoretischen Voraussetzungen nur in dem Maße abhängiger, in dem sie (die Voraussetzungen, J.H.) wahrhaftige Widerspiegelung des Geschichtsprozesses sind. Die Voraussetzungen, durch die der Historiker geleitet wird. sollen die Rolle von Arbeitshypothesen spielen, von Annahmen, die überprüft, präzisiert und, falls notwendig, im Forschungsprozeß zurückgewiesen werden, aber keine Schemata sein, denen die Tatsachen mit Gewalt angepaßt werden."- Ebd., 87.

30 Ebd., 88

31 Objektiv, weil sie (1.) unabhängig vom Hıstoriker existieren und (2.) mehr oder weniger objektive Informationen über wirkliche geschichtliche Phänomene enthalten würden. Subjektiv, weil die enthaltenen Informationen Resultat der Wechselbeziehungen von Subjekt (Autor der Quelle) und Objekt (geschichtliche Wirklichkeit) seien. - Dorošenko, O sootnołenii, 89.

32 Die gewonnene Erkenntnis ,(...) besteht aus Wissen, welches aus den Quellen gezogen wurde, und aus Wissen, welches vom Subjekt kommt. Die erste Art des Wissens ist die hauptsächliche, wesentliche; sie stellt den objektiven Inhalt der Tatsache, unabhängig vom einzelnen Menschen, unabhängig von der Menschheit, dar. Die zweite Art des Wissens ist eingefügt als zusätzliches Wissen. Dieses ist Resultat der theoretischen Bearbeitung der Tatsache (der Erklärung und Bewertung).“ - Ebd., 92. Die „doppelte Subjektivität" historischen Wissens erkannte auch Želenina, I.A.: Ob ob-ektivnosti istoriceskogo znanija (kritiðeskij analiz nekotorych sovremennych koncepcij), in: VMU Serija 8: Filosofija 1969, H. 2, 51-59, hier 53.

33 Dorošenko, O sootnošenii, $90 \mathrm{f}$.

34 Ebd., 92.

3s „Der Historiker erforscht Gesetze und in gleichem Maß Fakten. Darin unterscheidet sich seine Arbeit von der Tätigkeit der Repräsentanten vieler anderer wissenschaftlicher Disziplinen, die ihr Ziel ausschließlich in der Aufdeckung von Gesetzmäßigkeiten sehen." - Gulyga, Istorija, 20. 
fungierten nicht nur als Material zur Verallgemeinenung. ${ }^{36}$ Gefährlicher als Empirismus sei die Vernachlässigung der realen Tatsachen: Wegen der, großen Wahrheit" dürfe der Historiker nicht die ,kleine Wahrheit", die der Fakten ignorieren, verunstalten oder beschönigen. ${ }^{37}$ Andererseits deutete nur Gurevič auf den dynamischen Charakter des Erkenntnisprozesses und die Relativität der geschichtswissenschaftlichen Tatsache hin, ${ }^{38}$ während andere Autoren, auch Gulyga, den Eindruck erweckten, das materialistische Geschichtsverständnis biete ein logisches Kriterium dafür, die Bedeutung von Tatsachen und Ereignissen endgültig festzulegen. ${ }^{39}$ (Als könne die Logik einer Theorie Diskussion und Kontrolle in der ,scientific community" ersetzen.)

Zusammenfassend ist folgendes festzuhalten: Gemessen an der seit Anfang der sechziger Jahre laufenden Methodologiediskussion und der grundlegenden Bedeutung des Problems historischer Fakten, wandten sich erst verhältnismäßig spät einige wenige Historiker dem Thema zu. ${ }^{40}$ Dem entsprach, da $B$ vor dem Abbruch der Diskussionen an der Wende zu den siebziger Jahren nur ein Anfang gemacht und das Bewußtsein für dieses Problem geschärft wurde. Immerhin wurden dabei die Entwicklung des Tatsachenbegriffs in der Geschichtsschreibung seit Ranke, die ontologische und gnoseologische Bedeutung des Terminus, die Komplexität und Dynamik historischer und geschichtswissenschaftlicher Tatsachen, Möglichkeiten und Grenzen der Rekonstruktionsfähigkeit durch den Historiker herausgearbeitet. Die ausgereiftesten Positionen vertrat dabei ohne Zweifel Gurevič. Manches hätte durch die sorgfaltige Rezeption bereits vorliegender Fachliteratur schneller und besser erfaßt werden können. Nur auf zwei - sehr unterschiedliche - Publikationen, deren Nichtbeachtung sich nachteilig auswirkte, sei hier hingewiesen:

36 „Historische Verallgemeinerung ersetzt die Tatsache nicht. In diesem Sinn haben Tatsachen für die Geschichte sich selbst genügende Bedeutung." - Ebd., 21.

37 Ebd., 22.

38 Der Erkenntnisprozeß beginne mit Hypothesen und gesicherten Fakten, führe zu neuen historiographischen (wissenschaftlichen) Tatsachen. Diese fungierten wiederum als Ausgangspunkt (Hypothese) für neue Nachforschungen über Ursachen und Resultate von Ereignissen und Prozessen. - Gurevic, Cto takoe istoričeskij fakt, 87.

39 „Die Ereignisse, die eine Beziehung zur Verwirklichung einer Gesetzmäßigkeit haben, diese ermöglichen oder behindern, sind historische Ereignisse." - Gulyga, Istorija, 22.

40 Dies geschah erst, nachdem die theoretische Grundlegung der Quellenkunde, insbesondere für die Geschichte der sowjetischen Gesellschaft, einige Fortschritte gemacht hatte. Vgl. dazu Strel'skij, V.I.: Osnovnye principy naučnoj kritiki istoxnikov po istorii SSSR, Kiev 1961 (Rezension von V.A. Kondrat'ev in: VI 1962, H. 2, 139-142); TMGIAI, tom 17: Voprosy istoxnikovedenija istorii SSSR, M. 1963; TMGIAI, tom 24. Voprosy istoxnikovedenija istorii SSSR, vyp.2, M. 1966; Voprosy istoriografii i istočnikovedenija istorii SSSR. Sbornik statej, M.L. 1963; Istoð̌nikovedenie istorii Sovetskogo obščestva. M. 1964 (Rezension von V.I. Buganov in: ISSSR 1966, H. 1, 164-168); Gubenko, M.P./B.G. Litvak: Konkretnoe istocnikovedenie istorii sovetskogo obščestva, in: VI 1965, H. 1, 3-16; Seleznev, M.S.M.N. Cernomorskij: Voprosy sozdanija istočnikoveď̌eskoj bazy po istorii sovetskogo obščestva, in: VI 1965, H. 9, 15-24. 
1961 hatte der britische Historiker Edward Carr seine Antworten auf die Frage, was Geschichte ist, vorgelegt, danunter auch Ausfuihrungen, die ,zum Kristallisationspunkt der Tatsachen-Diskussion geworden sind. ${ }^{{ }^{441}}$ Carr widersprach überzeugend der im 19. Jahrhundert dominierenden Faktengläubigkeit, ohne die Bedeutung der empirischen Evidenz historischer Aussagen zu schmälern. Es komme darauf an. aus der Flut bloßer Tatsachen die wirklich bedeutsamen ,historischen" Tatsachen herauszufinden; über die Aufnahme in den ,auserlesenen Klub" geschichtlicher Fakten könne nicht das logische Kriterium einer Geschichtstheorie entscheiden. sondern nur der Verlauf von Interpretation und Diskussion in der internationalen Fachwelt. ${ }^{42}$ Carr kam zu dem Schluß, daß in der Geschichtswissenschaft der Streit zwischen Fakten- und Theorie-Orientierung nicht zugunsten einer Seite entschieden werden dürfe, und daß sowohl

„(...) die Scylla der unhaltbaren Theorie, Geschichte sei eine objektive Anhäufung von Fakten (...)", als auch „(...) die Charybdis der ebenso unhaltbaren Theorie, Geschichte sei das subjektive Produkt des Historikers (...)"

zurückzuweisen sei. ${ }^{43}$ So sei denn auch die ,Dichotomie von Tatsache und Interpretation" im Forschungs- und Schreibprozeß allgegenwärtig. ${ }^{44}$

Auch wichtige marxistische Arbeiten wurden nicht beachtet, so zum Beispiel Bollhagens Monographie "Soziologie und Geschichte"“ ${ }^{45}$ Darin wären Anregungen zu finden gewesen, um die Spezifik der historischen Tatsache und das Verhältnis zwischen historischer und soziologischer Wissenschaft im materialistisch-dialektischen Rahmen zu präzisieren. Zu diesen beiden Problemen finden sich bei Bollhagen unter anderem folgende $-m$. E. für den marxistischen Diskussionsstand außerhalb der Sowjetunion während der zweiten Hälfte der sechziger Jahre repräsentative Überlegungen:

\footnotetext{
4 So Schulz-Hageleit, P.: Was lehrt uns die Geschichte? Annäherungsversuche zwischen geschichtlichem und psychoanalytischem Denken, Pfaffenweiler 1989, 24. - Dabei kannte zumindest Gulyga die Arbeit von Carr: In seinem Aufsatz „Über den Gegenstand der Geschichtswissenschaff" von 1964 hatte er sich auf Carrs Kritik an irrationalistischen und positivistischen Geschichtsauffassungen gestützt: vgl. Gulyga, O predmete, 22.

42 Siehe Carr, E.H.: Was ist Geschichte? (1961), Stuttgart 1963, besonders 10ff. - Analog schon Wittram, R.: Das Faktum und der Mensch. Bemerkungen zu einigen Grundfragen des Geschichtsinteresses, in: HZ 1958, H. 1, 55-87, 62f.

43 Carr, Was ist Geschichte, 29. - Analog hatte drei Jahre vorher Reinhard Wittram formuliert: „Es ist völlig sinnlos, das Faktum gegen den Zusammenhang, den Zusammenhang gegen das Faktum auszuspielen. Wir begreifen die Einzelheit nur von einem mehr oder weniger hypothetischen Ganzen her, und wir treiben leere Spekulation, wenn wir das Ganze nicht immer wieder von den Einzelheiten her anschauen und bezweifeln."- Wittram, Das Faktum, 59.

44 ,Jeder Historiker weiß, daß er bei der Arbeit (...) in einem kontinuierlichen Prozeß die Fakten seiner Interpretation und seine Interpretation den Fakten anpaßt. Man kann nicht dem einen den Vorrang vor dem anderen einräumen. (...) Der Historiker und die historischen Fakten brauchen einander. Der Historiker ist ohne die Fakten wurzellos und überflüssig: die Fakten sind ohne den Historiker tot und bedeutungslos.“- Carr, Was ist Geschichte, $29 f$.
} 
Hinsichtlich der „(...) Beziehung soziologische Tatsache - historische Tatsache (...) können wir mit vollem Recht die Schlußfolgerung ziehen, daß der Unterschied zwischen beiden nicht darin bestehen $k a n n$, da $B$ die eine singulär, die andere aber allgemein ist. Beide müssen beides zugleich sein. Der Unterschied zwischen ihnen kann also nur in der Qualität der Beziehung zwischen Einzelnem und Allgemeinem und der Form dieser Beziehung, wie sie jeweils in der soziologischen bzw. in der historischen Tatsache existiert, bestehen. "to

"Als Momente der objektiven Realität (...) sind soziologische und historische Tatsache nicht voneinander unterschieden (...), weil jede Tatsache des gesellschaftlichen Lebens grundsätzlich eine historische Tatsache ist, auch wenn von ihrem historischen Charakter in bestimmten Bereichen der gesellschaftlichen Erkenntnis zeitweise abstrahiert werden kann, und weil zweitens jede dieser historischen Tatsachen in sich Momente enthält, in Beziehungen zu anderen Tatsachen steht, die in diesem oder jenem Umfange sowohl zum Gegenstand der allgemeinen als auch der konkreten marxistischen Soziologie gehören.

Was in der Realität gemeinsam existiert - was durchaus nicht bedeutet, daß es dort unterschiedslos ist -, wird in der theoretischen Abstraktion getrennt, um dann in seiner Einheit gedanklich erneut reproduziert zu werden. Daraus ergibt sich, daß nurhistorischer oder nur-soziologischer Standpunkt beide gleich unwahr, weil abstrakt und einseitig sind, daß sie beide also nicht fähig sind, den ganzen Reichtum des gesellschaftlichen, des geschichtlichen Lebens gedanklich zu erfassen und zu verarbeiten. (...) ebenso wie durch das Prinzip des materialistischen Historismus in der marxistischen Soziologie die Geschichte nicht mehr als Äußerliches und Fremdes erscheint. sondern als immanentes Prinzip jeder soziologischen Forschung, so erscheint jetzt, je weiter wir in der historischen Untersuchung und der Analyse ihrer logischen Eigenschaften vordringen, die Soziologie nicht mehr als Äußerliches und Fremdes gegenüber der Geschichtswissenschaft, sondem als immanentes Prinzip und Ergebnis jeder geschichtswissenschaftlichen Forschung. “47

Wenn die Einheit von historischer und soziologischer Tatsache und ihr ständiger Übergang ineinander während des historischen (und soziologischen) Forschungsprozesses unbewußt blieben - so Bollhagen - entstehe der Schein, die historische Tatsache müßte aus der Soziologie erklärt werden, ganz so als würde , $(. .$.$) eine$ rein logische Wesenheit neben und außerhalb der Geschichte stehen. ${ }^{، 48}$

„Hier, bereits bei der Frage der Beziehung von soziologischer und historischer Tatsache, liegt also die tiefste erkenntnistheoretische Wurzel für die Gegenüberstellung

\footnotetext{
46 Bollhagen. Soziologie. $162 \mathrm{f}$.

47 Ebd., 170f.

48 Ebd., 158.
} 
von Geschichte und Soziologie, wie sie ihren ausgeprägtesten Ausdruck in der idiographischen Konzeption gefunden hat $(. . .)^{\text {c49 }}$

...und in der sowjetmarxistischen ebenfalls anzutreffen war, wie zu ergänzen wäre.

49 Ebd., 169. 


\subsection{GesetzmäßBigkeit und Alternativität in der Geschichte}

Gesetzmäßigkeiten der Geschichte, Kontingenz und Notwendigkeit in der historischen Entwicklung der Menschheit - das ist ein gleichermaßen altes wie umstrittenes Thema im Geschichtsdenken und in der Geschichtsschreibung. ${ }^{1}$ Endgültige Antworten sind hier noch weniger sinnvoll und leistbar als bei manch anderen geschichtsmethodologischen Problemen. Die historische Disziplin tut im allgemeinen gut daran, temporäre, dem aktuellen Stand der Wissenschaft entsprechende, erkenntnisfördernde Hypothesen als methodologische Voraussetzungen zu suchen, die in der konkret-historischen Forschung erprobt und in geschichtstheoretischen Diskussionen überprüft und gegebenenfalls weiterentwickelt werden können. Mit dieser zurechtgerückten Erwartungshaltung ist in unserem Kontext zu fragen, was die sowjetischen Geschichtsdiskussionen in den sechziger Jahren zur Lösung dieser Aufgabe beigetragen haben.

Dabei ist davon auszugehen, daß infolge der restriktiven Gegenstandsbestimmung der Geschichtswissenschaft unter Stalin (vgl. Kapitel 3.1.3. und 4.3.) der historischen Disziplin auch eine verengte Gesetzesauffassung vorgegeben war. Diese unterschied ,allgemeine Gesetze des historischen Prozesses“ von „besonderen Gesetzen der betreffenden Formation", wobei die besonderen Gesetze lediglich als spezifische Form und Konkretisierung der allgemeinen aufgefaßt wurden. ${ }^{2}$ Die ökonomische Determination allen menschlichen Tuns und der objektive Charakter der „Entwicklungsgesetze“" wurden übermäßig betont. ${ }^{3}$ Trotz verbalem Bekenntnis zum Kampf gegen Stalins Ökonomismus und Dogmatismus hielten einige Historiker und Philosophen an der Position fest, daß die Geschichtswissenschaft auf der Grundlage der Gesetzeserkenntnisse durch den historischen Materialismus und durch andere Gesellschaftswissenschaften den geschichtlichen Ereignisverlauf darlege und lediglich die Erscheinungsweise ökonomischer, sozialer, politischer und

1 Siehe Maier, F.G.: Der Gesetzesbegriff in den historischen Wissenschaften, in: Studium Generale 1966, H. 11, 657-667; Weiss, A. v.: Gesetz, Gesetzmäßigkeit, in: SDG 2, 1005-1017; Ladriere, J./H. Fleischer: Kontingenz, in: SDG 3, 877-889; Barloewen, W.D. von/C. von Barloewen: Die Gesetzmäßigkeit der Geschichte. Evolution und Zivilisation: Von den Anfängen der Menschheit bis ins dritte Jahrtausend. 2 Bände, Frankfurt/Main 1988, hier v.a. Bd. 1, 13-46 und Bd. 2, 545ff; Huguet, M.G.: Freiheit, in: EEPhW 2, 157-180; Hörz, H.: Gesetz/Gesetzmäßigkeit, ebd., 425-436; Müller, R.: Thukydides' Auffassung von historischer Gesetzmäßigkeit, in: Historiographiegeschichte, 92-101; Barthel, R.: Zur Entwicklung der Gesetzesauffassung in der Geschichtswissenschaf, ebd., 124-128.

2 Sceglov, A.: Istorija kak nauka, in: BSE (I) 30, 14-29, hier 24.

3 Ebd., 23f; nicht wesentlich anders bei Ovander, Ob ob-ektivnom charaktere, 40f; Chomenko, E. A.: O sootnošenii obščich i specifičeskich zakonov obščestvennogo razvitija, in: VF 1954, H. 4, 39-47, besonders 40f; Glezerman, O zakonach, 125ff; Trubicyn. O.N.: Ob ispol'zovanii zakonov obščstvennogo razvitija, in: VF 1961, H. 9, 105-116, hier 105ff passim. 
geistiger Entwicklungs- und Funktionsgesetze, ${ }^{4}$ nicht aber ,historische“ GesetzmäBigkeiten selbst aufdecke.

Abgesehen von diesen wiederholt publizierten Auffassungen und den halbherzigen Diskussionen über „das ökonomische Grundgesetz“ des Feudalismus und über ökonomische Gesetzmäßigkeiten antagonistischer Gesellschaftsformationen, die 1954 bis 1957 gefuihrt worden sind, ${ }^{6}$ zählte die Problematik der Gesetzmäßigkeiten in der Geschichte bis Anfang der sechziger Jahre zu den ,weißen Flecken" in der sowjetischen Geschichtswissenschaft. ${ }^{7}$ Die Relevanz der Thematik erkannten allerdings zunehmend mehr Historiker. Sich damit zu beschäftigen wurde nicht nur von „oben“ angewiesen, ${ }^{8}$ es wurde auch von ,unten" angeregt. ${ }^{9}$ Dabei wurde gegen die aus der Stalinzeit überkommenen Auffassungen als neue Position der Anspruch formuliert, daß die marxistische Geschichtswissenschaft spezifische historische Gesetzmäßigkeiten erforscht und erforschen muß, um nicht den Status als Wissenschaft $\mathrm{zu}$ verlieren und, $\mathrm{Ru}$ einem neokantianischen Idiographismus ${ }^{\text {“10 }} \mathrm{zu}$

\footnotetext{
$4 \quad$ Zu dem Bemühen, allgemeine Entwicklungsgesetze präziser als Entwicklungsgesetze einerseits. Funktionsgesetze andererseits zu verstehen, siehe Mamzin. A.S./V.P. Rožin: O zakonach funkcionirovanija i zakonach razvitija, in: FN 1965, H. 4, 3-9 (die deutsche Übersetzung findet sich leicht gekürzt in: SW 1966, H. 5, 527-533).

3 Siehe Rožin. Istorǐeskij materializm. 16f, vgl. ders.. Vvedenie. 36ff: Chaina. K.G. Ontologičeskij i gnoseologið̌eskij aspekt sootnoßenija obß̌cestvennogo zakona I ob̌̌čestvennoj zakonomernosti, in: Lið̌nost' i obక̌čestvo, M. 1969, 49f.; Popov, St:: Suščestvujut li specifičeskie istoriðeskie zakony? In: FN 1971, H. 6, 147-152.

6 Siehe Kapitel 3.1.2.

1 So M.P. Kim bei der unionsweiten Historikerkonferenz im Dezember 1962; Vsesojuznoe sovešranie 1964, 386.

8 Beispielsweise von den Akademiemitgliedern Fedoseev und Francev in ihrem programmatischen Eingangsreferat zu der gesellschaftswissenschaftlichen Konferenz im Januar 1964; siehe Istorija 1964, 16ff.

9 Bei der Konferenz im Dezember 1962 bezeichnete V.M. Kuricyn vom Institut fur Staat und Recht an der AdW der UdSSR es als vordringliche Aufgabe, die "Furcht vor Verallgemeinerungen" in der Geschichtswissenschaft und die alte Aufgabenteilung (Geschichtswissenschaft beschreibe Fakten. Philosophie decke Gesetzmäßigkeiten auf) zu überwinden. Der Philosoph M.D. Kammari sagte im Januar 1964: „Die Erforschung spezifischer historischer Gesetzmäßigkeiten, (...) die Erforschung der Wechselwirkung widersprüchlicher konkreter Tendenzen der historischen Entwicklung, unterschiedlicher Möglichkeiten und der Eigenar von Wegen der Geschichtsentwicklung verschiedener Länder, der Rolle der Volksmassen und der Persönlichkeit. verschiedener Arten von Zufälligkeiten in der Geschichte (...) - all das hat größte Bedeutung für den Kampf gegen Fatalismus in der Geschichtswissenschaft, gegen Dogmatismus in der Philosophie, gegen die Ideologie der Spontaneität und des Selbstlaufs in der revolutionären Bewegung." - Hervorhebungen von Kammari; Vsesojuznoe soveščanie 1964, 383: Istorija 1964, 1396.

10 So Devjał̌in, N.A: K voprosu o roli istoričeskogo zakona v istoričeskom poznanii, in: Voprosy teorii kak formy myšlenija, vyp. 1, T. 1970, 71-86, hier 76: .Die Geschichtswissenschaft kann nicht nur, sondern muß historische Gesetze aufdecken, ansonsten wird sie empirischen, beschreibenden Charakter haben (...)“.
} 
werden. " 1964, im fünten Band der Sowjetischen Historischen Enzyklopädie, definierte Kon die ,historische Gesetzmäßigkeit“ als

„(...) ein bestimmtes, objektiv existierendes, notwendig sich wiederholendes Verhältnis zwischen den Erscheinungen und Prozessen des gesellschaftlichen Lebens, ein Verhältnis, das aus ihrer inneren Natur hervorgeht und die fortschreitende Entwicklung der Geschichte ausdrückt: eine gewisse Regelhaftigkeit, Regularität der Aufeinanderfolge oder des Nebeneinanderbestehens sozialer Phänomene, bedingt durch ein Gesetz oder durch mehrere. “"12

Kons Definition und Erläutenungen zufolge kennzeichnen diese Merkmale historische Gesetzmäßigkeiten: ihr tendenzieller Charakter; ihre Verknüpfung mit dem Fortschrittsbegriff; die Anerkennung verschiedener Entwicklungsmöglichkeiten und eine gewisse Bedeutung des Zufalls sowie des personalen Elements für die Durchsetzung der einen oder anderen Möglichkeit; der historische Charakter der Gesetze und die Möglichkeit ihres Außerkrafttretens. ${ }^{13}$ Zum Zweck der inhaltlichen Füllung des neuen Gesetzesbegriffs unterbreiteten im Lauf der Diskussion der Moskauer Mediävist Gurevič und ein Historiker aus Perm, Kertman ${ }^{14}$, die beiden weitestgehenden Vorschläge.

In den Diskussionen am Geschichtsinstitut der Akademie und seinen Aufsätzen ${ }^{15}$ stellte Gurevič folgende Thesen auf: Die Tendenz-Gesetze, von denen bislang die Rede war - allgemein-soziologische Gesetze der Menschheitsentwicklung, für die

"So knüpften Fedoseev und Francev den Status der Geschichte als Wissenschaft an die Erkenntnis spezifischer historischer Gesetzmäßigkeiten: "Es wäre unrichtig anzunehmen, daß in der Geschichte nur allgemeine soziologische Gesetze wirken und der Historiker mit keinerlei anderen Verallgemeinerungen zu tun habe. Eine solche Ansicht verarmt die Geschichte als Wissenschaft." An anderer Stelle formulierten sie kategorisch: „Der marxistische Historiker erforscht den Wirkungsmechanismus der grundlegenden soziologischen Gesetze und weist dadurch nicht nur ihre Existenz anhand der Fakten nach, sondern er vertieft und erweitert auch unser Verständnis dieser Gesetze. Zugleich deckt er spezifische historische Gesetzmäßigkeiten in der Entwicklung des Klassenkampfs, in der Entwicklung des politischen und geistigen Lebens der Gesellschaft auf. Mit diesem Ziel analysient er die Häufigkeit (povtorjaemost) in den geschichtlichen Erscheinungen und deckt deren Wesen und soziale Natur auf." - Istorija 1964, 25.

12 Kon, I.S.: Zakonomernost' istorizeskaja, in: SIE 5, 603-606, hier 603

13 Ebd., 603f.

14 Lev Efimovǐ̌ Kertman (01.09.1917-30.11.1987), absolvierte 1940 die Historische Fakultät der Staatsuniversität und war anschließend bis Dezember 1941 bei der Roten Armee. Er beendete seine Aspirantur bei E.V. Tarle an der Universität Kazan' mit einer Dissertation über „Die Evolution der Geschichtsauffassungen T.N. Granovskijs“ im Jahr 1943. Von 1949 bis „zum letzten Tag" arbeitete Kertman an der Universität Perm, wo er sich 1961 mit einer Untersuchung der Strömungen in der englischen Arbeiterbewegung habilitierte und seitdem einen Lehrstuhl für neuere und neueste Geschichte leitete Er nahm 1970 am Internationalen Historikerkongress teil und gehörte u.a. dem Wissenschaftlichen Rat für die Geschichte der Geschichtswissenschaft an der AdW der UdSSR an. - Nekrolog in: NNI 1988, H. 3, 234.

is Gurevič, Obščij zakon (geringfügig gekürzt in: SW 1966, H. 2, 177-193); ders., Ob istoriceskoj zakonomernosti (Es handelt sich hier um eine leicht überarbeitete und erweiterte Fassung des Artikels von 1965.). 
antagonistischen Gesellschaftsformationen gültige Gesetze, Gesetze einzelner Formationen - seien soziologische, aber keine spezifisch historischen Gesetze; ${ }^{16}$ sie könnten weder den Inhalt einer solchen sozialen Revolution, wie den Untergang Roms und den Übergang von der Antike zum Mittelalter, noch die ,konkrete historische Tätigkeit" der Menschen erklären, weil sie nur die Dialektik von Produktivkkäften und Produktionsverhältnissen, also logische Zusammenhänge auf der sozial-ökonomischen Ebene ausdrückten $;{ }^{17}$ für den Historiker könnten sie nur Ausgangspunkt (Hypothese) seiner Arbeit sein, als Forschungsresultat aber nicht genügen. ${ }^{18}$ Die konkret historische Tätigkeit hänge nicht nur von ökonomischen, sondern von vielen ,historischen Faktoren“ ab, die zu verschiedenen Zeiten ganz unterschiedliche Bedeutung erlangen könnten (Geographie, Klima, Mentalität. Kult, Religion usw.). So ,mehrdeutig" und „vielschichtig“ daher geschichtliche Phänomene seien, so wenig eindeutig dürfe die Erklärung sein und nicht bloß auf eine allgemeine Gesetzmäßigkeit rekurrieren. ${ }^{19}$ Nur wenn über die sozialökonomischen Basistrends hinaus stoffliche Grundlagen und sogenannte Überbauphänomene erforscht und ihre jeweilige konkret-historische Bedeutung bestimmt würden, könne der Historiker zu befriedigenden Erkenntnissen gelangen, die sich günstigenfalls als spezifisch historische Gesetzmäßigkeiten formulieren ließen.

„So entsteht also die Notwendigkeit des Begriffs der konkreten historischen Gesetzmäßigkeit. Während soziologische Geseze den Geschichtsprozeß als Ganzes erklären und nur bei der Betrachtung historischer Epochen und großer Perioden als allgemeine Tendenzen der Entwicklung aufgedeckt werden können, zeigt sich die konkrete Gesetzmäßigkeit der Geschichte im Verlauf begrenzter Zeitabschitte, in der konkreten Lage, und sie formiert sich auf der Grundlage der Gesamtheit aller Kausalbeziehungen der sozialen Entwicklung in einer bestimmten Gesellschaft und in einem gegebenen Moment.“

„(...) die historische GesetzmäBigkeit (...) kommt auf Grund der Wirkung nicht nur einiger soziologischer Gesetze zustande, sondern auch ökonomischer und demographischer Gesetzmäßigkeiten sowie Gesetzmäßigkeiten des biologischen und psychischen Lebens des Menschen, des geistigen Lebens der Gesellschaft und Gesetzen der Natur (...). Nur die Gesamtheit der Wirkung all dieser Gesetze und Gesetzmäßigkeiten (...) erzeugt die geschichtliche Bewegung. Die konkrete historische Gesetzmäßig-

\footnotetext{
16 Gurevix, Obšxij zakon, $14 f$.

17 Ebd., 15ff.

18 Ebd., 22. Vgl. auch Gulyga, O charaktere, 31, der die allgemeinen Entwicklungsgesetze analog als "methodologischen Leitfaden“ bezeichnete und feststellte: "Tatsächlich, nicht aus einem einzigen gesellschaftichen Gesetz darf man auf deduktivem Wege auch nur eine einzige Tatsache der lebendigen, konkreten Geschichte ableiten. Das ist nicht möglich und übrigens auch nicht nötig: Die Geschichtswissenschaft beansprucht nicht die Lorbeeren der Naturwissenschaft. sie hat andere Möglichkeiten und Aufgaben."
}

19 Gurevið, Obక̌xij zakon, 19f; ders., Ob istoriðeskoj zakonomernosti, 54. 
keit ist das Resultat der Überschneidung, der Verbindung von Gesetzmäßigkeiten verschiedener Systeme. ${ }^{\text {“20 }}$

Spezifisch historische Gesetzmäßigkeiten seien daher stets systemimmanent, konkret und an die Aktivität geschichtlich handelnder Menschen gebunden, aus deren Tätigkeit sie nur hervorgingen. ${ }^{21}$ Das Verhalten und die Handlungen der Geschichtssubjekte (Kollektive, Klassen, Individuen) ${ }^{22}$ seien sozial determiniert und frei ${ }^{23}$ die Verhaltensalternativen seien nicht äquivalent, so daß sich in der Wahl auch die Verantwortung des Menschen zeige. ${ }^{24}$ Die Aktivität und Energie der Subjekte entscheide über die Realisierung der einen oder anderen Variante! Die Effektivität der Handlungen hänge jedoch in hohem Maß von unzähligen und unvorhersehbaren Umständen ab. Schon ein einzelner Umstand und mehr noch die Summienung solch ,zufälliger" Faktoren könne zu „Vektorenschwankungen“ führen. Die Aussage, das ,historische Gesetz" bahne sich seinen Weg durch das "Chaos der Zufälligkeiten", könne den Historiker nicht befriedigen; ihn müßten gerade diese Abweichungen, ihre Ursachen und Folgen interessieren. ${ }^{25}$ Es sei blo $B$ der - retrospektive - Blick des Historikers, der das Gewordene als einzig Mögliches und Gesetzmäßiges erscheinen lasse. ${ }^{26}$ Nachteilig - so Gurevið - wirkten in diesem Zusammenhang Hegels Ideen über den gesetzmäßigen Geschichtsablauf nach, die unkritisch in das Geschichtsdenken bei und nach Marx eingeflossen seien. Richtig sei Hegels These, daß alles Wirkliche „vernünftig“, das heißt nie ohne Grund und Ursache sei. Der Umkehrschluß - ,alles Vernünftige ist wirklich" - sei jedoch nicht akzeptabel, weil er immer nur eine einzige Entwicklungsmöglichkeit zulasse. "Zufälligkeit" und „Gesetzmäßigkeit" wollte Gurevið nicht mehr als Anti-

20 Ders., Obšxij zakon, 16-20. - Im gleichen Sinn schrieb Gulyga, Istorija, 18, von „Jokalen“ Gesetzmäßigkeiten, die „(...) unter der Einwirkung einer großen Vielzahl von Faktoren - geographischen, klimatischen, demographischen, ökonomischen, politischen, geistigen, - die in verschiedenen Situationen unterschiedlich zusammenwirken“, entstünden.

21 Gurevič, Obščij zakon, 18ff passim; ders., Ob istoričeskoj zakonomernosti, 51 und 67

22 „Das Verhalten und die Handlungen der menschlichen Kollektive, Klassen und Individuen in ihrer Wechselwirkung und Verflechtung bilden die geschichtliche Entwicklung." - So schrieb Gurevič, Ob ob̌̌̌cij zakon, 18, um die Subjektabhängigkeit des Geschichtsprozesses, der in der sowjetischen Literatur stets als wesentlich „naturgeschichtlich-gesetzmäßig“ charakterisiert wurde und wird zu betonen.

23 "Freiheit" und "Notwendigkeit" allgemein gebe es nicht, abstrakte Begriffe machten hier keinen Sinn; beides sei als Problem des Determinismus zu betrachten: Das Individuum sei den Normen, Regeln und Gesetzen des Systems, in dem es lebt, unterworfen, die Persönlichkeit sei sozialisiert und institutionalisiert: zugleich böten sich beständig Verhaltensalternativen. - Ders., Ob istoričeskoj zakonomernosti, 69.

\section{Ebd., 70 \\ 2s Ebd, $71 \mathrm{ff}$. \\ 26 Ebd., 75}

27 „Diese Hegelsche These geht hervor aus der idealistischen Vorstellung von einem Gesetz der Geschichte, das über den Menschen steht, wobei Gesetzmäßigkeiten der Geschichte in der Tat nichts anderes sind als das Resultat der jedesmal sich konkret entwickelnden Umstände, die von der objektiven Lage der Produktion und der Gesellschaft bedingt sind, aber in kolossalem Maße 
thesen, sondern als gleichsam wesensverwandte Eigenarten der Geschichte verstanden wissen. Die historische Gesetzmäßigkeit existiere in der Realgeschichte nicht außerhalb der Zufälligkeit:
"Wenn man aber in der Geschichte das Resultat der ständigen Wirkung und Wech- selwirkung vieler Gesetzmäßigkeiten verschiedener Betrachtungsweisen und Ebenen sieht, (...) und wenn man die sozialen Gesetze als die grundlegenden und profilieren- den anerkennt, dann erweist sich bei einer solchen Betrachtung die Zufälligkeit als notwendiges Produkt der Überschneidung dieser Gesetzmäßigkeiten. (...) Gerade aus dem, was wir Zufälligkeiten nennen, entwickelt sich auch die konkrete Gesetzmäßig- keit, die nichts anderes ist als das statistische Mittel der ganzen Summe der Entwick- lungstendenzen, der zahllosen, und daher von der Wissenschaft nie vollständig fest- stellbaren, 'zufälligen' Willen, Handlungen, Ereignissen und Wirkungen".

Abschließend betonte Gurevič, daß sich die Vorstellung von der Invarianz des Geschichtsprozesses in historiographischer und ethischer Hinsicht negativ auswirke: Die Annahme, das Wirken von Gesetzmäßigkeiten lasse nur eine bestimmte Entwicklung zu und schließe andere Varianten aus, mache die konkrete Erforschung und Erklärung der Geschichte überflüssig und müsse zu fatalistischen Lebenseinstellungen und Geschichtsauffassungen fuihren. ${ }^{29}$

L.E. Kertman stellte seine Thesen zuerst 1968 bei einer wissenschaftlichen Konferenz anläßlich der 150. Wiederkehr des Geburtstags von Karl Marx und 1971 einem größeren Publikum in Voprosy istorii vor. ${ }^{30}$ Im Rahmen der von ihm entwikkelten fünfgliedrigen Typologie von Entwicklungsgesetzen kam er wie Gurevič zu der Auffassung, daß ,konkret-historische Gesetzmäßigkeiten“ den Gegenstand der Geschichtswissenschaft darstellten, während ,allgemein-soziologische“, ,besondere Gesetze" der Formationen sowie „besondere Strukturgesetze" vom historischen Materialismus und „besondere Gesetze einzelner Systeme“ von gesellschaftswissenschaftlichen Einzeldisziplinen bearbeitet würden. ${ }^{31}$ Das Neue bestand darin, daß Kertman die konkret-historische Gesetzmäßigkeit mit dem Begriff der ,historischen Situation“ verband. Nur diese Gesetzmäßigkeiten seien als For-

vom Willen und von den Handlungen der die Gesellschaf bildenden Klassen. Gruppen und Individuen abhängen." - Ebd., 76. Ebenso auch schon ders., Obšcij zakon, 27. Vgl. Hegel, G.W.F.: Vorlesungen über die Philosophie der Geschichte. Frankfurt/Main 1970. Einfuihrend: Kolakowski. Die Hauptströmungen. Bd. 1, 72ff.

28 Gurevič, Obščij zakon, 28

29 Ebd., 29.

30 Kertman, L.E.: K. Marks i problema konkretno-istoriceskich zakonov, in: Voprosy istorii. Materialy naučnoj konferencii, posvjašcennoj 150-letiju so dnja roždenija Karla Marksa. Ufa 1969, 5-14; ders., Zakony istoričeskich situacij, in: VI 1971, H. 1, 55-68. - Bei der Historikerkonferenz im Dezember 1962 war Kertman in der Sektion für Allgemeine Geschichte aufgetreten, hatte für die Erneuerung der Beziehungen zwischen den geschichtswissenschaftlichen Institutionen plädiert sowie davor gewarnt, weiterhin die Peripherie zu vernachlässigen und ihr die Sachkompetenz abzustreiten; vgl. Vsesojuznoe sovešcanie 1964, 449-451.

31

Kertman, K. Marks 1969, 14. 
schungsgegenstand für Historiker relevant, sie seien von geringerem Abstraktionsgrad, aber inhaltsreicher als jene soziologischen Gesetze.

„Konkret-historische Gesetze sind Gesetze der Wechselwirkung verschiedener Seiten des geschichtlichen Prozesses in wesentlich gleichartigen Situationen, die den Wirkungsmechanismus soziologischer Gesetze ausdrücken."

Das klang wiederum so, als seien konkret-historische Gesetzmäßigkeiten bloß die Konkretisienung allgemeiner soziologischer Gesetze. 1971 präzisierte Kertman unter Berufung auf geschichtsmethodologische Aussagen Lenins seine Auffassungen: Das „Wesen“" einer historischen Situation werde bestimmt durch die „Wechselbeziehung der Klassen" ${ }^{33}$ Den sich gegebenenfalls wiederholenden, dergestalt struktural verwandten „Situationstypen“ entsprächen eben diese konkrethistorischen Gesetzmäßigkeiten, die nicht von allgemeinen Gesetzen abgeleitet werden könnten, sondern erkennbar nur durch die konkret-historische Erforschung der Klassenlage und -beziehungen seien. ${ }^{34}$ Weiter betonte Kertman, daß es auf dieser, für den Historiker relevanten Abstraktionsebene um die typologische Verallgemeinerung von historischen Situationen, nicht Systemen gehe; daß die Gesetze historischer Situationen nur die Möglichkeit oder Unmöglichkeit bestimmter Folgen fixierten, und nicht deren Unausweichlichkeit; daß auch Wahrscheinlichkeitsgrade der Realisierung ausgedrückt werden könnten; daß schließlich auch die „Nutzung" dieser Gesetze konkret-historischen Charakter habe.

Kertmans Vorschlag, spezifisch historische Gesetzmäßigkeiten als „Gesetze historischer Situationen" zu verstehen, dessen Diskussion in Auseinandersetzung etwa mit dem systemischen Ansatz von Kon und Grušin, oder mit den Thesen von Gurevič sich als fruchtbar hätte erweisen können, fand - soweit überschaubar - kein Echo in den sowjetischen Fachzeitschriften, was als Folge der wissenschaftspolitischen Interventionen Ende der sechziger Jahre und als Ausdruck der darauffolgenden Öde in der Geschichtswissenschaft zu deuten ist. ${ }^{36}$

$32 \quad$ Ebd., 13.

33 .Das Wesen der Situation (...) besteht in der Gruppierung der Klassenkräfte, in den Wechselbeziehungen zwischen den Klassen." - Kertman, Zakony, 58.

34 Aus Lenins Gesetzesauffassung ergebe sich, ,.(..) daß das direkte 'Anlegen' eines allgemeinen Gesetzes an die konkrete Situation unausweichlich zum Fehler in der Analyse des realen Geschichtsverlaufs fuihn." Exemplarisch bezog sich Kerman hier auf Lenins Vergleich der historischen Situationen 1848 in Frankreich und im Frühjahr 1917 in Rußland: Trotz etlicher, nicht unwesentlicher Unterschiede, hatte Lenin die Wesensverwandtschaft der "Situationstypen" aufgnund der seines Erachtens analogen „Wechselbeziehung der Klassen“ behauptet und daraus den Schluß gezogen, daß auch das russische Bürgertum unausweichlich versuchen würde, mit Gewalt die Arbeiterklasse niederzuhalten. - Kertman, Zakony, 56ff. Vgl. Lenin, V.I.: Iz kakogo klassovogo istoðnika prichodjat i .pridut“" Kaven’jaki? (zuerst in: Pravda Nr. 83, 29. (16.) 06.1917), in: LPSS 32, 343-346.

3s Kertman. Zakony, 63ff.

36 Vgl. dazu Kapitel 5.1. 
Während der Theoriediskussion der sechziger Jahre bezogen sich auf Gurevič vor allem Verbin und Egides mit interessanten kritischen Einwänden. Zunächst monierten sie die ihres Erachtens widersprüchliche Definition der historischen GesetzmäBigkeit bei Gurevič, der sie einerseits als Zufälligkeit ${ }^{37}$, andererseits als Kausalbeziehung ${ }^{38}$ bestimmt habe. ${ }^{39}$ Verbin und Egides meinten, daß zwar jedes Gesetz eine Kausalbeziehung ausdrücke, aber nicht jede ursächliche Verbindung historischer Phänomene schon eine Gesetzmäßigkeit darstellen könne. ${ }^{40}$ Auch die Zuordnung bestimmter Gesetze zur Soziologie, weil sie „Tendenz-Gesetze“ wären, hielten die Kritiker von Gurevic nicht für schlüssig. Denn das Allgemeine und die Tendenz erschienen im Einzelnen und Einmaligen. Daher gebe es

„(...) keine Gesetze (oder Gesetzmäßigkeiten), in denen entweder das Allgemeine, eine allgemeine Tendenz oder das Konkrete ausgedrückt würde: Jedes Gesetz ist Ausdruck einer allgemeinen Tendenz unter konkreten Bedingungen. "“1

Die von Gurevic gewählte Zuordnung führe doch wieder zu der auch von ihm abgelehnten Gegenüberstellung der Soziologie und der Geschichtswissenschaft, wonach jene das Allgemeine, Wesentliche und die Tendenz erforsche, diese das Einmalige, das Phänomen und den gegebenen Moment. Dann könnte die historische Disziplin jedoch keine Gesetze oder Gesetzmäßigkeiten aufdecken, weil diese immer mit dem Allgemeinen verbunden seien, und wäre keine Wissenschaft, sondern reine Faktensammlung. ${ }^{42}$ Die Gesetzmäßigkeiten beider Disziplinen seien mit solchen oder ähnlichen Kriterien nicht zu trennen. Sie verhielten sich - so Verbin und Egides - zueinander wie Soziologie und Geschichtswissenschaft im Erkenntnisprozeß, der (gemäß der marxistischen Gnoseologie) vom Konkret-Sinnlichen über das Abstrakt-Wesentliche zum Konkret-Wesentlichen aufwärts steige. ${ }^{43}$ Beide Diszi-

39 Verbin/Egides, Istoričeskij materializm, 13.

38 „Historische Gesetzmäßigkeit ist die Determiniertheit und ursächliche Verbindung geschichtlicher Phänomene. " Diese mißverständliche Formulienung änderte Gurevið̌ 1969 dahingehend: „Die historische Gesetzmäßigkeit zeigt sich als Determiniertheit geschichtlicher Phänomene.“- Vgl. Gurevič, Obščij zakon, 21, ders., Ob istoričeskoj zakonomernosti, 64.

39 Meines Erachtens berücksichtigten Verbin/Egides hier nicht ausreichend, daß Gurevið mit seinen definitorischen Sätzen verschiedene Aspekte der konkret-historischen Gesetzmäßigkeit charakterisierte: Erstens ging es um den Ursprung der Gesetzmäßigkeit (,Resultat der Uberschneidung, der Verbindung von Gesetzmäßigkeiten verschiedener Systeme"), zweitens um ihren Wirkungsbereich („Gesetzmäßigkeit eines bestimmten sozialen Systems oder einer bestimmten sozialen Struktur"), drittens um ihr Erscheinungsbild (,Determiniertheit und ursächliche Verbindung geschichtlicher Phänomene“). - Vgl. Gurevið̌, Ob istoričeskoj zakonomernosti, 63f und 67; ders., Obsxij zakon, 21.

40 Verbin/Egides, Istoričeskij materializm, 13.

41 Ebd., 14.

42 Ebd., 15.

43 Mit den Worten von Verbin/Egides: „von der Erforschung des Kaleidoskops geschichtlicher Ereignisse mittels der Überleitung in Gesetze des allgemeinen Verlaufs des Geschichtsprozesses. aufgedeckt vom historischen Materialismus, zur Erschließung der Gesetze des Besonderen, der Fülle des Konkret-Wesentlichen im Leben der Gesellschaft, was auch Gegenstand der Geschichtswissenschaft ist." - Ebd. Vgl. die fundamentalen Aussagen zur marxistischen Gnoseolo- 
plinen hätten somit ihre „Reihen“ des Einmaligen, Besonderen und Allgemeinen, sowie ihre „Phasen“ des Konkret-Sinnlichen, Abstrakt- und Konkret-Wesentlichen. Die von der Geschichtswissenschaft aufgedeckten Gesetzmäßigkeiten seien im Rahmen der Einzelwissenschaft ,allgemein“. In Relation zur Soziologie und Philosophie seien sie ,konkret" und drückten das Besondere sowie die konkretwesentliche Fülle des Geschichtsprozesses aus. ${ }^{44}$ Zudem seien die ,historischen Gesetze" nicht solche

„(...) über den gegebenen konkreten Moment, sondem über den unmittelbaren, konkreten Verlauf der Geschichte. ${ }^{\text {(4) }}$

Derartige Gesetze hätten Morgan ${ }^{46}$ und Grekov ${ }^{47}$ aufgedeckt. Aus diesen Beispielen zogen Verbin und Egides den Schluß, daß die marxistische Geschichtswissenschaft nicht bloß die Theorie des historischen Materialismus illustriere,

„(...) sondern sie verallgemeinert selbst; auf den Gesetzen des historischen Materialismus basierend, geht sie nicht zurück - zum Konkret-Sinnlichen, sondern nach vom - zum Wesentlich-Konkreten. ${ }^{448}$

In diesem Sinne bezeichneten Verbin und Egides die historische Disziplin auch als „konkret-wesentliche Windung in der Spirale des Erkenntnisprozesses geschichtlicher Wirklichkeit"“ ${ }^{49}$

Während Verbin und Egides Gurevic’ Positionen so weit in kritischer Rezeption auf der Grundlage ihrer eigenen, an Marx angelehnten erkenntnistheoretischen

gie bei Fedossejew, P. (= Fedoseev, P.N.) u.a.: Materialistische Dialektik. Kurzer Abriß, Berlin 1983 (zuerst Russisch: Materialističeskaja dialektika. Kratkij oxerk teorii, M. 1980), v.a. 166-205 sowie von Alfred Kosing und Dieter Wittich in: Klaus, G./M. Buhr ( $\mathrm{Hg}$.): Philosophisches Wörterbuch. 13. Auflage als fotomechanischer Nachdruck der 12., durchgesehenen Auflage. Westberlin 1985, hier 351-366 und Sandkühler, H.J.: Erkenntnis/Erkenntnistheorie, in: EEPhW 1, 772-904.

44 Verbin/Egides, Istorið̌eskij materializm, $15 f$.

4s Ebd., 16. Hervorhebung im Original.

46 Der Historiker, Ethnologe und Archäologe Lewis Henry Morgan (1818-1881) aus den Vereinigten Staaten habe unter anderem aufgezeigt. daß die Gentilordnung ein gesetzmäßiges Stadium in der Menschheitsentwicklung und der Weg von Matriarchat zu Patriarchat ein Entwicklungsgesetz der Urgesellschaft gewesen seien. Ebd., 17f. - Vgl. die Würdigung Morgans bei Engels, F.: Der Ursprung der Familie, des Privateigentums und des Staats. Im Anschluß an Lewis H. Morgans Forschungen (1884), in: MEW 21, 25-173; vgl. auch Devjašin, K voprosu, 80ff: Guhr, G.: Familie und Gens im Werk von L.H. Morgan, in: Matriarchat und Patriarchat. Zur Entstehung der Familie. Ethnographische Forschung/theoretische Diskussion: Beiträge aus der UdSSR, den USA, der DDR, hg. v. IMSF, Frankfurt/Main 1986, 86-103.

47 Boris Dmitrievic Grekov (1882-1953) habe die Gesetze der Entwicklung der Bauern als Klasse und der Städte unter den Bedingungen des Feudalismus sowie die Gesetze der Wandlung der ursprünglichen Dorfgemeinschaft (obstina) zum feudalen Erbgut (votcina) aufgedeckt. Verbin/Egides, Istoričeskij materializm, 18; eine Übersicht zum Werk und zu den zentralen Aussagen Grekovs bietet Oxerki 1985, 11 off.

48 Verbin/Egides, Istoričeskij materializm, 19.

49 Ebd., 16. 
Überlegungen weiterentwickeln wollten, stieß Gurevič dagegen mit seinem Plädoyer, neue strukturanalytische Ansätze aus dem Ausland aufzunehmen und in der historischen Forschung zu erproben, auf harsche Ablehnung. ${ }^{50}$ Indes, mit diesem Anliegen stand Gurevič in den sechziger Jahren nicht allein. Die Althistorikerin Staerman, der Mediävist Bessmertnyj, der Neuzeit-Historiker Barg und andere fochten für die Strukturanalyse in der historischen Forschung, um generell verbesserte logische Verfahren zu finden, die das ,wertende" Herangehen auf ein Mindestma $B$ einschränken sollten, und um insbesondere das Problem des historischen Determinismus besser in den Griff zu bekommen. ${ }^{\text {s1 }}$ Als Hypothese hielt Gurevič es für annehmbar, vom strukturellen oder systemischen Charakter (strukturnost', sistemnost') ${ }^{\text {s2 }}$ aller Wirklichkeit auszugehen. Gerade die marxistische Formationstheorie und die Lehre über Basis und Überbau böten eine perspektivreiche Grundlage für die Anwendung der strukturellen Analyse auf die Erforschung der Gesellschaft. $^{53}$ Man müsse allerdings die ökonomistische Betrachtungsweise überwinden und erkennen, da $B$ der Strukturbegriff nicht nur auf Klassenverhältnisse und Kapitalbeziehungen, sondern auch auf das geistige und politische Leben anwendbar sei. ${ }^{54}$ Aus dem strukturanalytischen Zugang ergab sich für Gurevič, daß die historische Forschung keinen allgemeinen Determinismus, sondern konkrete Gesetzmäßigkeiten bestimmter, konkreter Systeme zu suchen und zu untersuchen habe. Das lasse auch deutlich werden, daß derartige Gesetzmäßigkeiten keine unabhängigen, von außen (geradezu mystisch) wirkenden Kräfte, sondern immanente,

so Vgl. Gurevič, Ob istorizeskoj zakonomernosti, 66ff. Nach damit im Zusammenhang stehenden scharfen Auseinandersetzungen wurde am 13.07.1970 die Zulassung des Buches von Gurevic über „Ursprungsprobleme des Feudalismus in Westeuropa“ (M. 1970) als Lehrbuch fur historische Fakultäten wieder zurückgenommen. - Pleß̌kova, S.L.: Ob uð̌ebnom posobii „Problemy genezisa feodalizma v Zapadnoj Evrope“ (Informacija o chode obsuždenija knigi A.Ja. Gureviča), in: VI 1970, H. 9, 154-167; Marko, K.: Dogmatismus und Emanzipation in der Sowjetunion. Philosophie, Reformdenken, Opposition, Stuttgan-Berlin-Köln-Mainz 1971, 128ff.

s1 Schtajerman, J.M.: Über die Wiederholbarkeit in der Geschichte, in: SW 1965, H. 12, $1328-$ 1343, 1328 ff passim (der Beitrag beruht auf einen im Sektor für Geschichtsmethodologie gehaltenen Vortrag und wurde zuerst in VI 1965, H. 7 veröffentlicht); Staerman, E.M.: K probleme strukturnogo analiza $v$ istorii, in: VI 1968, H. 6, 20-37; Barg. M.A.: O nekotorych predposyl 'kach formalizacii istoriðeskogo znanija, in: Problemy issledovanija sistem i struktur. Materialy k konferencii, M. 1965, 183-186; ders., Die Strukturanalyse, 195 f; Bessmertnyj, Ju.L.: Sistema vnutriklassovych otnošenij sredi sen'orov Severnoj Francii i Zapadnoj Germanii, in: SV, vyp. 30, M. 1967, 138-156; Vitkin, M.A.: Estestvennoe i obక̌cestvennoe, in: VF 1969, H. 4; ders., Problema perechoda ot pervienoj formacii ko vtorienoj, in: Problemy istorii 1968; Danilova. L.V.: Diskussionnye problemy teorii dokapitalističeskich obščestv, in: ebd. (Die drei letztgenannten Titel waren mir nicht zugänglich; J.H.)

32 Unter „Struktur“ verstand Gurevič eine ,funktionale Einheit einer Gesamtheit von Elementen“, die von nur ihr eigenen, immanenten Gesetzen gelenkt wird und daher über eine „eigene Kausalität" verfügt. - Gurevið, Ob istoriðeskoj zakonomernosti, 66.

s3 Auch Staerman, K probleme, 22 schrieb, „....) daß die Strukturmethode (...) nicht nur der Methode von K. Marx nicht widerspricht, sondern im Gegenteil direkt deren Forderung entspricht, ahistorische, universelle Theorie-Schlüssel zu vermeiden.“

s4

Gurevic, Ob istoriðeskoj zakonomernosti, $66 f$. 
dem bestimmten System eigene, stabile Verbindungen seien. Weiter folgerte Gurevič daraus, daß mit einem Systemwechsel ein Determinismuswechsel verbunden sein müsse. ${ }^{\text {ss }}$ Für eine wahrscheinliche Hypothese hielt Gurevič es auch, daß es bei einem solchen Wechsel zu einer Pause, zu einer Unterbrechung jeglichen Determinismus kommen könne, wodurch ein soziologisches „Vakuum“ entstehe, das durch „freie menschliche Aktivität" ausgefüllt werden würde. ${ }^{56}$ Das erkläre den besonderen Bedeutungszuwachs individueller und massenhafter Aktivität in geschichtlichen Übergangssituationen. $^{57}$

Präziser und weitergehend als Gurevič (und dabei eigentlich ganz in dessen Sinn) hatte Barg schon Mitte der sechziger Jahre dargelegt, daß die für die historische Forschung relevanten Determinationstypen nicht erst bei einer Formationsablösung, sondern bereits bei der (soll man sagen: ganz normalen?) Weiterentwicklung des gleichen Systems wechselten. ${ }^{58}$ Denn wenn davon ausgegangen werde, daß Gesellschaft eine Gesamtheit hierarchisch gegliederter, ihrer inneren Struktur und ihrer Qualität nach unterschiedlicher Systeme darstelle, daß diese Systeme sich selbst regulierten (das heißt, trotz der Wirkung allgemeiner Formationsgesetze eine gewisse funktionelle Autonomie besäßen) und zugleich statischer und dynamischer Natur seien, dann könne angenommen und gezeigt werden, daß

1. die funktionelle Struktur der einzelnen Systeme einer Formation nicht konstant bleibe, daß

2. sich dabei auch die dynamischen Potenzen der einzelnen Systeme und ihre Hierarchie untereinander veränderten, und daß

3. sich auch die innere Struktur eines jeden Elements bei einer neuen Korrelation ändere. $^{59}$

Diese Evolutionen manifestieren nach Bargs Überzeugung die „Entwicklungsphasen" oder "-stufen" eines Gesellschaftssystems; und an diese seien die konkret historischen Gesetzmäßigkeiten gebunden, die nur so lange wirkungsvoll blieben, wie die jeweilige Hierarchie oder Subordination der funktionellen Systeme unverändert bleibe.

\footnotetext{
ss Ebd., 67
}

s6 „Die Krise eines gesellschaftlichen Systems, sein Niedergang und seine Auflösung werden dadurch charakterisiert, daß die dem System eigenen, inneren Gesetzmäßigkeiten aufhören, effektiv zu wirken und die Fähigkeit der Selbstregulierung und Aufrechterhaltung des Gleichgewichts der systembildenden Strukturen verlieren; (...) es tritt ein Moment ein, da der frühere, traditionelle Determinismus schon nicht mehr 'arbeitet', nicht mehr die Bewegung des Systems bestimmt, und der neue Determinismus, der das neue System regulieren soll, noch nicht herausgebildet ist." - Ebd., 68.

s7 Ebd.

\$8 Barg. Die Strukturanalyse.

39 Ebd., 197ff. In verwandter Weise argumentierte auch Gulyga, Istorija, $29 f f$. 
„Damit wird deutlich, daß die historischen Stadien nur mit Hilfe der Strukturanalyse erkannt werden können. Die eigentliche wissenschaftliche Grundlage jeder historischen, d.h. genetischen Analyse besteht aber gerade darin, die Geschichte als einen Prozeß zu behandeln, der durch Entwicklungsstufen markiert wird. “60

Die Ablehnung des strukturanalytischen Ansatzes und insbesondere seiner Verbindung mit der Erklärung spezifisch historischer Gesetzmäßigkeiten artikulierte am entschiedensten die bereits bekannte Stimme aus der Peripherie: Der damalige „Kopf“ der Tomsker „Schule“, A.I. Danilov, kritisierte zuerst in der sechsten Ausgabe des voluminösen Tomsker Periodikums „Methodologische und historiographische Fragen der Geschichtswissenschaft" das ,methodologische Suchen einiger Historiker".61 Nur unwesentlich verändert übernahm das Theorieorgan der KPdSU, Kommunist, den Aufsatz ${ }^{62}$ dessen Übersetzung bald auch in der Zeitschrift "Sowjetwissenschaft“ in der Deutschen Demokratischen Republik erschien. ${ }^{63}$ Diese Art der Weiterverbreitung signalisierte, daß gewisse Historiker in Tabuzonen eingebrochen und ihre Diskussionsbeiträge zu einem Politikum geworden waren. Das verdeutlichte auch der Stil, der die Beiträge Danilovs prägte. Es ging ihm offensichtlich nicht um die Kritik oder Verbesserung möglicherweise fehlerhafter Vorschläge, sondern um die grundsätzliche Ablehnung des Ansatzes. Schon die Bestandsaufnahme, mit der etwa Barg, Bessmertnyj, Gurevič und Staerman ihr Plädoyer für die Strukturanalyse begründet hatten, wies Danilov zurück: Methodologische Fragen würden nicht deshalb intensiv diskutiert, weil sie bislang vernachlässigt worden wären, sondern weil die Weiterentwicklung der Geschichtsmethodologie notwendig sei. ${ }^{64}$ Und wer Strukturanalyse für die ,konsequente Verwirklichung der Prinzipien des dialektischen Materialismus ${ }^{\text {cos }}$ halte und in diesem Sinne befürworte, der negiere nolens volens das materialistische Geschichtsverständnis, im einzelnen vor allem den historischen Materialismus. ${ }^{66} \mathrm{Da}$ dieser sich aber bewähre, müsse er nicht erneuert oder gar ersetzt, sondern stets nur dem Wissenschaftsfortschritt entsprechend weiterentwickelt werden. Eine effektivere Verbesserung des Erkenntnispotentials als die ,immer tiefere Aneignung der marxistischleninistischen Methodologie" vermochte Danilov nicht zu erkennen. ${ }^{67}$ Ohnehin sei in der marxistischen Geschichtswissenschaft ,immer" die notwendige Aufmerksamkeit auf die Analyse der Strukturen unterschiedlicher Glieder des Geschichts-

\footnotetext{
60 Barg, Die Strukturanalyse, 204.

61 Danilov, A.l.: Materialističeskœe ponimanie istorii i metodologičeskie iskanija nekotorych istorikov, in: MIVIN, vyp. 6, T. 1969, 227-245. - Zu Aleksandr Danilov siehe oben Kapitel 4.2.4.

62 Danilov, A.: K voprosu o metodologii istoričeskoj nauki, in: K 1969, H. 5, 68-81.

63 Danilow, A.: Zur Methodologie der Geschichtswissenschaft, in SW 1969, H. 12, 1246-1259.

64 „Man darf nicht mit der pessimistischen Zustandsbewertung der Angelegenheit mit dem gnoseologischen und logischen Ausrüstungsgrad der sowjetischen Historiker einverstanden sein. - Danilov, Materialisticeskoe ponimanie, 228.
}

6s So wörtlich bei Staerman, K probleme, 23.

66 Danilov, Materialisticeskoe ponimanie, $229 f$.

67 Ebd., 233. 
prozesses gelenkt worden. Schließlich teilte Danilov explizit mit, daß der Streit sich nicht um die Strukturanalyse als Methode drehe, sondern um ihre Interpretation und um die Inhalte und Resultate, zu denen „einige" Historiker gekommen seien. ${ }^{68}$ Denn diese liefen darauf hinaus, zentrale Kategorien des historischen Materialismus, vor allem den Formationsbegriff, zu entwerten und Begriffe und Konzeptionen aus der „bürgerlichen Historiographie“ und dem „Strukturalismus" einzuführen. ${ }^{69}$

Abschließend kann gesagt werden, daß die von Gurevič, Kertman, Verbin, Egides und anderen gegebenen Anregungen im Rahmen des Möglichen konstruktiv waren. Ganz aus jeglichen Gesetzeskonzeptionen auszubrechen, war zweifellos nicht möglich, ohne Dissident zu werden. ${ }^{10}$ Und den Erinnerungen von Beteiligten zufolge war es in den sechziger Jahren noch ein ehrliches Anliegen der Diskutanten, das marxistische Geschichtsverständnis nicht zu überwinden, sondern es von dogmatischem Ballast zu befreien, um es zu emeuem. ${ }^{71}$ Das Dargelegte richtete sich vor allem gegen eine Gesetzesauffassung, die darauf hinauslief, der Geschichtswissenschaft Forschungsinhalte und -resultate vorzugeben, und gegen jenen ökonomistischen Determinismus, der alle Vergangenheit aus der wechselseitigen widersprüchlichen Beziehung von Produktivkräften und Produktionsverhältnissen zu erklären beanspruchte. In diesem Sinne rückte Gurevič ,historische Faktoren“" ins Blickfeld, welche die von dem Historiker zu erklärende konkret-historische Tätigkeit der Menschen bedingten und die nicht von allgemeinen Gesetzen abzuleiten, sondern stets konkret-historisch zu untersuchen, zu gewichten und für die Formulierung von spezifisch historischen Gesetzmäßigkeiten konstitutiv seien. Auch Kertmans Vorschläge waren dazu angetan, den bislang ökonomistischen Blick auf durch Raum und Zeit bestimmte, historische Situationen zu richten und ihn gleichzeitig zu weiten für die Wahrnehmung von Klassenbeziehungen und -interessen, perspektivisch für die Analyse von Schichten, Gruppen und - nicht immer aus der Ökonomik ableitbaren - Partikularinteressen. So anregend die Beiträge von Gurevǐ̌ und Kertman, die Kritik von Verbin und Egides für das Nachdenken und Neudenken von Gesetzmäßigkeiten und Alternativität in der Geschichte waren, so blieben doch, weil bis zum Abbruch der Diskussionen zu wenig Zeit war, zentrale Probleme und Begriffe ungeklärt.

1. Der Tendenzcharakter der historischen Gesetzmäßigkeiten: Diese Frage war aufgeworfen durch die widerstreitenden Aussagen von Kon, Verbin und Egides einerseits - historische Gesetzmäßigkeiten hätten tendenziellen Charakter -, Gure-

$\begin{array}{ll}68 & \text { Ebd., } 245 . \\ 69 & \text { Ebd. passim. } \\ 70 & \text { Im Gespräch mit dem Autor am 08.04.1992 sagte Svetlana Sergeevna Neretina, Michail }\end{array}$ Gefter sei zumindest ein „Halb-Dissident“ geworden. Diese Entwicklung gipfelte 1981 mit seinem Austritt aus der KPdSU. - Vgl. Gefter, M.Ja.: 12 tech i etich let, 184ff passim.

11 Vgl Neretina, Istorija; Gefter, Iz tech i etich let; so äußerten sich im Gespräch mit dem Autor auch A.Ja. Gurevič (am 17.12.1990) und P.V. Volobuev (08.04.1993). 
vič andererseits - historische Gesetzmäßigkeiten seien von (soziologischen) Tendenzgesetzen verschieden -, aber sie ist nicht beantwortet worden. Der Vorwurf gegenüber Gurevið̌, er negiere den tendenziellen Charakter historischer GesetzmäBigkeiten, kann sicherlich, wenn man seine Aussagen im Ganzen berücksichtigt. nicht aufrechterhatten werden. Denn gerade er war es, der auf unvorhersehbare „Vektorenschwankungen" infolge von alternativem individuellem Verhalten einzelner Personen und auf Grund des Eintretens zufälliger Faktoren hingewiesen hat. Ohne Erläuterung blieb in der sowjetischen Literatur allerdings die Frage, in welchem Sinn von einem Tendenzcharakter gesprochen werden könnte. Dies präzisierte zur gleichen Zeit Bollhagen in der DDR dahingehend, daß historische Gesetzmäßigketten, die er als genetisch-strukturelle Gesetze der gesellschaftlichen Entwicklung verstand, ${ }^{72}$ in der Beziehung eindeutig bestimmt seien, daß sie die „Bewegungsrichtung“ bei der Entstehung von Neuem, der Entwicklung vom Niederen zum Höheren eindeutig ausdrückten. Und er fügte hinzu:
"Wir sagen, in dieser Beziehung eindeutig bestimmt, weil sich auch die genetisch- strukturellen Gesetze immer nur annähernd im Sinne der Modifizienung durch äu- Berliche Umstände, äußere historische Zufälle, die also nicht Erscheinungsformen der Bewegung des Gesetzes selbst sind usw., durchsetzen." "73

Dieses Verständnis war näher am klassischen Marxismus als die zeitgenössischen sowjetischen Aussagen zum gleichen Problem. Wenn auch Marx und Engels gem emphatisch von den „Naturgesetzen gesellschaftlicher Entwicklung“ oder von der Geschichte als einem ,naturgeschichtlichen Prozeß" sprachen, ${ }^{74}$ so kann doch kein Zweifel daran bestehen, daß auch sie davon überzeugt waren, daß historische Gesetzmäßigkeiten immer nur annähernd und tendenziell realisiert würden, ${ }^{75}$ also nicht mit naturwissenschaftichen Kriterien ${ }^{76}$ definiert werden könnten. Diese Seite wollten oder konnten die sowjetischen Autoren in den veröffentlichten Diskussionen nicht angemessen berücksichtigen.

\footnotetext{
12 Siehe Bollhagen, P.: Gesetzmäßigkeit und Gesellschaft. Zur Theorie gesellschaftlicher Gesetze (1967), s'Gravenhage 1973, 135ff.

73 Ebd., 139.

14 So etwa Karl Marx im Vorwort zu seinem Hauptwerk; siehe Marx, K.: Das Kapital. Kritik der politischen Ökonomie. Erster Band. Buch I: Der Produktionsprozeß des Kapitals (1867), in: MEW 23, hier 12ff passim.

15 Marx sprach an gleicher Stelle von „(...) mit eherner Notwendigkeit wirkenden und sich durchsetzenden Tendenzen." Gesetze würden immer in ihrer „(...) Verwirklichung durch mannigfache Umstände modifiziert (...)“. - Ebd., 12 und 673f. Vgl. Hörz, Gesetz, $431 \mathrm{ff}$; Barthel, Zur Entwicklung, 125ff, Jaeck, H.-P.: Der Gesetzesbegriff bei Montesquieu und Marx, in: Historiographiegeschichte, 118-123; nicht auf Marx, sondern auf Weber aufbauend: Eulenburg. F.: Sind „Historische Gesetze" möglich? Eine methodologische Untersuchung, in: Palyj, M. (Hg.): Hauptprobleme der Soziologie. Erinnerungsausgabe für Max Weber, 1. Band, München-Leipzig 1923, 23-71.
}

So bei Maier, Der Gesetzesbegriff, besonders 66 Iff. 
2. Gesetzmäßigkeit und Alternativität in der Geschichte gehören zusammen, bilden ontologisch eine Einheit, die gnoseologisch reflektiert werden muß. Denn

„weder fungiert ein 'Primat der Ökonomie' als universales Deduktionsprinzip noch ein universaler 'Wirtschaftsprozeß' als historisches Meta-Subjekt von eigener Zielstrebigkeit. Die angemessene Kategorie des historischen Kalküls ist nicht die einer zentralen und monothematischen Notwendigkeit, sondem die der Möglichkeit. In der 'Ökonomie', genauer in der Produktivkräfte-Entwicklung liegen Möglichkeitsbedingungen beschlossen."

Über die Realisierung verschiedener Möglichkeiten entscheidet jedoch nicht die Ökonomie, sondern die ,Antriebsstruktur der tätigen Subjekte ${ }^{\text {“. }{ }^{78} \text { In diesem Sinne }}$ äußerte sich in der sowjetischen Diskussion in den sechziger Jahren - wie wir oben gesehen haben - lediglich Gurevic; seine Anregungen sind, so weit überschaubar, nicht aufgegriffen worden. Wie zurückhaltend mit diesem Problem umgegangen wurde, können wir auch bei einer Publikation des Tomsker Historikers Mogil'nickij zu einer anderen Thematik sehen: Er führte dort zwei Lenin-Zitate an, welche die Ansprüche an den materialistischen Historiker formulierten. ${ }^{79}$ Beide implizieren dringend die Frage nach Alternativen in der Vergangenheit. Das sprach Mogil'nickij jedoch nicht aus; ihn interessierte nur Lenins Orientienung auf die Analyse der Klassenverhältnisse. Das Problem der Alternativität in der Geschichte umging auch er. Gurevic blieb in der Sowjetunion mit seinen Hinweisen auf determinierte Verhaltensalternativen in der geschichtlichen Entwicklung ein einsamer Rufer, ähnlich Emst Engelberg in der DDR. ${ }^{80}$

3. Die Differenzienung des Determinismus: Auch die Vielschichtigkeit des Determinismus-Problems wurde nicht erfaßt. Infolgedessen wurde bei der Rezeption der bürgerlichen Geschichtsschreibung meist übersehen, daß auch dort von namhaften Vertretern Kausalerklärungen als unumgänglich betrachtet werden. ${ }^{81}$ Andererseits

17 Fleischer, H.: Marxismus und Geschichte (1969), 3. Auflage, Frankfurt am Main 1970, 134 (kursiv bei Fleischer).

78 Ebd

19 Erstens: „Ob es nicht für den Marxisten Pflicht ist, die ganze Sache zur Erklärung dessen zu fuihren, was ist und wanum es gerade so und nicht anders ist?" (LPSS 1, 457) Zweitens: Der bürgerliche „(...) Objektivist spricht über die Notwendigkeit eines bestimmten historischen Prozesses; der Materialist konstatiert mit Präzision die gegebene ökonomische Gesellschaftsformation und die durch sie hervorgebrachten antagonistischen Verhältnisse. Der Objektivist riskiert immer, da er die Notwendigkeit einer bestimmten Reihe von Fakten nachweist, sich auf dem Standpunkt des Apologeten dieser Fakten zu verirren; der Materialist deckt die Klassenwidersprüche auf und bestimmt dadurch seinen Standpunkt." (Ebd., 418). - Zitiert nach Mogil'nickij, B.G.: Ob-ektivnost' i partijnost ' $v$ istoriceskom issledovanii, in: MIVIN, vyp. 2, T. 1964, 3-34, hier 5.

80 Engelberg bezeichnete es als ,(...) unerläßlich, daß wir das historische Alternativdenken als methodologisches Prinzip energisch und konsequent anwenden", wobei es ihm vor allem um die „(...) präzise Herausarbeitung progressiver Ansätze, auch ungenutzter, unrealisierter historischer Möglichkeiten" ging - Engelberg, Über Gegenstand, 24.

81 „Das Studium der Geschichte ist ein Studium der Ursachen“. - Carr, Was ist Geschichte, 86. „Würde man aufhören, unter Hinweis auf das Zufällige und Neue eines (...) Faktums nach seinen Ursachen zu suchen, dann wäre jede Geschichtswissenschaft am Ende.“ - So Karl-Georg Faber, 
wurde in der sowjetischen Fachliteratur das Kausalitätsprinzip nicht kritisch diskutiert. Unreflektiert blieb die - im Westen von Helmut Fleischer hervorgehobene „begrenzte kognitive Bedeutung“ der Kausalerklärung sowie die ihr innewohnende Tendenz zur Geschichtsapologie. ${ }^{82}$

Die Versuche, den Gesetzesbegriff inhaltlich auszufullen, liefen im großen und ganzen auf eine Hypostasierung desselben hinaus. Das lag daran, daß die ganze Diskussion gegen die vorangegangene Negation des Begriffs spezifisch historischer Gesetzmäßigkeiten und gegen die Infragestellung des Status' der Historie als Wissenschaft gerichtet war. Das brachte mit sich, daß bei der insgesamt wenig ergiebigen Lenin-Exegese die von Hegel herrührende Überzeugung von der strengen Gesetzmäßigkeit der Geschichte unkritisch übernommen und besonders betont wurde. $\mathrm{Da} B$ Marx demgegenüber bei der Formulierung von Determinationen begrifflich zu differenzieren wußte, wurde dabei vernachlässigt. ${ }^{83}$ Auch geriet die Frage aus dem Blick, ob es überhaupt Sinn macht, sei es für den Geschichtsmethodologen oder für den Historiker der Realgeschichte, soziologische und historische Gesetzmäßigkeiten streng zu unterscheiden. Hier gingen die Einwände von Verbin und Egides gegen Gurevic m. E. in die richtige Richtung: Da das Allgemeine und die Tendenz sich immer im Singulären und Besonderen zeigen, kann es keine Gesetzmäßigkeiten geben, die nur das eine oder nur das andere ausdrücken.

"Jedes Gesetz drückt eine allgemeine Tendenz unter konkreten Bedingungen aus. “"st

Demnach sind es unterschiedliche Abstraktionsniveaus, auf denen das Denken des Historikers sich bewegt, und er muß nicht zurückschrecken, wenn das Historische sich ins Soziologische verwandelt; seine Aufgabe besteht darin, immer wieder auch auf das Historische zurückzukommen und die Verbindung zum Soziologischen zu

der darauf hinwies, daß auch der erzählende Historiker, der nicht die kausale Erklärung sucht. wegen des „Pluralismus der Ursachen“ vor das Problem der Auswahl gestellt ist: „Das Setzen von Ursachen in einer kausalen Erklärung und das Auswählen von Ereignissen in einer Geschichtserzählung bewegen sich auf derselben Ebene." Insofern stimmte Faber mit Bollhagens Feststellung überein, daß sich in der Sozialwissenschaft das Historische in das Logische verwandle. - Faber, K.-G.: Theorie der Geschichtswissenschaft, 3., erweiterte Auflage, München 1974, 69, 72 und 80; vgl. Bollhagen, Soziologie, 44ff.

82 Die formale Strenge der Kausalerklärung führe dazu, daß „(...) die Aporien der Determination sich noch verschärfen. $\mathrm{Zu}$ sagen, daß Handlungen eindeutig und notwendig aus ihren Entstehungsbedingungen (...) 'eindeutig und notwendig folgen', bedeutet einen großen Sprung über den Umsetzungsprozeß hinweg, der in den handelnden Subjekten vor sich geht. (..) Als Selbstreflexion menschlicher Tätigkeit ist die Kausalbetrachtung geradezu irreführend, weil sie die Faktizität der Ergebnisse theoretisch sanktioniert." - Fleischer, Marxismus, 137f.

83 Marx schrieb, daß die Produktionsverhältnisse, die die Menschen eingehen, der Entwicklungsstufe der Produktivkräfte „entsprechen“, daß die materielle Produktionsweise den sozialen, politischen und geistigen Lebensprozeß der Gesellschaft „bedingt“, daß das gesellschaftliche Sein das gesellschaftliche Bewußtsein ,bestimmt“. - Marx, K.: Zur Kritik der Politischen Ökonomie (1859), in: MEW 13, 7-160, hier 8f; vgl. Fleischer, Marxismus, $129 f$.

\$4 Verbin/Egides, Istoriそeskij materializm, 14. 
erhellen, um Wiederholungen und Regelmäßigkeiten, wiederkehrende konkrete Verbindungen in der Geschichte zeigen und erklären zu können. ${ }^{85}$

Ein weiteres Defizit sei nur noch erwähnt. „Notwendigkeit“ - als Antithese des Zufalls und als besonderer Aspekt des Geschichtsdeterminismus, der dessen praktischen Sinn ausdrückt ${ }^{86}$-, dieser Begriff wurde in der sowjetischen Diskussion gänzlich vergessen. Wie dieser Terminus in der Tradition und Weiterführung der Anregungen von A. Brunner, R. Luxemburg, N. Bucharin, A. Gramsci und J. Habermas differenziert und ausgefüllt werden könnte, hat Helmut Fleischer gezeigt und muß hier nicht referiert werden. ${ }^{87}$

8s Vgl. Eulenburg, Sind „Historische Gesetze“ möglich; Marx, K./F. Engels: Die deutsche Ideologie. Kritik der neuesten deutschen Philosophie in ihren Repräsentanten Feuerbach, B. Bauer und Stirner, und des deutschen Sozialismus in seinen verschiedenen Propheten (1846), in: MEW 3, 9-530, 28ff; Bollhagen, Soziologie, 172ff; Naumann, Ökonomische Gesellschaftsformation, $32 \mathrm{f}$ und $57 \mathrm{ff}$.

86 So, wenn Marx und Engels schrieben, daß das Proletariat „(...) auch unmittelbar durch die nicht mehr abzuweisende, nicht mehr zu beschönigende, absolut gebieterische Not - den praktischen Ausdruck der Notwendigkeit - zur Empörung gegen diese Unmenschlichkeit gezwungen ist (...)". - Engels, F./K. Marx: Die heilige Familie oder Kritik der kritischen Kritik. Gegen Bruno Bauer und Konsorten (1845), in: MEW 2, 3-223, hier 38 (Kursiv im Original).

8. Siehe Fleischer, Marxismus, $142 \mathrm{ff}$. 


\subsection{Diskussion der Forschungsprinzipien}

Der Antirevisionismus von 1957 führte insofem zu einer Restalinisienung, daß er die Geschichtswissenschaft wieder vollständig und nachhaltig auf die kommunistische Parteilichkeit als dem wichtigsten, ja im Grunde: dem einzigen Prinzip der historischen Forschung im Sozialismus verpflichtete. ${ }^{1}$ Hier ist nun zu fragen, inwieweit sich die Geschichtsdiskussionen der sechziger Jahre mit diesem Problem befaßten, ob es neue Versuche gab, das Parteilichkeitsprinzip zu negieren oder es zumindest durch die Aufnahme des Postulats weiterer Prinzipien, etwa denen der Objektivität und des Historismus, zu relativieren. Keinen Anlaß zu einer derartigen Hoffnung gaben die offiziellen Verlautbarungen bei der Historikerkonferenz im Januar 1964. Dort stellte Akademiemitglied Fedoseev kategorisch fest, daß der historische Materialismus Parteilichkeit direkt einschließe, da $B$ das materialistische Geschichtsverständnis als

„(...) parteiliches Verständnis geschichtlicher Prozesse von den Positionen der Arbeiterklasse, der marxistisch-leninistischen Partei, und unter unseren Bedingungen von den Positionen des ganzen sowjetischen Volkes aus (...)" verstanden werden müsse. ${ }^{2}$

Der führende Revolutionshistoriker Isaac Minc sagte während der gleichen Konferenz, das Parteilichkeitsprinzip sei

"(...) das wichtigste methodologische Prinzip der Historiker, der hoffnungsvollste Kompa $B$ im Chaos der Fakten und historischen Erscheinungen. “"

Die Historiker, die das Parteilichkeitsprinzip mit diesem Anspruch verteidigten, begründeten es mit dem Klassencharakter der Realgeschichte und der Systemkonfrontation zwischen Sozialismus und Kapitalismus: Weil der Klassenkampf der wichtigste Faktor in der geschichtlichen Wirklichkeit sei, könne kein Historiker unparteiisch sein; $;^{4}$ die Entwicklung der Geschichtswissenschaft sei eng verbunden mit der politischen Geschichte und jede Klasse forme ihre Weltanschauung und

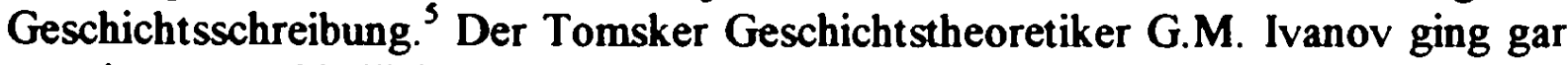
soweit, unterschiedliche Interpretationen in der Geschichtswissenschaft direkt aus

Vgl. Kapitel 3.2.3. In der DDR wurde zur gleichen Zeit im Rahmen einer zur UdSSR analogen antirevisionistischen Wende der Wirtschafts- und Sozialwissenschaftler Jürgen Kuczynski wegen seiner abweichenden Interpretation der Parteilichkeit heftig kritisiert. - Kuczynski, Frost; Rumpler, H.: Parteilichkeit und Objektivität als Theorieproblem der Historie in der DDR, in: Fischer, A./G. Heydemann (Hg.): Geschichtswissenschaft in der DDR, Band 1: Historische Entwicklung. Theoriediskussion und Geschichtsdidaktik, Berlin 1988, 334-362 (Wiederabdruck aus: Koselleck, R./W.J. Mommsen/J. Rüsen (Hg.): Objektivität und Parteilichkeit in der Geschichtswissenschaft, München 1977).

2 Siehe Istorija 1964, 328.

3 Ebd., 67.

4 So etwa Pripiznov, O sootnošenii, $110 \mathrm{f}$.

5 Mogil'nickij, B.G.: Ob-ektivnost' istoričeskogo poznanija i sovremennost', in: MIVIN, vypusk 5, T. 1967, 30-51, hier 43. 
der individuellen Zugehörigkeit der einzelnen Historiker zu verschiedenen Klassen zu erklären. ${ }^{6}$ In den konservativ ausgerichteten Aussagen hieß es - in der Regel ganz in Übereinstimmung mit den Parteilichkeitsfordenungen von 1957/58 -, kommunistische Parteilichkeit verlange

"(...) die offene Verteidigung der Interessen der Volksmassen und der fortschrittlichen Klasse (...), der Interessen, die am vollständigsten durch die Avantgarde der Klasse - durch die Partei - ausgedrückt werden. “"

Dabei war es ganz gleich, ob der betreffende Autor sich auf jenen ZK-Beschluß vom 9. März 1957, ${ }^{8}$ auf die 11. Feuerbach-These von Marx ${ }^{9}$ oder auf einige der zahllosen Aussagen Lenins zu diesem Thema ${ }^{10}$ berief. Die Interessen der „Volksmassen“, der Arbeiterklasse, der proletarischen Partei, die allesamt als übereinstimmend betrachtet wurden, - das waren die Kriterien der kommunistischen Parteilichkeit. Wie es die Antirevisionisten schon in den füfziger Jahren getan hatten, " leitete Fedoseev auch 1964 aus dem Parteilichkeitsprinzip die Notwendigkeit ab, den Kampf gegen die bürgerliche Ideologie zu führen und sich in der historischen Forschung besonders auf die Geschichte des Klassenkampfs zu konzentrieren. ${ }^{12}$

Punktuell setzten einige Historikerinnen und Historiker andere Akzente, mit denen den Bedürfnissen der Wissenschaft Geltung verschafft werden sollte. Sogar im gestrengen Theorieorgan der Parteifuhrung wurden wissenschaftliche Diskussionen als unverzichtbare Bedingung für jede „Vorwärtsbewegung" in der historischen Disziplin bezeichnet; wenn mit bürokratischen Maßnahmen versucht würde, das Parteilichkeitsprinzip durchzusetzen, so führe das lediglich zu Subjektivismus und dem Diktat politischer Konjunkturen in der Geschichtsschreibung. ${ }^{13}$ Želenina, eine

Ivanov, $\mathrm{K}$ voprosu 1963, $10 \mathrm{f}$.

' Gorodeckij, E.N.: Voprosy metodologii istorižeskogo issledovanija $v$ posleoktjabr 'skich trudach V.I. Lenina, in: VI 1963, H. 6, 16-34, hier 28.

8 Wie beispielsweise Pripiznov, $\mathrm{O}$ sootnosenii, 11 of.

- Wie Zastenker, N.E.: Problemy istoričeskoj nauki v trudach K. Marksa i F. Engel'sa, in: VI 1964, H. 6, 3-26, hier 23f. - Bei der Interpretation der Marx'schen Feuerbach-Thesen, sollte nicht übersehen werden, was Friedrich Engels 1888 bei der Erstveröffentlichung festhielt: sie seien „rasch hingeschrieben, absolut nicht für den Druck bestimmt, aber unschätzbar als das erste Dokument, worin der geniale Keim der neuen Weltanschauung niedergelegt ist“. In der berühmten 11. These - „Die Philosophen haben die Welt nur verschieden interpretiert, es kömmt drauf an, sie zu verändern." - hatte Marx jede differenzierte philosophische Bewertung hinter sich und seiner revolutionären Euphorie freien Lauf gelassen. Das ist bei der unkritischen Rezeption im Marxismus-Leninismus nicht berücksichtigt worden. Siehe Marx, K.: Thesen über Feuerbach (1845/88), in: MEW 3, 5-7 und 533-535; vgl. die Anmerkung 1, ebd., 547.

10 So Gorodeckij. Voprosy, $28 f$.

1 Vgl. Pod znamenem, 12.

12 Siehe Istorija 1964, 329.

13 Pašuto, V./V. Salov/L. Cerepnin: Princip partijnosti v istoriðeskom issledovanii i ego sovremennye kritiki, in: K 1966, H. 4, 72-79, hier 74. 
Historikerin der Staatlichen Lomonosov-Universität in Moskau, warf die Frage nach der Korrelation von Geschichte und Politik im Rahmen des Marxismus auf: Wie kann der marxistische Historiker der Partei dienen und die wissenschaftliche Wahrheit gewährleisten? Wie soll er bei der Forschungsarbeit an die Ereignisse, Prozesse und Bewegungen, an denen er unter Umständen selbst teilgenommen hat, herangehen? Soll respektive kann (!) er diese „,von der Seite“ betrachten oder „,von innen"?" "Zelenina erinnerte daran, daß der alte Friedrich Engels sich gegenüber August Bebel für die Unabhängigkeit des sozialistischen Denkens von der Partei ausgesprochen und in einem Brief 1891 formuliert habe:

„Ihr - die Partei - braucht die sozialistische Wissenschaft, und diese kann nicht leben ohne Freiheit der Bewegung. Da muß man die Unannehmlichkeiten in den Kauf nehmen, und man tut's am besten mit Anstand, ohne zu zucken. “15

Desweiteren zitierte \%̌elenina die Bemerkung Lenins in einem Brief an den Wirtschaftshistoriker Eugen Varga, daß die Wahrheit nicht von der Frage abhängen dürfe, wem sie dienen solle. ${ }^{16}$ Das sei wichtig im Kampf gegen den Subjektivismus. der die These vom Zusammenfallen der kommunistischen Parteilichkeit und der Objektivität auf den Kopf stelle. Z/elenina bezog sich explizit auf den Subjektivismus sozialistischer Couleur: Wenn die Objektivität einer falsch verstandenen Parteilichkeit angepaßt würde, dann würde die Geschichtswissenschaft der politischen Konjunktur unterworfen werden. Also keine administrativen Richtersprüche, sondern nur

"(..) die ununterbrochene Fortsetzung des wissenschaftlichen Suchens, die beständige Lösung neuer Probleme“"

könnten Objektivität und Parteilichkeit in Einklang bringen. ${ }^{17}$

Anhand zweier Aufsätze des Tomsker Historikers Mogil'nickij, die im Abstand von drei Jahren erschienen, ist die vorsichtige Neufassung der Vorstellungen über Parteilichkeit und Objektivität erkennbar: 1964 widmete sich Mogil'nickij vor allem der ausführlichen Kritik der Parteilichkeits- und Objektivitäts-Begriffe „bourgeoiser" Historiker ${ }^{18}$ und behauptete kategorisch,

\footnotetext{
14 Zelenina, Ob ob-ektivnosti, 58.

15 Engels. F. an August Bebel am 1./2. Mai 1891, in: MEW 38, 89-97, hier 94 (Kursiv bei Engels). - Hintergrund dessen war der Widerstand einiger führender Sozialdemokraten gegen die Veröffentlichung von Marx' "Randglossen zum Programm der deutschen Arbeiterpartei“ aus dem Jahr 1875, die endlich 1890/91 in der theoretischen Zeitschrif der deutschen Sozialdemokratie, „Die Neue Zeit“, erscheinen konnten (siehe MEW 19, 11-32; 22, 90f).

16 Vgl. Lenin, V.I. - E.S. Varge (01.09.1921), in: LPSS 54, 446.

17 Telenina, Ob ob-ektivnosti, 58.

18 Unter anderen N.I. Kareev, H.R. v. Srbik, G. v. Below, P. Geyl, F. Wagner, H. Heimpel, L. v. Muralt, A. Dempf, O. Brunner, H. Bechtel, Th. Schieder. - Mogil'nickij, Ob-ektivnost' 1964.
} 
„(...) daß nur die konsequente Verwirklichung des Prinzips kommunistischer Parteilichkeit in der Praxis der Geschichtsforschung echte Objektivität bei der Analyse der Vergangenheit sichert. “19

Dem „bürgerlichen Objektivismus“, der die Parteinahme zu verschleiern suche, setzte Mogil'nickij unter Berufung auf Lenin den „Objektivismus des Klassenkampfs ${ }^{\text {‘20 }}$ entgegen. Nur wer das Wesen der Klassenverhältnisse und die sozialen Widersprüche aufdecke und dies aus der Sicht der fortschrittlichsten Klasse, die an der Überwindung aller Ungleichheit interessiert sei, bewerte, könne die tatsächlichen Tendenzen der gesellschaftlich-geschichtlichen Entwicklung erkennen und wahrhaft objektiv die Wirklichkeit widerspiegeln. ${ }^{21}$ Schien Mogil'nickij 1964 hierzu die strikte Beachtung des Parteilichkeitsprinzips noch ausreichend zu sein, so wies er 1967 nachdrücklich auf die ,relative Selbständigkeit der historiographischen Praxis ${ }^{\mathbf{2 2}}$ hin, die ungeachtet des klassenmäßigen Charakters der Geschichtsschreibung doch immer bestehe: Ebensowenig wie konservative oder reaktionäre Weltanschauung geschichtswissenschaftliche Leistungen unmöglich mache, garantiere kommunistische Weltanschauung die richtige Erkenntnis. Entscheidend seien die professionellen Fähigkeiten des marxistischen Historikers, die dieser sich speziell aneignen müsse und nicht durch die ,richtige“ Weltanschauung ersetzen könne. Das Parteilichkeitsprinzip allein, ohne Beachtung der umfassenden, unabhängigen Quellenauswertung, der allseitigen, konkreten Analyse geschichtlicher Phänomene, führe unweigerlich zur Vulgarisierung der gnoseologischen Auffassungen und zu falschen Erkenntnissen. ${ }^{23}$ Objektivität figurierte bei Mogil'nickij 1967 nicht mehr als automatische Folge kommunistischer Parteilichkeit, sondern als ein zusätzliches Forschungsprinzip, welches besondere Aufmerksamkeit verlangte. Die beiden Prinzipien bedingten sich gegenseitig. ${ }^{24}$ Auch suchte Mogil'nickij die enge Bindung des Parteilichkeitsprinzips an vermeintlich einheitliche Volksinteressen und die Beschlußlage der Kommunistischen Partei zu lockern. Seines Erachtens orientierte die kommunistische Parteilichkeit den Wissenschaftler vor allem auf die sozialen Widersprüche und Interessenskonflikte in einer Gesellschaft und sollte ihm dabei als „Leitfaden" dienen, nicht als „Schablone“ behindern.

Einige Autoren brachten ein weiteres Prinzip in die Diskussion, welches wahre Erkenntnis ermöglichen sollte: Historismus - freilich nicht im Sinne der ,historistischen Historiker Ranke, Burckhardt, Droysen u.a. ${ }^{26}$, sondern in der Tradition

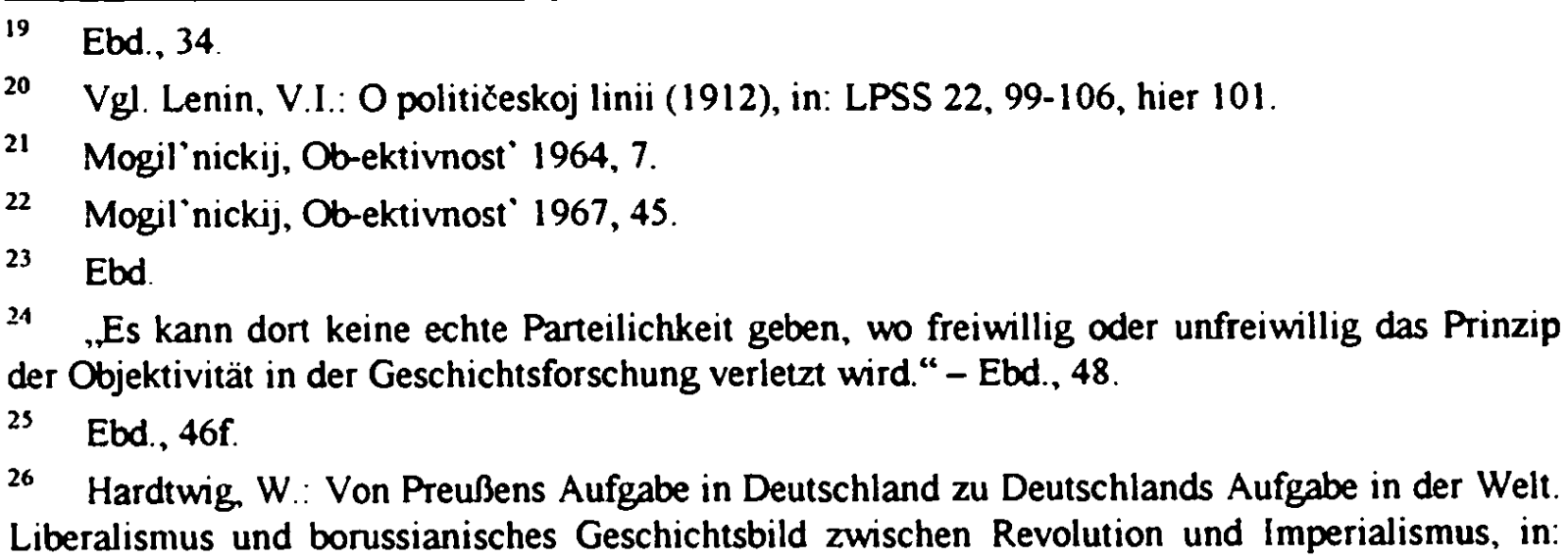


Lenins. Wer sich in diesem Kontext auf den Staatsgründer berief, zitierte meist wieder, wie das schon 1959 der damalige Chefredakteur der Istorija SSSR, M.P. Kim, getan hatte, aus Lenins Brief an Inessa Armand. ${ }^{27}$ Lenins Briefbemerkung folgend, definierte Kon in der "Historischen Enzyklopädie“ den „Historismus" als eigenständiges methodologisches Prinzip der materialistischen Geschichtswissenschaft, welches ,erstrangige Bedeutung für die Praxis historischer Forschung“ habe und verlange, die Phänomene der Vergangenheit erstens in ihrer Entstehung, Entwicklung und Veränderung, zweitens nicht isoliert, sondern in Verbindung mit anderen Erscheinungen und Bedingungen der gegebenen Epoche und drittens in Verbindung mit der konkreten historischen Erfahrung zu untersuchen. Dies orientiere den Forscher auf die Analyse innerer Gesetzmäßigkeiten der Geschichtsentwicklung, der Eigentümlichkeit und Einheit sozialer Strukturen sowie der Kontinuität des historischen Prozesses, was vor subjektivistischen und ahistorischen Deutungen schütze. Auch dem (Stalinschen) Dogmatismus liege die Verletzung des Historismus zugrunde. ${ }^{28}$ Wie Kon machten auch Minc und V.V. Ivanov deutlich, daß der Historismus vor allem deshalb (wieder) hergestellt werden müßte, um den Dogmatismus der Stalinzeit zu überwinden. ${ }^{29}$

Weitere, wesentlich über Lenins Aussage hinausgehende Erläuterungen des Historismus lassen sich in der Fachliteratur der sechziger Jahre nicht finden. Bei manchen Autoren war sogar die Neigung erkennbar, Historismus nicht als ein spezifisches Forschungsprinzip der Geschichtswissenschaft anzuerkennen, sondern bloß als allgemeine Methode aller Gesellschaftswissenschaften seit Marx. ${ }^{30}$ Auch der genaue Stellenwert des Historismus-Prinzips in der Geschichtsforschung und sein

ders., Geschichtskultur und Wissenschaft, München 1990, 103-160, hier 106 (Wiederabdruck aus: $H Z$ 1980, 265-324). - Zum Historismus siehe Troeltsch, E.: Der Historismus und seine Überwindung (1924), Aalen 1966; Hardtwig. W.: Konzeption und Begriff der Forschung in der deutschen Historie des 19. Jahrhunderts, in: Diemer, A. (Hg.): Konzeption und Begriff der Forschung in den Wissenschaften des 19. Jahrhunderts, Meisenheim am Glan 1978, 11-26; Oexle. O.G.: „Historismus“. Überlegungen zur Geschichte des Phänomens und des Begriffs, in: JbBWG 1986, 119-155; Blanke, H.W.: Historismus als Wissenschaftsparadigma. Einheit und Mannigfaltigkeit, in: Fohrmann, J./W. Voßkamp (Hg.): Wissenschaft und Nation. Zur Entstehungsgeschichte der deutschen Literaturwissenschaft, München 1991, 217-231; Jäger, F./J. Rüsen: Geschichte des Historismus. Eine Einfuihrung, München 1992; Wittkau, A.: Historismus. Zur Geschichte des Begriffs und des Problems, Göttingen 1992.

27 Vgl. Kim, O nekotorych zadačach, 6; LPSS 49, 329; Minc, Ivanov, Kon und Zastenker beriefen sich auf diese Textstelle oder zitierten sie; vgl. Istorija 1964, 64f: Ivanov, V.V.: O leninskom ponimanii principa istorizma, in. MIVIN, vyp. 4, T. 1966, 3-13, hier 7, Kon, I.S. Istorizm, in: SIE 6, 453-455, hier 454; Zastenker, Problemy, 25; vgl. Kapitel 3.2.4.

28 Kon, Istorizm, 454.

$29 \mathrm{Vgl}$. Istorija 1964, 65; Ivanov, O leninskom ponimanii, 9.

30 Dies erfolgte bevorzugt unter Berufung auf die Randbemerkung von Marx und Engels in der "Deutschen Ideologie“: „Wir kennen nur eine einzige Wissenschaft, die Wissenschaft der Geschichte." - Marx/Engels, Die deutsche Ideologie, hier 18. Vgl. Zastenker, Problemy, 25f, Ivanov, O leninskom ponimanii, 3 ff passim; Podkorytov, G.A.: Istorizm kak metod naučnogo poznanija, L. $1967,3 \mathrm{ff}$. 
Verhältnis zu den Prinzipien der Parteilichkeit und der Objektivität blieben unbestimmt. Insgesamt blieb die Diskussion in diesem Bereich im Vergleich zu den anderen Themen in den sechziger Jahren recht unterentwickelt. Vor allem das Problem der Parteilichkeit, zweifellos generell eine „Kernfrage der Geschichtswissenschaft ${ }^{\text {(31 }}$, wurde nicht annähernd als das komplizierte methodologische Problem erfaßt, welches es ist, sondern nur als Ausfluß des Klassenkampfs und der Systemkonfrontation verstanden. Typisch formuliert hat das, unter dem Eindruck der Ereignisse in Prag 1968, der namhafte DDR-Historiker Ernst Engelberg:

„Man könnte unter Umständen meinen, daß das Thema 'Parteilichkeit und Objektivität' schon reichlich abgegriffen sei. Das Thema wird uns jedoch so lange beschäftigen müssen, wie der Kampf zwischen Imperialismus und Sozialismus aktuell ist." ${ }^{\text {"32 }}$

Das entsprach der Haltung, mit der auch die sowjetischen Kollegen das Thema behandelten. Die von Johan Martin Chladenius (1710-1759) entdeckte prinzipielle Standortgebundenheit der Geschichtswissenschaf ${ }^{33}$ wurde nicht problematisiert, sondern in eins gesetzt mit der willentlichen Parteilichkeit des marxistischen Historikers, die an die Existenz der Klassen, des Klassenkampfs und der Systemkonfrontation geknüpft wurde. Die Rezeption der entsprechenden ausländischen Fachliteratur wurde - vor allem in Tomsk - im wesentlichen nur als, Entlarvung von Falsifizierem" betrieben und war daher wenig ergiebig. Auch die Entwicklung der Parteilichkeitsvorstellungen im eigenen Land wurde nicht thematisiert. Methodologiegeschichtliche Untersuchungen, etwa der Positionen von N.G. Cerny̌̌sevskij oder M.N. Pokrovskij, hätten Anregungen zum Problem geben können. ${ }^{34}$ Es wurde auch nicht berücksichtigt, daß das - durchaus diskutable - Parteilichkeitspostulat den traditionellen Wahrheitsbegriff notwendigerweise negiert; ungeachtet dessen hielt die sowjetische Geschichtswissenschaft an ihrem Anspruch fest, Geschichte objektiv wahrhaftig erkennen zu können. ${ }^{35}$ Ein gewisser Fortschritt bestand immerhin

31 Asendorf, M: Geschichte und Parteilichkeit. Historisches Bewußtsein in Deutschland, Berlin (West) 1984, 233.

32 Engelberg. E.: Parteilichkeit und Objektivität in der Geschichtswissenschaf, in: ZfG 1969. H. 1/2, 74-79, hier 74 .

33 Vgl. Chladenius, J.M.: Aus der 'Allgemeinen Geschichtswissenschaft' (1752), in: Hardtwig, W. (Hg.): Über das Studium der Geschichte, München 1990, 11-17.

$34 \mathrm{Vgl}$. Joravsky, D./C.N. Koblernicz: Parteilichkeit, in: SDG 4, 1119-1133, hier $1122 \mathrm{f}$.

$35 \mathrm{Vgl}$. ebd., $1132 \mathrm{f}$. 
darin, daß der alte Standpunkt, Objektivität bloß als Funktion oder logische Konsequenz der kommunistischen Parteilichkeit zu betrachten, ansatzweise überwunden und begonnen wurde, Objektivität als eigenständiges Forschungsprinzip zu konturieren (Mogil'nickij). 


\section{Die sowjetische Geschichtswissenschaft 1970 bis 1986: Routine und Retardation}

In diesem Kapitel wird auf die systematische Analyse einzelner geschichtstheoretischer und -methodologischer Probleme verzichtet. Es genügt, aus der Flut der Veröffentlichungen die wenigen bemerkenswerten Beiträge im 6. Kapitel bei der Untersuchung der Diskussionen während der späten achtziger Jahre zu berücksichtigen. Denn während der hier betrachteten Zeit drehten sich die Vertreter der historischen Zunft allzu sehr im Kreise und waren nicht in der Lage, wirklich Neues vorzulegen. In den beiden großen Instituten für Allgemeine Geschichte und für Geschichte der UdSSR an der Akademie der Wissenschaften und in der Historischen Fakultät der Moskauer Staatsuniversität war die Situation bis 1974 von den Kampagnen gegen die „Neue Richtung“ in der Oktoberrevolutionsforschung und gegen die von Gefter geleitete Methodologiesektion geprägt (dazu Kapitel 5.1.). Danach kehrte Ruhe in die historische Disziplin ein. Das „befehlsadministrative System “' kontrollierte die Geschichtswissenschaft wieder gänzlich und beschäftigte die Historikerinnen und Historiker mit den obligatorischen Parteitagsauswertungen und Jubiläumsfeiern derart, daß für originelle und seriöse Arbeiten kaum, für kritische, gar oppositionelle Zwischenrufe keine Luft mehr blieb. Die Arbeit desjenigen Teils der Geschichtswissenschaft, der sich mit der sowjetischen Gesellschaft befaßte, wurde im höchsten Maß standardisiert und formalisiert (Kapitel 5.2.).

Nach 1985 wurde es zuerst im Kreis der perestrojka-Protagonisten in der Sowjetunion, dann auch im Westen üblich, die Amtszeit Brežnevs (1964-1982) oder zumindest deren zweite Hälfte als ,Stagnationsperiode“ (period zastoja) zu bezeichnen. ${ }^{2}$ Ist der Terminus schon grundsätzlich in Bezug auf eine Gesellschaft problematisch. so hilft er im Fall der „Brežnev-Ära“ noch weniger, die Realität zu begreifen. Tragfähiger scheint mir die bereits 1981 von Victor Zaslavsky vorgeschlagene Bezeichnung ,Ära des 'organisierten Massenkonsens'“ zu sein. ${ }^{3}$ Die ,Aktiva dieser

1 Ob Gorbačev oder der Ökonom Gavriil Popov den Terminus zuerst prägte, kann hier getrost offen bleiben. Vgl. Haug. W.F.: Gorbatschow. Versuch über den Zusammenhang seiner Gedanken, Hamburg 1989, 129-135; Popov, G.: Blesk i niščeta administrativnoj sistemy, M. 1990, 182204.

2 Siehe beispielsweise die Ausfühnugen der Wirtschaftssoziologin Tatjana Saslavskaja, einer Vordenkerin der perestrojka, und die drastische Beschreibung des Stillstands sowie der Verdrängungsprozesse durch Friedrich Hitzer, bekannt als Übersetzter von Džingis Aitmatov. - Saslawskaja. T.: Die Gorbatschow-Strategie. Wirtschafts- und Sozialpolitik in der UdSSR (Aus d. Russ.), Wien 1989, 60ff; Hitzer, F.: Die große Unordnung. Glasnost und die Deutschen, Hamburg 1989, 42ff. Zu Fortschritt und Trägheit in dieser Zeit vom Standpunkt der perestrojka. siehe auch Istoričeskij opy i perestrojka. Celovečeskij faktor $v$ social'no-ekonomičeskom razvitii SSSR, $M$. $1989,231 \mathrm{ff}$.

3 Demnach existierte ,(...) ein politischer Kompromiß zwischen Staatsmacht und Bevölkerung, die die bestehende Machtverteilung und ihren Ausschluß von Entscheidungsprozessen hinnimmt und sich dafür mit sicheren Arbeitsplätzen, gewissen sozialen Rechten, größerer Bewegungsfreiheit und einem langsam steigenden Lebensstandard zufrieden gibt." - Zaslavsky, V.: 
Zeit" (Segbers) sollten nicht übersehen werden. ${ }^{4}$ Bei allen wichtigen wirtschaftlichen Kennziffern konnten noch Wachstumsraten verzeichnet werden. Infolge der weiteren Industrialisierung und Urbanisierung vollzog sich in der sowjetischen Gesellschaft in den zwanzig Jahren von 1960 bis 1980 ein sozialer Umbruch, der demjenigen der westlichen Industrienationen während der ersten sechs Jahrzehnte des zwanzigsten Jahrhunderts entsprach. ${ }^{5}$ Doch die Wachstumsziffern wurden beständig kleiner, und das Wachstum wurde seit Beginn der siebziger Jahre wieder in höherem Maß als noch in den sechziger Jahren durch extensive Methoden erzielt. ${ }^{6}$ Zugleich wurden die zentralen wirtschaftlichen, finanziellen, sozialen und technologischen Probleme ignoriert, und die Bedingungen ihrer Lösung verschlechterten sich zunehmend. Gegen Ende der siebziger und Anfang der achtziger Jahre bündelten sich die Entwicklungen zur Strukturkrise. ${ }^{7}$

Den Berichten und Erinnerungen von Insidern zufolge war das Politbüro nicht mehr handlungsfähig. Brežnev und sein Ideologiesekretär Suslov erwiesen sich als unüberwindliche Bremser. Als hilfreich erachteten die Geronten offenbar die stille Rehabilitienung Stalins. ${ }^{8}$ Unterhalb der Ebene des Politbüros war wohl dem größ-

In geschlossener Gesellschaft. Gleichgewicht und Widerspruch im sowjetischen Alltag (1981), Berlin 1982, 8.

$4 \quad$ Im Vergleich zu den vorangegangenen Erfahrungen (Erster Weltkrieg, Revolution, Bürgerkrieg, die unruhige Zeit der Neuen Ökonomischen Politik. Industrialisierung und Kollektivierung in den dreißiger Jahren mit einhergehenden Repressionen und Terror, der Zweite Weltkrieg. Nachkriegsrepressionen und Kalter Krieg, schließlich die diskontinuierliche Politik Chruščevs) wurden die Normalisierung des politischen und wirtschaftichen Mechanismus und die Beruhigung des gesellschaftlichen Klimas von den Menschen ,....) keineswegs als Stagnation oder als Langeweile empfunden, die Macht- und Funktionseliten konnten nicht unbeträchtliche Leistungen für sich reklamieren." - Segbers, K.: Der sowjetische Systemwandel, Frankfurt am Main 1989, 176 (Kursiv bei Segbers; J.H.).

3 Fedossow, P.: Leben in der Sowjetunion, Heilbronn 1987, $24 \mathrm{f}$.

6 Vgl. Meissner, B.: Bilanz der „Breschnew-Ära“, in: Aus Politik und Zeitgeschichte. Beilage zur Wochenzeitung ,Das Parlament“, B 7/83, 3-19, hier $11 \mathrm{ff}$, Huffschmid, J.: Umbau der Wirtschaft und Beschleunigung der sozialökonomischen Entwicklung. Zur neuen wirtschaftspolitischen Strategie in der Sowjetunion, in: Blätter 1987, H. 1, 73-88, hier 74ff; Segbers, Der sowjetische Systemwandel, 178ff, Conert, H.: Die Ökonomie des unmöglichen Sozialismus. Krise und Reform der sowjetischen Wirtschaft unter Gorbatschow, Münster 1990, 35ff und 127f; Jegorow, V.K. (= Egorov, V.K.): Aus der Sackgasse in die Ungewißheit. Die Perestroika des Michail Gorbatschow. Ansichten eines Politologen - eines ehemaligen Beraters eines ehemaligen Präsidenten eines ehemaligen Landes. Berlin 1992, 37f.

7 Segbers sprach von einer "Doppelkrise“, welche die internationalen Beziehungen und die Binnenverhältnisse umfasse, vorrangig aber innere Ursachen habe. - Segbers, Der sowjetische Systemwandel, 175.

8 Zahlreiche Belege für die „Wiedergeburt des Stalinkults“ lieferte Zaslavsky, der dieses Phänomen als "logische“ Folge der gesellschaftlichen Entwicklung bezeichnete. Roj Medvedev berichtete, daß vor dem 40. Jahrestag des Sieges über den Faschismus sogar die Umbenennung Volgograds in Stalingrad geplant gewesen sei; die neue Führung unter Gorbacev habe solche Pläne sofort gestoppt. - Zaslavsky, In geschlossener Gesellschaft, 11-27; Medvedev, R.: O Staline i stalinizme. M. 1990, 7. 
ten Teil der politischen Führung klar geworden, daß es so wie bisher nicht weitergehen konnte. ${ }^{9}$ Die Angehörigen der in den sechziger Jahren repressierten "Generation des Establishments" (Amalrik) ${ }^{10}$ sowie die jüngeren unzufriedenen Parteifunktionäre (beispielsweise M.S. Gorbačev, B.N. El'cin, E.A. Sevardnadze, A.N. Jakovlev) und Intellektuellen (Ju.N. Afanas'ev, E. Evtusenko, M.Ja. Gefter, A.Ja. Gureviz, D. Granin, V. Kataev u.a.) vermochten nicht, sich zu radikalen Maßnahmen durchzuringen: $\mathrm{Zu}$ stark waren sie mit dem System verhaftet; auch wäre die erforderliche Kooperation mit anderen Oppositionskräften kaum möglich gewesen; und zu sehr mußten sie fürchten, daß ihnen die Kontrolle über einen erzwungenen Machtwechsel entgleiten würde. Denn die politische Landschaft der sowjetischen Gesellschaft hatte sich gründlich verändert. Die Niederlage der Revisionisten im Jahr 1968 bedeutete den Anfang vom Ende jeder Kritik mit marxistischen Intentionen: Es war die „Geburtsstunde der Bürgerrechtsbewegung“ (Schlögel). Während der Ära Brežnevs verlagerten sich die Akzente „von einer früher marxistisch orientierten zu einer dezidiert a-ideologischen Bürgerrechtsbewegung", die den Widerstand organisierte und sich nicht gegen einzelne Unzulänglichkeiten, sondern gegen die Grundlagen des Systems selbst richtete. ${ }^{11}$

Das spiegelte sich auch im Umfeld der historischen Disziplin und bei der nachrükkenden Generation von Historikerinnen und Historikern wider: Kaum jemand, dessen Bildung und Denken in den siebziger Jahren geprägt wurde, bezog sich noch positiv auf den Marxismus. ${ }^{12}$ Hinzu kamen seit 1977 die Versuche von Arbeitern, autonome Organisationen zu etablieren, um ihre sozialökonomischen Grundrechte gegenüber dem System einzuklagen; sie wurden rigoros unterdrückt. ${ }^{13}$ Mit diesen neuen oppositionellen Kräften hätte rechnen müssen, wer die Macht gewahtsam hätte neu verteilen wollen.

Erst das Ableben von Suslov am 25. Januar 1982 und von Brežnev am 10. November des gleichen Jahres ermöglichte die schrittweise Einleitung von Reformen „von oben“. Unter dem neuen Generalsekretär Jurij Vladimirovič Andropov, des-

9 Vgl. Jegorow, Aus der Sackgasse, 33ff; Pozner, V.: Abschied von Illusionen. Das außergewöhnliche Leben und die kontroversen Ansichtern des führenden politischen Kommentators der Sowjetunion, Berlin 1991, 363ff.

10 Hier nach Schlögel, K.: Der renitente Held. Arbeiterprotest in der Sowjetunion 1953-1983, Hamburg 1984, 295.

1 Schlögel, Der renitente Held, 183-185.

12 Persönliche Gesprächserfahrungen des Autors in Moskau stimmen überein mit der Beobachtung von Robert Davies: „In diesem ganzen Durcheinander inoffizieller und nichtkonformistischer Anschauungen über die Vergangenheit waren Marxisten und demokratische Kommunisten aller Schattierungen eine stetig kleiner werdende Minderheit. Kaum ein Dissident berief sich auf Männer wie Bucharin und Trotzki. Der Mißbrauch des Marxismus als Werkzeug des Stalinismus und die Erstarrung des offiziellen Marxismus unter Breschnew hatten offenbar jede Möglichkeit zunichte gemacht, ihn als kreative Grundlage für das Verständnis der sowjetischen Vergangenheit zu nutzen."- Davies, Perestroika, 17.

$13 \mathrm{Vgl}$. Schlögel, Der renitente Held, 133ff. 
sen Wahl sicherlich bei vielen gemischte Emotionen weckte, ${ }^{14}$ wurden umgehend auf zwei Ebenen neue Akzente gesetzt: Auf wirtschaftlichem Gebiet wurde das sogenannte „Experiment in großem Maßstab" eingeleitet. ${ }^{15}$ Damit korrespondierte der Versuch, im Juni 1983 mit einem speziellen Plenum des Zentralkomitees zur Ideologie die Intelligenz dafür zu gewinnen, die wissenschaftliche Forschung zu aktivieren und die geistige Arbeit stärker als bisher an den praktischen Aufgaben des Landes auszurichten. Hier war auch die Geschichtswissenschaft direkt angesprochen, und im Kapitel 5.3. wird gezeigt, wie die historische Zunft darauf reagierte.

Nach Andropovs Tod am 9. Februar 1984 entstand die Frage, ob endlich der damals noch zweiundfünfzigjährige Michail Sergeevič Gorbacev, der seit längerem als Reformer und Hoffnungsträger galt, ${ }^{16}$ das Amt des Generalsekretärs bekleiden würde. Durch die Entscheidung für den bereits todkranken Konstantin Ustinovic Cernenko wurde weitere Zeit vergeudet, und der Druck komplexer Probleme nahm zu. ${ }^{17}$ Dreizehn Monate nach Andropov starb auch der „Anwalt der Alten Garde“,

14 Man konnte nicht sicher sein, was von dem langjährigen Vorsitzenden des Komitees für Staatssicherheit (KGB: seit 1967) zu erwarten war. Gemeinhin galt Andropov als ehrlicher, disziplinierter und unkorrumpierter Parteifunktionär, der mit Brežnevs Clique nichts zu tun hatte. Er kannte Gorbačev seit den sechziger Jahren und unterstützte ihn seit Mitte der siebziger. Valentin Falin beurteilte Andropov sehr differenziert und faßte zusammen: "Wenn man die Ökonomie beiseite läßt, (...) war er einen Kopf größer und moralisch besser als die meisten. " - Falin, Politische Erinnerungen, 405; vgl. Ruge, G.: Michail Gorbatschow. Biographie, Frankfurt am Main 1990, 122f, 142ff, 175ff: Pozner, Abschied 1991, $366 f$.

1s Am 14. Juli 1983 beschloß die Partei- und Staatsfihihrung die Änderungen im Planungs- und Leitungssystem der Wirtschaft, die darauf zielten, das System vorsichtig zu dezentralisieren und den Betrieben größere Selbständigkeit zu gewähren. Conert stellte allerdings fest: „Dem Inhalt nach kommt der Beschluß zum 'Experiment' einem formlichen Eingeständnis gleich, daß die 1965 erlassenen Änderungen auf den Gebieten der Planung. Steuerung und Stimulierung der gesellschaftlichen Produktion ebenso wenig in die Praxis umgesetzt wurden wie die Mehrzahl der in den siebziger Jahren erfolgten Modifikationen und Ergänzungen. Der im Umfang knappere Text von 1983 wiederholt die Deklarationen des Reformbeschlusses vom Oktober 1965 fast vollständig." - Conert, Die Ökonomie, 123; vgl. ebd., 117 ff sowie Segbers, Der sowjetische Systemwandel. 32ff und 209ff.

16 „Schon lange vor April 1985 hieß die verbreitete Parole 'Warten auf Gorbatschow', genaugenommen von dem Moment an, als bekannt wurde, daß Andropow todkrank war." - Tschernajew, A. Die letzten Jahre einer Weltmacht. Der Kreml von innen, Stuttgart 1993, 13; zu Gorbačevs Werdegang siehe Ruge. Gorbatschow 1990; Schmidt-Häuer, C.: Michail Gorbatschow, München 1985; Smith, H.: Die neuen Russen (1990), Reinbek bei Hamburg 1991, 62ff: Geller, M. (= Heller, M.): Sed'moj sekretar'. Blesk i niščeta Michaila Gorbačeva. London 1991, $18 \mathrm{ff}$.

19 „Das Wunder blieb aus. Tschernenko wurde gewählt (...) Die Enttäuschung der Anwesenden war augenblicklich spürbar (...) Mit wem man damals auch sprach, der Name Gorbatschow war in aller Munde. Keiner dachte, daß er nicht gewählt würde." - Tschernajew, Die letzten Jahre. 15ff. Pozner, Abschied, 367, schrieb in Erinnerung an die Wahl Cernenkos: "Ich kenne keinen einzigen Menschen in der Sowjetunion, der diese Nachricht mit Ernst aufnahm." Vgl. Ruge. Michail Gorbatschow 1990, 183ff; 
Cemenko (am 10.03.1985). ${ }^{18}$ Nun gab es zu Gorbačev keine ernsthafte Alternative mehr, zumal Gromyko, der weltweit dienstälteste Außenminister und eine Autorität im Politbüro, sich für ihn stark machte. ${ }^{19}$ Die Wirkungen der ,Strategie der Be-

18 Siehe Smith, Die neuen Russen, 33. - Egorov erinnert sich: „Die Gesellschaft ging schwanger mit Veränderungen. Bald nach dem XXVI. Parteitag der KPdSU (Februar-März 1981) starb ein Partei- und Staatsfuhrer nach dem anderen. Alter und Gesundheitszustand (...) forderten ihren Tribut. Ich möchte nicht, daß man das für eine Lästerung hält. Ein Volk aber betrügt man nicht; rasch hatte es den eben begonnenen Fünfjahresplan auf seine Weise getauft - die drei $P$. Pjatiletka Pyschnych Pochoron (Fünfjahresplan Prunkvoller Begräbnisse). Von 14 Mitgliedern des Politbüros waren zum Frühjahr 1985 sechs bereits verstorben (...)“: die drei Generalsekretäre, „der zweite Mann in der Partei und Chefideologe“ Suslov, der Verteidigungsminister Ustinov und der "Senior in der höchsten Herrschaftsetage“, der Vorsitzende des Komitees für Parteikontrolle Pel'̌̌e. - Jegorow, Aus der Sackgasse, 40.

19 A. Cernev, der das Protokoll der Politbüro-Sitzung des ZK der KPdSU vom 11. März 1985 veröffentlichte und kommentierte, geht davon aus, daß das Politbüro zweimal tagte, um die Nachfolge Cernenkos zu klären: am Abend des 10. und am Nachmittag des 11. März. Das publizierte Protokoll sei wahrscheinlich eine selektive Zusammenstellung der Mitschriften beider Sitzungen - so Cernev. Differenzen, gar einen Machtkampf im Führungskreis reflektiert die tradierte Quelle nicht. Alle Teilnehmer bekundeten demnach ihre Zustimmung zu Gromykos Vorschlag. M.S. Gorbacev als neuem Generalsekretär, alle mögliche Unterstützung und Hilfe" 
schleunigung der sozialökonomischen Entwicklung“ des neuen Generalsekretärs auf die Geschichtswissenschaft in den Zentren ist Thema des Kapitels 5.4.

zukommen zu lassen. Gorbačev reagierte der Quelle zufolge emotional bewegt und versuchte, Veränderungswillen und Traditionsbewußtsein zu demonstrieren:

„Wir durchleben eine sehr schwierige Umbruchszeit. Unsere Ökonomie braucht einen großen Dynamismus. Diesen brauchen auch unsere Demokratie und die Entwicklung unserer Außenpolitik. (...) Ich sehe meine Aufgabe vor allem darin, mit euch zusammen neue Lösungen zu suchen, Wege der weiteren Vorwärtsentwicklung unseres Landes, Wege der Erhöhung der wirtschaftlichen Stärke und Verteidigungskraft der Heimat. der Verbesserung des Lebens unseres Volkes. Ich bin der Idee der kollektiven Arbeit tief ergeben (...). Wir haben es nicht nötig. unsere Politik zu ändern. Sie ist wahrhaftig, richtig, eine wirklich Leninsche Politik." - Kak eto bylo. „Nam ne nužno menjat' politiku“, - zajavil M.S. Gorbǎ̌ev pri vydviženii ego na post General'nogo sekretarja CK KPSS, in: Istornik 1993, H. 0, 66-75; vgl. Ruge, Michail Gorbatschow 1990, 185ff; Jegorow, Aus der Sackgasse, 47. 


\subsection{Die Kampagnen gegen die Methodologiesektion und die „Neue Richtung“ der Oktoberrevolutionsforschung}

Aus der Sicht der Stalinisten und Konservativen war Boris Rybakov, der 1968 der erste Direktor des neuen Instituts für Geschichte der UdSSR an der Akademie der Wissenschaften wurde, der richtige Mann, um das Institut auf den von der Partei gewünschten Kurs zu bringen.' Nach der Auflösung der von Michail Gefter geleiteten Methodologiesektion 1969 ging es immerhin noch um die inhaltliche Kritik der Arbeit dieser Sektion einerseits und der „Neuen Richtung“ in der Oktoberrevolutionsforschung andererseits. Denn trotz aller administrativer Maßnahmen war noch nicht verlautet, was die Gerügten falsch gemacht hatten und was künftig offiziell ,richtig“ sein sollte. Rybakov, der noch immer Direktor des Akademie-Instituts für Archäologie war, übte seine neue Tätigkeit allerdings nur ,nebenberuflich" aus. ${ }^{2}$ In dieser Situation wandte sich D. Kovalenko, ein höherer wissenschaftlicher Mitarbeiter des Instituts für UdSSR-Geschichte, an den Generalsekretär des Zentralkomitees der KPdSU Leonid Brežnev. Kovalenko schrieb von einer „DirektorenKrise“, die entstanden sei. Denn als Nachfolger Rybakovs habe der Vizepräsident der Akademie Rumjancev Aleksandr Samsonov vorgeschlagen, der seinerzeit Aleksandr Nekrič unterstützt habe. Das zeuge, so Kovalenko,

„(...) entweder von der Unlust, die Lage im Institut zu festigen, oder von der Vernachlässigung der ideologischen Seite der Institutsarbeit. “"

Würde Samsonov Institutsdirektor werden, dann käme das der Annullierung der Parteibeschlüsse in der Nekrič-Sache gleich. ${ }^{4}$ Kovalenko war Erfolg beschieden: Samsonov, der durch umfangreiche und verhältnismäßig seriöse Publikationen ausgewiesene Spezialist für die Geschichte des Zweiten Weltkriegs, wurde nicht Direktor des Instituts. Im Frühjahr 1970 entschied das Zentralkomitee der Partei, Rybakov von der Verantwortung des Institutsdirektors zu entbinden und ,den Genossen Volobuev, P.V." für diese Funktion zu ernennen." Ausgerechnet Pavel Volobuev, einen namhaften Vertreter der „Neuen Richtung“! Höchstwahrscheinlich handelte es sich bei dieser Personalentscheidung schlicht um einen Irtum, einen

Unter Rybakovs Leitung, so erinnerte sich Nekrič, wurde die Atmosphäre im Institut „(...) immer konservativer. Die Stalinisten, einige von ihnen mit offensichtlichem antisemitischen Anflug, triumphierten. Es begann der planmäßige Angriff auf die Wissenschaftler der liberalen Richtung, die für die wichtigsten Arbeiten des Instituts verantwortlich waren." - Nekric, Otresis” ot stracha 1979, 338f, vgl. die biographischen Angaben zu B.A. Rybakov in Kapitel 3.1.2.

2 Nekrič, Otrešis' ot stracha, 338.

3 Kovalenko, D. am 02.10.1969 an den Generalsekretär des ZK der KPdSU L.I. Brežnev, in: CChSD f. 5, op. 61, d. 62, 201-205, hier 203.

4 Es sei kein Geheimnis, daß mancher davon träume, schrieb Kovalenko; ebd.

3 Cecharin, E. am 06.04.1970 an das ZK der KPdSU, in: CChSD f.5, op.61, d.62, 206. - Dem sei ein langer Kampf der Prätendenten vorausgegangen, schrieb Nekrið, Otreł̌is' ot stracha, 339f. 
Fehler des ZK-Apparats. ${ }^{6}$ Volobuev galt diesem als zuverlässig, weil er 1953 bis 1955 in der Wissenschaftsabteilung des Zentralkomitees rigoros gegen Pankratova und Burdžalov agiert hatte. Auch hatte er nicht zu den Mitgliedern der Methodologiesektion gezählt. Hinzu kommt, daß Volobuev sich bemühte, dem Apparat gegenüber als „unser Mann“ zu erscheinen. Der damals Siebenundvierzigjährige glaubte offenbar, er könne beiden Seiten dienen, dem Apparat und den kritischen Kollegen, und er schien zu hoffen, dabei auch seine eigene Stellung zu verbessern.' Als der ,frischgebackene“ Institutsdirektor 1970 auch Korrespondierendes Mitglied der Akademie wurde, durfte er seine Hoffnungen bestätigt sehen. Zudem richtete sich die Kampagne, die von der Spitze der Geschichtsabteilung und der Direktion des Instituts für Allgemeine Geschichte sowie der zugehörigen Parteiorganisation ausging, zunächst tatsächlich nur gegen diejenigen, die sich an der Arbeit der Methodologiesektion aktiv beteiligt hatten. ${ }^{8}$

Im Februar 1970 kritisierten drei Dozenten der Lomonosov-Universität in der vom ZK der KPdSU herausgegebenen Tageszeitung Sovetskaja Rossija den Sammelband „Geschichtswissenschaft und einige Probleme der Gegenwart“ in einer derart plumpen Weise, daß sich später selbst das Sekretariat des Zentralkomitees der KPdSU davon distanzierte. Anfang März bildete die damals noch von Evgenij

6.Ja. Gurevið äußerte diese Überzeugung im Gespräch mit dem Autor am 17.12.1990.
Nekrið berichtete, daß Volobuev lange von Trapeznikov und Rybakov unterstützt worden sei. Und er charakterisierte ihn folgendermaßen: „Aus der Sicht der Karriere war sein Professionalismus Volobuevs Achillesferse. Als Historiker, der eine gute Schule durchlaufen hatte, mußte Volobuev früher oder später bei seinen Forschungen mit den offiziellen konformistischen Ansichten der sehr einflußreichen Gruppe parteitreuer Historiker zusammenstoßen (...). Volobuev war ehrgeizig. Und die Stellung, die er einnahm, gab ihm das trügerische Gefühl der Sicherheit. $\mathrm{Er}$ glaubte offenbar, er könne es sich allen Ernstes erlauben, gleichzeitig gegen den Dogmatismus und den sogenannten Revisionismus zu kämpfen. In Wirklichkeit holte er jedoch, vielleicht sogar unbewußt, zum Schlag gegen den parteilichen Konformismus aus. Volobuev versuchte einerseits seine unerschütterliche Ergebenheit dem Marxismus gegenüber zu demonstrieren, hielt es aber andererseits für möglich, die Arbeiten parteitreuer Historiker, die jahrzehntelang in den Gesellschaftswissenschaften das Klima bestimmt hatten, zu kritisieren." - Nekrið, Otrełis” ot stracha, 339f. Vgl. die Fußnote zu Volobuev in Kapitel 3.2.1.

- Zeitgenössische, durchaus detaillierte Untersuchungen der Auseinandersetzungen anhand der damals zugänglichen Publikationen unterschieden nicht die beiden Kampagnen gegen die Methodologiesektion einerseits und die "Neue Richtung“ andererseits. Auf Grundlage der inzwischen zugänglichen, unveröffentlichten Materialien aus der Methodologiesektion muß von zwei Kampagnen (freilich mit der gleichen Stoßrichtung) gesprochen werden. - Vgl. Marko, K.: Streit in der sowjetischen Geschichtswissenschaft. Notiz zur ideologischen Gegenwartssituation in der Sowjetunion, Bericht des BOIS 23/1972; Enteen, A Recent Trend. 122-131; Bonwetsch, Oktoberrevolution, hier besonders $154 \mathrm{ff}$.

9 Den Autoren, besonders Gefter und Gunt, warfen die drei Rezensenten vor, menschewistische und kleinbürgerliche Fälschungen über Lenin und die revolutionäre Entwicklung in Rußland ausgebreitet zu haben. Das Fazit der Rezension lautete: „Faktisch verbreiten sie (die Autoren; J.H.) unter dem Vorwand der wissenschaftlichen Suche unmarxistische Ansichten, verfälschen die historischen Ereignisse und gießen Wasser auf die Mühlen bourgeoiser Fälscher der Geschichte der Kommunistischen Partei und des Sowjetstaates." - Kornilov, A.N. Prokopen- 
Žukov geleitete Geschichtsabteilung der Akademie eine Kommission, die eine offizielle Bewertung jenes Sammelbandes erarbeiten sollte; ihr gehörten das Ordentliche Akademiemitglied P.N. Pospelov und die beiden Korrespondierenden Mitglieder M.P. Kim und P.A. Žilin an.

Am 18. März fand eine öffentliche Parteiversammlung am Institut für Allgemeine Geschichte statt, deren Protokoll Einblick in die Art der Auseinandersetzung und die Solidarisienung etlicher Kollegen untereinander erlaubt. Michail Barg verteidigte die kritisierte Theoriearbeit der letzten Jahre mit der Begründung, nach jahrelanger Materialakkumulation sei die Synthese, die theoretische Reflektion über die Ergebnisse notwendig. " A.A. Kurnosov, einer der Autoren des Sammelbandes zu theoretischen und methodischen Problemen der Quellenkunde, sagte, zur Lösung der Forschungsaufgaben sei am Institut eine ruhige, schöpferische Atmosphäre, die scharfe Diskussionen ausdrücklich einschließe, nötig. Rezensionen, wie diejenige in Sovetskaja Rossija, störten die Arbeit nur. ${ }^{12}$ L.N. Rastopčina klagte darüber, daß es für die Angegriffenen nicht möglich sei, sich öffentlich zu wehren - etwa im Theorieorgan des Zentralkomitees der Partei, Kommunist. Žukovs Aussage, die Menschen müßten in der Auseinandersetzung geschont werden, gelte offenbar nicht für Michail Gefter. ${ }^{13}$ Ja.S. Drabkin widersprach Žukovs These, man dürfe sich mit der Alternativität und dem Variantenreichtum (mnogovariantnost') in der Geschichte nicht beschäftigen, weil die ideologischen Gegner dies ausnutzten. Gerade deshalb müsse man sich damit auseinandersetzen! ${ }^{14}$ Die Kritisierten wollten jedenfalls weitere Diskussionen, ,aber nicht auf der Basis der Fälschung", wie es in

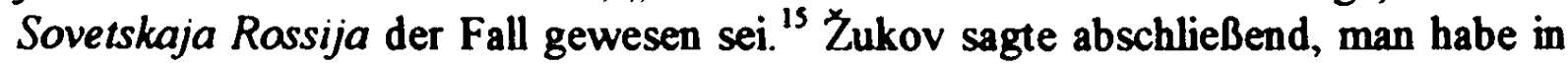
der Institutsleitung lange überlegt, ob der Veröffentlichung des Sammelbandes "Geschichtswissenschaft und einige Probleme der Gegenwart" zugestimmt werden solle; nicht, weil man gegen Diskussionen gewesen sei, sondern weil dem an ein Massenpublikum gerichteten Band die erforderliche „Reife“ fehle. „Ich denke, daß ich einen Fehler gemacht habe", sagte Žukov dazu, daß er als Institutsdirektor schließlich doch der Veröffentlichung zustimmte. ${ }^{16} \mathrm{DaB}$ der bereits fertiggestellte

ko/A. Sirokov: Pod vidom nauxnogo poiska, in: Sovetskaja Rossija, 28.02.1970; vgl. Marko, Streit, $6 f$.

10 Siehe Obsuždenie knigi v Odelenii istorii (o.J.), in: NA 7, 1. - Es handelt sich hierbei um eine kurze Chronik der Ereignisse vom März 1970 bis Januar 1971, die vermutlich von L.N. Cernova angefertigt wurde.

1 Protokol obsuždenija doklada akad. Zukova na otkrytom partijnom sobranii Instituta vseobšxej istorii 18 marta $1970 \mathrm{~g}$., in: NA 12, 2f.

12 Ebd., 5.

13 „Aber alles, was ich beobachte im Lauf jenes Jahres, das mit der Liquidierung der Methodologiesektion begann und mit dem Artikel in 'Sov. Rossija' endete, zeugt davon, daß wir M.Ja. Gefter nicht schonen. Sondern wir tun alles, um ihn nicht zu schonen." - Ebd., $6 f$.

14 Ebd., 7.

is Ebd., 8.

16 Nach seiner persönlichen Meinung über das Buch gefragt, verweigerte Zukov eine Stellungnahme und verwies auf die Kommission, die eine Bewertung vorbereite; ebd., 13. 
Band zur 100. Wiederkehr des Geburtstags von Lenin nicht zur Publikation freigegeben wurde, habe auch daran gelegen, so Zukov weiter, daß ein Zitat von Boris Pasternak verwendet worden sei. ${ }^{17}$ Als einer der Diskutanten selbstkritisch sagte, die Historiker unterschätzten die Bedeutung von glasnost', von Transparenz und offenem Meinungsstreit, kommentierte Zukov das mit den Worten:

„Aber laßt uns Realisten sein! Schon rein physisch können wir nicht alle Fragen erörtern." "18

Zu Rastop cinas Vorschlag, die Gescholtenen in Kommunist sich wehren zu lassen, bemerkte Zukov:

"(...) Kommunist ist kein Diskussionsblättchen, sondem eine Publikation, die den Standpunkt der Partei ausdrückt. “19

Solcherart primitiv waren die Reaktionen des langjährigen Akademischen Sekretärs, des Direktors des Instituts für Allgemeine Geschichte und Herausgebers der voluminösen "Weltgeschichte" auf die Diskussionsbeiträge, in denen eine plan- und niveauvolle Entwicklung der historischen Disziplin sowie echter Meinungsstreit eingeklagt wurden.

Am 25. Mai faßte das Parteibüro des Instituts für Allgemeine Geschichte einen Beschluß, in dem die Notwendigkeit einer wissenschaftlichen Beratung über den Sammelband "Geschichtswissenschaft" ausgedrückt wurde. ${ }^{20} \mathrm{Am}$ Tag darauf wandten sich die Mitglieder dessen Redaktionskollegiums, Cemova, Gefter, Grunt und Mal'kov, an den Vizepräsidenten der Akademie, Rumjancev, und an Zukov mit dem Vorschlag, eine solche ruhige und sachliche Diskussion entweder bei der Sektion Gesellschaftswissenschaften der Akademie oder als Veranstaltung der beiden Geschichtsinstitute abzuhalten. ${ }^{21}$ Zur gleichen Zeit ging an Rumjancev ein Brief analogen Inhalts, den füfzehn Wissenschaftlerinnen und Wissenschaftler unterzeichnet hatten, die an der Arbeit der Methodologiesektion beteiligt gewesen waren. $^{22}$

Ende Juni beriet die Führungsspitze der Geschichtsabteilung, das sogenannte Büro der Abteilung, das Ergebnis der von Pospelov, Kim und Žilin gebildeten Kommission. Isaak Minc bezeichnete die Kritik als zu ,akademisch“ und zu wenig ,parteilich", und er wurde daraufhin zur Überarbeitung des Entwurfs hinzugezogen. Auch

17 Im Protokoll heißt es: „(...) als eines der Epigraphen wurde ein Wort Pasternaks genommen / Zurufe: Wie entsetzlich! Nun, was ist dabei? / Das ist zumindest eine Taktlosigkeit.“- Ebd., 14.

18 Ebd.

19 Ebd.

20 Gefter, M.Ja.: „Vice-prezidentu AN SSSR, akademiku A.M. Rumjancevu“, 03.01.1971 (vierseitige Abschrift), in: NA 17, 2.

21 NA 13.

22 NA 14. Der Brief trug die Unterschriften von M. Gefter, A. Grunt, E. Gorodeckij, V. Bibler, A. Gal'kin, A. Arsen'ev, N. Ter-Akopjan, N. Rodnij, V. Dalin, I. Bestužev-Lada, A. Stanislavskaja. I. Smirnov, G. Alekseev, L. Cernova, K. Miziano. 
die Mitglieder des Büros unterstützten nun die Absicht, im Herbst öffentlich über den umstrittenen Sammelband zu diskutieren. ${ }^{23}$

Am 13. Juli informierte Žukov das Redaktionskollegium über die geplante Beratung, wies aber dessen Bitte zurück, der Redaktion das bisherige Ergebnis der Kommission zukommen zu lassen; Zukov verneinte sogar kategorisch, daß es ,irgendwelche Schlußfolgenungen, Bemerkungen, Dokumente der Kommission“ gebe. ${ }^{24}$ Bei der Parteiversammlung am 19. Oktober vertröstete Žukov die Genossen, die angekündigte Beratung finde „bald“ statt. ${ }^{25}$ Gefter sprach während dieser Sitzung nochmals über die seines Erachtens notwendige Weiterentwicklung des historischen Materialismus. In der sogenannten Dritten Welt und in den bürgerlichen Demokratien hätten sich gesellschaftliche Verändenungen im Weltmaßstab vollzogen; Friedrich Engels zufolge, so Gefter, müsse der historische Materialismus nach solchen „Entdeckungen“ eine neue Form annehmen. ${ }^{26} \mathrm{Zu}$ der gegen ihn gerichteten Kampagne sagte er, den Schlägen der Bürokraten stehe er gelassen gegenüber. Thm drohe keine Niederlage; diese erleide vielmehr Žukov selbst. ${ }^{27}$

Im Dezember wurde Gefter und den anderen Redaktionsmitgliedern vollends klar, daß hinter ihrem Rücken längst in allen beteiligten Institutionen - dem Büro der Geschichtsabteilung, der Direktion und dem Parteibüro des Instituts für Allgemeine Geschichte, den ZK-Abteilungen für Wissenschaft einerseits, für Propaganda und Agitation andererseits, dem Institut für Marxismus-Leninismus und der Akademie für Gesellschaftswissenschaften beim ZK der KPdSU - Beratungen stattgefunden hatten und Wertungen beschlossen worden waren, ohne die Neuerer zu hören: Der Parteisekretär des Instituts für Allgemeine Geschichte, M.I. Michajlov, informierte Gefter über ein Papier jener beiden ZK-Abteilungen, in dem von ,prinzipiellen Fehlem methodologischen und konkret-historischen Charakters" die Rede sei. Dies sei, so hieß es dort weiter, Ergebnis einer „ernsthaften Kritik“, die auch in Sitzungen des Büros der Geschichtsabteilung geübt worden sei. ${ }^{28}$ Die angekündigte öffentliche Beratung wurde jedoch immer wieder verschoben. ${ }^{29}$ Bei der Parteiversammlung des Instituts für Allgemeine Geschichte am 21. Dezember wiederholte

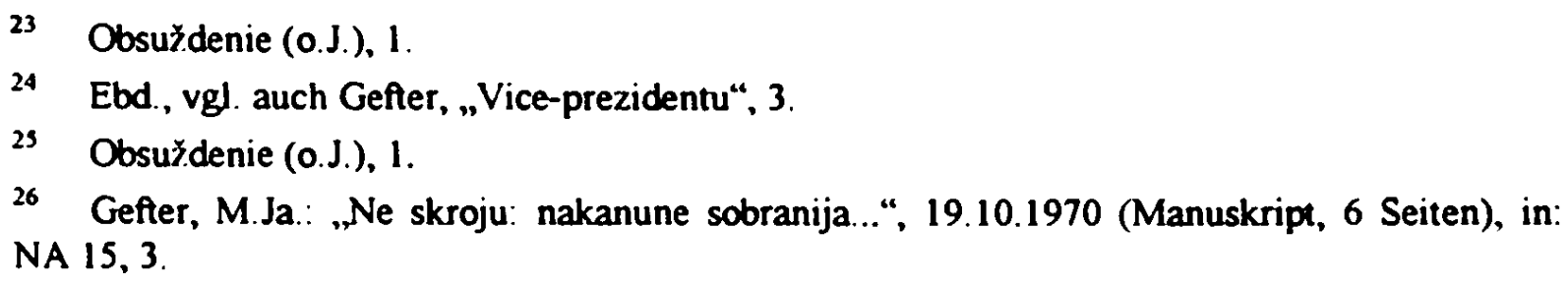

27 „(..) wenn ein Mensch, der jahrzehntelang mit der Wissenschaft verbunden war, versucht, zu fuhren und die Richtigkeit seiner Auffassung mittels Strafen zu beweisen, dann ist das seine Niederlage. Die Jahre der gemeinsamen Arbeit mit Evgenij Michajlovið Zukov verpflichten mich, freimütig und öffentlich darüber zu reden." - Ebd., 6.

28 Siehe Obsuždenie (o.J.), 2; Gefter, „Vice-prezidentu“, $3 f$.

29 Das lag wohl auch daran, daß Minc und Kim sich nicht einig wurden über die zu treffende Bewertung. Weil Kim mit einigen Bemerkungen von Minc zum Problem sozialer Revolutionen nicht einverstanden war, wollte er nicht länger an der Kommissionsarbeit teilnehmen. Minc konnte ihn am 21.12. jedoch dazu bringen, weiterzumachen. - Siehe Obsuždenie (o.J.), 1. 
Žukov lediglich sein Standard-Statement. Besonders heftig wandte er sich gegen das Ansinnen Gefters, die Klassiker ,neu zu lesen“: Das käme ja einer Infragestellung der theoretischen Fundamente gleich! ? $^{30}$

Am 3. Januar 1971 schilderte Gefter dem Vizepräsidenten der Akademie in einem vierseitigen Schreiben einige jener Ereignisse; sie zeugten von der systematischen Verletzung der elementaren Rechte der angegriffenen Wissenschaftler und von dem Unwillen der Leitungen des Geschichtsinstituts und der Geschichtsabteilung, eine wissenschaftliche Besprechung zu veranstalten. Jetzt sei es so, daß die Parteiorganisation und das wissenschaftliche Kollektiv des Instituts in ,ihrem" Namen Erklänungen über "die prinzipiellen Fehler des Buches" abgegeben hätten, ohne eine inhaltliche Diskussion gefuihrt und den Autoren ermöglicht zu haben, ihre Meinung dazu zu äußern. Gefter bat Rumjancev, sich in die Sache einzuschalten, da es nicht nur um eine einzelne Publikation, sondern um ,die Prinzipien der wissenschaftlichen Arbeit und Kritik" gehe. ${ }^{31}$

Am 10. Februar kam es endlich zu der lang hinausgeschobenen Beratung. Dem Bericht in Voprosy istorii zufolge wurde daraus allerdings eher ein Tribunal. ${ }^{32}$ Reihenweise traten die Kritiker auf und verurteilten die ,neue Lesart" der Klassiker, Gefters Thesen zur Geschichte des Bolschewismus und gegenwärtigen Entwicklung des Marxismus sowie die Diskussionsbeiträge von Drabkin und Majdanik zur Imperialismus- und Revolutionstheorie. Neu gegenüber den 1970 schon vorgebrachten Vorwürfen war folgendes: Akademiemitglied Chvostov stelte dem Ansinnen einer ,neuen Lesart" der Klassiker die These entgegen, es gebe aufgrund der marxistisch-leninistischen Methode

„(..) eine bestimmte Summe absolut präziser Erkenntnisse (...), eine Summe objektiver, durch die Wissenschaft präzis festgestellter GesetzmäBigkeiten, die wahr sind und der Revision nicht unterliegen, eben weil sie wahr sind. “33

Aleksandr Samsonov verteidigte das Bestreben der gerügten Autoren, die Klassiker neu zu lesen. Ihnen gehe es ja selbstverständlich nicht um die Widerlegung des Marxismus, sondern darum, ,die neue Spezifik“ der gegenwärtigen gesellschaftlichen Lage zu bestimmen, welche die Klassiker nicht kennen konnten. Das sei ein

30 „Unsere Theorie ist ein Monolith (...)“, rief Zukov aus. In gleicher Weise empörten sich M.I. Michajlov und A.A. Iskenderov über den Sammelband, der auf das ganze Institut einen Schatten geworfen habe (Iskenderov). - Siehe Kratkaja zapis' otkrytogo partsobranija In-ta, 21.12.1970 (Typoskript, 4 Seiten), in: NA 16, $2 \mathrm{ff}$.

31 Gefter, „Vice-prezidentu“, 4.

32 Zu der erweiterten Sitzung des Büros der Geschichtsabteilung der AdW der UdSSR wurden „(...) auch Spezialisten (...) aus angrenzenden Instituten der AdW der UdSSR, dem Institut für Marxismus-Leninismus und der Akademie für Gesellschaftswissenschaften beim ZK der KPdSU sowie aus anderen Institutionen" hinzugezogen. - Siehe Surbovanyj, G.P.: Obsuždenie nekotorych problem metodologii istorii, in: VI 1971, H. 10, 159-166; vgl. Neretina, Istorija, 163; Marko, Streit, 17ff; Enteen, A Recent Trend, 124ff.

33 Siehe Surbovanyj, Obsuždenie, 164. 
„völlig unbestreitbarer Gedanke“. ${ }^{34}$ Pavel Volobuev meinte, daß auch dann, wenn man - wie Chvostov - von der Existenz allgemeiner, ,axiomatischer" Lehren ausgehe, Forschungs- und Diskussionsbedarf über die besondere Erscheinungsweise und Spezifik allgemeiner Gesetzmäßigkeiten blieben. ${ }^{35}$ Minc und Kim monierten Gefters Überlegungen hinsichtlich der Ganzheit (celostnost'), der Aufrechterhaltung (sochranenie) und der Reproduktion (vosproizvedenie) des Marxismus. ${ }^{36}$ Minc und Pospelov warfen Gefter vor, die Agrarfrage als wesentliches Element des Leninismus dargestellt und fälschlicherweise eine Kontinuität von den „Volkstümlern“ (narodniki) zur revolutionären Sozialdemokratie gezeichnet zu haben. Statt dessen sei die Diktatur des Proletariats der zentrale Topos des Marxismus-Leninismus, und die Lösung allgemeindemokratischer Aufgaben, die Gefter so betonte, sei im revolutionären Kampf um den Sozialismus nur eine ,kleine Stufe" gewesen ${ }^{37}$ Den Antworten von Gefter, Drabkin, Gal'kin und Majdanik auf ihre Kritiker räumte der Berichterstatter in Voprosy istorii keinen Platz ein. Er behauptete, die Genannten hätten eine, höchst negative Haltung" $\mathrm{zu}$ den kritischen Bemerkungen eingenommen ${ }^{38}$ und wären auf die wichtigsten Fragen inhaltlich nicht eingegangen. Letzterem kann hier nur im Falle von Jakov Drabkin, dessen Referat über ,ungelöste Probleme der Erforschung sozialer Revolutionen“ in den Sammelband eingegangen war, widersprochen werden; nur sein Redebeitrag, in dem Drabkin auf alle wichtigen Vorwürfe reagierte, fand sich unter dem von S.S. Nere-

\footnotetext{
34 Ebd., 162.
}

35 Ebd., 163.

36 Aus dem Bericht ging allerdings nur hervor, daß die beiden Referenten Gefters Thesen für falsch hielten, nicht, wanum sie das taten. Gefter hatte hinterfragt, ob es - neben dem Prinzip des Historismus - eine weitere allgemeine Grundbedingung der Entwicklung der Marxschen Logik gebe. Und er formulierte folgenden "Widerspruch zwischen Allgemeinheit und Historismus“, der die aktuelle Entwicklung des Marxismus kennzeichne: .Einerseits Aneigung der Dialektik neuer Bereiche, Expansion der Dialektik (...). Andererseits die Tendenz des Marxismus zur Verengung und Konzentration auf das für ihn Spezifische, zur Verdichtung des Kerns." Auffallend an dieser Stelle des Berichts war, daß Gefters Position sorgfältiger wiedergegeben (zitiert) wurde, als die Kritik von Minc und Kim. - Hier zitiert nach Surbovanyj, Obsuždenie, 159; vgl. Istoričeskaja nauka 1969, 356.

39 Surbovanyj, Obsuždenie, 160 und 164. Hier stießen wirklich zwei unterschiedliche, wohl unvereinbare Sichtweisen aufeinander. Das von den Bedürfnissen der Agitation und Propaganda bestimmte Konzept einerseits: Bolschewiki als Arbeiterpartei, Lenin als Arbeiterführer, der Oktober 1917 als proletarische Revolution usw. Der unverstellte Blick des Historikers andererseits: Gefter wollte das demographische, politische, ideologische Gewicht der Bauernschaft, die soziale Bedeutung der Landfrage, die starken nichtproletarischen Elemente in den revolutionären Bewegungen Rußlands u.a. wieder in Erinnerung holen. - Zwar stimmt es, daß in der geistigen Genealogie nicht die „Volkstümler“ dem Bolschewismus direkt vorausgingen, sondern - in der Tradition der "Westler“ stehend - Plechanovs Gruppe „Befreiung der Arbeit“. Aber die Verbindungen. die Gefter betonen wollte, weil sie vergessen und verdrängt worden waren, gab es. Das spiegelte sich besonders deutlich in Lenins Bündnistheorie wider. - Vgl. Hofmann. W.: Ideengeschichte der sozialen Bewegung des 19. und 20. Jahrhunderts, 6., erweiterte Auflage, Berlin-New York 1979, 203-216.

38 Das heißt, daß sie die Kritik nicht anerkannten und keine „Fehler“ eingestanden. 
tina aufbewahrten Material. Drabkin verteidigte nochmals das Buch als Ganzes, welches eben kein Lehrbuch, sondem ein problemorientierter Diskussionsbeitrag sei. ${ }^{39}$ Er zitierte den Aufruf zum ,Neu-Lesen“ der Klassiker im Kontext der Einleitung des Sammelbandes ${ }^{40}$ und bezeichnete die Werke von Marx, Engels und Lenin als „Primärquellen“, die von den Historikern selbstverständlich immer wieder von neuem fragend gelesen werden müßten. ${ }^{41}$ Ausführlich ging Drabkin auf einige Aspekte der Revolutionstheorie ein (was hier nicht weiterverfolgt werden kann), präzisierte, was er wirklich geschrieben hatte und was ihm zu Unrecht von Minc vorgeworfen wurde. Drabkin erinnerte das Auditorium daran, daß Issak Minc selbst im Dezember 1962 während der unionsweiten Konferenz über die Diffamienung und Vernichtung von Historikern unter Stalin gesprochen hatte. ${ }^{42}$ Auch in der gegenwärtigen Auseinandersetzung gehe es nicht bloß um Detailfragen; es sei nichts Beunruhigendes dabei, wenn ein Buch oder einige Autoren kritisiert würden. Aber es gehe wieder
„(...) um die Bedingungen der schöpferischen Entwicklung der Geschichtswissen- schaft, insbesondere ihrer theoretisch-methodologischen Aspekte, um die Bedeutung wissenschaftlicher Diskussionen, um das Recht des Wissenschaftlers auf die wissen- schaftliche Suche, um die wissenschaftliche Ethik und Kritik. (...) Und ich denke, da $B$ das Schicksal der Wissenschaft, danunter auch das der Geschichtsmethodologie, alle beunruhigen sollte. ${ }^{\text {(433 }}$

Unbeeindruckt von den Gegenargumenten hielten ,die Mitglieder der Abteilung، ${ }^{\text {(4t }}$ an der Verurteilung des Sammelbandes fest: Er sei unzeitgemäß, weil die Hauptaufgabe - die Kritik bürgerlicher Konzeptionen - unerfüllt bleibe und statt dessen die Kernthesen des Marxismus-Leninismus angezweifelt würden, von denen die sowjetischen Historiker sich leiten lassen sollten. ${ }^{45}$ Seitens der Geschichtsabteilung

\footnotetext{
39 Drabkin, Ja.S.: „Ja pozvolju sebe...“, 10.02.1971, (Typoskript, 15 Seiten), in: NA 19. 1.

40 Vgl. Kapitel 4.2.4

41 Drabkin, „Ja pozvolju sebe“, 5.
}

42 Siehe oben in Kapitel 4.1. respektive in: Vsesojuznoe Sovešcanie 1964, 75. - Drabkin fugte hinzu: „Ich spreche darüber, um die Genossen, die mit uns in dem einen oder anderen Fall nicht einverstanden sind, die bei mir oder anderen irgendwelche mehr oder weniger ernsthaften Fehler sehen (...) zu bitten, nicht den Weg der Anspielungen zu gehen, die generell außerordentlich gefährlich sind." - Drabkin. „Ja pozvolju sebe“, $13 f$.

43 Ebd., 14. - Aleksandr Grunt, Redaktionsmitglied des Sammelbandes und Autor des Beitrags „Über Charakter und Mechanismus der Entwicklung des revolutionären Schöpfertums der Massen", konnte aus Gesundheitsgnünden nicht an der Sitzung am 10. Februar teilnehmen und reichte Bemerkungen im Umfang von vier Seiten für das Stenogramm ein, in dem er eigene Thesen und solche, die Gefter vertreten hatte, präzisierte. Auch das blieb in dem Bericht in Voprosy. istorii unerwähnt. - Grunt, A.: „Ne imeja vozmožnosti...“, 1971, in: NA 18, hier 3f: Surbovanyj, Obsuð̌denie.

44 Der Bericht suggerierte, daß hier absolute Einigkeit unter allen Akademiemitgliedern herrschte, was offensichtlich nicht der Fall war, wenn man an die Einwände von Samsonov und Volobuev denkt.

4s Siehe Surbovanyj, Obsuždenie, 166. 
der Akademie war damit das letzte Wort über die Arbeit der Methodologiesektion unter der Leitung Michail Gefters gesprochen. ${ }^{46}$ In dem von Leonid Brě̌nev am 30. März 1971 verlesenen Rechenschaftsbericht des ZK an den 24. Parteitag der KPdSU erinnerte ein Satz an die langjährige Auseinandersetzung. ${ }^{47}$ Von der Parteiorganisation am Institut für Allgemeine Geschichte wurde Gefter darüber hinaus noch mit einer Parteistrafe belegt, was nicht unwidersprochen von allen Mitgliedern hingenommen wurde, wie beispielsweise die Stellungnahme von Petr Lisovskij während der Parteiversammlung am 18. Juni 1971 zeigt. Lisovskij bezeichnete es als unerhörte Forderung, wenn von Gefter unter Androhung einer Parteistrafe verlangt werde, entgegen seiner Forschungsergebnisse sogenannte „Fehler“ einzugestehen. Es sei vorbildlich von Gefter, an seinen Überzeugungen festzuhalten. ${ }^{48}$ Heute treffe es Gefter und morgen?

„Wenn die Sache so weitergeht, dann können wir uns eines schönen Tages der Tatsache der vollständigen administrativ-bürokratischen Kontrolle über unsere Wissenschaft gegenübersehen. Es ist nicht schwer, sich vorzustellen, welche Folgen das hätte. Man darf nicht zulassen, daß bei uns die Praxis der Anwendung solch 'überzeugender' Argumente, wie Parteistrafen, in wissenschaftlichen Diskussionen gefestigt wird."

Die Gefahr der Bürokratisierung der Geschichtswissenschaft sei nicht eingebildet, werde nicht herbeigeredet, sondern sei ,vollkommen real", wie die Parteiversammlung selbst am besten beweise. Lisovskij plädierte deshalb für die Autonomie der Wissenschaft und dafür, auf die wissenschaftsimmanenten Kräfte der Selbstkorrektur zu setzen:

„(..) die Geschichte der Wissenschaft (ist) eine Geschichte des Ideenkampfes, in dem Fehler unausweichlich mit den Mitteln der Wissenschaft selbst überwunden werden. Die zahlreichen Versuche, von außen in die Wissenschaft Anschauungen einzuführen, die sich nicht aus der Logik ihrer Entwicklung ergaben, führten niemals zu etwas Gutem. Die Wissenschaft selbst enthält alles Notwendige, um mit ihren Aufgaben fertig zu werden und den Weg zur Wahrheit zu finden. Die Methode der Parteistrafen kann den wissenschaftlichen Fortschritt nur aufhalten. Falls mich das Gedächtnis nicht täuscht, dann war das auch der Standpunkt der Klassiker des

\footnotetext{
46 Ob ein Beschluß gefaßt wurde, läßt der Bericht in "VI" offen.

4" .Einer scharfen, gerechtfertigten Kritik wurden einzelne Versuche unterzogen, von unparteilichen, klassenfremden Positionen aus den historischen Weg des Sowjetvolkes zu bewerten und die Bedeutung seiner sozialistischen Errungenschaften herabzusetzen." - Dvadcat' četvertyj s-ezd Kommunističeskoj partii Sovetskogo Sojuza 30 marta-9 aprelja 1971 goda. Stenografičeskij otcet, tom 1, M. 1971, 128. Diese Bemerkung bezog sich, wie sich aus der richtigen zeitlichen Einordnung ergibt. auf die Kritik an der Methodologiesektion, nicht auf die - spätere - Verurteilung der „Neuen Richtung“, wie Bonwetsch irrtümlich meinte. Vgl. Bonwetsch, Oktoberrevolution, 155; Gusev, K V. 'Dvadcat' 'etvertyj s-ezd KPSS i otečestvennaja istoriografija, in: ISSSR 1971, H. 3, 3-12, hier 4ff.
}

48 Seine wissenschaftlichen Überzeugungen zu verteidigen, sei „(...) nicht nur das Recht, sondern auch die Pflicht des Wissenschaftlers". - Lisovskij, P.: Za svobodu tvorčeskoj naučnoj mysli (Vystuplenie na partijnom sobranii instituta vseobక̌čej istorii), 28.06.1971 (Typoskript, 3 Seiten), in: NA 20, hier $2 f$. 
Marxismus (...). Und so, muß man also die Wissenschaft schützen? Ja, man muß, aber nicht vor imaginären Fehlem, sondem vor Anschlägen auf ihre Freiheit! ${ }^{\text {(49 }}$

Die administrative Art der Auseinandersetzung spiegelt sich darin wider, daß zuerst 1969 die Methodologiesektion zerschlagen wurde, dann im Februar 1971 die inhaltliche Verurteilung durch die Geschichtsabteilung und die Parteiorganisation des Instituts erfolgte und erst danach - 1971/72 - sogenannte Rezensionen in den Fachzeitschriften publiziert wurden, die nun den offiziellen Standpunkt zu wiederholen und zu verbreiten hatten. ${ }^{\text {so }}$ Damit klang die Kampagne gegen Gefter und ,seine" Methodologiesektion aus. Pavel Volobuev war als Institutsdirektor für diese mit verantwortlich; er hatte im großen und ganzen ohne Fortune versucht, Schlimmeres zu verhüten: Die Arbeit der Methodologiesektion konnte nicht fortgesetzt werden; fast alle, die an ihr teilgenommen hatten, mußten den Arbeitsplatz, für den sie qualifiziert waren, verlassen und in meist ganz fachfremde Positionen abwandern.

Nach Abschluß dieser Kampagne wurden seit Mitte des Jahres 1971 die Vertreter der „Neuen Richtung“ der Oktoberrevolutionsforschung zunehmend zum Objekt der Kritik des ZK-Apparats; auch Volobuevs Stellung wurde prekär. Wie sehr sich das Klima verschärft hatte, zeigte der denunziatorische Angriff von S.F. Najda gegen Isaak Minc Anfang 1972. Letzterer hatte sich zwar eben noch als Kritiker der Methodologiesektion hervorgetan, aber den Rückwärtsgewandten blieb Minc - als Jude und ,Kosmopolit", als Zeitzeuge der Revolution und als Pokrovskij-Schüler ein Dorn im Auge. Najda wollte verhindern, daß Minc die Vorbereitungen zu einer wissenschaftlichen Konferenz anläßlich des 50. Jahrestags der Beendigung des Bürgerkriegs leitete; Minc sei dessen aus moralisch-politischen und wissenschaftlichen Gründen nicht würdig! ${ }^{51}$ In diesem Fall schützte allerdings der ZK-Apparat den Angegriffenen: Die Stellung von Minc blieb unangetastet. ${ }^{52}$ Vielleicht auch deshalb, weil er noch gebraucht wurde, um als angesehenes Akademiemitglied gegen die „Neue Richtung“" aufzutreten. Denn Minc gehörte zusammen mit Akademiemitglied B.G. Gafurov, damals Direktor des Instituts für Orientalische Studien, sowie den Korrespondierenden Akademiemitgliedern P.A. Žilin, einem Militärhistoriker, D.M. Kukin, dem stellvertretenden Direktor des Instituts für MarxismusLeninismus, Ju.A. Poljakov und M.P. Kim zu der Kommission, welche die offizielle

49 Ebd.

so Siehe Rybakov, M.V.: O nekotorych neopravdannych pretenzijach, in: VIKPSS 1971, H. 7, 123-133; Levykin, K.G.: O nekotorych problemach istoxnikovedenija, in: Vl 1972, H. 1, 152158; Smirnov, A.: Za stroguju naurnoct', dostovernost' i istoričeskuju pravdu, in: K 1972, H. 16, 113-124; zu Rybakov, O nekotorych, siehe Marko, Streit, 8ff.

51 1949 sei Minc vom ZK der KPdSU gemaßregelt und aus der Leitung der Forschungsgnuppe zur Geschichte des Bürgerkriegs entfernt worden; Minc habe sich durch keine Veröffentlichungen als Spezialist der Bürgerkriegsgeschichte ausgewiesen. - Siehe Najda, S.F. am 02.02.1972 an den Kandidaten des Politbüros und ZK-Sekretär P.N. Demičev, in: CChSD f. 5, op. 64, d. 108, 30-33.

32 Siehe Cecharin, E. am 14.04.1972 an das ZK, in: CChSD f. 5., op. 64, d. 108, 34. 
Stellungnahme der Geschichtsabteilung der AdW zu den Sammelbänden ,Russisches Proletariat ${ }^{\text {s3 }}$ und ,Der Sturz der Selbstherrschaft ${ }^{\text {s4 }}$, den wichtigsten Publikationen der ,Neuen Richtung“, vorbereitete. Am 9. und 10. März 1972 beriet der Wissenschaftliche Rat des Instituts für UdSSR-Geschichte das KommissionsErgebnis, das im wesentlichen von allen Diskutanten - mit Ausnahme Volobuevs bekräftigt wurde. ${ }^{55}$ Jurij Poljakov stellte die entscheidenden Kritikpunkte zusammen. Es handelte sich um Probleme, die konstitutiv für das in der Agitation und Propaganda zu verwendende Revolutionsmodell waren. Erstens die Wechselbeziehung von Spontaneität und Bewußtheit: in den Sammelbänden würde die Spontaneität der Massen in der Februarrevolution überbewertet und nicht gezeigt, daß die bolschewistische Partei den ,revolutionären Stoß“ vorbereitet habe. Zweitens die Hegemonie des Proletariats: es werde eine gewisse Unreife der russischen Arbeiterklasse überbetont, anstatt zu zeigen, daß das Proletariat in keiner Etappe der Revolution die führende Rolle abgegeben habe. Drittens die Bündnispartner der russischen Arbeiterklasse: anstatt sich an Lenins Aussagen über die Klassenkonstellation im Lande zu halten, behaupteten die Autoren, die Arbeiterklasse habe sich nach der Februarrevolution mit der ganzen Bauernschaft im Bündnis befunden (und nicht mit deren ärmsten Schichten). Viertens die Intensität der sozialistischen Revolution auf dem Lande und in den Randgebieten des Reiches: sie werde von den Autoren unterschätzt, denn tatsächlich habe eine einheitliche Revolution im ganzen Lande stattgefunden ${ }^{56}$ Die These der sogenannten Mehrbasigkeit oder Heterogenität der sozialökonomischen Verhältnisse Rußlands wurde bei dieser Beratung weder von Poljakov noch von den anderen Rednern in Frage gestellt!

Žilin und Bovykin wiesen auf die besondere Verantwortung hin, die Volobuev als Institutsdirektor habe. Seine Fehler wögen aufgrund seiner leitenden Funktion viel schwerer als die der anderen Autoren. ${ }^{57}$ Volobuev übte sich in Selbstkritik: Ja, er persönlich sei verantwortlich für das Erscheinen der kritisierten Sammelbände und für die darin verbreiteten Fehler. Seine These über das Bündnis der Arbeiterklasse mit der ganzen Bauernschaft suchte er abzuschwächen; es habe nur, in einem bestimmten Moment" für kurze Zeit bestanden. Alle anderen Kritikpunkte an seinen Auffassungen wies er jedoch zunück und räumte lediglich allgemein ein, daß manches nicht exakt formuliert worden sein mag. ${ }^{58}$ Der damals kommissarisch ${ }^{59}$ amtie-

\footnotetext{
33 Rossijskij proletariat.

s4 Sverženie samoderžavija.

ss Obsư̌denie knig ,Rossijskij proletariar: oblik, bor'ba, gegemonija“ i "Sverženie samoderžavija“, in: ISSSR 1973, H. 1, 211-214.

36 Ebd., $212 \mathrm{f}$.

37 Ebd., 213.

38 Ebd., 213f. Vgl. Enteen, A Recent Trend, 127f.

39 Eine ungeschickte Personalpolitik fuihrte zu raschem Wechsel in dieser Funktion: Der „Multi-Funktionär“ Zukov, Jahrgang 1907, hatte 1971 die Funktion des Akademischen Sekretärs der Geschichtsabteilung an V.M. Chvostov, Jahrgang 1905, der von 1959 bis 1967 Direktor des Instituts für Geschichte gewesen war, abgegeben. Chvostov starb am 09.03.1972, woraufhin P.N.
} 
rende Akademie-Sekretär Petr Pospelov brachte einen kurzgehaltenen Resolutionsentwurf ein, den das Büro der Geschichtsabteilung im Anschluß an die Diskussion verabschiedete. Darin wurde die Direktion des Instituts für Geschichte der UdSSR angewiesen, ,konkrete Maßnahmen“ zu ergreifen, um die besagten Mängel zu beseitigen, die Vorbereitungen zum 50. Jahrestag der UdSSR-Gründung zu intensivieren und die Arbeit an der dreibändigen „Geschichte der drei russischen Revolutionen“ weiterzufuihren. Der Institutsleitung wurde empfohlen, „die Frage über die Festigung der Führung der Sektion der UdSSR-Geschichte in der Periode des Imperialismus“ zu erörtern. Es wurde ferner als zweckmäßig bezeichnet, ,eine detaillierte Information" über die vorangegangene Beratung und Aufsätze zu den inhaltlichen Problemen der Diskussion in den Fachzeitschriften zu veröffentlichen. ${ }^{60}$

Nachdem die „Neue Richtung“ offiziell verurteilt worden war, kamen nun auch hier die ,Rezensenten“ zum Zuge, die als Multiplikatoren der wichtigsten Kritikpunkte in der Fachliteratur zu fungieren hatten. ${ }^{61}$ Vier Aspekte sind an diesen Rezensionen interessant: Erstens nahm die Kritik an Volobuevs Thesen nun den größten Raum ein. ${ }^{62}$ Zweitens wird aus der Entstehungsgeschichte der Verrisse deutlich, daß Druck von außen auf den ZK-Apparat ausgeübt wurde, damit dieser die Kampagne verstärke und möglichst harte Kritiken freigebe. So lancierte G. Sarapov, der Rektor der Hochschule der Gewerkschaftsbewegung, die von V. Laveryčev, A. Sivolobov und P. Sobolev, Historikern an der Akademie der Wissenschaften, geschriebene Stellungnahme in das Zentralkomitee und drängte, diese in der Gewerkschaftszeitung Trud publizieren zu lassen. ${ }^{63}$ Drittens wird durch den

Pospelov, der langjährige Direktor des Instituts für Marxismus-Leninismus, die Funktion kommissarisch übernahm, bis am 19.06.1973 B.A. Rybakov, Jahrgang 1908, als neuer Akademischer Sekretär der Geschichtsabteilung bestätigt wurde. - BSE (III) 22, 437f, BSE (III) 28, 224; VI 1972, H. 4, 219 ; VI 1973, H. 9, 144.

6o Postanovlenie bjuro otdelenija istorii AN SSSR ob itogach obsuy̌denija v Institute istorii SSSR izdannych v 1970 godu sbornikov „Rossijskij proletariat: oblik, bor'ba, gegemonija“ i "Sverženie samoderžavija“, in: VI 1972, H. 8, 140-145, hier 144f (der Beschluß wurde auch veröffentlicht in: ISSSR 1973, H. 1, 214-218); vgl. Enteen, A Recent Trend, 128.

61 Siehe Golub, P.A./V.Ja. Laveryčev/P.N. Sobolev: O knige „Rossijskij proletariat: oblik. bor'ba, gegemonija“, in: VIKPSS 1972, H. 9, 120-132; VI 1972, H. 11, 153-164, wo E.D. Cermenskij den Sammelband "Sverženie samodeř̌avija“ rezensierte; Levykin, K.G./A.M. Sivo lobov/G.V. Sarapov: O knige „Voprosy istorii kapitalističeskoj Rossii. Problema mnogoukladnosti“, in: VIKPSS 1973, H. 11, 106-115.

62 Siehe Golub/Laveryčev/Sobolev, O knige, 121ff; VI 1972, H. 11, 154ff.

63 Außer den bekannten Aufsatzsammlungen „Russisches Proletariat“, „Sturz der Selbstherrschaft" und "Geschichtswissenschaft und einige Probleme der Gegenwar" nannte Sarapov noch die Monographien von O.I. Skaratan, Problemy social'noj struktury rabołego klassa v SSSR, M. 1970, sowie von Ju.V. Arutjunjan, Social'naja struktura sel'skogo naselenija, M. 1970. Die Aussagen in all diesen Publikationen, so Sarapovs pauschales Urteil, stünden in vollständigem Widerspruch zu den Beschlüssen des 24. Parteitags der KPdSU. Die Angelegenheit wurde in den Monaten Mai und Juni im Apparat des Zentralkomitees beraten und dahingehend entschieden. daß doch die beiden Fachzeitschriften Voprasy istorii und Voprosy istorii KPSS Artikel zu der Auseinandersetzung veröffentlichen sollten. Daraus gingen dann die oben genannten Rezensionen in VIKPSS 1972, H. 9 und 1973, H. 11 hervor. - Siehe Sarapov, G.: O nekotorych osibkach 
Streit über die „Fragen der Geschichte des kapitalistischen Rußlands ${ }^{664}$ nochmals bestätigt, daß die Kampagne gegen die „Neue Richtung“ deutlich später begann als diejenige gegen die Methodologiesektion. Dieser Sammelband enthält die Materialien der Konferenz „V.I. Lenin über die sozial-ökonomische Struktur des kapitalistischen Rußlands", die im Mai 1969 in Sverdlovsk stattgefunden hatte. Er konnte 1972 noch erscheinen, als die Kampagne gegen die Methodologiesektion schon abgeschlossen war. Freilich richteten sich gleich nach der Veröffentlichung die Kritiken umso heftiger gegen die Materialsammlung, vor allem gegen die Beiträge von Tarnovskij und Gefter. ${ }^{65}$ Viertens ist erkennbar, daß zentrale sachliche Befunde der „Neuen Richtung“ - etwa die Heterogenität der sozialökonoumischen Verhältnisse, die kulturelle Unreife der russischen Arbeiterklasse im Vergleich zur westeuropäischen, das Element der Spontaneität im Februar 1917 - nicht negiert wurden. Den Neuerern wurde lediglich vorgeworfen, diese Tatsachen überzubewerten, sie zu wesentlichen Faktoren zu erklären und damit den klassischen, beispielhaften Charakter der Oktoberrevolution in Frage zu stellen, die demnach zu einem Sonderfall würde. ${ }^{66}$ Ganz offen nannten Levykin, Sovolobov und Sarapov die eigentlichen Gründe für die Verurteilung der ,Neuen Richtung“, die politischideologischer Natur waren:
„Versuche, den russischen Imperialismus als einen besonderen Typ, als ein besonde- res Modell der sozial-ökonomischen Entwicklung zu präsentieren, müssen auch des- halb zur Vorsicht mahnen, weil gegenwärtig bürgerliche Ideologen, wenn sie über die Oktoberrevolution sprechen, mit Nachdruck betonen, daß sie gerade wegen der besonderen Entwicklung Rußlands stattfinden konnte, und daher ihre historische Er- fahrung keine intermationale Bedeutung hat. ${ }^{\text {"67 }}$

Am 6. Januar 1973 schien eine kurze Mitteilung in der Pravda darauf hinzudeuten, daß die Kampagne gegen die „Neue Richtung“ zu einem Ende komme und besonders der Druck gegen Volobuev nachlasse. ${ }^{68} \mathrm{Daß}$ dem nicht so war, zeigten neben

$v$ osveščenii istorii i roli rabočego klassa $v$ otdel'nych rabotach Instituta istorii Akademii nauk SSSR (29.04.1972), in: CChSD f. 5, op. 64, d. 108, 66-70, hier 70; Laverycev, V./A. Sivolobov/P. Sobolev: Vopreki istoriceskoj pravde (28.04.1972), in: CChSD f. 5, op. 64, d. 108, 71-81; Trapeznikov, S./A. Jakovlev: O predloženii t. Selepina A.N. (12.06.1972), in: CChSD f. 5, op. 64, d. $108,82-84$

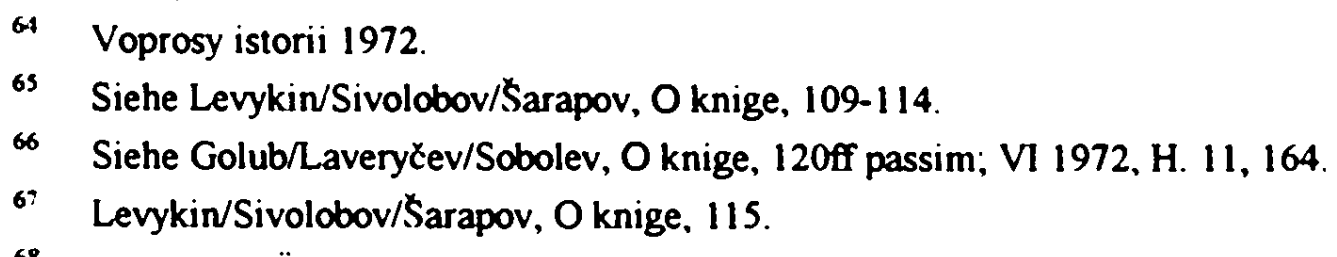

68 Unter der Überschrift „Nach der Kritik: Schlußfolgerungen gezogen“ hieß es: „Wie der Direktor des Instituts für UdSSR-Geschichte, das Korrespondierende Akademiemitglied P. Volobuev, und der Sekretär des Parteibüros des Instituts V. Neupokoev der Redaktion mitteilten, ist der Artikel 'Die reiche Erfahrung der Leninschen Partei aneignen' ('Pravda' vom 13. Oktober 1972), in dem das Buch 'Das russische Proletariat: Charakter, Kampf, Hegemonie' kritisiert wurde, von der Direktion und dem Parteibüro des Instituts erörtert worden. Es wurde festgestellt, daß der Artikel gemäß seiner politischen Richtung und der aufgeworfenen Kernfragen prinzipiell richtig war. (...) Den Mitgliedern des Redaktionskollegiums (...) sind Strafen auferlegt worden. Das Parteibüro stellte auch fest, daß die Direktion des Instituts und die Leitung des Wissen- 
den oben angefuihrten Kritiken nachdrücklich auch die Leitartikel, die im Laufe des Jahres 1973 in den Fachzeitschriften erschienen. Darin wurden von neuem die Leistungen der sowjetischen Geschichtswissenschaft bilanziert und die künftigen Aufgaben bestimmt. Die Autoren bezogen sich auf folgende Dokumente der KPdSU: den Beschluß des Zentralkomitees „Über die Maßnahmen zur weiteren Entwicklung der Gesellschaftswissenschaften und zur Erhöhung ihre Rolle im kommunistischen Aufbau“vom 14. August 1967, die Beschlüsse des 24. Parteitags von 1971, das ZK-Plenum vom Dezember 1972 und auf Leonid Brežnevs Festvortrag zum 50. Jahrestag der Gründung der UdSSR ${ }^{69}$ Unmittelbarer Anlaß aller Leitartikel war allerdings die Beratung führender Historiker aus der ganzen Sowjetunion am 21. und 22. März des Jahres 1973 in der von Sergej Trapeznikov geleiteten ZKAbteilung Wissenschaft und Lehrinstitutionen, in der auch Volobuev als Institutsdirektor Bericht erstattete. ${ }^{70}$ Die Leitartikel boten im allgemeinen wenig Aussagekräftiges über die verschiedenen Bereiche der historischen Disziplin, von der Lenin-Forschung bis zur Archäologie. Sie versäumten es aber nicht, auf die „einmütige“ Auffassung der Beratungsteilnehmer hinzuweisen, daß die der „Neuen Richtung" zugeordneten Sammelbände ,wesentliche Unzulänglichkeiten und Fehler theoretischen und methodologischen Charakters", "fehlerhafte Thesen", ,prinzipielle Fehler" usw. enthielten." Die Kritik war vor allem gegen Pavel Volobuev gerichtet, und die Fehler galten als noch nicht überwunden. Weitere repressive Maßnahmen wurden angedeutet. Denn:

„Die Fehler einiger Historiker zeugen (...) von ihrem Abgehen von der marxistischleninistischen Methodologie (...). Leider haben einige dieser Wissenschaftler noch nicht erkannt, daß sie auf fehlerhaften Positionen verharren, andere, die formal ihre Fehler anerkannten, tun nichts, um sie zu berichtigen. Und es gibt auch solche, die, obwohl sie die Verantwortung für die wissenschaftliche Forschungsorganisation tragen, öffentlich in den allgemeinsten Zügen die einen oder anderen Publikationen kri-

schaftlichen Rats 'Geschichte der Großen sozialistischen Oktoberrevolution' die Verantwortung für die Veröffentlichung des Buches 'Das russische Proletariat...' tragen (...). Von der Direktion und dem Parteibüro sind konkrete Maßnahmen ausgearbeitet worden, die es ermöglichen, die wissenschaftlich-organisatorische und ideologisch-erzieherische Arbeit im Kollektiv zu verbessern." - Posle kritiki: Vyvody sdelany, in: Provda v. 06.01.1973, 2; vgl. Kosul'nikov, A./A. Pedosov: Ovladevat' bogatym opytom leninskoj partii, in: Pravda v. 13.10.1972, 2.

69 Siehe Važnye zadax̌i istoričeskoj nauki, in: VIKPSS 1973, H. 5, 7-23; Sovetskaja istoričeskaja nauka na sovremennom etape, in: VI 1973, H. 5, 3-14, besonders 4f: Minc, I.I.M.V. Nečkina/L.V. Cerepnin: Zadači sovetskoj istoričeskoj nauki na sovremennom etape ee razvitija, in: ISSSR 1973, H. 5, 3-16, besonders 5f, Trapeznikov, S.: Sovetskaja istoriceskaja nauka i perspektivy ee razvitija, in: K 1973, H. 11, 68-86, besonders 69 .

10 Einem Pravda-Bericht zufolge referierten bei der Beratung außer Volobuev der kommissarische Sekretär der Geschichtsabteilung P.N. Pospelov und der stellvertretende Direktor des Instituts für Marxismus-Leninismus D.M. Kukin. In der Diskussion traten ausgewiesene Gegner der „Neuen Richtung" auf: P.N. Fedoseev, B.G. Gafurov, E.M. Zukov, I.I. Minc, A.L. Naročnickij, B.A. Rybakov und S.P. Trapeznikov. - Neotložnye zadaxi istorikov, in: Pravda, 29.03.1973, 2.

71 Važnye zadači, 11f; Sovetskaja istoričeskaja nauka 1973, 12; Minc/Nexkina/Cerepnin, Zadaxi, 11 . 
tisierten, aber die eigenen Fehler, ungeachtet ihrer Evidenz und Unbestreitbarkeit, nicht anerkennen, sondern fortfahren, faktisch diese Fehler zu vertiefen."

Der letzte Satz war offenkundig auf Volobuev gemünzt. Er war für den ZK-Apparat und für die Geschichtsabteilung an der Akademie als Institutsdirektor nicht länger tragbar. Zu sehr hatte er mit seinen Thesen im Rahmen der ,Neuen Richtung“ und mit seiner halbherzigen „Selbstkritik“ die führenden Funktionäre und Historiker provoziert. Über Volobuevs unrühmlichen Abgang - höchstwahrscheinlich bei dieser Beratung im März 1973 - schrieb Nekric:

„Die Episode mit Volobuev endete mit seinem vollständigen Reuebekenntnis bei einer Beratung im ZK. Und nicht nur mit Reue: Volobuev trat auf mit einer scharfen Kritik der Auffassungen Tamovskijs und mit einer milden Kritik, die an seinen engsten wissenschaftlichen Mitarbeiter Aaron Avrech gerichtet war. Danach beantragte Volobuev seine Befreiung von den Pflichten des Direktors. “73

Fortan fanden einige zentrale Veranstaltungen der Historiker ohne den Direktor des Instituts für UdSSR-Geschichte statt, so auch diejenige zum 50. Jahrestag der Gründung der Sowjetunion, ${ }^{74}$ bis das Präsidium der Akademie der Wissenschaften Volobuev offiziell entließ und Arkadij Naročnickij ${ }^{75}$ zu seinem Nachfolger ernann-

\footnotetext{
12 Važnye zadači, 12.

73 Nekrič, Otrešis' ot stracha, 342.

14 Siehe Enteen, A Recent Trend, 129.

13 Aleksej Leont'evið Naroxnickij (16.02.1907-14.06.1989) war Fachhistoriker für Kolonialpolitik und internationale Beziehungen des 18. und 19. Jahrhunderts und insofern fachlich eine Fehlbesetzung als Direktor des Instituts für UdSSR-Geschichte! Er war offensichtlich dadurch
} 
te. ${ }^{76}$ Damit war auch die Kampagne gegen die „Neue Richtung“ in der Oktoberrevolutionsforschung abgeschlossen. Nach dieser, Zerschlagung einer ganzen Richtung ${ }^{677}$ blieben etwa füfzehn Jahre lang die produktivsten Ansätze in der sowjetischen Revolutionsforschung ungenutzt; die gebrandmarkten Thesen verschwanden aus den Veröffentlichungen oder wurden verwässert. ${ }^{78}$

qualifizien, daß er stets - ob es 1948 gegen die .Kosmopoliten“ ging oder in den sechziger und siebziger Jahren gegen Nekric und andere - auf der richtigen Seite der Barrikade stand. - VI 1967, H. 5, 168f, VI 1989, H. 8, 189; Nekric, Otresis' ot stracha, 53 und 380.

76 Siehe Tichonov, Ju.A.: Obsxee godičnoe sobranie, in: V1 1974, H. 5, 137-140, hier 137.

$"$ Afanassjew, J. (= Afanas'ev, Ju.N.): Vom Standpunkt der Wahrheit und des Realismus, in: Huffschmid, J. (Hg.): Glasnost/ Perestrojka, Band 1: Streiten für die Umgestaltung. Die sowjetische Diskussion, Köln 1987, 61ff, hier 67.

$18 \mathrm{Zu}$ dem, was nun wieder dominierte, siehe etwa Bovykin, V.I.: Probleme der industriellen Entwicklung Rußlands, in: Geyer, Winschaft, 188-209; Laveryčev, V.Ja.: Staatsmonopolistischer Kapitalismus im vorrevolutionären Rußland, in: JbW 1985, H. 4, 57-67; Bovykin. V.1.: Organisationsformen des Finanzkapitals in Rußland. Industrie und Banken vom Ende des 19. Jh. bis zum Beginn des 20. Jh., ebd., 69-81; Korelin, A.P.: Die Banken und die Entwicklung der Landwirtschaft in Rußland Ende des 19./Anfang des 20. Jh., ebd., 83-94. Vgl. auch Bonwetsch. Rußland, 738. 


\subsection{Die sowjetische Geschichtswissenschaft im Zeichen von Routine und Retardation}

Die äußeren Merkmale der beiden großen Fachzeitschriften Voprosy istorii und Istorija SSSR reflektierten die rückläufige Entwicklung der historischen Disziplin in den siebziger Jahren. Die Auflage des zuerst genannten Journals sank zunächst langsam, fiel zu Beginn der achtziger Jahre schnell weiter ab und war 1983 gegenüber der Auflagenhöhe von 1971 halbiert. ${ }^{\prime}$ Die bereits sehr niedrige Auflage der zweimonatlich erscheinenden Istorija SSSR von zehn- bis elftausend Exemplaren stagnierte während des ganzen Jahrzehnts, ehe sie anfangs der achtziger Jahre unter zehntausend sank. ${ }^{2}$ Aus den Redaktionskollegien schieden nach und nach diejenigen Historiker aus, die von der Parteilinie abgewichen und genügt worden waren, und parteitreue etablierte Repräsentanten der Historie übernahmen die Funktionen. Zur Redaktion der Voprosy istorii stieß 1971 ein neuer verantwortlichen Sekretär, I.V. Sozin, der gemeinsam mit dem Chefredakteur Truchanovskij bis in die Zeiten der perestrojka auf dem Posten blieb. ${ }^{3}$ Bei Istorija SSSR löste Ivan Koval'cenko 1970 den bisherigen Chefredakteur Poljakov ab. Koval'čenko hielt die Zeitschrift bis zum Ende des Jahres 1988 auf dem gewünschten Kurs. ${ }^{4}$ Pavel Volobuev schied nach seiner Ablösung als Direktor des Instituts für Geschichte der UdSSR 1974 auch aus der Redaktion der Istorija SSSR aus. ${ }^{5}$ Nach einigen weiteren personellen Umsetzungen befanden sich seit Mitte der siebziger Jahre auch in

1971 lag die Auflagenhöhe bei 32.000 Exemplaren, sie sank in der ersten Hälfte der siebziger Jahre auf 25.000 , von 1979 bis 1982 unter 25.000 bis auf 20.000 , bis schließlich Anfang 1983 der Tiefstand mit 16.000 Exemplaren erreicht wurde. Auch der Heftumfang wurde 1979 um 32 Seiten reduziert. - Vgl. VI 1971, H. 1, 224; 1972, H. 7, 224; 1975, H. 7, 224; 1978, H. 12, 224; 1979, H. 7, 192; 1982, H. 1, 192; 1983, H. 1, 192; 1985, H. 6, 192.

2 Siehe ISSSR 1970, H. 1, 232; 1978, H. 1, 232. Von 1982 an waren es nur noch 9.400 Exemplare, vgl. ISSSR 1982, H. 1, 223.

3 Zu Beginn des Jahres 1971 schieden Koval'čenko, Chrenov und Judačev aus der Redaktion aus. Neben Sozin und dem neuen Stellvertreter des Chefredakteurs A.G. Kuz'min kamen V.I. Bovykin, N.N. Demoxkin, L.N. Nežinskij, Ju.A. Poljakov und A.N. Sacharov - alle ausgewiesene Kritiker der "Neuen Richtung" - neu hinzu. 1973 schieden Zukov, der neue Führungsaufgaben übernahm, und der Mediävist Skazkin, der 82-jährig starb, aus. 1975 wurde die Zahl der Redaktionsmitglieder auf 20 erhöht: Golikov, Demozkin und Nežinskij verließen das Kollegium; acht, dezidiert konservative Historiker kamen hinzu: P.A. Golub, I.I. Zigalov, Ju.S. Kukuß̌kin, N.V. Matkovskij, A.I. Nedorezov, N.G. Nefedov, B.A. Rybakov und S.S. Chromov. 1977 löste A.I. Titov Kuz'min ab. Nach dem Ausscheiden von Matkovskij 1978, von Achramovix, Dudinskij und Nedorezov 1981, ergänzten V.A. D’jakov, V.A. Kumanev, A.L. Naročnickij und B.B. Piotrovskij die Redaktion wieder. Siehe VI 1971, H. 3, 224; VI 1973, H. 4, 224; VI 1975, H. 7, 224; VI 1978, H. 12, 224; VI 1981, H. 6, 192.

4 Siehe ISSSR 1970, H. 2, 2; ISSSR 1988, H. 5, 2 und H. 6, 2.

3 Für ihn kam G.D. Komkov in die Redaktion; siehe ISSSR 1974, H. 5, 2. 
diesem Redaktionskollegium nur noch konservative und farblose Vertreter der historischen Disziplin. ${ }^{6}$

Leitartikel spielten anders als in den füfziger und sechziger Jahren in dieser Etappe eine untergeordnete Rolle. Von 1970 bis 1982 erschienen in Voprosy istorii vier ungezeichnete Leitartikel, ${ }^{7}$ in Istorija SSSR in der gleichen Zeit sogar nur drei. ${ }^{8}$ Auf anderem Wege wurden die Fachzeitschriften allerdings in viel stärkerem Maße politisiert und (im schlechtesten Sinne) aktualisiert. In den Hauptaufsätzen dominierten gegenwartsbezogene politische Themen, die ernsthafte historische Forschungsbeiträge in den Hintergnund drängten. Die Zeitschriften nahmen die Züge politischer Magazine an. ${ }^{9}$ Für die historische Disziplin kristallisierten sich dabei zwei zentrale, eng miteinander verknüpfte Begriffe heraus, welche die „Botschaft“ des 24. Parteitags der KPdSU im Jahr 1971 ausgedrückt hatten: Erstens der Terminus „entwickelte sozialistische Gesellschaft" (razvitoe socialisticeskoe obscestvo), womit die aktuelle Entwicklungsetappe der Sowjetunion und die Aufgaben

- Mit Poljakov schieden 1970 Vorob'ev und Poletaev aus der Redaktion aus, S.S. Chromov kam neben Koval'cenko neu hinzu. Im Frühjahr 1974 löste B.I. Krasnobaev den bisherigen stellvertretenden Chefredakteur Milov ab. 1975 bekam die Zeitschrift acht neue Redaktionsmitglieder: A.L. Naroxnickij, I.E. Zelenin, K.V. Gusev, V.I. Kas'janenko, V.I. Kulikov, V.Ja. Laverycev, A.P. Okladnikov und A.M. Sacharov. Drobižev, Milov, Rybakov, Chromov, Grunt und Samsonov (die beiden zuletzt Genannten zählten zu den Revisionisten der sechziger Jahre) schieden aus. Am 12.06.1977 starb L.V. Cerepnin, der seit der Gründung der Zeitschrif 1957 dem Redaktionskollegium angehört hatte, am 01.04.1978 A.M. Sacharov. Als neuer stellvertretender Chefredakteur wurde 1980 M.A. Rachmatullin eingesetzt. Ein Jahr später ersetzten V.A. Georgiev, V.P. Naumov, A.P. Novosel'cev und I.V. Rusinov Kulikov, Naroxnickij, Cypkin und Kas'janenko. Siehe ISSSR 1970, H. 2, 2; 1974, H. 4, 2; 1975, H. 1, 2; H. 5, 2; H. 6, 2; 1978, H. 1,$2 ;$ H. 4, 2; 1980, H. 5, 2; 1981, H. 6, 2 .

1 Anläßlich des 24. Parteitags der KPdSU: Dvadcat' cetvertyj S-ezd KPSS, in: VI 1971, H. 5 , 3-12; im Zusammenhang mit der Verurteilung der „Neuen Richtung“: Sovetskaja istoričeskaja nauka na sovremennom etape, in: VI 1973, H. 5, 3-14; zum 70. Jahrestag des 2 . Parteitags der Russischen Sozialdemokratischen Arbeiterpartei: Istoričeskoe značenie Il s-ezda RSDRP, in: VI 1973, H. 7, 3-16; zu den wichtigsten Forschungsrichtungen in den Jahren 1981 bis 1985, ,im Lichte der Beschlüsse des 26. Parteitags der KPdSU": Osnovnye napravlenija istoriceskich issledovanij $\vee$ XI pjatiletke $v$ svete rešenij XXVI s-ezda KPSS, in: VI 1981, H. 10, 3-11.

8 Zur 100. Wiederkehr des Geburtstags Lenins: Idei Leninizma bessmertny. 100 let so dnja roždenija V.I. Lenina, in: ISSSR 1970, H. 2, 3-7; zum 50. Jahrestag der Staatsgründung: Znamenitel'naja data $v$ istorii narodov SSSR, in: ISSSR 1972, H. 6, 5-10; anläßlich des 30. Jahrestages des Sieges über den Faschismus: Vsemirno-istoriCeskaja pobeda sovetskogo naroda, in: ISSSR 1975, H. 3, 3-11.

- Den größten Raum beanspruchten Aufsätze zur Gegenwart der sozialistischen Bewegungen und Staaten in aller Welt, der Außen- und Sicherheitspolitik, des sozialistischen und kommunistischen Aufbaus, der entsprechenden Fünfjahrpläne und der sozialökonomischen Entwicklung in der UdSSR usw. Vgl. die typischen Beispiele in: VI 1976, H. 7, 4ff; 1977, H. 2, 3ff; H. 6, 3ff; 1978, H. 1, 13ff; 1979, H. 11, 58ff; 1980, H. 11, 3ff; 1981, H. 4, 3ff; 1983, H. 6, $21 \mathrm{ff}$. Darüber hinaus in: ISSSR 1973, H. 6, 3ff; 1974, H. 5, 3ff, 71ff; H. 6, 3ff; 1976, H. 6, 169ff; 1977, H. 1, 3ff; H. 9, 3ff; 1978, H. 3, 3ff; 1980, H. 5, 3ff; 1981, H. 4, 3ff; H. 5, 3ff; H. 6, 3ff; 1982, H. 1, 3ff; H. 6, 3ff, 1983, H. 2, $21 \mathrm{ff}$. 
aller Gesellschaftsmitglieder, auch der Historiker, bezeichnet sein sollten. ${ }^{10}$ Fortan wurden viele Arbeitsstunden dem Bemühen gewidmet, den Begriff zu begründen und inhaltlich zu bestimmen sowie die Entwicklung des realen Sozialismus zu periodisieren." Zweitens das Theorem "Sowjetvolk" (Sovetskij narod), welches die Lösung der Nationalitätenfrage und die erfolgreiche Entwicklung einer neuen historischen Gemeinschaft, des multinationalen, aber monolithischen Bündnisses der „Erbauer des Kommunismus“ postulierte. ${ }^{12}$

10 Brežnev hatte den Begriff erstmals in seiner Festansprache zum 50. Jahrestag der Oktoberrevolution verwendet. Der 24. Parteitag der KPdSU 1971 bestätigte die These, daß die UdSSR im Lauf der sechziger Jahre in die Phase des entwickelten Sozialismus eingetreten sei, den es nun zu vervollkommnen und dessen Möglichkeiten es zu nutzen gelte. Politbüromitglied Suslov, zuständig für Fragen der Ideologie, schrieb in seiner für die Gesellschaftswissenschaften bestimmten Auswertung des Parteitags: „Das Wichtigste, worauf der XXIV. Parteitag der KPdSU unsere Gesellschaftswissenschaftler orientiert - das ist die theoretische Ausarbeitung der Grundprobleme der entwickelten sozialistischen Gesellschaft, die wissenschaftiche Begründung der Wege und der Mittel ihres Hinüberwachsens in den Kommunismus." - Suslov, M.: Obšcestvennye nauki boevoe onuzie partii v stroitel'stve kommunizma, in: K 1972, H. 1, 18-30, hier 19. Vgl. Jubilejnaja sessija 1968; Chromov, S.S.: XXIV s-ezd KPSS i nekotorye voprosy social'nogo razvitija sovetskogo obšcestva, in: ISSSR 1972, H. 3, 3-19.

"In welche Erklärungsnöte die Parteifuihnung die Historiker damit ein weiteres Mal brachte, veranschaulicht die 1985 publizierte Erläuterung der beiden DDR-Historiker Günter Rosenfeld und Horst Schützler: „Gegenwärtig erarbeitet die sowjetische Geschichtsschreibung die Periodisienung des entwickelten Sozialismus. Es gibt unterschiedliche Auffassungen über den Zeitpunkt des Eintritts des Landes in den entwickelten Sozialismus - Ende der fünfziger/Anfang der sechziger Jahre. Mitte der sechziger Jahre. Ende der sechziger/Anfang der siebziger Jahre, 1977 mit der Verfassung, auf die hier nur verwiesen werden kann. Gemeinsam ist der Gedanke, daß es sich um einen Prozeß des Reifens neuer Wesenszüge und komplexer Entwicklungen handelt, der in den sechziger Jahren deutlich einsetzt und zur Ausprägung des entwickelten Sozialismus führt. Ein genaues Datum, ein bestimmtes Jahr für den Beginn der neuen Etappe anzugeben ist deshalb nicht möglich." - Rosenfeld. G./H. Schützler: Kurze Geschichte der Sowjetunion 1917-1983, Berlin 1985, 326.

Vgl. die Bemühungen: Kas'janenko, V.l.: Razvitoj socializm: istoriografija i metodologija problemy, M. 1976; ders., Istoriografija razvitogo socializma v SSSR, M. 1976; ders., Nekotorye voprosy istoriografii razvitogo socializma v SSSR, in: VI 1976, H. 8, 3-25; ders., Istoriografija razvitogo socializma v SSSR, in: Izučenie otečestvennoj istorii v SSSR meždu XXIV i XXV sezdami KPSS. Vyp. 1: Sovetskij period, M. 1978, 178-212; ders., Kapital'nyj trud o postroenii razvitogo socializma $\vee$ SSSR, in: VI 1981, H. 9, 134-141; Social'no-ekonomičeskie problemy istorii razvitogo socializma v SSSR, M. 1976; Kovełnikov, E.M.N.M. Pugačev: Sovetskaja literatura o razvitom socialističeskom obšcestve. Naučno-analističeskij obzor, M. 1977; Gamalij, N.V.: Novejšxaja sovetskaja istoriografija o kul'ture razvitogo socializma, in: VI 1980, H. 9, 117 123

12 Der Begriff des „Sowjetvolks“ wurde erstmals 1945 von der sowjetpatriotischen Propaganda im großen Stil verwendet, als die „Freundschaft der Völker der Sowjetunion" und der Zusammenhalt des "Sowjetvolks" als für den militärischen Sieg entscheidend bezeichnet wurden. Seit Anfang der sechziger Jahre wurde der Terminus allmählich in die historische Forschung mit einbezogen, oftmals in interdisziplinärer Kooperation mit der Ethnographie. Nach dem 24. Parteitag der KPdSU 1971 wurde die geschichts, wissenschaftliche“ Auseinandersetzung damit intensiviert. Der damalige Leiter des Büros der Geschichtsabteilung an der Akademie, V.M. Chvostov, stellte bei der Parteitagsauswertung fest: „Die im Kampf für den Sozialismus erfolgte 
Aus diesen beiden Paradigmen einerseits und aus den historischen Jahrestagen andererseits leitete die Ordnungs- und Kontrollbehörde der historischen Disziplin, die Geschichtsabteilung an der Akademie der Wissenschaften, die Aufgaben der Forschungsinstitutionen und der Fachzeitschriften ab. ${ }^{13}$ Die Beschäftigung mit der sowjetischen Geschichte seit 1917 bekam dabei gegenüber der Erforschung der vorrevolutionären Geschichte ein noch größeres Übergewicht. ${ }^{14}$ Die auf die Ge-

Bildung neuer, harmonischer Beziehungen zwischen Klassen und sozialen Gruppen, Nationen und Nationalitäten des Sowjetlandes, die Schaffung ihrer monolithischen Geschlossenheit auf der Grundlage der marxistisch-leninistischen Ideologie (...) bilden den Hauptbereich der historischen Forschungen, die diesen geschichtlichen Prozeß erklären und zugleich die weitere Geschlossenheit des Sowjetvolkes im Kampf gegen alle Erscheinungen des Nationalismus unterstützen müssen." - Zitiert nach Pol'skij, M.P.: XXIV s-ezd KPSS i zadači sovetskoj istoričeskoj nauki. Koordinacionnoe soveščanie $v$ otdelenii istorii Akademii nauk SSSR, in: ISSSR 1972, H. 2, 178183 , hier 179

Exemplarisch: Kim, M.P.: Sovetskij narod - novaja istoriðeskaja obščnost’, M. 1972: Kim, M.P./V.P. Serstobitov: Sovetskij narod - novaja istoriceskaja obßznost ljudej, in: VI 1972, H. 10, 3-17; Jurin, Ju.M.: Sessija, posvjaš̌ennaja 50-letiju obrazovanija SSSR, in: ISSSR 1973, H. 3, 211-223, hier besonders zu dem Vortrag von M.P. Kim, 212f; Sovetskij narod - novaja isto riceskaja obડ̌čnost' ljudej. Stanovlenie i razvitie, M. 1975; Serstobitov, V.P.: Sovetskij narod monolitnaja obł̌nost stroitelej kommunizma, M. 1976; Velikij sovetskij narod. Kiev 1976; Kulixenko, M.I.: Ekonomið̌eskie osnovy ukreplenija internacional nogo edinstva sovetskogo naroda. in: ISSSR 1976, H. 3, 3-21; ders., Obrazovanie i razvitie sovetskogo naroda kak novoj istoričeskoj ob̌̌čnosti (istoriografija), in: VI 1979, H. 4, 3-23; ders., Rascvet i sblið̌enie nacij v SSSR. M. 1981; Licholat. A.V.IV.F. Panibud'laska: $V$ edinoj sem'e narodov. Družba i sotrudničestvo narodov SSSR v uslovijach razvitogo socializma, M. 1979; Razvitie sovetskogo naroda - novoj istoriðeskoj obšnosti, M. 1980; Stanovlenie i razvitie novoj istoričeskoj obßxnosti - sovetskogo naroda. Kruglyj stol "Istorii SSSR“, in: ISSSR 1980, H. 6, 23-83; Drobiževa, L.M.: Duchovnaja obšcnost narodov SSSR. Istoriko-sociologičeskij ocerk mežnacional'nych otnošenij, M. 1981; Rosenko, M.N.: Rol' russkoj socialisticeskoj nacii $v$ razvitii i ukreplenii internacional'nogo edinstva sovetskogo naroda, in: ISSSR 1982, H. 1, 50-61; Serstobitov, V.P.: Razvitie sovetskogo naroda - novoj istorizeskoj obšžnosti na sovremennom etape. in: ISSSR 1982, H. 6, 17-31. - Vgl. Martiny, A.: Das Verhältnis von Politik und Geschichtsschreibung in der Historiographie der sowjetischen Nationalitäten seit den sechziger Jahren, in: JbbGO 1979, 238-272; Kappeler, A.: Die Historiographien der nichtrussischen Völker der RSFSR in den siebziger Jahren, JbbGO 1981, 53-79; Lewytzkyj, B.: „Sovetskij narod", "Das Sowjetvolk“. Nationalitätenpolitik als Instrument des Sowjetimperialismus, Hamburg 1983; vgl. Oberländer, Sowjetpatriotismus, 28ff und 78ff; Meissner, Bilanz, $15 f$.

13 Als beispielsweise der Chefredakteur von Voprosy istorii Truchanovskij im Mai 1976 in Kiev die Arbeit seiner Zeitschrift während des zurückliegenden 9. Fünfjahrplans (sic!) erläuterte, sagte er, man habe sich konzentriert auf die Parteibeschlüsse und historischen Jubiläen: das waren folgende Jahrestage: der 30. des Sieges im Großen Vaterländischen Krieg, der 50 . der UdSSR-Gründung, der 70. der ersten nussischen Revolution, der 150. des Aufstands der Dekabristen und der 250. der Gründung der Akademie der Wissenschaften! - Siehe VI 1976, H. 8, 162; typisch auch der Rückblick auf die Tätigkeit der Geschichtsabteilung in den Jahren 1970 bis 1974 in: VI 1975, H. 8, 148-162.

14 Von 1975 bis 1979 murden unionsweit 214 ,Doktor-Dissertationen“ (Habilitationsschriften) zur "Vaterländischen Geschichte“ angenommen. Nur 92 Arbeiten davon (42,9\%) behandelten Themen der vorrevolutionären „Vaterländischen Geschichte“, 122 (57,1\%) die sowjetische Periode seit 1917. Bei den 783 „Kandidaten-Dissertationen“ (Promotionen) war das Mißverhältnis noch krasser: Weit weniger als ein Viertel der Doktoranden beschäftigte sich mit der vorrevolu- 
schichte der sowjetischen Gesellschaft spezialisierten Historikerinnen und Historiker blieben angehalten, die ,klassischen"Schwerpunkte zu bearbeiten. Den größten Aussto $B$ an Literatur und Dokumentationen gab es zur Geschichte der Oktoberrevolution und des Bürgerkriegs. ${ }^{15}$ Zahllose Publikationen zur Geschichte der Arbeiterklasse und der Industrialisierung, ${ }^{16}$ der Bauem und der Kollektivierung ${ }^{17}$ sollten

tionären Geschichte der UdSSR (136 bzw. 17,4\%); 647 Arbeiten waren der Geschichte der sowjetischen Gesellschaft gewidmet (82,6\%). - Gusev, K.V./V.Z. Drobižev/V.K. Pokrovskij: O podgotovke kadrov vyš̌ej kvalifikacii po otečestvennoj istorii (Po materialiam VAK SSSR), in: ISSSR 1981, H. 1, 121-126, hier 123ff.

is Siehe Kim, M.P./Ju.A. Poljakov: Istorija sovetskogo obšestva, in: Razvitie sovetskoj istoričeskoj nauki 1970-1974, M. 1975, 56-78, hier 56ff; dies., Izučeme istorii sovetskogo obšcestva, in: Sovetskaja istoričeskaja nauka v 1975-1979 gg., M. 1980, 40-62, hier 40ff; Gorodeckij, E.N.: Sovremennaja sovetskaja literatura o Velikom Oktjabrja, in: ISSSR 1977, H. 6, 104-127; Naumov, V.P.: Osnovnye certy sovremennoj sovetskoj istoriografii Velikogo Oktjabrja, in: VI 1977, H. 10, 56-74; Strižkov, Ju.K./A.I. Suslov: Novejక̌ja istoričeskaja literatura o bor'be na prodovol'stvennom fronte v gody grałdanskoj vojny, in: VI 1980, H. 2, 118-127; Piotrovskij, B.B./V.A. Tiškov: Itogi issledovanij sovetskich istorikov v desjatoj pjatiletke, in: VI 1981, H. 2, 3-25, hier 5f; Chromov, S.S.: Aktual'nye problemy izučenija otexestvennoj istorii v svete rešenij XXVI sezda KPSS, in: ISSSR 1981, H. 3, 3-24, hier 8; Chromov, S.S./V.I. Buganov/V.P. Serstobitov: Nekotorye itogi i aktual'nye problemy izučenija otečestvennoj istorii v svete rešenij XXVI s-ezda KPSS, in: Izučenie otečestvennoj istorii v SSSR meždu XXV i XXVI s-ezdami KPSS, M. 1982, 3-48, hier $12 \mathrm{ff}$.

Herausragende Publikationen waren hier: die erste (1967-1973) und zweite (1977-1979) Auflage der dreibändigen "Geschichte des Großen Oktobers" von I.I. Minc sowie die Monographie von E.G. Gimpel'son über die Politik, Praxis und Ideologie des „Kriegskommunismus“ (M. 1973; vgl. dazu die Diskussion in: ISSSR 1974, H. 3, 169f).

16 Vgl. Lel'cuk, V.S.: Socialističeskaja industrializacija SSSR i ee osveščnie v sovetskoj istoriografii, M. 1975; Kuz'min, V.I.: Nekotorye problemy istorii industrializacii SSSR v svete novogo dokumental'nogo izdanija, in: ISSSR 1975, H. 4, 156-166; Kim/Poljakov, Istorija, 61f; dies., Izučenie, 42ff; Lebedeva, N.B.: Novye issledovanija o sovetskom rabočem klasse v pervye gody proletarskoj diktatury, in: ISSSR 1976, H. 5, 171-177; Naroxnickij, A.L. u.a.: Nekotorye aktual'nye problemy istorii sovetskogo raboxego klassa, in: ISSSR 1978, H. 4, 3-18; Vasil'ev, A.F.: Novejక̌ie issledovanija po istorii promyšlennosti i raboxego klassa SSSR perioda Velikoj Orečestvennoj vojny, in: VI 1977, H. 6, 141-148; Vorožejkin, I.E./S.L. Senjavskij: Rabočij klass vedušcaja sila sovetskogo obšxestva (Voprosy metodologii i istoriografii), M. 1977; Piotrovskij/Tiškov, Itogi 1981, 7; Chromov, Aktual'nye problemy 1981, 8ff; Popov, V.G.: Sovetskaja istoriografija likvidacii bezrabotnicy v SSSR. Obzor, in: ISSSR 1981, H. 5, 184-188; Chromov/Buganov/Serstobitov, Nekotorye itogi, 14ff, Drobižev, V.Z.: Social'naja politika Sovetskogo gosudarstva i rabočij klass (Nekotorye itogi i zadači izučenija problemy), in: ISSSR 1984, H. 2, 71-84.

Zu wichtigen Standardwerken wurden: Raboxij klass SSSR (1951-1965 gg.), M. 1969; Raboxij klass SSSR (1966-1970 gg), M. 1979; Vdovin, A.I./V.Z. Drobižev: Rost rabočego klassa SSSR. 1917-1940, M. 1976. - Dieser Problematik war der größte Teil der 214 Habilitationsschriften und der 783 Promotionsarbeiten 1975 bis 1979 gewidmet: 63 (29,5\%) bzw. 186 (23,7\%) Stück; siehe Gusev/Drobižev/Pokrovskij, O podgotovke, 123 und 125.

$17 \mathrm{Vgl}$. Volkov, I.M.: Nekotorye voprosy istorii sel'skogo chozjajstva i krest'janstva v poslevoennye gody, in: ISSSR 1973, H. 1, 3-19; Kim/Poljakov, Istorija, 62ff; dies., Izučenie, 44ff; Volkov, I.M./V.P. Danilov/V.P. Serstobitov: Problemy istorii sovetskogo krest'janstva, in: ISSSR 1977, H. 3, 3-18; Zelenin, I.E.: Problemy kollektivizacii sel'skogo chozjajstva v SSSR v novejక̌ej sovetskoj istoriografii, in: ISSSR 1978, H. 1, 74-91; Davydov, Ju.S.N.K. Figurovskaja: Razvitie 
das staatliche Legitimationsbedürfnis befriedigen. Enorme Anstrengungen wurden unternommen, um die Gründung der Sowjetunion ${ }^{18}$ sowie die staatliche und kulturelle Integration ${ }^{19} \mathrm{zu}$ dokumentieren und zu legitimieren. Umfangreiche Neuerscheinungen wurden infolge der Jubiläen - 1970: die 100. Wiederkehr des Geburtstags Lenins; 1975/80: 30 und 35 Jahre nach dem Sieg im Weltkrieg - bei der „Leniniana ${ }^{\prime 20}$ und der Kriegsgeschichte ${ }^{21}$ verzeichnet. Was nicht in das gewünschte Heroenbild paßte, etwa die Neue Ökonomische Politik, das Schicksal der Verlierer in den revolutionären Umwälzungen, das Leid der Bevölkerung im Krieg aufgrund militärischer Führungsfehler, die sozialen und ökologischen Folgen der forcierten Industrialisienung, ganz zu schweigen vom staatlichen Terror und den Repressionen, wurde konsequent vernachlässigt oder ausgeblendet. Die für alle Fachzeitschriften und Forschungsinstitutionen gleichermaßen gültigen Leitlinien führten zur permanenten Doppelung, die auch durch die endlosen Koordinationsberatungen

agrarno-promyకlennoj integracii v SSSR, in: VI 1978, H. 8, 3-24; Kabanov, V.V.: Dokumenty po istorii kollektivizacii sel'skogo chozjajstva, in: ISSSR 1978, H. 5, 160-166; Piotrovskij/Tißkov, Itogi. 7f; Chromov/Buganov/Serstobitov, Nekotorye itogi, $20 f$.

Wichtige Standardwerke wurden die beiden Monographien von Viktor Petrovið Danilov: Sovetskaja dokolchoznaja derevnja: naselenie, semlepol'zovanie, chozjajstvo, M. 1977; ders., Sovetskaja dokolchoznaja derevnja: social'naja struktura, social'nye otnołenija, M. 1979.

$18 \mathrm{Vgl}$ die Artikelserie anläßlich des 50. Jahrestags der Staatsgründung in: VI 1972, H. 9-12; Kukuškin, Ju.S.: Problemy izučenija istorii sozdanija Sojuza SSR, in: ISSSR 1972, H. 6, 11-21; Zajceva, E.A.: Obrazovanie SSSR (Obzor dokumental'nych publikacij), in: ISSSR 1972, H. 3, 126-132; Bataeva, T.V.: Novye dokumental'nye izdanija po istorii obrazovanija Sojuza SSR, in: ISSSR 1974, H. 1, 189-194; Kim/Poljakov, Istorija. 73ff; Piotrovskij/Tiłkov, Itogi, 6; Sovetskie istoriki - K 60-letiju obrazovanija SSSR (Obzor literatury za 1981-1983 gg.), in: ISSSR 1984, H. 4, 60-80

19 Vgl. Zak, L.M.: Sovremennaja sovetskaja istoriografija o problemach nacional'no-kul'turnogo stroitel'stva, in: ISSSR 1971, H. 5, 82-95; Ermakov, V.T.: Sovetskaja kul'tura kak predmet istoriceskogo issledovanija, in: VI 1973, H. 11, 20-33; Kim, M.P.: O kul'ture kak predmete istoričeskogo izučenija, in: VI 1974, H. 11, 32-38; Kim/Poljakov, Istorija, 68ff; dies., Izučenie, 5 Iff; Kim. M.P.: Glavnaja zadača - sozdat' obobzcajuščij trud po istorii sovetskoj kul'tury, in: ISSSR 1976, H. 5, 240-243; Bromlej, Ju. V.: K izu飞̌eniju osnovnych etapov i napravlenij nacional'nych otnošenij v SSSR, in: ISSSR 1979, H. 2, 58-67; Piotrovskij/Tiłkov, Itogi, 9; Chromov/Buganov/Serstobitov, Nekotorye itogi, 23 und $26 \mathrm{ff}$.

20 1968 bis 1971 sollen allein in Russisch mehr als 13.500 Bücher und Aufsätze über Lenins Leben und Werk erschienen sein. Dazu und zur Mystifizierung Lenins insgesamt, siehe Ennker, B.: Ende des Mythos? Lenin in der Kontroverse, in: Geyer, Die Umwertung, 54-74, hier 56. Vgl. desweiteren Kim/Poljakov, Istorija, 68. - Innerhalb von zwölf Jahren erschien mit „Vladimir Il'ið Lenin. Biografičeskaja chronika 1870-1924“, M. 1970-1982, ein nützliches Nachschlagewerk in zwölf Bänden.

21 Zu der ausufernden sowjetischen Geschichtsschreibung, siehe Segbers, K.: Die Sowjetunion im Zweiten Weltkrieg. Die Mobilisierung von Verwaltung. Wirtschaft und Gesellschaft im "Großen Vaterländischen Krieg“ 1941-1943, München 1987, 20ff; vgl. ISSSR 1975, H. 1 und H. 3; Żilin, P.A.: Aktual'nye problemy issledovanija Velikoj Otexestvennoj vojny, in: VI 1977, H. 5. 3-23; ISSSR 1980, H. 3, 3ff. 
nicht vermieden wurden, und dazu, daß die Periodika ihre eigentlichen Schwerpunkte hintanstellen mußten. ${ }^{22}$

Die vorangegangenen Fußnoten zeugen auch von der Konjunktur der Historiographie im Sinne der Annotation konkret-historischer Forschungsarbeiten. Nachdem die historiographische Aktivität nach den Kampagnen zu Beginn der siebziger Jahre kurzzeitig ganz unterbrochen worden war, erlebte sie seit Mitte des Jahrzehnts einen neuen Aufschwung. Allerdings blieb die kritische Bemerkung von Neckina, Poljakov und Čerepnin aus dem Jahre 1962 gültig, die historiographischen Übersichten hätten bloß formalen Charakter. ${ }^{23}$ Es wurde weiterhin versäumt, die Historiographie zu nutzen, um auf der Grundlage der wissenschaftlichen Bilanz die theoretisch-methodologischen Fundamente der historischen Forschung zu analysieren. Anstatt die in den sechziger Jahren begonnenen Diskussionen über methodologische und gnoseologische Probleme der historischen Disziplin weiterzufuihren und in Verbindung mit dem Quellenmaterial und dem Forschungsstand zu konkretisieren, wandten sich die Historiographen meta-theoretischen Fragen zu. Anstatt die Methodologie der historischen Forschung zu entwickeln, begannen sie über die Methodologie der historiographischen Arbeit nachzudenken. Ging es in den sechziger Jahren um den Gegenstand der Geschichtswissenschaft, um die historische Tatsache, um die Prinzipien von Parteilichkeit und Historismus in der historischen Forschung, so diskutierten in den siebziger Jahren die Historiographen über den Gegenstand der Historiographie, die historiographische Tatsache, über Parteilichkeit und Historismus bei der historiographischen Analyse und Kritik usw. ${ }^{24}$ Auch wenn man über die beiden zentralen Fachzeitschriften hinaus den Blick auf die zahlreichen Aufsätze und Monographien von Autoren wie A.K. Cemenko, N.M. Dorošenko, A.M. Gugnin, A.V. Gulyga, V.V. Ivanov, V.V Kosolapov, N.G. Kozin, E.N. Loone, B.G. Mogil'nickij, N.K. Smolenskij, A.I. Uvarov, E.M. Zukov und anderen richtet, erhellt sich das düstere Bild nur unwesentlich; denn in deren Arbeiten, die vor allem in der zweiten Hälfte der siebziger Jahre erschienen sind und die im 6. Kapitel teilweise mitberücksichtigt werden, wurden in der Regel nur die De-

22 So mußten „VI“ und „ISSSR“ beispielsweise ebenfalls intensiv über die internationale Arbeiter- und Gewerkschaftsbewegung, über die Parteigeschichte und über den „Großen Vaterländischen Krieg“ publizieren, obwohl es dafur eigentlich die Fachzeitschriften fur „Neuere und Neueste Geschichte“, „Fragen der Geschichte der KPdSU“ und die "Militärgeschichtliche Zeitschrift“ gab. Vgl. auch Vručenie žurnalu „Voprosy istorii“ ordena Trudovogo Krasnogo Znamenii, in: VI 1978, H. 1, 3-12, hier 9.

23 Das gab Sacharov, A.M.: O predmete istoriograficeskich issledovanij, in: ISSSR 1974, H. 3, 90-112, hier 90, offen zu. Vgl. Neckina/Poljakov/Cerepnin, O projdennom puti, 31.

$24 \mathrm{Vgl}$. Sacharov, O predmete, 93ff; Gorodeckij, E.N.: Istoriografija kak special'naja otrasl' istoriceskoj nauki, in: ISSSR 1974, H. 4, 96-116; Neckina/Gorodeckij, Istoriograficeskie issledovanija (vgl. die Übersetzung bei Donnert, E./A. Anderle ( $\mathrm{Hg}$.): Studien zur Geschichte und Theorie der Geschichtswissenschaft in der UdSSR, Halle 1981, 5-33); Sacharov, A.M.: Nekotorye voprosy metodologii istoriografičeskich issledovanii, in: Voprosy metodologii i istorii istoričeskoj nauki, M. 1977, 5-59; Metodologið̌eskie i teoretiðeskie problemy istorii istoričeskoj nauki. Mežvuzovskij tematičeskij sbornik, Kalinin 1980; Zevelev, A.I./V.P. Naumov: Istoriografičeskij fakt: Kriterii ocenki i analiza, in: VI 1980, H. 5, 18-30. 
batten der sechziger Jahre mehr oder weniger zutreffend rekapituliert und die alten. systemkonformen Thesen zusammengefaßt.

Die Lenkung der Geschichtswissenschaft erfolgte in den siebziger Jahren stärker denn je im Rhythmus der Parteitage, denn - so die offiziell verkündete Auffassung - sie sind ,historische Meilensteine“, ${ }^{25}$ und es gibt nicht eine Seite in der Tätigkeit sowjetischer Bürger außerhalb ihres direkten Einflusses. ${ }^{26}$ Seit dem Ende der sechziger Jahre ging man dazu über, die geschichtswissenschaftliche Arbeit von Parteitag zu Parteitag im Rahmen der dort jeweils beschlossenenen Fünfjahrpläne zu konzipieren und zu rekapitulieren. Daraus gingen unter anderem jene staubtrokkenen Annotationen hervor, in denen die publizistischen Ergebnisse der Geschichtswissenschaft seit dem jeweils letzten Parteitag zusammengestellt wurden. ${ }^{27}$ Jede erdenkliche Gelegenheit wurde genutzt, um auf die „Fehler“ der Methodologiesektion Gefters und besonders der „Neuen Richtung“ hinzuweisen und damit die Notwendigkeit zu begründen, das, ,ideologisch-theoretische Niveau“ der Arbeit zu heben. ${ }^{28}$ Der 25. Parteitag der KPdSU (24. Februar-5. März 1976) wiederholte die bekannten Formeln der „entwickelten sozialistischen Gesellschaft“ und des „Sowjetvolks" und verlangte somit von den Historikern keine Neuorientierung. ${ }^{29}$ Als

25 Gusev, K.V.: XXIV s-ezd KPSS i otečestvennaja istoriografija, in: ISSSR 1971, H. 3, 3-12, hier 3.

26 7.ukov, E.M: Osnovnye itogi i zadaci istoriðeskich issledovanij v svete rešenij XXV šezda KPSS, in: VI 1976, H. 4, 3-14, hier 3.

27 Vgl. Razvitie 1975; Izučenie otečestvennoj istorii v SSSR mež.du XXIV i XXV s-ezdami KPSS, M. 1978; Sovetskaja istoričeskaja nauka 1980; Izučenie 1982; Izučenie istorii sovetskogo obšcestva v 1980-1984 godach. Sbornik statej, M. 1985.

28 Vgl. Laveryčev, V.Ja: $K$ voprosu ob osobennostjach imperializma v Rossii, in: ISSSR 1971, H. 1, 75-90; Kostrikin, V.I./A.P. Tjurina: Naučno-issledovatel'skaja rabota instituta istorii SSSR AN SSSR v 1972 godu, in: ISSSR 1973, H. 3, 237-241, hier 241; Kostrikin, V.I.: Perspektivy naučno-issledovatel'skoj raboty instituta istorii SSSR AN SSSR v 1976-1980 gody, in: ISSSR 1974, H. 6, 238-240, hier 238; Minc, I.I.: Velikij Oktjabr' - povorotnyj punkt $v$ istorii čeloveCestva (Nekotorye itogi i zadaci izučenija problemy), in: ISSSR 1975, H. 6, 3-21, hier 10; Sobolev, P.N.: Razrabotka osnovnych problem istorii Velikoj Oktjabr'skoj socialističeskoj revoljucii i graždanskoj vojny, in: ISSSR 1976, H. 1, 220-223; Naroxnickij, A.L./V.I. Buganov/V.P. Serstobitov: XXV s-ezd KPSS i zadači izučenija otečestvennoj istorii, in: ISSSR 1976, H. 2, 3-21, hier 6; Laveryčev, V.Ja.: V.I. Lenin ob istoričeskom značenii gosudarstvenno-monopolističeskogo kapitalizma, in: ISSSR 1978, H. 1, 43-55; Kuznecov, I.V.: Ob ukladach i mnogoukladnosti kapitalisticeskoj Rossii, in: VI 1974, H. 7, 20-32; VI 1975, H. 8, 150ff; 1979, H. 2. 145-147.

Bei der Zurückweisung der Thesen über die relative Unreife des russischen Proletariats und den zeitweiligen Hegemonieverlust gingen die Kritiker so weit zu behaupten. die Arbeiterklasse sei Hegemon der Bewegungen in allen drei russischen Revolutionen gewesen. - Volin, M.S. et al.: O gegemonii proletariata v pervoj russkoj revoljucii, in: ISSSR 1973, H. 4, 48-67; die Rezension des Sammelbandes "Gegemonija proletariata $v$ trech russkich revoljucijach" (M. 1975) von S.A. Artem'ev und A.Ja. Utenkov in VI 1977, H. 3, 153-156, hier 154.

29 Vgl. Narőnnickij/Buganov/Serstobitov, XXV s-ezd, 4f; Zukov, Osnovnye itogi. 3f und 12; sowie den Bericht über Naroxnickijs Redebeitrag bei der Jahreshauptversammlung der Geschichtsabteilung der AdW am 16.03.1976 in: VI 1976, H. 6, 137f. - Auch Rosenfeld/Schützler, 
Voprosy istorii 50 Jahre alt wurde, bestätigte Anatolij Sacharov in seinem Rückblick die vorherrschende konservative Haltung: kein Stalinismus, kein AntiStalinismus, aber stillschweigend an Stalin angelehnte Wertungen. So konstruierte Sacharov wieder einen Gegensatz zwischen den Geschichtskonzeptionen Lenins und Pokrovskijs und bewertete die Maßnahmen der Stalinschen Führung 1934 sowie den Antirevisionismus von 1957ff positiv. ${ }^{30}$

Der 60. Jahrestag der Oktoberrevolution versetzte die Geschichtswissenschaft in eine Art Ausnahmezustand. 1977 war die gesamte historische Disziplin von diesem Jubiläum geprägt. ${ }^{31}$ Wieder und wieder wurden die Ergebnisse der Revolutionsforschung resümiert und die künftigen Aufgaben und Perspektiven dargelegt. ${ }^{32}$ Dezidiert wurden die Positionen der ,Neuen Richtung“ zurückgewiesen ${ }^{33}$ Forschungskontroversen wurden bei den Feierlichkeiten nicht zugelassen. Neu war zu dieser Zeit allenfalls die intensivere Erforschung der Entwicklung nichtproletarischer Parteien während der drei russischen Revolutionen; eigentlich entsprach dies einer lobenswerten Themenergänzung, die allerdings erneut nur genutzt wurde, um weitere Belege gegen die Thesen der „Neuen Richtung“ zu sammeln. ${ }^{34}$ Nach dem 60. Jahrestag fält auch ein zusätzliches „Argument“ - aus dem ideologischen Arsenal Stalins - für die extreme Indienstnahme der Geschichtswissenschaft durch die Kommunistische Partei auf. Wie bisher wurden die Forderungen an die Historie mit dem kommunistischen Aufbau begründet. „Neu“ war seit 1977 der ständige Hinweis auf den sich verschärfenden ideologischen Kampf, der es erfordere, alle Revi-

Kurze Geschichte, 213f, schrieben: „Der XXV. und der XXVI. Parteitag standen im Zeichen seiner (der des XXIV. Parteitags; J.H.) Kontinuität.“

30 Siehe Sacharov, A.M.: Zurnalu „Voprosy istorii“ - 50 let, in: Vl 1976, H. 6, 3-19, hier besonders 6ff; in verfälschender Weise berief Sacharov sich im ersten Punkt auf Nexkina, obwohl gerade sie sich gegen diese Wertung, die von Najdenov Anfang der sechziger Jahre vertreten wurde, gewandt hatte. Vgl. Kapitel 4.2.3.

31 .Es ist anzunehmen, daß ohne Ausnahme alle wissenschaftlichen Kollektive und Problemräte aktiv an der Vorbereitung zu diesem allgemeinen Feiertag des ganzen Volkes teilnehmen." So äußerte sich der „erste“ Historiker im Lande, Evgenij Zukov, am 16.03.1976 in der Versammlung der Geschichtsabteilung der AdW der UdSSR; Zukov, Osnovnye itogi, 10. Vgl. VI 1977, H. 9. 15Iff, H. 11, 166ff: ISSSR 1978, H. 1, 222ff.

32 Vgl. Gorodeckij, Sovremennaja sovetskaja literatura; Golub, P.A.: Voennaja podgotovka Velikogo Oktjabrja (Leninskaja voennaja programma i ee osušcestvlenie), in: VI 1977, H. 7, 325; Demoxkin, N.N.: Velikij Oktjabr i roždenie sovetskoj socialistǐ̌eskoj demokratii, in: VI 1977, H. 8, 3-20; Naumov, Osnovnye Certy.

33 Siehe etwa Naumov, Osnovnye certy, 60ff; Gaponenko, L.S.: Rešajušcaja sila Velikogo Oktjabrja, M. 1977 (Rezension in VI 1978, H. 9, 140-142).

34 Ganz offen schrieb G.L. Sobolev: „Die ernsthafte Erforschung nichtproletarischer Parteien Rußlands begann vor relativ kurzer Zeit, aber jetzt kann mit vollem Recht über wesentliche Erfolge bei der Lösung dieses wichtigen und vielschichtigen Problems gesprochen werden. Die sowjetischen Historiker zeigten überzeugend, daß Rußland sowohl ökonomisch als auch politisch für den Übergang von der bürgerlich-demokratischen zur sozialistischen Revolution vorbereitet war." - Sobolev, G.L.: Važnoe napravlenie v istoriografii Velikogo Oktjabrja, in: VI 1982, H. 8, 118-123, hier 118. Vgl. VI 1979, H. 7, 49ff; H. 8, 116ff: 1981, H. 10, 115ff; ISSSR 1981, H. 6, 225ff 
sionsversuche entschieden zurückzuweisen und streng parteiliche populärwissenschaftliche Arbeiten als Agitationsmaterial zu verfassen. ${ }^{35}$

In den Beiträgen zur Zusammenfassung der Forschungsergebnisse im 10. Planjahrfüft (1976-1980) und zur Auswertung des 26. Parteitags der KPdSU (23. Februar-3. März 1981) wurde behauptet, in der zweiten Hälfte der siebziger Jahre seien geschichtsmethodologische Forschungen und Diskussionen besonders wichtig und prägend gewesen. ${ }^{36}$ Das stimmte zwar überein mit dem 1974 beschlossenen Arbeitsplan, in dem die ,Ausarbeitung methodologischer und historiographischer Probleme" an die erste Stelle gerückt war ${ }^{37}$ allerdings zeugten die Fachzeitschriften und die Bibliographien davon, da $B$ auch in dieser Zeit die Geschichtstheorie und -methodologie sträflich vernachlässigt wurden. Den einzigen Lichtblick während der siebziger Jahre stellten die Beiträge von Michail Barg dar, der mit bemerkenswerter Ausdauer geschichtstheoretische und -methodologische Probleme erörterte. $^{38}$ Seine Wortmeldungen blieben jedoch weitgehend ohne Widerhall. In die offizielle Sprachregelung wurde lediglich Bargs Forderung aus den sechziger Jahren übernommen, endlich auf der Grundlage der geleisteten Materialakkumulation die theoretischen Diskussionen und Analysen zu intensivieren, um fundierte Synthesen formulieren zu können. Ohne den von Barg vorausgesetzten offenen Disput blieb das eine Floskel. ${ }^{39}$

Die sowjetische Geschichtswissenschaft war in dieser Etappe desweiteren davon geprägt, daß der internationalen Entspannungspolitik entsprechend bessere Kontakte mit Kollegen im ,kapitalistischen Ausland" gesucht und gepflegt wurden. Die

33 Chromov, S.S.: Idejno-vospitatel'nye funkcii sovetskoj istoričeskoj nauki, in: VI 1980, H. 7, 3-19; Titov, A.I.: Zasedanie Otdelenija istorii v Leningrade, ebd., 125-127, hier 125. Vgl. VI 1978, H. 5, $127 \mathrm{ff}$.

36 „Wichtigste Richtung der wissenschaftichen Forschungen im Bereich der Geschichte im vergangenen Jahrfünt war die weitere Ausarbeitung von Fragen der Geschichtsmethodologie. und vor allem der allgemeinen Konzeption der Welt- und der vaterländischen Geschichte." Piotrovskij/Tiß̌kov, Itogi, 4. Vgl. auch Osnovnye napravlenija, 4f.

39 Kostrikin, V.I.: Perspektivy naurno-issledovatel'skoj raboty instituta istorii SSSR AN SSSR v 1976-1980 gody, in: ISSSR 1974, H. 6, 238-240, hier 238.

38 Barg. M.A.: O nekotorych metodach tipologizacii istorizeskich javlenij $v$ trudach V.I. Lenina, in: ISSSR 1973, H. 2, 21-41; ders., Istoričeskij fakt: struktura, forma, soderžanie, in: ISSSR 1976, H. 6, 46-71; ders., Istoriceskie zakonomernosti kak poznavatel'naja cel' istoriðeskoj nauki, in: ISSSR 1979, H. 1, 96-120; ders., Kategorii „vsemirno-istoričeskij“ i „Iokal'noistoričeskij" v marksistsko-leninskom istorizme, in: VI 1980, H. 1, 61-78; ders., Princip sistemnosti $v$ marksistskom istoriceskom issledovanii, in: ISSSR 1981, H. 2, 78-98; ders., O kategorii , istoriceskoe vremja" (Metodologiceski aspekt), in: ISSSR 1982, H. 6, 82-100; ders., Istoričeskoe soznanie kak problema istoriografii, in: VI 1982, H. 12, 49-66. - Seine und die vereinzelten Arbeiten anderer Autoren werden im 6. Kapitel berücksichtigt.

39 „Das gewaltige Tatsachenmaterial zur Geschichte der sowjetischen Gesellschaf, das in zahlreichen konkret-historischen Arbeiten und Dokumentarpublikationen enthalten ist, verlangt immer dringlicher den verallgemeinernden, problemorientierten Zugang " - Poljakov, Ju.A.IV.P. Dmitrenko: Issledovanie kompleksnych problem istorii sovetskogo ob cestva. in: ISSSR 1977, H. 2, 194-198, hier 194. Vgl. Osnovnye napravlenija, 4 
Teilnahme an den Internationalen Historikerkongressen war inzwischen wieder selbstverständlich, und sie wurde in den sowjetischen Periodika mit Genugtuung als Zeichen des wachsenden Einflusses des marxistisch-leninistischen Gesellschaftsund Geschichtsverständnisses gedeutet. ${ }^{40}$ Auch die Treffen mit französischen und italienischen Kollegen waren in den siebziger Jahren nichts Neues mehr. ${ }^{41}$ Mit finnischen Historikern fanden - nach ersten Kontakten seit 1966 - seit 1971 regelmäßig Kolloquien statt. ${ }^{42} 1973$ trafen sich namhafte sowjetische Historiker erstmals mit Geschichtswissenschaftlern der Vereinigten Staaten von Amerika, Japans und der BRD. ${ }^{43}$ An der Isolation der historischen Zunft in der Sowjetunion änderte das allerdings wenig; das Gros der Historikerinnen und Historiker blieb davon unberührt.

Gegen Ende der siebziger und zu Beginn der achtziger Jahre veröffentlichte die Zeitschrift Istorija SSSR wieder häufiger kurze Informationen über Treffen von Redaktionsmitgliedern mit Lesern, also Historikern in Moskau, Leningrad und anderen Universitätsstädten. ${ }^{44}$ Vielleicht wollte man in der Redaktion wirklich auf dieses Mittel, das Pankratova und Burdžalov in den fünfziger Jahren zur Ankurbelung von Diskussionen genutzt hatten, zurückgreifen, um die in der Routine der Parteitagsauswertung und Jubiläumsvorbereitung gelähmten Historikerinnen und

$10 \mathrm{Vgl}$. Guber, A.A.: Moskovskij kongress istorikov, in: VI 1970, H. 3, 3-11; ders., XIII mex.dunarodnyj kongress istoričeskich nauk $v$ Moskve (nekotorye itogi i perspektivy), in: $\mathrm{VI}$ 1971, H. 6, 3-16; Pasuto, V.T./Ju.A. Poljakov: Voprosy istorii SSSR na XIII Mełddunarodnom kongress istorikov, in: ISSSR 1971, H. 1, 3-22; Tiłkov, V.A.: Predstojašij XIV meždunarodnyj kongress istoriceskich nauk, in: ISSSR 1975, H. 1, 242-245; Cubar'jan, A.O.: Sovetskie istoriki i XIV meždunarodnyj kongress istoriceskich nauk, in: VI 1975, H. 6, 62-75; Istorija i obšcestvo, in: VI 1977, H. 1, 3-29; Tichvinskij, S.L./V.A. Tiškov: XV Meždunarodnyj kongress istoričeskich nauk, in: VI 1980, H. 12, 3-23; Pašuto, V.T./Ju.A. Poljakov/S.S. Chromov: Nekotorye problemy otečestvennoj istorii i prepodavanija istorii $v$ škole na XV meždunarodnom kongresse istorikov, in: ISSSR 1981, H. 5, 115-130; Dudzinskaja, E.A.: Meźdunarodnye svjazi sovetskich istorikov, M. 1978 (Rezension in: VI 1979, H. 3, 15 Iff). - Sehr guten Überblick auch zur Bedeutung der Aktivität sowjetischer Historiker auf internationalen Foren bietet Erdmann. Die Ökumene.

41 Die erste französisch-sowjetische Historikerkonferenz hatte bereits 1958 in Paris stattgefunden. Es folgten Konferenzen in Moskau $(1961,1973,1978)$, Paris $(1966,1971,1976,1983)$ und Erevan (1969); siehe VI 1979, H. 1, 145ff; ISSSR 1984, H. 4, $210 f$ f.

Mit italienischen Historikern trafen sich die sowjetischen 1972 bereits zum funftenmal; vgl. VI 1975, H. 8, 161.

42 In erster Linie ging es um die sozial-ökonomische Geschichte beider Länder; vgl. VI 1978, H. 8, 179f; 1979, H. 6, 149f, 1983, H. 2, $161 \mathrm{ff}$.

43 Vgl. VI 1975, H. 8, 161. - Dem folgten auch hier weitere Kolloquien: mit den USAmerikanern 1975 in Stanford, 1978 in Moskau, 1981 in Princeton (vgl. VI 1976, H. 1, 174f; 1979, H. 7, 158ff; ISSSR 1982. H. 1, 194ff), mit den Japanern 1975 in Tokio (VI 1976, H. 6, 138) und mit den Bundesdeutschen 1975 in Leningrad, 1978 in München (vgl. ISSSR 1975, H. 5, $216 \mathrm{ff}$, VI 1978, H. 8, 175ff).

4 Vgl. ISSSR 1973, H. 6, 220f; 1977, H. 3, 225f; 1978, H. 1, 225f; 1979, H. 5, 232ff; 1980, H. 2, 232ff; 1980, H. 6, 210ff; 1981, H. 3, 229ff; H. 5, 235; 1983, H. 12, 209ff. - In Voprasy istorii finden sich in der gleichen Zeit nur zwei solche Berichte: VI 1976, H. 8, 162ff; 1981, H. 1, 146ff. 
Historiker zu mobilisieren. In den Berichten war allerdings fast nur stereotypes Lob über die Arbeit der Zeitschrift zu lesen. Wenn überhaupt Kritik laut wurde, dann bezog sie sich auf die Vernachlässigung historiographischer und geschichtsmethodologischer Themen.$^{45}$ Echte Anstöße lieferten auch diese Veranstaltungen nicht.

45 Typisch etwa: ISSSR 1980, H. 2, 232; H. 6, 211; 1981, H. 5, 235. 


\subsection{Die Ideologiediskussion der KPdSU 1983 und die Trägheit der historischen Disziplin}

Der neue Generalsekretär der KPdSU Jurij Andropov nutzte seine Rede zur 100. Wiederkehr des Todestags von Karl Marx, um die Modifikation der bisherigen Konzeption der „entwickelten sozialistischen Gesellschaft" vorzustellen: Der entwickelte Sozialismus sei kein schnell zu passierender Übergang zum Kommunismus, sondern eine eigenständige historische Etappe in der kommunistischen Formation. Diese Gesellschaft verfuge über genuine ökonomische Grundlagen und politisch-soziale Strukturen. Die bevorstehenden Aufgaben ließen sich bezeichnen als „Vervollkommnung des entwickelten Sozialismus“. Ausdrücklich betonte Andropov, daß das Land ,am Anfang dieser langen historischen Etappe“ stehe. ${ }^{1}$ Um die Gesellschaftswissenschaftler auf die Ausarbeitung der neuen Konzeption - mit besonderer Berücksichtigung des Aspekts der Vervollkommnung - zu orientieren, beendete die Parteiführung auch den Streit der Philosophen über das sogenannte

1 Siehe Andropov, Ju.: UCenie Karla Marksa i nekotorye voprosy socialističeskogo stroitel'stva SSSR, in: K 1983, H. 3, 9-23, hier nach der Beilage der Zeitschrift „Sowjetunion heute“ 1983, H. 4, 1-VIII, besonders VII. Vgl. zur besseren Einordnung dieser Korrektur in der langjährigen Entwicklung der Konzeption Dmitrenko, V.P.: Stanovlenie koncepcii razvitogo socializma v SSSR, in VI 1984, H. 8, 3-22; Dahm, H.: Die Ideologie als Chiffre der Politik, in: Sowjetunion 1984/85. Ereignisse, Probleme, Perspektiven, München-Wien 1985, 73-83; ders., Sozialistische Krisentheorie. Die sowjetische Wende - ein Trugbild. München 1987, hier besonders 43ff; Ahlberg. $R$.: Die sowjetische Gesellschaftstheorie in der Mitte der achtziger Jahre, in: OE 1986, H. 5, 339-355.

Ahlberg ignorierte allerdings, daß die Konzeption des entwickelten Sozialismus sich seit Beginn der sechziger Jahre in der marxistisch-leninistischen Terminologie eingebürgert hatte und bereits 1967/71 zur offiziellen Formel geworden war; er datierte um ein Jahrzehnt zu spät, als er schrieb: „Die klassische Sozialismusidee ist im Verlauf der siebziger Jahre von einer modernen, realistischen Konzeption abgelöst worden." - Ahlberg. Die sowjetische Gesellschaftstheorie, 339; vgl. Dmitrenko, Stanovlenie, 7ff.

Dahm brachte eigenartigerweise Cernenko mit den aufgeschlosseneren Philosophen in Verbindung die von antagonistischen Widersprüchen sprachen. Cernenko habe im September 1981 die Diskussion über Widersprüche im Sozialismus ermuntert; unter Andropov sei jedoch die dogmatische Richtung wieder ,auf der ganzen Linie“ durchgesetzt worden, und C.ernenko habe sich der "Rückkehr zum ideologischen Rigorismus und Prinzipalismus" unterordnen müssen (Kursiv bei Dahm. Sozialistische Krisentheorie, 45; J.H.). Dahm konnte nicht schlüssig erklären, warum auch unter dem vermeintlich progressiveren Cernenko soziale Antagonismen als "dem Sozialismus wesensfremd" galten. Der Vergleich der Reden beider Funktionäre, das Verschleppen der unter Andropov eingeleiteten Reformen in der Amtszeit Cernenkos, die Aussagen von Zeitzeugen über die beiden Generalsekretäre usw. geben m.E. keinen Anlaß dazu, den Thesen Dahms zu folgen. - Vgl. etwa Tschernajew, A.: Die letzten Jahre, 13ff.

In der DDR übernahm die SED-Führung - namentlich der für Ideologie verantwortliche Kurt Hager - 1983 umgehend die neue sowjetische Position und sprach fortan sogar von ,antagonistischen Widersprüchen im Sozialismus". Diese zur Kenntnis zu nehmen und zu analysieren hatte Jürgen Kuczynski bereits Anfang der siebziger Jahre angeregt. Der Wirtschafts- und Gesellschaftswissenschaftler hatte daraufhin Druckverbot für diese These bekommen. Siehe Kuczynski, „Ein linientreuer Dissident“", $250 \mathrm{f}$. 
Widerspruchsproblem. ${ }^{2}$ Andropov setzte sein salomonisch anmutendes Urteil durch, wonach es im Sozialismus ,sowohl Widersprüche als auch Schwierigkeiten", aber keine Antagonismen gebe; doch auch nichtantagonistische Widersprüche könnten „ernsthafte Kollisionen hervorbringen (...), wenn sie nicht beachtet werden." Sie müßten als "Quelle und Ansporn" genutzt werden. ${ }^{3}$

Bei dem ZK-Plenum der KPdSU am 14. Juni 1983 schloß sich Konstantin Cernenko, der zusammen mit Michail Gorbačev seit dem Tode Suslovs verantwortlich war für die Ideologie der Partei, der These an, daß die sowjetische Gesellschaft erst am Anfang der historisch langen Etappe des entwickelten Sozialismus stehe. ${ }^{4}$ Am darauffolgenden Tag legte der neue Generalsekretär nachdrücklicher als Cernenko dar, da $B$ es nicht blo $B$ um neue propagandistische Anstrengungen, sondern um die schonungslose Prüfung bisheriger Positionen, um die objektive Analyse der bestehenden Probleme und die Neuformulienung der ideologischen Positionen auch im Parteiprogramm gehe. ${ }^{5}$ Andropov sprach offen aus, daß „einige“ der Aussagen im Parteiprogramm, ,...) die Prüfung durch die Zeit nicht in vollem Umfang bestanden (...)“ hätten und es jetzt darum gehe, eine ,(...) realistische Analyse der gegenwärtigen Situation und klare Orientierungen für die Zukunft (...) “ zu erarbeiten. ${ }^{6}$ Andropov revidierte die Legende, Partei und kommunistische Wissenschaftler verfügten unbeirrbar über die richtigen Erkenntnisse:

„(...) wenn wir aufrichtig sind, müssen wir sagen, daß wir die Gesellschaft, in der wir leben und arbeiten, noch nicht im erforderlichen Maße erforscht und die ihr innewohnenden Gesetzmäßigkeiten, insbesondere die ökonomischen, noch nicht voll-

\footnotetext{
2 Vgl. die in der DDR erschienenen Übersetzungen der 1982/83 in der sowjetischen Fachzeitschrift ,Fragen der Philosophie", in Kommunist und in der Pravda veröffentlichten Diskussionsbeiträge: Semjonow, W.S. (= Semenov, V.S.): Das Widerspruchsproblem im Sozialismus, in: SW 1983, H. 1, 16-31; ders., Zur theoretischen Vertiefung und Konkretisierung des Widerspruchsproblems im entwickelten Sozialismus, in: SW 1984, H. 4, 368-378; Butenko, A.P.: Widersprüche der Entwicklung des Sozialismus als Gesellschaftsordnung in: SW 1983, H. 2, 226-251; ders., Noch einmal über die Widersprüche im Sozialismus, in: SW 1984, H. 4, 360-367; Kossolapow, R.: Sozialismus und Widersprüche, in: SW 1984, H. 6, 588-594; Kusmenko, W.: Diskussionen, Kritik und Selbstkritik in den Gesellschaftswissenschaften. Einige Randbemerkungen, in SW 1985, H. 2, 189-198.
}

Es hatte in der Auseinandersetzung drei Positionen gegeben: a) im Sozialismus wirkten lediglich die Widersprüche der alten Gesellschaftsordnung nach (so die traditionelle Auffassung unter Berufung auf den von Marx geprägten Begriff von den „Muttermalen der alten Gesellschaft“ (vgl MEW 19, 20), die der Sozialismus aufweise); b) es gebe genuine, nichtantagonistische Widersprüche der sozialistischen Produktionsweise (dies war laut Kuz'menko die Mehrheitsmeinung während der Diskussion, vgl. Kusmenko, Diskussionen, 189ff); c) diese Widerprüche hätten antagonistischen Charakter (zu dieser Ansicht gelangte Butenko, vgl. Butenko, Widersprüche, 226ff und ders., Noch einmal über die Widersprüche, 360ff).

3 Vgl. in der Beilage der Zeitschrift "Sowjetunion heute" 1983, H. 4, VIf.

4 Siehe Auf dem Wege des Friedens und des Fortschritts. Dokumente, in: Beilage der Zeitschrift „Sowjetunion heute“ 1983, H. 7, IX.

s Ebd., IIff.

6 Ebd 
ständig aufgedeckt haben. Deshalb sind wir zuweilen gezwungen, sozusagen empirisch, auf recht irrationale Weise, mit Versuchen und Fehlem, zu handeln."

Die Verantwortlichen in der Geschichtswissenschaft reagierten umgehend und pflichtschuldig auf die neuen, kritischen Parteiaussagen. Erwähnt sei dabei, daß die für die Geschichte der KPdSU zuständigen Institutionen und Historiker das ZKPlenum besonders intensiv auswerteten. Insbesondere diskutierten die "Partei“Historiker unter unmittelbarem Bezug auf die Thesen des Zentralkomitees über die Erforschung und Nutzung der historischen Erfahrung (opyt) der KPdSU. ${ }^{9}$ Für die Historikerinnen und Historiker der sowjetischen Geschichte und Gesellschaft leitete die Führung der Akademie der Wissenschaften die Auswertung ein. Zu Recht bezeichnete Dietrich Geyer diesen Vorgang im Jahr 1983 als typisches Beispiel eines Entscheidungsprozesses bei vorsichtigen Planungskorrekturen in der historischen Forschung: Nach dem ZK-Plenum am 14. und 15. Juni tagte am 30. Juni das Präsidium der Akademie. In mehreren Sitzungen in den Monaten Juni, September und Oktober befaßte sich das Büro der Geschichtsabteilung mit den Thesen des ZK-Plenums. Am 20. September schließlich wurden die wissenschaftlichen Kollektive der Geschichtsabteilung in einer allgemeinen Versammlung mit den neuen Direktiven vertraut gemacht. ${ }^{10}$ Akademischer Sekretär war seit dem 1. März 1982 Sergej Tichvinskij ${ }^{11}$. Er prägte nun die Auswertung der neuen Parteivorgaben ent-

1 Ebd., VI. - Andropov dürfte nichts geahnt haben von der Prägnanz seiner Annahme, „(...) daß die bevorstehenden Jahre und Jahrzehnte beträchtliche Veränderungen auch im politischen und ideologischen Überbau. im geistigen Leben der Gesellschaft mit sich bringen werden." Ebd., V

8 Siehe Maslov, N.N.: Nekotorye aktual'nye voprosy metodologii istoriografii istorii KPSS, in: Metodologixeskie problemy istoriko-partijnoj istoriografii (Materialy naux̌noj konferencii), $M$. 1984, 3-15; VIKPSS 1983, H. 8, 18-35; H. 11, 3ff; 1984, H. 2, 138-142; H. 7, 22-36.

9 Siehe Maslov, N.N./V.S. Ovčinnikov: Istoričeskij opyt KPSS: Problemy issledovanija i praktiCeskogo primenenija, in: VIKPSS 1984, H. 6, 59-72; Sovokin, A.M.: V.1. Lenin ob istoričeskom opyte, in: VIKPSS 1984, H. 10, 31-43; Varß̌avčik, M.A.: K voprosu o strukture i funkcijach istoričeskogo opyta KPSS, in: VIKPSS 1984, H. 10, 44-52; Ivanov, V.V.: Leninskaja metodologija obobšxenija istoričeskogo opyta partii i poznanija sovremennosti, in: VIKPSS 1985, $H$. 1, 50-60; Cernyšev, B.V.: V.I. Lenin o značenii urokov istorii dlja razrabotki politiki Kommunističeskoj partii, in: VIKPSS 1985, H. 3, 63-73; Titov, A.G.: Nekotorye voprosy osvešcenija i primenenija istoričeskogo opyta KPSS, in: VIKPSS 1985, H. 7, 30-40; Vaganov, F.M.: K voprosu o sušx̌nosti i značenii istoričeskogo opyta KPSS, in: VIKPSS 1985, H. 8, 61-70; Meženin, N.M.: O marksistsko-leninskom ponimanii istoriceskogo opyta KPSS i ego ispol'zovanii $v$ sovremennych uslovijach, ebd., 71-82.

10 Geyer, Klio, 31.

11 Sergej Leonidovic Tichvinskij, geboren am 01.09.1918 in Petrograd, studiente Sinologie und Geschichte. 1939 bis 1957 bekleidete er diplomatische Ämter in China, England und Japan. Anschließend leitete er die Asien-Abteilung des Staatskomitees für internationale Kulturbeziehungen beim Ministerrat der UdSSR. Er habilitierte sich - für sowjetische Verhältnisse außerordentlich frühzeitig - im Alter von knapp 35 Jahren im Juni 1953. Seit Beginn der sechziger Jahre übernahm er leitende Funktionen in der Geschichtswissenschaft: er war Direktor des Akademieinstituts für Sinologie, Stellvertretender Direktor des Instituts für die Völker Asiens und des Instituts für die Wirtschaft des sozialistischen Weltsystems; er leitete den Lehrstuhl für die Geschichte der Völker des Ostens in dem Moskauer Staatsinstitut für internationale Beziehungen beim Au- 
scheidend mit, und er war der erste Akademische Sekretär, der in seinen Stellungnahmen der Kritik mehr Raum gewährte als dem (Eigen-) Lob. Kürzer als bisher gewohnt zählte Tichvinskij die Leistungen der historischen Zunft auf, um sich ausfuihrlicher der kritischen Bewertung zuzuwenden. ${ }^{12}$ Bei der Abteilungsversammlung am 20. September 1983 konzentrierte Tichvinskij sich auf fünf Felder: ${ }^{13} \mathrm{Er}$ stens die Anhebung des theoretisch-methodologischen Forschungsniveaus; hier geißelte Tichvinskij den verbreiteten Empirismus, die Engstirnigkeit, belanglose Verallgemeinerungen und schematisches Soziologisieren. Vernachlässigt würden die Konzeption des entwickelten Sozialismus, die Prinzipien und Methoden des marxistisch-leninistischen Historismus, der vergleichenden Formations- und Revolutionsforschung und die inhaltliche Ausfüllung solcher Kategorien wie ,soziale Revolution“, „Weltrevolution“, „Allgemeines und Besonderes“, „Nationales und Internationales" usw. ${ }^{14}$ Abhilfe erhoffte sich Tichvinski von speziellen Beratungen, welche die Wissenschaftlichen Räte ${ }^{15}$ in Absprache mit dem Abteilungsbüro 1984

Benministerium. 1974 bis 1981 war er Chefredakteur der Zeitschrift „Neue und neueste Geschichte“, verantwortlicher Redakteur der Zeitschrift „Sinologie“ (Kitaevedenie) und gehörte den Redaktionskollegien der Journale für „Probleme des Fernen Ostens“ und „Internationales Leben“" an. Von 1980 an leitete er das Nationale Komitee der Historiker der Sowjetunion. Zugleich blieb er durch verschiedene Funktionen dem Außenministerium verbunden, gehörte dem dortigen beratenden Kollegium an, erhielt den Rang eines Außerordentlichen und Bevollmächtigten Botschafters der UdSSR und war schließlich von 1980 bis 1986 Rektor der Diplomatischen Akademie beim Außenministerium. Darüber hinaus soll er Autor von über dreihundert Publikationen, darunter fünf Monographien sein, in erster Linie zu Problemen der chinesischen Geschichte. Siehe Vsemirnaja istorija i vostok. Sbornik statej, M. 1989, 3-20; VI 1978, H. 8, 130-132; ISSSR 1978, H. 2, 225f, 1988, H. 5, $210 \mathrm{f}$.

12 So bereits bei der außerordentlichen Sitzung des Büros der Geschichtsabteilung am 28. Juni 1983, wo Tichvinskij vor den Instituts-Direktoren und Akademiemitgliedern das ZK-Plenum erstmals auswertete. - Vgl. Obsuð̌denie zadač istorið̌eskoj nauki v svete rešenij ijun'skogo (1983 g.) plenuma CK KPSS, in: VI 1983, H. 9, 18-25, hier $18 \mathrm{ff}$.

13 Siehe Tichvinskij, S.L.: O zadačach istorizeskoj naukj po realizacii rešenij ijun'skogo (1983 g.) plenuma CK KPSS, in: VI 1984, H. 1, 3-19. Vgl. die zusammenfassenden Berichte in: ISSSR 1984, H. 2, 206-210 und VI 1984, H. 1, 115ff.

14 Siehe Tichvinskij, O zadačach, 7f.

15 Zu Beginn der achtziger Jahre gab es acht Wissenschaftliche Räte. Drei davon waren noch die gleichen wie in den füfziger Jahren, und hatten die gleichen Leiter: Zur Historiographie (Nexkina), zur Revolutionsforschung (Minc), zum sozialistischen Aufbau (Kim). Drei Räte waren im Zuge der antirevisionistischen Reorganisation zu Beginn der siebziger Jahre aufgelöst worden. diejenigen zur Erforschung nationaler Befreiungsbewegungen, der geschichtlichen Voraussetzungen der Oktoberrevolution und der Genesis des Kapitalismus in Rußland. Neu geschaffen waren folgende fünf Räte: „Gesetzmäßigkeiten der historischen Entwicklung und der Abfolge von ökonomischen Gesellschaftsformationen“ (Z.V. Udal"cova), „Geschichte der Außenpolitik der UdSSR und der internationalen Beziehungen" (A.L. Naroznickij), für Probleme der Orientalistik (E.M. Primakov), der Slawistik und Balkanistik (D.F. Markov), der historischen Demographie und Geographie (Ju.A. Poljakov). Mit Ausnahme des Rates für die „Geschichte der Geschichtswissenschaft" (geleitet von M.V. Nexkina) spielten die anderen in den sechziger und siebziger Jahren bei der Entwicklung der historischen Disziplin keine besondere Rolle. - VI 1984, H. 2, 120; NNI 1984, H. 3, 178f; Tichvinskij, S.L.: Sostojanie i zadači koordinacii istorið̌eskich issledovanij, in: VI 1986, H. 9, 3-15, 7; vgl. Kapitel 3.2.4. 
realisieren sollten, und von geschichtsphilosophischen und -methodologischen Seminaren in allen sieben Instituten der Geschichtsabteilung. ${ }^{16}$ Zweitens die Hinwendung zu aktuellen Problemen; Tichvinskij verlangte die intensivere Erforschung der Geschichte nationaler Beziehungen, des Bürgerkriegs und der Interventionen in Rußland 1918-20, der Geschichte kapitalistischer und vorkapitalistischer Formationen auf dem Territorium der heutigen UdSSR, der Geschichte Westeuropas und von Anti-Kriegs-Bewegungen. ${ }^{17}$ Drittens die verstärkte Kritik bürgerlicher und revisionistischer Konzeptionen; neu war hier, daß Tichvinskij nicht den ungenügenden Umfang, sondern das zu niedrige Niveau der Kritik rügte. Man müsse sich endlich mit den neuesten bürgerlichen Schulen, Theorien und Konzeptionen auseinandersetzen. ${ }^{18}$ Viertens - und diesen Punkt bezeichnete der Redner als vorrangig - die Bedeutung der politisch-erzieherischen Funktion der Geschichtswissenschaft; in der Belletristik gebe es Tendenzen des historischen Romantizismus, der Legendenbildung, der Sensationslust, des Nationalismus und der Idealisienung des Alten sowie Versuche, die geschichtlich-gesellschaftliche Bedeutung der Freimaurerloge zu überschätzen und die Slawophilie zu idealisieren. Die Historiker müßten sich stärker als bisher dagegen wenden und hierfür die Kontakte mit Schulen und Massenmedien verbessern, attraktivere, fundierte Lehrbücher schreiben und enger mit Schriftstellern zusammenarbeiten. ${ }^{19}$ Fünftens die Verbesserung der Arbeitsorganisation; Planung und Organisation, Stil und Methoden der Forschungsarbeit seien unzulänglich; die „Reaktionsfähigkeit“ der historischen Disziplin müsse erhöht werden. Bisherige Vorschläge, zum Beispiel zur Aktivienung der beiden Wissenschaftlichen Räte für Orientalistik und Slawistik/Balkanistik, seien zu allgemein geblieben. Bei der Vorbereitung von Konferenzen müßte auch auf die Bedingungen echter Diskussionen geachtet werden; sie seien ,(...) notwendig für die Aufdekkung und Lösung umstrittener Probleme. ${ }^{\text {“20 }}$ Zur Überwindung dieser Mängel schlug Tichvinskij vor, sechs langfristig, bis zum Jahr 2000 angelegte ,komplexe Forschungsprogramme“" zu konzipieren. ${ }^{21}$ Dadurch sollten die traditionellen For-

16 Tichvinskij, O zadačach, 7ff. - Die Geschichtsabteilung der AdW der UdSSR verfuigte zum damaligen Zeitpunkt neben dem Archiv der AdW über die Institute für Allgemeine Geschichte (Direktorin Z.V. Udal'cova), für Archäologie (B.A. Rybakov), Ethnographie (Ju.V. Bromlej), Geschichte der UdSSR (S.S. Chromov), Orientalistik (E.M. Primakov) sowie Slawistik und Balkanistik (D.F. Markov). - Zur Struktur der Akademie der Wissenschaften und Stellung der historischen Disziplin siehe Kasack. W.: Die Akademie der Wissenschaften der UdSSR, Boppard, 3. Auflage 1978, 22ff und 53ff.

17 Tichvinskij, O zadačach, $9 f$.

18 Im einzelnen nannte Tichvinskij die Sozialgeschichte, die Theorie des Sonderwegs (teorija 'iskljuXitel'nosti ) und die Konzeption regionaler Gemeinsamkeiten (koncepcija regional'nych 'obstnastej ). - Ebd., $11 \mathrm{ff}$.

19 Ebd., 13ff.

20 Ebd., 15ff.

21 Folgende Schwerpunkte und Verantwortliche wurden bestimmt: 1. „Revolutionen und sozialer Fortschritt“ (I.I. Minc), 2. „Geschichte des Aufbaus der entwickelten sozialistischen Gesellschaft“ (M.P. Kim), 3. „Historischer Beitrag der Völker der UdSSR zur Kultur der sowjetischen Gesellschaft" (B.A. Rybakov), 4. „Ethnogenese und ethnische Prozesse der Gegenwart" (Ju.V. 
schungspläne nicht überflüssig, aber der Einsatz der personellen Kräfte, der Informationsaustausch, die unionsweite Koordination und Kooperation verbessert werden. $^{22}$

Über die acht Wissenschaftlichen Räte diskutierten die führenden Akademiemitglieder im Büro der Geschichtsabteilung noch vor Ablauf des Jahres 1983. Dabei stellte sich heraus, daß die Tätigkeit der Räte von der Mehrheit für unzulänglich gehalten wurde und grundsätzlich umstritten war. ${ }^{23}$ Aleksandr Samsonov schlug vor, jeden einzelnen Wissenschaftlichen Rat zu überprüfen; Maksim Kim plädierte dafür, einen übergeordneten Wissenschaftlichen Rat zur Koordination einzurichten. $^{24}$

Die Absichtserklärung der Geschichtsabteilung an der Akademie, die Anregungen des ZK-Plenums vom Juni 1983 zu nutzen für die Intensivierung der Theoriediskussionen, die Aktualisienung und Effektivienung der Geschichtsforschungen, wurde bei der Jahreshauptversammlung der Abteilung im März 1984, also einen Monat nach Andropovs Tod bestätigt. ${ }^{25}$ Endlich wurde auch eine Kommission gebildet, die den Auftrag hatte, die Gründung einer ,Allunions-Gesellschaft der Historiker" vorzubereiten. ${ }^{26}$ Kurz darauf, Ende Mai 1984, berichtete der Chefredakteur der Voprasy istorii dem Büro der Geschichtsabteilung über die Arbeit der Zeitschrift. Truchanovskij konnte nicht umhin, etliche Mängel zu konstatieren; vor allem würden za wenige echte Diskussionen geführt, und schmeichelnde Besprechungen hätten längst kritischen Rezensionen Platz gemacht. ${ }^{27}$ Häufiger als bisher sollten die in Forschungskollektiven, herangereiften" Meinungsverschiedenheiten öffentlich ausgetragen werden. Truchanovskij forderte von den Wissenschaftlern eine positive Einstellung zur Kritik; zu oft werde darauf mit Erregung und Gereiztheit reagiert. Der Chefredakteur versprach, daß die Zeitschrift künftig ausführlicher über Konferenzen berichten und mit Rundtischgesprächen (besedy za kruglym stolom) und anderen Beiträgen lebhafter über neue Publikationen und Thesen dis-

Bromlej), 5. „Probleme von Krieg und Frieden im 20. Jahrhunder" (A.M. Samsonov), 6. „Allgemeine Gesetzmäßigkeiten und spezifische Besonderheiten der Entwicklung vorkapitalistischer Klassenformationen" (Z.V. Udal'cova). - Ebd., 18.

2 Vgl. ebd. und VI 1987, H. 4, 82f.

23 Bemängelt wurde u.a. die fehlende juristische Grundlage für die Tätigkeit der Räte, ihre uneinheitliche Struktur, ihre unzulängliche personelle, finanzielle und materiell-technische Ausstattung, daß sie nicht alle Landesteile und nicht alle inhaltlichen Hauptrichtungen der Geschichtswissenschaft abdeckten, daß sie unvollständig über die führenden Spezialisten informierten und die Planung von Doktorarbeiten unzureichend beeinflussten. - VI 1984, H. 2, $120 \mathrm{ff}$.

24 Vgl. ebd., 121. - Der entsprechende Beschluß murde erst im Januar 1987 gefaßt. Vgl. Kapitel 5.4 .

25 Vgl. VI 1984, H. 6, 113ff. Analog auch die Kernaussagen in dem Leitartikel Aktual'nye problemy izučenija istorii SSSR, in: ISSSR 1984, H. 2, 3-19, besonders 3-5.

26 Vgl. VI 1984, H. 6, 118. Die Bildung einer solchen unionsweiten Gesellschaft war seit langem im Gespräch.

29 Vgl. VI 1984, H. 9, 103ff. 
kutieren werde. ${ }^{28}$ In der sich anschließenden Aussprache ließen sich die atten akademiki von Truchanovskijs Streitlust anstecken: Aleksandr Samsonov verordnete gegen die Krankheit der Schmeichelei und Lobhudelei die Medizin glasnost', also Offenheit im Umgang miteinander und das Bekenntnis zur individuellen Meinung. ${ }^{29}$ Zinaida Udal'cova schlug vor, zu einer Monographie häufiger mehrere Rezensionen mit unterschiedlichen Positionen zu veröffentlichen. Jurij Poljakov unterstütze den Gedanken, regelmäßig Rundtischgespräche abzuhalten, und er regte an, wieder eine ständige Diskussionsrubrik in der Zeitschrift einzurichten. Pavel Volobuev, der 1973 „Verbannte“, äußerte die Hoffnung, daß sich jetzt wieder eine für echte Diskussionen günstige Atmosphäre entwickle; man dürfe vor der Wahrheit keine Angst haben. ${ }^{30}$

Doch auch wenn diese selbstkritischen Statements im Mai 1984 ein wenig an jene lebhafte Diskussion vienundzwanzig Jahre zuvor ${ }^{31}$ erinnerten, bleibt festzuhalten, daß es nach dem Tode Brežnevs, in den Jahren 1982 bis 1985 in der Geschichtswissenschaft bei Absichtserklärungen und einigen organisatorischen Maßnahmen blieb. Andropovs nüchtere Feststellung, man kenne die Gesellschaft nicht, in der man lebe, war zwar ein Schritt in die richtige Richtung, weil tatsächlich die Selbsterforschung in der sowjetischen Gesellschaft sträflich vernachlässigt worden ist. Aber die generelle Aktualitätsforderung, wie sie nach dem ZK-Plenum im Juni 1983 üblich wurde, war nicht geeignet, die sowjetische Geschichtswissenschaft, die ohnehin die allgemeine und die vorrevolutionäre Geschichte unterbelichtete, von ihren Disproportionen ${ }^{32}$ und Hemmnissen ${ }^{33}$ zu befreien. Auch wurden bei der Auf-

\footnotetext{
28 Ebd., 104

29 In dem Begriff glasnost' steckt das alte Wort glas, heute: golos, d.h. Stimme. Es geht nicht nur um Offentlichkeit und Transparenz, sondern um die Stimme und Stimmhaftigkeit des Einzelnen.
}

$30 \mathrm{Vgl}$. VI 1984, H. 9, $105 \mathrm{f}$

31 Gastgeber jener Diskussion am 30. Juni 1960, die den Auftakt der relativ offenen Auseinandersetzungen in den sechziger Jahren dargestellt hatte, war der damals ,frischgebackene“ Chefredakteur Truchanovskij. Außer ihm waren Maksim Kim und Isaak Minc sowohl 1960 als auch 1984 mit dabei. Inzwischen waren die drei Genannten 69, 76 und 88 Jahre alt geworden. - Vgl. Kapitel 3.2.4.

32 Dietrich Geyer zufolge beschäftigten sich Anfang der achtziger Jahre nur „(...) schätzungsweise zwanzig bis fünundzwanzig Prozent der in der Forschung tätigen sowjetischen Historiker (...)“ mit Problemen der allgemeinen Geschichte. - Siehe Geyer, Klio, 7. Erinnert sei an das unverhältnismäßige Übergewicht der Promotions- und Habilitationsschriften zur sowjetischen Periode im Vergleich zur vorrevolutionären Geschichte, vgl. Kapitel 5.2.

33 Die Aktualitätsforderung verlangte auch von den Archäologen, Ethnographen und Mediävisten ihren Tribut! Besonders 1984/85 urrden wieder viele Kräfte der sowjetischen Geschichtswissenschaft durch die Begehung des 40. Jubiläums des Sieges über den Faschismus und die Auseinandersetzung mit dem 12. Fünfjahrplan gebunden - Vgl. Chromov, S.S./V.I. Buganov/V.P. Serstobitov: Nekotorye itogi i aktual'nye problemy izucenija otexestvennoj istorii v svete rě̌enij XXVI s-ezda KPSS, in: Izučenie 1982, 35; Bromlej, Ju.V.: K izuceniju nacional'nych processov socialistið̌eskogo obšcestva v kontekste etměeskoj istorii, in: ISSSR 1984, H. 6, 40-56; 
listung neuer Schwerpunkte die tabuisierten Probleme nicht benührt. ${ }^{34}$ An die Wiederaufnahme der unter Chruščev begonnenen Untersuchungen der stalinistischen Repressionen - sei es durch Partei- oder Regienungskommissionen, sei es durch professionelle Historiker - war noch nicht zu denken. Die allgemeine Kritik von Dogmatismus und Empirismus sowie die hektische Betriebsamkeit zur Verbesserung der Koordination blieben im wesentlichen folgenlos für die Praxis des Forschungsbetriebs. Die von Tichvinskij angekündigten sechs langfristigen Forschungsprogramme wurden jahrelang geplant, konzipiert und beraten, ohne da $\beta$ sich Besserungen zeigten und der Eindruck der doppelten Planung (neben derjenigen an den Instituten der Akademie und in den Wissenschaftlichen Räten) vermieden worden wäre. ${ }^{35}$ Auch die von Tichvinskij erwähnten philosophischen Seminare an den Geschichtsinstituten der Akademie stellten nicht das angekündigte „wichtige Mittel der theoretisch-methodologischen und ideologisch-erzieherischen

ISSSR 1984, H. 5, 3ff und H. 6, 3ff, 1985, H. 1, 3ff, H. 2, 3ff; H. 3 vollständig sowie den Jahrgang 1985 der Voprasy istorii.

34 Im Gegenteil wurde die Tabuisierung noch erweitert. So „(...) wurde 1984 der funfzigste Jahrestag des 17. Parteitages (Januar) und der Ermordung Kirows (Dezember) praktisch stillschweigend übergangen." - Davies, Perestroika, 16.

35 Die ersten Entwürfe stellten B.A. Rybakov und A.M. Samsonov am 21.02.1984 im Büro der Geschichtsabteilung vor. Ihnen folgten Ju.V. Bromlej und M.P. Kim am 27.03.1984, Z.V. Udal'cova am 10.04.1984 und I.I. Minc am 10.05.1984 sowie am 19.02.1985 - VI 1984, H. 4, 109; H. 5, 94ff; H. 6, 117ff; H. 7, 112ff; 1985, H. 4, 123ff. 
Arbeit der Historiker ${ }^{\star 36}$ dar. $\mathrm{Zu}$ schwach waren das Interesse und die Beteiligung wissenschaftlicher Mitarbeiter an den Seminaren, ${ }^{37}$ die obendrein streng dirigiert und kontrolliert wurden. ${ }^{38}$ Das Dasein dieser Seminare kann als symptomatisch für die Lage der sowjetischen Geschichtswissenschaft insgesamt bezeichnet werden. Unter Cemenko änderte sich daran nichts. „Kontinuität“ war das Losungswort, mit dem der bereits todkranke Generalsekretär am 13. Februar 1984 sein Amt antrat. ${ }^{39}$

\footnotetext{
36 So der Titel eines Aufsatzes von Tichvinskij, S.L./V.A. Tił̌kov: Vał̌noe sredstvo teoretikometodologixeskoj i idejno-vospitatel'noj raboty istorikov, in: VI 1983, H. 9, 84-93.

37 Tichvinskij und Tiškov schätzten, daß etwa fünfzehn Prozent der Wissenschaftler der Akademie-Institute in Moskau und Leningrad regelmäßig teilnahmen, in überwiegender Mehrheit allerdings Historikerinnen und Historiker mit dem Grad „Doktor der Geschichtswissenschaften“, die in der Regel über füfzig Jahre alt waren. - Ebd., $86 f$.

38 .Die Tätigkeit der Seminare wird ausgerichtet und kontrolliert von den Parteibüros der Institute, welche die Zusammensetzung der Seminarteilnehmer, die Arbeitspläne und Rechenschaftsberichte bestätigen, und auch die Fragen der allgemeinen und laufenden Seminararbeit erörtern. Große Hilfe (...) leisten die Stadt- und Rayon-Komitees der Partei, die Häuser der politischen Aufklärung, aber auch der Zentralrat für philosophische (methodologische) Seminare beim Präsidium der AdW der UdSSR (...)". - Ebd., 87.

39 Siehe Materialy vneoxerednogo Plenuma Central'nogo Komiteta KPSS 13 fevralja 1984 goda. M. 1984, 10, hier nach dem Leitartikel Dejatel'nost' KPSS po stroitel'stvu razvitogo socializma v 60-e gody, in: VI 1984, H. 4, 3-14, hier 3.
} 


\subsection{Die Geschichtswissenschaft und der Beschleunigungskurs 1985/86}

Die Jahreshauptversammlung der Geschichtsabteilung an der Akademie der Wissenschaften begann am 11. März 1985 in gewohnter Routine. Doch nachdem der Staatliche Rundfunk um 13.57 Uhr Moskauer Zeit den Tod Cernenkos und nur vier Stunden später die Wahl des jüngsten Politbüromitglieds Michail Sergeevič Gorbačev zum neuen Generalsekretär gemeldet hatte, 'unterbrach der Akademische Sekretär Tichvinskij die Sitzung für vier Tage; erst am 15. März wurde die Versammlung fortgesetzt und mit Neuwahlen abgeschlossen. ${ }^{2}$ Ohne auf den politischen Führungswechsel einzugehen, bestätigte das oberste Gremium der historischen Disziplin die Fortsetzung der seit 1983 verfolgten Maßnahmen zur Aktualisierung und Effektivierung der Forschungsarbeit. ${ }^{3}$ Dieser Beschluß stimmte durchaus mit den Auffassungen der neuen Parteifuhrung überein, denn:

„In den ersten 18 Monaten nach Gorbatschows Emennung bezog das Politbüro eine zurückhaltende, ja sogar konservative Haltung zur sowjetischen Geschichte. “4

Die Quintessenz dieser Einstellung der neuen Führung bestand darin, daß umgehend Reformen eingeleitet werden müßten, um die sozialökonomische Entwicklung zu beschleunigen, daß aber bei dem Bemühen, schneller vorwärts u kommen, der Blick nicht nach hinten gerichtet werden dürfe. ${ }^{5}$ Dem Politbüro ging es um die

1 Siehe Schmidt-Häuer, Michail Gorbatschow 1985, 31f; Smith, Die neuen Russen, 115; Geller, Sed'moj sekretar', 14ff.

2 S.L. Tichvinskij wurde als Akademischer Sekretär bestätigt. Er bekam vier Stellvertreter: Ju.V. Bromlej, P.A. Žlin, I.D. Koval'cenko, und Ju.S. Kukuskin. Außer diesen wurden in das Büro der Geschichtsabteilung gewählt: M.P. Kim, I.I. Minc, A.L. Naroznickij, B.A. Rybakov, A.M. Samsonov, V.P. Alekseev, A.A. Iskenderov, G.F. Kim, Ju.A. Poljakov, V.G. Truchanovskij, Z.V. Udal'cova, V.L. Janin. - VI 1985, H. 7, 113ff.

3 Ebd. Siehe auch Tichvinskij, S.L.: Itogi i perspektivy issledovanij sovetskich istorikov, in: VI 1985, H. 7, 3-13.

4 Davies stellte die entscheidenden Belege zusammen: Gorbačev rühmte im Mai 1985 Stalins „Verdienste“ im Zweiten Weltkrieg; er lobte vier Monate später die Stachanovbewegung, sprach im Februar 1986 verharmlosend von ,subjektive(n) Verzerrungen" in der sowjetischen Geschichte, wies den „Stalinismus“-Begriff als verleumderisch zurück usw. - Davies, Perestroika, 159f.

s Wörtlich soll Gorbačev im Juni 1986 gegenüber sowjetischen Schriftstellern gesagt haben: „Wenn wir anfangen, uns mit der Vergangenheit auseinanderzusetzen, werden wir unsere ganze Energie einbüßen. Das wäre so, als würden wir den Leuten auf den Kopf schlagen. Dabei müssen wir vorwärts gehen. Wir werden Klarheit bezüglich der Vergangenheit schaffen. Wir werden alles gebührend einordnen. Doch jetzt müssen wir unsere Energie nach vorn richten." - Zitiert nach Davies, Perestroika, 160. Mit fast den gleichen Worten beschrieb der Moskauer Historiker Vladlen Loginov bei seinen Vorträgen in Wuppertal am 05.12.1987 und in Frankfurt/Main am 08.06.1989 diesen bis Ende 1986 gültigen Standpunkt der KPdSU-Führung zu der Auseinandersetzung mit der Vergangenheit. Valentin Falin zitierte Gorbačev und Ligačev (aus der Diskussion mit Publizisten im Juni 1986) mit den Worten: „Man kann nicht gleichzeitig für die Zukunft arbeiten und sich in eine Auseinandersetzung mit der Vergangenheit versenken." „Man darf den 
Vermeidung einer öffentlichen, die Gesellschaft verunsichernden Geschichtsdiskussion. In aller Stille wurden die ersten Rehabilitierungsverfahren eingeleitet. ${ }^{6}$

In einer routinemäßigen Sitzung des Büros der Geschichtsabteilung am 21. Mai 1985 trat D.V. Kuznecov, ein Vertreter der ZK-Abteilung für Wissenschaft und Lehrinstitutionen, auf und fragte,

„(...) wie die Abteilung (für Geschichte; J.H.) und ihre Einrichtungen beabsichtigten, die Beschlüsse des April-Plenums (1985) des ZK der KPdSU zu erfülen, und was sie festlegten, in Verbindung mit dem bevorstehenden XXVII. Parteitag zu tun. “"

Zwar stieß Kuznecov auf Zustimmung, ${ }^{8}$ und bereits bei der nächsten Sitzung vierzehn Tage später war das Thema Tagesordnungspunkt Nummer eins, ${ }^{9}$ aber die Diskussionen und ergriffenen Maßnahmen bewegten sich weiterhin in dem Rahmen des bisher Gewohnten. So bezeichnete Ju.V. Bromlej die Erhöhung der Effektivität als das Wichtigste; B.A. Rybakov forderte eine strengere Arbeitsdisziplin; A.L. Naroznickij sprach sich dafür aus, nur noch Autoren und Kollektive mit wirklich neuen Themen zu unterstützen; Ju.A. Poljakov schlug vor, in speziellen Konferenzen die Bedeutung des ZK-Plenums vom April 1985 für die Geschichtswissenschaft sowie „Leninsche Prinzipien der Arbeits- und Alltagsdisziplin“ zu erörtern; einig waren sich alle, daß in den neuen Forschungsplänen die ahen Ziele nicht einfach weitergeschrieben werden dürtten. Als zentrale Subjekte einer perestrojka rückte Tichvinskij in seinem Schlußwort bei der Bürositzung am 4. Juni die acht Wissenschaftlichen Räte in den Vordergrund. ${ }^{10}$

Doch allen Bekenntnissen zu einer Umgestaltung zum Trotz dominierten das alte Denken und die eingeübten Mechanismen weiter: Am 5. November beispielsweise klammerte V.I. Bovykin in seinem Referat über die ,Ergebnisse und Probleme der Erforschung der sozialökonomischen Voraussetzungen der Großen Sozialistischen Oktoberrevolution“ die alternativen Auffassungen der ,Neuen Richtung“ aus und vertrat ungerührt, so als habe es nie Kontroversen gegeben, die dogmatischen The-

Karren nicht so vollpacken, daß der Gaul zusammenbricht." - Falin, Politische Erinnerungen, 422.

6 „1985 begann die Kontrollkommission der Partei, die Fälle einiger ehemaliger Parteimitglieder zu prüfen, die in der Chruschtschow-Ära nicht rehabilitiert worden waren (...)“. Am 5. April 1985 wurde der Arzt D.D. Pletnev, der im März 1938 als Angehöriger des ,antisowjetischen rechtstrotzkistischen Blocks" ermordet worden war, rehabilitiert. Ein Jahr später wurde der ehemalige „Trotzkist“ N.I. Muralov (1877-1938) rehabilitien - Wheatcroft, S.G.: Glasnast" and Rehabilitations, in: Ito, Facing up to the Past, 199-218, hier 211; Davies, Perestroika, 160; über Muralov siehe Vozvrašcennye imena. Sbornik publicistiðeskich statej $\vee 2$-ch knigach, $M$. 1989, hier kniga II, 25-40.

7 Siehe VI 1985, H. 8, $105 f$.

8 Nach der Aussprache, in der Bromlej, Koval'čenko, Poljakov und Udal'cova über die Arbeit in ihren Verantwortungsbereichen berichteten, ,....) empfahl das Büro, die Verwirklichung entsprechender Maßnahmen zu beschleunigen.“ - Ebd., 106.

9 Vgl. VI 1985, H. 9, $101 \mathrm{f}$.

10

Ebd 
sen über die staatsmonopolistische Entwicklung des russischen Kapitalismus. "Im Dezember 1985 erklärte Tichvinskij in seinem Rechenschaftsbericht an die Generalversammlung der Akademie, Grundlage für die Entwicklung der Geschichtswissenschaft sei die „Beschleunigungsstrategie“ der KPdSU. „Isoliert" von der Gesellschaft könne die historische Disziplin ihre theoretischen Fundamente, die Wissensakkumulation und die Verallgemeinerungen nicht vervollkommnen. Thre Hauptaufgabe sei

„(...) die Darlegung der Entwicklungsgesetze der menschlichen Gesellschaft. Die gesamte schöpferische Tätigkeit des Historikers muß den Interessen der Gegenwart untergeordnet sein, muß von ihren Interessen ausgehen, vor allem von der Notwendigkeit einer effektiven Einflußnahme der Wissenschaft auf das gesellschaftliche Bewußtsein." Die Parteidokumente „(...) bestimmen die Thematik, das theoretische Niveau und die praktische Ausrichtung der Schlußfolgerungen der historischen Forschungen." 12

Tichvinskij akzeptierte also weiterhin die absolute Fremdbestimmung der historischen Disziplin, leugnete ihre Fähigkeit zur eigenständigen Entwicklung und Selbstkorrektur. Er negierte erneut die in den sechziger Jahren geforderte ,Freiheit der Wissenschaft" und die Auffassung, die Geschichtswissenschaft verfüge als relativ selbständiges Subsystem in der Gesellschaft über eigene Entwicklungsmethoden. $^{13}$

In dieser herbstlichen Atmosphäre 1985 ertönte einsam die erste Stimme eines etablierten Historikers für einen Neuanfang in der Geschichtswissenschaft ausgerechnet in der ,theoretischen und politischen Zeitschrift des Zentralkomitees der KPdSU“, Kommunist. Es war der Historiker Jurij Nikolaevic Afanas'ev, damals noch Redaktionsmitglied der Zeitschrif, der, sich immer wieder berufend auf die jüngsten Parteidokumente, auf Hegel, Marx, Engels, Lenin, Puškin und Cernyకevskij u.a., anmahnte, die sowjetische Geschichtswissenschaft auf die neuen Herausfordenungen der Zeit einzustellen. Er formulierte bereits die erst gut ein Jahr später in der Parteispitze anerkannte Auffassung, daß ein klares Geschichtsbewußtsein notwendig sei für die Zukunftsgestaltung, wobei er nicht der bekannten maßlosen Forderung nach der Aktualität der Geschichtsforschung das Wort redete; fundamentale und angewandte Forschung müßten auch in der Geschichtswissenschaft in ausgewogenem Verhältnis stehen. ${ }^{14}$ Doch sehr viel intensiver als bisher müsse die historische Disziplin die Vergangenheit im Dienste der sozialistischen Gesellschaft als Laboratorium der weltweiten sozialen Erfahrung auswerten. Das erfordere auch Neuorientierungen in der Akademie der Wissenschaften; die sechs

\footnotetext{
"Zwar nahm auch Volobuev an der Sitzung teil, aber in Voprasy istorii wurde nichts über eine Diskussion zwischen Befurwortern und Kritikern der "Neuen Richtung“ berichtet. - Vgl. VI 1986, H. 1, 94.

12 VI 1986, H. 3, 100-102, hier 100f. - Analog äußerte sich Tichvinskij im Präsidium der AdW am 13.02.1986, vgl. VI 1986, H. 6, $91 \mathrm{ff}$.

$13 \mathrm{Vgl}$. Kapitel 5.1., besonders die Stellungnahme von Petr Lisovskij.

14 Afanas'ev, Ju.: Prošloe i my, in: K 1985, H. 14, 105-116, hier 105, 107ff und 113.
} 
komplexen Forschungsprogramme (siehe Kapitel 5.3.) etwa hielt Afanas'ev für unzulänglich, sie müßten ergänzt werden. ${ }^{15}$ Recht offen sprach Afanas'ev abschlieBend aus, daß etliche Themen auch der "Vaterländischen Geschichte" nur schwach bearbeitet oder, gänzlich vernachlässigt" seien. Im einzelnen nannte er:

„(...) die Periode der Petrinischen Reformen, die erste russische Revolution, die $\mathrm{He}-$ terogenität (mnogoukladnost') der Wirtschaft des vorrevolutionären Rußland, die demokratischen und sozialistischen Bündnispartner des Proletariats (...) ${ }^{\text {ac }}{ }^{16}$

Der 27. Parteitag der KPdSU (25. Februar bis 6. März 1986), bei dem Gorbačev noch so verharmlosend über ,Fehler in der Politik und verschiedenerlei subjektive Verzernungen ${ }^{\text {(17 }}$ in der Vergangenheit sprach, bestätigte den Kurs der Partei zur „Beschleunigung der sozialökonomischen Entwicklung" bis zum Jahr 2000. ${ }^{18}$ In dem Rechenschaftsbericht und in der Neufassung des Parteiprogramms deuteten sich Veränderungen der parteioffiziellen Haltung gegenüber der Geschichtswissenschaft an: Gorbačev bekundete in dem ZK-Bericht das dringende Bedürfnis der Partei nach ,tiefgehenden historischen Forschungen ${ }^{\text {(19 }}$ und fügte hinzu:

is Unberücksicht blieben in diesen Programmen solche Probleme wie die Beschleunigung des wissenschaflich-technischen Fortschritts, die Entwicklung der Produktionsverhältnisse, die Umgestaltung der Wirtschaftslenkung, die Vertiefung der Wechselwirkung und wechselseitigen Bereicherung der Kulturen. - Ebd., 115.

16 Ebd., 116.

17 Hier zitien nach Davies, Perestroika, 159

18 In dem Bericht des Zentralkomitees hieß es zur Beschleunigung: „In erster Linie geht es um die Temposteigerung beim Wirtschaftswachstum. Doch nicht nur darum. lhr Wesen besteht in einer neuen Qualität des Wachstums: in der größtmöglichen Intensivierung der Produktion auf der Grundlage des wissenschaftlich-technischen Fortschritts, der strukturellen Umgestaltung der Wirtschaft, der Anwendung effektiver Formen der Leitung, der Arbeitsorganisation und stimulierung." - Zitiert nach Meyer, Gert ( $\mathrm{Hg}$.): Sowjetunion zu neuen Ufern? 27. Parteitag der KPdSU März '86. Dokumente und Materialien mit einer Einleitung von Dr. Gert Meyer, Düsseldorf 1986, 50; vgl. ebd., 312ff. Vgl. auch Aganbegjan, A.A.: Strategie der Beschleunigung der sozialökonomischen Entwicklung der UdSSR, in: Aus Politik und Zeitgeschichte. Beilage zur Wochenzeitung "Das Parlament", B 45/87, 3-14; Sitarjan. S.: Politische und ökonomische Aspekte der Konzeption der Beschleunigung, in: Umbruch in der Sowjetunion. Sowjetische Autoren über die Umgestaltung 70 Jahre nach der Oktoberrevolution, Düsseldorf 1987, 93-113; Ritm perestrojki. Ekonomika na novom etape, M. 1987.

$\mathrm{Vgl}$. die Analyse und Kritik der Beschleunigungsstrategie bei Huffschmid, J.: Umbau der Wirtschaf und Beschleunigung der sozialökonomischen Entwicklung. Zur neuen wirtschaftspolitischen Strategie in der Sowjetunion, in: Blätter 1987, H. 1, 73-88; Höhmann, H.-H.: Sowjetische Wirtschaft unter Gorbatschow. Auf der Suche nach neuem Profil, in: Sowjetunion 1986/87. Ereignisse, Probleme, Perspektiven, hg. vom BOIS, München-Wien 1987, 112-132; Conert, Die Ökonomie, 127ff: sowie das Gespräch mit Abel Aganbegjan und Hansgeorg Conert in: Blätter 1987, H. 10, 1301-1309.

19 Siehe Meyer, Sowjetunion, 145. 
„Nicht durch Deklarationen und Vorschriften gelangt man zur Wahrheit: Sie wird in wissenschaftlichen Diskussionen und im Meinungsstreit geboren und in Aktion erprobt. ${ }^{\prime 20}$

Im neugefaßten Parteiprogramm wurde darauf verzichtet, den Wissenschaftlem nebst Fragen und Aufgaben zugleich auch die Antworten vorzuschreiben. Ausdrücklich wurden sie angewiesen, die

„(..) objektiven Widersprüche der sozialistischen Gesellschaft wissenschaftlich zu analysieren und fundierte Empfehlungen für deren Lösung sowie zuverlässige ökonomische und soziale Prognosen zu erarbeiten (....).

Diesmal ließ die historische Zunft ihre gewohnt eilfertige Reaktion auf die neue Programmatik der Partei allerdings vermissen: Die dogmatische Haltung der führenden Historiker in der Akademie der Wissenschaften änderte sich nicht. In der Jahreshauptversammlung der Geschichtsabteilung kurz nach dem 27. Parteitag überwogen die Momente der Kontinuität. ${ }^{22}$ Am 8. April 1986 dachten die Mitglieder des Büros der Geschichtsabteilung wieder darüber nach, wie die Beschleunigungsstrategie der Partei in der historischen Disziplin umgesetzt werden könnte. Greifbare Ergebnisse waren noch nicht vorzuweisen. Immerhin hielt der Berichterstatter fest, die Akademiemitglieder hätten erkannt,

"(...) daß bis jetzt unter den Historikem noch keine Atmosphäre der kritischen Beziehung zu den Unzulänglichkeiten entstanden ist, über die beim Parteikongreß gesprochen wurde; es vollzog sich keine psychologische Umgestaltung. ${ }^{\text {“23 }}$

Trotz dieser Selbsterkenntnis änderte sich bis Ende des Jahres nichts Entscheidendes, obwohl die Geschichtsabteilung aktiv wie selten zuvor war. Die hektische Betriebsamkeit drehte sich vor allem um das Problem der, ,Koordination als Mittel zur Erhöhung der Qualität und Effektivität der historischen Forschungen“. ${ }^{24}$ Dabei

$20 \quad$ Ebd., 146.

21 Ebd., 238. - Neu war auch das Bekenntnis, ,(...) kühnes Forschen, den Wettstreit von Ideen und Richtungen in der Wissenschaft sowie fruchtbare Diskussionen (...)" zu unterstützen. Ebd., 239. - Im vorher gültigen Parteiprogramm aus dem Jahre 1961 waren hingegen die gewünschten Ergebnisse vorformuliert: Die Wissenschaftler sollten den gesetzmäßigen Vormarsch der Menschheit zum Kommunismus, die Veränderung des internationalen Kräfteverhältnisses zugunsten des Sozialismus, die sich verschärfende Krise des Kapitalismus, die siegreichen Erfahrungen der KPdSU usw. usf. aufdecken; siehe Programm der KPdSU. Angenommen auf dem XXII. Parteitag, Oktober 1961, Berlin 1961, hier 121f.

22 Lediglich Akademiemitglied Samsonov brachte einen Hauch von perestrojka in die Sitzung, als er für mehr Kritik und Selbstkritik plädierte. - VI 1986, H. 7, 88ff, besonders 91 .

23 Ebd., 92.

24 So lautete der Titel einer unionsweiten Konferenz, welche die Geschichtsabteilung der Akademie vom 24. bis zum 26. Juni abhielt. Das Problem war gigantisch und im Grunde unlösbar, solange die Geschichtsabteilung der AdW in Moskau an ihrem Führungsanspruch festhielt; sie wollte mit Unterstützung der acht Wissenschaftlichen Räte, der Sektion Gesellschaftswissenschaften und dem Präsidium der AdW nicht nur die Arbeit der sieben Akademieinstitute in Moskau koordinieren, sondern auch die der historischen Fakultäten der Staatlichen Hochschulen des Landes, des Instituts für Geschichte, Philologie und Philosophie an der Sibirischen Abteilung in 
stellte Tichvinskij die größten Mängel im Bereich der - unionsweiten - Arbeitsplanung, der Organisation und schließlich beim theoretischen und methodologischen Niveau der Ergebnisse fest. ${ }^{25}$ Tichvinskijs Referat bei der Konferenz im Juni, die anschließende Diskussion und die beschlossenen Empfehlungen zeigten allerdings, $\mathrm{da} B$ die Ansprüche überzogen und die Maßnahmen sehr begrenzt blieben. ${ }^{26}$ An die längst überfällige Dezentralisierung und Demokratisierung des komplexen Systems wurde nicht gedacht. ${ }^{27}$ Am 2. September waren Vertreter verschiedener historischer Fachzeitschriften in der Bürositzung der Geschichtsabteilung zu Gast. Man war sich schnell einig, daß Kontroversen unter den Historikern und der Meinungsaustausch mit anderen Gesellschaftswissenschaftlern künftig einen höheren Stellenwert in den Publikationen einnehmen müßten. ${ }^{28}$ Dieses Bekenntnis blieb allerdings noch viele Monate ohne Folgen in den Periodika. Am 9. Dezember setzten sich fuihrende Akademiemitglieder mit Vertretern des Hauptarchivs beim Ministerrat der UdSSR ${ }^{29}$ zusammen, um den seit Jahrzehnten völlig unbefriedigenden $\mathrm{Zu}$ -

Novosibirsk, des Instituts für Geschichte. Archäologie und Ethnographie der Völker des Ostens am Fernöstlichen Wissenschaftszentrum in Vladivostok, der Hauptinstitute der AdW Uzbekistans, Kazachstans, Georgiens und Litauens, besonderer Koordinationsräte in den Akademiefilialen Belorußlands, Lettlands. Estlands und Tadžikistans sowie vieler anderer Kommissionen für spezielle Aufträge (im Zusammenhang mit Jahrestagen u.ä.). - Siehe Tichvinskij, Sostojanie; Rekomendacii koordinacionnogo sovešanija rukovoditelej akademið̌eskich i drugich naučnych učreždenij istorižeskogo profilja SSSR, sojuznych i avtonomnych respublik „Koordinacija kak sredstvo povyšenija kað̌estva i effektivnosti istoričeskich issledovanij v SSSR v svete rełenij XXVII s-ezda KPSS“, Moskva, 24-26 ijunja $1986 \mathrm{~g}$., in: VI 1986, H. 12, 111-115.

25 Tichvinskij, Sostojanie, 8ff und Rekomendacii, $112 \mathrm{f}$.

26 Die Moskauer Zentrale sollte den unionsweiten Informations- und Erfahrungsaustausch sicherstellen, ein System regelmäßiger und operativer Zusammenarbeit dirigieren, die Institutionen landesweit wissenschaftlich-methodisch anleiten usw. Im Vordergrund standen folgende funf Maßnahmen: 1. die weitere Erarbeitung der sechs, landesweit und bis zum Jahr 2000 gültigen komplexen Forschungsprogramme; 2. eine neue Verordnung (ustav), die Rechte und Pflichten der sieben Geschichtsinstitute der AdW festlegen sollte; 3. die Modernisierung des Instituts für Wissenschaftliche Information im Bereich Gesellschaftswissenschaften (INION) und der Fachzeitschriften; 4. die Analyse des Personalstands und Herausgabe eines historischen Jahrbuchs (IstoriYeskij ezegodnik), in dem besonders über Kandidaten- und Doktor-Dissertationen berichtet werden sollte; 5 . die Verbesserung der Grundlagen kontinuierlicher Kollektivarbeiten über die Republiksgrenzen hinaus. - Tichvinskij, Sostojanie, 8ff und Rekomendacii, 114f.

27 Vgl. ebd. sowie Tichvinskij, S.L.: Nekotorye voprosy raboty sovetskich istorikov, in: VI 1986, H. 12, 3-12.

28 VI 1986, H. 11, 115f. - Am 21.10.1986 sagte Tichvinskij vor der Generalversammlung der AdW: „Wir haben verlernt, wissenschaftichen Streit und Diskussionen zu fuhren, of rufen Meinungsverschiedenheiten seitens einzelner Wissenschaftler eine krankhafte Reaktion hervor, haben einen 'Instanzenweg' zur Folge oder das Abwiegen der Etiketten." - Tichvinskij, Nekotorye voprosy, 7.

29 Den Weisungen der 1961 gebildeten Hauptarchivverwaltung (Glovarchiv) unterstanden alle staatlichen Archive: die Zentralen Staatsarchive für die Oktoberrevolution (CGAOR), für alte Akten (CGADA), für die Volkswirtschaft der UdSSR (CGANCh), das Zentrale Historische Staatsarchiv in Leningrad (CGIAL), die regionalen (oblastmoj) Archive und viele andere. - Vgl. Geyer, D.: Perestrojka in der sowjetischen Geschichtswissenschaft, in: ders., Die Umwertung, 931 , hier $23 \mathrm{ff}$. 
gang zu den Archivbeständen zu erörtern. Der nach ,langer Aussprache“ gefaßte Beschluß sah vor, künftig Quelleneditionen nicht mehr zu limitieren, die Zugangsmöglichkeiten in den Archiven zu verbessern und die Lesesäle zu modernisieren. Der Fortgang konkreter Maßnahmen sollte bei weiteren Beratungen 1987/88 geprüft werden. ${ }^{30}$ Ende 1986 wurde die im Lauf des Jahres intensivierte Beratung der sechs komplexen Forschungsprogramme abgeschlossen. ${ }^{31}$ Konsequenzen manifestierten sich auch hier nicht. Stattdessen gab Tichvinskij in der Bürositzung am 16. Dezember bekannt, daß nach der Annahme jener sechs Programme das Präsidium der Akademie der Wissenschaften die Geschichtsabteilung beauftragt habe, zusätzlich sogenannte prognostische Berichte (doklady-prognozy) für zehn Forschungsrichtungen auszuarbeiten. ${ }^{32}$ Konnte schon der Akademische Sekretär selbst den Sinn dieser neuen Berichte nicht recht erklären, so wurde dieser auch in den folgenden Beratungen der doklady-prognozy, die zum Teil mit den vorangegangenen „Komplexprogrammen“ übereinstimmten, nicht deutlich. ${ }^{33}$ Am 15. Januar 1987, in der letzten Sitzung vor dem berühmt gewordenen Plenum des Zentralkomitees, beschloß das Büro, einen Rat für die Koordination der wissenschaftlichen Tätigkeit der Geschichtsabteilung einzurichten. ${ }^{34}$ Ähnlich wie bei den acht Wissenschaftlichen Räten sollten auch diesem Repräsentanten der zentralen und regionalen Akademieinstitutionen, des Instituts für Marxismus-Leninismus, der Akademie für Gesellschaftswissenschaften, der Universitäten, Archive und Schulen des Landes angehören. Hauptaufgabe dieses Rats sollte es sein, unionsweit die Kräfte der Histo-

$30 \mathrm{Vgl}$. VI 1987, H. 2, 128f.

311984 wurden drei, 1985 vier Programmentwürfe vorgestellt und diskutiert. Von März bis Oktober 1986 fanden sieben solche Beratungen statt. - VI 1986, H. 5, 91ff; H. 7, 93; H. 9, 116; H. 10,$113 ; 1987$, H. 1,101 .

32 Tichvinskij nannte die folgenden Themen und die dafür Verantwortlichen: „Theorie des weltgeschichtlichen Prozesses" (Z.V. Udal'cova), "Geschichte des sozialistischen Aufbaus in der UdSSR und in anderen Ländern“ (Ju. A. Poljakov), „Geschichte der Entstehung und Entwicklung des multinationalen Russischen Staates“ (I.D. Koval'cenko), „Geschichte des revolutionären Befreiungsprozesses in der Welt" (I.I. Minc), "Geschichte der Außenpolitik der UdSSR und der internationalen Beziehungen“ (A.L. Narǒnickij), „Geschichte der Kultur des russischen Volkes und anderer Völker der UdSSR“ (B.A. Rybakov), "Ethnische Geschichte und gegenwärtige nationale Prozesse“ (Ju.V. Bromlej); „Geschichte der Weltkultur“ (B.B. Piotrovskij), „Rolle der Religion in der Vergangenheit und Gegenwar" (G.M. Bongard-Levin) "Geschichtliche Wege der Entwicklung der Völker Asiens, Afrikas und Lateinamerikas" (G.F. Kim). Die drei zuletzt genannten Prognosen sollten interdisziplinär in der Sektion Gesellschaftswissenschaften der AdW erarbeitet werden. - Siehe VI 1987, H. 3, $96 \mathrm{ff}$.

33 Tichvinskij sagte in der Sitzung am 16.12., jede Prognose solle den Forschungsschwerpunkt begründen, den nationalen und internationalen Forschungsstand charakterisieren, die praktischen und wissenschaftlichen Ziele sowie die Maßnahmen ihrer Realisienung bis zum Jahre 2000 festlegen. In dieser Zeitspanne würden die Institutionen der Geschichtsabteilung ,(..) auf der Grundlage dieser Prognosen und unter Berücksichtigung der angenommenen Komplexprogramme arbeiten." - Siehe VI 1987, H. 3, 96.

34 Für diesen Koordinationsrat hatte M.P. Kim bereits Ende 1982 plädiert, vgl. Kapitel S.3. 
riker auf die in den Prognosen und Programmen festgelegten Forschungsschwerpunkte zu konzentrieren und Überschneidungen zu vermeiden. ${ }^{35}$

Zwei Beiträge im November/Dezember-Heft der Istorija SSSR ${ }^{36}$ dokumentierten, wie stark die führenden Historiker zu dieser Zeit dem bisherigen System und Denken verhaftet waren, und wie sehr dies jedes Bemühen um eine Öffnung lähmte. Der Direktor des Instituts für UdSSR-Geschichte Chromov $^{37}$ wertete die neuen Parteidokumente aus. Er registrierte die ersten, oben skizzierten Korrekturen, die im Rechenschaftsbericht und im Parteiprogramm hinsichtlich der Geschichtswissenschaft gemacht worden waren ${ }^{38}$ In die Auflistung bestehender Mängel und die Verbesserungsvorschläge flo $\beta$ lediglich ein, was an anderer Stelle bereits gesagt worden war. ${ }^{39}$ Die eine oder andere Formulierung mochte Chromovs Wunsch nach Veränderungen ausdrücken, ${ }^{40}$ aber seine Darlegungen blieben allgemein, er löste sich in keinem Punkt von den Vorgaben der KPdSU.

35 Als Vorsitzenden bestimmten die Büromitglieder den Akademischen Sekretär Tichvinskij; seine Stellvertreter wurden I.D. Koval'cenko, Ju.S. Kukuškin und V.A. Kumanev. Wissenschaflicher Sekretär des Rats wurde V.G. Ovčinnikov. - VI 1987, H. 3, 115

36 Diese Artikel müssen spätestens im Juli 1986 abgeschlossen worden sein, denn das Heft 6 der ISSSR ging Anfang August in Satz, und am 13.10.1986 erhielt die Redaktion die Druckerlaubnis. - Siehe ISSSR 1986. H. 6, 223.

37 Semen Spiridonovic Chromov, ein Spezialist für die frühe Sowjetzeit (vgl. seine Monographie über die Tätigkeit von Feliks Dzerł̌inskij an der Spitze der Metallindustrie aus dem Jahre 1966), hatte 1982 A.L. Naroxnickij (den Nachfolger Volobuevs) als Direktor des Instituts fuir Geschichte der UdSSR abgelöst.

38 Siehe Chromov, S.S.: XXVII s-ezd KPSS i nekotorye aktual'nye problemy izučenija otečestvennoj istorii, in: ISSSR 1986, H. 6, 3-20, hier 4ff. Vgl auch die inhaltlich nicht abweichende, fur die KPdSU-Geschichtsschreibung bestimmte Parteitagsauswertung von Egorov, A.G.: XXVII s-ezd KPSS i voprosy marksistsko-leninskoj metodologii, in: VIKPSS 1986, H. 12, 3-26.

39 Chromov kritisierte planloses Veröffentlichen von Arbeiten, die keine gesellschaftliche Resonanz fänden; die unzureichende historische Ausbildung künftiger Juristen. Philosophen, Ökonomen und Philologen; ungelöste organisatorische Probleme, die die Publikationspraxis behinderten: daß unter den Historikern keine schöpferische, streitbare Atmosphäre bestehe; die Gewohnheit. die Geschichte nach politischen Konjunkturen umzuschreiben (kon-junkturšina); die mangelhafte interdisziplinäre Zusammenarbeit. Er schlug vor, die dialektisch-materialistische Methodologie aufmerksamer weiterzuentwickeln (Chromov sprach nur von einer allgemeinen Methodologie, nicht von der Notwendigkeit einer spezifischen Geschichtsmethodologie!); bürgerliche und revisionistische Konzeptionen sachlicher zu kritisieren: Arbeitsergebnisse stärker an qualitativen Kriterien zu messen; die Erforschung der Volksmassen und besonders der Arbeiterklasse in der Geschichte wieder in den Mittelpunkt zu rücken. Inhaltlich bestätigte Chromov die offiziellen Lehrmeinungen zur Geschichte der sowjetischen Gesellschaft. - Chromov, XXVII sezd, 7 ff und $1 \mathrm{Iff}$.

40 In vielen wissenschaftlichen Kollektiven sei die „Krankheit wechselseitigen Lobpreisens“ schon chronisch, so daß, wenn nicht sofortige „Behandlungsmaßnahmen“ ergriffen würden, „(...) der Lebensorganismus der Wissenschaft ernsthaften, unerwünschten Deformationen ausgesetzt werden kann. (...) Auf die verderbliche Praxis der Beweihräuchenung zu verzichten, die Fenster unserer Institute fur frischen Wind der Kritik immer offen zu halten - das ist eine der wichtigsten Lehren aus der Praxis der Vergangenheit, (...).“- Ebd., $15 f$. 
Einen Schritt weiter ging der damals achtundsiebzigiährige Samsonov mit seinem Appell, ,zu neuen Ufern" aufzubrechen. ${ }^{41}$ Der alte Gelehrte legte dar, daß die historische Disziplin sich nicht länger in der passiven Rolle gefallen dürfe, sondern aktiv mit neuen Ideen und Thesen in das geistige Leben der Gesellschaft eingreifen müsse. Er bestand darauf, daß vor allem äußere Einschränkungen und Hindernisse beseitigt werden müßten; implizit kritisierte Samsonov die Parteifühnung und die Zensurbehörden, explizit auch einige willfährige Autoren, die aufgeschlossene Historiker und Schriftsteller ${ }^{42}$,anschwärzten “ ${ }^{43}$ Letztere seien den Wissenschaftlern oft voraus, griffen tabuisierte Themen früher und aufrichtiger auf, könnten aber die historische Forschung nicht ersetzen. ${ }^{44}$ Poeten und Historiker müßten unter den Bedingungen offener Diskussionen und Kritik zusammenarbeiten. Die Kenntnis der Lehren des Vergangenen sei nicht hinderlich, sondern ,einer der wichtigen Faktoren der Vorwärtsbewegung““ ${ }^{45}$ Damit nahm - ein knappes Jahr nach Afanas'ev nun auch Samsonov die prinzipiell neue Position der KPdSU-Führung zur Geschichte aus dem Jahr 1987 partiell vorweg.

Ein weiteres Signal setzten die auf die Erforschung der Oktoberrevolution spezialisierten Historiker mit ihrem Rundtischgespräch am 5. Dezember 1986, dem wohl überhaupt ersten mit vergleichsweise offenen Diskussionsbeiträgen, die - wenn auch erst mehr als sieben Monate später, als sich die Lage an der ,historischen Front" bereits entscheidend geändert hatte - im Wortlaut veröffentlicht wurden. ${ }^{46}$ Pavel Volobuev trat spätestens seit Mitte 1986 wieder regelmäßig im Kreis seiner Fachkollegen auf, und er erinnerte an die zu Beginn der siebziger Jahre abgebrochenen fruchtbaren Forschungsansätze; seitdem habe die Untersuchung der Oktoberrevolution stagniert. ${ }^{47}$ Volobuevs Stellungnahmen hatten umso größere Bedeutung, da der Nestor der Revolutionsforschung Isaac Minc in seinem einleitenden Vortrag am 5. Dezember die „Neue Richtung“ von einst faktisch rehabilitierte: Alle

41 „In einer qualitativ neuen Entwicklungsetappe der sowjetischen Gesellschaft muß auch die vaterländische Geschichtswissenschaft zu neuen Ufern der Erkenntnis von Ereignissen und Lehren der Vergangenheit aufbrechen." - Samsonov, A.M.: K novym rubežam (Strichi problemy), in: ISSSR 1986, H. 6, 61-71, hier 62.

42 Zu diesen zählte Samsonov Anatolij Cepurov, Evgenij Evtušenko und Daniil Granin. - Ebd., 65.

43 Siehe ebd., 61 ff passim. Samsonov erwähnte einen Autor namens P. Ul'jašov, der das Poem „Fuku!" von E. Evtusenko in der Pravda v. 12.01.1986 verrissen hatte.

4 Das zeigte Samsonov u.a. anhand des bereits 1974 veröffentlichten Romans „Der Krieg“ von Ivan Stadnjuk; dort wurde erstmals das Schicksal des auf Stalins Befehl ermordeten Armeegenerals D.G. Pavlov beleuchtet. Stadnjuk stellte den Vorgang allerdings - historisch unkorrekt - so dar, als habe Pavlov zwar keinen Verrat begangen, wohl aber seine Pflicht versäumt; er rechtfertigte das willkürliche Todesurteil Stalins, den er unter anderem als, geistigen Titanen" erscheinen ließ. - Ebd., 68ff; Zaslavsky, In geschlossener Gesellschaft, 12f; Davies, Perestroika, 132.

45 Samsonov, K novym rubežam, 71.

46 IzuCenie istorii Velikogo Oktjabrja. Itogi i perspektivy, in: VI 1987, H. 6, 51-72.

47 Ebd., 57ff. - Analog hatte sich Volobuev im September 1986 bei einem Forum der „Oktober-Historiker" geäußen. Vgl. ISSSR 1987, H. 5, 214ff; VI 1987, H. 4, $119 f$ ff. 
„(..) administrativen, künstlichen, durch Routine bedingten Hindernisse, die der Untersuchung der Voraussetzungen der Oktoberrevolution im Wege stehen", müßten beseitigt, „(..) die Verfahrensweisen und (...) Ergebnisse jener denkwürdigen 'Diskussion' (...) überprüft werden. ${ }^{48}$

Nach der Wiederherstellung des guten Namens der Neuerer durch Minc und nach den Auftritten von Volobuev im Herbst 1986 nahmen die Repräsentanten der „Neuen Richtung“ wieder am wissenschaftlichen Dialog teil. ${ }^{49}$ Zur gleichen Zeit begann die Führung der KPdSU ihre Auffassung zum Problem einer Geschichtsdiskussion zu überdenken. Robert Davies stellte fest:

"Gegen Ende 1986 änderte sich die Haltung (des Politbüros; J.H.) zur sowjetischen Geschichte schlagartig (sharply). "

Das deutete sich bereits während des Schriftstellerkongresses im Juni 1986 an, als eine starke Einschränkung der staatlichen Zensur inoffiziell angekündigt wurde. ${ }^{\text {s1 }}$ In den folgenden Wochen und Monaten kündigten Fernsehen und Printmedien die Publikation lange unterdrückter historischer Romane an. ${ }^{52}$ Einige Zeitschriften,

48 Minz, I.I: Stand und Perspektiven der Forschungen zur Geschichte der Oktoberrevolution (zuerst in VI 1987, H. 4, 3-9), in: SW 1987, H. 5, 443-448, hier 444.

49 Siehe Grunt, A.Ja.: Istoričeskoe tvořestvo narodnych mass $v$ trech rossijskich revoljucijach, in: ISSSR 1987, H. 1, 69-91; Volobuev, P.V.: 1917 god: Rossija na istoriceskom pereput'e, in: Velikij Oktjabr'. Problemy istorii, M. 1987, 5ff; ders., Vybor putej obš̌̌estvennogo razvitija: teorija, istorija, sovremennost', M. 1987, siehe auch ISSSR 1987, H. 5, 218ff, Vinogradov, L.K.: Istoriko-partijnaja nauka puti perestroiki i dal'nejకsego razvitija, in: VIKPSS 1987, H. 7, 137 152.

so Davies, Perestroika, 160; vgl. das englische Original bei Davies, Soviet History, 130. Die Übersetzung des engl. sharply mit schlagartig überbetont den zeitlichen Aspekt. Die Haltung des Politbüros änderte sich jedoch nicht schlagartig-schnell, sondern im Lauf einer monatelangen Diskussion, dann aber inhaltlich sehr deutlich und klar.

s1 Literatur und Perestrojka. Die Diskussion auf dem sowjetischen Schriftstellerkongreß, Köln 1987; Hielscher, K.: Der neue Frühling in Literatur und Kunst, in: Mommsen, M./H.-H. Schröder $(\mathrm{Hg})$ : Gorbatschows Revolution von oben. Dynamik und Widerstände im Reformprozeß der UdSSR, Frankfurt/Main-Berlin 1987, 31-51, hier besonders 32ff; Davies, Perestroika, 160.

32 Siehe Kasack, W.: Literatur und Literaturpolitik in der UdSSR im Wandel. Das Jahr 1986, in: OE 1987, H. 2, 93-105, hier 95ff und $101 \mathrm{ff} ;$ Davies, Perestroika, 160. - Auf ein Massenpublikum stießen umgehend nach ihrer Veröffentlichung vor allem die Romane „Die Ernennung" von Aleksandr Bek (1903-1972), ,Die Kinder vom Arbat" von Anatolij Rybakov (geboren 1911) und „Die weißen Gewänder" von Vladimir Dudincev (geboren 1918), die die Stalinzeit behandeln. Diese Romane hatten etwa zwei Jahrzehnte lang ohne Druckerlaubnis in den Schubladen gelegen und erschienen Ende 1986/Anfang 1987 in den Literaturzeitschriften Znamja, Druzba narodov und Neva; nicht zufällig konnten diese Periodika im Jahr darauf ihre Auflagen erheblich steigern, Znamja um 80,5\%, Družba narodov um 433,3\%, Neva um $89,7 \%$ (jeweils gegenüber der Auflage von 1987). - Siehe MN v. 21.02.1988, 2.

$\mathrm{Zu}$ den Romanen siehe Roman ob odnom romane. $\mathrm{K}$ istorii romana Aleksandra BEKA ,Novoe naznačenie“, in: MN v. 31.05.1987, 16; Istorija bez rebusov i Sarad. Žurnal „Družba narodov“" načinaet pečatat' roman Anatolija Rybakova „Deti Arbata“, in: MN v. 12.04.1987, 11; „So etwas darf sich niemals wiederholen". Der sowjetische Schriftsteller Anatolij Rybakow über Stalin und die Stalin-Zeit, in: Der Spiegel 1987, H. 43, 170-183; Wittstock, U.: Gorbatschows Dichter. Ab- 
Zeitungen und das Staatliche Institut für Geschichte und Archivwesen in Moskau bekamen neue Leiter, die sich bald als leidenschaftliche Reformer herausstellten. ${ }^{53}$

"(...) das alles muß von sehr hoher Stelle im Parteiapparat, vielleicht von Gorbatschow selbst, genehmigt worden sein." $"$ "4

Diese Vermutung von Davies ist auch angesichts eines kritischen ZK-Beschlusses über das Theorieorgan des Zentralkomitees der Partei Kommunist und aufgrund der Allunionskonferenz von Gesellschaftswissenschaftlem im Oktober $1986 \mathrm{zu}$

rechnungen mit Stalin auf der 6. Moskauer Buchmesse, in: FAZ v. 14.09.1987; Walter, K.-P.: Die Zeit arbeitet gegen Stalin. Anatolij Rybakow, Gründungspräsident des sowjetischen PENZentrums, wird achtzig Jahre alt, in: FAZ v. 14.01.1991; Sochina, V./G. Sitkovskij: Eto moja istorija... Oxernenie vsego i vsja - samœe strašnoe, čto sejčas proischodit, in: NG v. 12.10.1994, 5; Dudinzew, W.: Perestrojka? Alle sind pro, wer ist contra? Ein Gespräch mit Igor Gamajunow. 1987, in: Hitzer, F. (Hg.): Zeitzeichen aus der Ferne. Glasnost, Neues Denken in der Sowjetunion, Hamburg 1987, 206-219; Wittstock, U.: Ich freue mich auf scharfe Fragen. Der sowjetische Autor Wladimir Dudinzew in der Bundesrepublik, in: FAZ v. 12.04.1989; vgl. auch die Besprechungen von $M$. Keiper in der UZ v. 20.05. 1989 und von G. Ziegler in der FAZ v. 28.06.1989.

Die Rückkehr dieser und vieler anderer Autoren beobachtend, schrieb Karl Schlögel: .Moskau liest - aufmerksam, konzentriert. Es ist, als ob ein Volk ein zweites Mal lesen lernte." - Schlögel, K.: Im Widerschein des Feuers. Die dramatische Geschichte der Sowjetunion erfaßt die Lebenden, in: FAZ v. 21.11.1987.

33 Beispielsweise die neuen Chefredakteure Sergej Salygin bei Novyj mir. Grigori Baklanov bei Znamja, Egor Jakovlev bei Maskovskie novosti, und besonders Jurij Afanas'ev als Rektor des genannten Instituts; siehe Kapitel 6; Davies, Perestroika, 160.

s4 Davies, Perestroika, $160 \mathrm{f}$. 
bekräftigen. In dem Beschluß forderte das Zentralkomitee die Redaktion und die Autoren der Zeitschrift auf, sich stärker für den neuen politischen Kurs und bei der theoretischen Durchdringung der aktuellen Probleme zu engagieren. ${ }^{55}$ Zum erstenmal seit Chruščev appellierte die Parteifuhrung wieder an Ökonomen, Philosophen und Historiker, sich von den bisher gültigen Dogmen zu lösen. Schärfer als je zuvor kritisierte Gorbačev im Oktober 1986 vor den Wissenschaftlem die „Scholastik“ und „Langeweile“, den „Dogmatismus" und „Formalismus“, welche die Gesellschaftswissenschaften seiner Ansicht nach prägten. Dadurch, so Gorbačev, werde "die gesamte emotionale Anziehungskraft des Ideengehaltes des Marxismus-Leninismus" zunichte gemacht. ${ }^{56}$ Auch die Tatsache, daß das für September 1986 angesetzte ZK-Plenum aufgrund andauernder Diskussionen dreimal verschoben wurde, ${ }^{57}$ deutete darauf hin, daB die Parteiführung ihre bisherige $\mathrm{Ab}$ lehnung einer öffentlichen und professionellen Geschichtsdebatte zu revidieren beabsichtigte. Die Anzeichen bestätigten sich zu Beginn des Jahres 1987.

s5 O žurnale „Kommunist“. Postanovlenie CK KPSS, in: K 1986, H. 12, 3-10.

36 Gorbacev, M.S.: Učit' po-novomu myslit' i dejstvovat'. Vsesojuznoe sovešcanie zavectujuščich kafedrami obšcestvennych nauk, in: K 1986, H. 15, 3-7, hier 4f.

57 „Es fand erst - nach insgesamt dreimaliger Vertagung - vom 27. bis 28. Januar 1987 statt.“ - Brahm, H.: Gorbatschows erste Schritte, in: Sowjetunion 1987, 21-33, hier 29. 
ond And

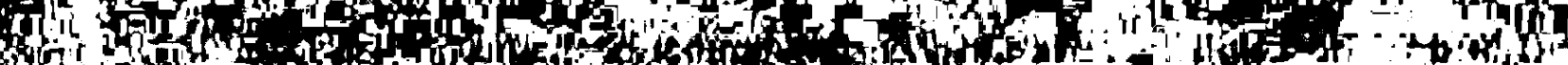

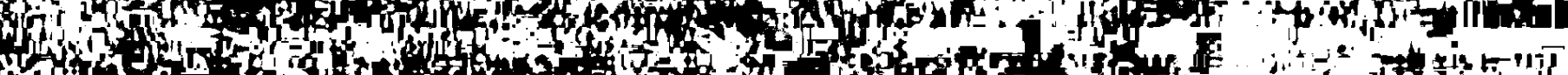
4ho

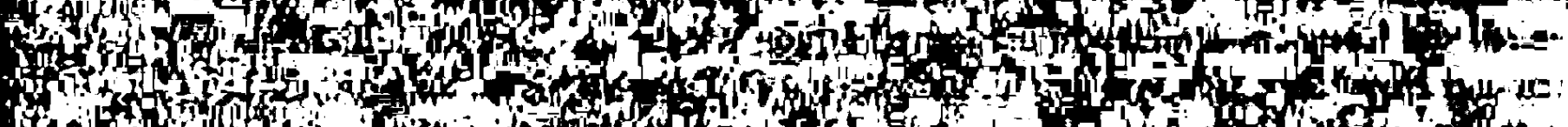

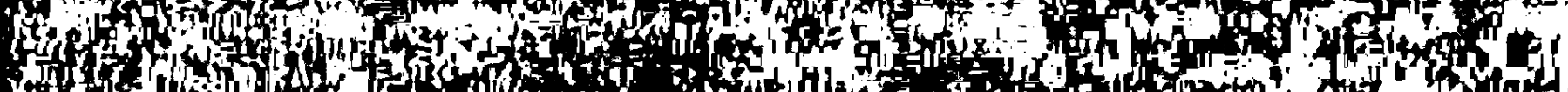

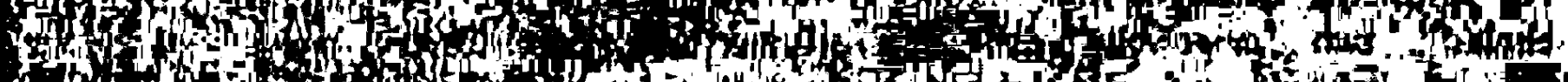

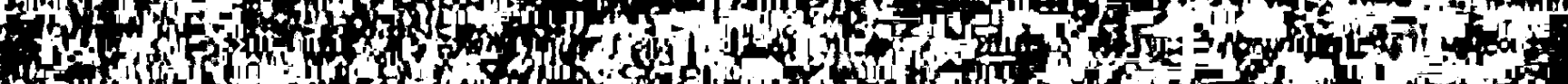

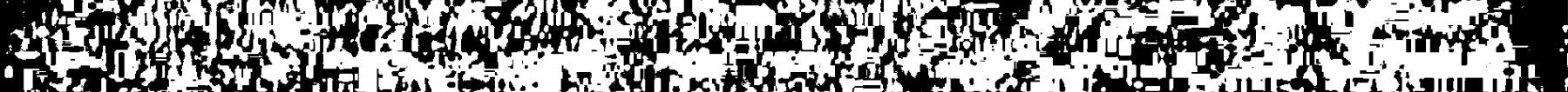

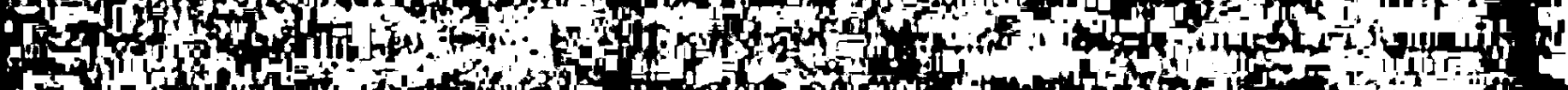

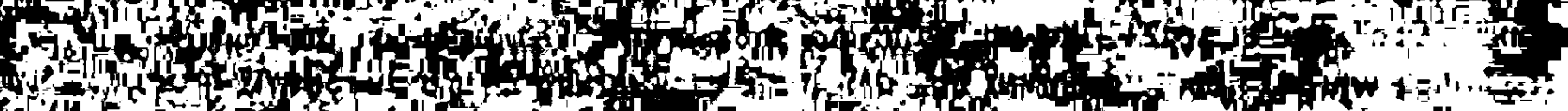

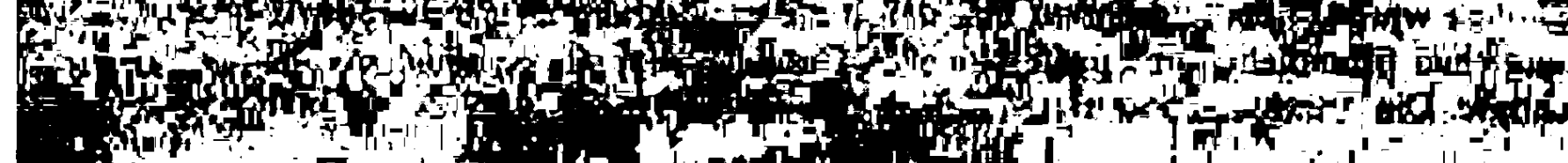

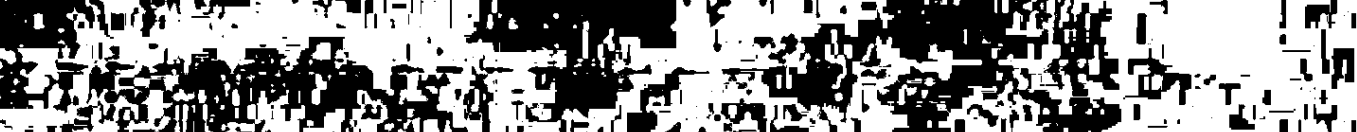

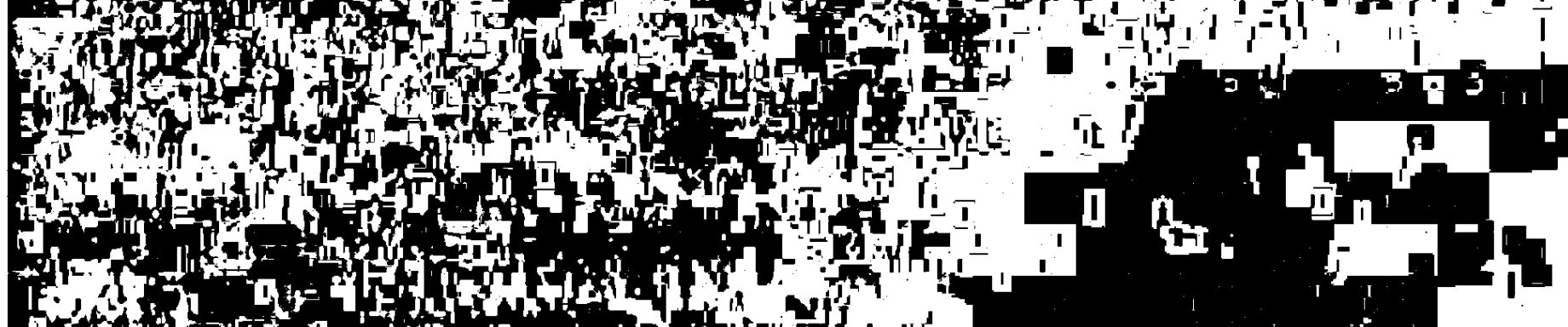

(3)

rof

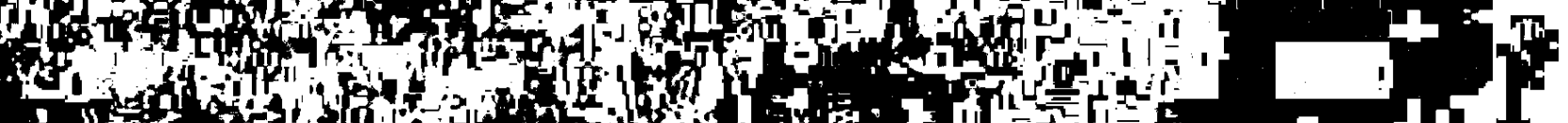

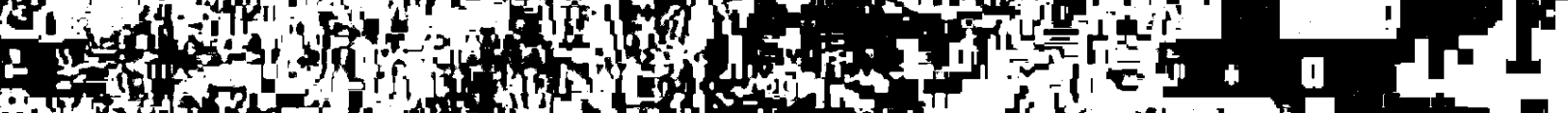
hive H. If

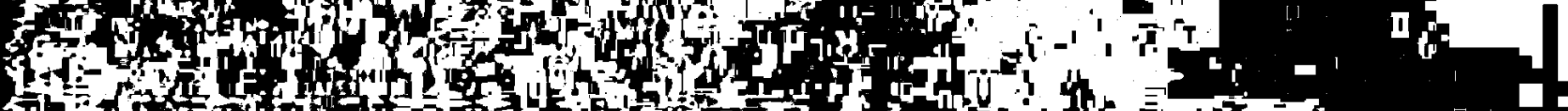

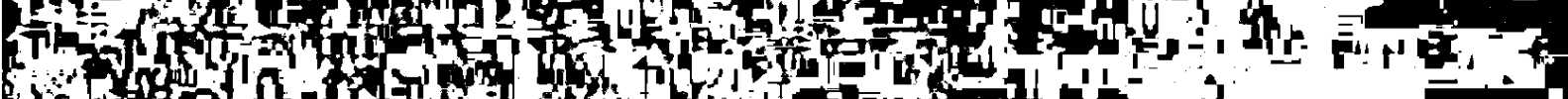

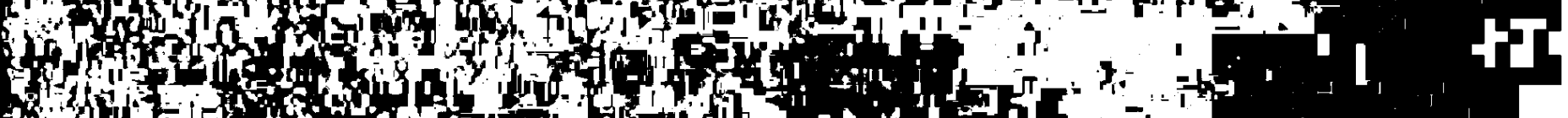

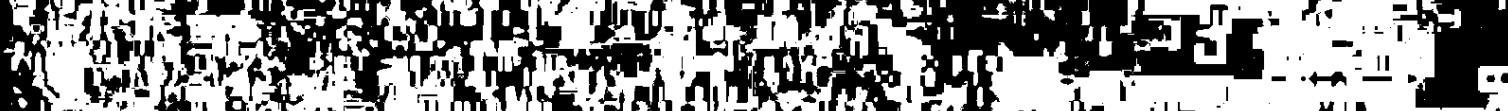

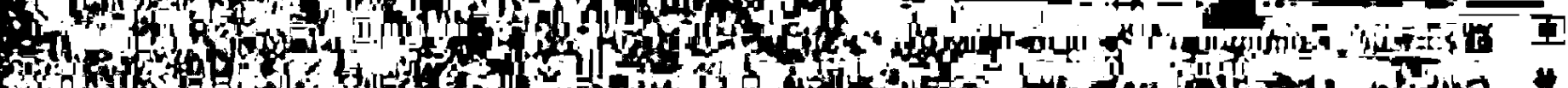

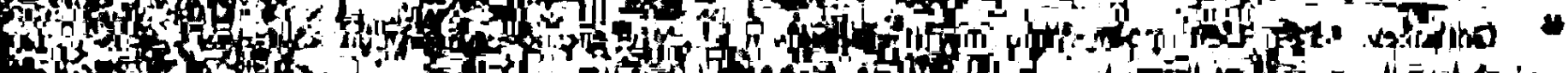

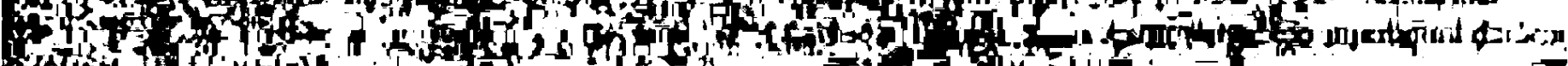

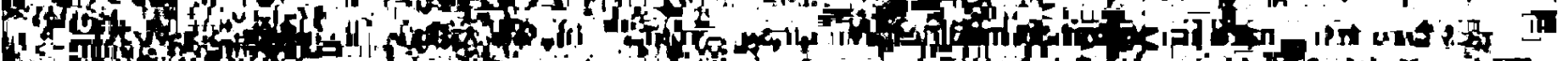
6. 1 inf Fis ald

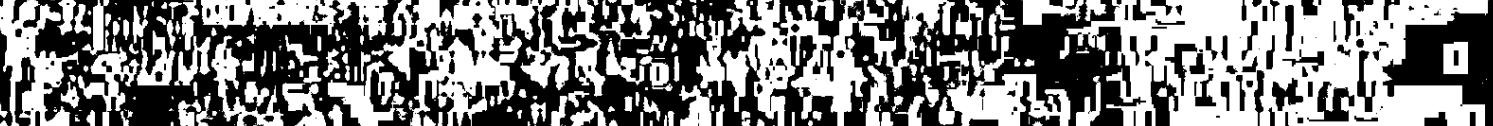
She

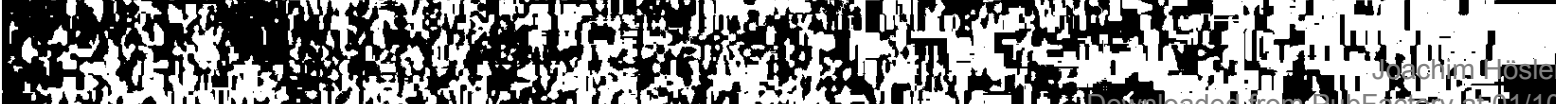

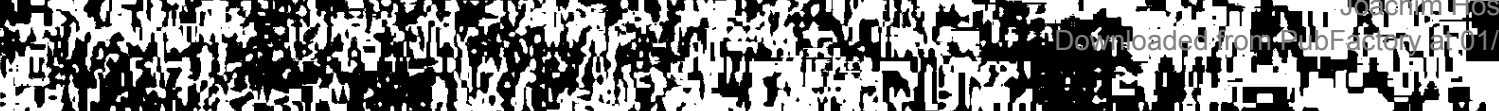




\section{Die letzte Etappe der sowjetischen Geschichtswissenschaft 1987-1991: Aufbruch - Umbruch - Abbruch}

Erst in Gorbačevs drittem Amtsjahr Anfang 1987 - nach den Etappen des Aufbaus, der Stalinisienung, der Entstalinisienung und der Retardation - begann die fünte, kürzeste und letzte Etappe der sowjetischen Geschichtswissenschaft. Jetzt erst trat die historische Zunft als Ganzes mit in die Geschichtsdiskussion ein. Hier soll zunächst im Rahmen der Perioden der Umgestaltung das Verhältnis von Politik und Geschichtswissenschaft beleuchtet werden (6.1.). Nur ein kurzer Blick wird auf die allgemeine Geschichtsdiskussion, die sogenannte Liquidienung weißer Flecken, geworfen, da dieses Phänomen bereits bestens dokumentiert und interpretiert worden ist, ${ }^{1}$ und eine detaillierte Analyse den Rahmen dieser Arbeit sprengen würde.

\footnotetext{
1 Bonwetsch, B.: Die Bewältigung der Vergangenheit. Geschichts- und Gesellschaftswissenschaften in der "Perestrojka”, in: Mommsen/Schröder, Gorbatschows Revolution, 74-88; Geyer, D.: Perestrojka und die sowjetische Geschichte, in: GuG 1989, H. 3, 303-319; Fedossow, P.: .glasnost" und ,perestrojka" machen auch um die Geschichte keinen Bogen. Entwicklungen und Diskussionen in der Sowjetunion, in: Blätter 1987, H. 9, 1152-1164; Fedossow, P.: Die Geschichtsdebatte in der Sowjetunion wird schärfer, in: Blätter 1988, H. 4, 473-485, Rejman, M.: Perestrojka i izuðenie sovetskoj istorii, in: VI 1989, H. 12, 145-158; Laqueur, W.: Stalin. Abrechnung im Zeichen von Glasnost, München 1990; Wheatcrof, Unleashing the energy; ders., Steadying the energy; Sherlock, Politics; Hagen, History; Meyer, Wir brauchen die Wahrheit; Wada. H.: Perestroika and the Rethinking of History in the Soviet Union, 1986-88, in: Ito, Facing Up to the Past, 35-79; Liszkowski, Die Revision; Davies, Perestroika; Geyer, Die Umwertung.
} 
Wie in den anderen Kapiteln auch, bleiben dabei die Probleme der vorrevolutionären Geschichte Rußlands ${ }^{2}$, der Geschichte der KPdSU ${ }^{3}$ und der Umschreibung der Schulbücher ${ }^{4}$ außen vor (6.2.). Im Anschluß daran wird anhand von drei geschichtsmethodologischen Problemen analysiert, inwieweit der neugewonnene Freiraum genutzt wurde, um die vor knapp zwei Jahrzehnten abgebrochenen Debatten wieder aufzugreifen und fortzufüren (6.3. bis 6.5.).

Siehe dazu Torke, H.-J.: The History of Pre-Revolutionary Russia in the Current Debate of Soviet Historians, in: Ito, Facing up to the Past, 97-109; Kuryuzawa, T.: The Debate of Russian Feudalism in Recent Soviet Historiography, in: Ito, Facing up to the Past, 111-147; Davies, Perestroika, 22-42; McKean, R.B. (Ed.): New Perspectives in Modern Russian history, London 1992.

3 Vgl. Enteen, G.M.: Problems of CPSU historiography, in: Problems of Communism 1989, H. 5, 72-80.

4 Dazu Husband, W.B.: Rewriting Soviet History Texts: The First Phase, in: Ito, Facing up to the Past 1989, 81-94; Davies, Perestroika, 217-224. 


\subsection{Die Umgestaltungspolitik und die Geschichtswissenschaft 1987 bis 1991}

Orientiert man sich an den von der KPdSU-Führung verfolgten Hauptzielen der Umgestaltungspolitik und an den zentralen ökonomischen, sozialen, politischen und nationalen Problemen der Gesellschaft, so sind $m$.E. fünf Phasen der Reformpolitik zu unterscheiden: erstens der Prolog von 1982 bis 1985, zweitens der Versuch der „Beschleunigung“ der sozialökonomischen Entwicklung (März 1985 bis Ende 1986), drittens die Hoch-Zeit der perestrojka (1987), viertens die Transformation (Anfang 1988 bis Ende 1989) und fünttens die Agonie des Systems (1990 bis Dezember 1991). ${ }^{1}$ Es wurde bereits dargelegt, daß die offiziellen Geschichtsauffassungen des Politbüros der KPdSU und der führenden Organe der sowjetischen historischen Disziplin während des Prologs, als unter Andropov das „Experiment im großen Maßstab“ eingeleitet worden ist, und während Gorbacevs erstem Amtsjahr, als die sozialökonomische Entwicklung beschleunigt werden sollte, im wesentlichen unverändert blieben. In diesem Kapitel sind die drei weiteren Phasen der Umgestaltungspolitik und die sich verändernde Haltung der KPdSU-Führung zur Geschichte zu charakterisieren. Vor diesem Hintergrund werden die Einmischungen der ,führenden" Historiker, d.h. der Akademiemitglieder, Institutsdirektoren, Leiter von Redaktionskollegien usw. zur Geschichtsdebatte während dieser Phasen untersucht.

\subsubsection{Der Aufbruch während der „Perestrojka-Flitterwochen ${ }^{62} 1987$}

Nach dem 27. Parteitag der KPdSU begann - mitausgelöst von der Atom-Katastrophe in Cernobyl am 26. April $1986^{3}-$ bei Gorbacev und seinen Beratern das

Vgl die leicht abweichende Periodisienung bei Kux, S.: Demokratisierung und Föderalisierung. Das politische System der ehemaligen UdSSR im Wandel, in: Veen, H.-J./P.R. Weilemann (Hg.): Rußland auf dem Weg zur Demokratie? Politik und Parteien in der Russischen Föderation, Paderborn 1993, 43-78, hier 50ff, und die faktenreiche Darstellung und Dokumentation von Simon, G.N. Simon: Verfall und Untergang des sowjetischen Imperiums, München 1993.

2 So bezeichnete Boris Kagarlickij die kurze Blüte von Gorbačevs glasnost'- und perestrojkaPolitik. - Kagarlickij, B.: „Wir sind der linke Flügel der Perestrojka“ (Interview), in: Arbeiterkampf v. 07.03.1988, 10 f.

3 „Beim Reaktorunfall von Tschernobyl im April 1986 sind vermutlich radioaktive Teilchen mit einer Gesamtstrahlung von etwa 185 Millionen Curie freigesetzt worden. Das ist etwa vierbis funfmal soviel wie in Moskau seinerzeit angegeben wurde." - „Tschernobyl und kein Ende“, in: FAZ v. 23.02 1994, Nl; vgl. Baier, W.: Eine Anlage zur kontinuierlichen Gewinnung von Bomben-Plutonium. Warum der sowjetische Reaktor vom Typ Tschernobyl eine so exotische und systemimmanent äußerst gefährliche Konstruktion besaß, in: FR v. 22.04.1989, 13 (mit Hinweisen auf weiterführende Spezialliteratur); Medwedew, G.: Verbrannte Seelen. Die Katastrophe von Tschernobyl, München 1991; Medwedjew, Z.: Das Vermächtnis von Tschernobyl, Münster 1991; OE 1991, H. 7, A 369-A 383. 
Nachdenken über die Notwendigkeit, die Reformen radikaler und umfassender zu implementieren. ${ }^{4}$ Einer der engsten Berater des Generalsekretärs, Anatolij Cernaev, erinnerte sich 1993 an die ,rasche Entideologisierung“ des Denkens Gorbačevs im Sommer 1986. ${ }^{5}$ Für Gorbačev sei die umfassende Demokratisienung der Gesellschaft zum wichtigsten Anliegen geworden. ${ }^{6}$ Die wiederholte statutenwidrige Verschiebung des für September 1986 angesetzten ZK-Plenums nutzte Gorbačev, um seine neuen Positionen im Politbüro und im Parteiapparat zu verankern, wobei das Politbüro wiederholt schon am Rande einer ,Spaltung“ (Gorbačev) gestanden haben soll. ${ }^{7}$ Das schließlich Ende Januar 1987 abgehaltene ZK-Plenum markiert den Beginn der dritten Phase, der Hoch-Zeit der perestrojka, die m.E. nur gut ein Jahr lang währte. Die Verlautbarungen Gorbačevs und seiner Mannschaft während des Plenums und im Frühjahr 1987 zeigten, daß es nicht mehr nur um die Effektivierung des bestehenden Systems, sondern um dessen „Umgestaltung“ ging. ${ }^{8}$ Die Demokratisienung der Partei und Gesellschaft erklärte Gorbačev zum „Herzstück“ seiner Politik. ${ }^{9}$ Fraglos war eine sozialistische Gesellschaft anvisiert. ${ }^{10}$

Radikal änderte sich die offizielle KPdSU-Position zur Aufarbeitung der Geschichte: Hieß es 1986 noch, letztere behindere Reformen, so wurde nun das Schicksal der perestrojka damit verknüpft. ${ }^{11}$ Die neue Offenheit (glasnost') sollte nicht nur

\footnotetext{
4 Siehe Wada, Perestroika, 36; Haug, Gorbatschow, 96ff.

3 Tschernajew, Die letzten Jahre, 86
}

- Auch habe Gorbačev bereits Ende 1986 ein besonderes ZK-Plenum, das sich mit den Beziehungen zwischen den Sowjetrepubliken befassen sollte, für nötig gehalten. - Ebd., $116 \mathrm{f}$.

7 Ebd., 115.

8 Zu den sozialökonomischen Dimensionen siehe Gorbatschow, M.: Wir brauchen Demokratie wie die Luft zum Atmen! Die Dokumente des Plenums des Zentralkomitees der KPdSU am 27./28. Januar 1987 im Wortlaut, in: Blätter 1987, H. 3, 377-438, hier 380-392, ders., Perestroika. Die zweite russische Revolution. Eine neue Politik für Europa und die Welt, München 1987, 103-128. Vgl. die Analysen bei Götz-Coenenberg, R.: Manager gegen Bürokraten. Probleme bei der Umgestaltung des sowjetischen Wirtschaftssystems, in: Mommsen/Schröder, Gorbatschows Revolution, 157-174; Lewin, M.: Gorbatschows neue Politik. Die reformierte Realität und die Wirklichkeit der Reformen, Frankfurt/Main 1988, 117-123; Segbers, Der sowjetische Systemwandel, 223ff; Conert, Die Ökonomie, 127ff.

9 Die Rede Michail Gorbatschows vom 2. November 1987 aus Anlaß des 70. Jahrestages der Oktoberrevolution (Auszüge), in: Blätter 1987, H. 12, 1602-1616, hier 1609; vgl. Gorbatschow, Wir brauchen Demokratie, 393ff; Gorbatschow, M.: Perestroika. Die zweite Etappe hat begonnen. Eine Debatte über die Zukunft der Reformpolitik, Köln 1988, hier 21.

10 „Die Umgestaltung stellt die Aufgabe, den Sozialismus als Ganzes zu erneuern und nicht einfach nur einzelne Seiten, Bereiche und Randgebiete zu vervollkommnen." - Jakowlew, A.: Die Sicherung einer neuen Qualität der sowjetischen Gesellschaft und die Gesellschaftswissenschaften, in: Umbruch in der Sowjetunion. Sowjetische Autoren über die Umgestaltung 70 Jahre nach der Oktoberrevolution, Düsseldorf 1987, 195-243, hier $216 \mathrm{f}$ (vgl. die russische Fassung in: K 1987, H. 8, 3-22, hier 11); vgl. ders., Die humanistische Orientierung der Perestroika, in: PFS 1989, H. 2, 156-165, besonders 160ff; Medvedev, V.A: Velikij Oktjabr' i sovremennyj mir, in: Velikij Oktjabr' i mirovoe razvitie: Materialy sekcionnogo zasedanija. M. 1988, 5-28, hier $12 \mathrm{ff}$.

11 „Die Kritik an der Vergangenheit gibt (...) die Möglichkeit, Lehren und Schlußfolgerungen für den heutigen und morgigen Tag zu ziehen, sie unterstützt das konstruktive Herangehen bei 
für die Gegenwart, sondern auch für die Geschichtsdiskussion gelten. ${ }^{12}$ Der für Ideologie- und Wissenschaftsentwicklung zuständige ZK-Sekretär Aleksandr Jakovlev - ein gelemter Historiker - las den Gesellschaftswissenschaftlern am 17. April 1987 in der Akademie der Wissenschaften nicht nur die Leviten, ${ }^{13}$ sondern er kündigte revolutionär anmutende Veränderungen innerhalb der wissenschaftlichen Disziplinen sowie in dem Verhältnis zwischen den Gesellschaftswissenschaften und der KPdSU an: Nachdem Jakovlev den Philosophen, den Fachleuten für „wissenschaftlichen Kommunismus“ und den Soziologen ein niedriges professionelles Niveau bescheinigt hatte, wandte er sich der Geschichtswissenschaft zu: $\mathrm{Zu}$ wenige Historiker beschäftigten sich ,(...) mit einem selbständigen Studium der Quellen und mit der Ausarbeitung wissenschaftlicher Ideen oder mit dem kritischen Überdenken veralteter Vorstellungen.“ „Vulgärsoziologie“ und „Faktenillustrationen" seien weit verbreitet. Jakovlev warnte allerdings auch vor Tendenzen, die sowjetische Geschichte nicht mehr vom Klassenstandpunkt aus zu beurteilen und die vorrevolutionäre Geschichte Rußlands zu beschönigen. In der Parteigeschichte seien viele erstrangige Fragen noch unerforscht.

„Die Verletzung des Historismusprinzips, die Entpersönlichung des historischen Prozesses, 'weiße Flecken' im Bereich ganzer Geschichtsperioden, Schematismus und farblose Darlegungen sind nur einige der gerechtfertigten Vorwürfe."

Demokratie, Toleranz, Publizität und Gleichberechtigung bezeichnete Jakovlev als Elemente einer wissenschaftlichen Ethik, die künftig - anstelle der bisherigen Gängelung - der Wissenschaftsentwicklung zugrundeliegen sollte. Nach der jahrzehntelangen Praxis der Überwachung wollte Jakovlev nun ,die Autorität des Denkens“ derjenigen von Dienststellen überordnen:

„Es darf nicht geduldet werden, daß es ein Beamtenmonopol auf die Wahrheit gibt, daß bei der geistigen Arbeit nicht die Wahrheit, sondern die Dienststelle das letzte Wort hat. (...) Die Wissenschaft kann sich nur bei konstruktiven Diskussionen, beim Zusammenprall von Meinungen entwickeln."

Ohne ihre Namen zu nennen, hatte Jakovlev damit A. Pankratova, E. Burdžalov, M. Gefter, A. Gurevix̌ und die vielen anderen Historikerinnen und Historiker, die in den füfziger und sechziger Jahren repressiert worden waren, weil sie mit genau dieser Haltung neue Gedanken in die Forschung eingebracht hatten, rehabilitiert. ${ }^{14}$

der richtigen Wahl der Mittel und Wege des Voranschreitens." - Gorbatschow, Wir brauchen Demokratie, 386; vgl. Wheatcrof, Unleashing the energy, $85 \mathrm{ff}$.

12 „Das Volk braucht die ganze Wahrheit“, sagte Gorbačev am 28.01.1987 in seinem Schlußwort vor den Mitgliedern des Zentralkomitees, und er bekräftigte die neue Haltung des Politbüros im Februar und im Juli des gleichen Jahres bei seinen Treffen mit Journalisten. - Gorbatschow, Wir brauchen Demokratie, 436; Davies, Perestroika, $161 \mathrm{ff}$.

13 Jakowlew, Die Sicherung, 234-238; vgl. K 1987, H. 8, 19 f.

14 Als einer der ersten fragte Jakovlev auch, ob es Alternativen beim wirtschaftichen Aufbau der Sowjetunion gegeben habe. - Jakowlew, Die Sicherung, 239f, vgl. K 1987, H. 8, 21; Davies, Perestroika, 161f; Sherlock, Politics, 18. 
Allerdings war die Fühnung der KPdSU in der Haltung gegenüber der Geschichtswissenschaft und -diskussion gespalten, was Robert Davies sorgfaltig belegt hat. ${ }^{15}$ Die Dissonanz reflektierte auch die mit Spannung erwartete Ansprache Gorbačevs anläßlich des 70 . Jahrestags der Oktoberrevolution, die ,a mixture of innovation and traditional views" (Wada) darstellte. ${ }^{16}$ Der Generalsekretär verurteilte den „Trotzkismus“, kritisierte die angeblich dogmatische und undialektische Lageeinschätzung Bucharins und seiner Anhänger Ende der zwanziger Jahre, negierte eine historische Alternative zu der von Stalin durchgepeitschten Industrialisierung und Kollektivienung, und er verteidigte den deutsch-sowjetischen Nichtangriffsvertrag von 1939. ${ }^{17}$ Aber erstmals seit Chruščev sprach ein Parteivorsitzender wieder über „Verluste" und „die Repressalien der 30er Jahre“. ${ }^{18}$ Wenn das auch noch immer nicht mit der erforderlichen Offenheit geschah, so ging Gorbačev dennoch weit über Chrušcevs Rede von 1956 hinaus, als er das ,administrative Weisungssystem", die behördliche Ignoranz gegenüber der Landbevölkerung, die Doktrin von der „Verschärfung des Klassenkampfs“ und die fehlende Demokratisierung der sowjetischen Gesellschaft als Ursachen des Personenkults und der Verbrechen nannte. ${ }^{19}$ Gorbačev teilte mit, das Politbüro habe eine Kommission gebildet, um die mit den Repressionen der dreißiger und vierziger Jahre verknüpften Materialien zu untersuchen, weil Mitte der sechziger Jahre der „Prozeß der Wiederherstellung der Gerechtigkeit (...) praktisch eingestellt" worden sei. ${ }^{20}$ En pas-

is Der Sekretär des Schriftstellerverbandes. Karpov, der Chefredakteur der Izvestija, I. Laptev, der ZK-Sekretär E. LigaCev, der damalige KGB-Chef V. Cebrikov u.a. kritisierten die beginnende Umwertung der Geschichte und warnten vor einem ,politischen und ideologischen Pluralismus" (Čebrikov). Die wiederholten Störaktionen des ZK-Sekretärs Ligað̌ev veranlaßten Haruki Wada (Tokyo) zu der - m.E. nicht überzeugenden - Annahme einer ,Ligačev-Periode“, die von November 1987 bis April 1988 gedauert habe: "It was a strange time of stepping down of perestroika." Wada selbst räumte ein, daß Ligałev nur eine sehr begrenzte Kontrolle ausüben und nicht verhindern konnte, daß Ende 1987 die Stalinismus-Diskussion begann. Wada konnte auch die Veränderungen bei den etablierten Historikern nicht übersehen: „Finally at this moment we can see that real changes started also in the official sphere of historical science." - Wada. Perestroika, 48ff und 52 (Kursiv im Original); vgl. Davies, Perestroika, $162 \mathrm{f}$ und 166; Wheatcroft, Steadying the energy, 77ff.

16 Wada, Perestroika, 47; vgl. auch Hagen, History, 2f; Wheatcroft, Steadying the energy, 87ff: Broue, P.: Gorbachev and history, in: White, St. (Ed.): New directions in Soviet history, Cambridge 1992, 3-23, hier $3 \mathrm{ff}$.

17 Die Rede, 1603ff.

18 „Es gab - ich sage das offen - regelrechte Verbrechen durch Machtmißbrauch. Massenrepressalien waren Tausende und aber Tausende von Parteimitgliedern und Parteilosen ausgesetzt. (...) Heute wissen wir, daß die politischen Anklagen und Repressalien gegen eine Reihe von Partei- und Staatsfunktionären, gegen viele Kommunisten und Parteilose, Wirtschaftskader und Militärs, Wissenschaftler und Kulturschaffende auf vorsätzliche Fälschungen zurückgingen." Ebd., $1606 f$.

19 Ebd., 1605ff. Vgl. Davies, Perestroika, 167f.

20 Dieser „Kommission beim Politbüro des ZK der KPdSU zum ergänzenden Studium des Materials, das im Zusammenhang mit den Repressionen der dreißiger, vierziger und zum Beginn der fünfziger Jahre steht“, gehörten M.S. Solomencev (als Vorsitzender), V.M. Cebrikov, A.N. Jakovlev, P.N. Demičev, A.I. Luk'janov, G.P. Razumovskij, V.I. Boldin und G.L. Smirnov an. 
sant rehabilitierte Gorbačev in seiner Ansprache die zu Beginn der siebziger Jahre verurteilte „Neue Richtung“ der Oktoberrevolutionsforschung und befürwortete weitere Untersuchungen der sozialökonomischen Heterogenität des vorrevolutionären Rußlands, was die Rückkehr damals verfemter Historiker an ihre alten Wirkungsstätten und die Fachdiskussion über die Revolution förderte. ${ }^{21}$ Von größter Bedeutung war die Tatsache, daß Gorbačev und seine Vertrauten die Rede lediglich als Problemaufriß verstanden. ${ }^{22}$ Die Zeiten, in denen Historiker nur die Formulierungen des Generalsekretärs, ,nachzubeten" hatten, sollten der Vergangenheit angehören. Versuchte Gorbacev, mit einer zentristischen Position die Konservativen zu gewinnen, ${ }^{23}$ so dominierte in praxi die Geschichtsaufarbeitung, bei der die KPdSU die führende Kraft sein sollte. Davon zeugen die vom Politbüro schon von April 1985 an veranlaßten Rehabilitierungen ehedem Repressierter. Unter ihnen befanden sich auffallend viele ,prominente Ex-Trotzkisten"(Sherlock). ${ }^{24}$

Es war kein nominell führender Historiker, sondern ein zur mittleren Generation gehörender wissenschaftlicher Mitarbeiter des Instituts für UdSSR-Geschichte, V.A. Kozlov, der nach dem radikalen Positionswandel der KPdSU-Führung die notwendigen Fragen an die historische Zunft richtete:

Eine weitere Kommission wurde beauftragt, einen neuen Abriß der KPdSU-Geschichte vorzubereiten. - Die Rede, 1607; Katkov, N.F.: Vosstanovlenie istoriceskoj pravdy i spravedlivosti (Chronika reabilitacii 7.ertv politiðeskich repressij 20-50-ch godov), in: VIKPSS 1991, H. 9, 8392, hier 86

21 Siehe dazu den vollständigen Text der Ansprache Gorbacevs in: SU-heute, Sondernummer, November 1987, 6; vgl. Kapitel 6.2.

22 „Wir kennen unsere Geschichte (...) jetzt tatsächlich besser. Zugleich ist jenes Verständnis unserer Geschichte, das wir bei der Vorbereitung auf den 70. Jahrestag der Oktoberrevolution erreichten, keineswegs etwas Starres, ein fur allemal Gegebenes. Es wird durch weitere Studien vertieft und weiterentwickelt werden." - Gorbatschow, Perestroika 1988, 14; analog äußerten sich Jakowlew, A.: Die Oktoberrevolution, die Umgestaltung und die Welt von heute (Pressekonferenz), in: SU-heute 1987, H. 12, Beilage, IV und der Direktor des Instituts für MarxismusLeninismus beim ZK der KPdSU, Smirnov, G.: Humanisienung der Geschichte. Die sowjetische Geschichtsforschung nach dem 70. Jahrestag der Oktoberrevolution, in: UZ v. 04.12.1987; vgl. Wada, Perestroika, 48

23 Wiederholt betonte Gorbačv ostentativ, auch er teile die Sorge, daß die sowjetische Geschichte nun einseitig negativ dargestellt werde. Der Chef der ZK-Abteilung fur Wissenschaft und Bildung V.A. Grigor'ev - der direkte Nachfolger von S.P. Trapeznikov - verurteilte Mitte 1987 ,beide Extreme“ - das Festhalten an überholten Konzeptionen und das übereilte Umschreiben der ganzen Geschichte. - Siehe Davies, Perestroika, 163ff; vgl. Meissner, B.: Gorbatschow am ,Rubikon“, in: OE 1988, H. 11, 981-1001; H. 12,1061-1090, hier 984ff.

24 Nach D.D. Pletnev (rehabilitiert am 05.04.1985) und N.I. Muralov (April 1986) wurde im Juli 1987 mit G.F. Grinko, der gemeinsam mit Pletnev vor Gericht gestanden hatte, der dritte "Trotzkist" rehabilitiert. - Am 16.07.1987 murden füfzehn prominente Wirtschaftswissenschaftler, die 1931 bis 1935 verurteilt worden waren (darunter N.D. Kondrat'ev, A.V. Cajanov) rehabilitiert. Vom Obersten Gericht der UdSSR wurden von 1985 bis September 1987 insgesamt ungefähr vierhundert Personen rehabilitiert. - Siehe Wheatcroft, Glasnast', 211; Tischler, C.: „Den guten Namen wiederherstellen“. Über die Rehabilitierung von Stalin-Opfern in der Sowjetunion, in: JHK 1993, 118-125, hier 122; Sherlock, Politics, 26. 


\begin{abstract}
„Werden sie (die Historiker; J.H.) lediglich die Ereignisse registrieren, oder aber werden sie die heutige soziale Praxis durch die theoretisch aufbereitete historische Erfahrung bereichern? Werden sie das Bedürfnis der heutigen Menschen nach Kenntnis der Vergangenheit und Gegenwart befriedigen, oder müssen sich diese an die Belletristik und die Publizistik wenden (...)? Werden die Historiker in der Lage sein, einem großen Leserkreis die konkret-historischen Gesetzmäßigkeiten der gesellschaftlichen Entwicklung näherzubringen, oder liefern sie lediglich Faktenmaterial?
\end{abstract}

Sensibel beschrieb Kozlov die Verunsicherung vor allem seiner auf die Sowjetzeit spezialisierten Kollegen ${ }^{26}$ Er verdeutlichte, daß nicht nur die äußeren Bedingungen der Wissenschaftsentwicklung zu verändern seien, sondern auch der bisherige „Mangel an methodologischer Kultur“ behoben werden müsse, und stellte klar:

„Niemand löst für uns, die Historiker, die Fragen unseres Faches.“27

Anhand der zentralen Fachzeitschriften und der Geschehnisse in der Geschichtsabteilung an der Akademie der Wissenschaften ist zu erkennen, daß die Leitungsorgane der sowjetischen Geschichtswissenschaft mit der ihnen eigenen Behäbigkeit allmählich mobil wurden. In der ersten Sitzung des Abteilungsbüros nach dem aufsehenerregenden ZK-Plenum übernahm der Akademische Sekretär Tichvinskij den Terminus perestrojka für die Historie. ${ }^{28}$ Seine Ausführungen und diejenigen der Instituts-Direktoren blieben allerdings farblos und formal. ${ }^{29}$ Erst die Jahreshauptversammlung der Geschichtsabteilung am 9. März 1987 signalisierte das Erwachen der etablierten Historiker. Offener als je zuvor benannte Tichvinskij Mängel der geschichtswissenschaftlichen Arbeit und einige ihrer Ursachen. Einseitige Interpretationen und Wertungen, scholastisches Politisieren und konjunkturbedingte Konstruktionen, Simplifizienungen und das Vergessen von Widersprüchen, das Verschweigen ganzer historischer Etappen, von Ereignissen und Persönlichkeiten, nationalistische Idealisierungen, das Fehlen von Klassenanalysen, methodologischen Arbeiten und von schöpferischen Diskussionen ,als Triebkraft der Geschichtswis-

2s Koslow, W.A.: Der Historiker und die Umgestaltung, in: Meyer, Wir brauchen die Wahrheit, 64-77, hier 64 (Erstveröffentlichung in VIKPSS 1987, H. 5, 110-122).

26 „Die wissenschaftlichen Räte und die Verlage beginnen bereits (...), Bücher zurückzuweisen, die noch gestern ohne Beanstandung 'durchgegangen' wären. Die historischen Zeitschriften finden allmählich Geschmack an polemischen und kritischen Veröffentlichungen. In Zeitungen werden regelmäßig Leserbriefe mit Fragen veröffentlicht, auf die nicht einmal in historischen Spezialuntersuchungen, geschweige denn in den Lehrbüchern, eine Antwort zu finden ist. (...) Gleichzeitig aber erscheinen nach wie vor Bücher und Artikel, bei denen nur am Erscheinungsjahr und an der modernisienten Terminologie zu erkennen ist, daß sie in unserer Zeit fertiggestellt wurden." - Ebd., $64 f$.

27 Ebd., 66ff passim.

28 Die Umgestaltung sei eine langfristige Aufgabe, müsse aber rasch begonnen werden und sowohl die Verwaltung als auch die Forschung erfassen. - VI 1987, H. 4, 116.

29

$\mathrm{Vgl}$. ebd. 
senschaft" prägten die historische Disziplin. ${ }^{30}$ Der fehlende Zugang der Historiker zu den sowjetischen Archiven, v.a. zu den Materialien aus den zwanziger und dreißiger Jahren sowie zu Primär- und Sekundärquellen im Ausland, die unübersichtliche Planung im Wissenschaftsbetrieb, die unzureichenden Arbeitskontakte der sowjetischen Historiker untereinander sowie die fehlenden jüngeren Fachkräfte in scheinbar abgelegenen Disziplinen und in Führungspositionen verhinderten Fortschritte. ${ }^{31}$ Acht Maßnahmen waren den Ausführungen Tichvinskijs zu entnehmen:

1. Die endgültige Festlegung der sechs seit 1984 diskutierten langfristigen „komplexen Forschungsprogramme“ der Geschichtsabteilung. ${ }^{32}$

2. Diskussion und Verabschiedung der prognostischen Berichte für zehn Forschungsrichtungen. ${ }^{33}$

Diese Programme und Berichte „(..) sollen die Kräfte der Historiker des ganzen Landes auf die perspektivreichsten und wichtigsten Richtungen der Wissenschaft vereinigen und das Fundament der langfristigen Forschungsplanung an den Akademie-Instituten und Hochschul-Lehrstühlen bilden. “34

3. Aktualisierung und Intensivienung der Diskussionen in den Sitzungen des Büros der Geschichtsabteilung. ${ }^{35}$

4. Die stärkere Entfaltung von „Kritik, Selbstkritik, glasnost', Demokratisierung des wissenschaftlichen Prozesses." Das müßten die Grundprinzipien bei dem bevorstehenden Überdenken bisheriger Wertungen von historischen Ereignissen, Personen usw. sein. Die notwendige Revision (peresmotr) werde ein langanhaltender Prozeß sein:

"Es ist natürlich, daß er vom Konflikt unterschiedlicher Standpunkte, Methoden und Argumente begleitet wird. Und so ist es wichtig, nicht in Extreme zu verfallen."

Zentren der Kritik und Erörterung strittiger Probleme sollten nach Tichvinskijs Auffassung die Fachzeitschriften und die Wissenschaftlichen Räte der Geschichtsabteilung werden. ${ }^{36}$

30 Tichvinskij, S.L.: Janvarskij (1987 g.) Plenum CK KPSS i istoriceskaja nauka, in: VI 1987, H. 6, 3-13, hier 4 .

31 Siehe ebd., 6ff.

32 Vgl. Kapitel 5.3.

33 Vgl. Kapitel 5.4.

34 Tichvinskij, Janvarskij Plenum, 9.

35 Tichvinskij kündigte u.a. Vorträge von S.S. Chromov über die Erforschung der sowjetischen Arbeiterklasse, von I.D. Koval'cenko über ,Methodologische Grundlagen wissenschaftlicher Diskussionen“, von Ju.V. Arutjunjan über „Nationale Aspekte gegenwärtiger sozialer Prozesse in der UdSSR" an. Künftig sollten die Instituts-Direktoren in den Bürositzungen den Repräsentanten der Wissenschaftlichen Räte berichten, um diese direkter zu informieren. - Ebd., $9 f$.

36

Ebd., 10 f. 
5. Die Realisierung neuer Formen und Wege der Publikationen geschichtswissenschaftlicher Arbeiten. ${ }^{37}$

6. Verjüngung der ,fuihrenden Kader" und des wissenschaftlichen Personals. ${ }^{38}$

7. Juristische Klärung der höheren Selbständigkeit und Eigenverantwortlichkeit der Geschichtsinstitute.

8. Intensivierung internationaler wissenschaftlicher Verbindungen. ${ }^{39}$

Dieser Maßnahmenkatalog, Tichvinskijs abschließende Worte ${ }^{40}$ und die allgemeinen Aussagen anderer führender Historiker bei den 1987 schnell zur Gewohnheit werdenden Rund-Tisch-Gesprächen ${ }^{41}$ zeigten, daß es der Mehrheit im Büro der Geschichtsabteilung um verhältnismäßig umfassende Reformen zur Effektivierung des bestehenden Wissenschaftsbetriebes ging. Maßvoll plädierten beispielsweise

37 Tempo und Qualität der Veröffentlichungen müßten erhöht werden. - Ebd., 11.

38 Der Akademische Sekretär teilte mit, daß beim Büro der Geschichtsabteilung eine Kommission eingerichtet werde, die die Lage untersuchen und Empfehlungen für ein System zur jährlichen Förderung (vydvizenie) junger Nachwuchswissenschaftler aussprechen solle. - Ebd. Vgl zur Überalterung auch Liszkowskı, Die Revision, $655 f$.

39 Tichvinskij, Janvarskij Plenum, $11 \mathrm{f}$.

40 .Die durch die Beschlüsse des Plenums neu angeregten sowjetischen Historiker sind verpflichtet, ihre Arbeit umzugestalten und die Geschichtswissenschaft mit neuen Werken zu bereichern, die der von uns durchlebten Epoche der Beschleunigung der sozial-ökonumischen Entwicklung unserer Gesellschaft gerecht werden." - Ebd., 13. (Meine Hervorhebung. J.H.); vgl. VI 1987, H. 7, 97-99.

41 Die folgenden sogenannten Gespräche am Runden Tisch, die 1987 stattfanden, wurden im Wortlaut veröffentlicht: „Die Partei der Bolschewiki in der Großen Sozialistischen Oktoberrevolution“ (VIKPSS 1987, H. 5, 142-149); „Aktuelle Probleme und neue Aufgaben in der Erforschung der Geschichte des Großen Oktober" (VIKPSS 1987, H. 6, 143-147); „Die Wissenschaft von der Parteigeschichte. Wege ihrer Perestrojka und Weiterentwicklung“" (VIKPSS 1987, H. 7, 137-152); „Hauptetappen der Entwicklung der sowjetischen Gesellschaft“ (K 1987, H. 12, 6679); ,Der Kampf der UdSSR für Abrüstung, für eine Welt ohne Kernwaffen und Gewalt" (ISSSR 1987, H. 4, 3-48); „Über den Faktor der Persönlichkeit in der KPdSU-Geschichte“ (VIKPSS 1987, H. 9, 150-155); „Nationale Prozesse in der UdSSR“ (ISSSR 1987, H. 6, 50-120); „Der 27. Parteitag der KPdSU und die Aufgaben historiographischer und quellenkundlicher Forschungen“ (ISSSR 1988, H. 1, 141-149); „Die gegenwärtige nichtmarxistische Historiographie und die sowjetische Geschichtswissenschaf" (ebd., 172-202); "Über das Wesen des Bremsmechanismus" (VIKPSS 1988, H. 1, 128-134); "Die Rolle der Zeitschrift 'Fragen der Geschichte der KPdSU' bei der Umgestaltung der Wissenschaft von der Parteigeschichte (ebd., 135-150); „Aktuelle Aufgaben des Studiums der sowjetischen Arbeiterklasse“ (VI 1988, H. 1, 3-23); „Die Periodisierung der Geschichte der sowjetischen Gesellschaft“ (ISSSR 1988, H. 3, 127-142); „Der Große Vaterländische Krieg. Tatsache und Dokument in historischen Forschungen und schöngeistiger Literatur“ (ISSSR 1988, H. 4, 3-44); überwiegend noch im alten Stil verlief die ,internationale wissenschaftliche Konferenz" vom 08. bis 10.12.1987, die dem 70. Jahrestag der Oktoberrevolution gewidmet war, siehe Velikij Oktjabr i mirovoe razvitie. Materialy sekcionnogo zasedanija, $\mathrm{M}$. 1988; Velikij Oktjabr' i real'nyj socializm. Materialy sekcionnogo zasedanija, M. 1988; Velikij Oktjabr', bor'ba za mir i novoe političeskoe myšlenie. Materialy sekcionnogo zasedanija, M. 1988. 
Pavel Volobuev, ${ }^{42}$ Jurij Poljakov, ${ }^{43}$ Ivan Koval'Cenko ${ }^{44}$ und V.V. Zuravlev, ${ }^{45}$ der stellvertretende Direktor des Instituts für Marxismus-Leninismus (seit Januar 1987), für entsprechende Neuerungen.

Ganz in diesem Trend lagen auch die von Volobuev ${ }^{46}$ und Koval'cenko ${ }^{47}$ verfaßten fundamentalen Monographien, die wohl nicht zufällig 1987 veröffentlicht wurden. Beide Arbeiten zeichneten sich durch ihre Originalität aus. Volobuev legte eine Synthese der undogmatischen, ,nichtorthodoxen, aber 'sozialistischen' ${ }^{488}$ Interpretationen der Oktoberrevolution vor - seit seinem Hinauswurf aus dem Geschichtsinstitut im Jahr 1972 die erste große Monographie zu seinem Arbeitsgebiet. Seine Aussagen zur „Wahl des Weges" im Jahr 1917 förderten die Wiederaufnahme der Diskussion über die Gesetzmäßigkeit und Alternativität in der Geschichte im allgemeinen und in Sowjet-Rußland im besonderen. ${ }^{49}$ Koval'Cenkos Publikation stellte die erste systematische Untersuchung und Diskussion nicht nur der grundle-

12 Die Umgestaltung in der Geschichtswissenschaft verlange vor allem eine ernsthafte Analyse und Erörterung der die Disziplin hemmenden Elemente einer antileninistischen Methodologie. deren Wurzeln in den dreißiger Jahren lägen und die nach 1956 nicht überwunden worden sei. Hier nach Vinogradov, Istoriko-partijnaja nauka 139f; siehe auch VI 1987, H. 7, 98.

43 .Es wurde für uns schon zum Axiom. daß man die Wahrheit schreiben muß (...). Ich würde so formulieren: man muß Klio aus den Windeln der Konjunkturreiterei (kon-junkturscina) befreien (...), muß die Wechselbäder von zügellosem Lob und Zitieren einerseits, ständigem Verschweigen andererseits überwinden. (...) Unsere Methodologie ist wahrhaftig. und man darf nicht zulassen, daß man die marxistische Methodologie erniedrigt oder redet, als ob sie nicht die Möglichkeiten gebe, die Wahrheit aufzudecken. " - Osnovnye etapy razvitija sovetskogo obł̌̌cestva, in: K 1987, H. 12, 66-79, hier 74 .

44 .Es gibt Deskriptivität (opisatel'nost), Faktenhuberei (faktograficnast ) und bloßes Illustrieren (illjustrativnost ). " Besonders schädlich sei die fehlende Korrelation zwischen historiographischen Arbeiten zur Realgeschichte einerseits, zur Wissenschaftsgeschichte andererseits: .Problemorientierte historiographische Forschungen liefern kein Material für die Aufdeckung allgemeiner Gesetzmäßigkeiten der Entwicklung der Geschichtswissenschaft, und die Untersuchung der Geschichte der Geschichtswissenschaft ist keine konkret-wissenschaftliche Grundlage fur problemorientierte historiographische Forschungen." - Zitiert nach Vandalkovskaja, M.G./E.B. Emðenko: XXVII s-ezd KPSS i zadači istoriograficeskich i istoðnikovedzeskich issledovanij, in: ISSSR 1988, H. 1, 141-149, hier 141f.

45 Vor revisionistischem Übereifer warnend sagte Žuravlev am Ende der Round-TableKonferenz über die Parteigeschichtswissenschaft: „Umschreiben muß man unbedingt, aber nur die Seiten, wo sich Elemente des Dogmatismus und der Stagnation des Denkens zeigten." - Zitiert nach Vinogradov, Istoriko-partijnaja nauka, 151.

${ }^{46}$ Volobuev, Vybor 1987. Das Buch ging am 07.01.1987 mit einer Auflage von 23.000 Exemplaren in Druck. Vgl. auch ders., Vybor putej istoriðeskogo razvitija, in: Velikij Oktjabr' i mirovoe razvitie, 63-69; Rezension von N.A. Simonija in: VI 1988, H. 4, 110-113.

47 Koval Čenko, Metody. Drucklegung am 25.03.1987, 3.200 Exemplare. Vgl. die Rezensionen von M.A. Barg in: VI 1988, H. 4, 107-110, von N.I. Smolenskij und T.L. Moiseenko in: ISSSR 1990, H. 6, 167-171; von M. Schippan in: ZfG 1991, H. 9, 932ff.

48 Hildermeier, M.: Revolution und Revolutionsgeschichte, in: Geyer, Die Umwertung, 32-53, hier 48

49 Vgl. dazu Kapitel 6.5 
genden methodologischen Probleme und Methoden der historischen Forschung, sondern auch der Anwendungsmöglichkeiten und -grenzen quantitativer Methoden in der Geschichtswissenschaft dar. Wenngleich Koval'Cenko nicht den Eindruck einer Fülle offener Fragen hinterlassen wollte, dokumentierte seine Arbeit doch die Notwendigkeit einer neuen substantiellen Theorie- und Methodologiediskussion. ${ }^{50}$ Beide Veröffentlichungen reflektierten die erfolgreiche Karriere der Autoren. ${ }^{51}$

Auch Jurij Afanas'ev, inzwischen Rektor des Moskauer Instituts für Geschichte und Archivwesen, vertrat in seinen publizistischen Beiträgen und in den akademischen Debatten noch eine reform-sozialistische Position, deutete aber bereits seine Bereitschaft zur radikalen Hinterfragung derselben an. In seiner Antrittsrede, die am 11. Januar auszugsweise in Moskovskie novosti veröffentlicht wurde, sagte er, die „vaterländische Geschichtswissenschaft“ genüge weder marxistischen Ansprüchen, noch erreiche sie das Niveau der internationalen nichtmarxistischen Wissenschaft. $^{52}$ Seit den dreißiger Jahren habe eine ,Abkehr vom Marxismus hin zum Dogmatismus und vulgären Ökonomismus" stattgefunden. ${ }^{53}$ Im Herbst warf er den führenden Historikem an der Akademie vor, sie malten die Lage der Geschichtswissenschaft noch immer, in rosaroten Farben“, obgleich sie

„(...) in den letzten 25 Jahren bei der Erforschung der Geschichte der Sowjetzeit hinter der schöngeistigen und publizistischen Literatur weit zurückgeblieben ist, ihr Ansehen zunehmend eingebüßt und sich als unfähig erwiesen hat, der bürgerlichen Propaganda eigene Untersuchungsergebnisse entgegenzusetzen." "44

Afanas'ev fuihrte das vor allem auf den Abbruch der Theorie- und Methodologiediskussionen am Ende der sechziger Jahre und auf die Verdrängung der Erinnerung an den gefahr- und qualvollen historischen Weg aus dem sozialen Bewußtsein zurück. ${ }^{55}$ Um die Umgestaltung seitens der Geschichtswissenschaft zu unterstützen. sei es notwendig, sich endlich aus der, ,intellektuellen Selbstisolierung" zu befreien und die zahlreichen und bedeutenden Veränderungen in der ausländischen nicht-

\footnotetext{
so Als Motto war der Arbeit ein Zitat des jungen Karl Marx vorangestellt: ,Zur Wahrheit gehör nicht nur das Resultat, sondern auch der Weg. Die Untersuchung der Wahrheit muß selbst wahr sein, (...)" - Hier zitiert nach MEW 1, 7.

s1 Volobuev kehrte zu dieser Zeit wieder in das Institut für Geschichte der UdSSR zurück, wo er bald darauf die Leitung der Oktoberrevolutionsforschung übernahm. Koval'Cenko stieg ein Jahr nach der Veröffentlichung zum Akademischen Sekretär auf und erhielt für sein Buch 1989 den Staatspreis. - Kastueva, G.: Živoj Čelovek i vek neživoj materii, in: Moskovskij universitet 1990, Nr. 2, 13.

32 Afanas'ev, Ju.: Energija istoričeskogo znanija, in: MN vom 11.01.1987 (deutsch, leicht gekürzt in: Meyer, Wir brauchen die Wahrheit, 82-89).

s3 So Afanas'evs These bei einer Diskussion in der AdW am 16./17. April 1987. Zitiert nach Vandalkovskaja/Emčenko, XXVII s-ezd, 146.

34 Afanassjew, J.: Keine Termine für den Anbruch der allgemeinen Seligkeit, in: DVZ/die tat v. 06.11.1987, Il (Erstveröffentlichung in: Nauka $i$ zizn' 1987, H. 9, 56-60).

ss Siehe Afanas'ev, Energija.
} 
marxistischen Geschichtswissenschaft zu realisieren. ${ }^{56}$ Alle wichtigen Richtungen und Hauptaussagen der sowjetischen Geschichtswissenschaft müßten einer Inventur unterzogen werden. ${ }^{57}$ Hinsichtlich des Forschungs- und Lehrbetriebes plädierte Afanas'ev für eine „Polarisierung der Standpunkte“, für ,frische Kräfte“ auf den Leitungspositionen und für eine Archivreform ${ }^{58}$

Öffentliche Zustimmung erhielt Afanas'ev nur von einzelnen, eher unbekannten Historikern und einfachen Lesern. ${ }^{59}$ Namhafte Fachkollegen schwiegen bestenfalls oder attackierten ihn in scharfer Weise. ${ }^{60}$ Trotzdem waren Afanas'evs zahlreiche Auftritte produktiv und wirkten geradezu befreiend. Mit seinem rigorosen Moralismus fand er in den wissenschaftlichen Institutionen und bei einem Massenpublikum Gehör, und seine provokanten Thesen waren aus der aufgeregten öffentlichen Geschichtsdiskussion, die er mitinitiiert hatte, nicht mehr wegzudenken.

Die akademiki vergaßen wenigstens nicht wieder ihre guten Vorsätze: Die von Tichvinskij am 9. März genannten acht Maßnahmen griff man im Lauf des Jahres 1987 auf: Weitere prognostische Berichte wurden diskutiert, Entwürfe von drei komplexen Forschungsprogrammen in Voprosy istorii vorgestellt. ${ }^{61}$ Im Frühsommer wurde der Zugang zu Archiven für professionelle Historiker erheblich erwei-

36 "Schon die dritte Generation sowjetischer Historiker tritt ins Leben, die in ihrer Masse in Unkenntnis blieb hinsichtlich der Strömungen des geisteswissenschaftlichen sozialen Denkens im Ausland. Wir lebten ohne Durkheim, Mauss, Weber, Toynbee, Freud, Croce, Spengler, Braudel, Sorokin, Marcuse, ohne Collingwood, Jaspers, Althusser, Jakobson, Gurvitch, Carr, Saussure, Trubeckov, Boas (...).“ - Sovremennaja nemarksistskaja istoriografija i sovetskaja istoriðeskaja nauka. Beseda za „kruglym stolom“, in: ISSSR 1988, H. 1, 172-202, hier 185.

"D „Die Logik der wissenschaftlichen Entwicklung besagt, daß es kein Problem gibt, das als endgültig erforscht gelten könnte und auch in Zukunft keinerlei Berichtigungen bedarf." - Afanassjew, J.: Vom Standpunkt der Wahrheit und des Realismus, in: Huffschmid, J. (Hg.): Glasnost/Perestrojka Band 1: Streiten für die Umgestaltung. Die sowjetische Diskussion, Köln 1987, 61-76, hier 70. Vgl. Vandalkovskaja/Emčenko, XXVII s-ezd, 146.

s8 Siehe Afanassjew, Vom Standpunkt, 68ff.

39 Vgl. bei Meyer, Wir brauchen die Wahrheit, 98 und $100 \mathrm{f}$.

so Zu den Anfechtungen und Afanas'evs Repliken siehe ebd., 90ff; Wheatcroft, Unleashing the energy, 118ff. - Ausnahmsweise stand Afanas'ev in der Kontroverse um Satrovs historisches Drama, „Weiter... Weiter... Weiter...“, mit den Akademiemitgliedern Minc und Samsonov Seite an Seite. In einem gemeinsamen Schreiben an die Zeitschrift,Znamja“, das u.a. auch A. Ignat'ev, V. Loginov, A. Butenko, E. Gorodeckij, E. Ambarcumov unterzeichneten, protestierten sie gegen "die bewußte Entstellung von Sinn und Inhait des Stückes“. Siehe Schatrow, M. (= Satrov, M.): Weiter... Weiter... Weiter... Version des Verfassers zu den Ereignissen am 24. Oktober 1917 und bedeutend später. Aus dem Russischen von Friedrich Hitzer, Köln 1988, $175 f$ f.

61 Am 26.03.87 referierte Ju.A. Poljakov über den Programmentwurf „Geschichte des Aufbaus der sozialistischen Gesellschaft" (entgegen der ursprünglichen Planung wurden jetzt andere sozialistische Länder nicht mehr berücksichtigt); am 03.09.87 berichtete A.L. Naroðnickij über den Entwurf zur "Geschichte der Außenpolitik und der internationalen Beziehungen“. Drei Programme wurden veröffentlicht: „Revolutionen und sozialer Fortschritt“, „Ethnohistorie und zeitgenössische nationale Prozesse", "Geschichte des Aufbaus der sozialistischen Gesellschaft". - VI 1987, H. 4, 82-92; H. 6, 104; H. 9, 97-118; H. 10, 101-114; H. 11, 94. 
tert. ${ }^{62} \mathrm{Am} 25$. Juni stellten die führenden Akademiemitglieder ein Organisationskomitee für die Vorbereitung internationaler Konferenzen zusammen. ${ }^{63} \mathrm{Nach}$ der Fertigstellung des Juni-Heftes der Voprosy istorii trat der Chefredakteur V.G. Truchanovskij nach 27 Jahren von diesem Posten zurück. I.V. Sozin übernahm vertretungsweise bis Ende des Jahres die Funktion, da kein geeigneter Nachfolger gefunden wurde. ${ }^{64}$ Am 2. Juli konstituierte sich der Rat für die Koordination der wissenschaftlichen Tätigkeit der Geschichtsabteilung, der das Leitungsbüro und die Wissenschaftlichen Räte entlasten und die unionsweite Zusammenarbeit sicherstellen sollte. ${ }^{65}$ Anfang September berichtete Tichvinskijs Stellvertreter V.A. Kumanev über die Vorbereitung einer Diskussion am „Runden Tisch" zum Thema "Geschichtswissenschaft und perestrojka" ${ }^{66}$ Die Wissenschaftlichen Räte, Komitees und Kommissionen in der Geschichtsabteilung der Akademie wurden im Herbst reorganisiert und auf die strengere Beachtung der Forschungsprogramme verpflichtet. $^{67} \mathrm{Zu}$ dieser Zeit übernahm der international renommierte Historiker V.P. Danilov am Institut für UdSSR-Geschichte wieder die Leitung der Abteilung für die Erforschung der sowjetischen Bauernschaft, die er Ende der sechziger Jahre hatte aufgeben müssen. ${ }^{68} \mathrm{Am}$ 5. Oktober diskutierten die Büromitglieder mit Repräsentanten des Akademie-Verlages Nauka über Publikationsprobleme. Dabei wurden auch neue Konflikte zwischen Wissenschaftlem und Verlag infolge der Wirtschaftsreformen evident. ${ }^{69}$ Symptomatisch war es, daß dieses Jahr nach all den halbherzigen Reformschritten mit den Neuwahlen in der Akademie der Wissen-

62 Den Angaben des Chefs der Archivverwaltung F.M. Vaganov zufolge beherbergten zum damaligen Zeitpunkt 3.273 Staatliche Archive ungefähr dreihundertvierzig Millionen Akten (delo), von denen 1.109 .086 bislang dem "Regime eingeschränkten Zugangs" unterlagen. Von diesen sollten von nun an 767.195 (d.h. 69 Prozent) freigegeben werden. Das betraf Archivalien des Finanzministeriums der UdSSR, der Staatlichen Planungsbehörde, des Ministeriums für Zivillufffahrt und Meeresflotte, des Zentral rates der Gewerkschaften, der Nachrichtenagentur TASS, der Staatsbank, des Kultusministeriums, der Statistischen Zentralverwaltung u.a. - Vaganov, F.M.: Intensivnee ispol'zovat' dokumenty Gosudarstvennogo Archivnogo Fonda SSSR v interesach razvitija istoriłeskoj nauki, in: VI 1987, H. 10, 147-150; vgl. Geyer, Perestrojka, 23ff.

63 VI 1987, H. 9, 119.

64 Vgl. VI 1987, H. 7, 192; Davies, Perestroika, 213.

65 Tichvinskij, S.L.: Zadaxi koordinacii v oblasti istoriðeskoj nauki, in: ISSSR 1988, H. 1, 118130; vgl. VI 1987, H. 12, 90ff.

66 VI 1987, H. 11, 94f. - Diese Konferenz fand am 08.01.1988 unter dem Titel „Die Geschichtswissenschaft unter den Bedingungen der Umgestaltung" statt; siehe VI 1988, H. 3, 3-57.

67 VI 1987, H. 12, 98f; VI 1988, H. 1, 100f.

68 Siehe Davies, Perestroika, 212.

69 So verlangte Samsonov, daß nicht das Buch als Handelsobjekt, sondern die Entwicklung der Wissenschaft Priorität haben sollte; andererseits teilte der Verlagsdirektor S.A. Cibirjaev mit, die Verlagsarbeit sei auf Selbstfinanzierung umgestellt worden, und sein Stellvertreter ergänzte, bislang hätten nur zwei Prozent der Veröffentlichungen Gewinn gebracht. - VI 1987, H. 12, 100 . 
schaften, deren Ergebnis ebenfalls ambivalent war, zu Ende ging. ${ }^{70}$ In der Geschichtsabteilung, die durch sechs Ordentliche und elf Korrespondierende Mitglieder ergänzt wurde, führte die Wahl eher zur „Stärkung des konservativen Blocks“ (Davies) ${ }^{71}$ Bekannte aufgeschlossene Historiker wie Volobuev, Poljakov, Arutjunjan, Danilov, Drobižev und Skaratan, die von der Geschichtsabteilung vorgeschlagen worden waren, fielen bei der Abstimmung in der Vollversammlung der Akademie durch. ${ }^{72}$ Selbst die erhoffte Verjüngung gelang nur in relativer Hinsicht. ${ }^{73}$ Über die Ablösung und Nachfolge ihres ,primus inter pares", Tichvinskij, konnten sich die Akademiemitglieder noch nicht einigen.

Anders als die politische Elite um Gorbacev, die zu dieser Zeit bereits eine wirkliche Umgestaltung der Gesellschaft anvisierte, meinte die Majorität der führenden Historiker 1987 noch, ihre Maßnahmen zur "Qualitäts- und Effektivitätserhöhung ${ }^{\text {'74 }}$ fugten sich ein in eine Konzeption zur Beschleunigung der sozialökonomischen Entwicklung und Effektivierung des gegenwärtigen Systems, ohne dieses in Frage zu stellen.

\subsubsection{Historie und Systemtransformation $1988 / 89$}

In der ersten Hälfte des Jahres 1988 verdichteten sich die Momente, die aus dem systemimmanenten Umbau eine Systemtransformation werden ließen. Seit dem 1. Januar 1988 arbeiteten mehr als sechzig Prozent der sowjetischen Industriebetriebe unter den neuen Bedingungen der vollständigen Wirtschaftsrechnung und Selbstfinanzienung. Auch in anderen Bereichen wurden systemtranszendierende Veränderungen implementiert, etwa bei der Liberalisierung der individuellen Arbeitstätigkeit, beim Ausbau des Genossenschaftswesens, bei den Außenwirtschaftsbeziehungen (joint ventures) usw. ${ }^{75}$ Die dezentralen, marktwirtschaftlichen Projekte konnten allerdings aufgrund ihrer Abhängkeit von den weiterbestehenden planwirt-

10 Diese Vollversammlung der Akademie am 22. und 23. Dezember hatte über die von den verschiedenen Abteilungen vorgeschlagenen Kandidaten abzustimmen. "The result was not so encouraging, but not without impact." - Wada, Perestroika, 53.

11 Zu den neuen Vollmitgliedern zählten die Konservativen Koval'cenko und Kukuškin von der Lomonosov-Universität, unter den Korrespondierenden befand sich der "hardliner" Kas'janenko. In den neuen Korrespondierenden Mitgliedern A.A. Fursenko, N.N. Pokrovskij, V.A. Siškin, V.N. Grašcenkov und N.N. Bolchovitinov erkannte Wada immerhin ,respectable historians"; mit N.N. Pokrovskij war sogar ein ehemaliger politischer Häfling (1957-63) unter ihnen! - Wada. Perestroika, 53; Davies, Perestroika, 212.

12 Die beiden zuerst Genannten sollten Vollmitglieder werden, die übrigen Korrespondierende. - Davies, Perestroika, 212.

13 In den achtziger Jahren lag das Durchschnittsalter der akademiki meist über 75 Jahre, das der Korrespondierenden Mitglieder um die 65. Das Durchschnittsalter der Neugewählten betrug bei den Vollmitgliedern 60,2 Jahre, bei den Korrespondierenden Mitgliedern 57,9 Jahre. - VI 1988, H. 3, 124ff; vgl. Liszkowski, Die Revision, 655.

74 So Koval 'cenko, zitiert nach Vandalkovskaja/Emcenko, XXVII s-ezd, 142.

75 Siehe Segbers, Der sowjetische Systemwandel, 243ff. 
schaftlich arbeitenden Zentralen nicht gedeihen. ${ }^{76}$ Gorbacev gab weiterhin ,mehr Sozialismus" als Ziel an. ${ }^{77}$ Aber die politischen und ökonomischen Berater und Reformarchitekten begannen, pragmatischer und über den Sozialismus hinaus zu denken. ${ }^{78}$ Charakteristisch für diese vierte Phase der perestrojka kann man das Credo des damals einflußreichen Ökonomen Bogomolov ${ }^{79}$ nennen, der Anfang 1988 schrieb:

„(..) alles, was der dynamischen Entwicklung der Produktion und der Verwirklichung der kreativen Initiative der arbeitenden Bevölkerung dient, ist für unser soziales System von Nutzen". 80

Reformen sollten daher nicht danach beurteilt werden, ob sie ,mehr oder weniger Sozialismus" bringen, sondern nur nach ihrer Effektivität. Nach mehreren Gesetzesentwürfen stellte schließlich im Herbst 1989 der Ökonom Abalkin die Reformvariante vor, „die sich von der 1987 beschlossenen mehr als graduell“ unterschied (Conert). Nunmehr lag ein „Vorschlag zur Durchsetzung einer 'gemischtwirtschaftlichen Ordnung' vor. ${ }^{\text {(\$1 }}$ 'Zugleich rückte 1988/89 die Verändenung des staat-

16 Siehe Conert, Die Ökonomie, 162ff; vgl. auch die Wirtschaftsanalysen in: Sowjetunion 1988/89. Perestrojka in der Krise? Hg v. BOIS, München 1989, 123ff und Sowjetunion 1990/91 Krise - Zerfall - Neuorientierung, hg. v. BOIS, München 1991, $135 f$.

$"$ Vgl. Gorbaxev, M.S.: Revoljucionnoj perestrojke - ideologiju obnovlenija, in: Pravda vom 19.02.1988, 1-3. Auch nach dem Untergang der UdSSR befürwortete Gorbačev einen Sozialismus, der,$(. .$.$) einhergeht mit politischer und geistiger Freiheit, mit Achtung vor der Kultur, mit$ Vermenschlichung und Demokratie. " - Gorbatschow, M.: Der Zerfall der Sowjetunion, München 1992,204 ; vgl. dazu die quer zum „mainstream“ der neunziger Jahre verlaufende Kritik der als "Gorbatschowismus" gescholtenen Weltanschauung und Politik des letzten Generalsekretärs durch den langjährigen Leiter des IMSF Heinz Jung. Nach anfänglicher Begeisterung bewertete Jung die perestroika als verspäteten Thermidor, $\mathrm{d} . \mathrm{h}$. als, Zurücknahme der nachrevolutionären linken Linie und die ideologische Wende nach rechts". - Jung, $H$.: Abschied von einer Realität. Zur Niederlage des Sozialismus und zum Abgang der DDR. Ein politisches Tagebuch - Sommer 1989 bis Herbst 1990, Frankfurt/Main 1990, 44ff; vgl. dagegen noch den hoffnungsvollen Reform-Marxisten Jung. H.: Fixpunkte unserer Hoffnungen, in: Perestroika und die Linke in der Bundesrepublik. Zu den aktuellen Umgestaltungsprozessen in der UdSSR. Beiträge der gemeinsamen Tagung „Umbruch in der Sowjetunion?“, Frankfurt/Main, 5. September 1987, veranstaltet vom Institut für Internationale Arbeiterbewegung der AdW der UdSSR (IMRD, Moskau), der Zeitschrift ,sozialismus" (Hamburg) und dem IMSF, Frankfurt/Main. Hg. v. IMSF und der Zeitschrift ,sozialismus“, FrankfurtMain 1988, 89f.

78 „Die sich seit $1988 / 89$ drastisch verschlechternde Wirtschaftslage veranlaßte eine intensive Suche nach einem neuen Konzept für die Wirtschaftspolitik, dem nunmehr dritten Ansatz zur wirtschaftspolitischen Neuorientierung nach 1985, diesmal unter dem Vorzeichen eines Übergangs zur Marktwirtschaft." - Höhmann, H.-H.: Der ökonomische Systemwechsel, in: Schewardnadse, E./A. Gurkow/W. Eichwede u.a.: Revolution in Moskau. Der Putsch und das Ende der Sowjetunion, Reinbek bei Hamburg 1991, 207-224, hier 214.

19 Oleg Timofeevix Bogomolov, Vollmitglied der AdW und Direktor des Instituts für die Wirtschaft des sozialistischen Weltsystems an der Akademie, wurde 1989 Volksdeputierter.

Ho Hier zitiert nach Segbers, Der sowjetische Systemwandel, $218 f$.

81 In fünf Punkten wurden die Konturen zusammengefaßt: „1. Vielgestaltige Formen gesellschaftlichen Eigentums, 2. Arbeit als Grundlage des Eigentums, der Produktion und Verteilung (...), 3. 'Nutzung des Marktes als Hauptform der Koordination der Tätigkeit der Teilnehmer an 
lich-politischen Systems - also „der innerstaatlichen Machtverhältnisse“ (sic!) gegenüber der Wirtschaftsreform in den Vordergrund. ${ }^{82}$ Dies und die Tatsache, $\mathrm{daB}$ die KPdSU dabei in rasantem Tempo die Kontrolle über die von ihr eingeleiteten Verändenungen verlor, zeigte sich deutlich während und nach der von Gorbačev angeregten 19. Allunions-Parteikonferenz im Juni 1988, die einen entscheidenden Durchgangspunkt in der perestrojka darstelt. ${ }^{83}$ Von nun an bahnte sich die offene Aussprache in allen Medien des Landes trotz wiederholter Kontrollversuche

der gesellschaftlichen Produktion', 4. ein System sozialer Garantien (...), 5. Staatliche Regulierung ökonomischer Prozesse auf der Grundlage langfristiger Wirtschafts- und Sozialplanung." Conert, Die Ökonomie, 231; vgl. Höhmann, Der ökonomische Systemwechsel, $214 f$.

Olaf Steffen hat demnach Unrecht mit seiner Feststellung, das Wirtschaftsprogramm von Ministerpräsident Ryకkov von Mai 1990 (siehe Pravda v. 25.05.1990) sei „(...) das erstmalige offizielle sowjetische Bekenntnis zu einer Transformation in Richtung Marktwirtschaft (...)". - Steffen, O : Zur ökonomischen Krise in der Sowjetunion. Von der funktionierenden Mangelwirtschaft zur mangelhaft funktionierenden Wirtschaft, in: OE 1991, H. 4, 344-357, hier 345.

82 Entgegen der Empfehlung seiner Wirtschaftsberater, zuerst die Wirtschaft zu gesunden, bestand Gorbačev darauf, mit der staatlich-politischen Reform zu beginnen. Hierin liegt ein wesentlicher Unterschied zu den Reformen in China, wo Ende der achtziger/Anfang der neunziger Jahre unter Beibehaltung des politischen Systems marktwirtschaftliche Reformen implementiert wurden. - Gorbatschow, M.S.: Die Verwirklichung der Beschlüsse des 27. Parteitages der KPdSU und die Intensivierung der Perestroika. Referat des Generalsekretärs des ZK der KPdSU, Michail S. Gorbatschow, bei der 19. Gesamtsowjetischen Konferenz der KPdSU am 28. Juni 1988, in: Provda (Deutsche Ausgabe) v. 29.06.1988, 2-7, hier 4ff, Conert, Die Ókonomie, 209ff, besonders 212ff;. Haug, Gorbatschow, 248ff, besonders 254; Abalkin, L.: Die Wirtschaft ist krank, in: MN (Deutsche Ausgabe) 1989, Nr. 3, 7f; Ambartsumow, J.: Über die Wege zur Vervollkommnung des politischen Systems des Sozialismus, in: Afanassjew, Es gibt keine Alternative, 106-129; Migranjan, A.: Der Bremsmechanismus im politischen System und die Wege zu seiner Überwindung, ebd., 130-159; Trautmann, G.: Die Sowjetunion im Wandel - Wirtschaf, Politik und Kultur seit 1985, Darmstadt 1989, 194ff; Meissner, B.: Gorbatschows Umbau des Sowjetsystems, in: OE 1989, H. 7, 603-617; H. 8, 702-719; H. 10, 874-883; H. 11/12, 995-1020; 1990, H. 1, 68-85; H. 2, 105-114; Rahr, A.: Die Reform des politischen Systems, in: SchweglerRohmeis, W./K. Segbers $(\mathrm{Hg}$ ): Perestrojka passé? Eine Zwischenbilanz der Reformpolitik in der Sowjetunion, Opladen 1992, 39-52.

83 Ein gutes halbes Jahr später sagte Gorbaxev, ,....) daß die Konferenz ein Markstein im Leben des Landes war. (...) die Geschichte der Umgestaltung, läßt sich in zwei Etappen einteilen in die vor der XIX. Parteikonferenz und die danach, (...)". Auch Gorbacevs Berater Cernaev bezeichnete die Parteikonferenz, bei der alle hätten sagen können, was sie dachten, als "Wendepunkt": „Vor der Konferenz haben nicht nur das Politbüro, sondern auch Gorbatschow selbst Glasnost nur als eine steuerbare Einrichtung betrachtet. Danach war jedoch klar, daß sie eine selbständige, wenn nicht gar die einzige Kraft war, die das Land aus den Fängen des Totalitarismus befreien konnte." - Siehe Gorbatschow, M.S.: Das intellektuelle Potential der Umgestaltung enweitern, in: UZ v. 14.01.1989, 11-14, hier 13 und Tschernajew, Die letzten Jahre, 159. Vgl. die Dokumentationen der Konferenz: Devjatnadcataja Vsesojuznaja konferencija Kommunistið̌eskoj Partii Sovetskogo Sojuza. 28 ijunja-1 ijulja 1988 goda. Stenografiðeskij ot Cet, 2 Bde, M. 1988; Offene Worte. Sowjetunion 1988. Gorbatschow, Ligatschow, Jelzin und 4991 Delegierte diskutieren über den richtigen Weg. Sämtliche Beiträge und Reden der 19. Gesamtsowjetischen Konferenz der KPdSU in Moskau, Nördlingen 1988; vgl. desweiteren Meissner, Gorbatschow 1988, 1061ff: Schneider, E.: Die 19. Parteikonferenz: Reform des politischen Systems, in: Sowjetunion 1989, 38-48; Simon/Simon, Verfall, 36 und $73 f f$. 
ihren Weg. Thren schwindenden Einfluß bekam die KPdSU auch bei den Wahlen zum ersten Kongreß der Volksdeputierten am 26. März 1989 zu spüren, da trotz der „vielfältigen Kautelen gegen Machtverlust" (Simon/Simon) zahlreiche Parteifunktionäre nicht gewählt wurden. ${ }^{84}$ Die - wenn auch halbherzige - Einführung des Parlamentarismus ohne direktes Mandat stellte an einem weiteren Punkt die Grenzüberschreitung zu einem neuen gesellschaftichen System dar. Der großteils live im Fernsehen übertragene Kongreß der Volksdeputierten (25. Mai bis 9. Juni 1989) offenbarte die katastrophalen Probleme im Land sowie den Machtverlust der KPdSU und ihrer Apparate. ${ }^{85}$ Zwei grundlegende Fragen von zentraler gesellschaftlicher Bedeutung - die nationale und die soziale Frage - vermochte die KPdSU nicht mehr zu beantworten. Seit den schweren Unruhen in Berg-Karabach am 11. Februar 1988 enwuchsen dem nationalen Aktivismus systemsprengende Kräfte. ${ }^{86}$ Im Juli 1989 streikten mehr als dreihunderttausend Bergarbeiter in den Schwerindustriegebieten im größten Ausstand seit 1921 für bessere Lebens- und Arbeitsbedingungen. ${ }^{87}$

8

„Der Parteiapparat mußte eine vernichtende Niederlage hinnehmen. $30 \%$ der regionalen Parteifihrer blieben auf der Strecke." - Rahr, Die Reform, 45; siehe Simon/Simon, Verfall, 75; Schneider, Die 19. Parteikonferenz, 45ff; zur Entwicklung neuer politischer Organisationen siehe Luchterhandt, G./O. Luchterhandt: Die Genesis der politischen Vereinigungen, Bewegungen und Parteien in Rußland, in: Veen/Weilemann, Rußland, 125-213.

8s Vgl. Simon/Simon, Verfall, 76f, Hitzer, Die große Unordnung, 130ff, besonders 147ff, Brahm, H.: Glasnost - die Stunde der Wahrheit, in: OE 1991, H. 3, 236-246, hier 243f.

so Es entstanden „(...) formierte Nationalbewegungen mit politischen Programmen und Parteien, die Systemwechsel und Demokratisierung in der Sowjetunion mit dem Thema 'Wiedergeburt der Nation' verbanden." - Halbach, U.: Der Zerfall der Union. Vom nationalen Aufbegehren zur Souveränität, in: Schewardnadse, Gurkow, Eichwede, Revolution, 176-195, hier 187; Tschernajew, Die letzten Jahre, $211 \mathrm{ff}$. Vgl. zu den historischen Hintergründen die Analyse und Dokumentation (mit den wichtigsten Literaturhinweisen) von Meyer, Gert (Hg.): Nationalitätenkonflikte in der Sowjetunion, Köln 1990; desweiteren Zaslavsky, V.: Das russische Imperium unter Gorbatschow. Seine ethnische Struktur und Zukunf, Berlin 1991; Grotzky, J.: Konflikt im Vielvölkerstaat. Die Nationen der Sowjetunion im Aufbruch, München-Zürich 1991; Nolte, H.-H.: Zur Diskussion der Nationalitätenprobleme in der Zeitschrift „Kommunist“, in OE 1991, H. 3, 259268; Halbach, U.: Die Nationalitätenfrage: Kontinuität und Explosivität, in: Geyer, Die Umwertung, 210-237; Lapidus, G.W./V. Zaslavsky/Ph. Goldman (Ed.): From Union to Commonwealth: Nationalism and Separatism in the Soviet Republics, Cambridge 1992; Lötzsch, R.: Sowjetische Nationalitätenpolitik von Lenin bis Gorbatschow, in: Hertzfeldt, L. (Hg.): Die Sowjetunion. Zerfall eines Imperiums, FrankfurtMain 1992, 67-101; Simon/Simon, Verfall, 134ff.

n Noch war dies ein Streik pro perestrojka; vgl. Erler, G.: Nach dem großen Streik, in: DVZ/die tat v. 25.08.1989, 13; die Diskussion zwischen dem Vorsitzenden des Streikkomitees in Kemerovo, T. Avaliani, und dem Vorsitzenden des Zentralrates der Gewerkschaften, S. Salaev, in: MN (Deutsche Ausgabe) Nr. 9/1989, 10; Gordon, L./E. Klopov: Perestrojka i novoe rabočee dviženie, in: Cerez ternii, M. 1990, 748-770. - Auffallend selten nahm die bundesdeutsche Sowjetunion-Forschung die Arbeiterklasse als politisches Subjekt der perestrojka wahr; lediglich Knabe, B.: Die Streiks der sowjetischen Bergleute und Gorbatschows Perestrojka. Aktuelle Analysen des BOIS 37 und 38, Köln 1989; Krüger, U.: Die „Auferstehung der sowjetischen Arbeiterbewegung". Neue Gewerkschaften und gewerkschaftsähnliche Organisationen in der UdSSR, in: OE 1990, H.9, 819-832; dazu die Dokumentation ebd., A 530-540. 
Insgesamt verfestigte sich in diesen Entwicklungen 1988/89 jener Widerspruch,

„(...) der die Theorie der Perestroika von innen heraus sprengte. Dieser Widerspruch bestand darin, daß gleichzeitig Reformen und Revolution verkündet wurden. Man reformiert jedoch, ohne sich an Grundsätzen zu vergreifen, und schafft revolutionäre Veränderungen dann, wenn man die Grundlagen demontiert. ".88

Die öffentliche Geschichtsdiskussion erreichte in dieser Phase der perestrojka ihren Höhepunkt. ${ }^{89}$ Die Reformer im Politbüro und im Zentralkomitee der KPdSU bemühten sich nach Kräften, die Avantgarde-Rolle der Partei in dieser Auseinandersetzung zu sichern, doch durch die Bremskraft der konservativen Funktionäre und Mitgliedermehrheit geriet die Partei auch hier ins Hintertreffen. Kristallisationspunkte, welche die gespaltene Haltung der Parteifuhrung zeigten, waren die Affäre um die Andreeva-Thesen ${ }^{90}$ und die 19. Parteikonferenz ${ }^{91}$. Beidemal wehrten die Reformer um Gorbačev und Aleksandr Jakovlev die Versuche, überkommene stalinistische Wertungen als parteioffiziell auszugeben, ab und erweiterten die Diskussionsmöglichkeiten. ${ }^{92}$ Das wurde auch dadurch gefördert, daß seit Januar 1989

\footnotetext{
88 Jegorow, Aus der Sackgasse, 66

89 Vgl. Kapitel 6.2
}

90 Unter dem Namen der Leningrader Chemie-Dozentin Nina Andreeva veröffentlichte die Tageszeitung Sovetskaja Rassija am 13.03.1988 ein neostalinistisches, antisemitisches Pamphlet gegen die perestrojka, welches nicht ohne Zutun von Gorbačevs damaligen Stellvertreter Egor Ligačev entstanden und so rasch verbreitet worden wäre. Nach mehreren Diskussionen im Politbüro veröffentlichte die Pravda an 05.04.1988 eine scharfe Kritik der Andreeva-Thesen. Dies und der darauffolgende Schulterschluß wichtiger Verbände und Persönlichkeiten mit diesem neuen perestrojka-Manifest bezeichnete Davies zu Recht als "Sieg für den Antistalinismus“. Cernaev berichtete, daß Gorbačev nach intensiven Gesprächen, die er mit insgesamt einhundertfünfzig Parteifunktionären vom 11. bis 18. April über Andreevas Thesen gefuhrt hatte, Stalin erregt verurteilte: „Solange wir nicht wußten, was damals geschah, war das etwas anderes. Aber inzwischen wissen wir Bescheid und erfahren immer mehr. Zu diesem Punkt kann es keine unterschiedlichen Meinungen geben. Stalin war ein Verbrecher ohne jegliche Moral. Euch (!) vertraue ich an: Eine Million Parteiaktivisten wurden erschossen, drei Millionen in Lager geschickt, wo man sie umkommen ließ. Die besten Männer wurden anhand von Listen erschlagen (...)". Zitiert nach Tschernajew, Die letzten Jahre, 184 (Hervorhebung dort; J.H.); siehe Davies, Perestroika, 184 und 173-180; vgl. die Dokumentation bei Simon/Simon, Verfall, 241-252; Wada, Perestroika, 56ff.

91 Wie Gorbačev mit moderaten Thesen vor der Konferenz versuchte, eine einheitliche Linie des Zentralkomitees zu sichern, wie hart dennoch während und nach der Parteikonferenz Antistalinisten (v.a. Ju.N. Afanas'ev, M. Uljanov, G. Baklanov) und Konservative (z.B. P. Kuznecov, Ju. Bondarev, E. Ligačv) aneinanderstießen, hat Robert Davies analysiert und dargestellt. Intern ließ Gorbačev durchaus wissen, daß die Konferenz eindeutig antistalinistische Zeichen setzen sollte. Cernaev zitierte ihn mit den Worten: „Wir lösen uns endgültig vom administrativen Kommandosystem und dem ganzen Erbe des Stalinismus. (...) Nina und ihresgleichen müssen das von dieser Tribüne aus hören." - Siehe Davies, Perestroika, 186ff und Tschernajew, Die letzten Jahre, 185.

92 Wichtig waren dabei: das klare Bekenntnis des Politbüro-Mitglieds Razumovskij zur sachlichen Geschichtsaufarbeitung in der Pravda vom 23.04.1988 anläßlich Lenins Geburtstag; die Verleihung des Lenin-Preises für Kunst an Tengis Abuladze, den Regisseur des antistalinistischen Films „Die Reue" (pokajanie) im Jahr 1988; Gorbacevs Klarstellung während der Konfe- 
die 1929 nach zehnjährigem Erscheinen eingestellte Informationszeitschrift des ZK der KPdSU mit etwa siebenhunderttausend Exemplaren wieder erschien. Heft fur Heft ließ das Politbüro bislang geheimgehaltene Archivmaterialien publizieren, darunter auch Chruščevs Vortrag ,über den Personenkult und seine Folgen" vom 25. Februar 1956. ${ }^{93}$ Nachdem A. Jakovlev am 11. Oktober 1988 die Leitung der Politbüro-Kommission für Rehabilitierungen übernommen hatte, wurden diese konsequenter als bisher fortgesetzt. ${ }^{94}$ Das Politbüro packte solch ,heiße Eisen" wie das deutsch-sowjetische Vertragswerk von $1939^{95}$ und den Fall ,Katyn ${ }^{\circ 6}$ an.

renz, daß ein Bruch mit dem stalinistischen politischen System unerläßlich sei; Gorbačevs Unterstützung der von der Vereinigung „Memorial“ getragenen Initiative zur Errichtung eines Denkmals für die Opfer des Stalinismus. - Davies, Perestroika, 183f; 188; 192ff.

${ }^{9}$ Izvestija CK KPSS (ICK) 1989, H. 3, 128ff. - Herausgegeben wurden etliche Protokolle richtungsweisender Parteiversammlungen, kritische Eingaben später repressierter Parteimitglieder und Wissenschaftler u.v.a. Verzeichnis der Materialien in ICK 1989, H. 12, $221 \mathrm{ff}$.

94 Zu den Rehabilitierten zählten N.I. Bucharin, A.I. Rykov und ihre Anhänger, der Antistalinist M.N. Rjutin, G.E. Zinov'ev, L.B. Kamenev, Ju.L. Pjatakov, K. Radek, G.Ja. Sokolnikov. Der Marschall Tuchacevskij und sieben weitere Opfer jenes Prozesses im Juni 1937 wurden wieder in die Partei aufgenommen (sie waren schon 1957 gerichtlich rehabilitiert worden). Am 10.07. teilte die Untersuchungskommission des Politbüros mit, daß Bucharin, Rykov, Tomskij, Rakovskij u.a. ebenfalls postum die Parteimitgliedschaft zurückerhalten hätten. Am 16.01.1989 erklärte das Präsidium des Obersten Sowjets alle Urteile und Entscheidungen der außergesetzlichen Sonderkomitees der Geheimpolizei und des Sicherheitsdienstes (GPU, NKVD und aller Nachfolgeorganisationen) für unrechtmäßig; daraufhin stellte die Politbüro-Kommission fest, daß die Rehabilitierung ,praktisch abgeschlossen" sei. Im Juni forderte die gleiche Kommission die Gerichte allerdings auf, die Überprüfung der Prozesse gegen die „Industriepartei“, die „Menschewiki“ und die ,Akademiker" aus den Jahren 1930/31 zu beschleunigen. L. Trockij wurde noch nicht rehabilitiert - Siehe die Auflistung aller Protokolle und Dossiers der Politbüro-Kommission in ICK 1989, H. 12, 219. Vgl. Tschernjak, A.: Die Wahrheit wird wieder hergestellt, in: Meyer, Wir brauchen die Wahrheit, 212-218; Iwanow, V. (= Ivanov, V.V.): Michail Tuchatschewski, Marschall der Sowjetunion, ebd., 175-184; Medwedjew, R. (= Medvedev, R. A.): Neue Rehabilitierungen, ebd., 381f; siehe ebd., 383-386; Wheatcrof, Glasnost', 212ff; vgl. die Beiträge sowjetischer Publizisten und Historiker über Repressierte und deren Rehabilitienung in: Vozvrašcennye imena; Vom Bann gelöst, M. 1989, „Unpersonen“ - wer waren sie wirklich? Bucharin, Rykow, Trotzki, Sinowjew, Kamenew, Berlin 1990; Katkov, Vosstanovlenie, 87; Volkov, F.D.: Vzlet i padenie Stalina, M. 1992, 98ff passim.

95 Die Untersuchung war, wie V. Falin berichtete, jahrzehntelang verhindert worden; der erste Kongreß der Volksdeputierten (Mai/Juni 1989) richtete endlich eine Untersuchungskommission ein, die A. Jakovlev leitete. Im August 1989 stellte die Kommission fest: „Das geheime Zusatzprotokoll zum Molotow-Ribbentrop-Pakt hat doch existiert!" - und erklärte alle damals unterzeichneten Verträge für ungültig. Erst nach dem Zusammenbruch der UdSSR wurde im Oktober 1992 in Moskau das Original des Nichtangriffsvertrages und des geheimgehaltenen Zusatzabkommens (über die Interessenssphären) vorgestellt. - Siehe die Untersuchung und Dokumentation des seit August 1988 öffentlich gefuihrten sowjetischen Streits um den Nichtangriffsvertrag bei Bühl, A. (Hg): Der Hitler-Stalin-Pakt. Die sowjetische Debatte, Köln 1989, hier 190f; vgl. König. H.: Das deutsch-sowjetische Vertragswerk von 1939 und seine Geheimen Zusatzprotokolle. Eine Dokumentation, in: OE 1989, H. 5, 413-458; Bereschkow, V.: Als Diplomat Stalins in Deutschland, in: DVZ/tat v. 19.05.1989, 14; Oberländer, E. (Hg.): Hitler-Stalin-Pakt 1939. Das Ende Ostmitteleuropas?, Frankfurt/Main 1989; Bonwetsch, B.: Vom Hitler-Stalin-Pakt zum „Unternehmen Barbarossa“. Die deutsch-russischen Beziehungen 1939-1941 in der Kontroverse, 
Weiterhin waren die Befüworter der Geschichtsdiskussion jedoch zu Kompromissen mit deren Gegnern gezwungen, wobei Gorbačev der Darstellung seines ehemaligen Beraters zufolge mehr manövrierte und nachgab als notwendig gewesen wäre. ${ }^{97}$ Ende 1989 war die weitgehendste Position in der Parteifuhrung antistalinistisch und zugleich entschieden leninistisch. ${ }^{98}$ Darüber war die öffentliche Geschichtsdiskussion zu dieser Zeit bereits hinweggegangen. ${ }^{99}$ Verlust der ideologischen Kontrolle und „Nachtrabpolitik“ - das begann 1988/89 die Haltung der KPdSU-Fühnung auch in der Geschichtsdiskussion zu kennzeichnen.

Anfang 1988 waren der politische Druck seitens der KPdSU-Führung, die Herausfordenung durch die historische Publizistik und die Ungeduld in den Reihen der Historikerinnen und Historiker so groß geworden, daß die Öffnung für das Neue auch in den akademischen Tempeln nicht mehr zu verhindern war. Die beiden zen-

in: OE 1991, H. 6, 562-579; Davies, Perestroika, 264ff, FAZ v. 31.10.1992; Falin, Politische Erinnerungen, 442ff.

96 Jahrzehntelang hielt die Sowjetunion an der Stalinschen Behauptung fest, jene 4143 polnischen Offiziere, deren Leichen von deutschen Wehrmachtsangehörigen am 13.04.1943 im Wald von Katyn bei Smolensk gefunden worden sind, seien im Spätsommer oder Herbst 1941 von deutschen Faschisten ermordet worden. Auch westliche Untersuchungen wollten zuweilen dieser Version eher folgen als derjenigen des Nazi-Propagandisten Goebbels, der seinerzeit die Tötung auf das Frühjahr 1940 datiert und den „bolschewistischen Horden“ vorgeworfen hatte. Im Herbst 1987 begann in der UdSSR die öffentliche Diskussion - wieder einmal war es Jurij Afanas'ev, der als erster das tabuisierte Thema ansprach. Bald darauf setzte die wissenschaftiche Untersuchung ein, die vom KGB bis zuletzt behindert wurde. Am 13.04.1990 gestand die UdSSR mittels TASS offiziell ein, daß die Verantwortung für die Ermordung von fast fünzehntausend (!) polnischen Offizieren beim sowjetischen Volkskommissariat für Innere Angelegenheiten (NKVD) gelegen habe. - Siehe FR v. 06.10.1987, 1; Korab, A.: Beseitigung von "weißen Flecken“ zwischen Moskau und Warschau? Polnisch-sowjetische Vereinbarungen zur Aufklärung der Geschichte, in: OE 1988, H. 5, 385-389; Bartosz, J.: Die Wahrheit über Katyn. Ein neues Kapitel in den polnisch-sowjetischen Beziehungen, in: DVZ/die tat v. 17.03.1989; Winters, P.J.: Im Wäldchen von Katyn. Über dem Massengrab polnischer Offiziere steht ein neues Kreuz, in: FAZ v. 04.04.1989; Schaworonkow, G.: MN-Nachforschungen belegen: Im Wald von Katyn wurde seit 1935 gemordet, in: MN (Deutsche Ausgabe) Nr. 9/ September 1989, 13; FAZ v. 24.03. und v. 14.04.1990; Bartosz, J.: Ein polnisches Trauma, in: VZ v. 18.05.1990, 15; Madajczyk, C.: Das Drama von Katyn. Hg. von D. Fuchs, Berlin 1991; Falin, Politische Erinnerungen, 445ff, vgl. Werth, A.: Russia at war 1941-1945, New York 1964, 639ff passim.

97 Vgl. Tschernajew, Die letzten Jahre, 188ff; Davies, Perestroika, $172 \mathrm{f}$ und 187. - Auch auf Jurij Afanas'evs Thesen reagierte das Politbüro uneinheitlich. So stand am 26.07.1988 in der Pravda in Form einer offiziellen Stellungnahme der Redaktion eine polemische Attacke gegen den Historiker, funf Tage später ein abwägender Artikel, der eher Jurij Afanas'ev Recht gab; vgl. Davies, Perestroika, 196ff.

98 So plädierte Politbüromitglied V.A. Medvedev am 03.10.1989 bei einer Beratung mit führenden Historikern für eine zentristische Haltung gegenüber den Verteidigern Stalins und jenen, die mit Stalin zugleich die maxxistische Ideologie "über den Haufen werfen“ (oprokinut) wollten. Es sei nötig, gegenüber beiden Seiten die ,prinzipiellen Positionen Lenins, der Oktoberrevolution, der sozialistischen Wahl" zu vertreten. - Istoričeskoe soznanie obšestva - na uroven' zadax perestrojki. Sovešcanie istorikov v CK KPSS 3.X.1989, in: VI 1990, H. 1, 3-23, hier 5 und 22f; Davies, Perestroika, $266 \mathrm{f}$.

99

Vgl. Kapitel 6.2. 
tralen Fachzeitschriften erhöhten ihre Auflagen jetzt erheblich, Voprosy istorii zu Beginn des Jahres 1989 sogar um das Vierfache. ${ }^{100}$ Die langjährigen Chefredakteure räumten 1988 ihre Plätze; ${ }^{101}$ im gleichen Zug wurde bei Voprosy istorii die Redaktion nahezu vollständig ausgewechselt. ${ }^{102}$ Bei Istorija SSSR erfolgte dieser Schritt erst 1990.

In beiden Zeitschriften zeigte sich 1988/89 das deutliche Bemühen, Reformen zu unterstützen. Auf bevormundende Leitartikel wurde fortan verzichtet. Die neue Redaktion der Voprosy istorii faßte lediglich Anfang 1988 bisher verstreut vorgetragene reformorientierte Thesen zur Geschichtsdiskussion zu einer Plattform zusammen, wobei hervorgehoben wurde, daß die Umgestaltung der Geschichtswissenschaft alle Seiten der Disziplin umfassen müsse: „die Forschungsthematik, die Methodologie, die Methodik, die hilfswissenschaftlichen Disziplinen, die interdisziplinären Verbindungen, die Organisation wissenschaftlicher Forschungen, die Personalpolitik, die historische Bildung, die Verbreitung historischer Kenntnisse im Volk. ${ }^{\text {"10.3 }}$ Widerstreitende Diskussionsbeiträge ${ }^{104}$ und Leserbriefe ${ }^{105}$ wurden in bis-

100 Die Auflage der Voprasy istorii betrug bis Ende 1987 16.000 Exemplare, stieg im Jahr 1988 auf $21.000,1989$ auf 75.000 bis 79.000. Istorija SSSR hatte bis Ende 1986 in der Regel weniger als zehntausend Exemplare; 1987 waren es 10.500, 1988 erstmals seit den funfziger Jahren wieder mehr als dreizehntausend, 1989 sogar 25.000 - VI 1987, H. 1, 192; 1988 H. 1, 192; 1989, H. 1, 192 und H. 6, 192; ISSSR 1986, H. 5, 223; 1987, H. 1, 224; 1988, H. 1, 224; 1989, H. 1, 2

101 Neuer Chefredakteur bei Voprosy istorii murde Anfang 1988 der damals sechzigjährige Japanologe Achmed Achmedovic Iskenderov, ,ein angesehener und reformorientierter Historiker" (Davies). "This was a happy decision“, schrieb Wada. Bei Istorija SSSR war die Ablösung des Chefredakteurs Koval'Cenko (seit 1970) langwieriger: Der aus der Geschichtsabteilung der AdW kommende Vorschlag, V.I. Bovykin, ein konservativer Historiker und scharfer Kritiker der "Neuen Richtung", solle ihn ablösen, wurde von der Parteiführung abgelehnt. So übernahm von Ende 1988 bis Frühjahr 1990 Koval 'čenkos Stellvertreter, Il'ja Evgen'evic Zelenin, die Aufgabe kommissarisch. Zelenin zählte nach 1956 - neben Danilov, Moskov u.a. - zu den Historikern, die auf der Grundlage „einer recht naiven kritischen Konzeption“ (Davies) quellenfundierte Untersuchungen der Kollektivierung und "Entkulakisienung" vorlegten, in denen sie die damalige Politik der Kommunistischen Partei heftig kritisierten. - VI 1988, H. 2, 192; Davies. Perestroika, 12 und 213f; ISSSR 1988, H. 6, 2; 1990, H. 4, 2; Wada, Perestroika, 54f.

102 Aus dem 21-köpfigen Redaktionskollegium schieden 16 Historiker aus, darunter Bovykin, M.P. Kim, Kukuškin, Narǒnickij, Poljakov, Rybakov und Chromov. 19 neue Mitglieder wurden berufen: A.A. Iskenderov, V.P. Alekseev, N.N. Bolchovitinov, P.V. Volobuev, A.S. Grossman, V.P. Danilov, A.P. Derevjanko, M.S. Kapica, I.D. Koval'cenko, A.I. Krułanov, V.L. Janin, B.V. Levšin, A.P. Novosel'cev, V.N. Pavlenko, O.A. Ržeševskij, K.I. Sedov, A.Ja. Sevelenko, V.V. Selochaev, V.A. Siskin. Nach dem Ausscheiden Pavlenkos im Frühjahr 1988 blieb die Zusammensetzung der Redaktion konstant bis Ende 1990. - VI 1987, H. 7, 192; 1988, H. 2, 192; H. 3, 192.

103 Perestrojka i zadaxi žurnala „Voprosy istorii“, in: VI 1988, H. 2, 3-10, hier 4. Weitere Leitartikel erschienen 1988/89 weder in VI noch in ISSSR.

104 Bemerkenswert waren vor allem fünf Repliken auf einen Artikel von A.M. Samsonov und O.A. RŽeševskij über die Wende im Zweiten Weltkrieg (VI 1987, H. 4, 70-81 und 1988, H. 5, 5774), dann die Beiträge von M.P. Kim über die Periodisierung der Geschichte der Sowjetgesellschaft (VI 1988, H. 6, 115-130), von L.M. Spirin über die Wahlergebnisse zur Allrussischen Konstituierenden Versammlung 1917 (ISSSR 1988, H. 2, 90-101), von V.I. Bovykin über die 
lang unbekanntem Ausmaß abgedruckt. Ausländische Historiker, deren Ansichten früher ignoriert oder bekämpft wurden, konnten sich nun direkt an die sowjetische Leserschaft wenden. ${ }^{106}$ Rund-Tisch-Gespräche über ,weiße Flecken“ in der Historiographie der sowjetischen Geschichte hatten in diesen beiden Jahren Hochkonjunktur und konnten nicht nur in Voprosy istorii und Istorija SSSR, sondern auch in anderen geschichts- und sozialwissenschaftlichen Periodika meist in der ganzen Länge des Wortlautes der Redebeiträge nachgelesen werden. ${ }^{107}$ Das Niveau der

"Neue Richtung“ in der Oktoberrevolutionsforschung (ISSSR 1988, H. 5, 67-100), von V.l. Star-
cev über fuihrende Politiker in der Sowjetunion 1922/23 (ebd., 101-122), von A.N. Artizov über
historiographische Probleme in den nach der Oktoberrevolution erschienenen Arbeiten der Hi-
storiker der ,alten Schule“ (ISSSR 1988, H. 6, 75-91), von A.P. Nenarokov über die "dogma-
tische Kanonisierung Stalinscher Zugänge zur Lösung der nationalen Frage und die Opfer der
sowjetischen Historiographie der Vereinigungsbewegung“" (ebd., 58-74), von I.E. Zelenin über
"weiße Flecken“ in der Historiographie der abschließenden Etappe der kompakten Kollektivie-
rung (ISSSR 1989, H. 2, 3-19), das Streitgespräch zwischen D.A. Volkogonov und R.A. Medve-
dev über Stalin und den Stalinismus (ISSSR 1989, H. 4, 89-108), der Artikel von B.P. Kurašvili
über die politische Doktrin des Stalinismus (ISSSR 1989, H. 5, 60-77) und die Antwort von I.V.
Bestužev-Lada darauf (ebd., 78-91), schließlich der Beitrag von V.1. Bugaj über „die Deportatio-
nen der Völker der UdSSR“ in den dreißiger und vierziger Jahren (ISSSR 1989, H. 6, 135-144). 10S In den Jahrgängen $1988 / 89$ veröffentlichten Voprasy istorii 71, Istorija SSSR nur drei Zuschriften von Leserinnen und Lesern. Darüber hinaus publizierte „VI" 142 Antworten auf eine Umfrage der Zeitschrift, siehe VI 1989, H. 7, 166-176; H. 8, 164-172; H. 9, 165-174; H. 10, 171178; H. 11, 171-176.

106 In Voprasy istorii schrieben Alexander Rabinovich (USA) über „die Bolschewiki und die Massen in der Oktoberrevolution" (1988, H. 5, 14-27), George Enteen (USA) über die sowjetische Auseinandersetzung um M.N. Pokrovskij (1989, H. 5, 154-159), Donald Cameron Watt (GB) über die Hintergründe der Repressionen gegen die sowjetischen Militärs 1937 (H. 6, 51-63), Robin Edmonds (GB) über den Kriegsbeginn 1939 (H. 10, 25-37), P. Dukes (GB - H. 9, 176178) und Michal Reiman (Westberlin) über aktuelle Aspekte der sowjetischen Geschichtsdiskussion (H. 12, 145-158). Istorija SSSR veröffentlichte einen Diskussionsbeitrag von William Rosenberg (USA) über die sozialökonomische Lage und die Politik des Sowjetstaats beim Übergang zur Neuen Ökonomischen Politik mit Anmerkungen von V.Z. Drobižev (1988, H. 4, 109-122) und ein Gespräch mit Terence Emmons (USA - 1989, H. 5, 208-212).

107 Diskutiert wurden 1988 und 1989 ,am Runden Tisch“ folgende Themen: „Die Geschichtswissenschaft unter den Bedingungen der Umgestaltung“" (VI 1988, H. 3, 3-57); „Historiker und Schriftsteller über Literatur und Geschichte“ (VI 1988, H. 6, 3-114); ,Die Sowjetunion in den zwanziger Jahren“ (VI 1988, H. 9, 3-58); „Aktuelle Fragen der Geschichte der europäischen sozialistischen Länder“ (VI 1988, H. 10, 94-111); "Die Periodisierung der Geschichte der sowjetischen Gesellschaft" (VMU 1988, H. 5, 3-17); "Philosophie und Geschichtswissenschaft" (VF 1988, H. 10, 18-64); ,Die Probleme bei der Ausarbeitung einer Konzeption des heutigen Sozialismus" (VF 1988, H. 11, 31-71); „Der sozialpolitische Charakter des Zweiten Weltkrieges“ (VI 1988, H. 11, 181-184); „Die revolutionäre Erneuerung der Gesellschaft und die Geschichtswissenschaft“ (ebd., 184-186); „Die Sowjetunion in den dreißiger Jahren“ (VI 1988, H. 12, 3-30); "Die Theorie des Sozialismus: Geschichte und Gegenwart" (PO 1988, H. 12, 33-48); neue Zugänge, methodologische und historiographische Probleme in der Allgemeinen Geschichte, siehe Vseobšcaja istorija: diskussii, novye podchody. Vypusk 1 und 2, M. 1989; „Probleme der historischen Ausbildung in der Schule“ (VI 1989, H. 1, 166-175); „Das zwanzigste Jahrhundert: Entwicklungsalternativen“ (RKSM 1989, H. 1, 60-71; H. 2, 77-94); die sowjetische Gesellschaftsordnung in den dreißiger Jahren unter dem Titel ,Nicht weinen, nicht lachen, sondern verstehen", siehe Stranicy istorii KPSS. Fakty. Problemy. Uroki. Kniga 2, M. 1989, 340-355; 
Hauptaufsätze stieg im allgemeinen merklich an; neue Fragen wurden gestelt, bislang unzugängliche Quellen herangezogen, abweichende Thesen vorgetragen, kurzum: Die historischen Fachzeitschriften schalteten sich in den Prozeß der „Liquidierung weißer Flecken" ein. ${ }^{108}$ Berücksichtigt man die Leserbriefe, die Beiträge ausländischer Historiker und die Round-Table-Konferenzen, so war Voprosy istorii im Jahr 1988 wesentlich aktiver als die Spezialzeitschrift für die Geschichte der UdSSR, Istorija SSSR, die erst 1989 gleichermaßen zum Forum der Geschichtsdiskussion wurde.

„Probleme der Geschichte und die Gegenwart“ (VIKPSS 1989, H. 2, 47-67); "Sozialismus: Die dreißiger Jahre“, ebd., 153-158; „Das Problem der politischen Führung in der sowjetischen Gesellschaft“ (ON 1989, H. 2, 85-113; H. 3, 39-59; H. 4, 62-78; H. 5, 53-80; H. 6, 64-97); „Krisenerscheinungen in der sowjetischen Geschichtswissenschaft" (ON 1989, H. 3, 184-192); "Neue Zugänge zur Geschichte des Großen Oktobers“ (VIKPSS 1989, H. 3, 148-152); „Wirtschaft und Politik in den Lehren des 'Großen Umschwungs"“ (K 1989, H. 5, 96-104); "Das neue politische Denken und die Aufgaben der Ausarbeitung einer Historiographie der KPdSU-Geschichte" (VTKPSS 1989, H. 5, 151-158); die Lage der Geschichtswissenschaft in der UdSSR und den USA (VI 1989, H. 4, 97-117); „Sozialer Fortschritt und 'Zivilisationskrise'“ (ON 1989, H. 6, 150172); „Die nationale Frage und zwischennationale Beziehungen in der UdSSR“ (VI 1989, H. 5, 3-97 und H. 6, 130-147); "Ausgangspunkte und Ursachen“ des Zweiten Weltkrieges (ebd., 3-32); „Die Kollektivierung: Ausgangspunkte, Wesen, Folgen“"(ISSSR 1989, H. 3, 3-62); „Alternativen der Geschichte und Geschichte der Alternativen“ (PMRP 1989, H. 8, 178-205); „Formationen oder Zivilisationen?“ (VF 1989, H. 10, 34-59); „Aktuelle Probleme der sowjetischen Quellenkunde“ (ISSSR 1989, H. 6, 36-91); „Das Geschichtsbewußtsein der Gesellschaft“ (VI 1990, H. 1, 323); über das neue Lehrbuch zur Geschichte der UdSSR für 10. Klassen (ebd., 188-191); „Die Vaterländische Geschichte in der gegenwärtigen Publizistik“" (ISSSR 1990, H. 1, 176-190).

108 Siehe dazu Kapitel 6.2. Dabei spielten Bücher 1988 noch eine untergeordnete Rolle. Neue Diskussionsbeiträge namhafter Historiker aus Moskau, Kazan und Novosibirsk (darunter allerdings nur zwei Akademiemitglieder, A.M. Samsonov und Ju. A. Poljakov) erschienen mit dem Diktum fuir "Meinungspluralismus“" in dem Sammelband Istoriki sporjat. Trinadcat' besed, $\mathbf{M}$. 1988; historiographische, geschichtstheoretische und -methodologische Fragen blieben hier ebenso ausgeblendet wie in: Istoriki otvexajut na voprosy. Sbornik statej, M. 1988. Im gleichen Jahr erschien ein von Jurij Afanas'ev zusammengestellter Sammelband mit dreißig Beiträgen sowjetischer Schriftsteller, Journalisten, Natur- und Gesellschaftswissenschaftler, der als Klassiker der Umgestaltungspolitik bezeichnet werden kann: Inogo ne dano, M. 1988; im gleichen Jahr noch auf Deutsch: Afanassjew, J. (Hg.): Es gibt keine Alternative zu Perestroika: Glasnost, Demokratie, Sozialismus, Nördlingen 1988. Außer Afanas'ev waren drei weitere Historiker als Autoren beteiligt: J. Ambarcumov, M. Gefter und V. Sirotkin. Ambarcumov schrieb über die „Vervollkommnung des politischen Systems" im Zuge der perestrojka, Gefter über die Entstehung und das Nachwirken des Stalinismus, Sirotkin über den Übergang vom Kriegskommunismus zur neuen Ökonomischen Politik. Das Buch war rechtzeitig vor der 19. Parteikonferenz Ende Juni 1988 fertig, doch die Veröffentlichung wurde von den „höchsten Autoritäten der Partei“ verschoben. Die erste russische Auflage verschwand. Die zweite, unveränderte, lediglich kleiner gedruckte Auflage mit 100.000 Exemplaren gelangte nur in die ,berühmten Moskauer Beriozka-Läden, in denen ausschließlich mit ausländischer Währung zu zahlen ist." - So berichtete J. Scherrer in: Die Zeit v. 09.06.1989, hier zitiert nach Roth, P.: Glasnost und Medienpolitik unter Gorbatschow, Bonn 1990, 181. 
Darüber hinaus berichtete Voprosy istorii 1988 und 1989 bis einschließlich Heft $8^{109}$ viel inhaltsreicher als früher über die Vorgänge in der Geschichtsabteilung, so $\mathrm{da} ß$ für die Leser personelle Veränderungen und die Meinungen der führenden Akademiemitglieder transparent wurden. Anfang 1988 wählten die beiden Institute für Geschichte der UdSSR und für Allgemeine Geschichte neue Direktoren, die von der Geschichtsabteilung bestätigt wurden. ${ }^{110}$ Der Akademische Sekretär Tichvinskij, der seit $1982 \mathrm{im} \mathrm{Amt} \mathrm{war,} \mathrm{wurde} \mathrm{am} \mathrm{1.} \mathrm{Dezember} 1988$ von Akademiemitglied Koval'Cenko abgelöst. ${ }^{11}$ Doch bereits in den letzten Sitzungen des Büros der Geschichtsabteilung unter Tichvinskijs Vorsitz kam frischer Wind auf. Nichtssagende Rechenschaftsberichte mochten weder die Akademiemitglieder noch der Vertreter des Zentralkomitees der KPdSU - zu dieser Zeit war meist V.V. Rjabov zugegen - mehr dulden. Für seinen letzten Jahresbericht vor dem Rücktritt als Institutsdirektor bekam Chromov von Rjabov eine geharnischte Kritik zu hören: Seine Ausführungen hätten ,eher traditionellen Charakter nach dem Prinzip 'ein bißchen von allem'" gehabt; alle entscheidenden Fragen - nach den Ursachen der Rückständigkeit im Institut, was im Institut inzwischen für die Umgestaltung getan worden sei und ,(...) warum im Institut nicht die Entwicklung von Schulen und Richtungen kultiviert wird, die hinsichtlich des schöpferischen Zugangs unterschiedlich, wenngleich hinsichtlich der marxistisch-leninistischen Methodologie einheitlich sind." - habe der Institutsdirektor offen gelassen. ${ }^{112}$ Andere leitende Historiker berichteten in bislang ungewohnter Offenheit über den Forschungsstand in ihrem Verantwortungsbereich. ${ }^{113}$ Nachdem das Politbüro der KPdSU die von

\footnotetext{
109 Eigenartigerweise stellte die Redaktion von da an die nützlich gewordene Information wieder ein
}

110 Den „ultra-konservativen“ - so Wada - Direktor des Instituts für UdSSR-Geschichte S.S. Chromov löste A.P. Novosel'cev, ,ein hervorragender Historiker auf dem Gebiet des alten Rußland, der keine Beziehung zum bisherigen Establishment des Instituts hatte“, (Davies) ab. Er erhielt von den Mitarbeitern des Instituts mehr Stimmen als sein konservativer Konkurrent V.P. Serstobitov. - Um die Nachfolge der Direktorin des Instituts für Allgemeine Geschichte Z.V. Udal'cova, die am 29.09.87 gestorben war, kandidierten A.O. Cubar'jan und A.A. Iskenderov. Hier setzte sich der eher konservative Cubar'jan in der Wahl durch. - Davies, Perestroika, 214; Wada, Perestroika, 53; VI 1988, H. 6, 188.

111 Siehe VI 1989, H. 2, 180.

112 Rjabovs Kritik floß auch in einen vom Büro verabschiedeten Beschluß ein. - Vgl. VI 1988, H. 3, 130 und ISSSR 1988, H. 3, 209.

113 Am 28.01.1988 sprach V.A. Vinogradov, der Direktor des Instituts zur wissenschaftlichen Information für Gesellschaftswissenschaften, über "das komplexe Forschungsprogramm zur Wirtschaftsgeschichte", am 14.02. Ju.I. Korablev vom Institut für Geschichte der UdSSR über „Weiße Flecken in der Geschichte der sowjetischen Verteidigungskräfte“, am 25.02. referierte A.Ja. Gurevič vom Institut für Allgemeine Geschichte über Probleme der historischen Anthropologie, am 10.03. Ju.G. Pereznev vom Institut für Militärgeschichte beim Verteidigungsministerium über die Konzeption der geplanten 10-bändigen „Geschichte des Großen Vaterländischen Krieges“; am 15.09. sprach Ju.A. Poljakov über aktuelle Konzeptionen „der Geschichte der Sowjetgesellschaft“, am 29.09. referierten I.D. Koval'̌enko über „einige Probleme der Methodologie der historischen Forschung" und G.L. Smirnov über die Historiographie der KPdSUGeschichte; am 16.11.1989 sprach D.A. Volkogonov über „Wesen, Genesis und Entwicklung des 
Nina Andreeva vorgetragenen Thesen zurückgewiesen hatte, erklärten sich auch die führenden Köpfe der sowjetischen Geschichtswissenschaft in der Pravda für die perestrojka und bekannten sich zu der Aufgabe,

„(...) unsere Geschichte in wahrheitsgerechter Form zu rekonstruieren und all das, was das Land am Vorwärtsgehen gehindert hat, zu verurteilen und zu verwerfen, damit unser Gang auf dem Leninschen Weg beschleunigt wird. “114

Koval'cenko, Poljakov und viele andere Wissenschaftler gingen in eigenen Stellungnahmen darüber hinaus. Thnen genügte das allgemeine Bekenntnis zur Umgestaltung, Effektivienung, Wahrheitssuche usw. nicht mehr. Sie verdeutlichten, da $B$ tiefergehende Ändenungen in der Organisation, Theorie und Methodologie der historischen Disziplin notwendig seien. Typisch für diese Haltung sind z.B. folgende Aussagen zum Zustand der Geschichtswissenschaft und zur Notwendigkeit ihrer „Umgestaltung" aus den ersten neun Monaten des Jahres 1988: ${ }^{115}$

I.D. Koval'cenko: Technokratismus, die Enthumanisierung der Wissenschaft, administrative Kommandomethoden und die Orientierung der Wissenschaftler auf die geforderten Kommentare und Illustrationen hätten die Disziplin gelähmt. Jetzt werde seriöse Forschung verlangt, die Erkenntniswert, praktischen Nutzen und ideologischerzieherische Wirkung aufweisen müsse. Notwendig sei ein Durchbruch (proryv) an der Forschungsfromt. Das erfordere historiographische Analysen, um zu wissen, wo man stehe, und die Diskussion und Erprobung neuer Zugänge und Methoden, um das Niveau zu erhöhen. ${ }^{116}$

Ju.A. Poljakov: „Die Frage der Demokratisienung ist die erste Aufgabe der Umgestaltung, auch im Bereich der Geschichtswissenschaft." Die Umgestaltung verlange,

Stalinismus“. - VI 1988, H. 4, 88ff; H. 5, 185ff; H. 10, 175f; H. 12, 150ff; Vinogradov, V.A.: Sostojanie i perspektivey istoriko-ekonomiceskich issledovanij, in: VI 1988, H. 4, 3-12; Poljakov, Ju. A.: Istoriceskij process mnogomeren, in: VIKPSS 1988, H. 9, 19-34; Volkogonov, D. A.: Stalinizm - suščnost', genezis, evoljucija, in: VI 1990, H. 3, 3-17.

114 Die Akademiemitglieder S.L. Tichvinskij, Ju.V. Bromlej, A.M. Samsonov, I.I. Minc, M.P. Kim, G. Sevost'janov, A.L. Naročnickij, B.A. Rybakov, I.D. Koval'Cenko, Ju.S. Kukuškin und die Korrespondierenden Mitglieder V.A. Kumanev, A.P. Novosel'cev, G. Bongard-Levin, G. Litvarin, Ju.A. Poljakov, V.N. Grašcenkov, M. Kapica und V. Kas'janenko unterzeichneten die Stellungnahme "Die Wahrheit über die Geschichte ist eine Quelle unserer Kraft", die am 24.04.1988 in der Pravda veröffentlicht wurde. Hier zitiert nach Meyer, Wir brauchen die Wahrheit, 305ff, hier 305.

11s $\mathrm{Vgl}$. neben den folgenden Statements auch die einleitenden Vorträge von P.N. Fedoseev und V.I. Kas'janenko zum Rund-Tisch-Gespräch zwischen Historikern und Schriftstellern: Istoriki i pisateli o literature $i$ istorii, in: VI 1988, H. 6, 3-114, hier 4ff; Zevelev, A.I.: Aktivizirovat' rabotu istoriografov, in: VIKPSS 1988, H. 12, 103-107 sowie die Berichte der Historiker D. A. Volkogonov, M.S. Kapica und V.I. Ukolova über die 19. Parteikonferenz im Juni 1988. Konsens unter den Diskutanten war: „Die Geschichtswissenschaft soll keine 'Schleppe' der offiziellen Beschlüsse sein, sondern eine neue Horizonte öffnende Vorhutabteilung, die unseren Bürgern hilft, klare Orientierungen für das Leben zu finden." - VI 1988, H. 10, $175 f$.

116 Vstreči s istoriej 1988, H. 2, 49f; VI 1988, H. 12, 150; vgl. Koval'čnko, I.D.: „Issledovanie istiny samo dolžno byt' istinno“' Zametki o poiskach istoričeskoj pravdy, in: K 1989, H. 2, 86-96; ders., Rol' diskussii $v$ istorizeskoj nauke (metodologičeskie problemy), in: Vsemirnaja istorija, 21-33. 
verwurzeite Stereotypen abzulegen, wie zum Beispiel die Gewohnheit, daß stets nur eine Sichtweise auf historische Ereignisse möglich sei. „Man muß lemen, die Mehrdimensionalität (mnogomernost') der Geschichte zu reflektieren. (...) Man muß die tragischen und dramatischen Ereignisse, die es in unserer Vergangenheit gab, nicht nur konstatieren, sondern auch ihre Ursachen und Wurzeln erklären. “117

\begin{abstract}
A.A. Iskenderov: „In dieser Zeit durchlebt die Geschichtswissenschaft keine leichte Periode." Einerseits sei ein außerordentliches öffentliches Interesse an Geschichte entstanden, andererseits vollziehe sich ein Prestigeverfall der historischen Disziplin „(...) das verlangt vor allem neue Ideen und Konzeptionen, neue Zugänge und Bewertungen, neue wissenschaftliche Richtungen und Arbeiten, die im Geist der Zeit geschrieben sind und auf die Bedürfnisse der Entwicklung unserer Gesellschaft antworten. "118
\end{abstract}

V.P. Danilov: „(...) die beginnende Umgestaltung besteht in der Wiederbelebung des wissenschaftlichen Charakters (...) des Geschichtsstudiums in seiner Gesamtheit (...). Unter den Bedingungen der Umgestaltung entsteht eine neue, die dritte Welle des Anwachsens wissenschaftlichen Wissens über den Geschichtsprozeß. "119

P.V. Volobuev: Die bisherige Geschichtsauffassung sei gekennzeichnet von Dogmatismus, vulgärem Soziologismus, Ökonomismus, der Beschönigung und Idealisierung der vaterlandischen Geschichte, Determinismus und Automatismus sowie dem Bestreben, „(..) unser russisches Modell geschichtlicher Entwicklung an das westeuropäische anzupassen. (...) Es zeigt sich, daß wir vor allem neue konzeptionelle Lösungen und Zugänge brauchen, wahrscheinlich für die Mehrzahl der historischen Probleme. “120

M.A. Barg: Die Umgestaltung verlange den Übergang zu einem anderen historischen Denken und eine aktivere Bearbeitung der Geschichts- und Erkenntnistheorie. Notwendig sei ein „Pluralismus der wissenschaftlichen Meinungen“ anstelle der bisherigen „Gesinnungsgleichheit unter Aufsicht“. 121

Wieder war es Jurij Afanas'ev, der - inzwischen mit Unterstützung einiger Kollegen - eine weitgehendere, dezidiert antistalinistische, aber noch reformsozialistische Position vertrat. ${ }^{122} \mathrm{Er}$ kritisierte den ,unbeholfenen, passiv-gequälten“ Brief

117, "Kruglyj stol“: Istoriðeskaja nauka v uslovijach perestrojki, in: VI 1988, H. 3, 3-57, hier, IIf; Vgl. zur Ausfuihrung des mehrdimensionalen Zugangs Poljakov, Istoričeskij process, 19ff, $25 \mathrm{ff}$.

118 „Kruglyj stol“ 1988, $4 f$

119 Ebd., 21.

120 Ebd., 36f.

121 VI 1988, H. 12, 152

122 Neu war 1988 Afanas'evs These, die „bei uns entstandene Gesellschaft" sei keine sozialistische, denn unter Stalin seien „(...) ihre Lebensgrundlagen, das politische System, die Produktionsverhältnisse und in hohem Ausmaß auch alle anderen Bereiche" wesentlich verändert worden. Afanas'ev hatte allerdings die „Hoffnung auf den Sozialismus, die freie Arbeit, den Wohlstand und die Demokratie" noch nicht aufgegeben. - Afanasjew, J.: Antworten des Historikers, in: Provda (Deutsche Ausgabe) v. 26.07.1988, 3. Afanas'evs Positionen im Jahr 1988 finden sich zusammengefaßt in einem noch vor der 19. Unionsweiten Parteikonferenz (Juni 1988) erschienenen Beitrag: Afanas'ev, Ju.: Perestrojka i istoriðeskoe znanie, in: Literaturnaja Rossija v. 
der Akademiemitglieder in der Pravda am 24. April. Noch immer seien die „ehrwürdigen Akademiemitglieder" nicht bereit, offen über die Lage der Geschichtswissenschaft zu sprechen und anzuerkennen, daß es kein anderes Volk mit einer solch falsifizierten Geschichte gebe. Denn das seit Stalin (sic!) bestehende Regime habe die Historie nicht als Wissenschaft gebraucht, sondern als „Dienerin der Propaganda und für die Rechtfertigung der Verbrechen". Jetzt gehe es darum,

„(...) den verderbenbringenden Stalinismus in unserer Geschichtswissenschaft (...)“, das heiBt vor allem das „Monopol auf Wahrheit, auf ein neues Wort, auf die Erstlektüre einer geschichtlichen Quelle" $\mathrm{zu}$ überwinden. ${ }^{123}$

So ungeschminkt wie Afanas'ev äußerten sich aus dem Kreise der führenden Historiker nachweislich nur noch Evgenij Ambarcumov vom Institut für die Wirtschaft des sozialistischen Weltsystems und V.D. Polikarpov, ein wissenschaftlicher Mitarbeiter des Instituts für UdSSR-Geschichte: Ambarcumov kritisierte namentlich Ju.A. Poljakov, I.B. Berchin, Ju.S. Kukuškin und V.I Kas'janenko, die noch vor kurzem und ohne Not dogmatische Auffassungen publiziert hätten; er bat Isaac Minc, seine Erinnerungen über die Entwicklung der sowjetischen Historiographie zu veröffentlichen. Polikarpov stellte u.a. fest, die Historiker bildeten immer noch die Nachhut der perestrojka; die im Widerspruch dazu stehenden optimistischen Töne erinnerten ihn daran, daß ,gerade mit solchen 'Selbstberuhigungen' nach dem XX. und XXII. Parteitag in der Geschichtswissenschaft die Beerdigung des 'Tauwetters' begann. “'124

Die wichtigste Aktion der Akademiemitglieder im Jahr 1988 war zweifellos der Beschluß über die Rücknahme der 1972 ausgesprochenen Verurteilung der ,Neuen Richtung“" in der Oktoberrevolutionsforschung. ${ }^{125}$ In der vorangegangenen Aussprache sagten die Büromitglieder, die damaligen Ereignisse seien bis in die $\mathrm{Ge}-$ genwart bemerkbar. Sie empfahlen, den damals Kritisierten Publikationsmöglichkeiten zu geben,

"damit die wissenschaftliche Öffentlichkeit eine Vorstellung über das System ihrer Ansichten zu den strittigen Problemen erhält. " ${ }^{126}$

Ein knappes Jahr später, am 10. April 1989, wurde bei der Jahrestagung der Geschichtsabteilung ein epochal za nennender Beschluß gefaßt, der den bisherigen

17.06.1988, 2f, 8f (überarbeitet und in deutscher Übersetzung in: Afanassjew, Es gibt keine Alternative, 563-583).

123 Siehe Istoriki i pisateli, $72 \mathrm{f}$.

124 Ebd., 82 ff und 94.

125 In dem am 09.06.1988 gefaßten Beschluß hieß es, daß die damalige Verurteilung, in einer Reihe von Punkten eine negative Rolle“ spielte, daß sie "den sozialistischen Meinungspluralismus in der Wissenschaft durch ein sattsam starres Schema ablöste, wobei alles, was nicht in dieses Schema paßte, zu Beiträgen mit unrichtigen methodologischen Positionen erklärt wurde.“ Infolgedessen „verloren die Vertreter eines anderen Standpunktes die Möglichkeiten, auf an sie gerichtete Kritik in der Presse zu antworten." - VI 1988, H. 10, 175.

126 Ebd. 
Zustand der historischen Disziplin, das heißt ihre politische Abhängigkeit und inhaltliche Eintönigkeit beenden sollte. Darin wurde die akademische Leitung der Geschichtsabteilung aufgefordert,

„(...) die Wissenschaft als ein sich selbst entwickelndes System zu behandeln und auf sie fesselnde normative Direktiven zu verzichten; die Erforschung methodologischer Probleme (die Theorie sozialökonomischer Formationen, die Zivilisationstheorie, die Alternativität im Geschichtsprozeß) auszuweiten; (...) das Entstehen verschiedener schöpferischer Richtungen und konkreter Schulen in der Geschichtswissenschaft zu fördern (...). “127

Während die Mehrheit der an der Akademie der Wissenschaften beschäftigten Historiker sich für die Eigenverantwortung der Disziplin und für echten Pluralismus von wissenschaftlichen Schulen aussprach, und in der Öffentlichkeit die historische Legitimation des Sowjetstaates hinterfragt wurde, war bei den führenden Historikern, deren Haltungen uns in diesem Kapitel interessieren, zunehmender Skeptizismus gegenüber der Geschichtsdiskussion festzustellen. So konstatierte Koval'Cenko, der 1988 einen theoretischen Durchbruch erhofft hatte, Ende 1989 an der ,ideologischen Front" und in der Geschichtswissenschaft Zersetzung und Unstimmigkeit (razbrod): Ohne Prüfung würden bisherige Theorien verworfen und ,unter der Flagge von Pluralismus und Radikalismus" unzutreffende Behauptungen verbreitet, also die neuen Probleme mit alten Methoden gelöst. ${ }^{128}$ Jurij Poljakov war beunruhigt über die Zeitungen und Zeitschriften überschwemmende „Welle eines angriffslustigen Dilettantismus"; er begrüßte zwar weiterhin den Meinungspluralismus, sah aber infolgedessen ein "Magnetfeld von Verfälschungen" entstehen. ${ }^{129}$ Iskenderov und Volobuev sagten, die sowjetische Geschichtswissenschaft stecke in einer „Krise“, weil sie nicht in der Lage sei, das enorm gewachsene gesellschaftliche Interesse an Geschichte zu befriedigen. ${ }^{130}$ Volobuev, der einstige Erneuerer und Befürworter von Forschungen über historische Wahlmöglichkeiten, bezeichnete die Suche nach menschewistischen Atternativen zur Oktoberrevolution als ,perspektivlos" und kritisierte die in der Publizistik immer häufiger vorkommende Identifizierung Stalins mit Lenin. Er plädierte für die Verteidigung des Leninismus und der sowjetischen Werte. ${ }^{131}$

\footnotetext{
127 VI 1989, H. 7, 179

128 Siehe Istoriceskoe soznanie, 6.

129 Siehe Otečestvennaja istorija v sovremennoj publicistike, in: ISSSR 1990, H. 1, 176-190, hier 177.

130 Siehe „Kruglyj stol“ sovetskich i amerikanskich istorikov, in: VI 1989, H. 4, 97-117, hier 97f; Krizisnye javlenija v sovetskoj istoričeskoj nauke. Diskussija istorikov, filosofov, pravovedov, in: ON 1989, H. 3, 184-192, hier 185; Trubinova, T.S.: Vstreca prezidenta Akademii nauk SSSR s vedušcimi sovetskimi istorikami, in: NNI 1990, H. 2, 251-253, hier 252; die Vorbemerkungen von A. Iskenderov in dem Sammelband Otkryvaja novye stranicy... Meždunarodnye voprosy. Sobytija i ljudi, M. 1989, 3-8, hier 4, und zu der Artikelserie „Istorija sovetskogo obščestva v novom osveščenii“" in: ISSSR 1989, H. 10, 61f.

131 Siehe Istoričeskoe soznanie, 12. Vgl. auch die Stellungnahmen von Ju.S. Kukuskin und V.V. Zuravlev, ebd., $16 \mathrm{f}$ und $20 \mathrm{f}$.
} 
Mit solchen Positionen befanden sich die fuihrenden Historiker, kaum daß sie sich in die Geschichtsdebatte eingeumischt hatten, in hoffnungslosen Verteidigungsstellungen. Das dokumentiert der Dialog zwischen dem englischen Historiker Robert Service und dem sowjetischen Akademiemitglied Georgij Smimov in dem Reformblatt Moskovskie novosti im Dezember 1989. Service registrierte und begrüßte es, daß sich im Lauf des Jahres das Interesse der sowjetischen Öffentlichkeit von der Stalin-Zeit auf die Oktoberrevolution und den Staatsgründer verlagert hatte. Er forderte, erstens die revolutionären Massenbewegungen von $1917 \mathrm{zu}$ studieren, um nicht "Tausende von Revolutionen" gegenüber der Machtergreifung der Bolschewiki in Petrograd zu vernachlässigen, und zweitens die ,Kultfigur" Lenin neu einzuschätzen, seine Bedeutung zu relativieren. Darüber hinaus stellte er fest, daß der Transformationsprozeß seit 1985 in eine andere Richtung gehe als die Oktoberrevolution. ${ }^{132}$ Smirnov hingegen blieb in seiner Antwort dabei, Leninismus und Stalinismus seien nicht miteinander "verwandt", und die gegenwärtige Politik sei eine „Rückkehr zu den Ursprüngen“, die zur „Wiederherstellung der Leninschen Sozialismus-Konzeption" führen werde. ${ }^{133}$

Anders als Koval'cenko und andere, mochte auch der Vorsitzende der Ende März 1989 gegründeten „Sowjetischen Assoziation junger Historiker" ${ }^{\text {“134 }}$ E.M. Koł̌okin die geistige Situation im Lande nicht in den Kategorien eines ideologischen Bürgerkriegs betrachten. Es gehe nicht darum, Andersdenkende zu bekämpfen, sondern das Zusammenleben und -arbeiten mit ihnen zu erlernen. ${ }^{135}$ Auch Aleksandr Samsonov und Michail Barg begriffen die neue Lage als wissenschaftlichen Lemprozeß. Samsonov wamte, voreilig neue Konzeptionen und Theorien entwickeln zu wollen; zunächst komme es darauf an, die „weißen Flecken“ zu liquidieren, die endlich zugänglichen Quellen zu studieren und das neue Tatsachenmaterial durchzuarbeiten. ${ }^{136}$ Barg verwies darauf, daß das, historische Denken" durch den Dogmatismus besonders beschädigt worden sei und neu erlernt werden müsse. Dazu müßten die Errungenschaften sowohl manxistischer als auch nichtmarxistischer Historiker und Philosophen im Ausland angeeignet werden. ${ }^{137}$ Jurij Afanas'ev radikalisierte sich 1989 weiter. Der ehemalige Redakteur der Theoriezeitschrift Kommunist schreckte nicht mehr davor zurück, die Legitimation der Oktoberrevolution

\footnotetext{
132 Service, R.: Die Kultfigur bedarf einer Neueinschätzung, in: MN (Deutsche Ausgabe) 1989, Nr. 12, 11 .

133 Smirnow, G.: Perestroika ist eine Rückkehr zu den Ursprüngen, ebd., 12.

134 Aus 67 Städten waren Historikerinnen und Historiker zur Gründungskonferenz nach Moskau gekommen. Das Höchstalter für die Mitglieder wurde auf 40 Jahre festgesetzt. Mitbegründer der Assoziation waren das ZK des Kommunistischen Jugendverbandes, die Geschichtsabteilung der AdW und die Allunionsgesellschaft Znanie. - VIKPSS 1989, H. 3, 157f; H. 8, $158 f$.

135 Siehe Istoričeskoe soznanie, 15.

136 Siehe Otečestvennaja istorija, $185 \mathrm{f}$.

137 „In den Begriff des historischen Denkens gehen sowohl die Theorie des objektiven historischen Prozesses als auch die Theorie der historischen Erkenntnis ein. Ohne historisches Denken ist keinerlei geschichtswissenschaftliche Analyse, und noch weniger die wissenschaftliche Synthese möglich.“ - Siehe Krizisnye javlenija, 192.
} 
und die historische Rolle Lenins zu hinterfragen. War seine Haltung bisher antistalinistisch, so bewertete er nun die gesamte Sowjetzeit und die sowjetische Geschichtswissenschaft in allen Phasen ihrer Entwicklung negativ. Nicht nur in der Stalinzeit, sondern
„(...) in allen Jahren der Sowjetmacht, ungeachtet des Lichtschimmers Ende der fuinfziger bis Anfang der siebziger Jahre, der das allgemeine Bild nicht änderte, blieb die sowjetische Geschichtswissenschaft (...) hauptsächlich nicht historisches Wissen, sondem eine Variante der Propaganda und eine Ergänzung zur Ideologie.“138

Damit befand sich Afanas'ev - wie schon mit seinen Thesen in den zwei vorangegangenen Jahren - unter den fuhrenden Historikern in den großen Geschichtsinstituten in einer isolierten Position; ${ }^{139}$ in der öffentlichen Geschichtsdiskussion hingegen war er ein anerkannter "Trendsetter“. 140

Die namhaften, ,großen“(krupnye) Historiker waren an den Büchern, die 1989 zur Geschichtsdiskussion erschienen, nur selten beteiligt. Akademiemitglied Samsonov stellte mit seiner Publikation eine Ausnahme dar: In einem 368-seitigen Band veröffentlichte er vier eigene Beiträge von 1987, etwa zweihundert Zuschriften, die ihn daraufhin erreicht hatten, und seine Bemerkungen zu den Briefen. ${ }^{141}$ Ansonsten

138 Siehe „Kruglyj stol“ $1989,102$.
139 Vorsichtiger als Afanas'ev, aber tendenziell analog $\mathrm{zu}$ ihm, wog V.1. Buganov bei einem Rund-Tisch-Gespräch am 16. Mai 1989 die Gedanken: „Mich erstaunt ein Moment, das in vielen Publikationen auftaucht: es hätte bei uns keinen Personenkult und andere Deformationen gegeben, wenn Lenin noch gelebt hätte, wenn es gelungen wäre, die Leninsche Garde zu retten usw. Aber was ist mit der Sprengung der Konstituierenden Versammlung? Und die schrittweise Liquidierung aller Parteien? Und der Gewaltkult? (...) Meiner Ansicht nach kam viel Unglück dadurch, daß sich nur eine Partei an der Macht befand." - In der gleichen Diskussion attackierte der Philologe V.V. Kožinov Jurij Afanas'ev: „Eine der traurigsten Erscheinungen der gegenwärtigen Geschichtswissenschaft ist das Phänomen Jurij Afanas'evs. Das ist ein erstaunlicher Mensch. Ein halbes Jahr nach dem April-Plenum (1985) veröffentlichte er einen totalen 'Stagnations'-Artikel (Kommunist 1985, H. 14), in dem er zum Beispiel schrieb, eine Aufgabe der Historiker bestehe darin, die Motive des selbstlosen Arbeitsenthusiasmus der Helden in den ersten Planjahrfüften zu erklären. Im gleichen Aufsatz fiel er über diejenigen her, die es gewagt hatten, Solochov wegen seines klassenmäßigen Herangehens an die Kollektivienung auf dem Lande zu kritisieren. Hier betonte Afans'ev auch, daß die Gesellschaftswissenschaften sich konsequent den Problemen bei der Vervollkommnung des entwickelten Sozialismus zuwenden müßten. Aber nur zwei Jahre später schreibt der gleiche Afanas'ev, daß es bei uns gar keinen Sozialismus gibt, daß die Kollektivienung das allergrößte Verbrechen war usw. usf." - Siehe Otečestvennaja istorija, 187 und 179. Natürlich ist es ein Leichtes, solche und weitere orthodoxe Aussagen (die Kožinov 1985 wahrscheinlich ohne weiteres unterschrieben hätte) in Afanas'evs Aufsatz zu finden; darüber hinaus gab Afanas'ev aber bereits Impulse für die künftigen Diskussionen, war seinen Kollegen um mindestens ein Jahr voraus. Von dem Vorwurf, sehr schnell die Fronten gewechselt zu haben, nicht immer gut fundierte Positionen vertreten zu haben, ist Afanas'ev m.E. jedoch nicht gänzlich freizusprechen. Siehe Afanas'ev, Prošloe und Kapitel 5.4.

$140 \mathrm{Vgl}$. Kapitel 6.2.

141 Samsonov, A.M.: Znat' i pomnit'. Dialog istorika s citatelem, M. 1989. Die Auflage betrug 200.000 Exemplare. 
wurden Diskussionen und Aufsätze, die bereits $1987 / 88$ in der Pravda ${ }^{142}$, der Sovetskaja Rossija ${ }^{143}$ oder anderen Periodika ${ }^{144}$ erschienen waren, nochmals im $\mathrm{Zu}$ sammenhang herausgegeben. In der Buchreihe „Perestrojka: Offenheit, Demokratie, Sozialismus" war der zweite Band dem „Stalin-Kult" gewidmet. Keiner der Diskussionsbeiträge stammte von einem leitenden Geschichtswissenschaftler. ${ }^{145}$ Das erste sowjetische, politische Porträt" Stalims schrieb denn auch kein Historiker, sondern der Philosophie-Professor Dmitri Volkogonov. ${ }^{146}$ Drei neue Untersuchungen der sowjetischen Geschichte legten mit vereinten Kräften acht Historiker der mittleren Generation, Mitarbeiter des Akademieinstituts für Geschichte der UdSSR und Hochschullehrer, vor. ${ }^{147}$ Geschichtstheoretisch und -methodologisch beriefen sich die Autoren auf die letzten Arbeiten Lenins; sie versuchten, mit einem ,abwägenden Herangehen" (vzvesenmyj podchod) an die sowjetische Geschichte praktische und theoretische Prinzipien Lenins wiederzubeleben. ${ }^{148}$ Von dem fuihrenden Historiographen der Tomsker Universität Boris Mogil'nickij wurden 1989 elf Jahre zuvor erstmals veröffentlichte Vorlesungen zur Geschichtsmethodologie in quantitativ erweiterter und strukturell überarbeiteter Fassung neu herausgegeben; inhaltlich hatte Mogil'nickij nichts Wesentliches geändert. ${ }^{14}$

\footnotetext{
142 Urok daet istorija, M. 1989 (Auflage: 200.000).

143 Perepiska na istoriðeskie temy. Dialog vedet citatel', M. 1989 (Auflage: 200.000).

14 Stranicy istorii KPSS 1989 (Auflage: 100.000); Vozvrašcennye imena. Sbornik publicistiZeskich statej v 2-ch knigach, M. 1989; Surovaja drama naroda. UCenye i publicisty o prirode stalinizma, M. 1989 (Auflage jeweils 200.000); Stranicy istorii sovetskogo obšcestva: Fakty, problemy, ljudi, M. 1989 (Auflage 540.000!).

145 Osmyslit' kul't Stalina, M. 1989. - Der erste Band dieser Reihe war von Jurij Afanas'ev herausgegeben, deutsch unter dem Titel: Es gibt keine Alternative.

146 Volkogonov, D.A.: Triumf i tragedija. Politizeskij portret I.V. Stalina. V 2-ch knigach, M. 1989 (deutsche Ausgabe: Wolkogonow, D.: Stalin. Triumph und Tragödie. Ein politisches Porträt, Düsseldorf 1989). In dieser Arbeit bemühte sich Volkogonov noch, die Unterschiede zwischen Stalin und Lenin zu verdeutlichen.

147 Gordon, L.A./E.V. Klopov: Čto eto bylo? Razmyšlenija o predposylkach $i$ itogach togo, čto sluxilos' s nami v 30-40-e gody, M. 1989; Istoriceskij opyt (Das Autorenkollektiv bildeten V.A. Kozlov, G.A. Bordjugov, E.Ju. Zubkova und O.V. Chlevnjuk); Volobuev, O.V./S.V. Kulešov: Oxišcenie. Istorija i perestrojka. PublicistiCeskie zametki, M. 1989.

$148 \mathrm{Vgl}$. die Schlußbemerkungen von V. Naumov in: Volobuev/Kulešov, Oxiš̌enie, 277ff. - Die gleiche Intention wurde mit der im Herbst 1989 begonnenen Artikelserie zur "Geschichte der sowjetischen Gesellschaft in neuem Licht“" (in: ISSSR 1989, H. 10ff, 1990, H. 2ff, 1991, H. 1 und 9-10, 1992, H. 6-7) verfolgt.

$149 \mathrm{Vgl}$. Mogil'nickij, B.G.: O prirode istoriðeskogo poznanija. T. 1978; ders., Vvedenie v metodologiju istorii, M. 1989; im einzelnen vgl. Kapitel 6.3.ff.
} 


\subsubsection{Die Geschichtswissenschaft während der gesellschaftlichen Agonie 1990/91}

Die gesellschaftliche Transformation geriet Ende 1989 ins Stocken, und in einer 1990/91 andauernden Agonie zerfiel das System. ${ }^{150}$ Durch die Kumulation systembedingter und wirtschaftspolitischer Probleme brach die Ökonomie des Landes zusammen. ${ }^{151}$ Gorbačev mußte angesichts des allgemeinen „Tohuwabohus ${ }^{\text {c152 }} \mathrm{im}$ mer häufiger depremiert sein. ${ }^{153}$ Er beging 1990 die entscheidenden bündnis- und wirtschaftspolitischen Fehler, die in ihrem Zusammenwirken das Schicksal der von ihm initiierten und definierten perestrojka besiegelten:

Im ersten Halbjahr wandte er sich von den Radikalreformern ab, um sich auf die Konservativen zu stützen. ${ }^{154}$ Im Gegenzug verließen viele prominente Reformer die

1s0 Zur Chronologie der Ereignisse siehe Meissner, B.: Die zweite Phase der soziopolitischen Reform Gorbatschows (I und II). Die Sowjetunion vor dem XXVIII. Parteitag der KPdSU, in: OE 1990, H. 11, 1031-1049; H. 12, 1145-1158; ders., Die KPdSU zwischen Macht und Ohnmacht, in: OE 1991, H. 1, 15-45; ders., Gorbatschow am Scheideweg (I und II), in: OE 1991, H. 5, $467-$ 492; H. 7, 671-694; ders., Gorbatschow, Jelzin und der revolutionäre Umbruch in der Sowjetunion (I-IV), in: OE 1991, H. 12, 1187-1205; 1992, H. 1, 21-40; H. 3, 205-226; H. 5, 482-500; ders., Das Ende der Sowjetunion, der Abgang Gorbatschows und Jelzins "Revolution von oben“. Transformation der „Union der Sozialistischen Sowjet-Republiken" in "Gemeinschaft unabhängiger Staaten", in: OE 1992, H. 9, 836-857. - Vgl. zu dieser letzten Phase der perestrojka die eindrucksvollen Erinnerungen des außenpolitischen Beraters Gorbacevs. Anatolij Cernaev, hier: Tschernajew, Die letzten Jahre, $261 \mathrm{ff}$.

151 Erstmals 1990 ging das Bruttosozialprodukt gegenüber dem Vorjahr deutlich zurück, und zwar um bis zu fünf Prozent, 1991 um ungefähr zwanzig Prozent; die entsprechenden Zahlen für die Industrieproduktion lauten minus 1,2\% und minus 6,2\%. Der Niedergang betraf alle Wirtschaftszweige. - Vgl. Sowjetunion 1991, 364; Höhmann, H.H.: Sowjetische Wirtschaft 1990/91: Krise und Notstandsregiment statt Systemwechsel, ebd., 135-151; Sowjetunion 1980-1991. Bilanz der letzten Jahre, hg. vom Statistischen Bundesamt, Wiesbaden 1992, 134ff; Hirsch, H.: Probleme der Perestrojka sowjetischer Planwirtschaft. Möglichkeiten und Schwierigkeiten der Umgestaltung, in: OE 1990, H. 8, 728-760, hier 739ff; Hoffer, F.: Perestroika. Die unfreiwillige Zerstörung des sowjetischen Vergesellschaftungszusammenhangs, oder: warum das letzte Gefecht verloren ging. Marburg 1992, 138ff.

152 Siehe Brahm, H.: Tohuwabohu in der Sowjetunion, in: Sowjetunion 1991, 21-31.

153 Cernaev berichtete beispielsweise, am 28.01.1990 sei Aleksandr Jakovlev zu. ihm gekommen: „Er vertraute mir 'unter dem Siegel der Verschwiegenheit' an: '(...) Er (Gorbacev; J.H.) ist ratlos und bekümmert, er fühlt sich einsam. Was soll ich tun? hat er gefragt. Aserbaidschan und Litauen, Radikalreformer einerseits, Sozialdemokraten andererseits, und die Schläge werden immer schmerzhafter, die Wirtschaf treibt vor sich hin, das Volk ist an der Grenze seiner Kraff. "“. - Tschernajew, Die letzten Jahre, 282 (Gorbacevs Worte sind von mir kursiv gestellt; J.H.); vgl. ebd., 316.

154 Cernaev schrieb, daß Gorbačev Anfang 1990 innerlich zum politischen Schulterschluß mit den Radikalreformern bereit gewesen sei, und es bereits Gespräche mit deren interregionaler Deputiertengruppe gegeben habe. Aber das Mißtrauen und die Kritik der Reformer an Gorbacevs Nachgiebigkeit gegenüber Ligaxev, und mehr noch die Wahlkundgebung der Vereinigung .Demokratisches Rußland" am 25.02.1990 in Moskau mit zwei- bis dreihunderttausend Teilnehmern sowie die „Donnerschläge“ am 1. Mai, als der erstmals erlaubte inoffizielle zweite Zug vor dem Lenin-Mausoleum Sprechchöre gegen Gorbačev skandierte, trieben den gekränkten 
KPdSU bzw. ihre staatlichen Ämter; es kam erstmals in der Parteigeschichte zu Massenaustritten. Das spezifische Gewicht der Konservativen in der KPdSU nahm dadurch zu, die Partei hörte auf, eine einflußreiche Kraft in der Gesellschaft zu sein. ${ }^{155}$ Die erstarkenden Nationalbewegungen, autonomen Arbeiter- und Bürgerrechtsbewegungen, informellen Gruppen, Wahlbündnisse, neuen Parteien, Kirchen und Religionsgemeinschaften stießen in ideologische Freiräume und beschleunigten den Zerfall der Kommunistischen Partei. ${ }^{156}$

Auf die Selbstzerstörung des Wirtschaftssystems ${ }^{157}$ reagierten Gorbacev und El'cin zunächst gemeinsam und initiierten die Vorbereitung des sogenannten ,500-Tage-

Generalsekretär wieder in die Arme der Partei, die er selbst im gleichen Jahr als, ,räudigen, tollwütigen Hund" bezeichnete, den er ,nicht von der Leine lassen“ dürfe. Radikal reformer, wie z.B. Ju. Afanas'ev, begannen, den unpopulär werdenden Gorbačev zu meiden; dieser wiederum protegierte die Männer, die im August 1991 zu putschen versuchten: Dmitrij Jasov war schon am 31.05.1987 nach der spektakulären Landung des Sportfliegers Mathias Rust auf dem Roten Platz neuer Verteidigungsminister geworden; Vladimir Krjučkov hatte Ende September 1988 die Leitung des Komitees für Staatliche Sicherheit (KGB) übernommen; Boris Pugo ernannte Gorbacev am 02.12.1990 zum Innenminister; am 27.12. setzte er die Wahl Genadij Janaevs zum VizePräsidenten durch; Mitte Januar 1991 traten Aleksandr Besmertnych (Außenminister) und Valentin Pavlov (Ministerpräsident) ihre Ämter an. - Tschernajew, Die letzten Jahre, 286ff; Simon/Simon. Verfall, $99 f$.

15s Im Frühjahr 1990 verließ Ju. Afanas'ev die Partei, am Ende des 28. Parteitags der KPdSU (01.-11.07.1990) traten Boris El'cin, Gavriil Popov und Anatolij Sobčak aus; spektakulär trat Eduard Sevardnadze am 20.12.1990 als Außenminister zurück und warnte vor einer neuen Diktatur; demonstrativ trat nach dem "Blutsonntag" in Vilnius am 13.01.1991 die gesamte Redaktion der Reformzeitung ,Moskovskie novosti“ aus der Partei aus; A. Jakovlev trat am 28.07.1991 als Präsidentenberater zurück und verließ nach dem Putschversuch im August die KPdSU. - „Allein von Juli bis September 1990 waren 530.000 Mitglieder aus der KPdSU ausgetreten. Am 1. Oktober 1990 hatte die Partei noch 17,7 Millionen Mitglieder, im März 1991 offensichtlich rund 16 Millionen, von denen 1,3 Millionen ihre Mitgliedsbeiträge nicht bezahlten.“- Brahm, Tohuwabohu, 27; vgl. Kljamkin, 1.: Der Übergang vom Totalitarismus zur Demokratie in der UdSSR. Tendenzen, Probleme, mögliche Etappen, in: OE 1990, H. 6, 479-494, besonders 490f;; Ahlberg. R.: Legitimationskrise der kommunistischen Herrschaft, ebd, 517-534; Ziemer, K.: Zur Erosion des Herrschaftsmonopols der KPdSU, ebd, 535-547; „Ich trete zurück..." Schewardnadses Rede auf dem Kongreß der Volksdeputierten, in: OE 1991, H. 5, A 251-A 255; Jakowlew, A.: Verfall der verfaulten Strukturen, in: TAZ v. 21.08.1991, 13; Simon/Simon, Verfall, 87; Tschernajew, Die letzten Jahre, 33 Iff.

156 Viele dieser Bewegungen verbreiteten atavistische (nationalistische, rassistische, xenophobe, antisemitische etc.) Inhalte. - Vgl. etwa Koenen, G.: „Pamjat“ und die russische „Neue Rechte“, in: OE 1990, H. 3, 203-209; Maryniak. I.: Valentin Rasputin, die neue Rechte und das Religiöse, ebd., 210-218; ebd., A 137-A 157; Koenen, G./K. Hielscher: Die schwarze Front. Der neue Antisemitismus in der Sowjetunion, Reinbek 1991; Glybowski, J./J. Winkel: Rückwärts marsch! Zum Konservatismusphänomen in der UdSSR, in: OE 1991, H. 8, 791-801, besonders 797ff, Luchterhand, G.: Neue politische Parteien und Bewegungen in Rußland. Geschichte und Gegenwart, in: OE 1992, H. 5, 396-409; Wiedergeburt des Kosakentums zur Verteidigung russischen Siedlungsraumes, in: OE 1992, H. 6, A 307-A 313; Wladimir Schirinowskij: Das politische Porträt eines russischen nationalistischen Populisten, ebd., A 314-A 322; Simon/Simon, Verfall, $88 \mathrm{ff}$.

157 „Viele Betriebe sind zu einem primitiven Tauschhandel übergegangen. Niemand stört sich daran, daß die Pläne, das Rückgral der sowjetischen Planwirtschaft, nicht ausgeführt und erfullt werden. Und jede weitere Nichterfüllung der Pläne zieht weitere nach sich. Das sowjetische Wirt- 
Programms", einer unter der Leitung des Akademiemitglieds Stanislav Satalin entworfenen dezentralistischen, marktorientierten Schocktherapie. ${ }^{158}$ Cernaevs Bericht zufolge war Gorbačev im Sommer 1990 entschlossen, auf der Grundlage dieses Programms den Übergang zu einer Marktwirtschaft einzuleiten. ${ }^{159}$ Unter dem Eindruck der unerträglich gewordenen Lage der Bevölkerung, der endlosen Streitereien der Wirtschaftsfachleute, der Ablehnung des Programms durch konservative Bündnispartner (z.B. Luk'janov und Ryškov) und die Wortführer der Russischen Kommunistischen Partei (z.B. Poloskov) sowie des eigenen rapiden Popularitätsverfalls, ließ Gorbačev sich zu der folgenschwersten wirtschaftspolitischen Fehlentscheidung verleiten: Er distanzierte sich im letzten Moment vom "SatalinProgramm" und setzte im Obersten Sowjet der UdSSR am 24. September die Annahme eines zentralistisch ausgelegten Rahmenplans für einen gradualistischen Übergang zu einer regulierten Mischwirtschaft durch. ${ }^{160}$

Zweimal handelte Gorbačev - folgt man Černaev - entgegen seiner eigenen Maxime „emotional“: Aus „Sorge um die Menschen“ habe er den weiteren Prozeß lenken wollen, habe sich deshalb nochmals - bündnis- und wirtschaftspolitisch - an die alten Stützen der untergehenden Macht gehalten und infolgedessen umso schneller jede Kontrolle über den Fortgang der politischen Entwicklung verloren. ${ }^{161}$ Nach dem militärischen Eingreifen sowjetischer Truppen in Litauen und Lettland am 13. Januar 1991 nahm die politische Polarisienung zu. Gorbačevs Popularität und Einfluß schwanden zusehends, während Boris El'cin eine „erdrutschartige Machtverschiebung za seinen Gunsten " ${ }^{\text {162 }}$ gelang. Die konzeptionslose Wirtschaftspolitik unter dem Ministerpräsidenten Pavlov verschlechterte die soziale Lage der Bevölkerungsmehrheit, verschärfte die Legitimationskrise der gesamten Gorbačev-Administration und lieferte vor allem den konservativen und stalinistischen Kritikern, die ihre Anhänger seit Herbst 1990 zum Gegenangriff mobilisier-

schaftssystem ist dabei, sich selbst zu zerstören." - Götz, R.: Sowjetische Wirtschaftsentwicklung und Winschaftsreformen, in: Schwegler-Rohmeis/Segbers, Perestrojka, 19-37, hier 31.

158 Cernaev zufolge soll Gorbaxev die Ausarbeitung dieses Programms „voller Enthusiasmus“ verfolgt haben. - Siehe Perechod k rynku. Koncepcija i Programma, M. 1990; Satalin, S.: Ekonomið̌eskaja programma politǐ̌eskoj partii, in: K 1990, H. 7, 31-38; Höhmann, Der ökonomische Systemwechsel, 215f, Götz, Sowjetische Wirtschaftsentwicklung. 31f.

159 Tschernajew, Die letzten Jahre, $310 f$; „Gorbatschow will die Wirtschaftsreform beschleunigen. Kontrollierter Übergang zur Marktwirtschaft angekündigt (...)", in: FAZ v. 29.03.1990.

160 „Damit war die Chance verpaßt, daß die Sowjetunion mit Gorbatschow an der Spitze den Übergang zum Markt vollzog. Der Oberste Sowjet der Russischen Föderation nahm zwar das 500-Tage-Programm an, ernsthaft war jedoch an eine Umsetzung nicht zu denken, weil die Geldund Finanzpolitik in der ausschließlichen Kompetenz der Zentralregierung lagen." - Simon/Simon, Verfall, 116; vgl. Götz, Sowjetische Wirtschaftsentwicklung, 32ff, Holtbrügge, D.: Die UdSSR auf dem Weg zur Marktwirtschaft. Programme, Maßnahmen, Widerstände, in: OE 1991, H. 7, 619-634; Tschernajew, Die letzten Jahre, 309ff.

$161 \mathrm{Vgl}$. Tschernajew, Die letzten Jahre, 316-320.

162 Simon/Simon, Der Verfall, 101. 
ten, ideologische Munition. ${ }^{163}$ Aus ihrer Sicht war Gorbacev nicht mehr in der Lage, das Allerschlimmste - die Auflösung der Sowjetunion und die Privatisierung in Industrie und Landwirtschaft - zu verhindern. Deshalb wurden sie einen Tag vor der geplanten Unterzeichnung des neuen Unionsvertrages selbst aktiv, um den Gang der Dinge zu stoppen. ${ }^{164}$ Der dilettantische Putschversuch (18. bis 21 . August 1991) und der Sieg El'cins im folgenden Machtkampf beschleunigten die Entwicklung, welche die Putschisten verhindem wollten. Mit umso größerem Schwung wurden von September bis Dezember 1991 die bereits vorher begonnene Auflösung der UdSSR und die Demontage Gorbačevs zu Ende gebracht; der Staatspräsident trat am 25. Dezember 1991 zurück. Die Sowjetunion war perdu. ${ }^{165}$

In diesen beiden Jahren der Agonie war die Parteifihrung auch in ihrer Haltung zur Geschichtsaufarbeitung in drei Strömungen gespalten: Es gab erstens die dogmatischen Leninisten, zweitens die humanistischen Reformsozialisten, drittens die liberalen Antileninisten.

$163 \mathrm{Vgl}$. Höhmann, Der ökonomische Systemwechsel, 216f: Simon/Simon, Der Verfall, 98ff passim und 116ff; Ahlberg, R.: Armut in der Sowjetunion, in: OE 1990, H. 12, 1159-1174; Steffen, O.: Schwieriger Übergang zur Marktwirtschaft - die Versorgungskrise in der Sowjetunion, in: OE 1991, H. 7, 646-656; Huber, M.: Die soziale Lage der Bevölkerung, in: Sowjetunion 1991, 165-173; Moskoff, W.: Hard times. Impoverishment and protest in the perestroika years. The Soviet Union 1985-1991, New York 1993, 101ff, I98ff; Dietz, B./W. Sörgel: Mehr Sorgen als Hoffnungen. Meinungsumfragen in der Sowjetunion, in: Schewardnadse u.a., Revolution, 225243; Pozner, Abschied, 478ff; „Die letzte Verteidigungslinie“. Achromejew. Armee soll die Einheit der Sowjetunion bewahren, in: FAZ v. 15.11.1990; Afanas'ev, Ju.: My dvižemsja v storonu diktatury. Možno li postavit' bar'er na puti chaosa i avtoritarizma? In: NG v. 21.12.1990, 5; Poloskow, I.: Für den sozialistischen Charakter der Perestroika, in: MB 1991, H. 3, $42-47$ (zuerst in: K 1991, H. 2); „Nichts ist für uns wertvoller als die große Sowjetunion“. Der ehemalige KGBChef (V. Krjučkov; J.H.) über die Notwendigkeit der Wachsamkeit nach innen und außen, in: $O E$ 1991, H. 11, A 633-A 639; „Von der Ideologie loskommen..." Interview mit dem sowjetischen Obersten Viktor Alksnis, ebd., A 640-A 645; „An unser Volk“ (Aufruf von Ju. Bondarev, B. Gromov, G. Sjuganov, V. Rasputin, V. Starodubcev u.a. an die „Bürger der UdSSR! Landsleute!", zuerst veröffentlicht in: Sovetskaja Rassija, 23.07.1991), hier in: Simon/Simon, Verfall, 296-301.

$164 \mathrm{Zu}$ den Ursachen und dem Verlauf des Putschversuchs siehe Schewardnadse/Gurkow/Eichwede, Revolution; Blätter 1991, H. 10; Chronika putča čas za Časom. Sobytija 1922 avgusta 1991 v svodkach Rossijskogo Informacionnogo Agentstva, L. o.J.; Putž. Chronika trevožnych dnej, M. 1991; Gorbatschow, M.: Der Staatsstreich, München 1991; ders., Der Zerfall, 188ff; Der August-Putsch. Erste russische Reaktionen und Analysen, in: OE 1992, H. 2, A 80-A89; Tschernajew, Die letzten Jahre, 397ff

$165 \mathrm{Vgl}$. Conert, H.: Überlegungen zur Analyse der Ursachen des Scheiterns der sowjetischen Perestrojka, in: Der Trümmerhaufen als Aussichtsturm. Historische, aktuelle und perspektivische Vermessungen einer gründlich veränderten Situation, Marburg 1991, 43-81; Hösler, J.: SowjetUnion perdu, in: FW 1991, H. 3, 62f: Schubert, D.: Irrweg oder Wegbereitung? Gorbatschows Perestrojka als Übergangsprozeß zu marktwirtschaftlich-demokratischen Strukturen, in: $O E$ 1992, H. 2, 110-120; Luks, L.: Das Ende der Doppelherrschaft in der Sowjetunion. Eine Revanche der russischen Demokraten, in: OE 1992, H. 3, 227-231; Geyer, D.: Das Ende des Sowjetimperiums. Eine historische Betrachtung, in: OE 1992, H. 4, 295-302; Hecker, H.: Untergang eines Weltreiches, in: OE 1992, H. 6, 465-481; Bonwetsch, B.: Das Ende der Sowjetunion: die untragbare Bürde der Weltmacht, in: OE 1992, H. 7, 551-563. 
Erstens: $\mathrm{Zu}$ den dogmatischen Leninisten ist der größte Teil des Politbüros und Zentralkomitees der KPdSU zu zählen; ihre Wortführer - Ligačev, Krjučkov, Poloskov, Prokofev u.a. - beriefen sich auf Lenin, der ihrer Ansicht nach seine Sozialismusauffassung auch in den späten Schriften nicht verändert habe. Sie hielten die Geschichtsdiskussion für den unverantwortlichen Versuch,

„(..) unsere Geschichte anzuschwärzen, um den Glauben unseres Volkes an unsere Ideale zu schwächen und patriotische Gefühle zu untergraben. “166

Sie bekannten sich zur bisherigen Konzeption der Oktoberrevolution und der „Diktatur des Proletariats“ und forderten in ihrer, dem 28. Parteitag der KPdSU (01.-11.07.1990) vorgelegten ,Marxistischen Plattform“ die Rückkehr zu sozialistischen Idealen, die Überwindung der Bürokratie und die Selbstverwaltung der Gesellschaft. ${ }^{167}$ Infolge des offenkundigen Systemverfalls lehnten die Leninisten zunehmend aggressiver die Geschichtsdiskussion grundsätzlich ab. Beim JanuarPlenum des Zentralkomitees der KPdSU am 31. Januar 1991 bezeichnete der Erste Sekretär der Moskauer Parteiorganisation Ju.A. Prokofev die historische Diskussion als ,heimlichen Krieg" gegen die Strukturen der Gesellschaft. ${ }^{168}$

Zweitens: Gorbačev, seine Mitstreiter und Berater (etwa Aleksandr Jakovlev, Sachnazarov, Cernaev, Falin, Vadim und Roj Medvedev) vertraten - mit unterschiedlichen Akzenten - die Idee eines humanen und demokratischen Sozialismus; sie beriefen sich auf den späten Lenin, dessen Werk aus ihrer Sicht auch am Ende des 20. Jahrhunderts nutzbare Anregungen enthalte. ${ }^{169}$ Sie befüworteten eine umfassende Geschichtsaufarbeitung, um ideologischen Ballast abwerfen und die undogmatische Lenin-Neuinterpretation bei der Bewältigung gegenwärtiger Aufgaben ,schöpferisch nutzen“ zu können. ${ }^{170}$ Dementsprechend wurde zu Beginn des

166 So Egor Ligačev bei seinem Redebeitrag während des außerordentlichen ZK-Plenums (25./26.12.1989), hier zitiert nach Davies, Perestroika, 269.

167 Siehe ebd. und ff.

168 Hier nach Davies, Perestroika, 282f.

169 A. Jakovlev, V. Falin und A. Cernaev blieben bis nach dem Putschversuch auf ihren Posten und drängten Gorbačev vergeblich, konsequenter antistalinistische Positionen gegenüber den Konservativen zu vertreten. Falin verortete die Hauptursache des Scheiterns der perestrojka in der zu späten und inkonsequenten Verurteilung des Stalinschen Systems: „Für mich ist im Herbst 1918 der sozialistische Prozeß im sowjetischen Rußland abgerissen. (...) Die Perestroika verhieß, den zerschnittenen Faden neu zu knüpfen. (...) Indem sie diese Hoffnung verriet, richtete sie sich selbst und öffnete der Konterrevolution Tür und Tor. Jeder Tag, jede Stunde Verzögerung der Absage an Stalin als dem Antipoden des Sozialismus war ein Verbrechen an der sozialistischen Alternative oder, wem das lieber ist, an der sozialistischen Utopie. Entweder Disqualifizienung des Stalinismus (...) oder Abkehr vom Sozialismus. Die Väter der Perestroika versäumten es, rechtzeitig klarzustellen, welche Vergangenheit unsere Gesellschaft verwirft. (...) Sie überließen es den Gegnern des Sozialismus, die antistalinsche Wende vorzunehmen (...)." - Falin, Politische Erinnerungen, 429f.

110 Siehe Jakovlev, A.: Socializm: of mexty k real'nosti, in: K 1990, H. 4, 8-21 (Dokumentation des Referats und der anschließenden Diskussion am 12.02.1990 in der Lomonosov-Universität, wo Jakovlev sagte: „Ich bin Kommunist und beabsichtigte nicht, mich mit der Schaffung einer 
Jahres 1990 der Kurs „Marxismus-Leninismus“ als Pflichtfach an den Universitäten abgeschafft und durch Gesellschaftskunde ersetzt. ${ }^{171}$ Gorbačev setzte am Ende des 28. Parteitags eine Resolution durch, in der erstmals in der post-Stalinschen Ära der KPdSU

"(...) das totalitäre Stalinsche System, das dem Land, dem Volk und der Idee des Sozialismus selbst riesigen Schaden zugefügt hat, (...)"

verurteilt wurde. ${ }^{172}$ Mittels Izvestija CK KPSS veröffentlichte das Zentralkomitee weiterhin bislang unzugängliche Dokumente, obwohl seit Mitte 1990 der Redaktionsrat in der Hand eher Konservativer lag. ${ }^{173}$ Die Zeitschrift dokumentierte bis zur vorletzten Ausgabe den Fortgang der Rehabilitierungen und die von der PolitbüroKommission zusammengestellten Dossiers über die betroffenen Gruppen. ${ }^{174}$ Dem Beschluß des Politbüros „Über die Herstellung der Rechte aller Opfer politischer Repressionen der zwanziger bis fünfziger Jahre" vom 13. August 1990 folgten keine weiteren Maßnahmen,

„(...) weil die Ausgestaltung der Gesetze den politischen Manifestationen nicht mehr nachkam. “.175

Die Rehabilitierung aller Repressionsopfer der sowjetischen Machtordnung blieb zu Zeiten der UdSSR unvollendet. ${ }^{176}$

Opposition gegen meine Partei zu befassen." - Ebd., 20f); analog auch Sachnazarov, G.: Obnovlenie ideologii $i$ ideologija obnovlenija, in: K 1990, H. 4, 46-59; Medvedev, R.: Vzaimosvjaz" ideologii, politiki i obšestvennych nauk, in: K 1990, H. 16, 3-14; Medvedev, $\mathrm{V}$.: Ispytanie istoriej, in: K 1990, H. 17, 3-14; vgl. auch die wirtschaftstheoretischen und philosophischen Beiträge in der Rubrik „Das Leninsche Erbe und die Umgestaltung“ in: K 1990, H. 5, 5ff sowie Davies, Perestroika, 266ff und Ennker, Ende, 57ff.

171 Meldung in: SZ v. 08.01.1990

172 Zitiert nach Davies, Perestroika, 272 (meine Hervorhebung; J.H.); Gorbačev bezeichnete das Stalinsche System wohl bei seinem Besuch in Litauen (10.-14.01.1990) erstmals öffentlich als "totalitär". - Meissner, Die zweite Phase, 1037.

173 Von Heft 8 (1990) an bildeten neben den Putschisten vom August 1991 - B.K. Pugo, V.I Boldin und G.1. Janaev - V.A. Ivaško, A.S. Dzasochov, O.S. Senin, N.E. Kručina und G.L Smirnov den Redaktionsrat der Izvestija CK KPSS. - Brisant waren vor allem die Quelleneditionen über Lenin, über innerparteiliche Diskussionen 1923, über Stalins Fahrt nach Sibirien zu Beginn der Kollektivierung 1928, zur Aktivität des antistalinistischen Altbolschewisten M.N Rjutin, zur Tätigkeit des repressierten Marschalls M.N. Tuchačevskij und zu den ersten Kriegsmonaten 1941, die Veröffentlichung des Stenogramms des Juli-Plenums des ZK der KPdSU (02.07.07.1953), bei dem Stalins Innenminister L.P. Berija als ,Feind der Partei und des sowjetischen Volkes" verurteilt worden ist, sowie die Kurzbiographien aller Mitglieder des Politbüros (zeitweilig Präsidium), des Organisationsbüros und des Sekretariats des Zentralkomitees von 1919 bis 1990; siehe Jahrgänge 1990/91 von Izvestija CK KPSS passim; die deutsche Übersetzung des Stenogramms jenes Juli-Plenums von 1953 veröffentlichten Knoll/Kölm, Der Fall

174 Siehe ICK 1990, H. 9, 72-84; H. 10, 75-88; H. 11, 63-74; H. 12, 84-93; 1991, H. 3, 75-85; H. 6, 71-89; H. 7, 42-56.

175. Ein Unionsgesetz über das Verfahren der Rehabilitierung wurde zwar vom Obersten Sowjet in erster Lesung am 8. Juni 1991 gebilligt. In Kraft trat es jedoch vor dem Auseinanderfallen der Sowjetunion nicht mehr.“- Tischler, „Den guten Namen wiederherstellen“, 124. 
Drittens: Die liberalen Antileninisten, in der Parteifuhrung von El'cin sowie den Bürgermeistern Popov (Moskau) und Sobčak (Leningrad) repräsentiert, forderten in der ,Demokratischen Plattform", die dem 28. Parteitag vorgelegt, aber von den Delegierten abgelehnt wurde, gemeinsam mit reformerischen Intellektuellen eine grundlegende Revision des bislang gültigen Theoriengebäudes und ließen zunehmend deutlich werden, daß sie mit der Leninschen Tradition grundsätzlich brachen. ${ }^{177}$ Nach dem Parteitag, bei dem Gorbačev seine zentristische Linie behauptet hatte, verließen die meisten der Antileninisten die KPdSU. ${ }^{178}$ Aleksandr Jakovlev behielt zwar noch das Parteibuch, schied aber aus dem Politbüro aus und näherte sich rasch den Auffassungen der liberalen Antileninisten. ${ }^{179}$ Innerhalb der KPdSU spielte diese Strömung seitdem kaum noch eine Rolle, doch außerhalb wurde sie in Gestalt wechselnder Organisationen zu einer erstarkenden politischen Kraft. Vor diesem Hintergnund gab Gorbačev nolens volens dem Druck der Konservativen nach und unterzeichnete als Generalsekretär der Partei bzw. als Staatspräsident der UdSSR die Beschlüsse „Über die Fakten des politischen Vandalismus und der gesetzwidrigen Handlungen gegenüber Lenin-Denkmälern “180 und „Über die Unterbindung von Freveltaten gegen Denkmäler, die mit der Geschichte des Staates zusammenhängen, und gegen Symbole des Staates ${ }^{\text {“181 }}$.

Nachdem A. Jakovlev die Geschichtswissenschaftler bereits am 17. April 1987 aus dem Befehlssystem des ZK-Apparats in die ,Selbstorganisation des Erkenntnisprozesses $^{\text {“182 }}$ entlassen hatte, sahen diese sich seit 1988 zeitweilig, seit 1990 dauerhaft, unterschiedlichen Vorgaben seitens der Parteiführung gegenüber. Die Historiker waren erstmals seit etwa sechzig Jahren sozusagen sich selbst überlassen. In zunehmendem Maß allerdings auch den Gesetzen des freien Marktes, was die wissenschaftliche Arbeit und die Nachwuchsförderung nicht gerade erleichterte. Auch war das weitere Erscheinen der beiden zentralen Fachzeitschriften zeitweise fraglich. Beide überdauerten aber mit neuem Erscheinungsbild, neuen Verlagen, neuem

\footnotetext{
176 Politisch signifikant ist, daß auch Trockij von den sowjetischen Gerichten nicht mehr rehabilitiert worden ist. Vgl. Broué, Gorbachev, 8ff; Wehner, M.: Rückkehr mit Hindernissen. Die gebremste" Diskussion um L.D. Trockij in der Sowjetunion, in: OE 1991, H. 3, 247-258.

17 Siehe die Demokratische Plattform in: Simon/Simon, Verfall, 281-289, besonders 282; Vgl. Davies, Perestroika, 269

178 Sie gründeten am 17./18.11.1990 die „Republikanische Partei der Föderation Rußland“. Siehe Luchterhandt, G.: Die politischen Parteien im neuen Rußland. Dokumente und Kommentare, Bremen 1993, 96ff.

179 Siehe Jakovlev, A.: Vremja tvorěeskoj smelosti, in: K 1990, H. 10, 5-13 und Jakovlevs Parteitagsrede; lange Zitate bei Davies, Perestroika, $270 f$ und $273 \mathrm{f}$.

180 Beschluß des ZK der KPdSU vom 14.08.1990, siehe ICK 1990, H. 9, 11 .

181 Dekret des Präsidenten vom 13.10.1990, vgl. Davies, Perestroika. 279.

182 Mit interdisziplinärer Gültigkeit formuliente der Philosoph Vladislav Žanovič Kelle einige Bedingungen dieser Selbstorganisation. Im wesentlichen sei, die Venwaltung in der Wissenschaft, aber nicht die Verwaltung der Wissenschaf" notwendig. - Kelle, V.Z̈: Samoorganizacija processa poznanija, in: Vestnik Akademii Nauk SSSR 1990, H. 9, 3-11, hier 9.
} 
Namen und schwankenden Auflagenzahlen die Sowjetunion. ${ }^{183}$ Bei Voprasy istorii blieb die Redaktion im wesentlichen in der gleichen Zusammensetzung, ${ }^{184}$ während bei Istorija SSSR im Spätsommer 1990 eine fast hundertprozentige personelle Erneuerung vollzogen wurde. ${ }^{185}$

Mit scheinbar stetig wachsender Offenheit publizierten beide Zeitschriften etliche Leserbriefe und Diskussionsbeiträge, ${ }^{186}$ in sehr viel größerem Umfang Artikel von ausländischen Historikern ${ }^{187}$ und Quellentexte ${ }^{188}$. Daß die Zensur nicht aufgehoben

183 Seit Anfang 1991 erschien VI nicht mehr im ZK-Verlag Pravda, sondern in dem staatlichen Verlag Progress. Aus finanziellen Gründen kam die Zeitschrift vor allem in diesem Jahr sehr unregelmäßig und in mehreren DoppeInummern heraus. Die Auflagenhöhe (Ende 1989: 77.000) stieg 1990 über 100.000, fiel aber im darauffolgenden Jahr wieder auf 77.000. Istorija SSSR erschien seit Anfang 1991 ohne die Symbole des Kremls und des Lenin-Mausoleums im Titelblatt. ein Jahr später zum letzten Mal mit dem gewohnten Namen. Seit Heft 2 (1992) heißt die Zeitschrift Otecestvennaja istorija (OI - „Vaterländische Geschichte"). Die Auflagenzahlen stiegen auch hier 1990 von etwa dreiundzwanzigtausend auf 28.400, fielen 1992 aber wieder unter das alte Niveau. - VI 1989, H. 12, 192; 1990, H. 1, 3f und 192; 1991, H. 1, 256 (sic!); H. 7-8, 256; ISSSR 1990, H. 1, 224; H. 3, 224; 1991, H. 4, 224; 1992, H. 1, 224.

184 Zu Beginn des Jahres 1991 uurde das 23-köpfige Redaktionskollegium geringfuigig verkleinert. Alekseev, Derevjanko, Krušanov, Kumanev, Tichvinskij, Kapica und Siskin demissionierten, B.V. OreX̌in und R.G. Pichoja kamen neu hinzu. - VI 1991, H. 1, 256; H. 9-10, 256.

185 Endlich erhielt die Zeitschrift einen neuen Chefredakteur: Kornelij Fedorovic Sacillo, der in den sechziger Jahren ein Vertreter der "Neuen Richtung“" in der Revolutionsforschung war und den Nekrič als "talentierten Historiker" bezeichnete. Von bisher elf Redaktionsmitgliedern schieden zehn aus, lediglich M.A. Rachmatullin blieb. Außer Sacillo traten 19 Historiker in das neue Redaktionskollegium ein: B.V. Anan'ix, V.l. Bovykin, G.A. Gerasimenko, V.Ja. Grosul, V.P. Dmitrenko, A.P. Korelin, N.E. Korolev, Ju.S. Kukuł̌kin, V.S. Lel'cuk, B.G. Litvak, L.V. Milov, L.N. Nežinskij, A.P. Nenarokov, E.I. Pivovar (Stellv. Chefredakteur), Ju. A. Poljakov, A.N. Sacharov, S.V. Tjutjukin, V.A. Fedorov, Ja.N. Scapov. - Nekrǐ, Otrełis' ot stracha, 342; ISSSR 1990 , H. 4, 2; H. 5, 2.

186 In VI erschienen 1990 63, 199118 Leserbriefe, in ISSSR nur insgesamt fünf in beiden Jahrgängen. Anfang 1990 begann die Redaktion der ISSSR, kapitelweise das neue populärwissenschaftliche Lehrbuch zur Geschichte der Sowjetgesellschaft 1917 bis 1945 vorab zu veröffentlichen. Erst jetzt sickerten auch in diese offizielle Darstellung grundumstürzende Fragen: „,...) über die logische und historische Verbindung von Marxismus. Leninismus und Stalinismus, über Alternativen zum Oktober und zur Stalinschen Politik der Industrialisierung und Kollektivierung, über den Verlust der Perspektive des sozialistischen Aufbaus im Sowjetland bei Lenin, über das Wesen des sowjetischen Sozialismusmodells (...)“. So fragte der stellvertretende Direktor des Instituts fuir UdSSR-Geschichte V.P. Dmitrenko in der Vorbemerkung in: ISSSR 1990, H. 1, 78. - Im Theorieorgan des Zentralkomitees Kommunist begann man im Sommer 1990 Studien zur Geschichte der KPdSU zu publizieren; siehe Oxerki istorii KPSS: Koncepcija, podchody, kontury, in: K 1990, H. 10, 5-24; H. 12, 19-30; H. 14, 95-105; H. 16, 84-93.

18. Zur Geschichte der sowjetischen Gesellschaft und Geschichtswissenschaf brachten VI insgesamt elf, ISSSR sieben aus dem Ausland stammende Beiträge. Besonders interessant für das sowjetrussische Publikum dürften folgende Aufsätze gewesen sein: von $R$. Conquest über den Terror während der Kollektivienung (VI 1990, H. 1, 137-160; H. 4, 83-100), von S. Fitzpatrick über „Klassen und Probleme der Klassenzugehörigkeit im Sowjetrußland der 20er Jahre“ (H. 8, 16-31), von Yu. Felshtinsky über, „zwei Episoden aus der Geschichte des innerparteilichen Kampfes: vertrauliche Gespräche Bucharins" (VI 1991, H. 2-3, 182-203), von D. Geyer über "Probleme und Perspektiven der Zusammenarbeit von Historikern der Sowjetunion und der BRD“ 
war, bekam Svetlana Neretina bei der Veröffentlichung ihres Artikels über die Zerschlagung der geschichtsmethodologischen Diskussionszirkel Ende der sechziger Jahre zu spüren. Es wurde ihr untersagt, die kritischen Stellungnahmen von Samsonov, Volobuev, Cubar'jan, Poljakov und Iskenderov gegen die „Neue Richtung“ in jener Sitzung am 10. Februar 1971 zu zitieren, obwohl seinerzeit ein Protokoll veröffentlicht worden war. ${ }^{189}$ Offensichtlich sollte das Ansehen der jetzt in der perestrojka engagierten Akademiemitglieder geschützt werden.

Charakteristisch für diese beiden letzten Jahre der sowjetischen Geschichtswissenschaft war, daß die bisherige Praxis, die historische Zunft mit Leitartiketn, Aufsätzen und Diskussionsbeiträgen fuihrender Historiker bei „Round-Table“-Gesprächen u.ä. orientieren zu wollen, fast vollständig eingestellt wurde. ${ }^{190}$ So blieben der Aufsatz von Poljakov und die Redebeiträge an dem ,Runden Tisch“ in der Redaktion der Voprosy istorii zur Lage der historischen Disziplin Ausnahmeerscheinungen. Dabei machte der Begriff der „Krise“ die Runde. Poljakov sah durchaus viel Positives in der jüngsten Zeit, sprach sogar von einer „Blüte“ der Geschichtswissenschaft, die von unvermeidlichen „Kinderkrankheiten“ begleitet sei. Aber die neuerliche ,maßlose Politisierung" sei der „Antipode der Wissenschaft" und drohe, den entstandenen Pluralismus wieder zu zerstören. Daher sei die im Stalinismus und der

(ISSSR 1990, H. 2, 207-210), A. Rabinovich über „Versuche, 1917 in Rußland eine demokratische sozialistische Mehrparteienregierung zu bilden" (H. 6, 191-207), R. Davies über die „sowjetische Ökonomie in der Periode der Krise 1930-1933“ (ISSSR 1991, H. 4, 198-210). Von 1990 an konnte auch Roj Medvedev endlich seine überarbeiteten und erweiterten Bücher "über Stalin und den Stalinismus", die bis dahin nur im Ausland erscheinen konnten, veröffentlichen: Medvedev, O Staline.

188 Folgende Erstveröffentlichungen historischer Dokumente - in russischer Sprache - sind, ohne Vollständigkeit anstreben zu wollen, hervorzuheben: Rosa Luxemburgs Text von 1918 über die russische Revolution (VI 1990, H. 2, 3-32); die Memoiren von Nikita Chruščev (ebenfalls 1990 in Heft 2 beginnend), die Erinnerungen des "weißen" Generals A.I. Denikin (ab VI 1990, H. 3) und A.F. Kerenskijs (VI 1990, H. 6 bis 1991, H. 11); „Neue Dokumente über eine Historiker-Beratung im ZK der VKP (b)" (d.i. die Allnussische Kommunistische Partei (Bol' 'eviki) im Jahr 1944 (VI 1991, H. 1, 188-205); Briefe, Telegramme, Beschlüsse Stalins, Berijas u.a. zur Deportation verschiedener Völker- (gruppen) von den dreißiger bis zu den fünfziger Jahren (ISSSR 1991, H. 1, 143-160); Archivmaterial zur Lage Moskaus im Krieg 1941 (H. 6, 101-122).

189 Vgl. Kapitel 5.1; Neretina, Istorija, 163; Surbovanyj, Obsuždenie, 162ff. - Herzlich danke ich S.S. Neretina für die Überlassung einer Kopie der von ihr eingereichten ursprünglichen Fassung ihres Artikels.

190 Kein einziger Leitartikel wurde mehr veröffentlicht, ebensowenig ein „orientierender“, programmatischer Artikel eines führenden Historikers. 1990/91 wurden nur noch ganz wenige „Rund-Tisch"-Gespräche zur sowjetischen Geschichte und Geschichtswissenschaft geführt und dokumentiert, u.a.: „Das historische Gedächtnis der sich erneuernden Gesellschaft“ (K 1990, H. 18, 6-22); über die Deformienung des Geschichtsbewußtseins in der UdSSR, siehe: Ne sudit', a ponimat', in: Molodoj Kommunist 1990, H. 9, 8-19; „Ist der Marxismus gestorben?“ (VF 1990, H. 10, 19-51); über die "Geschichtswissenschaft in den 20er und 30er Jahren" (in: Istorija i istoriki, M. 1990, 64-105); "Die Sowjet-Union und die Länder Osteuropas: Evolution und Zusammenbruch der politischen Regimes Mitte der 40er bis Ende der 80er Jahre des 20. Jh." (ISSSR 1991, H. 1, 3-68); „Aktuelle theoretische Probleme der gegenwärtigen Geschichtswissenschaft“ (VI 1992, H. 8-9, 159-166). 
Stagnationszeit wurzelnde Krise noch nicht überwunden, sondern lediglich in eine neue Etappe eingetreten. ${ }^{191}$ Iskenderov trug in seinem Eingangsstatement zum „Runden Tisch" am 29. Oktober 1991 nochmals die Aufforderung vor, die m.E. Konsens unter den Akademiemitgliedern war: Um zu klären, inwieweit die bislang vorherrschende Methodologie ,umfassende und objektive Information über die Vergangenheit" erlaube, sei es nötig, prinzipiell neue Zugänge zu erarbeiten und kritisch die ganze Erfahrung sowohl der eigenen, „vaterländischen“, als auch der ausländischen Geschichtswissenschaft zu überdenken. Wie schon 1988 Koval'čenko, mahnte nun auch Iskenderov einen ,theoretischen Durchbruch" an. ${ }^{192}$

In den zahlreichen Publikationen zur Geschichtsdiskussion von 1990/91, die reiBenden Absatz auf dem Büchermarkt fanden, waren es nur selten leitende Historiker, sondern vor allem Philosophen, Soziologen, Ökonomen, zuweilen auch Geschichtswissenschaftler der mittleren Generation, welche die Frage untersuchten und diskutierten, „was wir aufbauten“. ${ }^{193}$ Die leitenden Historiker hielten sich zurück, trugen nur in Ausnahmen Substantielles zur Geschichtsdiskussion bei. So stammte beispielsweise das Kapitel über die "Bucharinsche Alternative" in einer Bucharin gewidmeten Aufsatzsammlung von dem fuihrenden Agrarhistoriker Danilov. ${ }^{194}$ Volobuev war unter den Autoren des instruktiven Sammelbandes zu "Geschichte und Stalinismus" das einzige - Korrespondierende - Akademiemitglied. In seinem Beitrag unterschied er den "Leninschen Marxismus“, der in den zwanziger Jahren politischen und gesellschaftswissenschaftlichen Meinungskampf zugelassen und gefördert habe, vom "Stalinschen Marxismus-Leninismus“, der

\footnotetext{
191 „Der Weg zur authentischen Erkenntnis des Vergangenen ist offensichtlich. Fakten sind notwendig - bekannte und neu erworbene. Man muß sie klug, ehrlich, peinlich genau, gewissenhaft analysieren und sie schöpferisch und kompetent interpretieren. Kühne Hypothesen sind notwendig, frische Konzeptionen mit einem kritischen Verhältnis zum historiographischen Erbe, basierend auf einen vernüntigen Zugang, nicht auf einen Zugang, der sich auf das Prinzip 'Negation der Negation willen' gründet." - Poljakov, Ju.: Poznanie proß̌logo: preodolen li zastoj? Zametki istorika, in: K 1990, H. 15, 42-47, hier 47.
}

192 Aktual'nye teoretičeskie problemy sovremennoj istoriceskoj nauki, in: VI 1992, H. 8-9, 159166, hier 159 f und 166 , vgl. ebd., 160ff passim.

193 So der Titel bei Simonija, N.A.: Cto my postroili, M. 1991. Das Buch war Michail Sergeevic Gorbačev gewidmet. Vgl. aus der Reihe „Perestrojka: Offenheit, Demokratie, Sozialismus" die Bände: Drama obnovlenija, M. 1990; Cerez ternii, M. 1990; Pognuženie v trjasinu (Anatomija zastoja), M. 1991. Des weiteren z.B.: Istorija otečestva: ljudi, idei, rešenija. Oxerki istorii Sovetskogo gosudarstva, M. 1991; Dvadcatyj s-ezd KPSS i ego istorizeskie real'nosti, M. 1991; Trudnye voprosy istorii. Poiski. Razmyక̌lenija. Novyj vzgljad na sobytija i fakty, M. 1991; Popov, Blesk; Kapustin, M.: Konec utopii? Prołloe i budušcee socializma, M. 1990 (dieses Buch ist Boris El'cin, „dem Zerstörer der Utopie, mit der Hoffnung auf die Wiedergeburt Rußlands“ gewidmet); Zipko, A. (= Cipko, A.): Die Philosophie der Perestroika. Die Grundlagen der Reformpolitik Michail Gorbatschows, München 1990.

194 Danilov, V.P.: „Bucharinskaja al'ternativa“, in: Bucharin - Celovek, politik, uČenyj, M. 1990, 82-130. Danilov steuerte auch einen Abschnitt zur Artikelserie in Kommunist bei, siehe K 1990, H. 16, 90-93. 
kontroverse Diskussionen und die ,soziale Selbsterkenntnis“ für Jahrzehnte unterbrochen habe.

„Der schöpferische, nichtdogmatisierte Marxismus-Leninismus entspricht den höchsten Anforderungen der Wissenschaftlichkeit, denn seine Erkenntnis-Devise ist die furchtlose Wahrheitssuche um der Wiederherstellung eines wahrhaftigen Bildes der sich entwickelnden geschichtlichen Realität willen. "193

Wie Volobuev, so wies die überwiegende Mehrheit der akademiki bis zum Ende der Sowjetunion die radikale Forderung Ju. Afanas'evs, mit Lenin überhaupt zu brechen, ${ }^{196}$ zurück. Sie wollten das Leninsche Erbe nicht aufgeben, sondern es von neuem sich aneignen und vermitteln.

195 Volobuev, P.V.: Stalinizm i social'noe poznanie sovetskogo obšcestva, in: Istorija i stalinizm, M. 1991, 21-36, hier 23.

196 Afanasjew, J.: „Mit Lenin überhaupt brechen“ (1990), in: Meyer, F.: Die Katastrophe des Kommunismus - von Marx bis Gorbatschow. Spiegel Spezial Nr. 4, Hamburg 1991, 46f; vgl. Afanas'ev, Ju.: Perestrojka, zadumannaja partapparatom, udalas', in: Stolica. Ezenedel 'nik Mossoveta 1990, H. 1, 1-3; ders., Inogo ne dano, in: DemokratiCeskaja Rassija. Gazeta demokratiCeskich sil Rassii, Nr. 5, nojabr 1990, 1f, Afanassjew, J.: Gedächtnis und Geschichte in der Sowjetunion, in: Transit 1991, H. 2, 110-122. 


\subsection{Die Liquidation der "weißen Flecken“ 1986 bis 1991}

Aus dem Vorangegangenen ist deutlich geworden, daß die Geschichtswissenschaft im Unterschied etwa zur Wirtschaftswissenschaft nicht zu den Wegbereitern der Umgestaltungspolitik und eines, ,neuen Denkens“ in der Politik und Gesellschaftstheorie gehörte. Es bedurfte erst der gründlich veränderten Haltung des Politbüros zur Geschichtsdiskussion, um ,the first signs of change" in der historischen Publizistik registrieren zu können. 'Afanas'evs am 11. Januar 1987 auszugsweise veröffentlichte Antrittsrede und Gorbačevs Aussagen während des Januar-Plenums des Zentralkomitees der KPdSU gaben das Startsignal für die öffentliche Geschichtsdiskussion, die in der ersten Jahreshälfte 1987 durch die nun endlich herausgegebenen historischen Romane von Bek, Dudincev, Rybakov, ${ }^{2}$ D. Granin (,Der Genetiker"), M. Satrov (,Der Friede von Brest") und D. Aitmatov (,Der Richtplatz") reichlich Stoff geliefert bekam. ${ }^{3}$ Rasch wurde die Auffordenung, die „weißen Flekken" (belye pjatna) in den bislang gültigen Geschichtsdarstellungen zu tilgen, geläufig. Dabei war 1987, während der Hoch-Zeit der perestrojka noch die bloße Thematisierung bislang tabuisierter Probleme und Persönlichkeiten sensationell; dies fand in den verschiedensten Formen - mit Filmen, Theaterstücken, Romanen, großen öffentlichen Vorlesungsreihen, ,Round-Table-Konferenzen“, Zeitungs- und Zeitschriftenartikeln - statt. Es ging dabei vor allem um einzelne Seiten der Oktoberrevolution ${ }^{4}$, um die Neue Ökonomische Politik (die in dieser Phase der perestrojka eine Renaissance und Idealisierung erfuhr), um die Repressionen unter Stalin, die Einordnung des Stalinschen Systems in die Geschichte der sowjetischen Gesellschaft ${ }^{6}$ und schließlich - insbesondere in der Auseinandersetzung um die

1 Zu diesen ersten Anzeichen zählte Wada die Artikel von Samsonov in ISSSR 1986, H. 6., Ambarcumov in MN v. 09.11.1986 und Afanas'ev in MN v. 11.01.1987. - Wada, Perestroika, 37ff.

$2 \quad$ Siehe Kapitel 5.4.

3 Hielscher, Der neue Frühling, 31-51; Wada, Perestroika, 40ff; Davies, Perestroika, 77f, $114 \mathrm{ff}, 118 \mathrm{ff}, 172 \mathrm{ff}$.

4 Und zwar zuvorderst um die sozialökonomischen Voraussetzungen der Revolution, die führenden Revolutionäre und die ersten Regierungsmitglieder im Rat der Volkskommissare. - Vgl. exemplarisch „Hieb mit dem Pickel“, in: Der Spiegel 1987, H. 31, 93-95; Jakovlev, E.: Pervoe pravitel'stvo, in: Izvestija v. 12.07.1987; Meyer, Wir brauchen die Wahrheit, 22f; Hildermeier, Revolution, 35ff.

3 Siehe Shimotomai, N.: New Interpretation of the NEP and the Stalinist System under Glasnost', in: Ito, Facing up to the Past, 187-197; Davies, Perestroika, 44ff; Wehner, M.: Auf der Suche nach der „Wahrheit"? Zum polemischen Streit sowjetischer Historiker und Publizisten über die 1920er Jahre und die Ursprünge des Stalinismus, in: OE 1990, H. 12, 1129-1144.

6 Siehe Davies, Perestroika, 97ff, $113 \mathrm{ff}$; Wada, Perestroika, 41; Okuda, H.: Recent Rethinking of Collectivization in the Soviet Union, in: Ito. Facing up to the Past, 169-183; Xu, Z.: Several Thoughts on Stalin and Stalinism, in: Ito, Facing up to the Past, 219-239; Hoffmann, R.: Die Stalinismusdiskussion im Rahmen der Perestrojka, Hamburg 1990 (ungedruckte Examensarbeit ich danke Renate Hoffmann herzlich dafür, daß sie mir ihre Arbeit zugesandt hat). 
Thesen Jurij Afanas'evs - um die Situation der historischen Disziplin selbst. ${ }^{7}$ Hervorzuheben ist, daß 1987 erstmals Historiker und Publizisten neue Termini und Modelle zur Erklärung der Stalin-Zeit, die bislang als „Periode des Personenkults“ zu gelten hatte, diskutierten ${ }^{8}$, und daß verdrängte Historiker wieder in die Erinne-

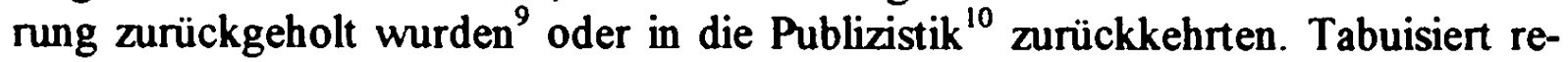
spektive von Mythen umgeben blieben unter anderem Lenin, Trockij und die geheimen Zusatzabkommen zum deutsch-sowjetischen Nichtangriffsvertrag 1939.'

Während der Transformationsphase 1988/89 befand sich die Geschichtsdiskussion auf dem Höhepunkt; eine Flut von Veröffentlichungen überschwemmte die Bibliotheken, Buchläden und die Verkaufsstände in den Straßen und Metrostationen. Dabei sind zwei Abschnitte zu unterscheiden: Bis in den Herbst 1988 dominierten die Bucharin-Renaissance und die von Lenin-Apologetik begleitete Stalin- bzw. Stalinismus-Kritik die öffentliche Debatte, die inzwischen von einer früher nicht für möglich gehaltenen Freiheit geprägt war. ${ }^{12}$ Gegen Ende des Jahres begannen der massive Angriff auf Lenin, den Leninismus und Marxismus, die sachliche Auseinandersetzung mit Trockij und die Infragestellung der geschichtlichen Entwicklung des Sowjetstaates seit $1917 .{ }^{13}$ Besonders die provozierenden Thesen des Philoso-

Siehe dazu Meyer, Wir brauchen die Wahrheit, 15ff, 82ff.

8 Bordjugov, G.A./V.A. Kozlov: Istorija i kon-junktura. Sub-ektivnye zametki ob istorii sovetskogo obšcestva, M. 1992, $137 \mathrm{f}$.

9 So wurde u.a. an das Leben und Werk von E.N. Burdžalov erinnert und seine Tätigkeit in der Redaktion der Voprosy istorii ausdrücklich gewürdigt, siehe Gorodeckij, E.N./G.Z. loffe/G.S. Akopjan/N.D. Kuznecov: E.N. Burdł̌alov - Istorik Fevral'skoj revoljucii 1917 goda, in: ISSSR 1987, H. 6, 168-173.

10 Dies traf neben Volobuev besonders auf Michail Gefter zu, der sich wieder rege in die allgemeine Geschichtsdiskussion einschaltete. - Gefter, M.: „Stalin ist erst gestern gestorben...“, in: Afanassjew, Es gibt keine Alternative, 379-412; ders., Iz tech i etich let, 265ff.

"Vgl. Leciejewski, K.: Blick nach vorn auf Trotzki und Staiin. Das Geschichtsbild und die Legitimation der Sowjetunion in der Gorbatschow-Ära, in: FAZ v. 22.02.1988, 10.

121988 jährte sich Bucharins Geburtstag zum 100., sein Todestag zum 50. Mal. Bucharin wurde rehabilitiert, seine Parteimitgliedschaft wiederhergestellt, sein Leben in einer Sonderausstellung in Moskau gewürdigt. - Vgl. dazu und zur allgemeinen Diskussion bis Ende 1988: Rhode, G.: Ende des Schweigens? Perestrojka und die Tabus sowjetischer Geschichtsschreibung, in: FAZ v. 21.09.1988, 35: Munier, G.: „Liebling der ganzen Partei“, in: Konkret 1988, H. 11, 2225; Bucharina, A.L.: Nun bin ich schon weit über zwanzig. Erinnerungen, Göttingen 1989; Laqueur, Stalin, 64, 280ff, 306ff; Geyer, Perestrojka, 303ff; Wada, Perestroika, 56ff; Davies, Perestroika, 182ff passim; Liszkowski, Die Revision, 657ff; Arslanov, V.: K sporam ob al'ternative stalinizmu, in: Ekonomiceskie nauki 1989, H. 10,69-77.

13 Siehe Davies, Perestroika, 195f, 247ff; Laqueur, Stalin, 71ff; Fülberth, G.: Trotzki als Gegengif, in: Konkret 1988, H. 11, 28-32 (dazu Konkret 1988, H. 12, 51f); Tschepurenko, A.: Das Marxbild der Perestrojka: Zusammenbruch oder Krise des Marxismus? In: Prokla 1990, H. 12, 123-145; Schäfer, P.: Geschichtslogik und GULAG. Gibt es einen Zusammenhang zwischen Stalinismus und Marxismus-Leninismus? In: VZ v. 25.05.1990, 6; Sidorow, A.W. (= Sidorov, A.V.): Stalinismus: Erfahrungen und Lehren der Interpretation, in: BzG 1991, H. 2,246-254 (zuerst in VIKPSS 1990, H. 7). 
phen Aleksandr Cipko ${ }^{14}$ markierten für die Geschichtsdiskussion eine Zäsur: Bis dahin wollte scheinbar niemand etwas auf Lenin kommen lassen, die perestrojka präsentierte sich in allen Belangen als Neo-Leninismus, ${ }^{15}$ seit Cipkos Artikelserie suchten immer mehr Kritiker im Leninismus und bei Marx die Ursachen der Unfreiheit. ${ }^{16}$ Seitdem formierten sich - ähnlich den Richtungskämpfen innerhalb der KPdSU - vier grob zu unterscheidende Strömungen in der historischen Publizistik, die sich in heftigen Kontroversen attackierten, die aber auch inhaltliche Überschneidungen aufwiesen: erstens nationalistische Antileninisten (I. Safarevič, B. Solouchin, A. Sol'ženicyn); zweitens Apologeten des Leninismus in seiner stalinistischen Couleur (N. Andreeva), die in ihren russophilen und antisemitischen Auffassungen teilweise übereinstimmten mit der ersten Strömung; drittens westlich orientierte, liberale Antileninisten (A. Cipko, Ju. Afanas'ev, V. Grossman); viertens die sich demokratischen Vorstellungen annähernden Leninisten (G. Bordjugov, V. Kozlov, V. Loginov, R. Medvedev). ${ }^{17}$ Darüber hinaus wurde während der Transformationsphase die Totalitarismus-Theorie in der sowjetrussischen Fach- und Populärliteratur wieder- bzw. neu entdeckt. 1988 versuchten nur einzelne (N. Popov, F. Burlackij, Ju. Afanas'ev), seit 1989 immer mehr Sozialwissenschaftler und Pu-

14 Cipko, A.: Istoki stalinizma, in: Nauka i sizn' 1988, H. 11, 45-55, H. 12, 40-47, 1989, H. 1, 46-56; H. 2, 53-61. Dazu Butenko, A.P.: Vinoven li Karl Marks v „kazarmennom socializme“? In: FN 1989 H. 4, 17-26; Sabatin. I.I.: O „marksizme“ Stalina (Razmyß̌lenija po povodu stat'i A. Cipko „Istoki stalinizma“, in: NK 1989, H. 8, 112-115; Bystrov, V.R.: K voprosu o „doktrinal'nych" istokach stalinizma. Ob očerke A. Cipko „O zonach, zakrytych dlja mysli“, in: NK 1989, H. 9, 111-115; Kljamkin, I.: Esče raz ob istokach stalinizma, in: PO 1989, H. 9, 41-50; Koloskova, T.G.: Ob idejno-psichologiðeskich predposylkach stalinizma, in: VIKPSS 1989, H. 9, 62-70; Kolodij, A.F.: K diskussii o doktrinal'nych predposylkach deformacii socializma. in: FN 1989, H. 12,61-68. - Vgl. dazu Paul, G.: Zwei Modelle des Sozialismus in der Geschichte Sowjetrußlands, in: Initial 1990, H. 5, 466-474; Davies, Perestroika, 248ff.

15 "Auf Lenin will man nichts kommen lassen."- Geyer, D.: Blick zurück ins alte Rußland. Als Bauer und Christ noch eins waren - Die Wurzeln des neuen sowjetischen Reformkurses, in: Die Zeit v. 11.11.1988, 49

16 „Nach dem Startkommando der Reformer: Zurück zu Lenin bricht sich jetzt die Forderung Bahn: Zurück hinter Lenin." - Schmidt-Häuer, C.: Ein Mausoleum vor dem Abbruch. Immer mehr Kritiker beschreiben das Marxistische System als Ursache der Unfreiheit, in: Die Zeit v. 12.05.1989, 11. Cepurenko schrieb, unter den Studierenden seien die Thesen Cipkos ,mit Begeisterung aufgenommen" worden. Als er bald darauf einen Aufsatz zu methodologischen Fragen der Marxschen Wertheorie veröffentlichen wollte, wurde ihm bei einer Zeitschrift erwidert „Was wollen Sie immer mit Ihrem Marx beweisen? Tsypko hat doch die Sache geklärt. Besinnen Sie sich - Sie sind doch noch nicht alt..." - Tschepurenko, Das Marxbild, 131. Eine bereits 1974 bis 1989 geschriebene, prinzipielle Marxismuskritik erschien um die Jahreswende 1989/90, deutsche Übertragung: Burtin, J.: Die Achillesferse der Marxschen Geschichtstheorie. in: MEJ 13, Berlin 1991, 170-245.

17 Besonders bei verschiedenen Antileninisten, hier bei Jurij Afanas'evs Auftritt bei der Internationalen Historikerkonferenz im April 1990, registrierte Davies ,eine Form von Intoleranz, die wir aus der sowjetischen Geschichte kennen." Vgl. Davies, Perestroika, 252ff, Wehner, Auf der Suche, $1129 f f$ passim; Wada Perestroika, 58ff. 
blizisten die Entwicklung der sowjetischen Gesellschaft seit 1917 mit Hilfe dieses Ansatzes zu erklären und zu bewerten. ${ }^{18}$

Während der Agonie des Systems 1990/91 war es für die Geschichtsdiskussion charakteristisch, daß sukzessive alle Tabus fielen, da $B$ im Zusammenhang damit und infolge der sich verschärfenden Wirtschaftskrise das öffentliche Interesse an der Geschichtsaufarbeitung wieder sank, während die Leninismus- und StalinismusKritik noch enweitert und vertieft wurde; ferner, da $\beta$ gründlicher als bisher die Prähistorie des Sowjetsozialismus von ihrer ideen- und sozialgeschichtlichen Seite sowie die Nachwirkungen des Stalinismus dokumentiert und debattiert wurden. ${ }^{19}$ Dabei krankten die Diskussionsbeiträge vor dem Hintergrund der sich 1991 zuspitzenden politischen Lage in zunehmendem $\mathrm{MaB}$ an einer starken Politisierung; die zu Recht beklagte kon-junkturstina der bisherigen sowjetischen Historiographie blieb - nun meist mit umgekehrten Vorzeichen - präsent. Besonders die Beschönigung der Sowjet-Periode einerseits und die Idealisierung des vorrevolutionären Rußlands andererseits prägten die Diskussionen. ${ }^{20}$ Begleitet war die sensations-

18 Vgl. Davies, Perestroika, 120, 185, 259; Schröder, H.H.: Stalinismus „von unten“? Zur Diskussion um die gesellschaftlichen Voraussetzungen politischer Herrschaft in der Phase der Vorkriegsfunfjahrpläne, in: Geyer, Die Umwertung, 133-166; Totalitarizm kak istoriCeskij fenomen, M. 1989; Davydov, Ju.: Totalitarizm i totalitarnaja bjurokratija, in: Nauka i zizn' 1989, H. 8, 44 51: Igrickij, Ju.I.: Koncepcija totalitarizma: uroki mnogoletnych diskussij na zapade, in: ISSSR 1990, H. 6, 172-190; Sacharov, A.N.: Revoljucionnyj totalitarizm v nasej istorii, in: K 1991, H. S, 60-71. - Zur Diskussion der Anwendungsmöglichkeit des Totalitarismus-Begriffs für die historische Analyse der sowjetischen Gesellschaft sind weiterhin anregend: Ruffmann, K.-H.: Autokratie, Absolutismus, Totalitarismus, in: Osteuropa in Geschichte und Gegenwart, Köln-Wien 1977, 345-358; Meyer, Gerd: Sozialistische Systeme. Theorie- und Strukturanalyse. Ein Studienbuch, Opladen 1979, 178ff; Borcke, A.von/G. Simon Neue Wege der Sowjetunion-Forschung. Beiträge zur Methoden- und Theoriediskussion, Baden-Baden 1980, 72ff passim: Gransow, V.: Konzeptionelle Wandlungen der Kommunismusforschung. Vom Totalitarismus zur Immanenz, Frankfurt-New York 1980, 13ff, Glaeßner, G.-J.: Sozialistische Systeme. Einführung in die Kommunismus- und DDR-Forschung, Opladen 1982, 44ff; Meyer, Gert: Stalinismus, in: EEPhW 4, 447456; Mackow, J.: Der Totalitarismus-Ansatz und der Zusammenbruch des Sowjetsozialismus, in: OE 1994, H. 4, 320-329.

19 Vgl. Davies, Perestroika, 283f; Simon/Simon, Verfall, 65ff; vgl. nun auch den Jahrgang 1990 der Theoriezeitschrift Kommunist.

20 „Die leidenschaftliche Politisierung der ganzen Gesellschaft zeigt sich auch in der Polarisierung der Historikermeinungen sowohl bei allgemeinen als auch bei engergefaßten Problemen eine Periode qualvoller Abgrenzung. " Grossmann, G.: Sowjetische Historiker bei der Arbeit. Ein persönlicher Erfahrungsbericht, in: OE 1991, H. 6, 580-592, hier 581; vgl. auch Bonwetsch, B.: Vom Hitler-Stalin-Pakt zum „Unternehmen Barbarossa“. Die deutsch-russischen Beziehungen 1939-1941 in der Kontroverse, in: OE 1991, H. 6, 562-579; Kerner, M./S. Stopinski: Vom Umgang mit der eigenen Geschichte. Über die selektive Wahrnehmung der Vergangenheit in den baltischen Republiken, in: OE 1991, H. 6, 602-610; Ahlberg, R.: Stalinistische Vergangenheitsbewältigung. Auseinandersetzung über die Zahl der GULAG-Opfer, in: OE 1992, H. 11, 921938: Pavlenko, N.I.: Istoriðeskaja nauka $v$ prošlom i nastojašcem (Nekotorye razmyšlenija vsluch), in: ISSSR 1991, H. 4, 81-99; Geyer, D.: Den toten Gott im Herzen tragen. Das Wiederaufleben der idealistischen russischen Philosophie, in: FAZ v. 24.05.1989; ders., Was in einem Namen liegt. Welches Rußland kehrt in die Geschichte zurück? In: FAZ v. 18.09.1991, N3f. 
heischende Liquidienung der „weißen Flecken" von den berechtigten Forderungen. von der empirischen Diskussion zur theoretisch-methodologischen Analyse überzugehen. Inwieweit dem nachgekommen wurde, ist in den nun folgenden Kapiteln an drei Problemen zu untersuchen. 


\subsection{Zur Gegenstandsbestimmung}

Nach dem Abbruch der Theorie- und Methodologiediskussionen an der Wende von den sechziger zu den siebziger Jahren wurden die bis dahin erörterten Ansätze zur Bestimmung des Gegenstands und der Spezifik der sowjetischen Geschichtswissenschaft $^{1}$ nicht mehr systematisch weiterverfolgt. Statt dessen wurden wiederholt vereinzelte Definitionsversuche vorgelegt, so daß der Philosoph Viktor Kosolapov schon 1977 - allerdings unter Einschluß der internationalen Historiographie dreißig verschiedene Bestimmungen des Begriffs der Geschichte und ihres Gegenstands zählte. ${ }^{2}$ Die folgenden waren in der sowjetischen Geschichtswissenschaft bis 1991 zu den gängigsten zu rechnen:

In der Regel wurde die Gegenstandsproblematik durch die Unterscheidung von allgemein-soziologischen und konkret-historischen GesetzmäBigkeiten, welche den Gegenstand der Soziologie einerseits, der Geschichtswissenschaft andererseits bildeten, beantwortet. Gegenstand der marxistischen Geschichtswissenschaft seien ,alle konkreten historischen Gesetzmäßigkeiten“, besonders diejenigen des Klassenkampfs.

"So erforscht die Geschichtswissenschaft konkrete, von bestimmten räumlichzeitlichen Rahmen begrenzte Gesetzmäßigkeiten der gesellschaftlichen Entwicklung, welche verbunden sind mit der Tätigkeit der Menschen, und sie erforscht auch die objektiven Voraussetzungen und Resultate dieser Tätigkeit." "3

Weiterhin gab es auch Autoren, die - ohne die beiden Gesetzestypen zu definieren - daran festhielten, die Geschichtswissenschaft erforsche allgemeine und spezifische Gesetzmäßigkeiten der gesellschaftlichen Entwicklung in ihrer konkreten Erscheinungsweise. ${ }^{4}$ Unter dem Einfluß des während der Hoch-Zeit der perestrojka intensiven Nachdenkens über globale ökologische Probleme erweiterte der Tomsker Geschichtstheoretiker Ja.D. Serovajskij diese Gegenstandsbestimmung. „Gesellschaft" verstand er in seinem Diskussionsbeitrag als Komponente des „MakroSystems 'Gesellschaft-Natur'“. Moderne Geschichtswissenschaft dürfe die „organische Verbindung" von Gesellschafts- und Natur-Entwicklung nicht vernachlässigen, und müsse demnach als ihren Gegenstand die

\footnotetext{
$1 \quad$ Siehe Kapitel 4.3.

2 Kosolapov, V.V.: Metodologija i logika istoričeskogo issledovanija, Kiev 1977, $137 \mathrm{ff}$.

3 Mogil 'nickij, B.G.: O prirode istoriceskogo poznanija, T. 1978, 56f (Kursiv bei B.G.M.). $\mathrm{Vgl}$ auch Andreev, I.D.: Metodologičeskie osnovy poznanija social'nych javlenij, M. 1977, 83; Loone. E.N.: Sovremennaja filosofija istorii, Tallin 1980, 38f. Vereinzelt gab es noch empiristische Definitionen in der Art, wie sie in den sechziger Jahren Rožin vertrat; so bei Spirin. L.M.: Teorija, metodologija i metodika issledovanij po istorii KPSS, M. 1982, 6.

„Geschichte hat die Gesetzmäßigkeiten des gesellschaftlichen Lebens in konkreten Formen und nach räumlich-zeitlichen Kriterien zum Untersuchungsgegenstand.“ Ivanov betonte, daß es um ,allgemeine und spezifische Gesetzmäßigkeiten" gehe. - Ivanov, V.V.: Metodologija istoričeskoj nauki, M. 1985, 28.
} 
„(...) Entwicklungsgesetze des Systems 'Gesellschaft-Natur' in den konkreten zeitlichen und räumlichen Erscheinungen"

betrachten. ${ }^{5}$ Anders als zum Beispiel noch Tamovskij 1964, der den Gegenstand der Einzelwissenschaft für,gleichbleibend und unveränderlich" hielt, meinte Serovajskij, die Weiterentwicklung jeder Wissenschaft drücke sich im „Dynamismus ihres Gegenstands" aus. ${ }^{6}$

1986 erschien ein von namhaften Historikern verantworteter Sammelband zu Fragen der Geschichtsmethodologie. ${ }^{7}$ Hinsichtlich der Gegenstandsbestimmung ignorierte das Autorenkollektiv vorangegangene Kontroversen und stellte fest, in der Geschichtswissenschaft gehe es um die Erforschung

„(...) der Geschichte der Menschen, ihrer Wechselwirkung im ProduktionsprozeB; der Geschichte der Klassen und des Klassenkampfs, der sozialökonomischen Beziehungen in verschiedenen Etappen der gesellschaftlichen Entwicklung, der konkreten GesetzmäBigkeiten revolutionärer gesellschaftlicher Veränderungen und der Schaffung des kommunistischen Systems."

Zur Abgrenzung gegenüber der Philosophie schrieb einer der Autoren, Gaponenko, diese erforsche, während sie von konkreten Erscheinungen und Ereignissen abstrahiere, die allgemeinen Gesetzmäßigkeiten der Natur- und Gesellschaftsentwicklung. Die Geschichtswissenschaft hingegen untersuche allgemeine und konkrete Gesetze der geschichtlichen Entwicklung und

"(...) schließt mit ein die ganze Gesamtheit von Phänomenen des gesellschaftlichen Lebens; darunter die Tatsachen und Ereignisse des Vergangenen."

Einen anderen Weg, Gegenstand und Spezifik der Geschichtswissenschaft zu bestimmen, beschritt der Neuzeithistoriker Barg. Er unterschied zwei Abstraktionsniveaus, auf denen die beiden Disziplinen, die marxistische Soziologie und die Geschichtswissenschaft, gesellschaftlich-geschichtliche Entwicklung untersuchten. Für Barg war ,evident“:

3 Serovajskij, Ja.D.: K voprosu o predmete istoriłeskoj nauki, in: Voprosy metodologii istorii, istoriografii $i$ istoxnikovedenija. T. 1987, 104-106. hier 106.

6 Ebd., 104.

7 Summa summarum waren die Beiträge der alten Orthodoxie verpflichtet, und lediglich partiell hinterließen die Umgestaltungspolitik und das sogenannte ,neue“, undogmatische Denken ihre Spuren. Der Sammelband ging am 26.05.1986 in Druck, die Auflage betrug nur 4.000 Exemplare. Zu den Autoren gehörten u.a. Ju.V. Bromlej. L.S. Gaponenko, V.A. D'jakov, M.P. Kim, N.N. Maslov, 1.I. Minc und B.G. Mogil'nickij. - Istoričeskaja nauka. Voprosy metodologii, M. 1986.

8 Ebd., 7. - Mit der Hinzufügung, wirklich authentische wissenschaftliche Geschichtsforschung habe erst mit der Entstehung des „wissenschaftlichen Kommunismus“ Mitte des 19. Jahrhunderts begonnen, fielen die Autoren in Positionen zurück, die Pankratova und Burdžalov während ihrer Redaktionstätigkeit bei Voprosy istorii 1953 bis 1957 schon zu überwinden versuchten.

9 Ebd., $10 \mathrm{f}$. 
"(...) die Geschichtswissenschaft muß ein eigenes Niveau der Theorie haben, ein ihrer Erkenntnisfunktion entsprechendes Niveau des kategorialen Wissens",

um die notwendige theoretische und logische Konkretisierung der allgemeinen Thesen des materialistischen Geschichtsverständnisses zu realisieren. ${ }^{10}$ Dem entsprach Bargs theoretische Gegenstandsbestimmung:

„Die Geschichtswissenschaft untersucht die Gesetzmäßigkeiten der räumlichzeitlichen Entwicklung des welthistorischen Prozesses, oder, was das gleiche ist, die GesetzmäBigkeiten der welthistorischen Entwicklung der Menschheit als gleichgerichtete formationsinterne und formationsverbindende Wechselwirkungen ethnopolitischer Gemeinschaften (...)."11

Barg verband damit die seines Erachtens aktuellste Aufgabe der sowjetischen Geschichtswissenschaft, nämlich die Ausarbeitung eines diesem spezifischen Abstraktionsniveau entsprechenden Systems kategorialer Kenntnisse. Diese Kenntnisse verortete er ,auf halbem Wege" (na polputi) zwischen den allgemeinen Gesetzen und Kategorien des historischen Materialismus einerseits und der Untersuchungsmethodik des Historikers andererseits. ${ }^{12}$

Nicht unerwähnt soll der begrifflich quer zu allen anderen Beiträgen liegende Vorschlag des Philosophen Anatolij Rakitov zur Terminologie bleiben. Demzufolge setze sich Geschichtswissenschaft zusammen aus der ,empirischen Historiographie“, die auf der Basis historischer Primärquellen empirisches Wissen über individuelle Ereignisse, konkrete geschichtliche Situationen und Prozesse sowie einzelne Strukturen erarbeite, und aus der ,Historiosophie“, die auf der Grundlage dieses empirischen Wissens theoretisches Wissen über Gesetzmäßigkeiten, Tendenzen, allgemeine Schemata und Strukturen der Geschichte liefere. ${ }^{13}$ Rakitov argumentierte also durchaus im Sinne der mehrheitlich anerkannten Auffassung, wonach die historische Disziplin sowohl empirisches als auch theoretisches Wissen produziert. ${ }^{14}$ Aber seine Terminologie setzte sich nicht durch: Der Begriff der „Historiographie“ war bereits der Erforschung der Geschichte der Geschichtswissenschaft vorbehalten; der von dem Hegelianer Graf August Cieszkowski (1814-1894) geprägte Terminus der ,Historiosophie ${ }^{\text {c15 }}$ stieß bei den sowjetischen Historikem

\footnotetext{
10 Barg. M. A.: Kategorii i metody istoriceskoj nauki, M. 1984, 15.

"Ebd., 23 (Kursiv bei M.A.B.).

12 Ebd., 24.

13 Rakitov, A.I.: Istoričeskoe poznanie. Sistemno-gnoseologið̌eskij podchod, M. 1982, 144ff.

14 Vgl. auch Kozin, N.G.: Empiričeskij i teoretið̌eskij urovni istoričeskogo poznanija, in: Metodologičeskie voprosy nauki. Mežvuzovskij naǔ̌nyj sbornik. Vypusk tretij, Saratov 1975, 3-16; ders., Poznanie $i$ istoričeskaja nauka. Empiriceskij i teoretičeskij urovni znanija i poznanija $i$ istorið̌eskaja nauka, Saratov 1980; Kuz'min, A.V.: O predmete istoriceskoj nauki, in: Predmet i struktura obふ̌čestvennych nauk, M. 1984, 111-125; Sancevið, A.V.: Empirið̌eskij i teoretičeskij urovni poznanija $v$ istoričeskom issledovanii, in: Metodologičeskie problemy obšcestvennych nauk, Kiev 1985, 186-203.
}

is Siehe Rakitov, Istoričesko poznanie. 145. 
meist auf Ablehnung und wurde nur in einigen kulturgeschichtlichen Arbeiten im ,halbdissidentischen" Spektrum mit einer anderen Bedeutung verwendet. ${ }^{16}$

1987 verdeutlichte Akademiemitglied Koval'čenko mit seiner Monographie über „Methoden historischer Forschung“ nochmals das für die sowjetische Geschichtswissenschaft bestehende Problem: der sowjet-marxistischen Philosophie zufolge haben historischer Materialismus und Geschichtswissenschaft das gleiche Erkenntnisobjekt ${ }^{17}$ - die Gesamtheit aller Erscheinungen des gesellschaftlichen Lebens in ibrer Entwicklung -, so daß, will man nicht die Identität beider Disziplinen annehmen, die Frage nach beider Gegenstand (predmet) ${ }^{18} \mathrm{zu}$ beantworten ist. Dabei bekannte Koval'čenko sich zum dynamischen Gegenstandsbegriff': Im Unterschied zur Objektbestimmung komme bei der Gegenstandsbestimmung dem Forscher bzw. dem Forschungsstand entscheidende Relevanz zu. Der Erkenntnisgegenstand werde im Maß der Wissensvertiefung erweitert und stelle somit ein Kriterium bei der Bewertung des Entwicklungsstands der Geschichtswissenschaft dar. ${ }^{20}$ Koval'cenko rekapitulierte auch die Gegenstandsdiskussion. ${ }^{21}$ Alle bisherigen Versuche, den Gegenstand der Geschichtswissenschaft zu bestimmen - a) durch die Abgrenzung allgemein-soziologischer und konkret-historischer Gesetzmäßigkeiten;22 b) durch die Definition des historischen Gesetzes als „Überschneidung" verschiedener gesellschaftlicher Gesetze $;^{23}$ c) durch die Definition des historischen Gesetzes als „Gesetz historischer Situationen“.,24 d) durch die Differenzierung der Ab-

16 Im Gespräch mit dem Autor bezeichnete Svetlana Neretina den Zusammenfluß von istorija, filosofija und religija als istoriosofija. „Das ist der Versuch, den von der Vorhersehung beschlossenen Weg Rußlands durch die Geschichte zu erkennen. Genau das ist Historiosophie." Die "Vechi“-Autoren von 1909 und die kritischen Historiker und Philosophen in den sechziger Jahren stünden in der Tradition dieses Nachdenkens. - Neretina, Interv ju, 4f: dies., Tvorčestvo kak su.šnost' (O koncepcii kul'tury M.K. Petrova), in: Petrov, M.K.: Jazyk, znak, kul'tura, M. 1991, 3-18, Wegzeichen. Zur Krise der russischen Intelligenz. Essays von Nikolaj Berdjaev, Sergej Bulgakov, Michail Geršenzon, Aleksandr Izgoev, Bogdan Kistjakovskij, Petr Struve und Semen Frank. Eingeleitet und aus dem Russischen übersetzt von Karl Schlögel, Frankfurt am Main 1990.

17 Das Erkenntnisobjekt bezeichne eine bestimmte objektive Realität, eine Gesamtheit qualitativ bestimmter Phänomene und Prozesse, die sich in ihrer inneren Natur, ihren Hauptmerkmalen, Funktions- und Entwicklungsgesetzen von anderen Objekten wesentlich unterscheide. - Koval'čenko, Metody, 42.

18 Den Erkenntnisgegenstand bildeten diejenigen Aspekte und Merkmale des Objekts, die von der Forschung erfaßt werden. - Ebd., 43

19 Wir hatten oben schon an Tarnovskij erinnert, der 1964 die Ansicht vertrat, der Gegenstand stelle die differentia specifica einer Disziplin dar und müsse daher gleichbleibend sein. - $\mathrm{Vgl}$. Kapitel 4.3.

20 Koval'cenko, Metody, 45

21 Ebd., 49ff.

22 So die Mehrheit der Autoren, u.a. Fedoseev, Francev, Glezerman, Gefter, Gurevič, Mogil'nickij u.a. - Vgl. Kapitel 4.3.

23 So Gurevič - Vgl. Kapitel 4.5.

24 So Kertman. - Vgl. ebd 
straktionsniveaus beider Disziplinen ${ }^{25}$ - „lösen die Probleme nicht“. Denn stets würden das Allgemeine, Besondere und Einzelne getrennt und den verschiedenen Disziplinen zugeordnet. In der geschichtlich-gesellschaftlichen Realität seien das Allgemeine, Besondere und Einzelne jedoch organisch miteinander verbunden, was geschichtstheoretisch reflektiert werden müsse. ${ }^{26} \mathrm{Um}$ die Gegenstände der soziologischen Forschung (des historischen Materialismus) und der Geschichtswissenschaft abzugrenzen, sei die Frage, was die Disziplinen untersuchen, nicht geeignet. Notwendig sei es, die Frage zu beantworten, wie und wofür grundlegende Erscheinungen, Merkmale und Gesetzmäßigkeiten erkannt würden: Während die auf hohem Abstraktionsniveau zu erzielende soziologische Erkenntnis wichtig sei für die Formulienung weltanschaulicher Standpunkte und als theoretische und methodologische Grundlage konkreter Analysen, liefere die Geschichtswissenschaft gerade die

„(...) erforderlichen konkreten Kenntnisse sowohl der räumlich-zeitlichen Spezifik bei der Erscheinungsweise allgemeiner Gesetze als auch der Gesetze, die dem Besonderen und Einzelnen eigen sind. “27

\section{Erkenntnisgegenstand der Geschichtswissenschaft sei also}

„(..) die Aufdeckung der menschlichen Tätigkeit als naturgeschichtlichem, fortschreitend-progressivem, innerlich begründetem und gesetzmäßigem Prozeß in all seiner Vielgestaltigkeit, räumlichen und zeitlichen Konkretheit. "28

Die Konkretheit und die bevorzugte Anwendung der historischen Methode zeichneten die Geschichtswissenschaft gegenüber der Soziologie bzw. des historischen Materialismus' aus. ${ }^{29}$ Diese Art der Gegenstandsbestimmung habe auch Konsequenzen für die Terminologie der Gesetzmäßigkeiten. ${ }^{30}$

Koval'čenkos Darlegung war die letzte komplexe Äußerung eines ,sowjetischen“ Historikers vor dem Ende der Sowjetunion zum Gegenstandsproblem. Außer ihr gab es lediglich noch Wiederholungen alter Standpunkte ${ }^{31}$ und verschiedene, auf

2s So Barg, siehe oben. - Vgl. dazu kritisch Zelenina, I.A.: O zakonach istoričeskoj nauki, in: Problema zakona $v$ obščestvennych naukach, M. 1989, 93-107, besonders $96 \mathrm{ff}$.

26 Koval'cenko, Metody, 53.

27 Ebd, 53ff, hier 54f - Koval'čenko erinnerte nicht daran, daß vor ihm bereits 1976 Erofeev diesen Gedanken publiziert, aber keine Resonanz gefunden hatte. Vgl. Erofeev, N.A.: Cto takoe istorija, M. 1976, 48.

28 Ebd., 55 (Kursiv ebendort)

29 „Geschichtswissenschaft kann und muß das Wesen gesellschaftlicher Entwicklung nicht nur auf dem Niveau des Einzelnen und Besonderen, sondern auch auf dem Niveau des Allgemeinen erkennen. jedoch in seinem konkreten Ausdruck." - Ebd.

30 Siehe dazu Kapitel 6.5.

31 So wiederholten Mogil'nickij in seiner neuen Monographie und Gurevix beim ,Rund-TischGespräch" zwischen Philosophen und Historikern im April 1988 ihre alten Standpunkte. - Mogil'nickij, Vvedenie, 32ff; Filosofija $\mathrm{i}$ istoričeskaja nauka. Materialy ,kruglogo stola“, in: VF 1988 , H. 10, 18-64, hier 23. 
einzelne Aspekte des Problems begrenzte Bemerkungen. ${ }^{32}$ So blieb die Gegenstandsbestimmung bis 1991 unbefriedigend. Die unterschiedlichen Auffassungen über den Gegenstand der historischen Disziplin bestanden nebeneinander, ohne daß die Autoren miteinander diskutierten oder in ihren schriftichen Arbeiten wenigstens Notiz voneinander nahmen. Trotz der neuen Offenheit in der Publizistik und den wissenschaftlichen Diskussionen kam kein kohärenter Dialog zustande; ohne diesen war die Meinungsvielfalt aber nutzlos. Bis zuletzt betonten alle Bestimmungen - mit Ausnahme vereinzelter empiristischer Positionen - die Fixierung der Geschichtswissenschaft auf die Gesetzmäßigkeit der Geschichte und knüpften daran die Wissenschaftlichkeit der historischen Disziplin. Das führ allzu leicht dazu, Zufälliges, Unvorhersehbares, Widersprüchliches, Rätselhaftes und Ungeschehenes ${ }^{33}$ in der Geschichte $\mathrm{zu}$ vernachlässigen und $\mathrm{zu}$ übersehen. Offensichtlich muß der Historiker zunächst ausgehen von gesellschaftlich-geschichtlichen Entwicklungen langer Dauer (,longue durée") $)^{34}$, von Strukturen, Tendenzen und Wiederholungen, um sich auf dieser Grundlage zu konzentrieren auf die quellenfundierte Analyse geschichtlicher Ereignisse und Prozesse. Dabei kommt es darauf an, diese in ihrer Vielgestaltigkeit und Konkretheit zu reproduzieren sowie Übereinstimmungen mit

\footnotetext{
32 Vgl. Filosofija 1988, 32ff passim.

33 Siehe dazu Demandt, A.: Ungeschehene Geschichte. Ein Traktat über die Frage: Was wäre geschehen, wenn...? Göttingen, 2. Auflage 1986.
}

34 .Die fruchtbarste, von den Pionieren der 'nouvelle histoire' entfaltete Perspektive war die der 'longue durée', also die Vorstellung. daß die Triebkräfte der Geschichte in langen Zeitabläufen wirken und sich nur in ihnen erfassen lassen. (...) in jedem Fall lassen allein die langen Zeitabläufe die dauerhaften Strukturen und die einschneidenden Veränderungen sichtbar werden. Ein Geschichtsbegriff, der dem Wechsel von Königen oder Regierungen folgt, begreift die Geschichte nicht, sondern entstellt sie." - Le Goff. J.: Neue Geschichtswissenschaft. in: Le Goff. J./R. Chartier/J. Revel (Hg.): Die Rückeroberung des historischen Denkens. Grundlagen der Neuen Geschichtswissenschaft (französische Originalausgabe 1978), Frankfurt am Main 1990, 11-61, hier 38; vgl. auch Vovelle. M.: Die Geschichtswissenschaft und die „Iongue durée", ebd., 103136; Braudel, F.: Die lange Dauer, in: Theorieprobleme der Geschichtswissenschaft, hg. v. Th Schieder und K. Gräubig. Darmstadt 1977, 164-204; 
und Abweichungen von den bekannten Tendenzen und Wiederholungen festzustellen. Dadurch wird die innere Relation der Beziehung zwischen Theorie und Empirie aktiviert. Die wissenschaftliche Arbeit wird in dem Maße auf höhere Niveaus gehoben, in welchem aus dieser Analyse neue theoretische Erkenntnisse abstrahiert werden. 


\subsection{Neues zur Definition historischer Fakten}

In den sechziger Jahren gab es lediglich erste Annäherungen an dieses Thema, wobei der internationale Diskussionsstand, auch der marxistische, nur ganz unzureichend rezipiert wurde. ${ }^{1}$ Im weiteren Verlauf wurde die Lage in diesem Bereich in terminologischer Hinsicht noch unübersichtlicher, weil durch das starke Aufkommen der Historiographie der Begriff ,historiographische Tatsache“ eine neue Bedeutung bekam. Gab es in den sechziger Jahren die Tendenz, die wissenschaftlich geklärte, formulierte Erkenntnis über geschichtliche Realität als, historiographische Tatsache" zu bezeichnen, ${ }^{2}$ so verstanden die sowjetischen Historiographen in den siebziger und achtziger Jahren darunter ein Element des Wissens über die Geschichte der Geschichtswissenschaft. ${ }^{3}$ Mehrere Autoren bemühten sich um begriffliche Klärung, aber die kursierenden Definitionen dokumentieren etliche Unklarheiten:

Nečkina nannte das, historische Faktum“ (istoriceskij fakt) kurz und bündig eine „Komponente, ein Element bestimmter historischer Ereignisse." Ein historisches Ereignis sei ein Komplex historischer Fakten. ${ }^{4}$ Damit setzte sie erstmals Faktum und Ereignis, die oft identifiziert worden waren, ${ }^{5}$ in Beziehung zueinander, berücksichtigte aber nur die ontologische Seite des Problems.

$\mathrm{Zu}$ allgemein und undeutlich blieb die Definition von Zevelev und Naumov: Das historische Faktum sei ,Ausgangsmaterial" und Basis für die historische Erkenntnis, die Verallgemeinenung und die Formulierung einer Theorie oder Hypothese sowie für die Aufdeckung von Gesetzmäßigkeiten des Geschichtsprozesses. ${ }^{6}$ Hier war offensichtlich die historische Tatsache als Teil der Geschichte und als Teil des Wissens gemeint. Aber wo ist der Übergang von einem zum anderen, wo die Grenze zwischen beiden? Können nicht historische Quellen und Forschungsfragen ebenso als Ausgangsmaterial und Basis geschichtswissenschaftlicher Erkenntnis verstanden werden?

\footnotetext{
$1 \quad$ Siehe Kapitel 4.4.

$2 \mathrm{Vgl}$. Topolski, Methodology, 220ff.

3 Vgl. die Beiträge von Durnovcev, V.I.: O soderžanii ponjatija ,istoriografičeskij fakt“, in Metodologičeskie $i$ teoretičeskie problemy istorii istoričeskoj nauki. Kalinin 1980, 42-53, Zevelev, A.I./V.P. Naumov: Istoriografičeskij fakt: Kriterii ocenki i analiza, in: ebd., 54-70.

4 Siehe das Nachwort von M.V. Nečkina zu: Metodologičeskie i teoretičeskie problemy, 132ff. hier 135 .

3 Vgl. Rakitov, Istoričeskoe poznanie, 187.

6 Siehe Zevelev, A.I.N.P. Naumov: Istoriografičeskij fakt: Kriterii ocenki i analiza, in: VI 1980, H. 5, 18-30, hier 19.
} 
Dorošenko definierte das historische Faktum als „objektives und reales geschichtliches Phänomen, adäquat widergespiegelt im Bewußtsein des Subjekts. " An anderer Stelle übernahm Dorošenko den von Lenin als Synonym für objektive Wahrheit (istina) verwendeten Begriff „objektives Faktum“; dieses beschreibe einen vom einzelnen Menschen und „,von der Menschheit" unabhängigen Inhalt. ${ }^{8}$ Auch hier fehlte die Abgrenzung zwischen dem ontologischen und gnoseologischen Aspekt des Problems. Einerseits sollte das geschichtliche Faktum Teil der Geschichte, andererseits bewußtseinsmäßig reflektiert sein. Das objektive geschichtliche Phänomen wäre demnach erst dann vergangene Wirklichkeit, wenn es vom Wissenschaftler erkannt worden wäre; (noch) nicht widergespiegelte historische Tatsachen wären demnach keine geschichtliche Realität!? Des Wissenschaftlers Erkenntnis wiederum, die ,objektive Wahrheit", sei unabhängig vom Menschen! Die Simplifizierung der Widerspiegelungsthesen ${ }^{9}$ und der ungebremste Erkenntnisoptimismus trieben seltsame Blüten.

Vollends auf die gnoseologische Seite beschränkten sich Uvarov und Egorova mit ihren Definitionen. Uvarov betonte die Synthese von sinnlichem und rationalem Wissen, welche die wesentliche Erkenntnis auszeichne $;^{10}$ Egorova hob die Beziehung zwischen Subjekt (Wissenschaftler) und Objekt (Informationen) sowie den klassenmäßigen Zugang hervor, welcher allein objektives Wissen ermögliche. ${ }^{11}$ Der in Sibirien arbeitende Historiker Antipov meinte schließlich, je nach Position bzw. Arbeitsschwerpunkt des Wissenschaftlers sei istoriceskij fakt etwas anderes: Für den Quellenkundler sei es Quellentatsache (fakt-istoxnik), für den phänomenologisch arbeitenden Historiker sei es eine Ereignistatsache (fakt-sobytie), für den Empiriker hingegen Tatsache als Wissen (fakt-znanie). ${ }^{12}$

? Dorošenko, N.M.: Leninskoe ponimanie problemy fakta $v$ istoričeskom poznanii, in: VLU, Serija 5, 1973, H. 1,67-72, hier 69; vgl. ders., K voprosu o soderžanii ponjatija ,istoričeskij fakt“, in: Problemy istoričeskogo materializma, vyp. 2, M. 1972, 73-83.

8 Siehe Dorošenko, Leninskoe ponimanie, 71; vgl. LPSS 17, 405ff; 24, 24ff, 25, 194 und 252.

9 Vgl. Narski, I.S.: Fragen der Erkenntnistheorie (1971), in: Sandkühler, H.J. (Hg.): Marxistische Erkenntnistheorie. Texte zu ihrem Forschungsstand in den sozialistischen Ländern, Stuttgart-Bad Cannstatt 1973, 30-58; Kopnin, P.V.: Das Zusammenfallen von Dialektik, Logik und Erkenntnistheorie (1969), ebd., 215-235, besonders 219ff, Klaus/Buhr, Philosophisches Wörterbuch, 1301.

10 .Jstoriteskij fakt - das ist ein solches wahrheitsgetreues Wissen über Ereignisse und Prozesse der sozialen Vergangenheit, bei dem sinnliches und rationales Wissen synthetisiert wird, (...) Wissen, das im Verhältnis zu einem bestimmten geschichtlichen Phänomen streng fixiert und in sich relativ vollständig ist." - Uvarov, A.I.: Gnoseologičeskij analiz teorii v istoričeskoj nauke, Kalinin 1973, $21 \mathrm{f}$ (Kursiv bei A.I.U.).

1 "Das historische Faktum bestimmen wir als Wissen über vergangene objektive Realität, erlangt im Resultat der Beziehung des erkennenden Subjekts zu den Informationen über Ereignisse und Prozesse des Vergangenen, die in geschichtlichen Quellen enthalten sind." - Egorova, V.S.: Problema fakta v istoriceskom poznanii, in: VMU, Serija 8, 1976, H. 5, 39-48, hier 45 und 47f

12 Antipov, G.A.: Istoričeskoe prošloe i puti ego poznanija. Novosibirsk 1987, 104. 
Bei allen Autoren fehlte die konsequente Unterscheidung der ontologischen und der gnoseologischen Seite des Problems. Zutreffend führte Kosolapov die Mängel der bisherigen Definitionen gerade darauf zurück. ${ }^{13}$ Er selbst definierte istoriceskij fakt ontologisch als „Fragment der sozialgeschichtlichen Wirklichkeit" und gnoseologisch als

„(..) Wissen solcher Art, welches retrospektiv irgendwelche geschichtlichen Veränderungen oder Zustände historischer Situationen oder von Ereignissen (...) reflektiert.“ Mit anderen Worten auch als „(...) 'Quant', das heißt als kleinstes, nicht teilbares Teilchen sozialgeschichtlicher Information über die Wirklichkeit, als ideale Abbildung eines geschichtlichen Ereignisses (...). ${ }^{\text {c14 }}$

Die Differenzierung war zweifelsohne ein Fortschritt, aber Kosolapov setzte die unglückliche Tradition fort, den Terminus istoriteskij fakt mit immer neuen Inhalten zu füllen, ohne zu versuchen, verschiedene Begriffe für die entsprechenden Bedeutungen zu finden. Diesen Schritt tat allein der Neuzeithistoriker und Theoretiker Barg: ${ }^{15}$ Das Faktum der Geschichte, das ,historische Faktum" sei ein „Knoten“, ein „Fragment“, ein ,Zusammenhang“ der objektiven Realität, in Dasein und Bedeutung unabhängig vom erkennenden Subjekt; es sei primär gegenüber der wissenschaftlichen Erkenntnis und bilde deren Ausgangspunkt. ${ }^{16}$ Die bestimmende Eigenschaft der historischen Tatsache sei ihre

„(...) Abgeschlossenheit und Unerschöpflichkeit (...) als 'Fragment' der historischen Wirklichkeit, welches ein für allemal gegeben und umveränderlich (...)" sei. ${ }^{17}$

Das in einer Primärquelle Fixierte apostrophierte Barg als "Quellenbericht" (soobscenie istocnika). ${ }^{18}$ Den vom Wissenschaftler verifizierten Quellenbericht nannte Barg schließlich, geschichtswissenschaftliche Tatsache" (noưno-isto-

\footnotetext{
13 Siehe Kosolapov, Metodologija, 2896.

14 Ebd., 292.
}

15 Michail Barg vertrat seine Position unverändert in drei weitgehend identischen Veröffentlichungen von 1976, 1984 und 1988: Vgl. Barg. IstoriCeskij fakt; ders., Kategorii, 141-173; ders., Leopold von Rankes Geschichtskonzeption aus der Sicht der heutigen Geschichtswissenschaft, in: Mommsen, W.J. ( $\mathrm{Hg}$ ): Leopold von Ranke und die moderne Geschichtswissenschaft, Stuttgart 1988, 223-263. - Die Übernahme des zuletzt genannten, mehr als zehn Jahre alten Textes von Barg in den Stuttgarter Sammelband zeugt von der Mangelhaftigkeit des Diskurses zwischen Historikern in Ost und West. Mit Ausnahme von Bargs Artikel gingen die übrigen Studien aus Beiträgen zu einem internationalen wissenschaftichen Symposium (10. bis 12. Juli 1986) anläßlich der 100. Wiederkehr des Todestags Leopold von Rankes hervor. Barg selbst nahm nicht an dem Symposium in Bad Homburg teil, seine Thesen wurden nicht diskutiert. Rankes Geschichtskonzeption streifte Barg in seinem Text 1976 und 1984 nur; für die letzte Fassung 1988 wurde lediglich eine kurze Einleitung hinzugefuigt, um eine Zuspitzung auf Ranke anzudeuten.

16 Barg. Istoriceskij fakt, 55 und 61; vgl. ders., Leopold von Ranke, 238 und 248.

17 Hier nach Barg. Leopold von Ranke, 238 (Kursiv bei Barg); vgl. auch Kosolapov, Metodologija, 293ff.

18 Barg. Istoričeskij fakt, 55; vgl. ders., Leopold von Ranke, 238. 
riðeskij fakt). ${ }^{19}$ Sie sei die sekundäre, das heißt, nur mehr oder weniger adäquate Widerspiegelung " des historischen Faktums. ${ }^{20}$

"Die bestimmende Eigenschaft der geschichtswissenschaftlichen Tatsache ist ihre Nichtabgeschlossenheit, weil ihr Inhalt veränderlich ist: sie kann sich selbst endlos bereichem und mit dem Fortschritt der Geschichtswissenschaft weiterentwickeln. ${ }^{\prime 21}$

Diese Definitionen bezeichnete Barg als ,die materialistische Lösung der Grundfrage der Philosophie im Bereich der Geschichtskonzeption".22 Darüber hinaus schlug Barg eine „Klassifizienung historischer Fakten“ vor. Er unterschied nach der genetischen Zugehörigkeit ökonomische, soziale, politische usw. Tatsachen, nach der Zeitdauer momentane Ereignisse (Vorfälle), periodische Ereignisse (zyklische Wiederholungen) und mehr oder weniger langandauernde Ereignisse (Erscheinungen, Prozesse), schließlich nach der Innenstruktur einfache und in unterschiedlichem Maße komplizierte Tatsachen. ${ }^{23}$

Der z.B. von Carr vertretenen Differenzierung zwischen bloßen Tatsachen und historischen Tatsachen, die geschichtlich bedeutsam seien, ${ }^{24}$ widersprach Barg: Konkret-historisch oder phänomenologisch seien historische Tatsachen, gleichartige und gleichwertige Meilensteine auf dem Wege der Geschichte“. ${ }^{25}$ Selbstverständlich gebe es ,auf der Ebene des 'Wesens'“ Unterschiede bei der Komplexität, dem Umfang und der objektiven Bedeutung. Das sei aber abhängig von der Frage-

\footnotetext{
19 Siehe ebd.

20 Barg. Leopold von Ranke. 248.

21 Ebd., 238 (Kursiv bei Barg).
}

22 Ebd. - Zur Grundfrage der Philosophie, der Frage nach dem Verhältnis von Materie und Bewußtsein. Natur und Geist, Sein und Denken, welche Karl Marx und Friedrich Engels bekanntlich in Anlehnung an Diderot, Helvètius, Holbach und La Mettrie materialistisch beantworteten, siehe Engels, F.: Ludwig Feuerbach und der Ausgang der klassischen deutschen Philosophie (1886), in: MEW 21, 259-307, hier 274ff; vgl. Schleifstein, J.: Einfuihrung in das Studium von Marx, Engels und Lenin, 4. Auflage, München 1983, 42ff, das Stichwort „Materialismus" in: Marx-Engels Begriffslexikon, hg. von K. Lotter, R. Meiners und E. Treptow, München 1984, $225 \mathrm{ff}$.

23 Barg, Leopold von Ranke, 239-242. - Der Geschichtstheoretiker Rakitov differenzierte epistemologisch zwischen existentialen Fakten, die beantworteten, ob ein Phänomen existierte; qualifizierenden Fakten, die beantworteten, was für ein Phänomen existierte (in empirischer Form - phänomenologisch - und in philosophischer Form - essentiell -. Weitere Typen seien quantifizierende, temporale, orts- und motivationsbeschreibende Fakten, die über Mengen, Zeit, Raum und Handlungsmotive informierten. Methodologisch unterschied er gemäß den Erkenntnismethoden typisierende, analytische, konfigurative und statistische Tatsachen. - Rakitov, Istoričeskoe poznanie, 196ff.

24 Carr, Was ist Geschichte, 10ff; vgl. Kapitel 4.4.

2s „Alle sozial relevanten Ereignisse, alle mannigfaltigen Erscheinungen des gesellschaftichen Lebens, alle Endlosigkeit der sozialen Welt, die als geschichtliche Wirklichkeit bezeichnet wird ganz gleich, wie sie eingeschätzt werden, welche Dimensionen sie haben, ob sie die Zeitgenossen erschüttert haben oder von ihnen unbemerkt geblieben sind - sind also potentiell historische Tatsachen." - Barg, Leopold von Ranke, 238f. 
stellung und dem Interesse des Wissenschaftlers. ${ }^{26}$ Scheinbar unwichtige Tatsachen des Alltagslebens einfacher Menschen seien für die Sozialgeschichte wichtiger als Tatsachen aus dem Leben, großer" Persönlichkeiten. ${ }^{27}$

$\mathrm{Zu}$ würdigen ist also, daß Barg für drei zu unterscheidende Aspekte drei Begriffe schlüssig definierte, und daß er nicht nur die ontologische und gnoseologische Seite unterschied, sondern auch hinwies auf den gleichsam dazwischenliegenden Quellenbericht, der historische Tatsachen widerspiegelt, aber keine ,fertigen“"geschichtswissenschaftlichen Tatsachen enthält. Richtig war sein Hinweis, daß das historische Faktum ein Fragment, aber auch ein Zusammenhang sein könne. Deutlicher als sonst in der sowjetischen Geschichtswissenschaft üblich, bekannte sich Barg zu einem dynamischen, akkumulativen Charakter der Erkenntnis, als er betonte, die geschichtswissenschaftliche Tatsache sei ihrem Wesen nach nicht abgeschlossen und inhaltlich veränderlich.

Barg unterschied sich nicht nur terminologisch von anderen Autoren. Während diese grenzenlos erkenntnisoptimistisch die mögliche Objektivienung des Widerspiegelungsprozesses hervorhoben, ${ }^{28}$ diskutierte Barg die gnoseologischen Probleme der Abbildtheorie recht offen: Historische Tatsachen könnten nicht einfach in die Wissenschaft, ,aufgenommen" oder ,übertragen" werden. Zwischen dem ,Historiker und der historischen Tatsache" stehe die ,historische Quelle"." Man müsse gründlich unterscheiden zwischen einer Tatsache der objektiv-historischen Realität und der in einer Quelle widergespiegelten Tatsache; letzteres sei eben nur widergespiegelte Wirklichkeit, of nur ,mittelbar", ,deformiert", „selektiv und zerstückelt “" ${ }^{30}$ Aus dem fragmentierten und deformierten Charakter der Quellenberichte erwachse die ,besondere Bedeutung" der geschichtswissenschaftlichen Abstraktion, der Theorie. ${ }^{31}$ Der Inhalt der Quelle sei aus der Sprache des Einzelnen in die des Besonderen ${ }^{32}$ zu übersetzen. Eine aus einer Quelle in das Forschungswerk

26 .Denn da entsteht wiederum die Frage: in welcher historischen, sozialen und kulturellen Hinsicht ist es bedeutend?" - Ebd., 239.

27 „Hätte die menschliche Wißbegierde ausführliche Angaben über das Alltagsleben wenigstens eines einzigen Pariser Zimmermanns aus Napoleons Zeiten für uns überliefert, statt den Gründer des Kaiserreiches unsterblich zu machen, so hätte die Geschichtswissenschaft als Wissenschaft daraus viel mehr gewinnen können." - Ebd.

28 Siehe besonders Kosolapov, Metodologija, 299ff.

29 Barg. Leopold von Ranke, 248f. Kursiv bei Barg.

$30 \quad,(\ldots)$ das ist eigentlich schon nicht mehr Wirklichkeit, sondern nur ihre mehr oder weniger adäquate Widerspiegelung. (...) Daher muß die Quellenkunde vor allem die Frage klären, was die Quelle in Wirklichkeit berichtet, (...) welche Bestandteile der 'Tatsache' durch die Darlegungsweise selbst (das Zeichensystem), durch Ont und Zeit der Fixierung und schließlich durch den Verfasser des 'Berichtes' deformiert werden (...)." - Ebd., 237 und 249. Kursiv bei Barg.

31 Sie „(...) ist das endgültige Bestimmende im Prozeß der Deutung der grundlegenden Dokumente bei einer geschichtlichen Konstruktion." - Ebd., 250.

32, ,...) dieser spezifischen Form der Verallgemeinerung in der Geschichtswissenschaft“ (...). Ebd. 
aufgenommene Information sei noch keine geschichtswissenschaftiche Tatsache; eine solche sei erst die im Zusammenhang analysierte, ,konzeptualisierte Tatsache, das heißt eine durch die Geschichtstheorie von innen her beleuchtete Tatsache. ${ }^{\text {(33 }}$ Die eigentliche Spezifik historischer und geschichtswissenschaftlicher Tatsachen (gegenüber naturwissenschaftlichen) sei von den Neokantianern erfät, aber auch "völlig entstellt" worden: ihr axiologischer Charakter. ${ }^{34}$ Bargs Antwort darauf blieb traditionell marxistisch: Das in Jahrhunderten gesammelte Arsenal der nichtmarxistischen Geschichtswissenschaft, die ,innere und äußere Kritik der Quelle“, lösten das Problem nicht. Nur die Erkenntnistheorie des dialektischen Materialismus gebe die ,volle und unzweideutig allgemein-philosophische Antwort“. ${ }^{35}$ Die materialistische Geschichtsforschung habe immer von den objektiven Tatsachen auszugehen und anhand von diesen ,echten Tatsachen“ die Forschungsergebnisse zu überprüfen. ${ }^{36} \mathrm{Um}$ sein inhaltliches Ergebnis zu objektivieren, müsse der materialistische Historiker sich auf das ,Kriterium der gesellschaftlich-historischen Praxis stützen. ${ }^{37}$ In folgender Weise realisiere der Historiker dieses Prinzip der objektiven Analyse:
„a) Die Geschichte der Gesellschaft wird als ein System der Subordinationsbezie- hungen betrachtet, die sich auf der Gundlage der 'endlichen' materiellen Determi- niertheit seines Funktionierens und seiner Entwicklung herausbilden. (...) b) Die Ge- schichte einer Gesellschaft muß vom Standpunkt des entscheidenden sozialen Anta- gonismus aus betrachtet werden. (...) c) Die Wissenschaft muß parteilich sein, d.h. den Standpunkt der Massen vertreten, also den Standpunkt derjenigen gesellschaftli- chen Klasse, deren objektive historische Lage von uns eine konsequente revolutio- när-kritische Position in der historischen Studie verlangt. (...) d) Schließlich geht es um das Prinzip der Integrität der Erkenntnis. Eine objektive Betrachtung setzt weder Beispiele noch lyrische Beschreibungen, sondern das Ding an sich voraus." ${ }^{38}$

Mit Ausnahme des Postulats der Parteilichkeit handelt es sich auch hier um tragfähige methodische Hinweise. Einer objektivistischen Auslegung beugte Barg vor, indem er den Begriff der ,objektiven Wahrheit" in einer Weise erläuterte, die seine Position von allen anderen wesentlich unterschied:

\footnotetext{
33 Ebd., 251.

34 Drei Arten der Selektion behinderten die wertfreie Analyse: die Auslese der Tatsachen bei der Entstehung des Quellenberichts, die Auslese durch die Zeit (,Eingriff der 'lebendigen Geschichte' in die Geschichtsakte") und die Auslese der Tatsachen bei der Untersuchung selbst. Siehe ebd., 25Iff.

\section{Ebd., 255f.}

36 „Im Bereich der Dialektik der geschichtlichen Erkenntnis akzeptiert die Theorie des Marxismus das Primat der Wirklichkeit, d.h der historischen Tatsachen, bedingungslos." - Ebd., 243 und 248.
}
37
Ebd., 259.
38
Ebd., $259 f$. 
„Die 'objektive Wahrheit' ist bekanntlich kein Oberbegriff für die Identität von Wissen und Wirklichkeit, sondern nur ein Verweis auf die mehr oder weniger große Ähnlichkeit, Annäherung oder 'Übereinstimmung' des einen mit dem anderen."

Es gehe um ideelle (myslennom), wissenschaftliche Wiedergabe, nicht um Identität von Objekt und Kopie! $!^{40}$

„Das Höchste, was ein materialistisch denkender Forscher anstreben kann, ist die maximale Annäherung des ideellen Bildes mit der Wirklichkeit; dabei darf er nie vergessen, da $B$ sie niemals identisch sein können. “41

Der Tomsker Historiograph Mogil'nickij ergänzte in seiner 1989 erschienenen "Einführung in die Methodologie der Geschichte" Bargs Position um die Kategorie der ,Interpretation“. Erst sie verwandle Fakten der Geschichte in Fakten der Wissenschaft. Die Interpretation, die sich in dem vom objektiven Inhalt historischer Fakten vorgegebenen Rahmen bewege, bringe das subjektive Element in die Geschichtserkenntnis ein, ohne welches diese unmöglich sei. Wissenschaftlicher Fortschritt zeige sich in der Vervollkommnung der Interpretation, die ihrerseits zur Erweiterung objektiver historischer Kenntnisse beitrage. ${ }^{42}$

Mit den Auffassungen von Barg und Mogil'nickij wurde der tradierte Rahmen des erkenntnisoptimistischen materialistischen Objektivismus' verlassen und Kompatibilität - nicht Identität - mit nichtmarxistischen Auffassungen hergestellt. Denn jenseits des historischen und dialektischen Materialismus nimmt auch die historische Sozialwissenschaft an, daß das historische Faktum ,(...) nicht als solches, sondern nur als interpretiertes zu haben" ist. ${ }^{43}$ Gleichgültig, von welcher theoretisch-methodologischen Grundlage ausgegangen wird, ist in der Forschungspraxis

\footnotetext{
$39 \quad$ Ebd., 257.
}

40 Kosolapov beispielsweise sprach dagegen von „idealer“" (ideal noe) Abbildung; vgl. Kosolapov, Metodologija, 292.

41 Barg, Leopold von Ranke, 257.

42 Mogil'nickij, Vvedenie, 104f.

43 Oelkers, J.: Rekonstruktion und Theorie. Probleme der historischen Methodologie, in: Ansichten einer künftigen Geschichtswissenschaft I: Kritik - Theorie - Methode, hg. von I. Geiss und R. Tamchina, München 1974, 120-139, hier 137. 
stets zu überprüfen, ob nicht bei der Auswertung der Quellenberichte und der Interpretation geschichtswissenschaftlicher Fakten, unbegründete Wertungen in Sachaussagen einfließen, ungekennzeichnete Vorauswahlen getroffen werden, $\mathrm{Hy}-$ pothesen sich unversehens in Behauptungen wandeln und falsche oder einseitige Kausalbeziehungen hergestellt werden. ${ }^{44}$

Vgl. Hofmann, W.: Grundelemente der Wirtschaftsgesellschaft. Ein Leitfaden fur Lehrende, Reinbek 1969, 17. 


\subsection{Alternativität und GesetzmäBigkeit in der Geschichte}

Der Angriff undogmatischer Philosophen und Historiker in den sechziger Jahren auf die damals offizielle Lehrmeinung, historischer Materialismus analysiere gesellschaftlich-geschichtliche Gesetze, Geschichtswissenschaft illustriere diese lediglich durch die Darstellung des konkreten Geschichtsverlaufs, drängte trotz des $\mathrm{Ab}$ bruchs der Diskussionen diese Auffassung in die Defensive. Sie wurde aus der geschichtswissenschaftlichen Literatur weitgehend verbannt, "überwinterte“ allerdings in einigen Standardwerken zur Philosophie bis 1987. Nachdem sich die Wogen der Aufregung über die ,halb-dissidentischen" Theorie- und Methodologiediskussionen geglättet hatten und wieder Ruhe eingekehrt war, wurde die zu Beginn der sechziger Jahre noch als Häresie geltende These von ,spezifisch historischen Gesetzmäßigkeiten" seit der Mitte der siebziger Jahre in der Geschichtswissenschaft dominant. Erst in den letzten Jahren der perestrojka, während des Transformationversuchs und der darauffolgenden gesellschaftlichen Agonie 1990/91, wurde diese Auffassung offen diskutiert und ansatzweise revidiert.

Der dogmatische Standpunkt - historischer Materialismus analysiere das Wesen, die Geschichtswissenschaft beschreibe die Vielfalt der Geschichte - wurde schon an anderer Stelle verdeutlicht. 'Hier ist nur bemerkenswert, daß er tatsächlich bis in die zweite Hälfte der achtziger Jahre im wesentlichen unverändert immer wieder in Lehrbücher zur Philosophie aufgenommen wurde ${ }^{2}$ und in leicht überarbeiteter Weise in den Tagen der perestrojka wieder gegen das Postulat der spezifisch historischen Gesetzmäßigkeiten ins Felde gefuihrt wurde. So warf die Philosophin Z̈elenina 1989 Gurevič, Kertman, Zuukov, Barg und Cernjak vor, nach Überwindung der alten Barriere - hier Gesetzesanalyse durch den historischen Materialismus, dort Faktensammlung durch die Geschichtswissenschaft - eine neue künstliche Grenze zwischen der Befassung mit allgemeinen Gesetzen einerseits, besonderen Gesetzen andererseits zu ziehen. ${ }^{3}$ Anstatt sich auf ein besonderes Abstraktionsniveau oder auf spezifisch historische Gesetzmäßigkeiten zu fixieren, könne und müsse der Historiker den historischen Materialismus als ,seine Theorie“ in der Geschichtswissenschaft betrachten und anwenden; denn der in der historischen Litera-

Siehe Kapitel 4.3. und 4.5.

Vgl. Marksistsko-leninskaja filosofija, M. 1964, 294; Marksistsko-leninskaja filosofija, M. 1981, 184; Marksistsko-leninskaja teorija istoričeskogo processa. Istoričeskij process: dejstvitel'nost', material'naja osnova, pervičnoe i vtoričnoe, M. 1981, 140f: Kelle, W. (= Kelle, V.Z.)/M. Kowalson (= Koval'zon, M.): Theorie und Geschichte, Berlin 1984, 88ff passim (Erstveröffentlichung in Russisch 1981); Istoriðeskij materializm kak social'no-filosofskaja teorija. Pod redakcii V.I. Razina, M. 1982, 40f; Teorija obక̌cestvenno-ekonomičeskoj formacij. Pod redakcii V.V. Denisova et al., M. 1982, 67; Dialektičeskij $i$ istoričeskij materializm. Pod redakcii A.P. Septulina, M. 1985, 223f; Alekseev, P.V./A.V. Panin: Dialektičeskij materializm (ob̌̌čie teoretičeskie principy), M. 1987, 63.

3 Želenina, O zakonach, 101. 
tur genutzte Begriff des Gesetzes sei das Synonym für den des gesellschaftichen Gesetzes mit Betonung des zeitlichen Aspekts. ${ }^{4}$

In der Absicht, den wissenschaftlichen Status der Historie zu betonen, wurde die Auffassung, die Geschichtswissenschaft untersuche und formuliere spezifische historische Gesetzmäßigkeiten, die in erster Linie ihren Gegenstand darstellten, mit solcher Ferve vertreten, daß der gesetzmäßige Charakter des Geschichtsprozesses überzeichnet wurde. 5 as war selbst in der Monographie Volobuevs über die „Wahl der Wege gesellschaftlicher Entwicklung“ so, in der zwar die Bedeutung der Ideen der Wahl und der Offenheit sowie der Alternativität für die marxistischleninistische Geschichtsforschung anhand der Geschichte der Oktoberrevolution herausgearbeitet wurden, Volobuev sich aber von der bisherigen - Leninschen Gesetzesauffassung nicht löste; ${ }^{6}$ seine Arbeit ist daher geschichtsmethodologisch zu dieser Strömung zu rechnen.

Allgemein-soziologische Gesetze bezeichnete Mogil'nickij als Kompaß der Geschichtswissenschaft;' sie deckten die innere wesentliche Verbindung von Phänomenen des gesellschaftlichen Lebens auf. Immer seien das ,abstrakt-allgemeine, generalisierende und unbedingte Gesetze“, 8 mit universalgeschichtlicher Gültigkeit

4 Ebd., 105; ("̌elenina zitierte S.I. Gončaruk ohne einen korrekten Beleg anzugeben; J.H.).

3 Bei einem Treffen sowjetischer Philosophen und Historiker im April 1988 fuhrte der Vizeprasident der Kasachischen AdW Z.M. Abdil'din die Reduktion der Geschichtswissenschaft auf das Einzelne und Individuelle auf Rickert zurück; beschränkte sich die historische Disziplin darauf, wurde sie den Status als Wissenschaft verlieren. - Filosofija 1988, 52. Analoge Argumentation bei Maslov, N.N.: Marksistsko-leninskie metody istoriko-partijnogo issledovanija, $M$. 1983, 10; Mogil'nickij, Vvedenie, 32f. Vgl. Barg. Istoriceskie zakonomernosti, 96-120; Sakina, T.D.: Gnoseologičeskaja priroda istoričeskoj zakonomernosti (Na materiale trudov A.I. Neusychina), in: MIVIN 13, T. 1979, 3-11; Teoretičeskie problemy vsemirno-istoričeskogo processa, M. 1979, 5-43.

6 Siehe Volobuev. Vybor 1987, 7ff und besonders 149ff; vgl. ders., Po novomu puti: utveridenie socialističeskogo vybora Strany Sovetov, in: ON 1987, H. 5, 24-42; ders., 1917 god: byla li al'ternativa? In: Rodina 1989, H. 10, 14-17 sowie seine Redebeiträge anläßlich mehrerer Disłussionen: Izučenie istorii Velikogo Oktjabrja. Itogi i perspektivy, in: VI 1987, H. 6, 51-72, hier 57ff, Filosofija 1988, 39ff, „Kruglyj stol“ 1988, 36f; Social'nyj progress, 164f; Istoričeskoe soznanie, 12. - Von alten Widersachern wurde er wegen der Wiederbelebung der 1972 offiziell verurteilten „Neuen Richtung“ gescholten. Vgl. Bovykin, Problemy perestrojki; Kolonickij, B.I.: Meżdunarodnyj kollokvium "Raboxij klass i revoljucionnye situacii v Rossii v nacale XX veka“" in: :SSSR 1991, H. 5, 212-215; Polikarpov, V.V.: "Novoe napravlenie“ - v starom proxtenii, in VI 1989, H. 3, 44-61. Polikarpov kritisierte Bovykin, daraufhin erschienen die Polemiken von V.I Bovykin. E.I. Družinina und P.V. Volobuev unter dem Titel „Eł̌̌e raz k voprosu o "novom napravlenii"“, in: VI 1990, H. 6, 164-184.

Mogil'nickij, B.G.: O specifičeskich istoriðeskich zakonach, in: MIVIN 18, T. 1986, 6-31, hier 10 und 16; analog ders., Vvedenie, $39 f$.

8 Mogil'nickij, Vvedenie, 42. - Zukov sah das „Wesen allgemeinsoziologischer Gesetze“ darn. daß sie die allgemeinsten Prinzipien der Entwicklung und Bewegung der Gesellschaft unashängig von den konkreten Formen, in denen sie verwirklicht werden", aufdeckten. - Zukov, E.N.: Ocerki metodologii istorii. Izdanie vtorce, ispravlennoe. Otvetstvennyj redaktor akademik Ju.Y. Bromlej, M. 1987, 67. 
und Systemcharakter; Gesetze, welche die Funktionsweise gesellschaftlicher Formationen vor allem in deren Reifestadium reflektierten. ${ }^{9} \mathrm{Zu}$ dieser Definition gehörte die Auffassung, daß soziologische Gesetze keine Ausnahme zuließen und den ,irreversibel-invarianten Charakter des Geschichtsprozesses in seinen Haupttendenzen" ausdrückten. ${ }^{10}$ Weil damit die ganze Vielfalt der Geschichte nicht zu erklären sei, müsse die Geschichtswissenschaft - quasi zwischen der Theorieebene des historischen Materialismus und der empirischen Basis - einen eigenen kategorialen Apparat entwickeln, dessen „Schlüsselbegriff” eben die „spezifisch historischen Gesetzmäßigkeiten" seien. Diese sollten

„(...) fähig sein, Ereignisse zu erklären, welche die Entstehung einer bestimmten geschichtlichen Situation bedingen, und auch die Dynamik der geschichtlichen Bewegung selbst in deren konkreten räumlich-zeitlichen Formen. "11

Historische Gesetze seien „Entwicklungsgesetze ${ }^{\text {c/2 }}$, ,konkret-allgemein, individualisierend-generalisierend und relativ (wahrscheinlich) ${ }^{\prime 13}{ }^{13}$ wiesen tendenziellen und retrospektiven ${ }^{14}$ sowie stadial-regionalen ${ }^{15}$ Charakter auf. Sie formulierten Verallgemeinerungen, die wesentliche, sich wiederholende Verbindungen von Phänomenen ausdrückten, Phänomenen, die ihrerseits konkret-historisch und individuell seien. Sie erklärten den konkreten Geschichtsverlauf als Produkt der vielfältigen menschlichen Tätigkeit; das heißt, historische Gesetzmäßigkeiten erfültten sich ihrerseits nur unter bestimmten Bedingungen und nur durch menschliche Tätigkeit, wohingegen soziologische Gesetze unabhängig vom Willen und Bewußtsein der Menschen wirkten. ${ }^{16}$ So erkläre das soziologische Gesetz der Dialektik von Produktionsverhältnissen und Produktivkräften das Reifen objektiver Bedingungen. welche sozialistische Revolutionen im Weltmaßstab ,notwendig und unausweichlich" machten. Daß eine solche Umwälzung gerade in Rußland stattfand, so Barg und Cernjak, sei auf dem Niveau des soziologischen Gesetzes zufällig, jedoch vorherbestimmt (predopredeleno) gewesen durch die geschichtliche Notwendigkeit. ${ }^{17}$

\footnotetext{
9 Barg. Kategorii, $197 \mathrm{f}$.

10 Zitat Mogil'nickij, O specificeskich zakonach, 17; vgl. auch ders., Vvedenie, 54ff. „Allgemeinsoziologische und soziologische Gesetze sind absolut und kennen keine Ausnahmen", schrieben Barg, M.A./E.B. Cernjak: O kategorii ,istoričeskij zakon“, in: NNI 1989, H. 3, 92-100,
} hier $95 f$.

1 Mogil'nickij, O specificeskich zakonach, 10f, ders., Vvedenie, $39 f$.

12 So Rakitov, Istoriðeskœe poznanie, 263.

13 Mogil'nickij, Vvedenie, 43.

14 So Kosolapov, Metodologija, 64

is Barg. Kategorii, 197.

16 Mogil'nickij, Vvedenie, 43. - „Jede historische Gesetzmäßigkeit ist 'handgemacht' (rukotvornoj) in dem Sinne, daß sie im Prozeß menschlicher Tätigkeit geschaffen ist." - Ebd., 47; ders., O specificeskich zakonach, 15.

17 „Die unmittelbare Wirkung der soziologischen Faktoren bestimmte die Unausweichlichkeit der sozialistischen Revolution als solcher, und die mittelbare Wirkung derselben Faktoren durch 
Historische Gesetzmäßigkeiten sollten also die Bedingungen aufdecken, welche die Äußerung (projovlenie) soziologischer Gesetze in einem bestimmten Raum und zu einer bestimmten Zeit sicherten oder, was nicht weniger wichtig sei, jene projavlenie verhinderten. ${ }^{18} \mathrm{Ob}$ aus einer revolutionären Situation eine Revolution hervorgehe, hänge ganz von der Entwicklung der widerstreitenden gesellschaftlichen Kräfte, vom Klassenkampf, also vom subjektiven Faktor ab (Lenin). ${ }^{19}$ Die historische Gesetzmäßigkeit wurde demnach betrachtet als ein in doppelter Hinsicht nur unter bestimmten Bedingungen wirksames (uslovnyj) Gesetz,

„(..) welches die für die Realisierung der Tendenz notwendigen Bedingungen, die aufgezeigt wurden durch das soziologische Gesetz, in bestimmten konkrethistorischen Umständen formuliert. “20

Die gleichen Autoren, die den Terminus der spezifischen historischen GesetzmäBigkeiten postulierten, um die Eigenständigkeit und Wissenschaftlichkeit der historischen Disziplin zu betonen, hoben andererseits die Relativität und Subordination des Begriffs gegenüber den vom historischen Materialismus $\mathrm{zu}$ formulierenden soziologischen Gesetzen hervor. Das historische Gesetz basiere auf dem soziologischen, bestimme die Besonderheit dessen Wirkung, hebe diese aber niemals auf. Die historische Gesetzmäßigkeit sei die „Wirklichkeit der soziologischen Gesetze“, sei deren Erscheinungsform. ${ }^{21}$ So oft auch in der Literatur betont wurde, das historische Gesetz stelle eine Einheit von Wesen und Erscheinung, von Inhalt und Form, von Notwendigem und Zufalligem dar, ${ }^{22}$ so deutlich war doch bei allen Autoren, daß sie die historische Gesetzmäßigkeit für abgeleitet, sekundär, für die bloBe Ausdrucksform zwingender soziologischer Gesetze hiehten. ${ }^{23}$ Damit hing auch die Korrelationsbestimmung von Gesetzmäßigkeit einerseits sowie Zufälligkeit und

den Mechanismus geschichtlicher Gesetze Raum und Zeit (im Rahmen einer bestimmten Periode) ihres Vollzuges." - Barg/Cernjak, O kategorii, 98.

18 Mogil'nickij, O specifiðeskich istoriČeskich zakonach, 18ff, Barg/Cernjak, O kategorii, 97f. Vgl. dazu auch Lenin, V.I.: Maevka revoljucionnogo proletariata (1913), in: LPSS 23, 296-305, hier 301 und 305 (vgl. LW 19, 208ff); ders., Krach II Internacionala (1915), in: LPSS 26, 209265, hier 221 (vgl. LW 21, 197ff).

19 Nur wenn die auf die Revolution drängenden Kräfte in ausreichendem Maß stärker seien als die sich gegen die Revolution stemmenden, gehe aus der revolutionären Situation eine Revolution hervor. Nur der Kampf entscheide. Die revolutionäre (und konterrevolutionäre) Aktivität habe insofern objektiven Charakter, daß sie durch die herangereiften objektiven Bedingungen, die die revolutionäre historische Situation ausmachten, bedingt sei. - Lenin, V.I.: I.I. SkvorcovuStepanovu (02./16.12.1909), in: LPSS 47, 223-225, hier 225 (vgl. LW 16, 110ff); vgl. Volobuev, Vybor 1987, 45ff; Mogil'nickij, O specificeskich istoriðeskich zakonach, $22 \mathrm{ff}$.

20 Mogil'nickij, O specifiðeskich istoriðeskich zakonach, 30.

21 Barg. Kategorii, 183f; Barg/Cernjak, O kategorii, 97.

22 Vgl. ebd.

23 Die durch das allgemein-soziologische Gesetz formulierte „dominierende Tendenz“ geschichtlicher Entwicklung könne durch die Gesamtheit konkret-geschichtlicher Faktoren beschleunigt, gebremst und zeitweise ausgesetzt, nicht aber wesentlich geändert werden, schrieb beispielsweise Volobuev, Vybor 1987, 32. 
Alternativität andererseits zusammen. Daher muß zunächst untersucht werden, wie diese Begriffe gedeutet wurden. Die historische Zufälligkeit definierte Mogil'nickij als

"(...) Widerspiegelung äußerer, nichtwesentlicher, einzelner Verbindungen der geschichtlichen Wirklichkeit, die nicht mit Notwendigkeit aus einer Gesamtheit objektiver Voraussetzungen und Bedingungen der gesellschaftlichen Entwicklung hervorgehen. ${ }^{.24}$

Es gebe erstens ,rätselhafte“ Zufälle ohne rationale Erklärung, zweitens nur in einer bestimmten Kausalbeziehung Zufalliges, ${ }^{25}$ drittens die mit der menschlichen Tätigkeit verbundene und aus ihr hervorgehende Zufalligkeit. ${ }^{26}$ Die Frage, ob nun solche Zufälle die geschichtliche Entwicklung wesentlich verändern könnten, ${ }^{27}$ beantwortete Mogil'nickij widersprüchlich. Einerseits führte er das durch den überraschenden Tod der Kaiserin Elisabeth II. mögliche „Mirakel des Hauses Brandenburg“ im Jahr $1762^{28}$ als Beispiel dafür an, daß an Personen geknüpfte Zufälligkeiten den Geschichtsverlauf wesentlich verändern könnten. Andererseits stellte er expressis verbis und ohne Einschränkung fest, daß Zufäligkeit zwar auf den Ereignisverlauf einwirke, aber seinen wesentlichen Inhalt nicht in irgendeinem bedeutenden historischen Rahmen bestimme: Die Zufälligkeit und vor allem die vielfältige Tätigkeit des Menschen bedingten die Multivarianz (mnogovariantmost') der Geschichte, die wiederum der geschichtlichen Altemativität zugrundeliege. Diese bedeute, da $B$ in einem bestimmten historischen Moment verschiedene, sich gegenseitig ausschließende Entwicklungsmöglichkeiten, ,alternative Tendenzen“ (tendencii-al'ternativy), bestünden - objektive (ökonomische, soziale etc.) und subjektive (gesellschaftlich-politische Kräfte) Bedingungen vorausgesetzt. ${ }^{29}$ Die „Haupttendenz" des im wesentlichen invarianten Geschichtsverlaufs zu verändern,

\footnotetext{
24 Mogil'nickij, Vvedenie, 47f (Meine Hervorhebung; J.H.).

2s Als Paradebeispiel dafur murde immer wieder die Entdeckung Amerikas durch europäische Seefahrer angefuhr, die in der wirtschaftich-technischen und politischen Entwicklung Europas gesetzmäßig, in der Kausalität der Geschichte des amerikanischen Kontinents zufällig gewesen sei. - Ebd.

26 Ebd., 49 .

29 Wenn man dem Beispiel von der - aus amerikanischer Sicht - zufälligen Entdeckung Amerikas folgt, muß diese Frage offensichtlich mit "Ja“ beantwortet werden.

28 Gegen Ende des „Siebenjährigen Kriegs“ hatten bekanntlich russische Truppen ganz Ostpreußen, Pommern und sogar Berlin erobert. Nur der Tod der Kaiserin am 25. Dezember 1761 (nach dem Julianischen Kalender), respektive am 5. Januar 1762 (nach dem heute gültigen Gregorianischen Kalender) befreite Friedrich Il. aus der verzweifelten Lage. Elisabeths Nachfolger Peter III., ein Bewunderer Friedrichs, verbündete sich wieder mit Preußen gegen Österreich. Da auch Katharina II. (1762-1796) an diesem Bündnis festhielt, hatten die russischen Truppen tatsächlich „(...) ihre Siege bei Großjägerndorf und Kunersdorf gegen den falschen Gegner errungen, und an die Verwirklichung territorialer Kriegsziele auf Kosten Preußens (Gewinnung Ostpreußens!) war nicht mehr zu denken." - Stökl, G.: Russische Geschichte von den Anfängen bis zur Gegenwart, 5., erweiterte Auflage, Stuttgart 1990, 414; vgl. Kahn, H.W.: Die Deutschen und die Russen. Geschichte ihrer Beziehungen, Köln 1984, 46ff.
}

29 Koval'Cenko, Issledovanie, 90; vgl. auch ders., Metody, 73ff. 
diese Potenz wurde Zufällen und Alternativen nicht eingeräumt. ${ }^{30}$ Analog dazu verband "Zukov Alternativität mit dem ,Zick-zack" in der Geschichte, das sich seiner Ansicht nach in Mikroprozessen sozialer Organismen abspielte und zu den Überbauphänomenen zu zählen sei. ${ }^{31}$

Auch der theoretisch anspruchsvollere Standpunkt, den die beiden NeuzeitHistoriker Barg und Cernjak vertraten, lief letztlich auf das gleiche Ergebnis hinaus. ${ }^{32}$ Sie unterschieden eine soziologische und eine konkret-historische Struktur in der Gesellschaft, ordneten jener das soziologische und dieser das konkrethistorische Gesetz zu, welches sie als das „Bewegungsprinzip konkreter historischer Formen des sozialen Systems" (social 'nost') bezeichneten. ${ }^{33}$ Die historische Gesetzmäßigkeit fixiere die Wechselwirkungen zwischen der herrschenden Produktionsweise einer Gesellschaftsformation sowie dem ihr entsprechenden Überbau einerseits und der Gesamtheit nichtsystemischer Elemente mit Basis- und ÜberbauCharakter andererseits. Sie lasse „Ausnahmen“, Abweichungen von der allgemeinen Tendenz nicht nur zu, sondern setze sie voraus. Sie könne zufällige, dem soziologischen Gesetz widersprechende Elemente enthalten. ${ }^{34}$ Letztlich aber werde die Gesamtheit der historischen Gesetzmäßigkeit bestimmt durch die Funktionsgesetze

30 Siehe Mogil'nickij, Vvedenie, 51ff. ..Im Unterschied also zu soziologischen Gesetzen, die den irreversibel-invarianten Charakter des Geschichtsprozesses in seinen Haupttendenzen aufdecken, verweisen historische Gesetze auf das Vorhandensein (und die Grenzen) der Alternativität in der Geschichte." - Mogil'nickij, O specifǐeskich istoriceskich zakonach, 17. Mit den gleichen Begriffen und Kategorien operierten auch Volobuev u.a. - Volobuev, Vybor 1987, 36ff: Dvadcatyj Vek: Al'ternativy razvitija. Kruglyj stol, in: RKSM 1989, H. 1, 60-71 und H. 2, 77-96, hier H. 1, 66f und H. 2, 79f; Ovčinnikov, V.F.: Mnogovariantnost ${ }^{\circ}$ razvitija socializma, in: Social 'no-politiceskie nauki 1990, H. 9, 14-19.

31 Zukov, Ozerki, 76. "Zukov berief sich hierbei auf einen Philosophen der DDR, Stiehler, G. Geschichte und Verantwortung. Zur Frage der Alternativen in der gesellschaftlichen Entwicklung, Berlin 1972, 15.

32 Die Entwicklungsbedingungen der sowjetischen Geschichtswissenschaf - so Barg - führten dazu, daß Fragen, die mit der Rolle der menschlichen Subjektivität in der Geschichte zusammenhängen. sowohl in theoretisch-methodologischer als auch in historiographischer Hinsicht vernachlässigt wurden. Es sei jetzt die Aufgabe materialistischer Historiker, das von der historischen Anthropologie akkumulierte, aber unzulänglich analysiente Material konzeptionell zu verallgemeinern und ein materialistisches theoretisches Modell dieses Gegenstandsbereichs zu schaffen. Gemeinsam mit Cernjak fuihne Barg drei Bedingungen an, um die Kategorie der historischen Gesetzmäßigkeit präzis zu interpretieren: erstens müsse Gesellschaft als komplexes, sich entwikkelndes System betrachtet werden; zweitens sei die Sphäre der historischen Gesetzmäßigkeit kein isoliertes Subsystem der Gesellschaft. sondern die Gesellschaft als Ganzes (celostnost); drittens müsse die Dialektik der zeitlichen und der räumlichen Dimensionen im geschichtlichen Prozeß beachtet werden. - Siehe Barg. M.A.: O roli čelovečeskoj sub-ektivnosti v istorii, in: ISSSR 1989, H. 3, 115-131, hier 119; Barg/Cernjak, O kategorii, 96.

33 Barg/Cernjak, O kategorii, 96f.

34 „Gerade daher erscheint der Geschichtsverlauf in Form von Zick-Zacks und Windungen (izlomov).“- Ebd., 98 (Meine Hervorhebung; J.H.). 
der dominierenden Produktionsweise, das heißt ,(...) durch die Gesetzmäßigkeiten der soziologischen Reihe. ${ }^{\text {c3s }}$

Mogil'nickij, der Mitte September 1988 am Ende einer Methodologiekonferenz in Tomsk feststellte, das Problem der Alternativität sei neu in der sowjetischen Historiographie, ${ }^{36}$ versuchte in seinen seit 1989 erscheinenden Arbeiten, seine bisherigen Auffassungen weiterzuentwickeln. ${ }^{37}$ Als Beispiel einer soziologischen Gesetzmäßigkeit wählte er nun die Prognose von Karl Marx über den ,rohen Kommunismus", der sich unmittelbar nach der sozialistischen Revolution in demokratischer oder despotischer Weise entfalten werde. ${ }^{38}$ Analog - so Mogil'nickij - könne über ,rohen Kapitalismus“" oder, ,rohen Feudalismus" in den ersten Phasen der jeweiligen Gesellschaftssysteme gesprochen werden; auch dort bestünden solche Alternativen. Daher handle es sich um eine für mehrere Formationen gültige - eben soziologische - Gesetzmäßigkeit. ${ }^{39}$ Neu war hier also die Feststellung, daß die soziologische Gesetzmäßigkeit nicht einen - gesetzmäßigen - Weg, sondern eine alternative Situation, alternative Richtungen formuliere. Es handle sich bei solchen Alternativen um eine der wichtigsten Gesetzmäßigkeiten des Geschichtsprozesses. ${ }^{40}$ Beide Varianten hätten ihre Grundlagen (osnovanija) in den materiellen und den geistig-psychologischen Bedingungen des gesellschaftlichen Lebens. ${ }^{41}$ Während die soziologische Gesetzmäßigkeit diese Alternativität ausdrücken und erklären solle, müsse mit historischen Gesetzmäßigkeiten aufgedeckt werden, warum die eine oder andere Variante Realität geworden sei. Wenn sozialökonomische Strukturen den objektiven Rahmen für die menschliche Tätigkeit bildeten, sie aber nicht vollständig determinierten, dann hänge die Realisierung der einen oder ande-

3s Ebd., $96 f$.

36 Siehe den Konferenzbericht von Nexuchrin, A.N./S.P. Ramazanov: Istoriceskaja nauka i perestrojka, in: ISSSR 1989, H. 3, 211-214, hier 214.

37 Mogil'nickij, B.G.: Al'ternativnost' $v$ istorii sovetskogo obšcestva, in: VI 1989, H. 11, 3-16; ders., Istorǐ̌eskaja al'ternativnost': metodologiceskij aspekt, in: NNI 1990, H. 3, 3-18.

38 Der sechsundzwanzigjährige Karl Marx schrieb in seinen ökonomisch-philosophischen Manuskripten zur Thematik Privateigentum und Kommunismus: „Die erste positive Aufhebung des Privateigentums, der rohe Kommunismus, ist also nur eine Erscheinungsform von der Niedertracht des Privateigentums, das sich als das pasitive Gemeinwesen setzen will. (...) Der Kommunismus (...) noch politischer Natur, demokratisch oder despotisch; (...)". - Marx, K.: Ökonomisch-philosophische Manuskripte aus dem Jahre 1844, in: MEW, Ergänzungsband Erster Teil, Berlin 1968, 467-588, hier 535f (Hervorhebungen bei Marx; J.H.).

39 Mogil'nickij, Al'ternativnost', 4.

40 Mogil'nickij bezeichnete in seinen Publikationen von 1989 und 1990 den Begriff „historische Alternative“ als eine „objektive Kategorie, die reale Verbindungen, welche in der geschichtlichen Wirklichkeit existieren, reflektiert. " Die „historische Alternativität" bestimmte er als den „einer Gesellschaft immanent eigenen Zustand, durch den das Vorhandensein und der Kampf verschiedener Alternativen charakterisien werden, wobei diese Alternativen objektiv bestehende Tendenzen der weiteren Entwicklung ausdrücken." Und an anderer Stelle betonte er nochmals: "Determiniert ist ja die Multivarianz (mnogovariantmost) der gesellschaftlichen Entwicklung. “" Mogil'nickij, Istoričeskaja al'ternativnost', 7f.

41 Mogil'nickij, Al'ternativnost', 5. 
ren Variante vom subjektiven Faktor ab: damit war das Problem der Alternativität zum Problem der „Freiheit der historischen Wahl ${ }^{142}$ geworden. Theoretisch seien drei Varianten möglich: Stagnation, Revolution und Reform - vorausgesetzt, es funktioniere der „Wirkungsmechanismus historischer Alternativen“ ${ }^{43}$ Diesen definierte Mogil'nickij als effektiv wirkendes System, fähig, erstens verschiedene Problemlösungen aufzuzeigen, zweitens eine davon auszuwählen. ${ }^{44}$ Es komme auf den Inhalt (soderzanie) der gesellschaftlichen Institutionen an; damit meinte Mogil'nickij:

„(..) das allgemeine Niveau des Selbstbewußtseins der Gesellschaft, die Reife ihrer politischen Kultur, den Charakter der in ihr dominierenden Geistesrichtungen (umonastroenij) und ähnliche Faktoren, die in ihrer Gesamtheit jene geistige Atmosphäre bilden, die in einer Gesellschaft herrscht, und die das Maß ihrer 'Zivilisiertheit' charakterisiert. ${ }^{\text {“4s }}$

Nur auf einem ausreichend hohen Stand der Zivilisation entstehe ein effektiver Mechanismus der Alternativität. Da in der Vergangenheit generell und in der sowjetischen Gesellschaft insbesondere das Zivilisationsniveau verhältnismäßig niedrig und der Mechanismus nicht voll entwickelt gewesen seien, hätten revolutionäre Lösungen meist gegenüber reformistischen obsiegt. Heute - auf höherem zivilisatorischem Niveau - dominiere der reformistische Weg. Es sei also ,antihistorisch", die revolutionäre oder reformistische Entwicklung a priori vorzuziehen. ${ }^{46} \mathrm{DaB}$ in Sowjet-Rußland die despotische Variante verwirklicht worden sei, führte Mogil'nickij auf (objektiv bedingte) subjektive Faktoren, besonders psychologische, zurück; er nannte die ,Psychologie der Sieger“ und den ,revolutionären Romantizismus", die die Sozialpsychologie am Ende der zwanziger und in den dreißiger Jahren dominierten. Hinzu seien die persönlichen Eigenschaften der führenden Politiker gekommen, besonders das „Phänomen" Stalin, Stalins Charisma; Stalin habe als charismatische Gestalt die Mentalität seiner ,Epoche“ verkörpert, ,,$(. .$.$) in der$ sich in bizarrer Weise revolutionär-kommunistische, chiliastische und sogar zaristi-

\footnotetext{
42 Mogil'nickij, Istoričeskaja al'ternativnost', $8 \mathrm{f}$.

43 „Das Problem der Alternativität ist somit ein Problem der normalen Funktionsweise des gesellschaftlichen Organismus, seiner Fähigkeit zur Selbstentwicklung und folglich zur stabilen fortschreitenden Bewegung."- Mogil'nickij, Al'ternativnost', 13.

4 Mogil'nickij, Istoričeskaja al'ternativnost', 1 of.

45 Ebd., 11f - Mogil'nickij berief sich hierbei auf V.S. Bibler, der bei dem Rund-TischGespräch Ende 1988 zum Thema „Das 20. Jahrhundert. Entwicklungsalternativen“ gesagt habe, „ohne geistige, kulturelle Alternativität kann es keinerlei andere Alternativität geben“. - Vgl. Dvadcatyj vek. 64.
}

46 Mogil'nickij, Istoričeskaja al'ternativnost', 12f. Deutlich wird hier der Unterschied zur bisherigen Position, die ausschließlich die proletarisch-sozialistische Revolution als adäquate Antwort auf die aus den Widersprüchen zwischen Produktionsverhältnissen und Produktivkraftentwicklung hervorgegangene revolutionäre Situation akzeptierte. So auch noch bei Volobuev, Vybor $1987,68 \mathrm{ff}$ und $83 \mathrm{ff}$. 
sche Stimmungen verflochten. ${ }^{\text {(47 } 7}$ Nicht weniger gesetzmäßig (auf der allgemeinsoziologischen Ebene) sei die demokratische Sozialismus-Variante in Gestalt der fortgesetzten Neuen Ökonomischen Politik gewesen. Doch infolge der Aufhebung des Klassenantagonismus, der Einfuihrung des Einparteiensystems, der ideologischen Vereinheitlichung und der autoritären Verwaltungsleitung sei der spontane Mechanismus der Alternativität seit dem Ende der zwanziger Jahre suspendiert worden. Die vorherrschende Sozialpsychologie habe die durch Stalins Politik der Zwangskollektivierung und beschleunigten Industrialisierung verkörperte despotische Sozialismus-Variante favorisiert, was eine echte Konkurrenz objektiv bestehender Alternativen und wiederholt das Einbiegen in die demokratische Entwicklungsvariante verhindert habe. ${ }^{48}$

Im Rahmen der oben dargelegten methodologischen Auffassungen von Mogil'nickij (bis 1989), Volobuev, Barg, Cernjak, Rakitov, ״ukov u.a. wurden die historische Alternativität, Zufälle und Brüche in der Geschichte zwar thematisiert und als Bewegungsformen der Geschichte ,zugelassen“, aber immer nur im Rahmen des soziologischen Gesetzes. Bildlich gesprochen spielten sich damit alle Windungen und Zick-Zacks innerhalb einer von soziologischen Gesetzen geformten Röhre ab. Demnach könnten die von spezifisch historischen Gesetzmäßigkeiten oder mit der Kategorie der Alternativität beschriebenen Ereignisse und Entwicklungen in der Geschichte deren Verlauf, ,in der Haupttendenz" oder, im wesentlichen" nicht verändern oder bestimmen. Die Geschichtswissenschaft würde also nur "Überbauphänomene" und im Ganzen betrachtet wenig bedeutsame Abwege der Historie untersuchen und beschreiben. Diese Korrelation von historischen und soziologischen Gesetzen, von Geschichtswissenschaft und historischem Materialismus brachte der Geschichtstheoretiker Petrjaev mit den Worten auf den Punkt:

„Die ganze Angelegenheit besteht darin, daß die Auswahl, die Systematisienung und Analyse 'notwendiger' und 'zufälliger' Faktoren den Prinzipien der dialektischmaterialistischen Methodologie als Leitfaden der Geschichtsforschung unterworfen werden. Insbesondere bei der Analyse von Ereignissen, Phänomenen und Handlun-

\footnotetext{
47 Der Stalinismus sei „organisch hervorgegangen aus bestimmten objektiven Bedingungen des gesellschaftlichen Lebens", insofern gesetzmäßig und doch nicht unausweichlich gewesen. Auf seinem Wege habe es auch subjektive Faktoren. Gewalt und Manipulation gegeben. Letztlich entscheidend sei aber die psychologische Seite gewesen. - Mogil'nickij. Al'ternativnost', 3 und $10 \mathrm{ff}$.

48 Ebd., 14f. Nicht im Zugang, aber im Resultat stimmt dies überein mit der Auffassung des renommierten Agrarhistorikers V.P. Danilov, der ebenfalls die ,Zeit der Alternativen“ nach der Zustimmung Bucharins zum Parteiausschluß Trockijs, Zinov'evs, Kamenevs und anderer Ende 1927 und der voluntaristischen Korrektur der ursprünglichen Fassung des ersten Fünfjahrplans im November 1929 für beendet hält. - Danilov, V.P.: Dvadcatye gody: NEP i bor'ba al'ternativ, in: Istoriki sporjat, 122-137, hier 129ff; vgl. zu Danilovs Publikationen Davies, Perestroika, 73ff; Merl, S.: Kollektivierung und Bauernvernichtung, in: Geyer, Die Umwertung, 103-132, hier $113 \mathrm{ff}$.
} 
gen irgendeiner Epoche ist es wichtig aufzuzeigen, in welcher Form von Zufälligkeiten die Notwendigkeiten dieser Epoche wirken. "49

Ginge man mit dieser methodologischen Grundlage an die Geschichte der sowjetischen Gesellschaft in den zwanziger und dreißiger Jahren heran, so erschiene die Etablierung der Stalinschen Machtordnung als gesetzmäßiger, unabwendbarer Prozeß, determiniert durch die Dialektik von Produktivkräften und Produktionsverhältnissen, durch die allgemeinen Gesetze des Klassenkampfs. Mit historischen Gesetzmäßigkeiten und Alternativen ließen sich Entwicklungen, in ihrer Haupttendenz" nicht verändert, sondern nur verzögert, beschleunigt oder partiell modifiziert vorstellen.

Erst mit Mogil'nickijs neuer methodologischer Position aus den Jahren 1989 bis 1990 waren Kategorien angeboten, die das Forschen nach und das Nachdenken über wirkliche historische Alternativen zum Stalinschen „Sozialismus in einem Land" nicht nur sinnvoll, sondem auch machbar erscheinen ließen. Deren Tragfähigkeit und die Frage, ob die immanenten Thesen von der determinierten Alternative zwischen despotischem und demokratischem sozialistischen Aufbau, zwischen Revolutionierung und Reformierung der sowjetrussischen Gesellschaft mit Leben zu füllen sind, müssen entsprechende konkret-historische Untersuchungen erweisen. Im Konnex der Einlassungen Mogil'nickijs zur geschichtlichen Entwicklung in den zwanziger und dreißiger Jahren entwickelte sich in der sowjetischen historischen Publizistik eine lebhafte Debatte über mögliche Alternativen zur Oktoberrevolution, zur Beendigung der Neuen Ökonomischen Politik und zur Etablierung der Stalinschen Machtordnung, die nachzuzeichnen den Rahmen dieses Kapitels sprengen würde. ${ }^{\text {so }}$ Die Diskussionen waren von neuem in hohem Maß von der politischen Entwicklung geprägt: ${ }^{51}$ Nach dem vorübergehend großen Interesse an alternativen Entwicklungswegen der sowjetischen Gesellschaft, ${ }^{52}$ wurde bald wie-

49 Petrjaev, K.D.: Voprosy metodologii istoričeskoj nauki, Kiev 1976, 68 (Kursiv im Original,
J.H.).
so Siehe dazu die Hinweise in den Kapiteln 6.1. und 6.2.
s1 Die neuerliche Indienstnahme von Geschichtsbildern für die Politik zeigte sich an der „etwas naiven Schwärmerei“ (Davies) für die Zarenzeit, an der zeitweisen Idealisierung der Neuen Ökonomischen Politik, an der verzögerten Beschäftigung mit Trockij, der anders, als Bucharin. politisch inopportun blieb, u.ä. - Davies, Perestroika, 22ff passim; Wehner, M.: Die Diskussion um den „Liebling der Partei“. Zur politischen Bedeutung der Rehabilitierung N.I. Bucharins, in: OE 1990, H. 4, 301-317; ders., Auf der Suche; ders., Rückkehr; Bordjugov/Kozlov, Istorija.

32 Vgl. exemplarisch Volobuev, Po novomu puti; ders., $1917 \operatorname{god} 1987$ und 1989; Bordjugow/Koslow, Die Wende; Poljakov, IstoriCeskij process; Dvadcatyj vek; Vodolazov, G.G.: Al'ternativy istorii $i$ istorija al'ternativ, in: Problemy mirovogo revoljucionnogo processa. Vyp. 8, M. 1989, 178-205; Bestužev-Lada, I.: Byla li al'ternativa stalinizmu? In: PO 1989, H. 3, 39-47; Ovčinnikov, V.F.: Socializm i problema istoričeskich al'ternativ, in: NK 1989, H. 9, 22-27; ders., Mnogovariantnost'; Arslanov, K sporam; Starzew, W.: Phantasie und Realität. Gab es eine Alternative zur Oktoberrevolution? In: Initial 1991, H. 1, 80-87 (zuerst in: K 1990, H. 15, 33-41); Sazonov, V.V.IV.T. Loginov: Nužno li bylo idti of fevralja k oktjabrju? In: Dialog 1991, H. 2, 8490; Tokarev, A.I.: Byla li al'ternativa Oktjabr'skoj revoljucii? In: Social 'no-polititeskie nauki 1991, H. 9, 21-32. - Der ehemalige kulturpolitische Berater Gorbačevs, der Historiker Vladimir 
der ein nomologisches Geschichtsbild, nun mit negativen Vorzeichen, dominant, in dem eine gesetzmäßig-logische Entwicklung von Marx über Lenin, den Revolutions- und Bürgerkriegsterror zu Stalin und zum stalinistischen Terror gezeichnet wurde $;{ }^{53}$ theoretische und methodologische Aspekte wurden in den Auseinandersetzungen vernachlässigt. So markierten die Ausführungen Mogil'nickijs die letzte beziehungsweise fortgeschrittenste Position zum Problemfeld von Alternativität und GesetzmäBigkeit in der Geschichte, die allerdings nur ansatzweise ausgearbeitet war und blieb.

Grundsätzlich neue geschichtstheoretische und -methodologische Anregungen, die aber nicht auf die hier behandelte Problematik bezogen waren, gab der Mediävist Gurevič. Wie die anderen, grauen Häupter" der sowjetischen Geschichtswissenschaft, Barg, Danilov, Koval'čenko, Mogil'nickij, Samsonov, Volobuev u.a., so plädierte auch Gurevič dafür, die perestrojka für intensive interdisziplinäre Theorie- und Methodologiediskussionen zu nutzen, um eine grundlegende Erneuerung der Geschichtswissenschaft zu erreichen. ${ }^{54}$ Diese sollte seines Erachtens nach wieder zu einer Humanwissenschaft werden, zu einer „Disziplin, in deren Zentrum der Aufmerksamkeit der Mensch steht" ${ }^{\text {ss }}$ In diesem Sinne sprach er sich implizit gegen die bisher gültige nomologische Sicht auf die Geschichte aus. Er explizierte dies für

Egorov, verpaßte in seiner Monographie über historisches Denken in Politik und Wissenschaf die Gelegenheit, Konstruktives zum Thema Alternativität beizusteuern; vgl. Egorov, V.K.: Istorija $\vee$ nał̌j ł.izni, M. 1990, $30 \mathrm{ff}$ (d.i. Jegorow, V.K.: Geschichte in unserem Leben. Betrachtungen zum historischen Denken in Politik und Wissenschaf, Berlin 1992, 37ff).

33 Aleksandr Cipko begründete die „Unvermeidbarkeit" des Stalinismus mit der ideologischen Kontinuität zwischen klassischem Marxismus, Leninismus und Stalinismus, Igor Kljamkin mit ökonomischen und politischen Zwängen Ende der zwanziger Jahre, Vadim Kožinov mit dem allgemeinen "Wesen" jeder Revolution. Nach anfangs scharfen Protesten und Polemiken gegen die genannten Autoren, wurden deren Auffassungen den Eindrücken des Autors in Moskau 1990 und 1992/93 zufolge in der Öffentlichkeit und in der scientific community der Historiker zunehmend anerkannt. - Siehe Cipko, Istoki; Kljamkin, I.: Byla li al'ternativa administrativnoj sisteme? In: PO 1988, H. 10, 55-65; ders., Ešce raz ob istokach stalinizma, in: PO 1989, H. 9, 41-50, den Beitrag von Kožinov zu Pravda i istina, in: Nas sovremennik 1988, H. 4, 165ff, hier 169-173, $\mathrm{Vgl}$. die Darlegung und Diskussion ideologischer, politischer und historischer Kontinuitäten bei Maier, R.: Stalinismus. Die zwanziger Jahre, Wiesbaden 1990; Leonhard, W.: War Lenin verantwortlich für den Stalinismus? Persönliche Betrachtungen eines Zeitzeugen, in: OE 1991, H. 10, 997-1007.

s4 Siehe dazu vor allem Gurjewitsch, A.J.: Die Theorie der Gesellschaftsformationen und die historische Wirklichkeit, in: Initial 1991, H. 4, $435-446$ (zuerst in VF 1990, H. 11, 31-43); noch nicht so entschieden, aber schon sehr kritisch, äußerte sich Gurevič beim Rund-Tisch-Gespräch im April 1988 in der Redaktion der "Fragen der Philosophie“, siehe Filosofija 1988, 20f. Der Diskussion und Erprobung neuer Theorien und Methoden soll auch die 1989 gegründete Zeitschrift „Odissej“ dienen; dazu Gurevič, A.Ja.: Vsled za „Odissei“, in: VF 1989, H. 12, 162f; 1989 bis 1991 erschienen drei Ausgaben mit jeweils 20.000 Exemplaren Auflage.

ss „Denn ihren authentischen Inhalt, ihren wahrhaftigen Gegenstand findet die Geschichte insofern, als sie die Geschichte der Menschen betrachtet, und zwar (...) nicht nur 'von außen', sondern auch 'von innen'. Aber für die Geschichte befindet sich der Mensch immer in einer Gruppe, in einer Gesellschaft; unser Gegenstand ist nicht der abstrakte Mensch, sondern der geschichtlich konkrete Teilnehmer des sozialen Prozesses.“- Gurevič, Social'naja istorija, 33. 
die hier behandelte Problematik allerdings nicht: sein Interesse galt der Historisierung der Formationstheorie ${ }^{\text {s6 }}$ und der - nach jahrzehntelanger Isolation endlich zu vollziehenden - Rezeption des Gedankenguts der Neokantianer, Max Webers und der ,Nouvelle histoire“. ${ }^{\text {. }}$

56 Gurevic würdigte durchaus den Beitrag von Marx und Engels zur weiteren Verwissenschaftlichung der Historie durch ihr materialistisches und systematisches Denken: „Mit der Einführung der Begriffe 'Produktionsweise der materiellen Güter' und 'ökonomische Gesellschaftsformation' und mit der Ausarbeitung ihres Inhalts wirkten Marx und Engels in höchstem Maße befruchtend auf die Entwicklung der Geschichtswissenschaft, denn sie stellten ihr einen konzeptuellen Apparat zur Verfügung mit dessen Hilfe die gesellschaftlichen Verhältnisse und die ihnen zugrundeliegenden Wirtschaftssysteme (...) herausgehoben und untersucht werden können. Die weitere Entwicklung des historischen Wissens verlief in vielem unter dem Einfluß von Marx, unabhängig davon, ob die verschiedenen Richtungen innerhalb der Geschichtsschreibung ihn anerkannten oder ablehnten." Den Grundfehler im marxistischen Geschichtsdenken sah Gurevic darin, daß die ,Klassiker“" Hegels Erkenntnisoptimismus und Panlogismus unkritisch übernommen und versucht hätten, mit der Formationstheorie eine „Philosophie des historischen Prozesses" zu formulieren. - Gurjewitsch, Die Theorie, $435 f$.

s) Insbesondere durch die theoretischen Anregungen von Rickert und Windelband (Geschichtswissenschaft als Kulturwissenschaften) und Max Weber (,Idealtypus“) sowie durch die Arbeiten der Nouvelle histoire sei im Westen die Hegelsche Tradition kritisiert und überwunden worden. Das marxistische Geschichtsdenken sei durch die vom wissenschaftlichen Kommunismus erzwungene Isolation erkenntnisoptimistisch, panlogistisch und positivistisch geblieben. Gurjewitsch, A.J.: Sozialismus und Geschichte. Die sowjetische Historie auf dem Weg von Marx zu Max Weber, in: FAZ vom 07.08.1991, N3; ders., Die Theorie, 438ff, ders. (= Gurevič, A.Ja.), O krizise sovremennoj istoriðeskoj nauki, in: VI 1991, H. 2-3, 21-36, $23 \mathrm{ff}$. 
lof

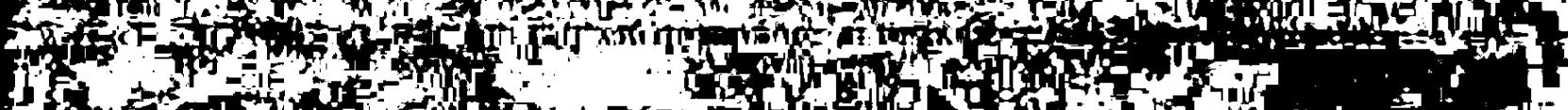

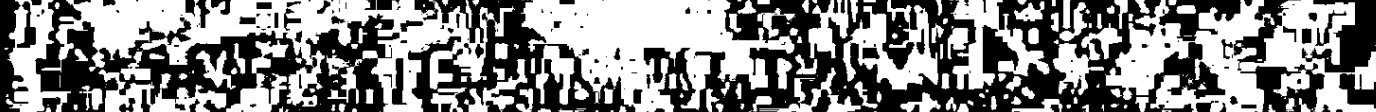

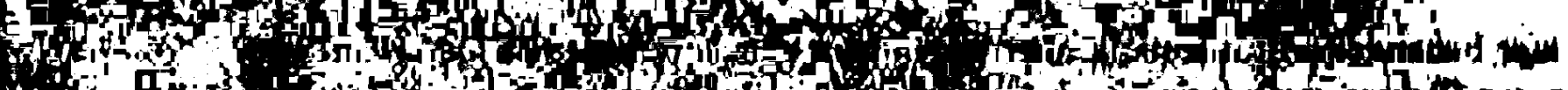

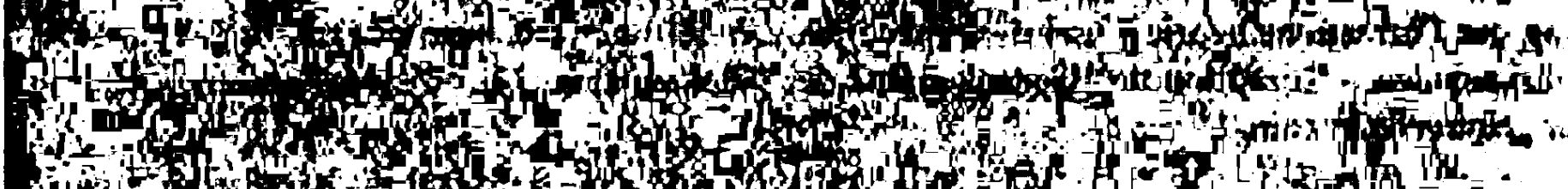

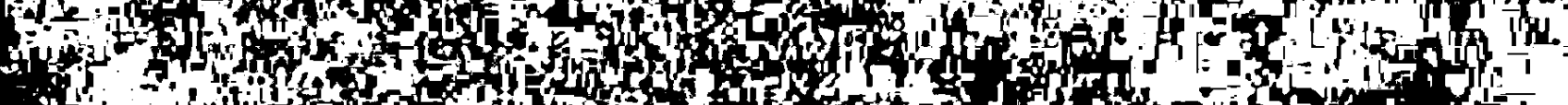

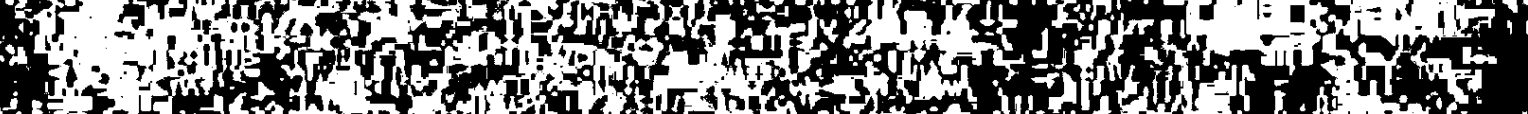

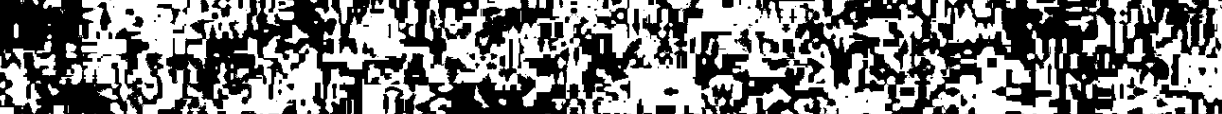

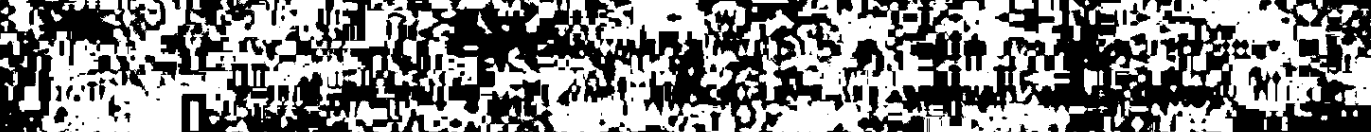
on 4 It fly

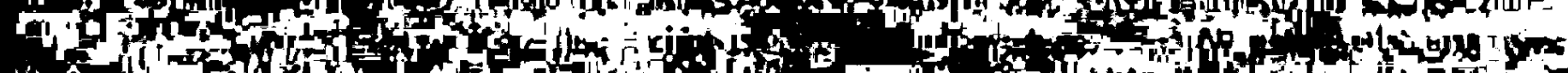

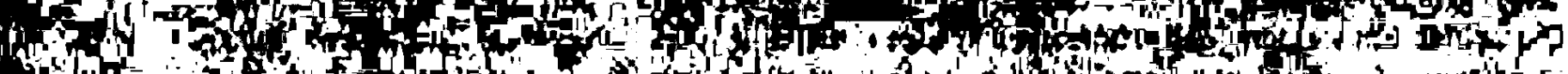

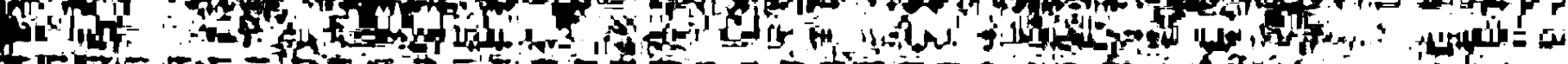
Tl S1

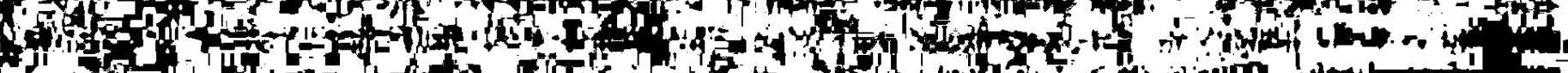

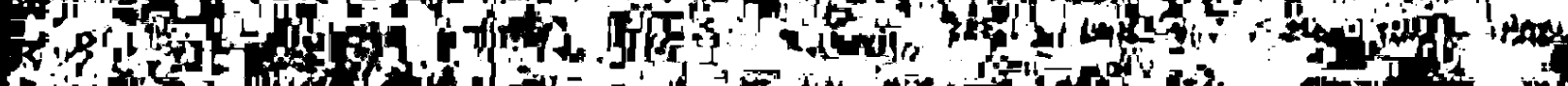

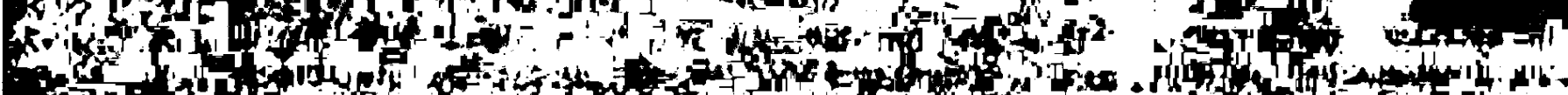
$\Rightarrow$ of for

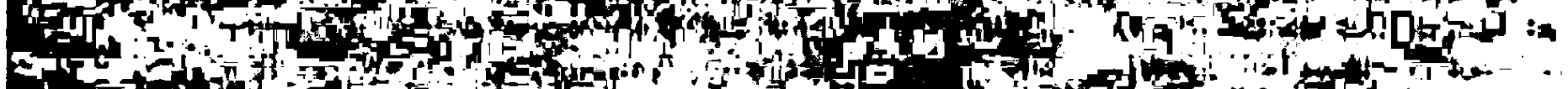

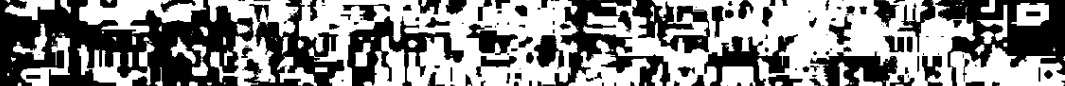
40

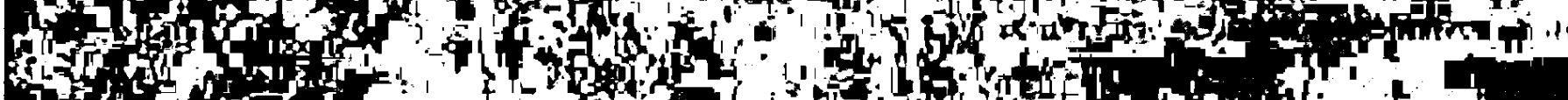

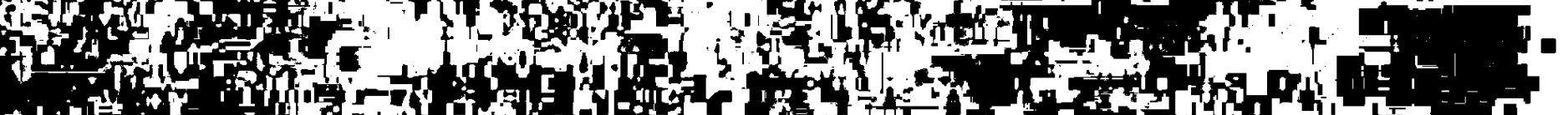
An

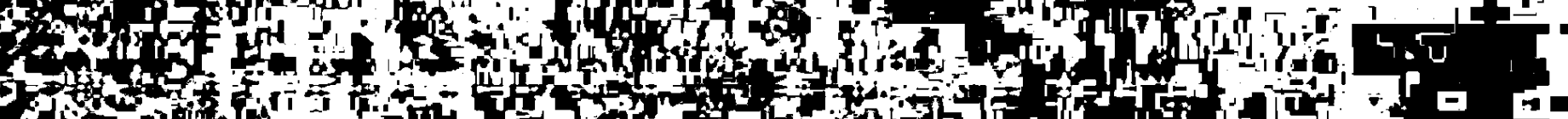

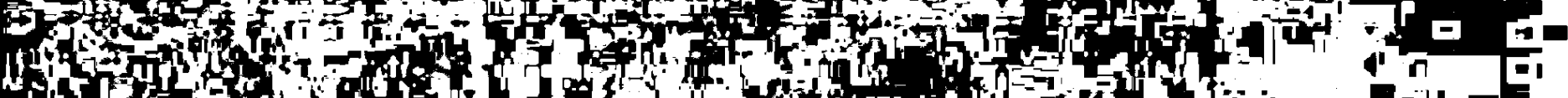
-

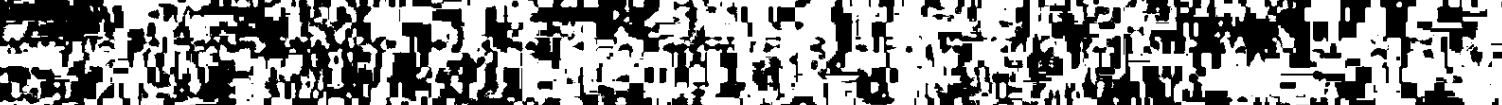
ir

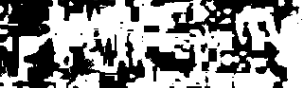

iffol

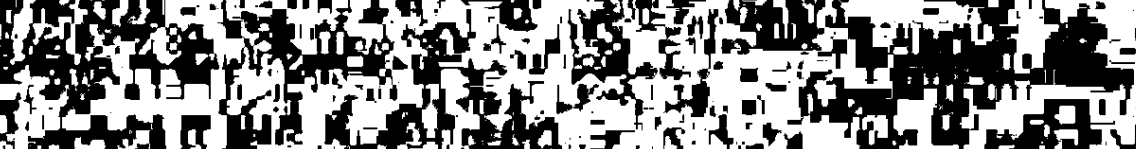

ifit

yiditip

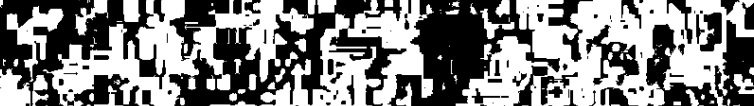

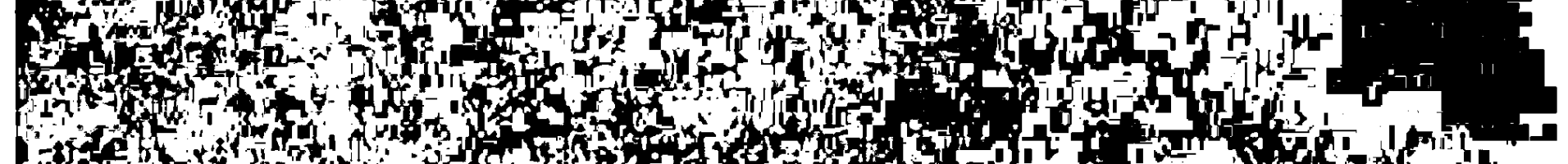

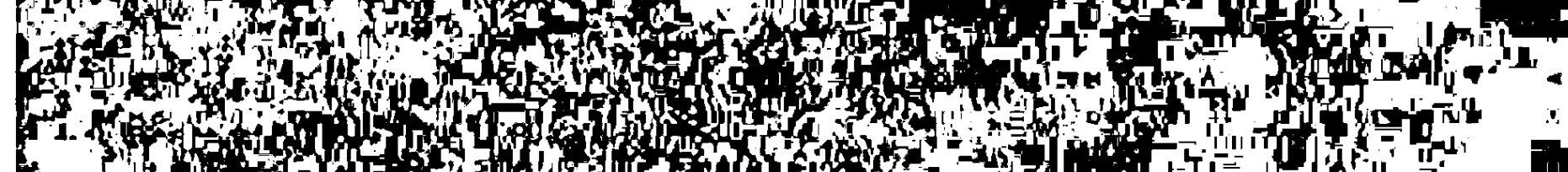
1. dis

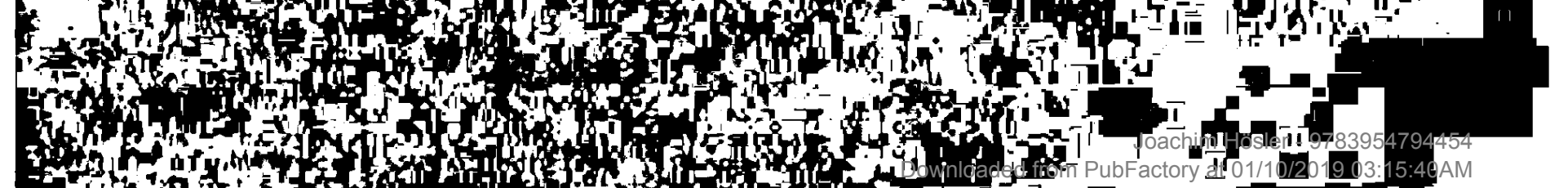

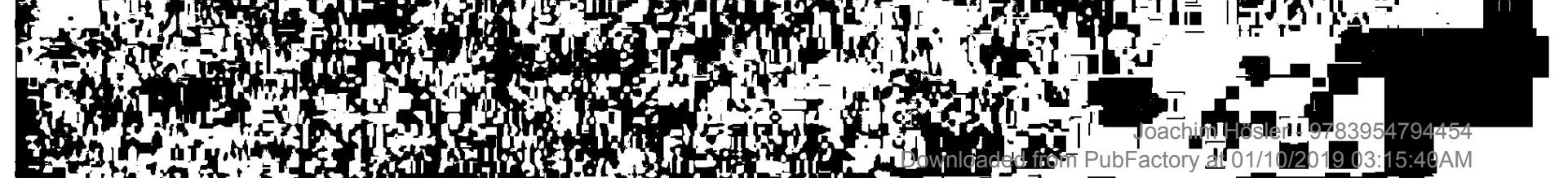

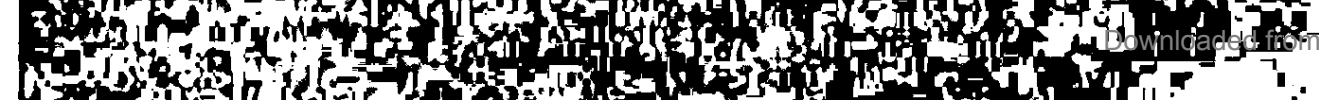

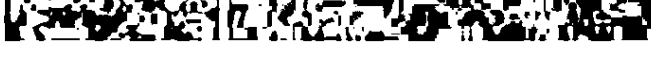




\section{Zusammenfassung}

Mit der Untersuchung wurde eine Geschichte der Niederlagen wissenschaftlichen Denkens gegen die Ignoranz der Macht erfaßt. Zu Stalins Lebzeiten gärte bereits seit längerem Unzufriedenheit auch unter den Geschichtswissenschaftlern, da ihr Fach zu einer bloßen Agentur für Agitation und Propaganda verkommen war, und sie sich mit ihren Arbeitsergebnissen in der internationalen ,scientific community“ nicht mehr profilieren konnten. Namhafte Historikerinnen und Historiker versuchten immer wieder, die Spielräume für ihre Disziplin zu erweitern, doch solange der Diktator lebte, blieb dies ohne Erfolgsaussicht.

Erst nach Stalins Tod eröffneten die sich rasch ändernden politischen und gesellschaftlichen Rahmenbedingungen echte Handlungsmöglichkeiten, und die Geschichtswissenschaftler gehörten 1953 tatsächlich, wie in Kapitel 3.1. gezeigt werden konnte, zu den ersten, welche die neue Lage für ihre Arbeit zu nutzen versuchten. Der Auffassung, das „Tauwetter" habe erst nach dem 20. Parteitag der KPdSU im Februar 1956 begonnen, muß im Hinblick auf die Geschichtswissenschaft widersprochen werden. Vom März 1953 an kam es zu personellen Veränderungen bei der führenden Fachzeitschrift, an der Moskauer Staatsuniversität und dem Geschichtsinstitut der Akademie der Wissenschaften. Dem folgten noch im gleichen Jahr Diskussionen über das Profil der Zeitschrift Voprosy istorii, über den Forschungsstand und über mögliche neue Orientierungen und Wertungen, über ein neues Verhältnis zwischen der Geschichtswissenschaft und dem historischen Materialismus im Zeichen einer Emanzipation der ersteren. Der 20. Parteitag der KPdSU und vor allem die Rede Chruščevs förderten die bereits eingeleitete Beseitigung der Hinterlassenschaft Stalins in der Geschichtswissenschaft, initiierten diesen Prozeß aber nicht. Bereits zwei, drei Jahre vor der von der Tribüne des 20. Parteitags herab verkündeten Kritik an Stalin diskutierten Historikerinnen und Historiker über ökonomische und historische Gesetzmäßigkeiten im Feudalismus, Kapitalismus und Sozialismus, über die Periodisierung der Geschichte der sowjetischen Gesellschaft und über die Neubewertung der Kolonialpolitik des russischen Kaiserreiches. Wiederholt wurden dabei Stalinsche Urteile und Leitideen offen für unzulänglich und falsch erklärt. Zugleich waren die Auseinandersetzungen in hohem Maß von der Stalinschen Dogmatik geprägt und offenbarten eine große ,methodologische Hilflosigkeit" (Kuznecov). Manche ketzerisch anmutende Vorschläge, wie zum Beispiel eine partiell grundsätzlich neue Periodisierung der sowjetischen Geschichte, die Rehabilitierung nationaler Befreiungsbewegungen gegen Rußland, die Duldung verschiedener marxistischer wissenschaftlicher Schulen (eines ,pluralen Marxismus“"?!), blieben im Raume stehen. Obwohl das Profil der Voprosy istorii nicht vollends geklärt worden ist, und bei allen Einschränkungen, die angesichts vieler dogmatischer Auslassungen zu machen sind, ist festzustellen, da $B$ es Pankratova und Burdžalov innerhalb von knapp vier Jahren gelang, die Arbeitsfähigkeht der Redaktion wieder herzustellen und die Zeitschrift - in Relation zu den vorangegangenen Jahren - zu einem verhältnismäßig zuverlässigen Informations- und Kommunikationsmittel der historischen Zunft zu wandeln. Unter den 
Wissenschaftlern wurden ein neues Problembewußtsein und höhere Ansprüche an die eigene Arbeit geweckt. Das Abhängigkeitsverhältnis, in dem sich die historische Disziplin befand, stelten die Revisionisten in dieser ersten Phase der Entstalinisierungsetappe in Frage, vermochten es aber noch nicht aufzulösen. Dennoch verdienen es die Aktivitäten von Anna Pankratova, für die die Auseinandersetzung tödlich endete, und Eduard Burdžalov, als Bemühen um Entstalinisienung und Befreiung vom Dogmatismus gewürdigt und im Gedächtnis gehalten zu werden.

Pankratova und Burdžalov waren aktiv geworden, bevor der politische Kampf um die Macht im Kreml endgültig entschieden war. Darin liegt der letzte Grund ihres Scheiterns. Ihr Wirken war abhängig von der Stellung und dem Verhalten Chruščevs, der sich nicht als zuverlässiger Kompagnon in Sachen Entstalinisienung erwies. Wie sich im Juni 1957 zeigte, war er durchaus in der Lage, sich einiger seiner Widersacher in der Parteispitze zu entledigen; doch er tat dies erst, als es um seine eigene Führungsposition ging, nicht im Februar des gleichen Jahres, als Burdžalov und Pankratova zu schützen und zu retten gewesen wären. Genau ein Jahr nach dem 20. Parteitag, in den oberflächlich gern als Zeit des Tauwetters beschriebenen Monaten im Frühjahr 1957, wurde die isolierte Rebellion der revisionistischen Historikerinnen und Historiker erstickt. Viele zeitgenössische Beobachter fürchteten, es würde alles wieder so werden wie früher. Hier konnte nachgewiesen werden, daß es genügend Gegenkräfte gab, um die begonnene „Restalinisierung" (Urban) zu verhindern. Die Unterbindung der Revisionsversuche Anfang 1957 mündete in die Koexistenz von regressiven und progressiven Tendenzen: auf der einen Seite die neuerliche Instrumentalisienung sämtlicher Leitartikel in den Fachzeitschriften, die Proklamation des absoluten Parteilichkeitsprinzips, die Aufforderung zum Kampf gegen die „bürgerliche“ Geschichtsschreibung, die Einführung der „Tonnenideologie“ in der Geschichtswissenschaft; auf der anderen Seite die ununterbrochene quantitative Ausweitung der Forschung, das Erinnern an den Leninschen Historismus als Korrektiv des Parteilichkeitsprinzips sowie der Beginn systematischer historiographischer Untersuchungen und Diskussionen, in deren Rahmen die faktische Rehabilitierung Pokrovskijs eingeleitet wurde.

Für die Mitte des Jahres 1960 konnte eine überraschende Aufbruchsstimmung unter den führenden Historikerinnen und Historikem festgestellt werden. Diese kann weder mit dem 20. Parteitag 1956, dessen Wirkung durch den Schlag gegen die Revisionisten um Burdžalov pulverisiert worden war, noch mit dem 21. Parteitag 1959, der sich mit Fragen der Ideologie und Historie nur mittelbar befaßt hatte, noch mit dem ZK-Beschluß vom 9. Januar 1960 über Parteipropaganda, der vor allem KPdSU-Institutionen angesprochen hatte, noch mit dem 22. „Entstalinisierungs-" Parteitag, der bekanntlich erst 1961 stattfand, erklärt werden. Ähnlich wie 1953 kam das Drängen auf Veränderung aus den Reihen der Historikerinnen und Historiker, diesmal aber weit weniger radikal und zugespitzt, dafür in umso breiterem Konsens: Ehrwürdige Akademiemitglieder, etablierte Wissenschaftler und Nachwuchskräfte waren in wachsender Zahl beunruhigt über die politische Bevormundung und den damit verbundenen Mangel an Professionalität ihrer Disziplin. 
Diese Sorge konnten auch konservative Historiker wie etwa Minc, Žukov u.a., die über das rebellische Auftreten Burdžalovs erschrocken waren, teilen. Rückwärtsgewandte wie Najdenov und Kuckkin, gerieten daher in eine Minderheitsposition. Die über die Geschichtsforschung und -schreibung wachenden Partei-Ideologen, z.B. Suslov und Ponomarev, waren gleichfalls für den Gedanken der Professionalisierung zu gewinnen und bereit, eine von ihnen dosierte Entstalinisierung sowie Forschungen und Diskussionen zur „Vervollkommnung" der marxistisch-leninistischen Geschichtstheorie zuzulassen. Dies war aus ihrer Sicht klüger, als sich den Kräften der Erneuerung entgegenzustemmen und den Konflikt mit der Mehrheit der Zunft zu riskieren. Damit erst, nicht schon 1953 oder 1956, waren die Voraussetzungen für die Auflösung des einfachen Abhängigkeitsverhältnisses der Geschichtswissenschaft von der Politik und die Entwicklung eines Dialogs zwischen Historikern und Politikem gegeben. In dieser Konstellation entwickelte sich diejenige „Dualität des Wissenschaftlichen und des Politischen“ (Heer), welche seither die sowjetische Geschichtswissenschaft prägte. Das zeitweilige relative Übergewicht des einen oder anderen Elements entschied fortan über die Ausgangsbedingungen geschichtswissenschaftichen Arbeitens.

Von 1960 bis 1968 war das Wissenschaftliche das stärkere Element in dieser Dualität. Die Partei gab zahlreiche Impulse, um geschichtstheoretische und -methodologische Diskussionen anzuregen und versuchte zugleich, sie zu kontrollieren. Bei der Historikerschaft fielen die Anregungen auf fruchtbaren Boden. Auf der Grundlage eines weiteren quantitativen Ausbaus der historischen Disziplin wurde vor allem die Erforschung der Geschichte der sowjetischen Gesellschaft und der Geschichtswissenschaft ausgedehnt und intensiviert. Dabei forderte das Legitimationsbedürfnis des Staates besonders in der konkret-historischen Erforschung der sowjetischen Gesellschaft seinen Tribut. Lediglich die sogenannte „Neue Richtung“ der Oktoberrevolutionsforschung wurde geduldet, weil sie dem Anliegen um Professionalisierung zu entsprechen verhie $B$. In der Historiographie wurden besonders nach 1966 deutlich fundiertere Positionen zur Periodisierung der Geschichte der sowjetischen Geschichtswissenschaft, zu den Auswirkungen der Stalinschen Wissenschaftspolitik, zur Würdigung Pokrovskijs und Pankratovas verankert. Der Tomsker Mediävist und Funktionär Aleksandr Danilov und der Moskauer Revolutionsforscher Michail Gefter repräsentierten die Alternative im Ansatz zu den Theoriediskussionen. Danilov wollte das ,granitene Fundament" der orthodoxen manxistisch-leninistischen Lehre bei der auch seines Erachtens notwendigen Erörtenung geschichtstheoretischer Probleme auf keinen Fall verlassen. Gefter sprach für all diejenigen, die das marxistische Geschichtsverständnis vom Dogmatismus befreien, mit den neuesten sozialwissenschaftichen Erkenntnissen ergänzen und als moderne, materialistisch-dialektische Konzeption bewahren wollten. Die relativ starke Unterstützung dieses revisionistischen Standpunktes war eine weitere Bedingung für die zahlreichen Veranstaltungen zu den Methodologiediskussionen. In Anknüpfung an die rudimentären Anfänge in den fünfriger Jahren standen dabei die Gegenstandsbestimmung, die Spezifik der Geschichtswissenschaft, die Tatsachendefinition und -diskussion, die Auffassungen von Gesetzmäßigkeit und Alternativi- 
tät sowie die Forschungsprinzipien im Mittelpunkt des Interesses. Die alten, einerseits empiristischen, andererseits theoretizistischen, unbegründet erkenntnisoptimistischen Auffassungen wurden dabei offen diskutiert, kritisiert und teilweise überwunden. Darin und in der Tatsache, daß sowohl in inoffiziellen als auch in offiziell eingerichteten Foren wissenschaftliche Diskurse über Grundprobleme der Historie gefuihrt wurden, bestand ein erheblicher Fortschritt. Generell kann angenommen werden, daß die Sensibilität unter den Historikern für diese und andere Fragen damals gefördert wurde. Es konnte als Mehrheitsmeinung verankert werden, da $B$ die Geschichtswissenschaft organisatorisch, theoretisch und methodologisch eine eigenständige Disziplin darstelle, und nicht nur ein Faktotum des historischen Materialismus. Neue Forschungsprojekte auf der Grundlage sozialpsychologischer Methoden und Kategorien wurden initiiert. Die Bewußtmachung der axiologischen und ästhetischen Aspekte der Geschichtsmethodologie half, die Spezifik der Geschichtswissenschaft besser zu erfassen. Der Begriff der Objektivität wurde vom Makel des „,bourgeoisen Objektivismus“ befreit und als eigenständiges Forschungsprinzip eingefuihrt. Dies relativierte ansatzweise das Parteilichkeitsprinzip. Mit all diesen Impulsen war auch die Kritik des ökonomistischen Determinismus verbunden. Bis zum Eingreifen der zentralen Parteifuhrung und dem Abbruch der Theoriedebatten blieb den Diskutanten allerdings zu wenig Zeit, die neuen Ansätze fundiert zu begründen oder dauerhaft und mit Breitenwirkung in der Forschung zu verankern. Weitere Defizite rührten daher, daß weder die marxistische noch die nichtmarxistische internationale Fachliteratur adäquat rezipiert wurden.

Die Ablösung Chruščevs durch Brežnev im Oktober 1964 stellte für die Historiographie noch keinen Einschnitt dar, wenngleich parteiintern eine neuerliche Umorientierung und die Einstellung der ,Fehlersuche bei Stalin“ (Kučkin) vorbereitet wurden. 1965 begannen die Repressionen zwar gegen Nekric als einzelnen Historiker. Die Historikerschaft als Ganzes oder die verschiedenen Gruppen und Kollektive wurden aber noch nicht attackiert.

Die wichtigsten Diskussionszentren in den sechziger Jahren bildeten die Gruppe von Wissenschaftlern, welche die „Neue Richtung“ in der Revolutionsforschung vertrat, und die Methodologiesektion unter der Leitung von Michail Gefter. Gemeinsam war beiden, daß ihre Arbeit gegen den in Dogmen erstarten MarxismusLeninismus gerichtet war. Das theoretische Gedankengut sollte durch das nochmalige „Lesen“, durch die nochmalige Analyse der klassischen Texte von Marx, Engels und Lenin vor dem Hintergnund der Sozialgeschichte des 20. Jahrhunderts erneuert werden. Inhaltlich ergänzten sich die Zwischenergebnisse und Thesen, am intensivsten beim Nachdenken über Gesetzmäßigkeit, Zufall und Alternativität in der Geschichte auf der theoretischen und methodologischen Ebene sowie der konkret-historischen Untersuchung der gesellschaftlichen Strukturen, der spontanen Massenaktionen und der alternativen Entwicklungsmöglichkeiten in Rußland zu Beginn des Jahrhunderts. So verwundert es nicht, daß Michail Gefter, der führende „Kopf“ der Methodologiesektion, - wie auch manch anderer aus diesem Kreis zugleich zu den Vertretem der ,Neuen Richtung“ zählte, und umgekehrt einige 
Emeuerer der Revolutionsforschung an der Tätigkeit der Methodologiesektion teilnahmen (wie etwa A.Ja. Grunt, Ja.S. Drabkin, K.L. Majdanik). Dennoch müssen die beiden Phänomene auseinandergehalten werden: Die „Neue Richtung“ ging Anfang der funfziger Jahre aus der Schule Sidorovs hervor und blieb ein Zusammenschluß von Historikern ohne feste Institution, deren Thesen im Verlauf der sechziger Jahre dominierend wurden. Die Methodologiesektion hingegen wurde 1964 als Arbeitsgruppe am Geschichtsinstitut der Akademie offiziell eingerichtet. Ihre Tätigkeit galt jedoch bald als ketzerisch und ,halbdissidentisch". Sie untergrub die Lehren des historischen Materialismus, der marxistisch-leninistischen Erkenntnistheorie sowie der Philosophie- und Ideengeschichte, stellte also die bisherigen theoretischen und methodologischen Grundlagen der historischen Forschung, der offiziellen Ideologie und Weltanschauung in Frage. So wurde die Methodologiesektion bereits 1967, als die „Neue Richtung“ noch dominierte, heftig kritisiert, Gefter 1968 als Sektionsleiter entlassen, die Sektion selbst 1969 aufgelöst. Die „Neue Richtung“ geriet in Bedrängnis, weil ihre Thesen mit dem offiziell propagierten Revolutionsmodell gegen Ende der sechziger Jahre kollidierten. Die KPdSU-Führung wollte die Oktoberrevolution als Umwälzung in einem kapitalistischen Land mittleren Niveaus und als proletarische Leitrevolution sowohl gegenüber den Industrienationen als auch gegenüber den schwach entwickelten Ländern in der sogenannten Dritten Welt propagieren. 1968 und in den folgenden Jahren zeigte es sich, daß die Thesen der „Neuen Richtung" weniger diese gewünschte Agitation und Propaganda unterstützten als vielmehr die Parolen der Neuen Linken in Westeuropa und das Revolutionsmodell Chinas. 1972/74 wurde daher auch diese Forschungsrichtung zerschlagen.

Damit endete die dritte Etappe der sowjetischen Geschichtswissenschaft, die der Entstalinisierung: Von 1953 bis Anfang der siebziger Jahre war immer wieder aus den Reihen der Historikerinnen und Historiker ein ernsthaftes Bemühen um die Überwindung der ,Folgen des Personenkults“ erkennbar gewesen. Damit hatte es seit Mitte der siebziger Jahre ein Ende. Die sowjetische Geschichtswissenschaft war von nun an gekennzeichnet durch Routine und Retardation, durch die Orientierung auf Jahres- und Parteitage, durch das Fehlen von Meinungsstreit und Innovationen. Die frühere eindimensionale Abhängigkeit der Geschichtswissenschaft von der Politik wurde nicht wiederhergestellt. Aber die Historikerschaft führte auch keinen Dialog mehr in dem Sinne, daß sie gegenüber den KPdSU-Ideologen die Grenzen der Handlungsmöglichkeiten ausgetestet hätte. Vielmehr stützte sie den ,organisierten Massenkonsens“ (Zaslavsky). Der Schlaf, in den die historische Zunft versank, war so tief, daß auch die Verschiebungen in der politischen Tektonik der sowjetischen Gesellschaft von 1982 bis 1987 ihn nicht beendeten. Auf den Prolog der Umgestaltungspolitik 1982 bis 1985 reagierten die leitenden Vertreter der historischen Disziplin ebenso zögerlich und mechanistisch wie auf die Beschleunigungsstrategie Gorbačevs 1985/86.

Erst Anfang 1987 begann eine neue, die füfte und letzte Etappe der sowjetischen Geschichtswissenschaft, die Etappe des verspäteten Aufbruchs, des chaotischen 
Umbruchs und des ungeplanten Abbruchs des bisherigen Wissenschaftsbetriebs. Nachdem die Parteifuihrung Anfang 1987 die Geschichtsdiskussion auf die Tagesordnung gesetzt hatte, und nachdem längst die Medien des Landes begonnen hatten, tabulos heikle Fragen der Gegenwart und Vergangenheit aufzuwerfen, reagierten die fuihrenden Historiker in den zentralen Institutionen der Geschichtswissenschaft und begannen, immer noch vorsichtig, Reformen zu planen und umzusetzen. Von 1987 bis 1991 hinkte die historische Disziplin als Ganzes der Führung der Kommunistischen Partei in der Vergangenheitsaufarbeitung hinterher; seit 1988 setzte auch die KPdSU nicht mehr die entscheidenden Impulse in den öffentlichen, nichtakademischen Geschichtsdiskussionen, sondern versuchte - aus ihrer Sicht den „Schaden“ zu begrenzen.

Nicht nur, daß die namhaften Historiker anders als noch 1953 oder 1960, verspätet auf die gesellschaftlichen Veränderungen reagierten, anstatt $\mathrm{zu}$ agieren; sie hatten in den eigenen Kreisen, unter den jüngeren Kolleginnen und Kollegen offensichtlich auch ihre wissenschaftlich-moralische Autorität eingebüßt. Thre wiederholten Aufforderungen, die neuen Freiräume für intensive Theorie- und Methodologiediskussionen und für einen geschichtstheoretischen Durchbruch zu nutzen, blieben ohne die erwünschten Folgen. Die Aufarbeitung historischer Tatsachen und Ereignisse, die Beseitigung "weißer Flecken" der Historiographie, stand diesmal im Vordergrund. Von den Ende der sechziger Jahre abgebrochenen Methodologiediskussionen wurden lediglich diejenigen zur Gegenstandsbestimmung, zur Tatsachendefinition und zur Problematik von Alternativität und Gesetzmäßigkeit wieder aufgenommen, und auch dies nur bruchstückhaft. Eine breite Anknüpfung an frühere Debatten kam nicht zustande. $\mathrm{Zu}$ schnell verblaßte der Glanz der perestrojka im Angesicht der Krise und der Agonie des Gesellschaftssystems, zu fern waren jene Auseinandersetzungen der sechziger Jahre für die jüngere und mittlere, desillusionierte Wissenschaftlergeneration, in deren Augen nicht nur das marxistische Geschichtsverständnis, sondern Geschichtstheorie und -methodologie an sich diskreditien waren. In den Kapiteln 6.3. bis 6.5. wurde deutlich, daß nur einzelne Historiker sich zu den genannten Themen äußerten. Abgerundete methodologische Konzepte erarbeiteten sie dabei nicht mehr. Bis zuletzt wurde der nomologische Erkenntnisanspruch aufrechterhalten und die Wissenschaftlichkeit der historischen Disziplin verknüpft mit der Aufdeckung spezifischer konkret-historischer Gesetzmäßigkeiten. Diese blieben unzulänglich definiert, ihre Beziehung za ,soziologischen" Gesetzen einerseits, zu Zufällen und Alternativen in der geschichtlichen Entwicklung andererseits blieb uneindeutig bestimmt. Da sich auf theoretischmethodologischem Niveau kein kohärenter Diskurs mehr entwickelte, blieben die objektiv bestehenden Diskussionsmöglichkeiten und die grundsätzlich vorhandene Meinungsvielfah unnütz. In positiver Hinsicht bleibt festzuhalten, daB sich in den Beiträgen zur Tatsachendiskussion die in den siebziger Jahren entstandenen terminologischen Wirrungen aufklärten. Barg bot eine ,materialistische Lösung“ der Definitionsprobleme. Er und Mogil'nickij bekannten sich zu dynamischen, relativen Erkenntnisambitionen und verwarfen den bisherigen grenzenlosen Erkenntnisoptimismus und absoluten Wahrheitsanspruch der sowjetischen Geschichtswissen- 
schaft. Das in den sechziger Jahren von Gurevix vorgebrachte Anliegen, den axiologischen Aspekt der Geschichtsmethodologie zu problematisieren, wurde jetzt anerkannt. Die Behauptung, die Beachtung der kommunistischen Parteilichkeit führe den Historiker zur Objektivität, wurde fallengelassen. Ansatzweise erarbeitete der Tomsker Historiker Mogil'nickij diskutable Grundaussagen über historische Gesetze und Alternativität. Er verwarf die bis dahin gültige These von der Dialektik von Revolution und Reform, welche der Revolution Priorität einräumte, zugunsten der konkret-historischen Analyse von "Zivilisationsniveaus", von denen der „Wirkungsmechanismus historischer Alternativen“ abhänge. Die an den Methodologiediskussionen beteiligten Autoren hielten im wesentlichen an spezifischen Grundthesen des traditionellen marxistischen Geschichtsverständnisses fest, oder sie entdeckten diese, ohne die dogmatische Verhüllung, neu. Mit den Annahmen einer inneren Kohärenz der geschichtlich-gesellschaftlichen Entwicklung und der Unmöglichkeit einer wertfreien, "objektiven" Geschichtswissenschaft wurden Brücken geschlagen zu analytischen Geschichtskonzeptionen, die, wie etwa die historische Sozialwissenschaft dies tut, marxistische Elemente fruchtbar machen.

Während der Agonie des gesellschaftlichen Systems der UdSSR waren - den Rufen der akademiki nach einem theoretischen Durchbruch zum Trotz - in der Historikerschaft eine breite, grundsätzliche Ablehnung und die Abkehr von theoretischmethodologischen Problemen feststellbar. Dies birgt die Gefahr in sich, daß - ein weiteres Mal nach 1917 bzw. 1929 - Entwicklungszusammenhänge im sowjetrussischen Geschichtsdenken und die objektiv bestehenden Theorieprobleme unbewußt bleiben oder verdrängt werden. Der von allen Seiten verkündete Neubeginn der russischen Geschichtswissenschaft kann jedoch nicht durch die Tilgung „weißer Flecken", die Enttabuisienung und Umwertung allein geleistet werden. Eine Erneuerung müßte von Grund auf erfolgen und das theoretisch-methodologische Fundament mit einbeziehen. Ohne dies würde auch die Rückkehr der russischen Geschichtswissenschaft zur Welt-Geschichtswissenschaft weniger gewinnbringend für beide Seiten sein. Jahrzehntelang war die historische Disziplin in der UdSSR international isoliert. Nur partiell, etwa in den Arbeiten von Gurevic, Barg, Mogil'nickij und wenigen anderen, wurden die ,Ablösung des herkömmlichen Wissenschaftsmodells des Historismus durch neuere Formen sozialwissenschafticher Geschichtsforschung" im Lauf unseres Jahrhunderts und die „linguistische Wende" in den letzten fünfzehn, zwanzig Jahren rezipiert. 'Mit gegenüber der theoretischmethodologischen Problematik der Historie verschlossenen Augen laufen die russischen Historikerinnen und Historiker Gefahr, diesen Rückstand lange Zeit, länger als notwendig, nicht aufholen zu können. Und die internationale Geschichtsforschung, in der es Georg Iggers zufolge jetzt kein Paradigma mehr, sondern eine „Vielfalt von Forschungsstrategien" gibt, ${ }^{2}$ würde durch die Reintegration der russischen Historiographie kaum eine Bereicherung erfahren. So endete die Geschichte

1 Siehe dazu Iggers, G.G.: Geschichtswissenschaf im 20. Jahrhundert. Ein kritischer Überblick im internationalen Zusammenhang, Göttingen 1993, 7ff passim.

2

Ebd., 101. 
der Niederlagen zwar mit einem Sieg der Wissenschaft über die Macht, doch dieser Sieg erwies sich nur als condicio sine qua non für die Inangriffnahme weitreichender Aufgaben unter andauernden höchst schwierigen Bedingungen. 


\section{Abkürzungsverzeichnis}

\begin{tabular}{|c|c|}
\hline AdW & Akademie der Wissenschaften \\
\hline AN SSSR & Akademija nauk SSSR $=$ AdW der UdSSR \\
\hline ASEER & The American Slavic and East European Review \\
\hline ASEES & Australian Slavonic and East European Studies \\
\hline Blätter & Blätter für deutsche und internationale Politik \\
\hline BOIS & Bundesinstitut für Ostwissenschaftliche und Internationale Studien \\
\hline $\operatorname{BSE}(I, I I, I I I)$ & $\begin{array}{l}\text { Bol'̌aja Sovetskaja Enciklopedija (Erste Ausgabe, M. 1926ff, zweite Aus- } \\
\text { gabe, M. 1949ff, dritte Ausgabe, M. 1970ff) }\end{array}$ \\
\hline $\mathrm{BzG}$ & Beiträge zur Geschichte der Arbeiterbewegung \\
\hline CChSD & $\begin{array}{l}\text { Centr chranenija sovremennoj dokumentacii (Zentrum zur Aufbewahrung } \\
\text { zeitgeschichtlicher Dokumente) }\end{array}$ \\
\hline CK KPSS & $\begin{array}{l}\text { Central'nyj Komitet Kommunističeskoj Partii Sovetskogo Sojuza }=Z \mathrm{~K} \text { der } \\
\text { KPdSU }\end{array}$ \\
\hline d. & delo $=$ Akte \\
\hline DDR & Deutsche Demokratische Republik \\
\hline DVZ & Deutsche Volkszeitung \\
\hline Ed. & Editor \\
\hline EEPhW & $\begin{array}{l}\text { Europäische Enzyklopädie zu Philosophie und Wissenschaften, hg. von } \\
\text { Hans Jörg Sandkühler. } 4 \text { Bände. Hamburg } 1990\end{array}$ \\
\hline f. & fond $=$ Fonds \\
\hline FAZ & Frankfurter Allgemeine Zeitung \\
\hline FN & Filosofskie nauki. Naučnye doklady vysšej školej \\
\hline FW & Forum Wissenschaft \\
\hline $\begin{array}{l}\text { g., gg. } \\
\text { GuG }\end{array}$ & $\begin{array}{l}\text { god, gody = Jahr, Jahre } \\
\text { Geschichte und Gesellschaft }\end{array}$ \\
\hline GWU & Geschichte in Wissenschaft und Unterricht \\
\hline $\mathbf{H}$. & Heft \\
\hline $\mathrm{Hg}, \mathrm{hg}$. & Herausgeber, herausgegeben \\
\hline $\mathrm{HZ}$ & Historische Zeitschrift \\
\hline ICK & Izvestija CK KPSS \\
\hline IMSF & Institut für Marxistische Studien und Forschungen \\
\hline ISSSR & Istorija SSSR \\
\hline $\mathrm{IZ}$ & Istoričeskie zapiski \\
\hline JbbGO & Jahrbücher für Geschichte Osteuropas \\
\hline JbBWG & Jahrbuch der Braunschweigischen Wissenschaftlichen Gesellschaft \\
\hline JbG & Jahrbuch für Geschichte \\
\hline JbGUV & $\begin{array}{l}\text { Jahrbuch für Geschichte der UdSSR und der volksdemokratischen Länder } \\
\text { Europas }\end{array}$ \\
\hline 乃bW & Jahrbuch für Wirtschaftsgeschichte \\
\hline JHK & Jahrbuch für Historische Kommunismusforschung \\
\hline K & Kommunist (Theorieorgan des ZK der KPdSU) \\
\hline KPdSU & Kommunistische Partei der Sowjetunion \\
\hline $\mathrm{L}$. & Leningrad \\
\hline LPSS & Lenin, V.I.: Polnoe Sobranie Soxinenij, 5. Auflage, M. 1960ff \\
\hline M. & Moskva $=$ Moskau \\
\hline MB & Marxistische Blätter \\
\hline MEJ & Marx-Engels-Jahrbuch \\
\hline
\end{tabular}




\begin{tabular}{|c|c|}
\hline MEW & $\begin{array}{l}\text { Marx, K.F. Engels: Werke, hg vom Institut für Marxismus-Leninismus } \\
\text { beim ZK der SED, Berlin 1956ff }\end{array}$ \\
\hline MIVIN & Metodologið̌eskie i istoriografǐ̌eskie voprosy istoričeskoj nauki, T. $1963 \mathrm{ff}$ \\
\hline $\mathbf{M N}$ & Moskovskie Novosti, Moscow News \\
\hline NA & $\begin{array}{l}\text { „Neretina-Archiv“- Die von S.S. Neretina (M.) aufbewahrten Materialien } \\
\text { der Methodologie-Sektion unter der Leitung von M.Ja. Gefter, durchnum- } \\
\text { meriert nach dem Register des Autors }\end{array}$ \\
\hline NG & Nezavisimaja gazeta \\
\hline NK & Naučnyj kommunizm \\
\hline NNI & Novaja i novejšaja istorija \\
\hline OE & Osteuropa. Zeitschrift für Gegenwartsfragen des Ostens \\
\hline OI & Otecestvennaja istorija \\
\hline ON & Obscestvennye nauki \\
\hline op. & opis' = Inventarliste \\
\hline PFS & Probleme des Friedens und des Sozialismus \\
\hline PMRP & Problemy mirovogo revoljucionnogo processa \\
\hline PO & Političeskoe obrazovanie \\
\hline $\mathrm{PZz}$ & Partijnaja žizn` \\
\hline RKSM & Raboxij klass i sovremennyj mir \\
\hline RSFSR & $\begin{array}{l}\text { Rossijskaja Sovetskaja Federativnaja Socialistiðeskaja Respublika = Russi- } \\
\text { sche Sozialistische Föderative Sowjet-Republik }\end{array}$ \\
\hline SDG & $\begin{array}{l}\text { Sowjetsystem und Demokratische Gesellschaft. Eine vergleichende Enzy- } \\
\text { klopädie, hg. von C.D. Kernig u.a., Freiburg-Basel-Wien 1966ff }\end{array}$ \\
\hline SED & Sozialistische Einheitspartei Deutschlands \\
\hline SIE & Sovetskaja istoriðeskaja enciklopedija. M. 1961-1976 \\
\hline SPR & Spravoznik partijnogo rabotnika, $M .1957 f f$ \\
\hline SR & Slavic Review \\
\hline SSSR & Sojuz Sovetskich Socialisticeskich Respublik $=$ UdSSR \\
\hline StW & $\begin{array}{l}\text { Stalin, I.V.: Werke, Band 1-13, Berlin 1953-1955 und ders., Works, Band } \\
\text { 14-16 (russisch, hg. von R.H. McNeal), Stanford } 1967\end{array}$ \\
\hline SV & Srednie veka \\
\hline SW & Sowjetwissenschaft/Gesellschaftswissenschaftliche Beiträge \\
\hline T. & Tomsk \\
\hline TAZ & Tageszeitung \\
\hline TMGIAI & Trudy Moskovskogo Gosudarstvennogo istoriko-archivnogo instituta \\
\hline UdSSR & Union der Sozialistischen Sowjetrepubliken \\
\hline UZ & Unsere Zeit \\
\hline VF & Voprosy filosofii \\
\hline $\mathrm{VI}$ & Voprosy istorii \\
\hline VIKPSS & Voprosy istorii KPSS \\
\hline VLU & Vestnik Leningradskogo universiteta \\
\hline VMU & Vestnik Moskovskogo universiteta. Serija istorija \\
\hline Vyp., vyp. & vypusk $=$ Ausgabe, Heft, Lieferung \\
\hline $\mathrm{VZ}$ & Volkszeitung \\
\hline ZfG & Zeitschrift für Geschichtswissenschaft \\
\hline ZK & Zentralkomitee \\
\hline
\end{tabular}




\section{Literaturverzeichnis}

\section{Unveröffentlichte Materialien}

Al'šcic, D.N. u.a. am 05.09.1956 an N.S. Chrušcev, in: CChSD f. 5, op. 35, d. 39, 143-152.

Belous/Korostarenko am 18.09.1956 an N.S. Chruščev, in: CChSD f. S, op. 35, d. 39, 74.

Burdzalov, E.N. am 30.05.1956 an D.T. Sepilov, in: CChSD f. S, op. 35, d. 39, 88-94.

Burdzalov, E.N. am 17.07.1956 an N.S. Chruševev, in: CChSD f. 5, op. 35, d. 39, 80-87.

Burdžalov, E.N. am 21.09.1956 an M.A. Suslov, in: CChSD f. 5, op. 35, d. 39, $78 f$.

Burdyalov, E.N. am 11.12.1956 an D.T. Sepilov, in: CChSD f. 5, op. 35, d. 39, $153 f$.

Burdyalov, E.N. am 08.02.1957 an Pospelov, Kirillin und Konstantinov, in: CChSD f. 5, op. 35, d. 39, 157-162.

Burdy̌alov, E.N. am 08.03.1957 an D.T. Sepilov, in: CChSD f. S, op. 35, d. 39, 163.

Cecharin, E. am 06.04.1970 an das ZK der KPdSU, in: CChSD f. 5, op. 61, d. 62, 206.

Cecharin, E. am 14.04.1972 an das ZK, in: CChSD f. 5., op. 64, d. 108, 34.

Cecharin, E.M.: Spravka (07.07.1967) v CK KPSS, in: CChSD f. 5, op. 59, d. 41, 29.

Cernova, L.N.: Chronika (der Sektionsarbeit 1964-1968), Typoskript (6 Seiten) in: NA 1.

Dal'skij, A.N. am 18.08.1956 an A.M. Pankratova und E.N. Burdy̌alov, in: CChSD f. 5, op. 35, d. $39,108-110$.

Danilov, V.P.: O trevožnom položenii v nekotorych otrasljach istoriceskoj nauki (an den Sekretär des ZK der KPdSU P.N. Demičev), in: CChSD f. 5, op. 59, d. 41, 21-27.

Drabkin, Ja.S.: „Ja pozvolju sebe...”, 10.02.1971, (Typoskript, 15 Seiten), in: NA 19.

Fedoseev, P.N., Vizepräsident der AdW der UdSSR, am 11.04.1967 an das ZK und die Abreilung fuir Wissenschaft, in: CChSD f. 5, op. 59, d. 41, 64.

Gavrilova, A.M. am 27.06.1956 an das ZK der KPdSU, in: CChSD f. S, op. 35, d. 39, 95-107.

Gefter, M.Ja.: „Ne skroju: nakanune sobranija...”, 19.10.1970 (Manuskript, 6 Seiten), in: NA 15.

Gefter, M.Ja.: „Vice-prezidentu AN SSSR, akademiku A.M. Rumjancevu“, 03.01.1971 (vierseitige Abschrift), in: NA 17.

Geffer, M.Ja.: Vystuplenie na partsobranii Instituta istorii po dokladu A.M. Rumjanceva ob itogach Oktjabr'skogo Plenuma CK KPSS 1965 goda. 30.10.1965, Typoskript (13 S.) in: NA 2.

Grunt. A.: „Ne imeja vozmožnosti...”, 1971, in: NA 18.

Hoffmann, R.: Die Stalinismusdiskussion im Rahmen der Perestrojka, Hamburg 1990 (ungedruckte Examensarbeit).

Kirillim, V.A. am 02.04.1956 an das ZK der KPdSU, in: CChSD f. 5, op. 17, d. 520, 112.

Kirillin, V.A. am 25.02.1957 an das ZK der KPdSU, in: CChSD f. 5, op. 35, d. 39, 155f, hier 155.

Kirillin, V.A./K.S. Kuznecova am 07.02.1956 an das ZK der KPdSU, in: CChSD f. S, op. 35, d. $23,20-25$.

Knjazev: Spravka o vystuplenii tov. Burdžalova E.N. v Leningrade na konferencii citatelej žurnala „Voprosy istorii“ (02.07.1956), in: CChSD f. 5, op. 35, d. 39, 57-59.

Kovalenko, D. am 02.10.1969 an den Generalsekretär des ZK der KPdSU L.I. Brežnev, in: CChSD f. 5, op. 61, d. 62, 201-205.

Kratkaja zapis' otkrytogo partsobranija In-ta, 21.12.1970 (Typoskript, 4 Seiten), in: NA 16.

Kukin, D./V. Snastin am 05.03.1959 an das ZK der KPdSU, in: CChSD, f. S, op. 35, d. 77, 277.

Kuznecova, K./A. Cernjaev/D. Kukin am 01.03.1958 an das ZK der KPdSU, in: CChSD f. S, op. 35, d. 77, 36f. 
Laveryčev, V./A. Sivolobov/P. Sobolev: Vopreki istoriceskoj pravde (28.04.1972), in: CChSD f. 5, op. 64, d. 108, 71-81.

Lisovskij, P.: Za svobodu tvorčeskoj naučnoj mysli (Vystuplenie na partijnom sobranii instituta vseobకčj istorii), 28.06.1971 (Typoskript, 3 Seiten), in: NA 20.

Markvik, R. (= Markwick, R.D.): Doklad po teme: „Katalizator istoričeskoj nauki i ideologii: sektor metodologii Instituta istorii AN SSSR, 1964-1968 gg.“(1992).

Markwick, R.D.: A Resurgent Intelligentsia: The Politics of Revisionist Historiography in the Soviet Union, 1956-74. Ph.D. thesis, Department of Government and Public Administration. University of Sydney 1994.

Matjuškin, N.I./Ju.V. Borisov/P.I. Fedotov am 05.03.1958 an M.A. Suslov, in: CChSD f. 5, op. 35, d. $77,38-46$.

Michrin, P. am 17.08.1956 an E.N. Burdžalov, in: CChSD f. 5, op. 35, d. 39, 121-124.

Minc, I.I./E. Gorodeckij/S. Jakubovskaja u.a. am 27.02.1967 an den ZK-Sekretär M.A. Suslov, in: CChSD f. 5, op. 59, d. 41, 61-63.

Mogil'nickij, B.G. am 14.06.1991 an den Autor.

Najda, S.F. am 02.02.1972 an den Kandidaten des Politbüros und ZK-Sekretär P.N. Demið̌ev, in: CChSD f. 5, op. 64, d. 108, 30-33.

Neretina. S.S.: Interv'ju s Neretinoj Svetlanoj Sergeevnoj (am 08.04.1992 mit Roger Markwick und dem Autor), Typoskript (25 Seiten).

Nesmejanov, A.N./A.V. Topxiev am 21.03.1953 an M.A. Suslov, in: CChSD f. 5, op. 17, d. 425, Sf.

Obsuždenie knigi v Otdelenii istorii (o.J.), in: NA 7.

Pankratova, A.M.: Spravka $v$ zvjazi s zapiskoj Otdela nauki i kul'tury o sodeř̌anii žurnala „Voprosy istorii“ za 1953-1954 gg, in: CChSD f. 5, op. 17, d. 520, 8-38

Pankratova, A.M.: Otcet o rabote redakcii žurnala „Voprosy istorii“" za 1954 god (26.04.1955), in: CChSD f. 5, op. 17, d. 520,81-94.

Pankratova A.M. im Mai 1955 an das ZK der KPdSU, in: CChSD f. 5, op. 17, d. 520, 8-38.

Pankratova, A.M. im Mai 1955 an N.S. Chrušcev, M.A. Suslov, P.N. Pospelov und A.M. Rumjancev, in: CChSD f. 5, op. 17, d. 520, 2-7.

Pankratova. A.M. am 24.03.1956 an M.A. Suslov, in: CChSD f. 5, op. 35, d. 39, 1.

Pankratova, A.M. am 04.05.1956 an M.A. Suslov, in: CChSD f. 5, op. 35, d. 39, 2.

Pankratova. A.M. am 23.08.1956 an M.A. Suslov, in: CChSD f. 5, op. 35, d. 39.61-63.

Pankratova. A.M. am 24.09.1956 an M.A. Suslov, in: CChSD f. 5, op. 35, d. 39, 15

Pospelov, P.M. Suslov/A. Rumjancev/A. Nesmejanov am 15.05.1953 an N.S. Chrušcev, in: CChSD f. 5, op. 17, d. 426, 28-30.

Protokol obsuždenija doklada akad. Žukova na otkrytom partijnom sobranii Instituta vseobščej istorii 18 marta $1970 \mathrm{~g}$., in: NA 12.

Rumjancev, A.M. am 17.06.1955 an das ZK der KPdSU, in: CChSD f. 5, op. 17, d. 520, 95-101

Rumjancev, A.M. am 11.08.1955 an das ZK der KPdSU, in: CChSD f. 5, op. 17, d. 520, 102 108.

Rumjancev, A.M. (27.06.1967) E.M. Cecharinu, in: CChSD f. 5, op. 59, d. 41, 28.

Rumjancev, A.M.N. Kružkov/E. Gromov am 30.04.1953 an M.A. Suslov, in: CChSD f. S, op. 17 , d. $425,7 f$.

Rumjancev, A.M.K. Kuznecova/A. Licholat/A. Cernjaev am 28.07.1955 an das ZK der KPdSU, in: CChSD f. 5, op. 17, d. 520, 42-55.

Sarapov, G.: O nekotorych ošibkach v osvešcenii istorii i roli rabožego klassa v otdel'nych rabotach Instituta istorii Akademii nauk SSSR (29.04.1972), in: CChSD f. 5, op. 64, d. 108, 66-70. 
Scerbakov, S., stellvertretender Leiter der Wissenschaftsabteilung des ZK der KPdSU, am 20.04.1967 an das ZK, in: CChSD f. 5, op. 59, d. 41, 65.

Sidorov, A.L. am 31.03.1953 an M.A. Suslov und P.N. Pospelov, in: CChSD f. 5, op. 17, d. 426, $6 f$.

Sidorov, A.L. am 04.07.1953 an P.N. Pospelov, in: CChSD f. 5, op. 17, d. 425, 238-242.

Sidorov, A.L. am 13.12.1958 an M.A. Suslov, in: CChSD, f. 5, op. 35, d. 77, 274-276.

Stenogramma soveščanija po voprosam istorii SSSR i vseobక̌̌ej istorii (23.Juni 1965), in: CChSD f. 5, op. 35, d. $212,86-151$.

Stenogramma zasedanija Ideologičeskoj komissii pri CK KPSS po voprosu razvitija obščestvennych nauk. 15-18 nojabrja $1965 \mathrm{~g}$, in: CChSD f. 5, op. 35, d. 210, 3-346.

Trapeznikov, S./A. Jakovlev: O predloženii t. Selepina A.N. (12.06.1972), in: CChSD f. 5, op 64, d. 108, 82-84.

Vjatkin, M.P. u.a. am 01.09.1956 an Kirillin, Bogdanov und Kurtynin, in: CChSD f. 5, op. 35, d. 39, $135-142$.

Volgin, V.P./A.M. Pankratova am 19.09.1953 an P.N. Pospelov, in: CChSD f. 5, op. 17, d. 425, $244 f$.

Zamčevskij, 1:: O vystuplenii tov. Burdłalova - zam. glavnogo redaktora žurnala „Voprosy istorii“ v g. Leningrade (28.06.1956), in: CChSD f. 5, op. 35, d. 39, 52-55.

\section{Veröffentlichungen sowjetischer Autorinnen und Autoren}

Abalkin, L.: Die Wirtschaft ist krank. in: MN (Deutsche Ausgabe) 1989, Nr. 3, 7f.

Afanas'ev, Ju.: Energija istoričeskogo znanija, in: MN vom 11.01.1987 (deutsch, leicht gekürzt in: Meyer, Wir brauchen die Wahrheit, 82-89).

Afanas'ev, Ju.: Inogo ne dano, in: Demokrati( eskaja Rassija. Gazeta demokraticeskich sil Rassii, Nr. 5, nojabr' 1990, 1 .

Afanas'ev, Ju.: My dvižemsja v storonu diktatury. Možno li postavit' bar'er na puti chaosa i avtoritarizma? In: NG v. 21.12.1990, 5.

Afanas'ev, Ju.: Perestrojka, zadumannaja partapparatom, udalas', in: Stolica. Ezenedel 'nik Mossoveta 1990, H. 1, 1-3.

Afanas'ev, Ju.: Prošloe i my, in: K 1985, H. 14, 105-116.

Afanasjew, J.: „Mit Lenin überhaupt brechen“ (1990), in: Meyer, F.: Die Katastrophe des Kommunismus - von Marx bis Gorbatschow. Spiegel Spezial Nr. 4, Hamburg 1991, $46 f$.

Afanasjew, J.: Antworten des Historikers, in: Pravda (Deutsche Ausgabe) v. 26.07. 1988, 3.

Afanassjew, J. (Hg.): Es gibt keine Alternative zu Perestroika: Glasnost, Demokratie, Sozialismus, Nördlingen 1988.

Afanassjew, J.: Gedächtnis und Geschichte in der Sowjetunion, in: Transit 1991, H. 2, 110-122.

Afanassjew, J.: Keine Termine für den Anbruch der allgemeinen Seligkeit, in: DVZ/die tat Nr. 45, 06.11.1987, II (Erstveröffentlichung in: Nauka i zizn' 1987, H. 9, 56-60).

Afanassjew, J.: Perestroika und historisches Wissen, in: ders., Es gibt keine Alternative, 563-583.

Afanassjew, J.: Vom Standpunkt der Wahrheit und des Realismus, in: Huffschmid, J. ( $\mathrm{Hg}$.): Glasnost/Perestrojka Band 1: Streiten für die Umgestaltung. Die sowjetische Diskussion, Köln 1987, 61-76.

Aganbegjan, A.A.: Strategie der Beschleunigung der sozialökonomischen Entwicklung der UdSSR, in: Aus Politik und Zeitgeschichte. Beilage zur Wochenzeitung „Das Parlament“, B 45/87, 3-14.

Aktual'nye problemy izučenija istorii SSSR, in: ISSSR 1984, H. 2, 3-19.

Aktual'nye teoretičeskie problemy sovremennoj istoričeskoj nauki, in: VI 1992, H. 8-9, 159-166. 
Aleksandrov, A.: Za podlinno-naučnyj podchod k voprosam istorii, in: Leningradskaja Pravda, 05.08.1956.

Alekseev, P.V./A.V. Panin: Dialektičeskij materializm (obšx̌ie teoretičeskie principy), M. 1987.

Alekseeva, G.D.: Pervaja „istoriografičeskaja sreda“, in: VI 1961, H. 6, 147-150.

Alksnis: „Von der Ideologie loskommen..." Interview mit dem sowjetischen Obersten Viktor Alksnis, in: OE 1991, H. 11, A 640-A 645.

Ambartsumow, J. (= Ambarcumov, E.): Über die Wege zur Vervollkommnung des politischen Systems des Sozialismus, in: Afanassjew, Es gibt keine Alternative, 106-129.

Anan'iž, B.V./R.S. Ganelin: Naučnaja sessija po probleme „Osnovnye zakonomernosti i osobennosti razvitija Rossii v epochu imperializma“, in: VI 1962, H. 3, 118-123.

Andreev, I.D.: Metodologičeskie osnovy poznanija social'nych javlenij, M. 1977.

Andropov, Ju.: UCenie Karla Marksa i nekotorye voprosy socialistiCeskogo stroitel'stva SSSR, in: K 1983, H. 3, 9-23

Anfimov, A.M.: K voprosu o charaktere agrarnogo stroja Evropejskoj Rossii v načale XX v., in: IZ 65, M. 1959, 119-162.

Anfimov, A.M.: Krupnoe pomešciče chozjajstvo Evropejskoj Rossii, M. 1969.

Anfimov, A.M.: V.I. Lenin o charaktere agrarnych otnošenij $\vee$ Rossii $\vee$ načale $X X$ veka, in: VI 1960, H. 4, 140-153

Anikeev, V.V.: Svedenija o bol'Yevistskich organizacijach s marta po dekabr' 1917, in: VI KPSS 1958, H. 2, 126-193.

Antipov, G.A.: Istoričeskoe proßloe i puti ego poznanija. Novosibirsk 1987.

Arslanov, V.: K sporam ob al'ternative stalinizmu, in: Ekonomi eskie nauki 1989, H. 10, 69-77.

Artizov, A.N.: Kritika M.N. Pokrovskogo i ego క̌koly (K istorii voprosa), in: ISSSR 1991, H. 1, 102-120.

Artizov, A.N: Sud’by istorikov školy M.N. Pokrovskogo (seredina 1930-ch godov), in: VI 1994, H. 7, 34-48.

Assaturova, M.I.: Obščee sobranie otdelenija istoričeskich nauk (Bericht), in: VI 1959, H. 6, 157 163.

Auf dem Wege des Friedens und des Fortschritts. Dokumente, in: Beilage der Zeitschrift "Sowjetunion heute“ 1983, H. 7.

Azabaev, F.A./B.V. Lunin: Ob-edinennaja naučnaja sessija, posvjaš̌ennaja progressivnomu znaKeniju prisoedinenija srednej Azii k Rossii (Bericht), in: ISSSR 1959, H. 5, 214-218.

Babičenko, L.G.: Pis'mo Stalina v „Proletarskuju Revoljuciju“ i ego posledstvija, in: VIKPSS 1990. H. 6, 94-108.

Badja, L.V.: Akademik A.M. Pankratova - istorik rabočego klassa SSSR, M. 1979.

Balašov, V.N.: Sessija otdelenij obšestvennych nauk AN SSSR po bor'be s sovremennym revizionizmom (Bericht), in: VI 1958, H. 7, 171-190.

Barg. M.A./E.B. Cernjak: O kategorii „istoriðeskij zakon“, in: NNI 1989, H. 3, 92-100.

Barg. M.A.: Die Strukturanalyse in der historischen Forschung, in: SW 1966, H. 2, 194-205 (zuerst in: VF 1964, H. 10).

Barg, M.A.: Istoriðeskie zakonomernosti kak poznavatel'naja cel' istoriðeskoj nauki, in: ISSSR 1979, H. 1, 96-120.

Barg. M.A.: Istoričeskij fakt: struktura, forma, soderžanie, in: ISSSR 1976, H. 6, 46-71.

Barg. M.A.: Istoričeskoe soznanie kak problema istoriografii, in: VI 1982, H. 12, 49-66

Barg. M.A.: Kategorii „vsemirno-istoričeskij“ i „lokal'no-istoričeskij“ v marksistsko-leninskom istorizme, in: VI 1980, H. 1, 61-78.

Barg. M.A.: Kategorii i metody istoriceskoj nauki, M. 1984. 
Barg, M.A.: Leopold von Rankes Geschichtskonzeption aus der Sicht der heutigen Geschichtswissenschaft, in: Mommsen, W.J. (Hg): Leopold von Ranke und die moderne Geschichtswissenschaft. Stuttgart 1988, 223-263.

Barg, M.A.: O kategorii „istoriceskoe vremja“ (Metodologiceski aspekt), in: ISSSR 1982, H. 6, 82-100.

Barg, M.A.: O nekotorych metodach tipologizacii istoriceskich javlenij v trudach V.I. Lenina, in: ISSSR 1973, H. 2, 21-41.

Barg. M.A.: O nekotorych predposylkach formalizacii istoriceskogo znanija, in: Problemy issledovanija sistem i struktur. Materialy k konferencii, M. 1965, 183-186.

Barg, M.A.: O roli čelovečeskoj sub-ektivnosti v istorii, in: ISSSR 1989, H. 3, 115-131.

Barg. M.A.: O tak nazyvaemom ,krizise feodalizma“ $v$ XIV-XV veka (k istoriografii voprosa), in: VI 1960, H. 8, 94-113.

Barg, M.A.: Ponjatie vsemirno-istorið̌eskogo kak poznavatel'nyj princip istoriðeskoj nauki, $\mathbf{M}$. 1973 (die deutsche Übersetzung - Barg. M.: Die Kategorie des Welthistorischen als Erkenntnisprinzip der maxxistischen Geschichtswissenschaft, in: Engelberg. E./W. Küttler (Hg.): Probleme der geschichtswissenschaftlichen Erkenntnis, Berlin 1977, 39ff).

Barg, M.A.: Princip sistemnosti v marksistskom istoričskom issledovanii, in: ISSSR 1981, H. 2 , 78-98.

Barsenkov, A.S.: Sovetskaja istoričeskaja nauka v poslevoennye gody (1945-1955), M. 1988.

Bataeva. T.V.: Istoriograficeskie raboty o sovetskom rabočem klasse, in: VI 1969, H. 4, 153-160.

Bał̌ova A.P.: Ob-edinennaja naučnaja sessija, posvjaščennaja progressivnomu značeniju prisoedinenija srednej Azii k Rossii (Bericht), in: VI 1959, H. 8, 173-183.

Bem, Ju.O.: Obłcee sobranie Otdelenija istoriðeskich nauk AN SSSR (Bericht), in: VI 1956, H. 6, 201-204.

Berchin, I.B.M.P. Kim: O periodizacii istorii sovetskogo obšestva, in: VI 1954, H. 10, 72-78.

Berchin, I.B.: Nekotorye voprosy istoriografii novoj ekonomiKeskoj politiki v SSSR, in: VI 1961, H. 3, 28-44.

Bereschkow, V.: Als Diplomat Stalins in Deutschland, in: DVZ/tat v. 19.05.1989, 14.

Bestužev, I. V.: K analizu charaktera vnešnej politiki i vojn. Kriterii progressivnosti i spravedimosti, in: Istoričeskaja nauka 1969, 394 ff (mit Diskussionsbeiträgen).

Bestužev-Lada, 1.: Byla li al'ternativa stalinizmu? In: PO 1989, H. 3, 39-47.

Bibler, V.S.: Istoriceskij fakt kak fragment dejstvitel'nosti (Logiceskie zametki), in: Istočnikovedenie 1969, 89-101.

Bikkenin. N.B.: K probleme sootnołenija obšxich i specificeskich zakonov razvitija in: Vestnik Maskovskogo universiteta. Serija Ekonomika. Filosofija, Prava 1957, H. 3, 103-120.

Biobibliografija učenych SSSR. Serija istorii, vyp. 15, M. 1983.

Biron, A.K.: Konferencija citatelej žurnala „Voprosy istorii“ (Bericht), in: VI 1959, H. 2, 209 f.

Bogdenko, M.L./.E. Zelenin: Istorija kollektivizacii sel'skogo chozjajstva v sovremennoj sovetskoj istoriko-ekonomiceskoj literature, in: ISSSR 1962, H. 4, 133-151.

Bogdenko, M.L.: K istorii načal'nogo etapa splošnoj kollektivizacii sel'skogo chozjajstva SSSR, in: VI 1963, H. 5, 19-35.

Bol'šie vnimanija izučeniju istorii raboxego klassa SSSR, in: VI 1962, H. 6, 3-16.

Bol'sie zadači, in: VI 1966, H. 6, 3-8.

Bonbar', N.N.: Naučnaja sessija Otdelenij obక̌cestvennych nauk Akademii nauk SSSR i Akademij nauk zakavkazskich respublik (Bericht), in: VI 1954, H. 6, 161-167.

Bordjugov, G.A./V.A. Kozlov: Istorija i kon-junktura. Sub-ektivnye zametki ob istorii sovetskogo obšcestva, M. 1992. 
Bordjugow, G./W. Koslow. Die Wende des Jahres 1929 und die Alternative Bucharins, in: Initial 1990, H. 1, 79-98 (zuerst in VIKPSS 1988, H. 8, 15-33).

Borisov, Ju.S.: NauČnaja sessija po istoriografii socialističeskogo i kommunističeskogo stroitel'stva (Bericht), in: VI 1960, H. 8, 124-132.

Borisov, L.P.: Obsuždenie perspektivnogo plana raboty redakcii žurnala „Voprosy istorii“ na 1959-1965 gody (Bericht), in: VI 1959, H. 11, 182-185.

Bovykin, V.I./.F. Gindin/K.N. Tarnovskij: Gosudarstvenno-monopolisticeskij kapitalizm v Rossii (k voprosu o predposylkach socialističeskoj revoljucii), in: ISSSR 1959, H. 3, 83117.

Bovykin, V.I.: Banki i voennaja promyšlennost' Rossii nakanune pervoj mirovoj vojny, in: IZ 64, M. 1959, 82-135.

Bovykin, V.I.: Organisationsformen des Finanzkapitals in Rußland. Industrie und Banken vom Ende des 19. Jh. bis zum Beginn des 20. Jh., in: JbW 1985, H. 4, 69-81.

Bovykin, V.1.: Pamjati A.L. Sidorova, in: VMU Serija IX (Istorija) 1967, H 2, 84-91.

Bovykin, V.I.: Probleme der industriellen Entwicklung Rußlands, in: Geyer, Wirtschaft. 188-209.

Bovykin, V.I.: Problemy perestrojki istoričeskoj nauki i vopros o „novom napravlenii“ $v$ izučenii social'no-ekonomičeskich predposylok Velikoj Oktjabr'skoj socialističeskoj revoljucii, in: ISSSR 1988, H. 5, 67-100.

Bromlej, Ju.V.: $\mathrm{K}$ izučeniju nacional'nych processov socialističeskogo obక̌čestva $v$ kontekste etniceskoj istorii, in: ISSSR 1984, H. 6, 40-56.

Bromlej, Ju. V.: $K$ izučeniju osnovnych etapov i napravlenij nacional'nych otnošenij $\vee$ SSSR, in: ISSSR 1979, H. 2, 58-67.

Bucharina, A.L.: Nun bin ich schon weit über zwanzig. Erinnerungen, Göttingen 1989.

Bugaev, E.: Kogda utračivaetsja naučnyj podchod, in: PŽ 1956, H. 14, 62-72.

Burdžalov, E.N.: Ešče raz o taktike bol'Kevikov v marte-aprele 1917 goda, in: VI 1956, H. 7 , 109-114

Burď̌alov, E.N.: O taktike bol'̌evikov v marte-aprele 1917 goda, in: VI 1956, H. 4, 38-56.

Burdð̌alov, E.N: Značenie truda I.V. Stalina 'Ekonomičeskie problemy socializma v SSSR' dija izuð̌enija istorii sovetskogo socialistið̌eskogo obł̌estva, in: VI 1953, H. 3, 3-32.

Burlazki, F. (= Burlackij, F.): Chruschtschow. Ein politisches Porträt (Aus dem Russischen), Düsseldorf 1990.

Burtin, J.: Die Achillesferse der Marxschen Geschichtstheorie, in: MEJ 13, Berlin 1991, 17G245.

Bušuev, S.K.: O kavkazckom mjuridizme, in: VI 1956, H. 12, 72-79;

Butenko, A.P.: Noch einmal über die Widersprüche im Sozialismus, in: SW 1984, H. 4, 360-367.

Butenko, A.P.: Vinoven li Karl Marks v „kazarmennom socializme“? In: FN 1989, H. 4, 17-26.

Butenko, A.P.: Widersprüche der Entwicklung des Sozialismus als Gesellschaftsordnung, in: SW 1983, H. 2, 226-251.

Bystrov, V.R.: K voprosu o „doktrinal'nych“ istokach stalinizma. Ob oxerke A. Cipko „O zonach, zakrytych dlja mysli“", in: NK 1989, H. 9, 111-115.

Cerez ternii. Sost. A.A. Protaščik, M. 1990.

Cernobaev, A.A.: „Professor c pikoj“, ili Tri žizni istorika M.N. Pokrovskogo, M. 1992.

Cernyšev, B.V.: V.I. Lenin o značenii urokov istorii dlja razrabotki politiki Kommunistǐeskoj partii, in: VIKPSS 1985, H. 3, 63-73.

Cubar’jan, A.O.: Sovetskie istoriki i XIV meždunarodnyj kongress istoriceskich nauk, in: VI 1975, H. 6, 62-75.

Chomenko, E.A.: O sootnošenii obščich i specifičeskich zakonov obక̌čestvennogo razvitija, in: VF 1954, H. 4, 39-47. 
Chrestomatija po istorii KPSS, 2 Bände, M. 1989.

Chromov, R.P.: Ob osnovnom zakone feodalizma, in: VI 1954, H. 11, 82-85.

Chromov, S.S./V.I. Buganov/V.P. Serstobitov: Nekotorye itogi i aktual'nye problemy izučenija otečestvennoj istorii v svete rešenij XXVI s-ezda KPSS, in: Izučenie otečestvennoj istorii v SSSR meždu XXV i XXVI s-ezdami KPSS, M. 1982, 3-48.

Chromov, S.S.: Aktual'nye problemy izučenija otečestvennoj istorii v svete rełenij XXVI s-ezda KPSS, in: ISSSR 1981, H. 3, 3-24.

Chromov, S.S.: Idejno-vospitatel'nye funkcii sovetskoj istoriceskoj nauki, in: VI 1980, H. 7, 3-19.

Chromov, S.S.: XXIV s-ezd KPSS i nekotorye voprosy social'nogo razvitija sovetskogo obšcestva, in: ISSSR 1972, H. 3, 3-19.

Chromov, S.S.: XXVII s-ezd KPSS i nekotorye aktual'nye problemy izučenija otečestvennoj istorii, in: ISSSR 1986, H. 6, 3-20.

Chrušxev, N.S.: Doklad na zakrytom zasedanii XX s-ezda KPSS „O kul'te lix̌nosti i ego posledstvijach“, M. 1959.

Cipko, A.: Istoki stalinizma, in: Nauka i zizn' 1988, H. 11, 45-55, H. 12, 40-47; 1989, H. 1, 4656; H. 2, 53-61.

Dadykin, R.P.: Rabota Instituta istorii AN SSSR v 1957 godu (Bericht), in: VI 1958, H. 3, 199204.

Danijalov, G.D.: O dviženii gorcev pod rukovodstvom Samilija, in: VI 1956, H. 7, 67-72.

Danilov, A.: K voprosu o metodologii istoriðeskoj nauki, in: K 1969, H. 5, 68-81.

Danilov, A.I.: Istoriografija kak naučnaja disciplina, izuð̌ajuščaja istoriju istoričeskoj nauki, in: SIE 6, M. 1965, 510-514.

Danilov, A.I.: Materialisticeskoe ponimanie istorii i metodologiceskie iskanija nekotorych istorikov, in: MIVIN 6, T. 1969, 227-245.

Danilov, A.I.: O nekotorych voprosach dal'nejకsego izučenija teoretiko-metodologiそ̌eskich problem istoriceskoj naukj, in: VI 1961, H. 3, $216 f$.

Danilov, V.P.: „Bucharinskaja al'ternativa“, in: Bucharin - Celovek, politik, učenyj, M. 1990, 82-130.

Danilov, V.P.: Dvadcatye gody: NEP i bor'ba al'ternativ, in: Istoriki sporjat. Trinadcat' besed, $M$ $1988,122-137$.

Danilov, V.P.: $K$ itogam izučenija istorii sovetskogo krest'janstva i kolchoznogo stroitel'stva $v$ SSSR, in: VI 1960, H. 8, 34-64.

Danilow, A. (= Danilov, A.I.): Zur Methodologie der Geschichtswissenschaft, in: SW 1969, H. $12,1246-1259$.

Davydov, Ju.: Totalitarizm i totalitarnaja bjurokratija, in: Nauka i zizn' 1989, H. 8, 44-51

Davydov, Ju.S.A.K. Figurovskaja: Razvitie agrarno-promyšlennoj integracii v SSSR, in: VI 1978, H. 8, 3-24.

Deborin, G.A.: Osnovnye problemy pervogo toma „Istorija Velikoj Otečestvennoj vojny Sovetskogo Sojuza“, in: VI 1961, H. 1, 18-41.

Dejatel'nost' KPSS po stroitel'stvu razvitogo socializma v 60-e gody, in: VI 1984, H. 4, 3-14.

„Delo A.M. Nekrica“ (Iz istorii gonenij na sovetskuju intelligenciju), in: Kentavr 1994, H. 4, 94 114.

Demočkin, N.N.: Velikjj Oktjabr' i roždenie sovetskoj socialistǐeskoj demokratii, in: VI 1977, H. 8, 3-20.

Devjašin, N.A.: K voprosu o roli istoriðeskogo zakona $v$ istoriðeskom poznanii, in: Voprosy teorii kak formy myక̌lenija, vyp. 1, T. 1970, 71-86.

Devjatnadcatyj Vsesojuznaja konferencija Kommunisticeskoj Partii Sovetskogo Sojuza. 28 ijunja 1 ijulja 1988 goda. Stenograficeskij otCet, 2 Bde, M. 1988. 
Dialektǐ̌eskij i istoričeskij materializm. Pod redakcii A.P. Septulina, M. 1985.

Die Rede Michail Gorbatschows vom 2. November 1987 aus Anlaß des 70. Jahrestages der Oktoberrevolution (Auszüge), in: Blätter 1987, H. 12, 1602-1616.

Diskussionsreden auf dem XX. Parteitag der KPdSU. 14.-25. Februar 1956, Berlin 1956.

Dmitrenko, V.P.: Stanovlenie koncepcii razvitogo socializma v SSSR, in: VI 1984, H. 8, 3-22.

Doklady sovetskoj delegacii. Desjatyj kongress istoričeskich nauk v Rime, M. 1956.

Dorołenko, N.M.: K voprosu o soderžanii ponjatija ,istoričeskij fakt“, in: Problemy istoričeskogo materializma, vyp. 2, M. 1972, 73-83.

Dorošenko, N.M.: Leninskoe ponimanie problemy fakta $v$ istoričeskom poznanii, in: VLU, Serija 5, 1973, H. 1, 67-72.

Dorošenko, N.M.: O sootnołenii ob-ektivnych i sub-ektivnych storon $v$ istoričeskom fakte, in: VLU Serija 5, 1968, H. 1, 85-92.

Dorošnko, N.M.: Problema fakta $v$ istorið̌eskom poznanii. Avtoreferat dissertacii na soiskanie učenoj stepem kandidata filosofskich nauk, L. 1968.

Drabkin, Ja.S.: Nerešennye problemy izučenija social'nych revoljucij, in: Istoričeskaja nauka 1969, 209ff (mit Diskussionsbeiträgen).

Drama obnovlenija. Pod obšcej redakciej M.I. Melkumjana, M. 1990.

Drobižev, V.Z.: Social'naja politika Sovetskogo gosudarstva i raboxij klass (Nekotorye itogi i zadači izučenija problemy), in: ISSSR 1984, H. 2, 71-84.

Drobiževa, L.M.: Duchovnaja obšnnost narodov SSSR. Istoriko-sociologičeskij oxerk mežnacional'nych otnosenij, M. 1981.

Dubrovskij, S.M.: Akademik M.N. Pokrovskij i ego rol' v razvitii sovetskoj istoričeskoj nauki, in: VI 1962, H. 3, 3-31

Dudzinskaja, E. A.: Meždunarodnye svjazi sovetskich istorikov, M. 1978 (Rezension in: VI 1979, H. 3, 151ff).

Dunaevskij, V.A./A.M. Sacharov/S.L. Senjavskij: Naučnaja rabota molodych istorikov, in: Vl 1963, H. 1, 36-49.

Dunaevskij, V.A./A.M. Stanislavskaja: Obsuždenie IV toma „Ozerkov istorii istoričeskoj nauki v SSSR“, in: VI 1965, H. 3, 154-158.

Dunaevskij, V.A.: Der wissenschaftliche Problemrat „Geschichte der Geschichtswissenschaft“ bei der Abteilung Geschichte der AdW der UdSSR, in: JbG 28, Berlin 1983, 265-274.

Durnovcev, V.I.: O soderžanii ponjatija ,istoriografičeskij fakt“, in: Metodologičeskie i teoretičeskie problemy istorii istoričeskoj nauki, Kalinin 1980, 42-53.

Dvadcat' četvertyj s-ezd Kommunističeskoj partii Sovetskogo Sojuza 30 marta-9 aprelja 1971 goda. Stenografičeskij otčet, tom 1, M. 1971.

Dvadcat' cetvertyj s-ezd KPSS, in: VI 1971, H. 5, 3-12.

Dvadcat' pervyj s-ezd i dal'nejšee uproxenie mirovoj socialisticeskoj sistemy, in: VI 1959, H. 5, 3-21.

Dvadcat' pervyj s-ezd KPSS - istoričeskoe sobytie v žisni partii i naroda, in: VI 1959, H. 3, 3-28.

Dvadcat' vtoroj s-ezd Kommunističeskoj partii Sovetskogo Sojuza - s-ezd stroitelej kommunizma, in: VI 1961, H. 11, 3-8.

Dvadcatyj s-ezd KPSS i ego istoričeskie real'nosti, M. 1991.

Dvadcatyj s-ezd KPSS i zadaci issledovanija istorii partii, in: VI 1956, H. 3, 3-12.

Dvadcatyj Vek: Al'ternativy razvitija. Kruglyj stol, in: RKSM 1989, H. 1, 60-71 und H. 2, 77-96.

Egorov, A.G.: XXVII s-ezd KPSS i voprosy marksistsko-leninskoj metodologii, in: VI KPSS 1986, H. 12, 3-26.

Egorov, V.K.: Istorija v nǎ̌ej žizni, M. 1990 (d.i. Jegorow, V.K.: Geschichte in unserem Leben. Betrachtungen zum historischen Denken in Politik und Wissenschaf, Berlin 1992). 
Egorova, V.S.: Problema fakta v istoričeskom poznanii, in: VMU, Serija 8, 1976, H. 5, 39-48.

Eremenko, A.l.: Protiv fal'sifikacii istorii vtoroj mirovoj vojny, M.-L. 1959.

Ermakov, V.T.: Sovetskaja kul'tura kak predmet istoriðeskogo issledovanija, in: VI 1973, H. 11, 20-33.

Erofeev, N.A.: Cto takoe istorija, M. 1976.

Ešce raz k voprosu o 'novom napravlenii', in: VI 1990, H. 6, 164-184.

Fadeev, A.V.: Razmyšlenija ob izuCenii istorii kul'tury, in: VI 1964, H. 1, 27-43.

Falin, V.: Politische Erinnerungen, München 1993.

Fedorova, A.T.: K voprosu o predmete istorizeskogo materializma, in: VF 1957, H. 3, 49-60.

Fedoseev, P.N./Ju.P. Francev: O razrabotke metodologiceskich voprosov istorii, in: Istorija i sociologija, M. 1964, 5-38.

Fedosov, I.A.: Istoričeskaja nauka v Moskovskom universitete (1956-1965 gg.), in: VI 1966, H. $10,134-144$.

Fedossejew, P. u.a.: Materialistische Dialektik. Kurzer Abriß, Berlin 1983 (zuerst Russisch: Materialistið̌eskaja dialektika. Kratkij oðerk teorii, M. 1980).

Fedossow, P.: ,glasnost“ und ,perestrojka“ machen auch um die Geschichte keinen Bogen. Entwicklungen und Diskussionen in der Sowjetunion, in: Blätter 1987, H. 9, 1152-1164.

Fedossow, P.: Die Geschichtsdebatte in der Sowjetunion wird schärfer, in: Blätter 1988, H. 4, 473-485.

Filosofija i istoriðeskaja nauka. Materialy „knuglogo stola“, in: VF 1988, H. 10, 18-64.

Filosofsko-metodologiðeskie voprosy istoričeskoj nauki. Osnovnaja sovetskaja literatura (1960$1979 \mathrm{gg}$.), M. 1981.

Filosofskie problemy istoriðeskoj nauki, M. 1969.

Gal'kin, I.S: Zną̌enie truda I.V. Stalina 'Ekonomičeskie problemy socializma v SSSR' dlja razrabotki voprosov novej:sej istorii, in: VI 1953, H. 4, 3-17.

Gamalij, N.V.: Novejłaja sovetskaja istoriografija o kul'ture razvitogo socializma, in: VI 1980, H. $9,117-123$

Gefter, M.: „Stalin ist erst gestern gestorben...“, in: Afanassjew, Es gibt keine Alternative, 379412.

Gefter, M.: Uroki Žisni, in: Izvestija, 20.11.1964, 3.

Gefter, M.Ja.: Iz tech i etich let, M. 1991.

Gefter, M.Ja.: Metodologija istorii, in: SIE 9, M. 1966, 387-401.

Geschichte der Kommunistischen Partei der Sowjetunion, Berlin 1960 ( = Übersetzung der Istorija Kommunističeskoj Partii Sovetskogo Sojuza, M. 1959).

Gimpel'son, E.G.: O politike „Voennogo Kommunizma“ (1918-1920 gg.), in: VI 1963, H. 5, 3650.

Gindin, I.F./.E. Sepelev: Protiv nekriti飞eskogo i proizvol'nogo ispol'zovanija archivnych dokumentov, in: ISSSR 1964, H. 5, 74-91.

Gindin, I.F.: Gosudarstvennyj kapitalizm v Rossii domonopolistiðeskogo perioda, in: VI 1964, H. 9, 72-95.

Gindin, I.F.: O nekotorych osobennostjach ekonomiðeskoj i social'noj struktury rossijskogo kapitalizma v načale XX v., in: ISSSR 1966, H. 2, 48-66.

Gleserman, G.J. (= Glezerman, G.E.): Der historische Materialismus und die Entwicklung der sozialistischen Gesellschaft (in Russisch M. 1967), 2. überarbeitete Auflage, Berlin 1973.

Glezerman, G.E.: I.V. Stalin ob ob-ektivnom charaktere zakonov obšcestvennogo razvitija $i$ ich soznatel'nom ispol'zovanii ljud'mi, M. 1953.

Glezerman, G.E.: K voprosu o predmete istoričeskogo materializma, in: VF 1960, H. 3, 8-22.

Glezerman, G.E.: O zakonach obšcestvennogo razvitija, M. 1960. 
Golikov, G.: K razrabotke istorii Oktjabr'skoj revoljucii, in: K 1956, H. 15, 44-58.

Golikov, G.N.: K izuCeniju istorii Velikogo Oktjabrja, in: VI 1962, H. 11, 33-53.

Golikov, G.N.: Na perednem krae istoriceskoj nauki, in: VI 1961, H. 11, 18-42.

Golub, P.A./V.Ja. Laverycev/P.N. Sobolev: O knige „Rossijskij proletariat: oblik, bor'ba, gegemonija“, in: VI KPSS 1972, H. 9, 120-132.

Golub, P.A.: Voennaja podgotovka Velikogo Oktjabrja (Leninskaja voennaja programma i ee osuscestvlenie), in: VI 1977, H. 7, 3-25.

Gorbacev, M.S.: Revoljucionnoj perestrojke - ideologiju obnovlenija, in: Pravda vom 19.02.1988, 1-3.

Gorbačev, M.S.: Učit' po-novomu myslit' i dejstvovat'. Vsesojuznoe sovešcanie zavedujuščich kafedrami obšestvennych nauk, in: $K$ 1986, H. 15, 3-7

Gorbatschow, M.: Der Zerfall der Sowjetunion, München 1992.

Gorbatschow, M.: Perestroika Die zweite Etappe hat begonnen. Eine Debatte über die Zukunft der Reformpolitik, Köln 1988.

Gorbatschow, M.: Perestroika. Die zweite russische Revolution. Eine neue Politik für Europa und die Welt, München 1987.

Gorbatschow, M.: Wir brauchen Demokratie wie die Luft zum Atmen! Die Dokumente des Plenums des Zentralkomitees der KPdSU am 27./28. Januar 1987 im Wortlaut, in: Blätter 1987, H. 3, 377-438.

Gorbatschow, M.S.: Die Verwirklichung der Beschlüsse des 27. Parteitages der KPdSU und die Intensivierung der Perestroika. Referat des Generalsekretärs des ZK der KPdSU, Michail S. Gorbatschow, bei der 19. Gesamtsowjetischen Konferenz der KPdSU am 28. Juni 1988, in: Pravda (Deutsche Ausgabe) v. 29.06.1988, 2-7.

Gordon, L./E. Klopov: Perestrojka i novoe rabotee dvizenie, in: Cerez ternii, 748-770.

Gordon, L.A.IE.V. Klopov: Cto eto bylo? Razmyšlenija o predposylkach i itogach togo, cto slučilos's nami v 30-40-e gody, M. 1989.

Gorodeckij, E.N./G.Z. Ioffe/G.S. Akopjan/N.D. Kuznecov: E.N. Burdžalov - Istorik Fevral'skoj revoljucii 1917 goda, in: ISSSR 1987, H. 6, 168-173.

Gorodeckij, E.N.: Istoriografija kak special'naja otrasl' istoriceskoj nauki, in: ISSSR 1974, H. 4, 96-116.

Gorodeckij, E.N.: Nekotorye Certy sovremennoj Sovetskoj istoriografii Oktjabr'skoj revoljucii, in: ISSSR 1967, H. 5, 7-28.

Gorodeckij, E.N.: Sovremennaja sovetskaja literatura o Velikom Oktjabrja, in: ISSSR 1977, H. 6, $104-127$.

Gorodeckij, E.N.: Voprosy metodologii istoriceskogo issledovanija v posleoktjabr'skich trudach V.I. Lenina, in: VI 1963, H. 6, 16-34.

Grekov, B.D.: Istorija, in: BSE (II), 19, M. 1953, 24-33.

Grigor'ev, F.G.: Konferencija Citatelej Žurnala „Voprosy istorii“ $v$ voenno-politiðeskoj akademii imeni V.I.Lenina (Bericht), in: VI 1959, H. 8, 190-193.

Grigor'ev, I.V.: Istoriðeskie vzgljady Antonio Gramš, M. 1978.

Grossmann, G.: Sowjetische Historiker bei der Arbeit. Ein persönlicher Erfahrungsbericht, in: OE 1991, H. 6, 580-592.

Grot, L.Ju.: $K$ voprosu o dejstvii ekonomičeskich zakonov $v$ antagonistiCeskich obß̌estvach, in: VI 1956, H. 1, 81-86.

Grunt, A.Ja.: Istoriðeskoe tvořestvo narodnych mass $v$ trech rossijskich revoljucijach, in: ISSSR 1987, H. 1, 69-91.

Grunt, A.Ja: V podderžku predloženij I.F. Gindina i L.E. Sepeleva, in: ISSSR 1965, H. 1, 229232.

Grušin, B.A.: Marks i sovremennye metody istoriłeskogo issledovanija, in: VF 1958, H. 3, 11-25. 
Grušin, B.A.: OCerki logiki istoričeskogo issledovanija (process razvitija i problemy ego naučnogo vosproizvedenija), M. 1961.

Gubenko, M.P./B.G. Litvak: Konkretnoe istoxnikovedenie istorii sovetskogo obšcestva, in: VI 1965, H. 1, 3-16.

Guber, A.A.: Moskovskij kongress istorikov, in: VI 1970, H. 3, 3-11.

Guber, A.A.: XIII meždunarodnyj kongress istoričeskich nauk v Moskve (nekotorye itogi i perspektivy), in: VI 1971, H. 6, 3-16.

Gukovskij, A.I.: Kak ja stal istorikom, in: ISSSR 1965, H. 6, 76-99.

Gukovskij, A.I.: Kak sozdavalas' „Russkaja istorija s drevnejł̌ch vremen“ M.N. Pokrovskogo (K 100-letiju so dnja roždenija M.N. Pokrovskogo), in: VI 1968, H. 8, 122-132 und H. 9, 130142.

Gulyga, A.V.: Istorija kak nauka, in: Filosofskie problemy, 7-50.

Gulyga, A.V.: O predmete istoričeskoj nauki, in: VI 1964, H. 4, 20-31 (deutsch in: SW 1964, H. $12,1282-1296$ ).

Gulyga, A.V.: Ponjatie i obraz v istoričeskoj nauke, in: VI 1965, H. 9, 3-14.

Gulyga, A.W.: Über den Charakter des historischen Wissens, in: SW 1963, H. 1, 38-51 (Erstveröffentlichung: O charaktere istoriðeskogo znanija, in: VF 1962, H. 9, 28-38).

Gurevic, A.Ja.: Cto takoe istoričeskij fakt? In: Istocnikovedenie 1969, 59-88.

Gurevic, A.Ja.: K voprosu ob osobennostjach istorii kak nauki, in: TMGIAI, tom 25: Voprosy metodologii istoriceskoj nauki, M. 1967, 178-198.

Gurevič, A.Ja.: Nekotorye aspekty izučenija social'noj istorii (obscestvenno-istoričeskaja psichologija), in: VI 1964, H. 10, 51-68, (deutsch in: SW 1965, H. 3, 323-336).

Gurevič, A.Ja.: O krizise sovremennoj istoričeskoj nauki, in: VI 1991, H. 2-3, 21-36.

Gureviz, A.Ja:: Ob istoričeskoj zakonomernosti, in: Filosofskie problemy, 51-79.

Gurevič, A.Ja.: Obx̌xij zakon i konkretnaja zakonomernost' v istorii, in: VI 1965, H. 8, 14-30.

Gurevic, A.Ja.: Vsled za „Odissei“, in: VF 1989, H. 12, $162 \mathrm{f}$.

Gurjewitsch, A.J.: Die Theorie der Gesellschaftsformationen und die historische Wirklichkeit, in: Initial 1991, H. 4, 435-446 (zuerst in: VF 1990, H. 11, 31-43).

Gurjewitsch, A.J.: Sozialismus und Geschichte. Die sowjetische Historie auf dem Weg von Marx zu Max Weber, in: FAZ vom 07.08.1991, N3.

Gusev, K.V.IV.Z. Drobižev/V.K. Pokrovskij: O podgotovke kadrov vyš̌ej kvalifikacii po otečestvennoj istorii (Po materialiam VAK SSSR), in: ISSSR 1981, H. 1, 121-126.

Gusev, K.V.: XXIV s-ezd KPSS i oteไestvennaja istoriografija, in: ISSSR 1971, H. 3, 3-12.

Idei Leninizma bessmertny. 100 let so dnja roždenija V.I. Lenina, in: ISSSR 1970, H. 2, 3-7.

Igrickij, Ju.I.: Koncepcija totalitarizma: uroki mnogoletnych diskussij na zapade, in: ISSSR 1990, H. 6, 172-190.

Ignatenko, T.A.: Izučenie istorii rabočego klassa SSSR v Institute istorii Kommunisticeskoj akademii pri CIK SSSR (1929-1935 gg.), in: Istorija i istoriki. Istoriografiðeskij ežegodnik 1973, M. 1975, 5-32.

Iljitschow, L. (= Il'i飞ev, L.F.): Die wissenschaftliche Grundlage der Leitung der gesellschaftlichen Entwicklung Einige Probleme der Entwicklung der Gesellschaftswissenschaften, in: SW 1963, H. 2, 113-140.

Iljitschow, L.F. (= Il'izev, L.F.): Methodologische Probleme der Naturwissenschaften und der Gesellschaftswissenschaften, in: SW 1964, H. 3, 217-268.

Inogo ne dano, M. 1988.

Istočnikovedenie istorii Sovetskogo obšcestva, M. 1964 (Rezension von V.I. Buganov in: ISSSR 1966, H. 1, 164-168).

Istő̌nikovedenie. Teoretičeskie i metodičeskie problemy, M. 1969. 
Istoričeskaja nauka i nekotorye problemy sovremennosti. Stat'i i obsuð̌denija, M. 1969.

Istoričeskaja nauka. Voprosy metodologii, M. 1986.

Istoričeskij materializm kak social'no-filosofskaja teorija. Pod redakcii V.I. Razina, M.1982.

Istoričeskij opyt i perestrojka. Čeloveceskij faktor v social'no-ekonomičeskom razvitii SSSR, $M$. 1989.

Istoričeskoe soznanie obščestva - na uroven' zadač perestrojki. Soveščanie istorikov v CK KPSS 3.X.1989, in: VI 1990, H. 1, 3-23.

Istorið̌eskoe značenie II s-ezda RSDRP, in: VI 1973, H. 7, 3-16.

Istorija i obščstvo, in: VI 1977, H. 1, 3-29.

Istorija i sociologija, M. 1964.

Istorija i stalinizm, M. 1991.

Istorija otečestva: ljudi. idei, rešenija. Oxerki istorii Sovetskogo gosudarstva, M. 1991.

Istorija SSSR s drevnejక̌ich vremen do našich dnej v dvuch serijach $v$ dvenadcati tomach. Vtoraja serija toma VII-XII ot Velikoj Oktjabr'skoj socialističeskoj revoljucii do našich dnej. Tom XI: Sovetskij Sojuz na puti k razvitomu socializmu 1945-1961 gg., M. 1980.

Istorija VKP(b). Kratkij kurs, M. 1938.

Istoriki i pisateli o literature $i$ istorii, in: VI 1988, H. 6, 3-114.

Istoriki sporjat. Trinadcat' besed, M. 1988.

Ivanov, G.M.: K voprosu o ponjatii „istoriceskij fakt“, in: MIVIN 6, T. 1969, 17-34.

Ivanov, G.M.: K voprosu o svoeobrazii istoričeskogo poznanija, in: MIVIN 1, T. 1963, 3-26.

Ivanov, L.M.: Sostojanie i zadači izučenija istorii proletariata Rossii, in: Vl 1960, H. 3, 50-74.

Ivanov, V.V.: Leninskaja metodologija obobł̌cenija istoriceskogo opyta partii i poznanija sovremennosti, in: VIKPSS 1985, H. 1, 50-60.

Ivanov, V.V.: Metodologija istoriceskoj nauki, M. 1985.

Ivanov, V.V.: O leninskom ponimanii principa istorizma, in. MIVIN 4, T. 1966, 3-13.

Iwanow, G.M.: Die Spezifik der Widerspiegelung der Wirklichkeit in der Geschichtswissenschaf, in: SW 1963, H. 6, 615-635 (zuerst in: VI 1962, H. 12, 18ff).

Izdanie v Sovetskom Sojuze knig i brosjur po istorii SSSR za 1956-1958 gg, in: ISSSR 1959, H. $1,264$.

Izučenie istorii sovetskogo obščestva v 1980-1984 godach. Sbornik statej, M. 1985.

Izucenie istorii SSSR mey̌du XX i XXII s-ezdami KPSS, in: ISSSR 1961, H. 5, 3-31.

IzuCenie istorii Velikogo Oktjabrja. Itogi i perspektivy, in: VI 1987, H. 6, 51-72.

IzuČenie otecestvennoj istorii $\vee$ SSSR mełdu XXIV i XXV s-ezdami KPSS. Vyp. 1: Sovetskij period, M. 1978.

Jakovlev, A.: Socializm: ot mecty k real'nosti, in: K 1990, H. 4, 8-21.

Jakovlev, A.: Vremja tvorčeskoj smelosti, in: K 1990, H. 10, 5-13.

Jakovlev, E.: Pervoe pravitel'stvo, in: Izvestija v. 12.07.1987.

Jakowlew, A.: Die Sicherung einer neuen Qualität der sowjetischen Gesellschaft und die Gesellschaftswissenschaften, in: Umbruch in der Sowjetunion. Sowjetische Autoren über die Umgestaltung 70 Jahre nach der Oktoberrevolution, Düsseldorf 1987, 195-243.

Jakowlew, A.: Verfall der verfaulten Strukturen, in: TAZ v. 21.08.1991, 13.

Jegorow, V.K. (= Egorov, V.K.): Aus der Sackgasse in die Ungewißheit. Die Perestroika des Michail Gorbatschow. Ansichten eines Politologen - eines ehemaligen Beraters eines ehemaligen Präsidenten eines ehemaligen Landes, Berlin 1992.

Jubilejnaja sessija Obšcego sobranii Akademii nauk SSSR, posvjał̌čennaja 50-letiju Velikoj Oktjabr'skoj socialistiłeskoj revoljucii, in: VI 1968, H. 1, 3-6. 
Jubilejnoe Obščee sobranie Oddelenija istorii Akademii nauk SSSR, posvjaščennoe 50-letiju Velikoj Oktjabr’skoj socialisticeskoj revoljucii, in: VI 1968, H. 1, 18.

Jurin, Ju.M: Sessija, posvjašcennaja 50-letiju obrazovanija SSSR, in: ISSSR 1973, H. 3, 211 223.

K diskussii o charaktere dvǐ̌enija gorcev Dagestana pod rukovodstvom Samilja, in: VI 1957, H. $1,195 f$.

$K$ voprosu ob osnovnom ekonomičeskom zakone feodal'noj formacii, in: VI 1954, H. 8, 65-78.

Kabanov, V.V.: Dokumenty po istorii kollektivizacii sel'skogo chozjajstva, in: ISSSR 1978, H. 5, 160-166.

Kachk, Ju.: Nužna li novaja istoričeskaja nauka? In: VI 1969, H. 3, 41-54.

Kagarlickij, B.: „Wir sind der linke Flügel der Perestrojka“ (Interview), in: Arbeiterkampf vom 07.03.1988, 1 of.

Kak eto bylo. „Nam ne nužno menjat' politiku“, - zajavil M.S. Gorbačev pri vydviženii ego na post General'nogo sekretarja CK KPSS, in: Istocnik 1993, H. 0, 66-75.

Kalašnikova, V.C.: Istoričeskij materializm kak nauka, M. 1954.

Kapustin, M.: Konec utopii? Prošloe i buduక̌cee socializma, M. 1990.

Kas janenko, V.I.: Istoriografija razvitogo socializma v SSSR, in: Izučenie 1978, 178-212.

Kas janenko, V.1.: Istoriografija razvitogo socializma v SSSR, M. 1976.

Kas'janenko, V.1.: Nekotorye voprosy istoriografii razvitogo socializma v SSSR, in: VI 1976, H. 8, 3-25.

Kas'janenko, V.I.: Razvitoj socializm: istoriografija i metodologija problemy, M. 1976.

Kastueva. G.: Z̈ivoj Celovek i vek neživoj materii, in: Moskovskij universitet 1990, Nr. 2, 13.

Katkov, N.F.: Vosstanovlenie istoričeskoj pravdy i spravedlivosti (Chronika reabilitacii žertv političeskich repressij 20-50-ch godov), in: VIKPSS 1991, H. 9, 83-92.

Kelle, V.Z: Samoorganizacija processa poznanija, in: Vestnik Akademii Nauk SSSR 1990, H. 9, 311.

Kelle, W.M. Kowalson: Theorie und Geschichte, Berlin 1984

Kertman, L.E.: K. Marks i problema konkretno-istoričeskich zakonov, in: Voprosy istorii. Materialy naučnoj konferencii, posvjašx̌ennoj 150-letiju so dnja roždenija Karla Marksa, Ufa $1969,5-14$.

Kertman, L.E.: Zakony istoričeskich situacij, in: VI 1971, H. 1, 55-68.

Kim, M.P.JJu. A. Poljakov: Istorija sovetskogo obscestva, in: Razvitie 1975, 56-78.

Kim, M.P./Ju.A. Poljakov: Izučenie istorii sovetskogo obscestva, in: Sovetskaja istoriceskaja nauka v 1975-1979 gg., M. 1980, 40-62.

Kim. M.P./V.P. Serstobitov: Sovetskij narod - novaja istorið̌eskaja obక̌čnost ljudej, in: VI 1972 , H. 10, 3-17.

Kim, M.P.: Glavnaja zadaca - sozdat' obobscajuscij trud po istorii sovetskoj kul'tury, in: ISSSR 1976, H. 5, 240-243.

Kim, M.P.: O kul'ture kak predmete istoričeskogo izučenija, in: VI 1974, H. 11, 32-38.

Kim, M.P.: O nekotorych zadačach istoričeskoj nauki $v$ svete rešenij XXI s-ezda KPSS, in: ISSSR 1959, H. 2, 3-23.

Kim, M.P.: O zadačach izučenija istoričeskogo opyta socialističeskogo stroitel'stva $v$ SSSR v svete rešenij XXII s-ezda KPSS, in: VI 1962, H. 2, 3-19.

Kim, M.P.: Sovetskij narod - novaja istoričeskaja obł̌rnost', M. 1972.

Kljamkin, I.: Byla li al'ternativa administrativnoj sisteme? In: PO 1988, H. 10, 55-65.

Kljamkin, I.: Der Übergang vom Totalitarismus zur Demokratie in der UdSSR. Tendenzen, Probleme, mögliche Etappen, in: OE 1990, H. 6, 479-494.

Kljamkin, I.: Ě̌če raz ob istokach stalinizma, in: PO 1989, H. 9, 41-50. 
Kolganov, M.V.: Ob osnovnom ekonomičeskom zakone feodalizma, in: VI 1954, H. 9, 73-80.

Kolodij, A.F.: K diskussii o doktrinal'nych predposylkach deformacii socializma, in: FN 1989, H. 12,61-68.

Kolonickij, B.I.: Meždunarodnyj kollokvium, Raboxij klass i revoljucionnye situacii v Rossii v nacale XX veka", in: ISSSR 1991, H. 5, 212-215.

Koloskova, T.G.: Ob idejno-psichologiðeskich predposylkach stalinizma, in: VIKPSS 1989, H. 9, 62-70.

Komolova, N.P.: Obšcestvenno-politiceskaja bor'ba i osobennosti razvitija poslevoennskoj ital'janskoj istoriografii, in: Istoriðeskaja nauka 1969, 159-176.

Kon, I.: Die Geschichtsphilosophie des 20. Jahrhunderts. Kritischer Abriß. 2 Bände, 2. Auflage Berlin 1966.

Kon, I.: Zur Frage der spezifischen Besonderheiten und der Aufgaben der Geschichtswissenschaft, in: SW 1951, H. 2, 230-250 (zuerst in: VI 1951, H. 6, 48-64).

Kon, I.S.: K sporam o logike istoriðeskogo ob-jasnenija (schema Poppera-Gempelja i ee kritiki), in: Filosofskie problemy, 263-295.

Kon, I.S.: Neopozitivizm i voprosy logiki istoriðeskoj nauki, in: VI 1963, H. 9, 45-65.

Kon, I.S.: O dejstvii ekonomiceskich zakonov $v$ antagonističeskich formacijach, in: VI 1954, H. $5,111-127$.

Kon, I.S.: Zakonomernost' istoričeskaja, in: SIE 5, M. 1964, 603-606.

Konferencija Citatelej Žurnala „Voprosy istorii“ v Kieve, in: VI 1956, H. 8, 198-203.

Konferencija čitatelej žurnala „Voprosy istorii“ v Leningrade, in: VI 1956, H. 7, 184-190.

Konferencija čtatelej Žurnala „Voprosy istorii“, in: VI 1956, H. 2, 199-213.

Kopnin, P.V.: Das Zusammenfallen von Dialektik, Logik und Erkenntnistheorie (1969), in: Sandkühler, H.J. (Hg.): Marxistische Erkenntnistheorie. Texte zu ihrem Forschungsstand in den sozialistischen Ländern, Stuttgart-Bad Cannstatt 1973, 215-235.

Kopnin, P.V.: Logika naučnogo issledovanija i ee osnovnye ponjatija, in: VF 1964, H. 3, 59-68.

Korelin, A.P.: Die Banken und die Entwicklung der Landwirtschaft in Rußland Ende des 19./Anfang des 20. Jh., in: JbW 1985, H. 4, 83-94.

Kornev, V.V.: Krizis istoričeskoj nauki, in: Kentovr 1994, H. 4, 87-93.

Kornilov, A./N. Prokopenko/A. Sirokov: Pod vidom naučnogo poiska, in: Sovetskaja Rassija, 28.02.1970.

Koroleva, N.A.: V komissii po istorii istoričeskoj nauki pri Institute istorii AN SSSR (Bericht), in: VI 1959, H. 9, 202-207.

Koslow, W.A. (= Koslov, V.A.): Der Historiker und die Umgestaltung, in: Meyer, Wir brauchen die Wahrheit, 64-77 (Erstveröffentlichung in: VIKPSS 1987, H. 5, 110-122).

Kosolapov, V.V.: Metodologija i logika istoriceskogo issledovanija, Kiev 1977.

Kossolapow, R.: Sozialismus und Widersprüche, in: SW 1984, H. 6, 588-594.

Kostrikin, V.I./A.P. Tjurina: Naučno-issledovatel'skaja rabota instituta istorii SSSR AN SSSR v 1972 godu, in: ISSSR 1973, H.3, 237-241.

Kostrikin, V.l.: Perspektivy naučno-issledovatel'skoj raboty instituta istorii SSSR AN SSSR v 1976-1980 gody, in: ISSSR 1974, H. 6, 238-240.

Kosul'nikov, A./A. Pedosov: Ovladevat' bogatym opytom leninskoj partii, in: Pravda, 13.10.1972, 2.

Koval'Cenko, I.D.: „Issledovanie istiny samo dolžno byt' istinno“. Zametki o poiskach istoričeskoj pravdy, in: K 1989, H. 2, 86-96.

Koval'čenko, I.D.: Metody istoričeskogo issledovanija, M. 1987.

Koval'cenko, I.D.: Naučnaja konferencija po voprosu o razvitii tovarnogo proizvodstva $v$ Rossii $v$ period imperializma (Bericht), in: VI 1953, H. 10, 144-148. 
Koval'Čenko, I.D.: Rol' diskussii $v$ istoriceskoj nauke (metodologičeskie problemy), in: Vsemirnaja istorija, 21-33.

Kovešnikov, E.M./V.M. Pugą̌ev: Sovetskaja literatura o razvitom socialističeskom obš̌cestve. Naučno-analisticeskij obzor, M. 1977.

Kozin, N.G.: Empiriðeskij i teoretiðeskij urovni istoriðeskogo poznanija, in: Metodologiðeskie voprosy nauki. Mežvuzovskij naucnyj sbornik. Vypusk tretij, Saratov 1975, 3-16.

Kozin, N.G.: Poznanie i istoričeskaja nauka. Empiričeskij i teoretið̌eskij urovni znanija i poznanija i istoričeskaja nauka, Saratov 1980.

KPSS v rezoljucijach i rešenijach s-ezdov, konferencij i plenumov CK, Teil 4, 7. Auflage, $M$. 1960.

Kratkij obzor statej ob osnovnom ekonomiceskom zakone feodalizma, in: VI 1955, H. 2, 76-90.

Kratkij slovar' po naučnomu kommunizmu, M. 1989.

Kretov, F.D.: K voprosu o sozdanii mnogotomnoj istorii SSSR, in: VI 1961, H. 2, 54-66.

Krizisnye javlenija $v$ sovetskoj istoriðeskoj nauke. Diskussija istorikov, filosofov, pravovedov, in: ON 1989, H. 3, 184-192.

Krjux̌kov: „Nichts ist für uns wertvoller als die große Sowjetunion“. Der ehemalige KGB-Chef (V. Krjuckov; J.H.) über die Notwendigkeit der Wachsamkeit nach innen und außen, in: OE 1991, H. 11, A 633-A 639.

"Kruglyj stol" sovetskich i amerikanskich istorikov, in: VI 1989, H. 4, 97-117.

„Kruglyj stol“: Istoričeskaja nauka v uslovijach perestrojki, in: VI 1988, H. 3, 3-57.

Kučkin, A.P.: K voprosu o periodizacii istorii sovetskogo obšestva, in: VI 1955, H. 3, 71-75.

Kuličenko, M.I.: Ekonomičeskie osnovy ukreplenija internacional'nogo edinstva sovetskogo naroda, in: ISSSR 1976, H. 3, 3-21.

Kuličenko, M.I.: Obrazovanie i razvitie sovetskogo naroda kak novoj istoriðeskoj obక̌čnosti (istoriografija), in: VI 1979, H. 4, 3-23.

Kurnosov, A.A./E.S. Lagutin: $K$ voprosu ob effektivnosti partizanskogo dviženija na territorii Sovetskogo Sojuza, in: Protiv fal'sifikacii istorii Velikoj mirovoj vojny, Sbornik statej, M. 1964, 266-305.

Kusmenko, W.: Diskussionen, Kritik und Selbstkritik in den Gesellschaftswissenschaften. Einige Randbemerkungen, in: SW 1985, H. 2, 189-198.

Kuz'min, A.V.: O predmete istoriðeskoj nauki, in: Predmet i struktura obక̌čestvennych nauk, $M$. 1984, 111-125.

Kuz'min, V.I.: Nekotorye problemy istorii industrializacii SSSR v svete novogo dokumental'nogo izdanija, in: ISSSR 1975, H. 4, 156-166.

Kuznecov, 1.I: O proizvol'nom obrašenii s archivnymi dokumentami, in: ISSSR 1966, H. 3, 229-231.

Kuznecov, I.V.: Ob ukladach i mnogoukladnosti kapitalisticeskoj Rossii, in: VI 1974, H. 7, 2032.

Laveryčev, V.Ja.: K voprosu ob osobennostjach imperializma v Rossii, in: ISSSR 1971, H. 1, 7590.

Laveryčev, V.Ja.: O gosudarstvennom regulirovanii ekonomika Rossii, in: VI 1963, H. 4, 50-62.

Laveryčev, V.Ja: Process monopolizacii chlop̌̌atobumažnoj promyšlennosti Rossii (1900-1914 gody), in: VI 1960, H. 2, 137-151.

Laveryčev, V.Ja:: Staatsmonopolistischer Kapitalismus im vorrevolutionären Rußland, in: JbW 1985, H. 4, 57-67.

Laveryčev, V.Ja.: V.I. Lenin ob istoriðeskom značenii gosudarstvenno-monopolistiðeskogo kapitalizma, in: ISSSR 1978, H. 1, 43-55.

Lavrovskij, V.M.: K voprosu o predmete i metode istorii kak nauki, in: VI 1966, H. 4, 72-77. 
Lebedeva, N.B.: Novye issledovanija o sovetskom rabocem klasse $v$ pervye gody proletarskoj diktatury, in: ISSSR 1976, H. 5, 171-177.

Lel'cuk, V.S.: Istoriografija socialističeskoj industrializacii nacional'nych respublik SSSR, in: ISSSR 1966, H. 2, 81-102.

Lel'čuk, V.S.: Socialističeskaja industrializacija SSSR i ee osveščenie v sovetskoj istoriografii, M. 1975.

Lenin, V.I. - E.S. Varge (01.09.1921), in: LPSS 54, 446.

Lenin, V.I.: (Brief an) I.F. Armand (am 30.11.1916), in: LPSS 49, 328-334.

Lenin, V.I.: I.I. Skvorcovu-Stepanovu (02./16.12.1909), in: LPSS 47, 223-225.

Lenin, V.I.: Iz kakogo klassovogo istočnika prichodjat i ,pridut“ Kaven'jaki? (zuerst in: Pravda Nr. 83, 29. (16.) 06.1917) In: LPSS 32, 343-346.

Lenin, V.I.: K charakteristike ekonomičeskogo romantizma Sismondi i naši otečestvennye sismondisty (1897), in: LPSS 2, 119-262.

Lenin, V.I.: Krach II Internacionala (1915), in: LPSS 26, 209-265.

Lenin. V.I.: Maevka revoljucionnogo proletariata (1913), in: LPSS 23, 296-305.

Lenin, V.I.: O politiðeskoj linii (1912), in: LPSS 22, 99-106.

Lenin, V.I.: Reč' v Moskovskom sovete rabočich, krest'janskich i krasnoarmejskich deputatov 12 marta $1918 \mathrm{~g}$, in: LPSS 36, 83-88.

Lenin, V.I.: VII Vserossijskij s-ezd sovetov 5-9 dekabrja $1919 \mathrm{~g}$. Doklad, in: LPSS 39, 387-414.

Leninskoe edinstvo partii nesokrušimo! In: VI 1957, H. 5, 3-16.

Letopis' Moskovskogo universiteta 1755-1979, M. 1979.

Levykin, K.G./A.M. Sivolobov/G.V. Sarapov: O knige „Voprosy istorii kapitalističeskoj Rossii Problema mnogoukladnosti“, in: VIKPSS 1973, H. I1, 106-115.

Levykin, K.G.: O nekotorych problemach istocnikovedenija, in: VI 1972, H. 1, 152-158.

Licholat, A.V.IV.F. Panibud'laska: V edinoj sem'e narodov. Drǔ̌ba i sotrudničestvo narodov SSSR v uslovijach razvitogo socializma, M. 1979.

Literatur und Perestrojka. Die Diskussion auf dem sowjetischen Schriftstellerkongreß. Köln 1987.

Logika naučnogo issledovanija, M. 1965.

Loone, E.N.: Sovremennaja filosofija istorii, Tallin 1980.

Luckij, E.A.: Osnovnye principy periodizacii razvitija sovetskoj istorið̌eskoj nauki, in: ISSSR 1961, H. 2, 102-115.

Luckij, E.A.: Razvitie istoriceskoj koncepcii M.N. Pokrovskogo, in: Istorija i istoriki, M. 1965, 334-370.

Mal'kov, V.L.: K sravnitel'no-istoričeskomu izučeniju radikal'nych social'nych dviženij v SSA. in: Istoričeskaja nauka 1969, 126-158.

Mamzin, A.S./V.P. Rožin: O zakonach funkcionirovanija i zakonach razvitija, in: FN 1965, H. 4, 3-9 (deutsche Übersetzung in: SW 1966, H. 5, 527-533).

Marksistsko-leninskaja filosofija, M.1981.

Marksistsko-leninskaja filosofija. Učebnoe posobie, M. 1964.

Marksistsko-leninskaja teorija istoričeskogo processa. Istoričeskij process. dejstvitel'nost', material'naja osnova, perviěnoe i vtoričnoe, M.1981.

Maslov, N.N./V.S. Ovčinnikov: Istorið̌eskij opyt KPSS: Problemy issledovanija i praktičeskogo primenenija, in: VIKPSS 1984, H. 6, 59-72.

Maslov, N.N.: Marksistsko-leninskie metody istoriko-partijnogo issledovanija, M.I 983.

Maslov, N.N.: Nekotorye aktual'nye voprosy metodologii istoriografii istorii KPSS, in: Metodologičeskie problemy istoriko-partijnoj istoriografii (Materialy naučnoj konferencii), $M$ 1984, 3-15.

Materialy vneocerednogo Plenuma Central'nogo Komiteta KPSS 13 fevralja 1984 goda. M. 1984. 
Matjugin, A.A.: Nekotorye voprosy izučenija istorii sovetskogo rabočego klassa, in: VI 1960, H. $6,102-116$.

Medvedev, R.: Lið̌nost' i epocha. Političeskij portret L.I. Brežneva. Kniga 1, M. 1991.

Medvedev, R.: Vzaimosvjaz' ideologii, politiki i obščestvennych nauk, in: K 1990, H. 16, 3-14.

Medvedev, R.A.: O Staline i stalinizme, M. 1990.

Medvedev, R.A.: Oni okružali Stalina, M. 1990.

Medvedev, V: Ispytanie istoriej, in: K 1990, H. 17, 3-14.

Medvedev, V.A.: Velikij Oktjabr' i sovremennyj mir, in: Velikij Oktjabr' i mirovoe razvitie, 528.

Medwedew, R.: Das Urteil der Geschichte. Stalin und Stalinismus, 3 Bände, Berlin 1992.

Medwedew, R.: Vom XX. zum XXII. Parteitag der KPdSU. Ein kurzer historischer Überblick, in: Crusius/Wilke, Entstalinisierung, 23-49.

Mejman. M.N./S.D. Skazkin: Ob osnovnom ekonomið̌eskom zakone feodal'noj formacii, in: VI 1954, H. 2, 71-91.

Methodologische Probleme der Naturwissenschaften und Gesellschaftswissenschaften. Sitzung des Präsidiums der Akademie der Wissenschaften der UdSSR vom 18. Oktober 1963, in: SW 1964, H. 2, 197-206.

Metodologičeskie i filosofskie problemy istorii, Novosibirsk 1983.

Metodologið̌eskie $i$ teoretičeskie problemy istorii istoriČeskoj nauki. Mežvuzovskij tematiČeskij sbornik, Kalinin 1980.

MetodologiCeskie problemy nauki. Materialy zasedanija Prezidiuma AN SSSR, M. 1964.

Metodologiceskie problemy sovremennoj nauki. Sbornik statej, M. 1964 (=1. Buch).

Metodologiceskie problemy sovremennoj nauki. Sbornik statej, M. 1970 (=2. Buch).

Meženin, N.M.: O marksistsko-leninskom ponimanii istoriceskogo opyta KPSS i ego ispol'zovanii $v$ sovremennych uslovijach, in: VIKPSS 1985, H. 8, 71-82.

Michajlov, V.N/F.S. Sabanov: O periodizacii istorii sovetskogo obšestva, in: VI 1955, H. 9, 5961 .

Migranjan, A.: Der Bremsmechanismus im politischen System und die Wege zu seiner Überwindung, in: Afanassjew, Es gibt keine Alternative, 130-159

Minc, I.I./A.B. Mel'nikov: Akademik I.I. Minc otvečaet na voprosy žurnala „Voprosy istorii“, in: VI 1968, H. 8, 182-189.

Minc, I.I.M.V. Nečkina/L.V. Cerepnin: Zadači sovetskoj istorǐ̌eskoj nauki na sovremennom etape ee razvitija, in: ISSSR 1973, H. 5, 3-16.

Minc, 1.I.: Velikij Oktjabr - povorotnyj punkt $v$ istorii Celovecestva (Nekotorye itogi i zadači izucenija problemy), in: ISSSR 1975, H. 6, 3-21.

Minkov, T.: Ob osnovnom ekonomixeskom zakone feodal'noj formacii, in: VI 1954, H. 11, 77 81.

Minz, I.I.: Stand und Perspektiven der Forschungen zur Geschichte der Oktoberrevolution (zuerst in VI 1987, H. 4, 3-9), in: SW 1987, H. 5, 443-448.

Mitasova, L.: Partizanskoe dviženie na Pskovščine v gody Velikoj Otečestvennoj vojny 19411945 gg. Rekomendatel'nyj ukazatel' literatury, Pskov 1964.

Mogil'nickij, B.G.: Al'ternativnost' v istorii sovetskogo ob̌̌čestva, in: VI 1989, H. 11, 3-16.

Mogil'nickij, B.G.: Das Tomsker Zentrum für historiographiegeschichtliche und methodologische Forschungen, in: JbG, Nr. 28, Berlin 1983, 275-294.

Mogil'nickij, B.G.: Istoričeskaja al'ternativnost': metodologičeskij aspekt, in: NNI 1990, H. 3, 318.

Mogil'nickij, B.G.: Naučno-pedagogið̌eskaja dejatel'nost' A.I. Danilova, in: MIVIN 15, T. 1982, 3-20. 
Mogil'nickij, B.G.: O prirode istoriðeskogo poznanija, T. 1978.

Mogil'nickij, B.G.: O specificeskich istoriceskich zakonach, in: MIVIN 18, T. 1986, 6-31.

Mogil'nickij, B.G.: Ob-ektivnost' i partijnost' $v$ istoriCeskom issledovanii, in: MIVIN 2, T. 1964, 3-34.

Mogil'nickij, B.G.: Ob-ektivnost' istoriceskogo poznanija i sovremennost', in: MIVIN 5, T 1967, 30-51.

Mogil'nickij, B.G.: Vvedenie v metodologiju istorii, M. 1989.

Najdenov, M.E.: M.N. Pokrovskij i ego mesto v sovetskoj istoriografii, in: ISSSR 1962, H. 3, 4871.

Najdenov, M.E.: O leninskom etape $v$ istoriceskoj nauke, in: VI 1966, H. 2, 21-37.

Najdenov, M.E.: Problemy periodizacii sovetskoj istoriceskoj nauki, in: VI 1961, H. 1, 81-96.

Najdenov, M.E.: Sovetskaja istoriceskaja nauka nakanune XXII s-ezda KPSS, in: VI 1961, H. 10, 3-24.

Najdenov, M.E.: Velikaja Oktjabr'skaja socialističeskaja revoljucija v sovetskoj istoriografii, in VI 1957, H. 10, 167-180.

Nakaz XXIII s-ezda KPSS, in: ISSSR 1966, H. 3, 3-9.

Naroxnickij, A.L. et al.: Nekotorye aktual'nye problemy istorii sovetskogo rabocego klassa, in: ISSSR 1978, H. 4, 3-18.

Naroxnickij, A.L./V.I. Buganov/V.P. Serstobitov: XXV s-ezd KPSS i zadači izučenija otecestvennoj istorii, in: ISSSR 1976, H. 2, 3-21.

Narskj, I.S.: Fragen der Erkenntnistheorie (1971), in: Sandkühler, H.J. (Hg): Marxistische Erkenntnistheorie. Texte zu ihrem Forschungsstand in den sozialistischen Ländern, Stuttgart-Bad Cannstatt 1973, 30-58.

Nasyrin. V.P.: O nekotorych voprosach socialistiCeskogo preobrazovanija promyšlennosti $v$ SSSR, in: VI 1956, H. 5, 90-99.

Naučno-issledovatel'skaja rabota po istorii v vyš̌sj łkole, in: VI 1964, H. 11, 3-12.

Naumov, V.P.: Osnovnye certy sovremennoj sovetskoj istoriografii Velikogo Oktjabrja, in: VI 1977, H. 10, 56-74.

Navstrexu istoriceskoj date, in: ISSSR 1969, H. 1, 3-7.

Ne sudit', a pommat', in: Molodoj Kommunist 1990, H. 9, 8-19.

Nexkina, M.V./E.N. Gorodeckij: Istoriograficeskie issledovanija v SSSR, in: Razvitie 1975, $79-$ 100 (vgl. die Übersetzung bei Donnert. E./A. Anderle (Hg.): Studien zur Geschichte und Theorie der Geschichtswissenschaft in der UdSSR, Halle 1981, 5-33).

Neckina, M.V./Ju.A. Poljakov/L.V. Cerepnin: O projdennom puti, in: Sovetskaja istoriðeskaja nauka 1962, 5-36.

Neckina, M.V.: Vopros o M.N. Pokrovskom v postanovlenijach partii i pravitel'stva 1934-1938 gg. o prepodavanii istorii $\mathrm{i}$ istorið̌eskoj nauke ( $\mathrm{K}$ istoðnikovedð̌eskoj storone temy), in: $\mathrm{IZ}$ 118, M. 1990, 232-246.

Nexuchrin, A.N./S.P. Ramazanov: Istoriceskaja nauka i perestrojka, in: ISSSR 1989, H. 3, 211 214.

Nekrasov, V.F. (Hg.): Berija - konec kar'ery, M. 1991 (Übersetzung aus dem Russischen: Berija - Henker in Stalins Diensten. Ende einer Karriere, hg. von V.F. Nekrassow, Berlin 1992).

Nekric, A.: Otrešis' ot stracha. Vospominanija istorika, London 1979.

Neotložnye zadaxi istorikov, Pravda, 29.03.1973, 2.

Neretina, S.S.: Istorija S metodologiej istorii, in: VF 1990, H. 9, 149-163.

Neretina, S.S.: Tvorcestvo kak suščnost' (O koncepcii kul'tury M.K. Petrova), in: Petrov, M.K. Jazyk, znak, kul'tura, M. 1991, 3-18.

Nenusimoe edinstvo partii i naroda, in: V1 1958, H. 12, 3-26. 
Netschkina, M.W. (= Nečkina, M.V.): Ergebnisse der Diskussion über die Periodisierung der Geschichte der sowjetischen Geschichtswissenschaft, in: SW 1962, H. 12, 1369-1386, (leicht gekürzte Übersetzung und Wiedergabe aus ISSSR 1962, H. 2).

Netschkina, M.W.: Zur Periodisierung der Entwicklungsetappen der sowjetischen Geschichtswissenschaft, in: SW 1960, H. 7, 778-796 (zuerst in: ISSSR 1960, H. 1).

Novoe v sovetskoj istoriceskoj nauke, M. 1988.

Novye rubeži sovetskich istorikov, in: VI 1969, H. 8, 3-16.

Novyj istoričeskij etap v razvitii sovetskogo obšcestva, in: ISSSR 1959, H. 1, 3-9.

O doktorskich dissertacijach po istorii, in: VI 1954, H. 12, 163-165.

O druch osnownych stadijach razvitja feodal'noj formacii, in: VI 1955, H. 3, 181-184.

O naux̌noj razrabotke istorii Velikoj Oktjabr'skoj socialističeskoj revoljucii, in: VI 1953, H. 11, 3-11.

O nekotorych važnejక̌ch zadačach sovetskich istorikov, in: VI 1953, H. 6, 3-11.

O partijnoj i sovetskoj pečati. Sbornik dokumentov, M. 1954.

O periodizacii istorii sovetskogo obšcestva, in: VI 1955, H. 4, 81-86.

O periodizacii istorii sovetskogo obscestva, in: VI 1955, H. 9, 61f.

O periodizacii istorii sovetskogo obłčestva, in: VI 1956, H. 6, 58-62.

O preodolenii kul'ta lixnosti i ego posledstvij. Postanovlenie CK KPSS 30 ijunja 1956 goda, in: SPR 1, M. 1957, 321-338.

O profile i strukture žurnala „Voprosy istorii“", in: VI 1960, H. 8, 19-21.

O rabote istoriceskich fakul'tetov gosudarstvennych universitetov (K 25-letiju postanovlenija CK VKP(b) i Sovnarkoma SSSR „O prepodavanii graždanskoj istorii v skolach SSSR“), in: VI 1959, H. 7, 182-201; H. 10, 192-194; H. 11, 185-190; H. 12, 185-187.

O stat'e tov. E. Bugaeva, in: VI 1956, H. 7, 215-222.

O zurnale „Kommunist“. Postanovlenie CK KPSS, in: K 1986, H. 12, 3-10.

O zurnale „Voprosy istorii“, in: PŽ 1956, H. 23, 71-77.

O žurnale „Voprosy istorii“. Postanovlenie CK KPSS 9 marta 1957 goda, in: SPR 1, M. 1957. $381 \mathrm{f}$.

Ob izučenii istorii istoriceskoj nauki, in: VI 1956, H. 1, 3-12.

Ob osnovnom ekonomičeskom zakone feodal'noj formacii (k itogam diskussii), in: VI 1955, H. 5, 79-85.

Ob osnovnom ekonomiceskom zakone feodal'noj formacii, in: Vl 1954, H. 7, 117-129.

Ob osobennostjach imperializma v Rossii, M. 1963 (Rezension von Horst Giertz, in: JbGUV 10, Berlin 1967, 392-395).

Obšcee sobranie Otdelenija istoričeskich nauk AN SSSR, in: VI 1956, H. 6, 201-204.

Obsǔ̌denie knig ,Rossijskij proletariat: oblik, bor'ba, gegemonija“ $i$ „Sverženie samoderžavija“, in: ISSSR 1973, H. 1, 211-214.

Obsuždenie raboty zurnala „Voprosy istorii“, in: VI 1954, H. 9, 175-177.

Obsuždenie stat'i S.M. Dubrovskogo „Akademik M.N. Pokrovskij i ego rol' v razvitii sovetskoj istoriceskoj nauki“, in: V1 1962, H. 3, 31-40.

Obsuł̌denie voprosa o charaktere dviženij gorskich narodov Severnogo Kavkaza v 20-50-ch godach XIX veka, in: VI 1956, H. 12, 188-191.

Obsuždenie voprosa ob osnovnom ekonomiceskom zakone feodalizma, in: VI 1955, H. 4, 86-97.

Obsuždenie zadač istorǐ̌eskoj nauki v svete rełenij ijun'skogo (1983 g.) plenuma CK KPSS, in: VI 1983, H. 9, 18-25.

Oxerki istorii istoriceskoj nauki v SSSR, tom 1, M. 1955.

Oxerki istorii istoriceskoj nauki v SSSR, tom 4, M. 1966. 
Ozerki istorii istoričeskoj nauki v SSSR, tom 5, M. 1985.

Ozerki istorii KPSS: Koncepcija, podchody, kontury, in: K 1990, H. 10, 5-24; H. 12, 19-30; H. 14, 95-105; H. 16, 84-93.

Orerki po istoriografii sovetskogo obšcestva, M. 1965

Offene Worte. Sowjetunion 1988. Gorbatschow, Ligatschow, Jelzin und 4991 Delegierte diskutieren über den richtigen Weg. Sämtliche Beiträge und Reden der 19. Gesamtsowjetischen Konferenz der KPdSU in Moskau, Nördlingen 1988.

Orleanskij, A.l.: K voprosu o zakonomernostjach obščestvennogo razvitija, in: VI 1955, H. 10, 67-73.

Orlov, B.P.: K voprosu o periodizacii istorii sovetskogo obšcestva, in: VI 1955, H. 3, 75-77.

Osmyslit' kul't Stalina, M. 1989.

Osnovnye etapy razvitija sovetskogo obšcestva, in: K 1987, H. 12, 66-79.

Osnovnye napravlenija istoriðeskich issledovanij $\vee$ XI pjatiletke $\vee$ svete rešenij XXVI s-ezda KPSS, in: VI 1981, H. 10, 3-11.

Osnovnye problemy tret'ego toma „Istorii Velikoj Otečestvennoj vojny Sovetskogo Sojuza“, in: VI 1962, H. 10, 3-20.

Ot redakcii, in: ISSSR 1957, H. 1, 3-6.

Otexestvennaja istorija v sovremennoj publicistike, in: ISSSR 1990, H. 1, 176-190.

Otečestvennaja istorija v SSSR za 50 let, in: ISSSR 1967, H. 6, 3-15.

Otkryvaja novye stranicy... Meždunarodnye voprosy. Sobytija i ljudi, M. 1989.

Ovander, N.E.: Ob ob-ektivnom charaktere zakonov razvitija sovetskogo socialističeskogo obšcestva, in: VF 1953, H. 4, 40-49.

Ovxinnikov, V.F.: Mnogovariantnost' razvitija socializma, in: Social 'no-politiłeskie nauki 1990, H. 9, 14-19.

Ovxinnikov, V.F.: Socializm i problema istorizeskich al'ternativ, in: NK 1989, H. 9, 22-27.

Pamjati Aleksandra Ivanoviča Danilova, in: MIVIN 15, T. 1982, 178-181.

Panfilova, A.M./A.M. Anfimov: $K$ voprosu o periodizacii istorii sovetskogo obščestva, in: VI 1955, H. 3, 77f.

Pankratova, A.M.: O roli tovarnogo proizvodstva pri perechode ot feodalizma k kapitalizmu, in: VI 1953, H. 9, 59-77.

Pankratova, A.M.: Važnejక̌ie zadači sovetskich istorikov, in: VI 1954, H. 6, 161-166.

Pankratova. M.G.: Problematika russkoj revoljucii $v$ amerikanskoj rusistike, in: Istoričeskaja nauka 1969, 192-208.

Pašuto, V./V. Salov/L. Cerepnin: Princip partijnosti $v$ istoričeskom issledovanii i ego sovremennye kritiki, in: K 1966, H. 4, 72-79.

Paร̌uto, V.T./Ju.A. Poljakov/S.S. Chromov: Nekotorye problemy otečestvennoj istorii i prepodavanija istorii v łkole na XV meždunarodnom kongresse istorikov, in: ISSSR 1981, H. 5, $115-130$.

Pašuto, V.T./Ju.A. Poljakov: Voprosy istorii SSSR na XIII Meždunarodnom kongress istorikov, in: ISSSR 1971, H. 1, 3-22.

Pavlenko, N.I.: Istoričeskaja nauka v prołlom i nastojašxem (Nekotorye razmyšlenija vsluch), in: ISSSR 1991, H. 4, 81-99.

Pavlov, M.N./V.E. Poletaev: Obsuždenie itogov naučno-izdatel'skoj dejatel'nosti v svjazi s 40letiem Oktjabr'skoj revoljucii (Bericht), in: VI 1958, H. 7, 190-203.

Perepiska na istoričeskie temy. Dialog vedet čitatel', M. 1989.

Perestrojka i zadači Zurnala „Voprosy istorii“, in: VI 1988, H. 2, 3-10.

Persov, M.S.: O sootnošenii obščesociologičeskich i specifičeskich zakonov formacii, in: VI 1955, H. 1, 84-86. 
Petrjaev, K.D.: Voprosy metodologii istoriと̌eskoj nauki, Kiev 1976.

Petrovskij, A.B./L.K. Semenov/V.S. Malov: Kadry Akademii. Sostav, struktura, dinamika, in: Vestnik AN SSSR 1990, H. 11, 37-49.

Pikman, A.M.: O bor be kavkazskich gorcev s carskim kolonizatorami, in: VI 1956, H. 3, 75-84.

Pikman, A.M.: Polemiki prosto ne bylo, in: VI 1990, H. 2, 187-189.

Piotrovskij, B.B./V.A. Tiškov: Itogi issledovanij sovetskich istorikov $v$ desjatoj pjatiletke, in: VI 1981, H. 2, 3-25.

Pjaskovskij, A.V.: K voprosu o progressivnom značenii prisoedinenija srednej Azii k Rossii, in: VI 1959, H. 8, 21-46.

Plechanov, G.V. (N. Beltov): K voprosu o razvitii monističeskogo vzgljada na istoriju, S.Peterburg 1895.

Pleškova, S.L.: Ob uと̌ebnom posobii „Problemy genezisa feodalizma v Zapadnoj Evrope“ (Informacija o chode obsuž.denija knigi A.Ja. Gureviča), in: VI 1970, H. 9, 154-167.

Po povodu diskussii o dejstvii ekonomičeskich zakonov $v$ antagonističeskich formacijach, in: VI 1956, H. 7, 66-67.

Pod znamenem Velikogo Oktjabrja, in: VI 1957, H. 10, 3-22.

Podkorytov, G.A.: Istorizm kak metod naučnogo poznanija, L. 1967.

Podosetnik, V.M.: Gnoseologičeskœe značenie faktov $v$ poznanii obščestvennych javlenij, in: Teorija 1967, 207-230.

Pogruženie v trjasinu (Anatomija zastoja). Sost. i obšč. red. T.A. Notkinoj, M. 1991.

Pokrovskij, M.V.: O charaktere dviženija gorcev Zapadnogo Kavkaza v 40-60-ch godach XIX veka (Bericht), in: VI 1957, H. 2, 62-74.

Pol'skij, M.P.: XXIV s-ezd KPSS i zadaci sovetskoj istoriceskoj nauki. Koordinacionnoe sovešcanie v otdelenii istorii Akademii nauk SSSR, in: ISSSR 1972, H. 2, 178-183.

Polikarpov, V.V.: „Novoe napravlenie“ - v starom proctenii, in: VI 1989, H. 3, 44-61.

Poljakov, Ju.: Poznanie proslogo: preodolen li zastoj? Zametki istorika, in: K 1990, H. 15, 42-47.

Poljakov, Ju.A./V.P. Dmitrenko: Issledovanie kompleksnych problem istorii sovetskogo obscestva, in: ISSSR 1977, H. 2, 194-198.

Poljakov, Ju.A.: Istoričeskij process mnogomeren, in: VIKPSS 1988, H. 9, 19-34.

Poljakov, Ju.A.: Kommunističeskoe vospitanie i istorija, in: VI 1963, H. 7, 3-18.

Poljakov, Ju.A.: Načalo vosstanovlenija sel'skogo chozjajstva sovetskoj strany (1921-1922 gg.), in: ISSSR 1964, H. 4, 29-52.

Poljakov, Ju.A.: Stimul, mera, temp. Nekotorye problemy novoj ekonomičeskoj politiki, in: VI 1964, H. 7, 21-32.

Poljanskij, F.Ja: Problema osnovnogo ekonomiceskogo zakona feodalizma, in: VI 1954, H. 10, 79-85.

Poloskow, I. (= Poloskov, I.): Für den sozialistischen Charakter der Perestroika, in: MB 1991, H. 3, 42-47 (zuerst in: K 1991, H. 2).

Ponomarev, A.M./A.M. Ankudinova: Stalinizm i istoričeskaja nauka, Jaroslavl' 1991.

Ponomarjow, B.: Der kommunistische Aufbau und die Aufgaben der Historiker, in: SW 1963, H. $4,333-361$.

Ponomarjow, B.N.: Der Kommunismus in der sich verändernden Welt, Frankfurt am Main 1984 (Rezension von R. Steigerwald in: UZ, 17.02.1984).

Popov, G.: Blesk i niščeta administrativnoj sistemy, M. 1990.

Popov, V.G.: Sovetskaja istoriografija likvidacii bezrabotnicy v SSSR. Obzor, in: ISSSR 1981, H. $5,184-188$

Poršnev, B.F.: K voprosu ob osnovom ekonomiceskom zakone feodalizma, in: VI 1953, H. 6, 5267. 
Posle kritiki: Vyvody sdelany, in: Pravda, 06.01.1973, 2.

Postanovlenie bjuro otdelenija istorii AN SSSR ob itogach obsuždenija v Institute istorii SSSR izdannych v 1970 godu sbornikov "Rossijskij proletariat: oblik, bor'ba, gegemonija“ i "Sveržzenie samoderžavija“, in: VI 1972, H. 8, 140-145 (der Beschluß wurde auch veröffentlicht in: ISSSR 1973, H. 1, 214-218).

Povysit' rol' istoriceskoj nauki $v$ ideologiceskoj rabote, in: ISSSR 1963, H. 4, 3-9.

Pozner, V.: Abschied von Illusionen. Das außergewöhnliche Leben und die kontroversen Ansichten des führenden politischen Kommentators der Sowjetunion, Berlin 1991.

Pripiznov, V.I.: O sootnołenii istoričeskogo materializma i istorið̌eskoj nauki, in: VF 1961, H. 1, 103-113.

Problemy istorii dokapitalisticeskich obšcestv. Kniga 1, M. 1968.

Problemy logiki i teorii poznanija, M. 1968.

Problemy logiki nauxnogo poznanija, M. 1964.

Problemy metodologii social'nogo issledovanija, L. 1970.

Problemy myšlenija v sovremennoj nauke, M. 1964.

Problemy razvitija istoriceskoj nauki (V svjazi s vychodom v svet „Istorii KPSS“), in: VF 1960, H. 5, 15-25.

Problemy social'no-ekonomiceskoj istorii Rossii, M. 1971.

Proekt plana raboty žurnala „Voprosy istorii“" na 1959-1965 gody, in: VI 1959, H. 8, 207-213.

Programm der KPdSU. Angenommen auf dem XXII. Parteitag, Oktober 1961, Berlin 1961.

Protiv fal'sifikacii istorii vtoroj mirovoj vojny, M. 1959.

Protiv istoriceskoj koncepcii M.N. Pokrovskogo. Sbornik statej. Cast pervaja, M.-L. 1939.

Rakitov, A.I.: Istorið̌eskoe poznanie: Sistemno-gnoseologið̌eskij podchod. M. 1982.

Rakitov, A.I.: $\mathrm{K}$ voprosu o strukture istoriceskogo issledovanija, in: Filosofskie problemy, 161185.

Razvitie socialističeskoj ekonomiki SSSR v poslevoennyj period, M. 1965.

Razvitie sovetskogo naroda - novoj istoričeskoj obక̌̌nosti, M. 1980.

Razvitie sovetskoj istoriceskoj nauki 1970-1974, M. 1975.

Rekomendacii koordinacionnogo sovešcanija rukovoditelej akademiceskich i drugich naučnych učreždenij istorizeskogo profilja SSSR, sojuznych i avtonomnych respublik „Koordinacija kak sredstvo povstenija kaXestva i effektivnosti istoriceskich issledovanij v SSSR v svete rešenij XXVII s-ezda KPSS“, Moskva, 24-26 ijunja 1986 g, in: VI 1986, H. 12, 111-115.

Ritm perestrojki. Ekonomika na novom etape, M. 1987.

Rosenko, M.N.: Rol' russkoj socialistiðeskoj nacii $v$ razvitii $i$ ukreplenii internacional'nogo edinstva sovetskogo naroda, in: ISSSR 1982, H. 1, 50-61.

Rossijskij proletariat: oblik, bor'ba, gegemonija, M. 1970.

Rožin, V.P.: Istoriceskij materializm - vseobł̌aja metodologija obł̌̌cestvennych nauk, in: Meto dologiceskie voprosy obšcestvennych nauk. Vyp. I, L. 1968, 5-18.

Rožin, V.P.: Vvedenie v marksistskuju sociologiju, L. 1962.

Rumjancev, A.M.: Istoriceskij opyt Velikogo Oktjabrja, in: VI 1968, H. 1, 7-17.

Rusljakova, V.G.: Razrabotka istorii Oktjabr'skoj revoljucii posle XX s-ezda KPSS, in: VI 1960, H. 5, 85-102.

Rybakov, B.A.: Istorija i perestrojka, M. 1989.

Rybakov, M.V.: O nekotorych neopravdannych pretenzijach, in: VIKPSS 1971, H. 7, 123-133.

Ryndzjunskij, P.G.: Voprosy izucenija melkotovarnogo uklada v Rossii XIX v., in: ISSSR 1963, H. 4, 95-117.

Sabatin, I.I.: O „marksizme“ Stalina (Razmyక̌lenija po povodu stat'i A. Cipko „Istoki stalinizma“, in: NK 1989, H. 8, 112-115. 
Sachnazarov, G.: Obnovlenie ideologii i ideologija obnovlenija, in: K 1990, H. 4, 46-59.

Sakina, T.D.: Gnoseologiceskaja priroda istoriðeskoj zakonomernosti (Na materiale trudov A.I. Neusychina), in: MIVIN 13, T. 1979, 3-11.

Satalin, S.: Ekonomi eskaja programma politiðeskoj partii, in: K 1990, H. 7, $31-38$.

Sceglov, A.: Istorija kak nauka, in: BSE (I) 30, M. 1937, $14-29$.

Selestov, D.K.: Sovetskaja istoriografija graždanskoj vojny i voennoj intervencii v SSSR, in: VI 1964, H. 2, 22-48.

Selestov, D.K.: Važnye problemy istoriografii sovetskogo obšcestva, in: VI 1966, H. 4, 130-133.

Serman, I.L.: Sovetskaja istoriografija graždanskoj vojny v SSSR (1920-1931), Charkov 1964.

Serstobitov, V.P.: Razvitie sovetskogo naroda - novoj istoričeskoj obščnosti na sovremennom etape, in: ISSSR 1982, H. 6, 17-31.

Serstobitov, V.P.: Sovetskij narod - monolitnaja obšcnost’ stroitelej kommunizma, M. 1976.

Skaratan, O.I.: Metodologičeskie aspekty izučenija istorii sovetskogo raboð̌ego klassa, in: VI 1966, H. 4, 3-15.

Staerman, E.M.: Antičnoe obščestvo. Modernizacija istorii i istorið̌eskie analogii, in: Problemy istorii 1968, 638-671.

Staerman, E.M.: K probleme strukturnogo analiza v istorii, in: VI 1968, H. 6, 20-37.

Surbovanyj, G.P.: Obsuždenie nekotorych problem metodologii istorii, in: VI 1971, H. 10, 159166.

Sacharov, A.M.: Nekotorye voprosy metodologii istoriograficeskich issledovanii, in: Voprosy metodologii i istorii istoriceskoj nauki, M. 1977, 5-59.

Sacharov, A.M.: O predmete istoriograficeskich issledovanij, in: ISSSR 1974, H. 3, 90-112.

Sacharov, A.M.: O znax̌enii otexestvennoj istorii, in: ISSSR 1965, H. 4, 3-12.

Sacharov, A.M.: Žrnalu „Voprosy istorii“ - 50 let, in: VI 1976, H. 6, 3-19.

Sacharov, A.N.: Revoljucionnyj totalitarizm v nasej istorii, in: K 1991, H. 5, 60-71.

Sacharow, A. (= Sacharov, A.D.): Mein Leben. Aus dem Russischen übersetzt von A. Nitschke, A. Manzella und W. v. Timroth, München-Zürich 1991.

Salov, V.I.: O fal'sifikacii taktiki bol'Yevikov v marte-aprele 1917 goda zapadnagermanskoj buržuaznoj istoriografiej, in: VI 1959, H. 8, 120-129.

Samsonov, A.M.: K novym rubežam (Strichi problemy), in: ISSSR 1986, H. 6, 61-71.

Samsonov, A.M.: Znat' i pomnit'. Dialog istorika s citatelem, M. 1989.

Samsonow, A.M. u.a.: Geschichte der UdSSR in drei Teilen (aus dem Russischen), Teil III: Vom Anfang des Großen Vaterländischen Krieges bis zur Gegenwart, M. 1979.

Sancevið, A.V.: Empiričeskij i teoretið̌eskjj urovni poznanija $\mathbf{v}$ istoričskom issledovanii, in: Metodologixeskie problemy obšxestvennych nauk, Kiev 1985, 186-203.

Sarbej, V.G.: Eš̌e raz o leninskom etape $v$ istoričeskoj nauke (po povodu stat'i M.E. Najdenova), in: VI 1966, H. 9, 15-26.

Saslawskaja, T. (= Saslavskaja, T.): Die Gorbatschow-Strategie. Wirtschafts- und Sozialpolitik in der UdSSR (Aus d. Russ.), Wien 1989.

Sazonov, V.V.N.T. Loginov: Nužno li bylo idti ot fevralja k oktjabrju? In: Dialog 1991, H. 2, 84 90.

Schatrow, M. (= Satrov, M.): Weiter... Weiter... Weiter... Version des Verfassers zu den Ereignissen am 24. Oktober 1917 und bedeutend später. Aus dem Russischen von Friedrich Hitzer, Köln 1988.

Schaworonkow, G.: MN-Nachforschungen belegen: Im Wald von Katyn wurde seit 1935 gemordet, in: MN (Deutsche Ausgabe) Nr. 9 / September 1989, 13.

Schewardnadse: „Ich trete zurïck...“ Schewardnadses Rede auf dem Kongreß der Volksdeputierten, in: OE 1991, H. 5, A 251-A 255. 
Schmidt, S.O.: Über den Gegenstand der sowjetischen Geschichtsschreibung und einige Prinzipien ihrer Periodisierung, in: SW 1962, H. 6, 669-683.

Schtajerman, J.M.: Über die Wiederholbarkeit in der Geschichte, in: SW 1965, H. 12, 1328-1343 (zuerst in: VI 1965, H. 7).

Sedov, K.I.: Obšcee sobranie otdelenija istorið̌eskich nauk AN SSSR (Bericht), in: VI 1958, H. 5, 179-185.

Seleznev, M.S./F.V. Nikolaev: O periodizacii istorii sovetskogo obక̌cestva, in: VI 1955, H. 9, 5558.

Seleznev, M.S.M.N. Cernomorskij: Voprosy sozdanija istoðnikovedzeskoj bazy po istorii sovetskogo obšestva, in: VI 1965, H. 9, 15-24.

Semjonov, Ju.I. (= Semenov, Ju.I.): Ökonomische Gesellschaftsformationen und Weltgeschichte, in: Ökonomische Gesellschaftsformationen. Theorie und Geschichte, hg. v. IMSF, Frankfurt/Main 1981, 32-43.

Semjonow, W.S. (= Semenov, V.S.): Das Widerspruchsproblem im Sozialismus, in: SW 1983, H. $1,16-31$.

Semjonow, W.S.: Zur theoretischen Vertiefung und Konkretisierung des Widerspruchsproblems im entwickelten Sozialismus, in: SW 1984, H. 4, 368-378.

Senjawski, S.L. (= Senjavskij, S.L.)/W.B. Telpuchowski (= Telpuchovskij, V.B.): Die Arbeiterklasse der UdSSR. Berlin 1974 (zuerst russisch 1971).

Serovajskij, Ja.D.: K voprosu o predmete istoriCeskoj nauki, in: Voprosy metodologii istorii, istoriografii $i$ istoxnikovedenija. T. 1987, 104-106.

Sidorov, A.L.: EkonomiČeskie predposylki socialistiðeskoj revoljucii v Rossii, in: ISSSR 1957, H 4, 9-39.

Sidorov, A.L.: Finansovoe položenie Rossii v gody pervoj mirovoj vojny, M. 1960.

Sidorov, A.L.: Issledovanija po istorii imperializma v Rossii, in: VI 1963, H. 4, 121-126.

Sidorov, A.L.: Nekotorye problemy razvitija rossijskogo kapitalizma $v$ sovetskoj istoriそeskoj nauke, in: VI 1961, H. 12, 26-62.

Sidorov, A.L.: Nekotorye razmyšlenija o trude i opyte istorika, in: ISSSR 1964, H. 3, 118-138.

Sidorov, A.L.: O rabote Instituta istorii Akademii nauk SSSR, in: VI 1954, H. 2, 177-180

Sidorow, A.W. (= Sidorov, A.V.): Stalinismus: Erfahrungen und Lehren der Interpretation, in: BzG 1991, H. 2, 246-254.

Simonija, N.A.: Cto my postroili, M. 1991.

Sitarjan, S.: Politische und ökonomische Aspekte der Konzeption der Beschleunigung, in: Umbruch in der Sowjetunion. Sowjetische Autoren über die Umgestaltung 70 Jahre nach der Oktoberrevolution, Düsseldorf 1987, 93-113.

Smirnov, A.: Za stroguju naucnost', dostovernost' i istoriðeskuju pravdu, in: K 1972, H. 16, 113 124.

Smimova, L.1.: Protiv buržuaznoj fal'sifikacii istorii SSSR (Bericht), in: VI 1959, H. 7, 166-175.

Smirnow, G. (= Smirnov, G.L.): Perestroika ist eine Rückkehr zu den Ursprüngen, in: $M N$ (Deutsche Ausgabe) 1989, Nr. 12, 12.

Snesarevskij, P.V.: O dejstvii osnovnogo ekonomiceskogo zakona feodalizma, in: VI 1954, H. 10, 85-89.

Sobolev, G.L.: Važnce napravlenie v istoriografii Velikogo Oktjabrja, in: VI 1982, H. 8, 118-123

Sobolev, P.N.: Razrabotka osnovnych problem istorii Velikoj Oktjabr'skoj socialističeskoj revoljucii i graždanskoj vojny, in: ISSSR 1976, H. 1, 220-223.

Social'no-ekonomizeskie problemy istorii razvitogo socializma v SSSR, M. 1976.

Socialistið̌eskaja industrializacija SSSR. Ukazatel' sovetskoj literatury, M. 1972.

Sokolov, O.: Ob istoriðeskich vzgljadach M.N. Pokrovskogo, in: K 1962, H. 4, 69-79. 
Sokolov, O.D: Bor ba M.N. Pokrovskogo protiv dvorjansko-buržuaznoj istoriografii, in: ISSSR 1969, H. 5, 33-47.

Sokolov, O.D.: M.N. Pokrovskij - vydajuక̌cijsja organizator naučno-issledovatel'skoj raboty $v$ SSSR, in: VI 1969, H. 6. 30-45.

Sokolov, O.D.: M.N. Pokrovskij i sovetskaja istoričeskaja nauka, M. 1970.

Sokolov, O.D: Michail Nikolaevið Pokrovskij, in: ISSSR 1967, H. 1, 117-122.

Sokolov, O.D.: Razvitie istorizeskich vzgljadov M.N. Pokrovskogo, in: Pokrovskij, M.N.: Izbrannye proizvedenija, tom 1, M. 1966, 5-71.

Sokolov, O.D.: V.1. Lenin i formirovanie bol’̌̌evistskich vzgljadov M.N. Pokrovskogo, in: VI 1963, H. 8, 30-41.

Sokolov, V.Ju.: Istorija i politika. K voprosu o soderžanii i charaktere diskussij sovetskich istorikov 1920-ch - naxala 1930-ch gg. T. 1990.

Solov`eva, A.M.: Obsuždenie doklada V.I. Bovykina, I.F. Gindina i K.N. Tarnovskogo „Gosudarstvenno-monopolističeskij kapitalizm v Rossii“, in: ISSSR 1959, H. 3, 231-235.

Sovešcanie akademikov i členov-korrespondentov AN SSSR v redakcii žurnala "Voprosy istorii“", in: VI 1960, H. 8, 132-136.

Sovešcanie istorikov po voprosu o charaktere dviženija gorskich narodov Severnogo Kavkaza $v$ pervoj polovine XIX veka, in: VI 1956, H. 12, 191-198.

Soveščanie po koordinacii naučno-issledovatel'skoj raboty $v$ Otdelemi istoriceskich nauk AN SSSR, in: VI 1954, H. 1, $179 f$.

Sovetskaja derevnja v pervye poslevoennye gody. 1946-1950, M. 1978.

Sovetskaja istoričeskaja nauka na novom etape razvitija, in: VI 1960, H. 8, 3-18.

Sovetskaja istoriceskaja nauka na sovremennom etape, in: VI 1973, H. 5, 3-14.

Sovetskaja istorizeskaja nauka of XX k XXII s-ezda KPSS. Istorija SSSR. Sbornik statej, $M$. 1962.

Sovetskie istoriki obsułdajut zadaci nauki v svete resenij XXII s-ezda KPSS, in: VI 1962, H. 1, 313.

Sovetskij narod - novaja istoričeskaja obక̌čnost' ljudej. Stanovlenie i razvitie, M. 1975.

Sovokin, A.M.: V.I. Lenin ob istoričeskom opyte, in: VIKPSS 1984, H. 10, 31-43.

Sovremennaja nemarksistskaja istoriografija i sovetskaja istoriceskaja nauka. Beseda za „kruglym stolom", in: ISSSR 1988, H. 1, 172-202.

Sozdadim istoriju narodnogo partizanskogo dviženija 1941-1945 gg, in: ISSSR 1961, H. 2, 3-9.

Spirin, L.M.: Teorija, metodologija i metodika issledovanij po istorii KPSS, M. 1982.

Spločennost' $i$ edinstvo meždunarodnogo kommunističeskogo dviženija, in: VI 1958, H. 1, 3-21.

Stalin, I.: Ob učebnike istorii VKP(b). Pis'mo sostaviteljam učebnika istorii VKP(b), in: $K$ izučeniju istorii, M. 1937, 28-31.

Stalin, I.: Otvet t-šcu Notkinu, Aleksandru Il'icu (1952), in: StW 16, 246-257.

Stalin, I.V.: Ekonomiceskie problemy socializma v SSSR. UCastnikam ekonomičeskoj diskussii. Zamečanija po ekonomičeskim voprosam, svjazannym s nojabr'skoj diskussiej 1951 goda (1952), in: StW 16, 188-245.

Stalin, J.: Über einige Fragen der Geschichte des Bolschewismus. Brief an die Redaktion der Zeitschrift „Proletarskaja Rewoluzija“ (1931), in: ders., Fragen des Leninismus, Berlin 1955, 489-503.

Stanovlenie i razvitie novoj istoričeskoj obšcnosti - sovetskogo naroda. Kruglyj stol „Istorii SSSR“, in: ISSSR 1980, H. 6, 23-83

Starzew, W: Phantasie und Realität. Gab es eine Alternative zur Oktoberrevolution? In: Initial 1991, H. 1, 80-87 (zuerst in: K 1990, H. 15, 33-41).

Stranicy istorii KPSS. Fakty. Problemy. Uroki. Kniga 2, M. 1989. 
Stranicy istorii sovetskogo obšcestva: Fakty, problemy, ljudi, M. 1989.

Strel'skij, V.I.: Osnovnye principy naučnoj kritiki istočnikov po istorii SSSR, Kiev 1961 (Rezension von V.A. Kondrat'ev in: VI 1962, H. 2, 139-142).

Strižkov, Ju.K./A.I. Suslov: Novejక̌aja istoričeskaja literatura o bor'be na prodovol'stvennom fronte v gody graždanskoj vojny, in: VI 1980, H. 2, 118-127.

Strogo sobljudat' leninskij princip partijnosti $v$ istoriceskoj nauke, in: $K$ 1957, H. 4, 17-29.

Stroitel'stvo kommunizma i obszestvennye nauki, in: VI 1962, H. 11, 3-8.

Studien zur Logik der wissenschaftlichen Erkenntnis. Aus dem Russischen von G. Richter, Berlin 1967.

Sulimov, E.F.: Istoriceskij materializm kak nauka, M. 1960.

Surovaja drama naroda. Uzenye i publicisty o prirode stalinizma M. 1989.

Suslov, M.: Obšcestvennye nauki - boevoe oružie partii v stroitel'stve kommunizma, in: $K 1972$, H. 1, 18-30.

Suslow, M.A.: Der XXII. Parteitag der KPdSU und die Aufgaben der gesellschaftswissenschaftlichen Lehrstühle, in: SW 1962, H. 6, 569-604.

Sverženie samoderžavija, M. 1970.

Tarnovskij, K.N.: Formirovanie gosudarstvenno-monopolisticeskogo kapitalizma v Rossii v gody pervoj mirovoj vojny, M. 1958.

Tarnovskij, K.N.: Problema rossijskogo gosudarstvenno-monopolistiCeskogo kapitalizma perioda pervoj mirovoj vojny v sovetskoj istoriografii, in: VI 1961, H. 7, 33-53.

Tarnovskij, K.N.: Sovetskaja istoriografija rossijskogo imperializma (1917-1962 gg.), M. 1964 (Rezension von Joachim Mai in: JbGUV 10, Berlin 1967, 388-391).

Teoreticeskie problemy vsemirno-istoriceskogo processa, M. 1979, 5-43.

Teorija obక̌cestvenno-ekonomiceskoj formacij. Pod redakcii V.V. Denisova et al., M. 1982.

Teorija poznanija i sovremennaja nauka, M. 1967.

Tichomirov, M.N.: O nekotorych voprosach naučno-issledovatel'skoj raboty v oblasti istorii, in: VI 1954, H. 3, 179-182.

Tichonov, Ju.A.: Obšxee godičnoe sobranie, in: VI 1974, H. 5, 137-140.

Tichvinskij, S.L./V.A. Tiß̌kov: Važnoe sredstvo teoretiko-metodologičeskoj i idejno-vospitatel'noj raboty istorikov, in: VI 1983, H. 9,84-93.

Tichvinskij, S.L./V.A. Tiłkov: XV Mežcunarodnyj kongress istorizeskich nauk, in: VI 1980, H. 12, 3-23.

Tichvinskij, S.L.: Itogi i perspektivy issledovanij sovetskich istorikov, in: VI 1985, H. 7, 3-13.

Tichvinskij, S.L.: Janvarskij (1987 g) Plenum CK KPSS i istoričeskaja nauka, in: VI 1987, H. 6, 3-13.

Tichvinskij, S.L.: Nekotorye voprosy raboty sovetskich istorikov, in: VI 1986, H. 12, 3-12.

Tichvinskij, S.L.: O zadačach istoričeskoj naukj po realizacii rě̌enij ijun'skogo (1983 g.) plenuma CK KPSS, in: VI 1984, H. 1, 3-19.

Tichvinskij, S.L.: Sostojanie i zadaxi koordinacii istoriðeskich issledovanij, in: VI 1986, H. 9, 315.

Tichvinskij, S.L.: Zadači koordinacii v oblasti istoričeskoj nauki, in: ISSSR 1988, H. 1, 118-130.

Tiß̌kov, V.A.: Predstojǎ̌̌čij XIV meždunarodnyj kongress istoričeskich nauk, in: ISSSR 1975, H. 1, 242-245.

Titov, A.G.: Nekotorye voprosy osvescenija i primenenija istoričeskogo opyta KPSS, in: VIKPSS 1985, H. 7, 30-40.

Titov, A.I.: Zasedanie Otdelenija istorii v Leningrade, in: VI 1980, H. 7, 125-127.

TMGIAI, tom 17: Voprosy istoznikovedenija istorii SSSR, M. 1963.

TMGIAI, tom 24: Voprosy istoxnikovedenija istorii SSSR, vyp. 2, M. 1966. 
Tokarev, A.I.: Byla li al'ternativa Oktjabr'skoj revoljucii? In: Social 'no-polititeskie nauki 1991, H. 9, 21-32.

Totalitarizm kak istoriðeskij fenomen, M. 1989.

Trapeznikov, S.: Sovetskaja istoriceskaja nauka i perspektivy razvitija, in: K 1973, H. 11, 6886.

Trubicyn, O.N.: Ob ispol'zovanii zakonov obšcestvennogo razvitija, in: VF 1961, H. 9, 105-116.

Trubinova, T.S.: V otdelenii istorii AN SSSR, in: ISSSR 1991, H. 3, 232-234.

Trubinova, T.S.: Vstreca prezidenta Akademii nauk SSSR $s$ veduščimi sovetskimi istorikami, in: NNI 1990, H. 2, 251-253.

Trudnye voprosy istorii. Poiski. Razmyšlenija. Novyj vzgljad na sobytija i fakty, M. 1991.

Trudy Pervoj Vsesojuznoj konferencii Istorikov-marksistov. 28/XII 1928-4/I 1929. 2 Bände, M. 1930.

Tschepurenko, A.: Das Marxbild der Perestrojka: Zusammenbruch oder Krise des Marxismus? In: Prokla 1990, H. 12, 123-145.

Tschernajew, A.: Die letzten Jahre einer Weltmacht. Der Kreml von innen gesehen, Stuttgart 1993.

Tulenov, Z.: Istoriłeskij materializm kak nauka i zakony razvitija obšestva, Alma-Ata 1962.

„Unpersonen“ - wer waren sie wirklich? Bucharin, Rykow, Trotzki, Sinowjew, Kamenew, Berlin 1990.

Urok daet istorija, M. 1989.

Uvarov, A.I.: Gnoseologičeskij analiz teorii v istoriceskoj nauke, Kalinin 1973.

V Central'nom Komitete KPSS, in: VI 1969, H. 4, 3f.

$\checkmark$ učenom sovete Instituta istorii AN SSSR, in: VI 1954, H. 2, 1816.

V.1. Lenin o partijnosti $v$ istoriðeskoj nauke, in: VI 1958, H. 4, 3-22.

Vaganov, F.M.: K voprosu o suక̌nosti i značenii istoriłeskogo opyta KPSS, in: VIKPSS 1985, H. 8,61-70.

Vajnకtejn, O.L.: Stanovlenie sovetskoj istoriðeskoj nauki (20-e gody), in: VI 1966, H. 7, 32-47.

Vandalkovskaja, M.G./E.B. Emcenko: XXVII s-ezd KPSS i zadaxi istoriograficeskich i istožnikovedXeskich issledovanij, in: ISSSR 1988, H. 1, 141-149.

Varšav̌ik, M.A.: K voprosu o strukture i funkcijach istoričeskogo opyta KPSS, in: VIKPSS 1984, H. 10, 44-52.

Vasil'ev, A.F.: Novejక̌ie issledovanija po istorii promyకlennosti i rabozego klassa SSSR perioda Velikoj Otecestvennoj vojny, in: VI 1977, H. 6, 141-148.

Važnye zadax̌i istoriłeskoj nauki, in: VIKPSS 1973, H. 5, 7-23.

Velikie itogi i velikie perspektivy, in: VI 1959, H. 1, 3-21.

Velikie preimuščstva socializma v dejstvii, in: VI 1959, H. 2, 3-20.

Velikij Oktjabr' i mirovoe razvitie. Materialy sekcionnogo zasedanija, M. 1988.

Velikij Oktjabr' i real'nyj socializm. Materialy sekcionnogo zasedanija, M. 1988.

Velikij Oktjabr', bor'ba za mir i novoe politiðeskoe myšlenie. Materialy sekcionnogo zasedanija, M. 1988.

Velikij prodolžatel' dela Lenina, in: VI 1954, H. 12, 3-10.

Velikij sovetskij narod, Kiev 1976.

Velikoe edinstvo socialisticeskich stran nerusimo, in: K 1956, H. 16, 3-13.

Verbin, A./A. Furman: Mesto istoriteskogo materializma v sisteme nauk, M. 1965.

Verbin, A.I./A.P. Sercova: Istoriceskij materializm i nekotorye metodologiðeskie voprosy istorixeskoj nauki, in: Metodologixeskie voprosy obsčestvennych nauk (Sbornik statej). Vyp. 1, M. 1966, 331-350. 
Verbin, A.I./G.D. Karelova: $\mathrm{K}$ istoriografii voprosa o sootnošenii predmetov istoričeskogo materializma $\mathrm{i}$ istoričeskoj nauki, in: TMGIAI, tom 18: Voprosy istorii sovetskogo obšcestva. novoj i novejšej istorii, $M .1963,21-33$.

Verbin, A.I.P.M. Egides: Istoriðeskij materializm - metodologið̌skaja osnova istoriðeskoj nauki, in: TMGIAI, tom 25: Voprosy metodologii istoriceskoj nauki, M. 1967, 5-31

Vilenskij, B.V.: K voprosu o periodizacii istorii sovetskogo obšestva, in: VI 1955, H. 3, $78 f$.

Vinogradov, L.K.: Istoriko-partijnaja nauka - puti perestrojki i dal'nejšego razvitija, in: VIKPSS 1987, H. 7, 137-152.

Vinogradov, V./I. Maevskij: Protiv izvraščenija istorii obrazovanija socialističeskogo sposoba proizvodstva v SSSR, in: K 1956, H. 16, 122-128.

Vinogradov, V.A.: Sostojanie i perspektivy istoriko-ekonomičeskich issledovanij, in: VI 1988, H. 4, 3-12.

Vodolazov, G.G.: Al'ternativy istorii i istorija al'ternativ, in: Problemy mirovogo revoljucionnogo processa. Vypusk 8, M. 1989, 178-205.

Volin, M.S. et al:: O gegemonii proletariata v pervoj russkoj revoljucii, in: ISSSR 1973, H. 4, 4867.

Volkogonov, D.: Die interne Rede (Interview), in: Neue Zeit 1989, H. 16, 26-29.

Volkogonov, D.A.: Stalinizm - suščnost', genezis, evoljucija, in: VI 1990, H. 3, 3-17.

Volkov, F.D.: Vzlet i padenie Stalina, M. 1992.

Volkov, I.M./V.P. Danilov/V.P. Serstobitov: Problemy istorii sovetskogo krest janstva, in: ISSSR 1977, H. 3, 3-18.

Volkov, I.M.: Nekotorye voprosy istorii sel'skogo chozjajstva i krest'janstva v poslevoennye gody, in: ISSSR 1973, H. 1, 3-19.

Volkov, I.M.: Razvitie sel'skogo chozjajstva SSSR v poslevoennye gody (1946-1970), M. 1972.

Volobuev, O.V./S.V. Kuleł̌ov: Ołił̌̌cenie. Istorija i perestrojka. Publicističeskie zametki, M 1989

Volobuev, P.V.: 1917 god: byla li al'ternativa? In: Rodina 1989, H. 10, 14-17.

Volobuev, P.V.: 1917 god: Rossija na istoriðeskom pereput'e, in: Velikij Oktjabr'. Problemy istorii, M. 1987, 5ff.

Volobuev, P.V.: Charakter i osobennosti Fevral'skoj revoljucii, in: Sverženie 1970, 24-38.

Volobuev, P. V.: Monopolisticeskij kapitalizm v Rossii i ego osobennosti, M. 1956.

Volobuev, P.V.: Ob obßxich zakonomernostjach i nacional'no-istorizeskich uslovijach pobedy socialističeskoj revoljucii v Rossii, in: VI 1960, H. 11, 19-39.

Volobuev, P.V.: Po novomu puti: utverždenie socialističeskogo vybora Strany Sovetov, in: ON 1987, H. 5, 24-42.

Volobuev, P.V.: Stalinizm i social'noe poznanie sovetskogo obక̌estva, in: Istorija i stalinizm 1991, 21-36.

Volobuev, P.V.: Vybor putej obščestvennogo razvitija: teorija, istorija, sovremennost', M. 1987.

Volobuev, P.V.: Vybor putej istoriceskogo razvitija, in: Velikij Oktjabr' i mirovoe razvitie, 63-69.

Volobuev, P.V.: O gosudarstvenno-monopolistiðeskom kapitalizme v Rossii v $1917 \mathrm{~g}$ (martoktjabrja), in: VI 1959, H. 9, 44-63.

Vom Bann gelöst, M. 1989

Voprosy istorii kapitalisticeskoj Rossii. Problema mnogoukladnosti, Sverdlovsk 1972.

Vorožejkin, I.E./S.L. Senjavskij: Rabocij klass - vedušcaja sila sovetskogo obక̌cestva (Voprosy metodologii i istoriografii), M. 1977.

Vozvraščennye imena. Sbornik publicistǐ̌eskich statej v 2-ch knigach, M. 1989.

Vručenie žumalu „Voprosy istorii“ ordena Trudovogo Krasnogo Znamenii, in: VI 1978, H. 1, 312. 
Vsemirnaja istorija i vostok. Sbornik statej, M. 1989.

Vsemirno-istoriceskaja pobeda sovetskogo naroda, in: ISSSR 1975, H. 3, 3-11.

Vsesojuznoe Sovešcanie istorikov, in: VI 1963, H. 2, 3-75.

Vsesojuznoe Sovešcanie o merach ulučšenija podgotovki naučno-pedagogičeskich kadrov po istoriceskim naukam, 18-21 dekabrja 1962 g., M. 1964.

Vylcan, M.A.N.A. Ivnickij/Ju.A. Poljakov: Nekotorye problemy istorii kollektivizacii v SSSR, in: VI 1965, H. 3, 3-25.

Wegzeichen. Zur Krise der russischen Intelligenz. Essays von Nikolaj Berdjaev, Sergej Bulgakov, Michail Geršenzon. Aleksandr Izgoev, Bogdan Kistjakovskij, Petr Struve und Semen Frank. Eingeleitet und aus dem Russischen übersetzt von Karl Schlögel, Frankfurt am Main 1990.

7elenina, I.A.: O zakonach istoriceskoj nauki, in: Problema zakona v obščestvennych naukach, M. 1989, 93-107.

Želenina, I.A.: Ob ob-ektivnosti istorǐ̌eskogo znanija (kritičeskij analiz nekotorych sovremennych koncepcij), in: VMU Serija 8: Filosofija 1969, H. 2, 51-59.

Zilin, P.A.: Aktual'nye problemy issledovanija Velikoj Otečestvennoj vojny, in: VI 1977, H. 5, 323.

Żilin, P.A.: Buržuaznye fal'zifikatory istorii vtoroj mirovoj vojny, M. 1959.

Zuukov, E.M.: Istoričeskie nauki i obł̌čaja metodologija, in: Metodologičeskie problemy nauki 1964, 221-223.

Zukkov, E.M.: Očerki metodologii istorii. Izdanie vtoroe, ispravlennoe. Otvetstvennyj redaktor akademik Ju.V. Bromlej, M.1987.

"Jukov, E.M.: Osnovnye itogi i zadači istoričeskich issledovanij v svete rě̌enij XXV šezda KPSS, in: VI 1976, H. 4, 3-14.

Zukov, E.M.: Pjat'desjat let sovetskoj istoriceskoj nauki, in: VI 1968, H. 1, 18-28.

Zukov, E.M.: XXIl s-ezd KPSS i zadaxi sovetskich istorikov, in: VI 1961, H. 12, 3-13.

"Yurnal $\mathrm{i}$ istoriceskaja nauka, in: VI 1966, H. 1, 3-14.

Za dal'nejక̌ee ukreplenie naučnych svjazej meždu istorikami vsech stran, in: VI 1955, H. 8, 3-10.

Za glubokoe i vsestoronnee issledovanie istorii sovetskogo obšxestva, in: VI 1954, H. 9, 3-9.

Za leninskuju partijnost ${ }^{*} \mathrm{v}$ istoričeskoj nauke! In: VI 1957, H. 3, 3-19.

Za tvořeskoe izučenie istorii Sovetskich Vooružennych Sil, in: VI 1958, H. 2, 3-19.

Za tvorčeskoe izučenie istorii Velikoj Oktjabr'skoj socialističeskoj revoljucii, in: VI 1957, H. 7, 3-16.

Za tvorceskuju razrabotku istorii KPSS, in: K 1956, H. 10, 14-26.

Zadači istoričeskoj nauki v svete rešenij ijun'skogo Plenuma CK KPSS, in: VI 1963, H. 8, 3-18.

Zak, L.M.: Istorija kul'turnogo stroitel'stva SSSR v sovetskoj istoriografii (1956-1963 gg.), in: VI 1964, H. 2, 3-21.

Zak, L.M.: Sovremennaja sovetskaja istoriografija o problemach nacional'no-kul'turnogo stroitel'stva, in: ISSSR 1971, H. 5, 82-95.

Zamjatnin, V.N.M.I. Karuzina: $\mathrm{K}$ voprosu o dejstvii ekonomičeskich zakonov $\mathrm{v}$ antagonističeskich obščestvach, in: VI 1955, H. 5, 86-91.

Zastenker, N.E.: Problemy istoriceskoj nauki v trudach K. Marksa i F. Engel'sa, in: VI 1964, H. 6, 3-26.

Zelenin, I.E.: Problemy kollektivizacii sel'skogo chozjajstva v SSSR v novejšej sovetskoj istoriografii, in: ISSSR 1978, H. 1, 74-91.

Zevelev, A.I./V.P. Naumov: Istoriograficeskij fakt: Kriterii ocenki i analiza, in: VI 1980, H. 5, 18-30. 
Zevelev, A.I./V.P. Naumov: Istoriograficeskij fakt: Kriterii ocenki i analiza, in: Metodologiceskie i teoretiCeskie problemy, 54-70.

Zevelev, A.I.: Aktivizirovat' rabotu istoriografov, in: VIKPSS 1988, H. 12, 103-107.

Zipko, A. (= Cipko, A.): Die Philosophie der Perestroika. Die Grundlagen der Reformpolitik Michail Gorbatschows, München 1990.

Znamenitel'naja data $v$ istorii narodov SSSR, in: ISSSR 1972, H. 6, 5-10.

\section{Weitere Veröffentlichungen}

Ahlberg, R.: Armut in der Sowjetunion, in: OE 1990, H. 12, 1159-1174.

Ahlberg, R.: Die sowjetische Gesellschaftstheorie in der Mitte der achtziger Jahre, in: OE 1986, H. 5, 339-355.

Ahlberg, R.: Legitimationskrise der kommunistischen Herrschaf, in: OE 1990, H. 6, 517-534.

Ahlberg. R.: Stalinistische Vergangenheitsbewältigung. Auseinandersetzung über die Zahl der GULAG-Opfer, in: OE 1992, H. 11, 921-938.

Arazi, D.: Ein Putsch im Kreml, in: Die Zeit v. 30.08.1991, $45 f$.

Armstrong, J.A. (Hg): Soviet Partisans in World War II, Madison 1964.

Asendorf, M.: Geschichte und Parteilichkeit. Historisches Bewußtsein in Deutschland. Berlin (West) 1984.

Barber, J.: Soviet historians in crisis. 1928-1932, New York 1981.

Barber, J.: Stalin's letter to the editors of Proletarskaya revolyutsiya, in: Soviet Studies 1976, H. 1, 21-41.

Barloewen, W.D. von/C. von Barloewen: Die Gesetzmäßigkeit der Geschichte. Evolution und Zivilisation: Von den Anfängen der Menschheit bis ins dritte Jahrtausend. 2 Bände. Frankfurt am Main 1988.

Barthel, R.: Zur Entwicklung der Gesetzesauffassung in der Geschichtswissenschaft, in: Historiographiegeschichte 1991, 124-128.

Bartosz, J.: Die Wahrheit über Katyn. Ein neues Kapitel in den polnisch-sowjetischen Beziehungen, in: DVZ/die tat v. 17.03.1989.

Bartosz, J.: Ein polnisches Trauma, in: VZ v. 18.05.1990, 15.

Behrendt, L.-D.: Die Entwicklung der Ansichten M.N. Pokrovskjjs über den russischen Imperialismus. Zur Durchsetzung des Leninismus in der ersten Periode der sowjetischen Geschichtswissenschaf, in: ZfG 1971, H. 3, 382-392.

Beyrau, D./. Bock (Hg.): Das Tauwetter und die Folgen. Kultur und Politik in Osteuropa nach 1956, Bremen 1988.

Beyrau, D.: Die russische Intelligenz in der sowjetischen Gesellschaft, in: Geyer, Die Umwertung, 188-209.

Bloch, M.: Apologie der Geschichte oder Der Beruf des Historikers (1949), hg. von L. Febvre, München 1985.

Bollhagen, P.: Gesetzmäßigkeit und Gesellschaft. Zur Theorie gesellschafticher Gesetze (1967), s'Gravenhage 1973.

Bollhagen, P.: Soziologie und Geschichte, Berlin 1966.

Bonwetsch, B.: Das Ende der Sowjetunion: die untragbare Bürde der Weltmacht, in: OE 1992, H. 7, 551-563.

Bonwetsch, B.: Der „Große Vaterländische Krieg“ und seine Geschichte, in: Geyer, Die Umwertung, 167-187.

Bonwetsch, B.: Die Bewältigung der Vergangenheit. Geschichts- und Gesellschaftswissenschaften in der „Perestrojka“, in: Mommsen/Schröder, Gorbatschows Revolution, 74-88. 
Bonwetsch, B.: Die Blickwinkel wechseln. Geschichtswissenschaft in der „Umgestaltung“. Persönliche Erfahrungen mit einer Konferenz in Odessa, in: Das Parlament, 05./12.09. 1987, $8 f$.

Bonwetsch, B.: Oktoberrevolution. Legitimationsprobleme der sowjetischen Geschichtswissenschaft, in: Politische Vierteljahresschrift 1976, H. 2, 149-185.

Bonwetsch, B.: Rußland, Oktober 1917: Hegemonie des Proletariats oder Volksrevolution? Bemerkungen zur sowjetischen Historiographie seit Anfang der siebziger Jahre, in: OE 1987, H. 10, 733-747.

Bonwetsch, B.: Sowjetische Partisanen 1941-1944. Legende und Wirklichkeit des, allgemeinen Volkskrieges", in: Schulz, G. (Hg.): Partisanen und Volkskrieg. Zur Revolutionierung des Krieges im 20. Jahrhundert, Göttingen 1985, 92-124.

Bonwetsch, B.: Vom Hitler-Stalin-Pakt zum „Unternehmen Barbarossa“. Die deutsch-russischen Beziehungen 1939-1941 in der Kontroverse, in: OE 1991, H. 6, 562-579.

Borcke, A. von/G. Simon: Neue Wege der Sowjetunion-Forschung. Beiträge zur Methoden- und Theoriediskussion, Baden-Baden 1980.

Brahm, H.: Glasnost - die Stunde der Wahrheit, in: OE 1991, H. 3, 236-246.

Brahm, H.: Gorbatschows erste Schritte, in: Sowjetunion 1986/87. Ereignisse, Probleme, Perspektiven, hg. v. BOIS, München-Wien 1987, 21-33.

Brahm, H.: Tohuwabohu in der Sowjetunion, in: Sowjetunion 1991, 21-31.

Brandt, H.: Die soziale Revolution des Nikita Sergejewitsch Chruschtschow, in: Crusius/Wilke, Entstalinisierung, 285-320.

Braudel, F.: Die lange Dauer, in: Theorieprobleme der Geschichtswissenschaft. hg. v. Th. Schieder und K. Gräubig. Darmstadt 1977, 164-204.

Broué, P.: Gorbachev and history, in: White, St. (Ed.): New directions in Soviet history, Cambridge 1992, 3-23.

Bühl, A. (Hg.): Der Hitler-Stalin-Pakt. Die sowjetische Debatte, Köln 1989.

Carr, E.H.: Was ist Geschichte? (1961), Stuttgart 1963

Chladenius, J.M.: Aus der 'Allgemeinen Geschichtswissenschaft' (1752), in: Hardtwig, W. (Hg.): Über das Studium der Geschichte, München 1990, 11-17.

Conert, H.: Die Ökonomie des unmöglichen Sozialismus. Krise und Reform der sowjetischen Wirtschaft unter Gorbatschow, Münster 1990.

Conert, $\mathrm{H}$ : Überlegungen zur Analyse der Ursachen des Scheiterns der sowjetischen Perestrojka, in: Der Trümmerhaufen als Aussichtsturm. Historische, aktuelle und perspektivische Vermessungen einer gründlich veränderten Situation, Marburg 1991, 43-81.

Crusius, R.M. Wilke (Hg): Entstalinisienung. Der XX. Parteitag der KPdSU und seine Folgen, Frankfurt/Main 1977.

Dahm, H.: Die Ideologie als Chiffre der Politik, in: Sowjetunion 1985, 73-83.

Dahm, H.: Sozialistische Krisentheorie. Die sowjetische Wende - ein Trugbild, München 1987.

Dallin, A.: The Soviet Social Sciences After Stalin, in: Winger, H.W. (Ed.): Iron Curtons and Scholarship. The Exchange of Knowledge in an Divided World, Chicago 1958, 82-95.

Daniels, R.V.: The end of the Communist revolution, London 1993.

Davies, R.W.: Perestroika und Geschichte. Die Wende in der sowjetischen Historiographie, München 1991

Davies, R.W.: Soviet History in the Gorbachev Revolution, Birmingham 1989.

Deinand, A.: Ungeschehene Geschichte. Ein Traktat über die Frage: Was wäre geschehen, wenn...? 2. Auflage, Göttingen 1986.

Dietz, B.WW. Sörgel: Mehr Sorgen als Hoffnungen. Meinungsumfragen in der Sowjetunion, in: Schewardnadse/Gurkow/Eichwede, Revolution, 225-243. 
Dittrich, G.: Die sowjetische Historiographie zur Geschichte der Arbeiterklasse der UdSSR in der Übergangsperiode 1917-39. Entwicklungen und Ergebnisse, theoretisch-methodologische Positionen und Probleme, in: JbG 17, Berlin 1977. 267-315.

Dittrich, G.: Sowjetische Publikationen zur Geschichte der Arbeiterklasse der UdSSR, in: BzG 1973, H. 6, 1026-1040.

Durovic, S.: Marksisticka istoriografska škola Pokrovskog. Beograd 1977.

Eichwede, W.: Abweichendes Denken in der Sowjetunion, in: GuG 1987, H. 1, 39-62.

Engelberg, E.: Parteilichkeit und Objektivität in der Geschichtswissenschaft, in: ZfG 1969, H. $1 / 2,74-79$.

Engelberg, E.: Über Gegenstand und Ziel der marxistisch-leninistischen Geschichtswissenschaft. in: Marxismus Digest 1971, H. 2, 3-29

Engels, F. an August Bebel am 1./2. Mai 1891, in: MEW 38, 89-97.

Engels, F./K. Marx: Die heilige Familie oder Kritik der kritischen Kritik. Gegen Bruno Bauer und Konsorten (1845), in: MEW 2, 3-223.

Engels, F. an Joseph Bloch. 21./22. September 1890, in: MEW 37, 462-465

Engels, F.: Der Ursprung der Familie, des Privateigentums und des Staats. Im Anschluß an Lewis H. Morgans Forschungen (1884), in: MEW 21, 25-173.

Engels, F.: Ludwig Feuerbach und der Ausgang der klassischen deutschen Philosophie (1886), in: MEW 21, 259-307.

Ennker, B.: Ende des Mythos? Lenin in der Kontroverse, in: Geyer, Die Umwertung. 54-74.

Enteen, G.M.: A Recent Trend on the Historical Front, in: Survey 1974, H. 4, 122-131

Enteen, G.M.: The Soviet Scholar-Bureaucrat. M.N. Pokrovskij and the Society of Marxist Historians, London 1978.

Entin, Dz.. (= Enteen, G.M.): Spor o M.N. Pokrovskom prodolł̌aetsja, in: VI 1989, H. 5, 154-159.

Entin, Dł. (= Enteen, G.M.): Intellektual nye predposylki utverždenija stalinizma $v$ sovetskoj istoriografii, in: VI 1995, H. 5-6, 149-155.

Erdmann, K.D.: Die Ökumene der Historiker. Geschichte der Internationalen Historikerkongresse und des Comite International des Sciences Historiques (= Abhandlungen der Akademie der Wissenschaften in Göttingen. Philologisch-historische Klasse. Dritte Folge Nr. 158), Göttingen 1987.

Eulenburg, F.: Sind „Historische Gesetze“ möglich? Eine methodologische Untersuchung, in: Palyj, M. (Hg.): Hauptprobleme der Soziologie. Erinnerungsausgabe für Max Weber, 1. Band, München-Leipzig 1923, 23-71.

Faber, K.-G.: Theorie der Geschichtswissenschaft, 3., erweiterte Auflage, München 1974.

Fainsod, M.: Historiography and Change, in: Keep. Contemporary History, 19-33.

Fedenko, P.: Khrushchev's New History of the Soviet Communist Party, München 1963

Fleischer, H.: Marxismus und Geschichte (1969), 3. Auflage. Frankfurt am Main 1970.

Friese, C.: M.N. Pokrowskij, der führende sowjetrussische Historiker der zwanziger Jahre zwischen kritischer Wissenschaft, Geschichtstheorie und Parteidoktrin, in: Dietrich, R. (Hg.): Historische Theorie und Geschichtsforschung der Gegenwart, Berlin 1964, 117-149.

Fülberth, G.: Sieben Anstrengungen, den vorläufigen Endsieg des Kapitalismus zu begreifen, Hamburg 1991

Fülberth, G.: Trotzki als Gegengift, in: Konkret 1988, H. 11, 28-32.

Geller, M.: Sed'moj sekretar'. Blesk i nišceta Michaila Gorbačeva, London 1991

Geyer, D. (Hg.): Die Umwertung der sowjetischen Geschichte (= GuG Sonderheft 14), Göttingen 1991.

Geyer, D. (Hg.): Wirtschaft und Gesellschaft im vorrevolutionären Rußland, Köln 1975. 
Geyer, D.: Blick zurück ins alte Rußland. Als Bauer und Christ noch eins waren - Die Wurzeln des neuen sowjetischen Reformkurses, in: Die Zeit v. 11.11.1988, 49.

Geyer, D.: Das Ende des Sowjetimperiums. Eine historische Betrachtung, in: OE 1992, H. 4, 295-302.

Geyer, D.: Den toten Gott im Herzen tragen. Das Wiederaufleben der idealistischen russischen Philosophie, in: FAZ v. 24.05.1989.

Geyer, D.: Die russische Revolution. Neuerscheinungen im Jubiläumsjahr 1967, in: JbbGO 1968, 531-548.

Geyer, D.: Gegenwartsfragen der sowjetischen Geschichtswissenschaft, in: Vierteljahreshefte fur Zeitgeschichte 1967, H. 2, 109-120.

Geyer, D.: Klio in Moskau und die sowjetische Geschichte, Heidelberg 1985

Geyer, D.: Perestrojka in der sowjetischen Geschichtswissenschaft, in: ders., Die Umwertung, 931.

Geyer, D.: Perestrojka und die sowjetische Geschichte, in: GuG 1989, H. 3, 303-319.

Geyer, D.:Was in einem Namen liegt. Welches Rußland kehrt in die Geschichte zurück? In: FAZ v. 18.09.1991, N3f.

Glaeßner, G.-J.: Sozialistische Systeme. Einfuihrung in die Kommunismus- und DDR-Forschung. Opladen 1982.

Götz, R.: Sowjetische Wirtschaftsentwicklung und Wirtschaftsreformen, in: Schwegler-Rohmeis, W./K. Segbers $(\mathrm{Hg}$ ): Perestrojka passé? Eine Zwischenbilanz der Reformpolitik in der Sowjetunion, Opladen 1992, 19-37.

Götz-Coenenberg, R.: Manager gegen Bürokraten. Probleme bei der Umgestaltung des sowjetischen Wirtschaftssystems, in: Mommsen/Schröder, Gorbatschows Revolution, 157-174.

Gransow, V.: Konzeptionelle Wandlungen der Kommunismusforschung. Vom Totalitarismus zur Immanenz, Frankfurt-New York 1980.

Großer, G.: Der Gegenstand des wissenschaftlichen Kommunismus. Methodologische Probleme seiner Bestimmung. Berlin 1981.

Grotzky, J.: Konflikt im Vielvölkerstaat. Die Nationen der Sowjetunion im Aufbruch, MünchenZürich 1991.

Hagen, M. von: History and Politics under Gorbachev: Professional Autonomy and Democratization, in: The Harriman Institute Forum 1988, H. 11, 1-8.

Halbach, U.: Der Zerfall der Union. Vom nationalen Aufbegehren zur Souveränität, in: Schewardnadse/Gurkow/Eichwede, Revolution, 176-195.

Halbach, U.: Die Nationalitätenfrage: Kontinuität und Explosivität, in: Geyer, Die Umwertung, $210-237$.

Hardtwig, W.: Konzeption und Begriff der Forschung in der deutschen Historie des 19. Jahrhunderts, in: Diemer, A. (Hg.): Konzeption und Begriff der Forschung in den Wissenschaften des 19. Jahrhunderts, Meisenheim am Glan 1978, 11-26.

Hardtwig. W.: Von Preußens Aufgabe in Deutschland zu Deutschlands Aufgabe in der Welt. Liberalismus und borussianisches Geschichtsbild zwischen Revolution und Imperialismus. in: ders., Geschichtskultur und Wissenschaft. München 1990, 103-160 (Wiederabdruck aus: $\mathrm{HZ} 1980,265-324)$.

Haug, W.F.: Gorbatschow. Versuch über den Zusammenhang seiner Gedanken, Hamburg 1989.

Hecker, H.: Russische Universalgeschichtsschreibung. Von den „Vierziger Jahren“ des 19. Jahrhunderts bis zur sowjetischen „Weltgeschichte" (1955-1965), München-Wien 1983.

Hecker, H.: Untergang eines Weltreiches, in: OE 1992, H. 6, 465-481.

Heer, N.W.: Politics and History in the Soviet Union, Cambridge (Massachusetts)-London 1971.

Heller, I.: Die Entstehung und Entwicklung der neuen geschichtswissenschaftlichen Institutionen in der Sowjetunion (von 1917 bis zur Mitte der 30er Jahre), Halle 1986. 
Heller, M./A. Nekrich (=Nekrix. A.): Geschichte der Sowjetunion. Zweiter Band: 1940-1980, Königstein 1982.

„Hieb mit dem Pickel“, in: Der Spiegel 1987, H. 31, 93-95.

Hielscher, K.: Der neue Frühling in Literatur und Kunst, in: Mommsen/Schröder, Gorbatschows Revolution, 31-51.

Hildermeier, M.: Die russische Revolution 1905-1921, Frankfurt am Main 1989.

Hildermeier, M.: Revolution und Revolutionsgeschichte, in: Geyer, Die Umwertung, 32-53.

Hirsch, H.: Probleme der Perestrojka sowjetischer Planwirtschaft. Möglichkeiten und Schwierigkeiten der Umgestaltung, in: OE 1990, H. 8, 728-760.

Historiographiegeschichte als Methodologiegeschichte. Zum 80. Geburtstag von Ernst Engelberg (= Sitzungsberichte der Akademie der Wissenschaften in Berlin, Jahrgang 1991, Nr. 1), Berlin 1991.

Hitzer, F.: Die große Unordnung. Glasnost und die Deutschen, Hamburg 1989.

Hoffer, F.: Perestroika. Die unfreiwillige Zerstörung des sowjetischen Vergesellschaftungszusammenhangs, oder: wanum das letzte Gefecht verloren ging. Marburg 1992.

Hofmann, W.: Grundelemente der Wirtschaftsgesellschaft. Ein Leitfaden für Lehrende, Reinbek 1969.

Hofmann, W.: Ideengeschichte der sozialen Bewegung des 19. und 20. Jahrhunderts, 6., erweiterte Auflage, Berlin-New York 1979.

Hofmann, W.: Was ist Stalinismus? (Erstveröffentlichung 1967), Heilbronn 1984.

Höhmann, H.-H.: Der ökonomische Systemwechsel, in: Schewardnadse/Gurkow/Eichwede, Revolution, 207-224.

Höhmann, H.-H.: Sowjetische Wirtschaft unter Gorbatschow. Auf der Suche nach neuem Profil, in: Sowjetunion 1987, 112-132.

Höhmann, H.H.: Sowjetische Wirtschaft 1990/91: Krise und Notstandsregiment statt Systemwechsel, in: Sowjetunion 1991, 135-151.

Holm, K.: Verbrecher Nummer eins. Die erste und bisher einzige sowjetische Hitlerbiographie, in: FAZ v. 11.12.1991, N3.

Holtbrügge, D.: Die UdSSR auf dem Weg zur Marktwirtschaft. Programme, Maßnahmen, Widerstände, in: OE 1991, H. 7, 619-634.

Hörz, H.: Gesetz/Gesetzmäßigkeit, in: EEPhW 2, Hamburg 1990, 425-436.

Hösler, J.: Ein Anfang. Bemerkungen zum gerade erschienenen Buch „Stalin bewältigen“, in: MB 1989, H. 5, 94-100.

Hösler, J.: Sowjet-Union perdu, in: FW 1991, H. 3, 62f.

Huber, M.: Die soziale Lage der Bevölkerung, in: Sowjetunion 1991, 165-173.

Huffschmid. J.: Umbau der Wirtschaft und Beschleunigung der sozialökonomischen Entwicklung. Zur neuen wirtschaftspolitischen Strategie in der Sowjetunion, in: Blätter 1987, H. 1, 73-88.

Huguet, M.G.: Freiheit, in: EEPhW 2, Hamburg 1990, 157-180.

lggers, G.G.: Geschichtswissenschaft im 20. Jahrhundert. Ein kritischer Überblick im internationalen Zusammenhang, Göttingen 1993.

Ito, T. (Ed.): Facing Up to the Past. Soviet Historiography under Perestroika, Sapporo 1989.

Jaeck, H.-P.: Der Gesetzesbegriff bei Montesquieu und Marx, in: Historiographiegeschichte, 118123.

Jäger, F./J. Rüsen: Geschichte des Historismus. Eine Einführung, München 1992.

Joravsky, D./C.N. Koblernicz: Parteilichkeit, in: SDG 4, Freiburg-Basel-Wien 1971, 1119-1133.

Judick, G./K. Steinhaus $(\mathrm{Hg}$ ): Stalin bewältigen. Sowjetische Dokumente der 50er, 60er und 80er Jahre, Düsseldorf 1989. 
Jung, H.: Abschied von einer Realität. Zur Niederlage des Sozialismus und zum Abgang der DDR. Ein politisches Tagebuch - Sommer 1989 bis Herbst 1990, Frankfurt am Main 1990.

Kahn, H.W.: Die Deutschen und die Russen. Geschichte ihrer Beziehungen, Köln 1984.

Kaplan, K.: Die politische Krise in der Tschechoslowakei 1956, in: Beyrau/Bock, Das Tauwetter, 72-84.

Kappeler, A.: Die Historiographien der nichtrussischen Völker der RSFSR in den siebziger Jahren, JbbGO 1981, 53-79.

Kasack, W.: Die Akademie der Wissenschaften der UdSSR. Überblick über Geschichte und Struktur. Verzeichnis der Institute, 3. Auflage, Boppard 1978.

Kasack, W.: Literatur und Literaturpolitik in der UdSSR im Wandel. Das Jahr 1986, in: OE 1987, H. 2, 93-105.

Keep, J. (Ed.): Contemporary History in the Soviet Mirror, London 1964.

Kerner, M./S. Stopinski: Vom Umgang mit der eigenen Geschichte. Über die selektive Wahrnehmung der Vergangenheit in den baltischen Republiken, in: OE 1991, H. 6, 602-610.

Klaus, G./M. Buhr (Hg): Philosophisches Wörterbuch, 13. Auflage als fotomechanischer Nachdruck der 12. durchgesehenen Auflage, Westberlin 1985.

Knoll, V./. Kölm (Hg): Der Fall Berija. Protokoll einer Abrechnung. Das Plenum des ZK der KPdSU Juli 1953. Stenographischer Bericht, Berlin 1993.

Kolakowski, L.: Die Hauptströmungen des Marxismus. Entstehung, Entwicklung. Zerfall (1976), 3 Bände, 2., überarbeitete Auflage, München-Zürich 1981.

Kolendic, A.: Machtkampf im Kreml. Vom Tode Stalins bis zur Hinrichtung Berijas, BergischGladbach 1983.

König. H.: Das deutsch-sowjetische Vertragswerk von 1939 und seine Geheimen Zusatzprotokolle. Eine Dokumentation, in: OE 1989, H. 5, 413-458.

Korab, A.: Beseitigung von "weißen Flecken" zwischen Moskau und Warschau? Polnischsowjetische Vereinbarungen zur Aufklärung der Geschichte, in: OE 1988, H. 5, 385-389.

Kuczynski, J.: „Ein linientreuer Dissident“. Memoiren 1945-1989, Berlin und Weimar 1992.

Kuczynski, J.: Frost nach dem Tauwetter. Mein Historikerstreit, Berlin 1993.

Kuhn, T.S.: Die Struktur wissenschaftlicher Revolutionen (amerikanische Originalausgabe 1962, 2. Auflage 1970), Frankfurt am Main 1973.

Kunkel, W.: Geschichte als Prozeß? Historischer Materialismus oder Marxistische Geschichtstheorie, Hamburg 1987.

Küttler, W.: Historiographiegeschichte als Methodologiegeschichte. Zur Problemstellung einer Entwicklungsgeschichte der theoretischen und methodologischen Grundlagen der Geschichtswissenschaft, in: Historiographiegeschichte, 14-32.

Kux, S.: Demokratisierung und Föderalisierung. Das politische System der ehemaligen UdSSR im Wandel, in: Veen/Weilemann, Rußland 1993, 43-78.

Labica, G.: Der Marxismus-Leninismus. Elemente einer Kritik (1984), West-Berlin 1986.

Ladriere, J./H. Fleischer: Kontingenz, in: SDG 3, Freiburg-Basel-Wien 1969, 877-889.

Lapidus, G.W.N. Zaslavsky/Ph. Goldman (Ed.): From union to commonwealth: Nationalism and separatism in the Soviet republics, Cambridge 1992.

Laqueur, W.: Stalin. Abrechnung im Zeichen von Glasnost, München 1990.

Le Goff, J.: Neue Geschichtswissenschaft, in: Le Goff, J./R. Chartier/J. Revel (Hg.): Die Rückeroberung des historischen Denkens. Grundlagen der Neuen Geschichtswissenschaft (französische Originalausgabe 1978), Frankfurt am Main 1990, 11-61.

Leciejewski, K.: Blick nach vorn auf Trotzki und Stalin. Das Geschichtsbild und die Legitimation der Sowjetunion in der Gorbatschow-Ära, in: FAZ v. 22.02.1988, 10. 
Leitsch, W.: Die Veränderungen der historischen Bewertung, in: Boetticher, E./H.-J. Lieber/B. Meissner (Hg.): Bilanz der Ära Chruschtschow, Stuttgart-Berlin-Köln-Mainz, 1966, 258277.

Leonhard, W.: Am Vorabend einer neuen Revolution? Die Zukunft des Sowjetkommunismus, München etc. 1975.

Leonhard, W.: Die Dreispaltung des Marxismus. Ursprung und Entwicklung des Sowjetmarxismus, Maoismus und Reformkommunismus, Düsseldorf-Wien 1970.

Leonhard, W.: Die Revolution entläßt ihre Kinder, Köln-Berlin 1955

Leonhard, W.: Spurensuche. Vierzig Jahre nach „Die Revolution entläßt ihre Kinder“, Köln 1992.

Leonhard, W.: War Lenin verantwortlich für den Stalinismus? Persönliche Betrachtungen eines Zeitzeugen, in: OE 1991, H. 10,997-1007.

Lewin, M.: Gorbatschows neue Politik. Die reformierte Realität und die Wirklichkeit der Reformen, Frankfurt am Main 1988.

Lewytzkyj, B. (Ed.): Who's Who in the Soviet Union. A Biographical Encyclopedia of 5,000 Leading Personalities in the Soviet Union, München etc. 1984

Lewytzkyj, B./Ju. Stroynowski (Ed.): Who's Who in the Socialist Countries. A Biographical Encyclopedia of 10,000 Leading Personalities in 16 Communist Countries, First Edition, New York-München 1978.

Lewytzkyj, B.: „Sovetskij narod“, „Das Sowjetvolk“. Nationalitätenpolitik als Instrument des Sowjetimperialismus, Hamburg 1983

Liszkowski, U.: Die Revision der sowjetischen Geschichte im Zeichen der Perestrojka. Eine Zwischenbilanz, in: GWU 1990, H. 11, 653-674.

Lötzsch, R.: Sowjetische Nationalitätenpolitik von Lenin bis Gorbatschow, in: Hertzfeldt, L. (Hg.): Die Sowjetunion. Zerfall eines Imperiums, Frankfurt am Main 1992, 67-101.

Luchterhandt, G.: Die politischen Parteien im neuen Rußland. Dokumente und Kommentare, Bremen 1993.

Luks, L.: Das Ende der Doppelherrschaft in der Sowjetunion. Eine Revanche der russischen Demokraten, in: OE 1992, H. 3, 227-231.

Mackow, J.: Der Totalitarismus-Ansatz und der Zusammenbruch des Sowjetsozialismus, in: OE 1994, H. 4, 320-329.

Madajczyk, C.: Das Drama von Katyn, hg. von D. Fuchs, Berlin 1991.

Maier, F.G.: Der Gesetzesbegriff in den historischen Wissenschaften, in: Studium Generale 1966, H. 11, 657-667.

Maier, R.: Stalinismus. Die zwanziger Jahre, Wiesbaden 1990.

Malia, M.: The Soviet Tragedy. A History of Socialism in Russia, 1917-1991, New York-Toronto 1994.

Marko, K.: Dogmatismus und Emanzipation in der Sowjetunion. Philosophie, Reformdenken, Opposition, Stuttgart-Berlin-Köln-Mainz 1971.

Marko, K.: Sowjethistoriker über sich, in: Gedenkschrift Martin Göhring. Studien zur europäischen Geschichte, Wiesbaden 1968, 413-430.

Marko, K.: Sowjethistoriker zwischen Ideologie und Wissenschaft. Aspekte der sowjetrussischen Wissenschaftspolitik seit Stalins Tod, 1953-1963, Köln 1964.

Marko, K.: Streit in der sowjetischen Geschichtswissenschaft. Notiz zur ideologischen Gegenwartssituation in der Sowjetunion, Bericht des BOIS 23/1972.

Markwick, R.D.: Catalyst of Historiography, Marxism and Dissidence: The Sector of Methodology of the Institute of History, Soviet Academy of Sciences, 1964-68, in: Europe-Asia Studies 1994, H. 4, 579-596. 
Martiny, A.: Das Verhältnis von Politik und Geschichtsschreibung in der Historiographie der sowjetischen Nationalitäten seit den sechziger Jahren, in: JbbGO 1979, 238-272.

Marx, K./F. Engels: Die deutsche Ideologie. Kritik der neuesten deutschen Philosophie in ihren Repräsentanten Feuerbach, B. Bauer und Stirner, und des deutschen Sozialismus in seinen verschiedenen Propheten (1846), in: MEW 3, 9-530.

Marx, K.: Das Kapital. Kritik der politischen Ökonomie. Erster Band, Buch I: Der Produktionsprozeß des Kapitals (1867), in: MEW 23.

Marx, K.: Ökonomisch-philosophische Manuskripte aus dem Jahre 1844, in: MEW, Ergänzungsband Erster Teil, Berlin 1968, 467-588.

Marx, K.: Thesen über Feuerbach (1845/88), in: MEW 3, 5-7 und 533-535.

Marx, K.: Zur Kritik der Politischen Ökonomie (1859), in: MEW 13, 7-160.

Marx-Engels Begriffslexikon, hg. von K. Lotter, R. Meiners und E. Treptow, München 1984.

Meissner, B.: Bilanz der „Breschnew-Ära“, in: Aus Politik und Zeitgeschichte. Beilage zur Wochenzeitung ,Das Parlament“, B 7/83, 3-19.

Meissner, B.: Das Ende der Sowjetunion, der Abgang Gorbatschows und Jelzins „Revolution von oben". Transformation der „Union der Sozialistischen Sowjet-Republiken“ in „Gemeinschaft unabhängiger Staaten", in: OE 1992, H. 9, 836-857.

Meissner, B.: Die KPdSU zwischen Macht und Ohnmacht, in: OE 1991, H. 1, 15-45.

Meissner, B.: Die zweite Phase der soziopolitischen Reform Gorbatschows (I und II). Die Sowjetunion vor dem XXVIIl. Parteitag der KPdSU, in: OE 1990, H. 11, 1031-1049; H. 12. 1145-1158.

Meissner, B.: Gorbatschow am „Rubikon“, in: OE 1988, H. 11, 981-1001; H. 12, 1061-1090.

Meissner, B.: Gorbatschow am Scheideweg (I und II), in: OE 1991, H. 5, 467-492; H. 7, 671-694.

Meissner, B.: Gorbatschow, Jelzin und der revolutionäre Umbruch in der Sowjetunion (I-IV), in: OE 1991, H. 12, 1187-1205; 1992, H. 1, 21-40; H. 3, 205-226; H. 5, 482-500.

Meissner, B.: Gorbatschows Umbau des Sowjetsystems, in: OE 1989, H. 7, 603-617; H. 8, 702 719 ; H. 10, 874-883; H. 11/12, 995-1020; 1990, H. 1, 68-85; H. 2, 105-114.

Merl, S.: Kollektivierung und Bauernvernichtung, in: Geyer, Die Umwertung, 103-132.

Meyer, Gerd: Sozialistische Systeme. Theorie- und Strukturanalyse. Ein Studienbuch, Opladen 1979.

Meyer, Ger (Hg.): Nationalitätenkonflikte in der Sowjetunion, Köln 1990.

Meyer, Gert (Hg.): Sowjetunion zu neuen Ufern? 27. Parteitag der KPdSU März '86. Dokumente und Materialien mit einer Einleitung von Dr. Gert Meyer, Düsseldorf 1986.

Meyer, Gert: Industrialisierung. Arbeiterklasse und Stalinherrschaft in der UdSSR, in: Das Argument 106, Berlin 1977, 844-859.

Meyer, Gert: Stalinismus, in: EEPhW 4, 447-456.

Mommsen, M./H.-H. Schröder (Hg.): Gorbatschows Revolution von oben. Dynamik und Widerstände im Reformprozeß der UdSSR, Frankfurt am Main-Berlin 1987.

Moskoff. W.: Hard times. Impoverishment and protest in the perestroika years. The Soviet Union 1985-1991, New York 1993.

Müller, R.: Thukydides' Auffassung von historischer Gesetzmäßigkeit, in: Historiographiegeschichte, 92-101

Munier, G.: „Liebling der ganzen Partei“, in: Konkret 1988, H. 11, 22-25.

Naumann, K.: Ökonomische Gesellschaftsformation und historische Formationsanalyse, Köln 1983.

Nolte, H.-H.: „Drang nach Osten“. Sowjetische Geschichtsschreibung der deutschen Ostexpansion, Köln-Frankfurt am Main 1976. 
Nolte, H.-H.: Zur Diskussion der Nationalitätenprobleme in der Zeitschrift „Kommunist“, in OE 1991, H. 3, 259-268.

Oberländer, E. (Hg.): Hitler-Stalin-Pakt 1939. Das Ende Ostmitteleuropas?, Frankfurt/Main 1989.

Oberländer, E.: Sowjetpatriotismus und Geschichte. Dokumentation, Köln 1967.

Oberländer, E.: Zur Parteigeschichtsschreibung nach Stalin. Ein Vergleich der ersten und zweiten Auflage der neuen "Geschichte der KPdSU“ von 1959 und 1962, in: Ost-Probleme 1963, 753-759.

Oelkers, J.: Rekonstruktion und Theorie. Probleme der historischen Methodologie, in: Ansichten einer künftigen Geschichtswissenschaft I: Kritik - Theorie - Methode, hg. von I. Geiss und $R$. Tamchina, München 1974, 120-139.

Oexle, O.G.: „Historismus“. Überlegungen zur Geschichte des Phänomens und des Begriffs, in: JbBWG 1986, 119-155.

Okuda, H.: Recent Rethinking of Collectivization in the Soviet Union, in: Ito, Facing up to the Past, 169-183.

Paul, G.: Zwei Modelle des Sozialismus in der Geschichte Sowjetrußlands, in: Initial 1990, H. 5, 466-474.

Perestroika und die Linke in der Bundesrepublik. $\mathrm{Zu}$ den aktuellen Umgestaltungsprozessen in der UdSSR. Beiträge der gemeinsamen Tagung „Umbruch in der Sowjetunion?“, FrankfurtMain, 5. September 1987, veranstaltet vom Institut für Internationale Arbeiterbewegung der AdW der UdSSR (IMRD, Moskau), der Zeitschrift ,sozialismus“ (Hamburg) und dem IMSF (FrankfurtMain), hg. vom IMSF und der Zeitschrift ,sozialismus“, Frankfurt 1988.

Pethybridge, R.: A Key to Soviet Politics. The Crisis of the Anti-Party Group, New York 1962.

Piroschkow, V.: Sowjetische Geschichtswissenschaft im inneren Widerstreit, in: Saeculum 1960, H. $1 / 2,180-198$.

Popov, St:: Suscestvujut li specificeskie istoriceskie zakony? In: FN 1971, H. 6, 147-152.

Prominent Personalities in the USSR. A Biographic Directory Containing 6,015 Biographies of Prominent Personalities in the Soviet Union. Compiled by the Institute for the Study of the USSR (Munich), Metuchen, New Jersey 1968.

Rahr, A.: Die Reform des politischen Systems, in: Schwegler-Rohmeis/Segbers, Perestrojka, 3952.

Rauch. G.v.: Grundlinien der sowjetischen Geschichtsforschung im Zeichen des Stalinismus, in: Europa-Archiv 1950, 3383-3388; 3423-3432; 3489-3494.

Rejman, M.: Perestrojka i izuCenie sovetskoj istorii, in: VI 1989, H. 12, 145-158.

Rhode, G.: Ende des Schweigens? Perestrojka und die Tabus sowjetischer Geschichtsschreibung, in: FAZ v. 21.09.1988, 35.

Ritvo, H.: Twenty-First Party Congress - Before and After, in: ASEER 1961, H. 2, 203-219 und H. 3, 436-453.

Rogger, H.: Politics, Ideology and History in the USSR: The Search for Coexistence, in: Soviet Studies 1965, H. 3, 254-275.

Rosenfeld, G./H. Schützler: Kurze Geschichte der Sowjetunion 1917-1983, Berlin 1985.

Roth, P.: Glasnost und Medienpolitik unter Gorbatschow, Bonn 1990.

Ruffimann, K.-H.: Autokratie, Absolutismus, Totalitarismus, in: Osteuropa in Geschichte und Gegenwart, Köln-Wien 1977, 345-358.

Ruge, G.: Michail Gorbatschow. Biographie, Frankfurt am Main 1990.

Rumpler, H.: Parteilichkeit und Objektivität als Theorieproblem der Historie in der DDR, in: Fischer, A./G. Heydemann (Hg.): Geschichtswissenschaft in der DDR, Band I: Historische Entwicklung. Theoriediskussion und Geschichtsdidaktik. Berlin 1988, 334-362 (Wieder- 
abdruck aus: Koselleck, R./W.J. Mommsen/J. Rüsen (Hg.): Objektivität und Parteilichkeit in der Geschichtswissenschaft, München 1977).

Saff, A. (= Schaff, A.): Ob-ektivnyj charakter zakonov istorii, M. 1959.

Sandkühler, H.J.: Erkenntnis/Erkenntnistheorie, in: EEPhW 1, Hamburg 1990, 772-904.

Schäfer, P.: Geschichtslogik und GULAG. Gibt es einen Zusammenhang zwischen Stalinismus und Marxismus-Leninismus? In: VZ v. 25.05.1990, 6.

Schapiro, L.: Continuity and Change in the new History of the CPSU, in: Keep, Contemporary History, 69-82.

Schewardnadse, E./A. Gurkow/W. Eichwede u.a.: Revolution in Moskau. Der Putsch und das Ende der Sowjetunion, Reinbek bei Hamburg 1991.

Schleifstein, J.: Einfuihrung in das Studium von Marx, Engels und Lenin, 4. Auflage, München 1983.

Schlögel, K.: Der renitente Held. Arbeiterprotest in der Sowjetunion 1953-1983, Hamburg 1984

Schlögel, K.: Im Widerschein des Feuers. Die dramatische Geschichte der Sowjetunion erfaßt die Lebenden, in: FAZ v. 21.11.1987.

Schmidt-Häuer, C.: Michail Gorbatschow, München 1985.

Schmidt-Häuer, C.: Ein Mausoleum vor dem Abbruch. Immer mehr Kritiker beschreiben das Marxistische System als Ursache der Unfreiheit, in: Die Zeit v. 12.05.1989, 11.

Schneider, E.: Die 19. Parteikonferenz: Reform des politischen Systems, in: Sowjetunion 1989, 38-48.

Schröder, H.H.: Stalinismus „von unten“? Zur Diskussion um die gesellschaftlichen Voraussetzungen politischer Herrschaf in der Phase der Vorkriegsfunfjahrpläne, in: Geyer, Die Umwertung, 133-166.

Schubert, D.: Irrweg oder Wegbereitung? Gorbatschows Perestrojka als Übergangsprozeß zu marktwirtschaftlich-demokratischen Strukturen, in: OE 1992, H. 2, 110-120.

Schulz-Hageleit, P.: Was lehrt uns die Geschichte? Annäherungsversuche zwischen geschichtlichem und psychoanalytischem Denken, Pfaffenweiler 1989.

Schwegler-Rohmeis, W./K. Segbers (Hg.): Perestrojka passé? Eine Zwischenbilanz der Reformpolitik in der Sowjetunion, Opladen 1992.

Segbers, K.: Der sowjetische Systemwandel, Frankfurt am Main 1989.

Segbers, K.: Die Sowjetunion im Zweiten Weltkrieg. Die Mobilisierung von Verwaltung, Wirtschaft und Gesellschaft im „Großen Vaterländischen Krieg“" 1941-1943, München 1987.

Service, R: Die Kultfigur bedarf einer Neueinschätzung, in: MN (Deutsche Ausgabe) 1989, Nr. 12,11

Service, R.: The Russian Revolution 1900-1927, London 1986.

Sherlock, T.: Politics and History under Gorbachev, in: Problems of Communism 1988, H. 3-4, $16-42$.

Shimotomai, N.: New Interpretation of the NEP and the Stalinist System under glasnast ', in: Ito, Facing up to the Past, 187-197.

Shteppa, K.F.: Russian Historians and the Soviet State, New York 1962.

Simon, G.NN. Simon: Verfall und Untergang des sowjetischen Imperiums, München 1993.

Smith, H.: Die neuen Russen (1990), Reinbek bei Hamburg 1991.

Sowjetunion 1980-1991. Bilanz der letzten Jahre, hg. vom Statistischen Bundesamt, Wiesbaden 1992.

Sowjetunion 1984/85. Ereignisse, Probleme, Perspektiven, hg. vom BOIS, München-Wien 1985.

Sowjetunion 1986/87. Ereignisse, Probleme, Perspektiven, hg. vom BOIS, München-Wien 1987.

Sowjetunion 1988/89. Perestrojka in der Krise? Hg. v. BOIS, München 1989.

Sowjetunion 1990/91. Krise - Zerfall - Neuorientienung, hg. v. BOIS, München 1991. 
Steffen, O.: Schwieriger Übergang zur Marktwirtschaft - die Versorgungskrise in der Sowjetunion, in: OE 1991, H. 7, 646-656.

Steffen, O.: Zur ökonomischen Krise in der Sowjetunion. Von der funktionierenden Mangelwirtschaft zur mangelhaft funktionierenden Wirtschaft, in: OE 1991, H. 4, 344-357.

Stiehler, G.: Geschichte und Verantwortung. Zur Frage der Alternativen in der gesellschaftlichen Entwicklung, Berlin 1972.

Stökl, G.: Russische Geschichte von den Anfängen bis zur Gegenwart, 5., erweiterte Auflage, Stuttgart 1990.

Stökl, G.: Zur Ždanov-Ära in der sowjetischen Geschichtswissenschaft. Die RubinšteijnDiskussion, in: Sowjetsystem und Ostrecht. Festschrif fur Boris Meissner zum 70. Geburtstag, Berlin 1985, 197-210.

Tischler, C.: „Den guten Namen wiederherstellen“. Über die Rehabilitierung von Stalin-Opfern in der Sowjetunion, in: JHK 1993, 118-125.

Topolski, J.: Methodology of History (1973), Warszawa-Dordrecht-Boston 1976.

Trautmann, G.: Die Sowjetunion im Wandel - Wirtschaf, Politik und Kultur seit 1985, Darmstadt 1989

Troeltsch, E.: Der Historismus und seine Überwindung (1924), Aalen 1966.

Urban, P.K.: Smena tendencij v sovetskoj istoriografii, München 1959.

Urban, P.K.: The Re-Stalinization of the Soviet Historical Sciences, in: Bulletin, Institute for the Study of the USSR, Vol. V, January 1958, No. 1, 46-52.

Utechin, S.V.: Soviet Historiography after Stalin, in: Keep, Contemporary History, 117-129.

Veen, H.-J./P.R. Weilemann (Hg.): Rußland auf dem Weg zur Demokratie? Politik und Parteien in der Russischen Föderation, Paderborn 1993.

Vovelle, M.: Die Geschichtsuissenschaft und die „Jongue duree“, in: Le Goff, J./R. Chartier/J. Revel ( $\mathrm{Hg}$ ): Die Rückeroberung des historischen Denkens. Grundlagen der Neuen Geschichtswissenschaft (französische Originalausgabe 1978). Frankfurt am Main 1990, 103 136.

Wada, H.: Perestroika and the Rethinking of History in the Soviet Union, 1986-88, in: Ito, Facing up to the past, 35-79.

Wehner, M.: Auf der Suche nach der „Wahrheit"? Zum polemischen Streit sowjetischer Historiker und Publizisten über die 1920er Jahre und die Ursprünge des Stalinismus, in: $O E$ 1990, H. 12, 1129-1144.

Wehner, M.: Die Diskussion um den „Liebling der Partei“. Zur politischen Bedeutung der Rehabilitierung N.I. Bucharins, in: OE 1990, H. 4, $301-317$.

Wehner, M.: Rückkehr mit Hindernissen. Die ,gebremste“ Diskussion um L.D. Trockij in der Sowjetunion, in: OE 1991, H. 3, 247-258.

Weiss, A. v.: Gesetz, Gesetzmäßigkeit, in: SDG 2, Freiburg-Basel-Wien 1968, 1005-1017.

Wheatcroft, S: Steadying the energy of history and probing the limits of glasnost': Moscow July to December 1987, in: ASEES 1987, H. 2, 57-114.

Wheatcroft, S.: Unleashing the energy of history, mentioning the unmentionable and reconstructing soviet historical awareness: Moscow 1987, in: ASEES 1987, H. 1, 85-132.

Wheatcroft, S.G.: Glasnost' and Rehabilitations, in: Ito, Facing up to the Past, 199-218.

Who Was Who in the USSR. A Biographic Directory Containing 5,015 Biographies of Prominent Soviet Historical Personalities, Compiled by the Institute for the Study of the USSR (Munich), Metuchen, New Jersey 1972.

Winters, P.J.: Im Wäldchen von Katyn. Über dem Massengrab polnischer Offiziere steht ein neues Kreuz, in: FAZ v. 04.04.1989.

Wittkau, A.: Historismus. Zur Geschichte des Begriffs und des Problems, Göttingen 1992. 
Wittram, R.: Das Faktum und der Mensch. Bemerkungen zu einigen Grundfragen des Geschichtsinteresses, in: HZ 1958, H. 1, 55-87.

Wolfe, B.D.: Party Histories from Lenin to Khrushchev, in: Keep, Contemporary History, 43-61.

Xu, Z.: Several Thoughts on Stalin and Stalinism, in: Ito, Facing up to the Past, 219-239.

Zaslavsky, V.: Das russische Imperium unter Gorbatschow. Seine ethnische Struktur und Zukunf, Berlin 1991.

Zaslavsky, V.: In geschlossener Gesellschaft. Gleichgewicht und Widerspruch im sowjetischen Altag (1981), Berlin 1982.

Ziemer, K.: Zur Erosion des Herrschaftsmonopols der KPdSU, in: OE 1990, H. 6, 535-547. 


\section{Verzeichnis leitender Historiker}

\section{Die Direktoren des Instituts für Geschichte an der AdW 1953 bis 1967}
März 1953 bis 1959
A. L. Sidorov
1959 bis 1967
V.M. Chvostov

\section{Die Direktoren des Instituts für UdSSR-Geschichte 1968 bis 1991}

1968 bis 1970

1970 bis 4. März 1974

4. März 1974 bis 1982

1982 bis Dezember 1987

Januar 1988 -
B.A. Rybakov

P.V. Volobuev

A.L. Naroxnickij

S.S. Chromov

A.P. Novosel'cev

\section{Die Direktoren des Instituts für Allgemeine Geschichte 1968 bis} 1991

1968 bis 9. März 1980

1980 bis 29. September 1987

Dezember 1987 -
E.M. Zukov

Z.V. Udal'cova

A.O. Cubar'jan

\section{Die Akademischen Sekretäre 1953 bis 1991}

Herbst 1953 bis 1956

1956 bis 1971

1971 bis 9 . März 1972

9. März 1972 bis 19. Juni 1973

19. Juni 1973 bis November 1975

November 1975 bis 9 . März 1980

9. März 1980 bis 1. März 1982

1. März 1982 bis 1989

1989 -
M.N. Tichomirov

E.M. Žukov

V.M. Chrostov

P.N. Pospelov (kommissarisch)

B.A. Rybakov

E.M. Zukov

B.B. Pietrovskij (kommissarisch)

S.L. Tichvinskij

I.D. Koval'čnko

\section{Die Chefredakteure von Voprosy istorii 1953 bis 1991}

1950 bis 1953

1953 bis März 1957

März 1957 bis Ende 1958

1959 bis Mitte 1960

Mitte 1960 bis Juni 1987

Juni 1987 bis Ende 1987

1988 -
P.N. Tret'jakov

A.M. Pankratova

N.I. Matjuškin

S.F. Najda

V.G. Truchanovskij

I.V. Sozin (kommissarisch)

A. A. Iskenderov 


\section{Die Chefredakteure von Istorija SSSR 1957 bis 1991}

Januar 1957 bis Ende 1960

Anfang 1961 bis Anfang 1966

Frühjahr 1966 bis 1970

1970 bis Ende 1988

Ende 1988 bis Frühjahr 1990

Frühjahr 1990-
M.P. Kim

V.D. Močalov

Ju. A. Poljakov

I.D. Koval'Čenko

I.E. Zelenin (kommissarisch)

K.F. Sacillo 


\section{Personenindex}

Fette Seitenzahlen weisen auf die Fußnoten biographischen Inhalts hin.

A

Abalkin, L. $\cdot 234 ; 235 ; 307$

Abdil'din, Z.M. $\cdot 283$

Abuladze, T. $\bullet 237$

Achramovix, R.T. $\bullet 92 ; 185$

Adam, W. $\bullet 56$

Afanas'ev, Ju.N. $1165 ; 184 ; 209 ; 214 ; 216 ; 230$; $231 ; 237 ; 239 ; 242 ; 245 ; 246 ; 248 ; 252 ; 254$; $261 ; 264 ; 307$

Aganbegjan, A.A. $\cdot 209 ; 307$

Ahlberg. R. $\cdot 74 ; 197 ; 252 ; 254 ; 265 ; 334$

Aitmatov, D. $163 ; 262$

Akopjan, G.S. ・ 172; $263 ; 314$

Al'šic, D.N. $\bullet 42 ; 46 ; 305$

Al'tman, V.V. • 20

Alatorceva, A.I. $-3 ; 18$

Aleksandrov, A. • 42; 43; 46; 308

Alekseev, P.V. • 282; 308

Alekseev, V.P. - 172; 206; 240; 258

Alekseeva, G.D. • 103; 308

Alksnis, V. $\cdot 254 ; 308$

Ambarcumov, E. - 231; 242; 246; 262; 308

Anan'ic, B.V. • 98; 258; 308

Anderle. A. $\cdot 3 ; 191 ; 322$

Andreev, 1.D. $\bullet 267 ; 308$

Andreeva. N. • 237; 244; 264

Andropov, Ju. V. $・ 165 ; 166 ; 197 ; 198 ; 199 ; 221$; 308

Anfimov, A.M. $119 ; 30 ; 97 ; 98 ; 99 ; 100 ; 308$; 324

Anikeev, V.V. • 61; 308

Ankudinova. A.M. $\bullet 11 ; 325$

Antipov, G.A. $\cdot 275 ; 308$

Antonova, K.A. $\cdot 30$

Arazi, D. - 16; 334

Arcichovskij, A.V. $\bullet 20 ; 21 ; 74$

Armand. I. $-58 ; 160$

Armstrong, J.A. $\cdot 95 ; 334$

Arsen'ev, A. 172

Arslanov, V. $\bullet 263 ; 291 ; 308$

Artem'ev, S.A. 192

Artizov, A.N. 11 ; 19;20;64;65;241; 308

Arutjunjan, Ju. V. $1180 ; 227 ; 233$

Asendorf, M. $\bullet 161 ; 334$

Assaturova. M.I. - 56; 64; 112; 114; 308

Astachov, V.1. 109

Astrov $\cdot 20$

Avrech, A.Ja. $19 ; 183$

Azabaev, F.A. $\cdot 65 ; 308$
B

Babičenko. L.G. • 60; 61; 308

Bachrušin, S.V. • 59; 103

Badja. L.V. • 3; 20; 111; 308

Baehrel. R 127

Bagirov $\cdot 36$

Baier, W. $\bullet 221$

Baklanov, G. - 216; 237

Balał̌v, V.N. • 56; 308

Barber, J. $\bullet 10 ; 60 ; 334$

Barg, M.A. $57 ; 116 ; 124 ; 148 ; 149 ; 150 ; 171$; 194; 229; 245; 248; 268; 269; 271; 276; 277 ; $278 ; 279 ; 280 ; 282 ; 283 ; 284 ; 285 ; 287 ; 290$; 292; 300; 301; 308; 309

Barloewen, C. von - 139; 334

Barloewen. W.D. von - 139; 334

Barsenkov, A.S. $11 ; 309$

Barsukov, N. $\bullet 82$

Barthel, R. -139; 152; 334

Bartold. V.V. $\bullet 103$

Bartosz. J. $\bullet 239 ; 334$

Bataeva. T.V. • 94; 190; 309

Batkin, L.M. 127

Bažova, A.P. • 64; 309

Bechtel, H. 158

Behrend, L.-D. ・ 105; 334

Bejlina, E.E. 111

Bek. A. $-215 ; 262$

Belous - 42; 45; 305

Below, G. v. $・ 113 ; 158$

Bem, Ju. O. $21 ; 309$

Berchin, I. B. - 30; 31; 32; 33; 97; 246; 309

Bereschkow, V. $\bullet 238 ; 309$

Berija, L.P. ・ 16; 47; 256

Berlin, I. 127

Bernadskij, V.N. -38

Besmertnych, A. $\cdot 252$

Bessmertnyj, Ju.L. $148 ; 150$

Bestužev, I.V. - 116; 172; 241; 291; 309

Beyrau, D. • 4; 15; 87; 334

Bibler, V.S. - 130; 131; 132; 134: 172; 289; 309

Bikkenin, N.B. $\bullet 123 ; 309$

Biron, A.K. $\cdot 59 ; 309$

Blanke, H.W. $\cdot 3 ; 4 ; 160$

Blauberg, I.V. 1116

Bloch, J. $\bullet 86$

Bloch, M. 1 1; 86; 127; 128; 334

Bock. I. $\cdot 334$

Bogdanov $\bullet 42$

Bogdenko, M.L. • 97; 309

Bogomolov, O.T. • 234

Bolchovitinov, N.N. $\bullet 233 ; 240$ 
Boldin, V.I. • 224; 256

Bollhagen. P. • $5 ; 33 ; 129 ; 130 ; 137 ; 152 ; 154$; 334

Bonbar', N.N. $\bullet 21 ; 309$

Bondarev, Ju • 237; 254

Bonwetsch, B. $\cdot 2 ; 94 ; 95 ; 98 ; 100 ; 170 ; 184$; $219 ; 238 ; 254 ; 265 ; 334 ; 335$

Borcke, A. von $\cdot 265 ; 335$

Bordjugov, G.A. $250 ; 263 ; 264 ; 291 ; 309$

Borisov, Jus. • 123; 310

Borisov, Ju.V. • 49; 50; 57; 60; 66; 306

Borisov, L.P. $\cdot 310$

Bovykin, V.I. - 18: 19; 98; 100; 101; 179; 184; $185 ; 207 ; 240 ; 258 ; 283 ; 310$

Brahm, H. • 217; 236; 251; 252; 335

Brandt, H. • 15; 335

Braudel, F. $\bullet 231 ; 272 ; 335$

Breznev, L.I. 6 ; 72;82;83;86; 163;164;165; $169 ; 177 ; 187 ; 298 ; 305$

Bromlej, Ju.V. • 112: 190; 201; 202; 203; 204; $206 ; 207 ; 212 ; 244 ; 268 ; 283 ; 310 ; 333$

Broué, P. • 224; 257; 335

Brumner, A. 155

Brunner, O. 158

Bubnov, A.S. $\bullet 45$

Bucharin. N.I. - 19; 62:74; 155; 165; 238; 260; $263 ; 291 ; 311$

Bucharina, A.L. $\cdot 263 ; 310$

Bugaev, E. - 43; 45; 46; 310

Bugaj, V.1. 241

Buganov, V.1. $1135 ; 189 ; 190 ; 192 ; 203 ; 249$; $311 ; 315 ; 322$

Bühl, A. $\cdot 238 ; 335$

Buhr, M. $\cdot 275 ; 339$

Bulganin. N.A. $\cdot 53$

Burckhardt, J. • 159

Burdżalov, E.N. • 17; 18; 20;22; 26;36;39;40; $41 ; 42 ; 43 ; 44 ; 45 ; 46 ; 48 ; 49 ; 50 ; 52 ; 54 ; 56$; $85 ; 170 ; 195 ; 223 ; 263 ; 268 ; 295 ; 296 ; 305$; $306 ; 310 ; 314$

Burlackij, F. - 28; 54; 72; 82;83;264; 310

Burtin, J. • 264; 310

Busuev, S.K. - 36; 44; 310

Butenko, A.P. • 198; 231; 264; 310

Bystrov, V.R. $264 ; 310$

C

(agin, B.A. 124

Cajanov, A.V. $\cdot 225$

Cebrikov, V. 224

Cecharin, E.M. -96; 169; 178; 305

Cepurenko, A. 264

Cepurov, A. 214

Cerepain, L.V. $\bullet 49 ; 50 ; 51 ; 66 ; 104 ; 105 ; 106$; $107 ; 109 ; 157 ; 182 ; 186 ; 191 ; 321 ; 322 ; 324$

Cermenskij, E.D. 180

Cemaev, A. $\cdot 7 ; 222 ; 235 ; 237 ; 251 ; 253 ; 255$

Cernaja, L. 100
Cemenko, A.K. 191

Cemenko, K.U. - 166; 167; 197; 198; 205

Cemev, A - 167

Cemjaev, A. $\cdot 37 ; 40 ; 41 ; 50 ; 92 ; 305 ; 306$

Cemjak, E.B. - 284; 285; 287; 290; 308

Cemjak, E.N. - 116; 282

Cemobaev, A.A. 10;310

Cemomorskij, M.N. $\bullet 135 ; 328$

Cemova, L.N. $115 ; 116 ; 171 ; 172 ; 305$

Cernych, AG. 78

Cemyšev, B.V. • 199; 310

Cemyševskij, N.G. $\cdot 161 ; 208$

Cubar'jan, A.O. $195 ; 243 ; 259 ; 310 ; 346$

Camap, R. 121

Carr, E.H. $136 ; 153 ; 231 ; 277 ; 335$

Cassirer, E. 127

Chaina, K.G. 140

Chladenius, J.M. $\bullet 161 ; 335$

Chlevnjuk, O.V. $\cdot 250$

Chomenko, E.A. $139 ; 310$

Chrenov, I.A. $\cdot 21 ; 50 ; 185$

Chromov, R.P. - 30; 311

Chromov, S.S. - 30; 185; 186; 187; 189; 190; $194 ; 195 ; 201 ; 203 ; 213 ; 227 ; 240 ; 243 ; 311$; $324 ; 346$

Chruxcev, N.S. $115 ; 19 ; 28 ; 39 ; 40 ; 42 ; 46 ; 48$; $53 ; 54 ; 56 ; 60 ; 62 ; 72 ; 76 ; 77 ; 80 ; 81 ; 82 ; 84$; $94 ; 204 ; 217 ; 224 ; 259 ; 295 ; 305 ; 306 ; 311$

Chvostov, V.M. $\cdot 20 ; 21 ; 74 ; 83 ; 174 ; 175 ; 179$; $187 ; 346$

Cieszkowski, A. 269

Cipko, A. $\cdot 260 ; 264 ; 292 ; 311 ; 334$

Collingwood, R.D. $\bullet 121 ; 231$

Comte, A. - 121; 131

Conert. H.G. - 164; 166; 209; 222; 234; 235; 254; 335

Conquest, R. 258

Coulanges, F. de $\cdot 131$

Croce, B. $\cdot 27 ; 121 ; 231$

Crusius, R. $\bullet 15 ; 28 ; 46 ; 72 ; 335$

Cypkin, G.A. $\bullet 93 ; 186$

D

D'jakov, V.A. $\cdot 185 ; 268$

Dadykin, R.P. • 50; 55; $58 ; 66: 311$

Dahlmann, F. Ch. $\cdot 27$

Dahm, H. • 197; 335

Dal'skij, A.N. $\cdot 42 ; 305$

Dalin, V. 172

Dallin, A. 50; 335

Daniel, Ju.M. $\bullet 87$

Daniels, R.V. $\cdot 335$

Danijalov, G.D. • 36; 311

Danilov, A.I. $\cdot 102 ; 112 ; 150 ; 297 ; 311$

Danilov, V.P. - $32 ; 68: 85 ; 95 ; 97 ; 103 ; 189$; $190 ; 232 ; 233 ; 240 ; 245 ; 260 ; 290 ; 292 ; 305$; $311 ; 332$

Danilova, G.M. $\cdot 30$ 
Danilova, L.V. $\bullet 148$

Dašižev, V. $\bullet 88$

Davies, R.W. • 2; 15; 165; 204; 206; 207; 209; $214 ; 215 ; 216 ; 219 ; 220 ; 223 ; 224 ; 225 ; 232$; $233 ; 237 ; 238 ; 239 ; 240 ; 243 ; 255 ; 256 ; 257$; $259 ; 262 ; 263 ; 264 ; 265 ; 290 ; 291 ; 335$

Davydov, Ju.S. $・ 189 ; 265 ; 311$

Deborin. A.M. $\cdot 20 ; 74$

Deborin. G.A. $\bullet 97 ; 311$

Demandt. A. $272 ; 335$

Demicev, P.N. • 96; 178; 224; 305; 306

Demockin. N.N. $1185 ; 193 ; 311$

Dempf, A. $\cdot 158$

Derevjanko. A.P. - 240; 258

Devjał̌in, N.A. $140 ; 147 ; 311$

Diderot, D. $\bullet 277$

Dietz, B. - 254; 335

Ditthey, W. $1121 ; 131$

Dittrich, G. $\bullet 94 ; 336$

Dmitrenko, V.P. $1194 ; 197 ; 258 ; 312 ; 325$

Dmitriev, S.S. $\bullet 93$

Donnert. E. • 3; 191; 322

Donskoj, V.M. $\bullet 66$

Dorošenko. N.M. • 130; 131; 134; 191; 275; 312

Dotterweich, V. $\bullet 5$

Drabkin. Ja.S. $116 ; 171 ; 174 ; 175 ; 176 ; 299$; $305 ; 312$

Dray, W. $\bullet 121$

Drizul, A.A. $\cdot 59$

DrobiY.ev, V.Z. • 93; 186; 189; 233; $241 ; 312$; 315

Drobiževa, L.M. $188 ; 312$

Droysen, J.G. 159

Družinin, M.N. $\cdot 20 ; 25 ; 68$

Druzinina. El. $\bullet 283$

Dubina, K.K. $\bullet 84$

Dubrovskij, S.M. $\bullet 65 ; 109 ; 312$

Dudincev, V. $\bullet 215 ; 262$

Dudinskij, I.V. • 92; 185

Dudzinskaja, E.A. $195 ; 312$

Dukes, P. - 241

Dunaevskij, V.A. $\cdot 59 ; 96 ; 104 ; 109 ; 312$

Durnovcev, V.I. $\cdot 274 ; 312$

Durovic, S. $・ 10 ; 336$

Dzasochov, A.S. $\cdot 256$

Dzeržinskij, F. • 60;213

\section{$E$}

Edmonds, R. $\cdot 241$

Efimov, A.V. $\bullet 69$

Efremenkov, N.F. $\cdot 31$

Egides, P.M. $・ 125 ; 146 ; 147 ; 151 ; 154 ; 332$

Egorov, A.G. $\cdot 213$

Egorov, V.K. • 7; 164; 167; 292;312; 316

Egorova, V.S. $\bullet 275 ; 313$

Eichwede, W. $\cdot 87 ; 88 ; 89 ; 234 ; 336 ; 337 ; 343$

Eissenstat, B.W. $\bullet 10$

El'cin, B.N. ・ 165;252;253;257; 260
Emčenko. E.B. - 229: 230: 231: 233; 331

Emmons, T. $\bullet 241$

Engelberg. E. $-116 ; 119 ; 153 ; 161 ; 336$

Engels, F. $\bullet 26 ; 35 ; 85 ; 86 ; 115 ; 117 ; 147 ; 152$; $155 ; 157 ; 158 ; 160 ; 173 ; 176 ; 208 ; 277 ; 293$; 298; $303 ; 304 ; 336 ; 341$

Ennker, B. $\bullet 190 ; 256 ; 336$

Enteen, G.M. $\cdot 2 ; 10 ; 11 ; 60 ; 170 ; 174 ; 179$; $180 ; 183 ; 220 ; 241 ; 336$

Epifanov, P.P. $\cdot 20$

Erdmann. K.D. $\cdot 3 ; 10 ; 27 ; 195 ; 336$

Eremenko. A.I. $\bullet 57 ; 313$

Erler, G. $\bullet 236$

Ermakov, V.T. $・ 190 ; 313$

Erofeev, N.A. $\cdot 271 ; 313$

Erusalimskij, A.S. $\bullet 21 ; 50 ; 68$

Eulenburg. F. $\bullet 152 ; 155 ; 336$

Evtušenko, E. • 165; 214

$\mathbf{F}$

Faber, K.-G. - 153; 154; 336

Fadeev, A.V. $\cdot 51 ; 97 ; 313$

Fainsod. M. $\cdot 336$

Falin, V. • 7; 72; 166; 206; 207; 238; 239; 255; 313

Febvre, L. $\bullet 1 ; 127 ; 128$

Fedenko. P. - 2; 336

Fedorov, V.A. $\cdot 258$

Fedorova. A.T. $・ 119 ; 125 ; 313$

Fedoseev, P.N. • 81; 86; 111; 123;124; 140; $141 ; 147 ; 156 ; 157 ; 182 ; 244 ; 270 ; 305 ; 313$

Fedosov, 1.A. - 20;66; 94;313

Fedossow, P. - 164; 219;313

Fedotov, P.I. • 49; 50; 66; 306

Felshtinsky, Yu. 258

Figurovskaja, N.K. ・189; 311

Fitzpatrick, S. $\bullet 258$

Fleischer, H. $\bullet 139 ; 153 ; 154 ; 155 ; 336 ; 339$

Florin, P. $\cdot 82$

Fortupatov, P.K. $\cdot 22$

Francev, Ju.P. $・ 81 ; 86 ; 123 ; 124 ; 140 ; 141 ; 270$; 313

Freising. O. v. $\cdot 113$

Friese. C. $\bullet 10 ; 336$

Frunze, M.V. $\bullet 60$

Fueter, E. $\bullet 4$

Fülberth. G. $\cdot 33 ; 263 ; 336$

Furman. A. $-120 ; 125 ; 331$

Fursenko, A.A. 233

G

Gafurov, B.G. $\bullet 68 ; 178 ; 182$

Gal'kin, A. $172 ; 175$

Gal'kin, I.S. $\bullet 17 ; 23 ; 83 ; 84 ; 313$

Galanskov, Ju. $\cdot 87$

Gamalij, N.V. $187 ; 313$

Gandhi, M. $\bullet 108$ 
Ganelin. R. • 98: 308

Gaponenko. L.S. $19 ; 51 ; 66 ; 83 ; 193 ; 268$

Gardiner, P. $\cdot 121$

Gautier, E.V. $\bullet 103$

Gavrilova, A.M. $-41 ; 45 ; 46 ; 305$

Gefter. M.Ja. - 7; 19; 22; 84; 85; 89; 97; 100; $101 ; 110 ; 113 ; 114 ; 115 ; 116 ; 124 ; 151 ; 163$; 165: 169: 170; 171; 172: 173; 174; 175; 176; $177 ; 178 ; 181 ; 223 ; 242 ; 263 ; 270 ; 297 ; 298$; $299 ; 304 ; 305 ; 313$

Geller, M. 206

Genkina, E.B. - 31

Georgiev, V.A. 186

Gerasimenko, G.A. 258

Gershoy, L. $\bullet 127$

Gerstenmaier, C. $\cdot 87$

Geyer, D. $\cdot 2 ; 4 ; 12 ; 40 ; 61 ; 65 ; 87 ; 94 ; 98 ; 100$; $184 ; 190 ; 199 ; 203 ; 211 ; 219 ; 229 ; 232 ; 236$; $254 ; 258 ; 263 ; 264 ; 265 ; 290 ; 310 ; 334 ; 336$; $337 ; 341$

Geyl, P. 158

Giert2. H. • 99; 323

Gimpel'son. E.G. • 96: 189; 313

Gindin, I.F. • 91; 98; 99; 100; 310; 313

Ginzburg, A. $\cdot 87$

GlaeBner, G.-J. • 265; 337

Glezerman, G.E. - 34; 123; 124; 139; 270; 313

Glybowski. J. - 252

Goldman. Ph. $\cdot 236 ; 339$

Golikov, G. $\bullet 43 ; 45 ; 66 ; 75 ; 96 ; 102 ; 185 ; 314$

Golub, P.A. $1180 ; 181 ; 185 ; 193 ; 314$

Goncaruk. S.1. 283

Gorbacev, M.S. - 163; 164; 165; 166; 167; 168; $198 ; 206 ; 209 ; 217 ; 221 ; 222 ; 223 ; 224 ; 225$; $233 ; 234 ; 235 ; 237 ; 239 ; 251 ; 252 ; 253 ; 254$; $255 ; 256 ; 257 ; 260 ; 314 ; 317$

Gordon. L. - 236; 250; 314

Gorodeckij, E.N. - 3; 96; 110; 111; 116; 124; $157 ; 172 ; 189 ; 191 ; 193 ; 231 ; 263 ; 306 ; 314$; 322

Got'e, Ju. V. • 59

Gotlober, V.M. - 31

Gottschalk. L. $\bullet 127$

Götz. R. • 222: 253; 337

Götz-Coenenberg. R. 222; 337

Govorkov, A.A. 109

Graham, L.R. 11

Gramsci, A. - 116; 155

Granin. D. - 165; 214; 262

Gransow, V. • 265; 337

Grasčenkov, V.N. $\cdot 233 ; 244$

Grekov, B.D. • 19; 20; 21; 59; 119; 147; 314

Grigor'ev, F.G. • 59; 116; 314

Grigor'ev, I.V. ・ 116; 314

Grigor'ev, V.A. 225

Grinko. G.F. - 225

Gromov, B. • 254

Gromov, E. $24 ; 306$

Gromyko, A.A $\cdot 72: 167$
Grober, G. • 26; $119 ; 337$

Grossman, A.S. 240

Grossman, V. $\cdot 264$

Grossmann, G. • 265; 314

Grosul, V.Ja. $\cdot 258$

Grot, L.Ju. $35 ; 314$

Grotzky, J. • 236; 337

Grunt, A.Ja. $\bullet 92 ; 93 ; 98 ; 99 ; 100 ; 170 ; 172$; $176 ; 186 ; 215 ; 299 ; 305 ; 314$

Grušin, B.A. - 120;121;122;124;129;145; $314 ; 315$

Gubenko, M.P. • 135; 315

Guber, A.A. $\cdot 22 ; 195 ; 315$

Gugnin, A.M. $\cdot 191$

Guhr, G. 147

Gukovskij, A.I. $1109 ; 110 ; 315$

Gulyga, A.V. • 120;122; 123; 127; 129; 130; $132 ; 134 ; 135 ; 136 ; 142 ; 143 ; 149 ; 191 ; 315$

Gurevič, A.Ja. - 7; 88; 102;124; 125; 126;127; $128 ; 130 ; 131 ; 132 ; 133 ; 134 ; 135 ; 141 ; 142$; $143 ; 144 ; 145 ; 146 ; 148 ; 149 ; 150 ; 151 ; 152$; $153 ; 154 ; 165 ; 170 ; 223 ; 243 ; 270 ; 271 ; 282$; 292; $293 ; 301 ; 315$

Gurkow, A. $\cdot 234$

Guržij, I.A. • 51

Gusev, K.V. $\cdot 177 ; 186 ; 189 ; 192 ; 315$

Gutnova, E.V. $\bullet 30$

H

Habermas, J. - 74; 155

Hagen. M. von • 2; 219; 224; 337

Hager, K. $\bullet 197$

Halbach, U. • 236; 337

Hardtwig, W. $1159 ; 160 ; 161 ; 337$

Haug, W.F. • 163; 222; 235; 337

Hecker, H. • 10; 254; 337

Heer, N.W. • $3 ; 4 ; 29 ; 30 ; 43 ; 47 ; 53 ; 58 ; 61$; $62 ; 63 ; 70 ; 77 ; 83 ; 297 ; 337$

Hegel, G.W.F. • 122; 144; 154; 208

Heimpel, H. 158

Heller, I. • 9; 10; 337

Heller, M. $・ 16 ; 46 ; 47 ; 72 ; 82 ; 83 ; 88 ; 89 ; 166$; 338

Helvétius, C.-A. $\bullet 277$

Hempel, C. $\bullet 121$

Herder, J.G. • 27

Hielscher, K. • 215; 252;262; 338

Hildermeier, M. $\cdot 31 ; 40 ; 98 ; 229 ; 262 ; 338$

Hirsch, H. $\bullet 251 ; 338$

Hitzer, F. • 163; 216;231; 236; 327; 338

Hoensch, J.K $\bullet 89$

Hoetzsch, O. 10

Hofer, W. $\cdot 27$

Hoffer, F. • 251; 338

Hoffmann, R. $262 ; 305$

Hofmann, W. - 49; 175; 281; 338

Höhmann, H-H. • 209; 234; 235; 251; 253; 254; 338 
Holbach, P.H.D. Baron v. $\bullet 277$

Holm, K. $100 ; 338$

Holtbrügge, D. • 253; 338

Hōrz, H. • 139; 152; 338

Huber, M. • 254; 338

Huffschmid, J. • 164; 184;209;231;307; 338

Huguet, M.G. • 139; 338

Huizinga, J. • 127; 128

Husband, W.B. $\cdot 220$

\section{I}

Iggers, G.G. • $3 ; 301 ; 338$

Ignat'ev, A $\cdot 231$

Ignatenko, T.A • 93; 315

Igrickij, Ju.I. • 265; 315

Il'icev, L.F. • 72; 76; 77; 81; 315

Illerickij, V.E. • 59

loffe, G.Z. $113 ; 263 ; 314$

Ionkin, V.F. $\cdot 78$

Iskenderov, A.A. $174 ; 206 ; 240 ; 243 ; 245 ; 247$; $259 ; 260 ; 346$

Ito. $T$. $\cdot 2 ; 338$

Ivanov, G.M. $-120 ; 130 ; 131 ; 132 ; 156 ; 157$; 316

Ivanov, L.M. - 50; 66;94;99; 316

Ivanov, V.V. • 5; 160;191; 199; 238; 267; 316

Ivaško, V.A. • 256

Imickij, N.A. $\cdot 97 ; 333$

\section{$J$}

Jacunskij, V.K. - 51

Jaeck, H.-P. • 152; 338

Jäget, F. • 160; 338

Jakovcevskij, V.N. 93

Jakovlev, A.N. • 165; 181; 223; 224; 225; 237; $238 ; 251 ; 252 ; 255 ; 257 ; 307 ; 316$

Jakoviev, E. - 216;262;316

Jakubovskaja, S. • 111; 306

Janaev, G. - 252; 256

Janin, V.L. • 206; 240

Jaroslavskij, E.M. $\bullet 45$

Jasov, D. $\cdot 252$

Javorskij, M.I. 105

Joravsky, D. • 161; 338

Judacev, S.A. • 66; 185

Judick, G. • 28; 47; 53; 63; 338

Judina, E.G. 116

Jung, H. • 234; 339

Jurin. Ju.M. $\bullet 188 ; 317$

\section{K}

Kabanov, V.V. $\cdot 190 ; 317$

Kachk, Ju. 119; 317

Kaganovič. L.M. 53

Kagarlickij, B. $\cdot 221 ; 317$
Kahn, H.W. • 286; 339

Kalašnikova, V.C. $\bullet 125 ; 317$

Kalinin, M.I. $\bullet 60 ; 95 ; 312 ; 321$

Kalistratova, T.I. $\cdot 10$

Kamenev, L.B. $・ 19 ; 45 ; 238$

Kammari. M.D. $\bullet 140$

Kan, S.B. $\cdot 20$

Kapica, M.S. - 240; 244; 258

Kaplan, K. • 46: 339

Kappeler, A. $\cdot 188 ; 339$

Kapustin, M. $\bullet 260 ; 317$

Karamzin, N.M. $\cdot 27$

Karasev, A. V. • 97

Kareev, N.I. 158

Karelova, G.D. $120 ; 123 ; 125 ; 332$

Karpov, V.V. $\bullet 224$

Kanuzina, M.I. $\cdot 35 ; 333$

Kas'janenko, V.1. $186 ; 187 ; 233 ; 244 ; 246 ; 317$

Kasack. W. $\cdot 11 ; 12 ; 201 ; 215 ; 339$

Kastueva, G. $\cdot 230 ; 317$

Kataev, V. $\cdot 165$

Katkov, N.F. $\cdot 225 ; 238 ; 317$

Keep. J. - 1; 339

Keiper, M. $\bullet 216$

Kelle, V. • 257; 282; 317

Kerner, M. $\cdot 265 ; 339$

Kertman, L.E. • 141; 144; 145; 151; 270; 282; 317

Kim, G.F. $\cdot 212$

Kim, M.P. - 23; 30; 31; 32; 33; 51; 58; 59; 66: $67 ; 69 ; 74 ; 75 ; 83 ; 84 ; 92 ; 140 ; 160 ; 171$;

$172 ; 173 ; 175 ; 178 ; 188 ; 189 ; 190 ; 200 ; 201$; $202 ; 203 ; 204 ; 206 ; 212 ; 240 ; 244 ; 268 ; 309$; 317: 347

Kirillin, V.A. $41 ; 42 ; 43 ; 44 ; 45 ; 305 ; 307$

Kirov, S.M. $\cdot 60$

Kiselev, S. V. • 69

Kitaev, 1.1. 59

Klaus, G. • 275; 339

Kljamkin, I. • 252; 264; 292; 317

Ključevskij, V.O. $\bullet 27 ; 110$

Klopov, E. • 236; 250; 314

Ḱnabe, B. $\cdot 236$

Knjazev • 42; 45; 46; 305

Knoll, V. • 16: 256: 339

Knorin, V.G. 445

Koblemicz, C.N. • 161; 338

Kočakov, B.M. - 51

Koenen, G. $\cdot 252$

Kolakowski, L. • 74; 144; 339

Kolendic, A. - 16; 339

Kolganov, M.V. • 30; 318

Kölm, L. • 16; 256; 339

Kolodij, A.F. • 264; 318

Kolonickij, B.I. $\cdot 283 ; 318$

Koloskova, T.G. $\cdot 264 ; 318$

Komkov, G.D. $・ 185$

Komolova, N.P. - 116; 318 
Kon. I.S. $\bullet 4 ; 34 ; 120 ; 121 ; 129 ; 141 ; 145 ; 151$; $160 ; 318$

Kondrat'ev, N.D. -225

Kondrat'ev, V.A. $135 ; 330$

König. H. • 238; 339

Kopnin. P.V. $・ 130 ; 275 ; 318$

Korab, A. $239 ; 339$

Korablev, Ju.I. $\bullet 243$

Korelin. A.P. $・ 184 ; 258 ; 318$

Komev, V.V. $\bullet 318$

Komilov, A. $170 ; 318$

Komilov, L.G. $\cdot 70$

Korolev, N.E. $\bullet 258$

Koroleva, N.A. $\cdot 60 ; 63 ; 103 ; 318$

Korostarenko $\bullet 42 ; 45 ; 305$

Kosing, A. $\cdot 147$

Koslov, V.A. $\cdot 318$

Kosolapov, V.V. $・ 191 ; 267 ; 276 ; 278 ; 280 ; 284$; 318

Kossolapow, R. 1 198; 318

Kostrikin, V.I. $\bullet 192 ; 194 ; 318$

Kosul'nikov, A. $\cdot 182 ; 318$

Kosygin, A.N. $\cdot 82$

Koval'čenko. I.D. • 4; $29 ; 39 ; 92 ; 93 ; 185 ; 186$; $206 ; 207 ; 212 ; 213 ; 227 ; 229 ; 230 ; 233 ; 240$; $243 ; 244 ; 247 ; 248 ; 260 ; 270 ; 271 ; 286 ; 292$; $318 ; 319 ; 346 ; 347$

Koval'zon, M. $\cdot 282$

Kovalenko. D. - 169; 305

Kově̌nikov, E.M. $・ 187 ; 319$

Kožinov, V.V. • 249; 292

Kožokin. E.M. $\cdot 248$

Kozin. N.G. $・ 191 ; 269 ; 319$

Kozlov, V.A. $・ 225 ; 226 ; 250 ; 263 ; 264 ; 291$; 309

Ḱrasnobaev. B.I. 186

Kretov, F.D. $・ 101 ; 319$

Krjučkov, V. • 252; 254; 255; 319

Kručina, N.E. 256

Krüger, U. $\bullet 236$

Krupina, T.D. 19

Krušanov, A.l. $\cdot 240 ; 258$

Kružkov, A.V. • 24; 306

Kuxkin, A.P. - 30; 31; 33; 50; 61; 84; 97; 297; $298 ; 319$

Kuczynski. J. • 49; 156; 197; 339

Kuhn, T.S. $\bullet 6 ; 339$

Kukin, D. $\cdot 37 ; 66 ; 99 ; 178 ; 182 ; 305$

Kukuskin. Ju.S. $185 ; 190 ; 206 ; 213 ; 233 ; 240$; $244 ; 246 ; 247 ; 258$

Kulakov, V.M. $\cdot 92$

Kulešov, S.V. • 250; 332

Kuliženko, M.I. $188 ; 319$

Kulikov, V.M. $\cdot 66 ; 186$

Kumanev, V.A. III; 185; 213;232; 244; 258

Kunkel. W. • 339

Kurašvili, B.P. • 241

Kuricyn. V.M. 140

Kumnosov, A. A. $\cdot 95 ; 171 ; 319$
Kurtynin $\bullet 42$

Kuryuzawa, T. $\cdot 220$

Kusmenko. W. $\cdot 198 ; 319$

Küttler, W. • 3; 5; 116; 339

Kux, S. $\cdot 221 ; 339$

Kuz'min, A.G. $185 ; 189 ; 319$

Kuz'min, A.V. $\cdot 269$

Kuznecov, D.V. • 207

Kumecov, I.I. $\cdot 319$

Kuznecov, I.V. - 38; 92; 192; 295; 319

Kumecov, N.D. $\bullet 263 ; 314$

Kurnecov, P. • 237

Kumecova. K. $\cdot 37 ; 39 ; 40 ; 41 ; 45 ; 305 ; 306$

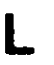

La Mettrie, J.O. de $\cdot 277$

Labica, G. • 74; 105; 339

Ladriere, J. • 139; 339

Lagutin. E.S. • 95; 319

Lamprecht, K. $\bullet 113$

Langlois, Ch.-V. $\bullet 131$

Lapidus, G.W. • 236: 339

Laptev, I. $\cdot 224$

Laqueur, W. • 2; 219; 339

Laveryčev, V.Ja. • 98; $99 ; 180 ; 181 ; 184 ; 186$; $192 ; 306 ; 314 ; 319$

Levrov, P.N. • 66; 92

Lavrovskij, V.M. $・ 124 ; 319$

Le Goff, J. • 272; 339

Lebedeva. N.B. $189 ; 320$

Lociejewski, K. • 263; 339

Lefebvir, G. • 27

Leitsch, W. $\cdot 2 ; 340$

Lejberov, I.P. $\bullet 100$

Lel'cuk, V.S. • 97; 189;258; 320

Lenin, V.I. $99 ; 26 ; 28 ; 30 ; 31 ; 33 ; 36 ; 47 ; 52$; $54 ; 55 ; 58 ; 59 ; 60 ; 62 ; 67 ; 76 ; 79 ; 90 ; 98$; $105 ; 106 ; 115 ; 117 ; 145 ; 153 ; 154 ; 158 ; 159$; $170 ; 172 ; 175 ; 176 ; 181 ; 182 ; 190 ; 192 ; 199$; 208; 236; 237; 247; 248; 249; 250; 251; 255; 256; 257; 258; 261; 263; 264; 275; 277; 285; $292 ; 298 ; 303 ; 307 ; 320 ; 331 ; 340$

Leonhard, W. $15 ; 46 ; 48 ; 53 ; 79 ; 82 ; 83 ; 292$; 340

Levebvre, G. $\bullet 127$

Levin, G.R. $111 ; 212 ; 244$

Levkovskij, A.l. $66 ; 92$

Levšin, B.V. • 240

Levykin, K.G. $・ 178 ; 180 ; 181 ; 320$

Lewin, M. $\cdot 222 ; 340$

Lewytzkyj, B. - 40;72; 76; 83; 87; 188; 340

Licholat, A.V. $\cdot 39 ; 40 ; 188 ; 306 ; 320$

Ligačev, E. - 206;224;237;251; 255

Lisovskij, P. • 177; 208; 306

Liszkowski, U. $\bullet 2 ; 219 ; 228 ; 233 ; 263 ; 340$

Litvak, B.G. $・ 135 ; 258 ; 315$

Litvarin, G. $\bullet 244$

Ljubavskij, M.K. $・ 103$ 
Loesdau, A. $\cdot 131$

Loginov, V. • 206; 231; 264; 291; 327

Loone, E.N. - 191; $267 ; 320$

Lotter, K. • 277; 341

Lötzsch, R. • 236; 340

Luchterhandt. G. - 236; 252; 257; 340

Luchterhandt, O. 236

Luckij, E.A. - 104; 105; 109; 320

Luk'janov, A.I. - 224; 253

Lukács. G. - 74

Luks, L. • 254; 340

Lunin. B.V. • 65; 308

Luxemburg, R. - 15s

\section{M}

Mackow, J. • 265; 340

Madajczyk, C. $\cdot 239 ; 340$

Maevskij, I. • 43; 332

Mai, J. 99

Maier, F.G. • 139; 340

Maier, R. • 292: 340

Maitland, F.W. 131

Majdanik, K.L. $\bullet 299$

Majskij. I.M. • 68; 69

Mal'kov, V.L. $\bullet 116 ; 172 ; 320$

Malenkov, G.M. • 53; 72

Malia, M. $\cdot 15 ; 340$

Malov, V.S. $\cdot 91 ; 325$

Mamzin. A.S. $\cdot 140 ; 320$

Mandrou, R. $\cdot 127$

Mannheim. K. 113

Marcuse, H. $\cdot 100 ; 231$

Marko, K. $\cdot 2 ; 80 ; 110 ; 148 ; 170 ; 171 ; 174 ; 178$; 340

Markwick, R.D. - 5; 85; $115 ; 306 ; 340$

Martiny, A. $\cdot 188 ; 341$

Marx, K. $\cdot 3 ; 26 ; 60 ; 79 ; 115 ; 117 ; 143 ; 144$; $147 ; 148 ; 152 ; 154 ; 155 ; 157 ; 160 ; 176 ; 197$; $198 ; 208 ; 230 ; 261 ; 264 ; 277 ; 288 ; 292 ; 293$; $298 ; 303 ; 304 ; 307 ; 315 ; 336 ; 341$

Maryniak. I. $\bullet 252$

Małkin, M. - 7

Maslov, N.N. $・ 116 ; 199 ; 268 ; 283 ; 320$

Matjugin, A.A. $\bullet 94 ; 321$

Matjuškin, N.I. $\bullet 49 ; 50 ; 51 ; 52 ; 66 ; 306 ; 346$

Matkovskij, N.V. - 66; 185

Mavrodin. V.V. 93

McKean. R. B. - 220

Medvedev, R.A. - 9; 10;72;76; 83; 86; 164; $238 ; 241 ; 255 ; 256 ; 259 ; 264 ; 321$

Medvedev, V.A. $\cdot 222 ; 239 ; 256 ; 321$

Medwedew, G. • 221

Meinecke, F. • 4; 113

Meiners, R. $\cdot 277 ; 341$

Meissner, B. - 2 ; 11 ; 164; 188; 225; 235; 251; $256 ; 341 ; 344$

Mejman, M.N. $\cdot 30 ; 321$

Mel'nikov, A.B. $\bullet 110 ; 321$
Melamid alias Melnikov, D. $\bullet 100$

Merl, S. • 290; 341

Meyer, A.G. $\bullet 61 ; 62$

Meyer, Gerd • 265; 341

Meyer, Gert • 94; 209; 219; 236; 262; 265; 341

Meł̌enin, N.M. - 199; 321

Michajlov, M.I. $\bullet 173 ; 174$

Michajlov, V.N. $\cdot 30 ; 31 ; 321$

Michrin, P. • 42; 306

Migranjan. A. $\cdot 235 ; 321$

Mikojan, A.I. $\cdot 28$

Mill, J.S. $\bullet 121 ; 131$

Mills, C.W. $\cdot 100$

Milov, L.V. $\bullet 93 ; 186: 258$

Minc, I.I. $\bullet 18 ; 20 ; 31 ; 40 ; 51 ; 68 ; 69 ; 79 ; 81$; $88 ; 93 ; 97 ; 110 ; 111 ; 156 ; 160 ; 172 ; 173$; $175 ; 176 ; 178 ; 182 ; 189 ; 192 ; 200 ; 201 ; 203$; $204 ; 206 ; 212 ; 214 ; 215 ; 231 ; 244 ; 246 ; 268$; 297; 306; 321

Minkov, T. $\cdot 30 ; 321$

Mitasova, L. - 95; 321

Močalov, V.D. $\bullet 92 ; 93 ; 347$

Mogil'nickij, B.G. - 7; 102; 113; 153; 156; 158; $159 ; 162 ; 191 ; 250 ; 267 ; 268 ; 270 ; 271 ; 280$; $283 ; 284 ; 285 ; 286 ; 287 ; 288 ; 289 ; 290 ; 292$; $300 ; 301 ; 306 ; 321 ; 322$

Moiseenko, T.L. $\bullet 229$

Molotov, V.M. $\cdot 53$

Mommsen, M. $\cdot 341$

Mongajt, A.L. 116

Morgan, L.H. $\cdot 147$

Mołkov, Ju. A. $\cdot 7 ; 114 ; 240$

Moskoff, W. $\cdot 254 ; 341$

Müller, R. $・ 139 ; 341$

Munier, G. $\bullet 263 ; 341$

Muralov, N.I. $\cdot 207 ; 225$

Muralt. L. v. $\bullet 158$

\section{$\mathbf{N}$}

Najda, S.F. • 19;20;51; 52;60;66;178;306; 346

Najdenov, M.E. $\bullet 60 ; 61 ; 63 ; 73 ; 78 ; 104 ; 105$; $106 ; 107 ; 109 ; 193 ; 297 ; 322$

Naročnickij, A.L. $50 ; 66 ; 92 ; 182 ; 183 ; 185$; $186 ; 189 ; 192 ; 200 ; 206 ; 207 ; 212 ; 213 ; 231$; $240 ; 244 ; 322 ; 346$

Narski, I.S. - 275; 322

Nasyrin, V.P. - 43;322

Natmeladze, M.V. $\bullet 78$

Naumann, K. • $5 ; 35 ; 37 ; 119 ; 121 ; 155 ; 341$

Naumov, V.P. $・ 186 ; 189 ; 191 ; 193 ; 250 ; 274$; $322 ; 333 ; 334$

Nečkina, M.V. • 3; $51 ; 56 ; 59 ; 60 ; 63 ; 64 ; 68$; $69 ; 74 ; 79 ; 83 ; 93 ; 102 ; 103 ; 104 ; 105 ; 106$; $107 ; 108 ; 182 ; 191 ; 193 ; 200 ; 274 ; 321 ; 322$. 323

Nexuchrin, A.N. $\cdot 288 ; 322$

Nedorezov, A.I. 185 
Nefedov, N.G. $\bullet 185$

Negt, O. $\cdot 74$

Nekrasov, V.F. -322

Nekriž, A. $17 ; 15 ; 18 ; 19 ; 20 ; 26 ; 40 ; 49 ; 50$; $57 ; 65 ; 72 ; 79 ; 84 ; 85 ; 87 ; 88 ; 89 ; 90 ; 92 ; 93$; $95 ; 109 ; 115 ; 116 ; 117 ; 169 ; 170 ; 183 ; 184$; $258 ; 298 ; 311 ; 322 ; 338$

Nenarokov, A.P. $\cdot 241 ; 258$

Neretina. S.S. $-7 ; 26 ; 84 ; 85 ; 89 ; 90 ; 115 ; 117$; $151 ; 174 ; 176 ; 259 ; 270 ; 304 ; 306 ; 322$

Nesmejanov, A.N. $・ 19 ; 23 ; 306$

Neupokoev, V.I. $\bullet 112 ; 181$

Neurath, $0 . \cdot 121$

Neusychin $\bullet 88 ; 102$

Nevskij, V.I. 45

Nežinskij, L.N. • 185; 258

Nikolaev, F.V. $\cdot 30 ; 33 ; 328$

Nikonov, A.D. $\cdot 19 ; 20$

Nolte, H.-H. $\bullet 4 ; 236 ; 341 ; 342$

Novosel'cev, A.P. $186 ; 240 ; 243 ; 244 ; 346$

\section{0}

Oberländer, E. • 2: $11 ; 36 ; 37 ; 81 ; 188 ; 238 ; 342$

Običkin, G.D. $\bullet 21 ; 22$

Oelkers. J. • 280; 342

Oexle. O.G. $1160 ; 342$

Okladnikov, A.P. $\bullet 186$

Okuda. H. $\cdot 262 ; 342$

Openkin. L.A. $\cdot 17$

Orbeli, I.A. - 50;66

Ordÿ.onikidze, G.K. $\bullet 60$

Orešin. B.V. $\bullet 258$

Orleanskij. A.I. - 35; 324

Orlov, B.P. • 30; $31 ; 33 ; 324$

Ovander, N.E. - $34 ; 139 ; 324$

Ovcinnikov, V.F. • 287; 291; 324

Ovčinnikov, V.G. $1199 ; 213$

Ovčinnikov, V.S. $\cdot 320$

\section{$\mathbf{P}$}

Panfilova. A.M. - 30; 324

Panibud'laska, V.F. $\bullet 188 ; 320$

Panin. A.V. • 282: 308

Pankratova. A.M. - 3; 18; 19; $20 ; 21 ; 22 ; 23 ; 24$; $25 ; 26 ; 27 ; 28 ; 29 ; 36 ; 39 ; 40 ; 41 ; 42 ; 43 ; 44$; $45 ; 48 ; 49 ; 50 ; 52 ; 59 ; 64 ; 66 ; 93 ; 110 ; 111$; $170 ; 195 ; 223 ; 268 ; 295 ; 296 ; 305 ; 306 ; 307$; $324 ; 346$

Pankratova, M.G. $・ 116 ; 324$

Pantin, I.K. $\cdot 85$

Paparigopulo, S.V. $\cdot 54$

Pašuto. V. • 157; 195: 324

Pasternak, B. 172

Paul, G. $\cdot 264 ; 342$

Pavlenko. N.I. $\cdot 265 ; 324$

Pavlenko, V.N. $\cdot 240$
Pavlov, D.G. $\cdot 214$

Pavlov, M.N. • 57; 324

Pavlov, V. $\bullet 252$

Pavlov-Sil'vanskij, N.P. • 27

Pedosov, A. - 182: 318

Perě̌nev, Ju G. $\cdot 243$

Persov, M.S. • 35; 324

Pervuchin, M.G. -53

Pethybridge, R • 53; 342

Petrjaev, K.D. $・ 290 ; 291 ; 325$

Petrovskij, A.B. $\bullet 91 ; 325$

Petruševskij. D.M. 103

Petty, W. 35

Pizeto, V.I. 59

Pichoja, R.G. 258

Pietrovskij, B.B. $\bullet 346$

Pikman, A.M. $\cdot 36 ; 325$

Piotrovskij. B.B. $-185 ; 189 ; 190 ; 194 ; 212 ; 325$

Piroschkow, V. • 2; 50; 342

Pivovar, E.I. $\bullet 258$

Pjaskovskij, A.V. $\cdot 64 ; 325$

Pjatakov, Ju.L. $\bullet 238$

Plechanov, G.V. • 45; 63; 64; 72; 325

Pleskova, S.L. • 148: 325

Pletnev, D.D. - 207; 225

Podkorytov, G.A. $\bullet 160 ; 325$

Podosetnik, V.M. $\bullet 132 ; 325$

Pokrovskij, M.N. • 3; 10; 19; 27; 38; 50; 56; 61; $64 ; 65 ; 66 ; 75 ; 77 ; 79 ; 81 ; 82 ; 85 ; 93 ; 101$; $105 ; 109 ; 110 ; 111 ; 161 ; 178 ; 241$

Pokrovskij, M.V. • 36; 325

Pokrovskij, N.N. $\bullet 233$

Pokrovskij, S.A. -54

Pokrovskij, V.K. $・ 189 ; 315$

Pol'skij, M.P. • 188; 325

Poletaev, V.E. - 57; 93; 186; 324

Polikarpov, V.D. $\cdot 246$

Polikarpov, V.V. $\cdot 283 ; 325$

Poljakov, Ju.A. • 32; 33; 39; 51; 80; 83; 93; 97; $104 ; 105 ; 106 ; 107 ; 178 ; 179 ; 185 ; 186 ; 189$; 190; 191; 194; 195; 200; 203; 206; 207; 212 ; 229; 231; 233; 240; 242; 243; 244; 245; 246; 247; $258 ; 259 ; 260 ; 291 ; 317 ; 322 ; 324 ; 325$; 333; 347

Poljanskij, F.Ja. $\bullet$ 30; 325

Poloskov, I. • 253; 255; 325

Pomeranc, G.S. 1116

Ponomarev, A.M. $\bullet 11 ; 325$

Ponomarev, B.N. $11 ;$ 56; 61; 77; 78; 79; 297; 325

Popov, G. $・ 163 ; 252 ; 257 ; 260 ; 325$

Popov, N. • 45; 264

Popov, St. $1140 ; 342$

Popov, V.G. $・ 189 ; 325$

Popper, K. $\bullet 121$

Poršnev, B.F. - 29; 68; 325

Pospelov, P.N. ・ 17; 18;19;20;24;25;39; 40; $43 ; 84 ; 171 ; 172 ; 175 ; 180 ; 182 ; 305 ; 306$; 307: 346 
Pozner, V. ・165; 166; 254; 326

Praslov, S.I. $\cdot 50$

Preobraženskij, A.A. 93

Presnjakov, A.E. • 27; 103

Primakov, E.M. $\cdot 200 ; 201$

Pripiznov, V.I. $120 ; 123 ; 125 ; 128 ; 156 ; 157$; 326

Prokofev, Ju. A. $\cdot 255$

Prokopenko, N. ・ 171; 318

Pugatev, V.M. $・ 187 ; 319$

Pugo, B. $\cdot 252 ; 256$

Puskin, A. 208

$\mathbf{R}$

Rabinovich, A $\cdot 241 ; 259$

Rachmatullin, M.A. $・ 186 ; 258$

Radek, K. $・ 238$

Rahr, A. - 235; 236; 342

Rakitov, A.I. $\bullet 269 ; 274 ; 277 ; 284 ; 290 ; 326$

Ramazanov, S.P. $\cdot 288 ; 322$

Ranke. L. v. $1113 ; 130 ; 131 ; 135 ; 159 ; 276$

Raskol'nikov, F.F. • 45

Rasputin. V. 254

Rastopima, L.N. - 171

Rauch, G.v. 1 I ; 342

Razumovskij, G.P. • 224; 237

Reed. J. • 9

Rejman. M. $\bullet 2: 219 ; 241 ; 342$

Rhode. G. • 263; 342

Ricardo. D. $\cdot 35$

Ricker, H. $1121 ; 131 ; 283 ; 293$

Ritter, M. $\bullet 4$

Ritvo, H. • 53; 342

Rjabov, V.V. $\bullet 243$

Rjutin, M.N. 238

Rodnij. N. 172

Rogger, H. • 2; 342

Romanov, B.A. 127

Roščevskij. P.I. $\bullet 57$

Rosenberg. W. • 241

Rosenfeld. G. - 187; 192: 342

Rosenko, M.N. - 188; 326

Roth, P. • 242; 342

Rožin. V.P. $-120 ; 123 ; 128 ; 140 ; 267 ; 320 ; 326$

Rubac. M.A. • 38

Rubinštejn. N.L. -50

Rude, G. 127

Ruffmann. K.-H. $265 ; 342$

Ruge, W. • 166; 168; 342

Rumjancev, A.M. $-19 ; 20 ; 24 ; 39 ; 40 ; 41 ; 96$; $169 ; 172 ; 174 ; 306 ; 326$

Rumpler, H. $1156 ; 342$

Rüsen, J. • S: 156: 160; 338; 343

Rusinov, I.V. $\bullet 186$

Rusljakova, V.G. • 57; 96; 326

Rust, M. • 252

Rybakov, A. $\cdot 215 ; 262$
Rybakov, B.A. - 25; $26 ; 64 ; 83 ; 169 ; 170 ; 180$, 182 ; $185 ; 186 ; 201 ; 204 ; 206 ; 207 ; 212 ; 240$; $244 ; 326 ; 346$

Rybakov, M.V. ・178; 326

Rykov, A.I. 238

Ryndzjunskij, P.G. • 93; 99; 326

Ryškov, N.I. 253

Ryženko, F.D. • 66; 92

Ržě̌evskij, O.A. $\cdot 240$

$\mathbf{S}$

Satrov, M. • 231: 327

Sabanov, F. - 30; 321

Sabatin, I.I. $\cdot 264 ; 326$

Sachnazarov, G. $\cdot 255 ; 327$

Sacillo, K.F. • 258; 347

Safarevið̌, I. • 264

Sakina, T.D. $\cdot 283 ; 327$

Samil $\cdot 36$

Sarapov, G.V. • 180; 181; 306: 320

Satalin. S. $\cdot 253 ; 327$

Scapov, Ja.N. - 258

Sceglov, A. $139 ; 327$

Scerbakov, S. $111: 307$

Selestov - 92: 96: 102: 327

Selochaev, V.V. $\bullet 240$

Senin. O.S. 256

Sepelev, L.E. $\cdot 91 ; 313$

Sepilov, D.T. $\bullet 41 ; 43 ; 44 ; 53 ; 305$

Serman. I.L. • 96; 327

Serstobitov, V.P. $-188 ; 189 ; 190 ; 192 ; 203$; $243 ; 311 ; 317 ; 322: 327 ; 332$

Sevardnadze. E.A. $165 ; 252$

Sevcenko, F.P. $\cdot 109$

Sevelenko. A.Ja. 240

Sirokov, A. $171 ; 318$

Siskin. V.A. $233 ; 240 ; 258$

Skaratan. O.I. - 94; 180;233; 327

Skarenkov, L.K. • 92: 93

Sljapnikov, A.G. $\cdot 45$

Smidt, S.O. • 51; 103; 105; 106; 107; 108

Sochina, V. $\cdot 216$

Staerman, E.M. $\bullet 116 ; 127 ; 148 ; 150 ; 327$

Sul'gin, V.S. 1111

Sunkov, V.I. $\bullet 66 ; 92$

Surbovanyj, G.P. • 174; 175; 176; 259; 327

Suster, U.A. - 38

Saburov, M.Z. 53

Sacharov, A.D. $\cdot 72 ; 87 ; 89 ; 327$

Sacharov, A.M. $\cdot 84 ; 96 ; 101 ; 102 ; 186 ; 191$; $193 ; 312 ; 327$

Sacharov, A.N. - 26; 83; 185; 258; 265; 327

Salov, V.I. • 57; 157: 324: 327

Salygin, S. $\cdot 216$

Samsonov, A.M. $\cdot 53 ; 93 ; 169 ; 174 ; 176 ; 186$; 202; 203; 204; 206; $210 ; 214 ; 231 ; 232 ; 240$; $242 ; 244 ; 248 ; 249 ; 259 ; 262 ; 292 ; 327$

Sancevix. A.V. $\cdot 269 ; 327$ 
Sandkühler, H.J. • 147; 275; 303; 318; 343

Sarbej, V.G. $\bullet 105 ; 109 ; 327$

Saslavskaja, T. $\bullet 163 ; 327$

Sazonov, V.V. • 291; 327

Schäfer, P. • 263;343

Schaff, A. $-119 ; 128 ; 343$

Schapiro. L. $\cdot 30 ; 343$

Schaworonkow, G. $\cdot 239 ; 327$

Schewardnadse, A. $\cdot 234$

Schieder, Th. $158 ; 272$

Schippan. M. $\cdot 229$

Schirinowskij. W. $\bullet 252$

Schlarp, K.-H. $\bullet 4$

Schleifstein. J. • 74; 277; 343

Schlick, M. $\bullet 121$

Schlögel, K. $\bullet 88 ; 165 ; 216 ; 270 ; 333 ; 343$

Schmiđt-Häuer, C. $166 ; 206 ; 264 ; 343$

Schneider, E. - 235; 236; 343

Schröder, H.H. $215 ; 219 ; 222 ; 265 ; 334 ; 341$; 343

Schubert, D. $\cdot 254 ; 343$

Schulz-Hageleit. P. • 136; 343

Schüzlet, H. $187 ; 192 ; 342$

Schwegler-Rohmeis, W. $\cdot 343$

Sedov, K.I. • 58; $240 ; 328$

Segbers. K. $1164 ; 166 ; 190 ; 222 ; 233 ; 234 ; 235$; $253 ; 343$

Seignobos, Ch. 131

Seleznev, M.S. $\bullet 30 ; 33 ; 135 ; 328$

Semenov, Ju.1. $116 ; 328$

Semenov, L.K. - 91; 325

Semenov, V.S. - 198: 328

Senjavskij. S.L. • 94: 96: 189; 312; 328: 332

Sercova. A.P. - 125; 331

Serovajskij, Ja.D. - 267; 268; 328

Service, R. - 31: $248: 343$

Sevost'janov, G.N. • 50; 66; 244

Sherlock. T. $2 ; 219 ; 225 ; 343$

Shimotomai. N. $\bullet 262: 343$

Shteppa, K. $11 ; 10 ; 11 ; 27 ; 50 ; 343$

Siderenko. S.A. $\cdot 30$

Sidorov, A.L. $17 ; 18$; $19 ; 20 ; 21 ; 22 ; 23 ; 24$; $39 ; 40 ; 65 ; 68 ; 84 ; 98 ; 110 ; 307 ; 328 ; 346$

Sidorov, A.V. $-263 ; 328$

Simon, G. $\bullet 221 ; 235 ; 236 ; 252 ; 253 ; 254 ; 265$; $335 ; 343$

Simon. N. • 221; 235; 236; 252; 253; 254; 265; 343

Simonija. N.A. $\cdot 229 ; 260 ; 328$

Sinjavskij, A.D. $\cdot 87$

Sirotkin. V. $\bullet 242$

Sitarjan, S. $\cdot 209 ; 328$

Sitkovskij, G. -216

Sivolobov, A.M. $1180 ; 181 ; 306 ; 320$

Sjuganov, G. $\bullet 254$

Sjuzjumov, M.Ja. 30

Skazkin. S.D. $\bullet 21 ; 30 ; 50 ; 68 ; 69 ; 185 ; 321$

Smirin. M.M. $\cdot 22$

Smimov, A. 328
Smimov, G.L. $・ 224 ; 225 ; 243 ; 248 ; 256 ; 328$

Smimov, N.A. $\bullet 20 ; 50 ; 92 ; 172 ; 178$

Smimov, V.A. $\cdot 54$

Smimova, L.1. $\bullet 57 ; 328$

Smith, A. $\cdot 35 ; 166 ; 167 ; 206 ; 343$

Smolenskij, N.I. $\cdot 229$

Smolenskij, N.K. $\cdot 191$

Snastin. V. • 66; 305

Snesarevskij. P.V. $・ 30 ; 328$

Sobzak, A. $\cdot 252 ; 257$

Sobolev, G.L. $\cdot 193 ; 328$

Sobolev, P.N. - 50; 66; 180; 181; 192; 193; 306; $314 ; 328$

Soboul, A. 127

Sofinov, P.G. $\cdot 33$

Sokolnikov, G.Ja. $\bullet 238$

Sokolov, O.D. • 3; 10; 65; 105; 109; 110; 328; 329

Sokolov, V.Ju. 329

Sol'zenicyn, A. 264

Solomencev, M.S. $\cdot 224$

Solouchin. B. $\cdot 264$

Solov'ev, S.M. $\bullet 27$

Solov'eva, A.M. • 98; 329

Sörgel, W. • 254; 335

Sosonkin, I. $\bullet 125$

Sovokin, A.M. $\bullet 199 ; 329$

Sozin. I.V. $185 ; 232 ; 346$

Spencer $\cdot 121$

Spirin. L.M. $\cdot 240 ; 267 ; 329$

Srbik, H.R v. $\bullet 158$

Stadnjuk, I. $\cdot 214$

Stalin, I.V. ・1;2; 9; 12;17;18; 26;28; 30;31; $33 ; 34 ; 35 ; 37 ; 45 ; 46 ; 47 ; 48 ; 50 ; 51 ; 53 ; 54$; $58 ; 60 ; 61 ; 62 ; 63 ; 64 ; 72 ; 73 ; 74 ; 77 ; 78 ; 79$; $81 ; 84 ; 86 ; 92 ; 94 ; 99 ; 106 ; 108 ; 119 ; 120$; $139 ; 176 ; 193 ; 224 ; 237 ; 239 ; 245 ; 246 ; 250$; 255; $262 ; 263 ; 265 ; 289 ; 292 ; 295 ; 298 ; 304$; $313 ; 329 ; 335$

Stanislavskaja, A.M. 104; 109; 172; 312

Starcev, V.I. $\cdot 241$

Starodubcev, V. $\bullet 254$

Starzew, W. $\bullet 291 ; 329$

Steffen, $0 . \cdot 235 ; 254 ; 344$

Steigerwald, R - 56;325

Steinhaus, K. $\bullet 28 ; 47 ; 53 ; 63 ; 338$

Stichler. G. • 287; 344

Stökl, G. $111 ; 286 ; 344$

Stopinski, S. $\cdot 265 ; 339$

Strel'skij, V.I. $\bullet 135 ; 330$

Strižkov, Ju.K. $\bullet 189 ; 330$

Stroynowski. Ju. - 72; 76; 83; 340

Stučebnikova, M.D. $\bullet 61 ; 78$

Sturua, N.I. 78

Sulimov, E.F. $・ 125 ; 330$

Suslov, A.I. • 189; 330

Suslov, M.A. $17 ; 18 ; 19 ; 23 ; 24 ; 39 ; 40 ; 41$; 42; 43; 49; 65; 72; 76; 86; $110 ; 111 ; 164$ : $165 ; 167 ; 187 ; 297 ; 305 ; 306 ; 307 ; 330$ 
Sverdlov, Ja. M. $\cdot 60$

Sviridov, A.A. $\cdot 111$

Sybel, H. v. • 5; 113

\section{T}

Tarle, E.V. $\bullet 103 ; 141$

Tamovskij. K.N. $119 ; 98 ; 99 ; 100 ; 123 ; 124$; $181 ; 268 ; 270 ; 310 ; 330$

Telepenin, M.S. $\cdot 30$

Telpuchovskij, V.B. • 94; 328

Ter-Akopjan, N. $\bullet 172$

Thieme, K. 27

Tichomirov, M.N. $\bullet 20 ; 24 ; 25 ; 51 ; 60 ; 108$; $330 ; 346$

Tichonov, Ju. A. $184 ; 330$

Tichvinskij. S.L. $\bullet 195 ; 199 ; 200 ; 201 ; 204 ; 205$; $206 ; 207 ; 208 ; 211 ; 212 ; 213 ; 226 ; 227 ; 228$; $231 ; 232 ; 233 ; 243 ; 244 ; 258 ; 330 ; 346$

Tił̌kov, V.A. - 73; 189; 190; 194; 195; 205; 325; 330

Tischler, C. • 225; 256; 344

Titarenko, S.L. $\bullet 70$

Titov, A.G. $\cdot 330$

Titov, A.I. $・ 185 ; 194 ; 199 ; 330$

Tjurina, A.P. $\bullet 192 ; 318$

Tjurjukin, S.V. $\bullet 258$

Tokarev, A.I. $\cdot 291 ; 331$

Tökes, R.L. $\bullet 88$

Topžiev, A.V. $\cdot 23 ; 306$

Topolski. J. • 5; 344

Torke. H.-J. $\bullet 220$

Trapeznikov, S.P. $\bullet 83 ; 84 ; 85 ; 86 ; 88 ; 89 ; 90$; $170 ; 181 ; 182 ; 225 ; 307 ; 331$

Trautmann. G. $\cdot 235 ; 344$

Treptow, E. • 277; 341

Tret'jakov, P.N. $\bullet 20 ; 49 ; 50 ; 51 ; 59 ; 66 ; 346$

Trjapicyn, E.I. $\bullet 66 ; 92$

Trockij, L.D. • 45; $238 ; 257 ; 263 ; 291$

Troeltsch. E. $160 ; 344$

Trubicyn. O.N. • 139; 331

Trubinova, T.S. $\bullet 40 ; 247 ; 331$

Truchanovskij, V.G. $55 ; 66 ; 69 ; 92 ; 93 ; 112$; $185 ; 188 ; 202 ; 203 ; 206 ; 232 ; 346$

Tschepurenko, A. $\cdot 263 ; 331$

Tschernajew. A. $1166 ; 197 ; 222 ; 235 ; 236 ; 237$; $239 ; 251 ; 252 ; 253 ; 254 ; 331$

Tschernjak, A. $\cdot 238$

Tucharevskij. M.N. • 45;238; 256

Tulenov, Z. $\bullet 125 ; 331$

\section{U}

Udal'cov, A.D. $\bullet 19 ; 20 ; 21$

Udal'cov, 1.1. 19

Udal'cova. Z.V. • 200; 201; 202; 203; 204; 206; $207 ; 212 ; 243 ; 346$

Ukolova, V.I. 244
Ul'jašov, P. • 214

Uljanov, M. $\cdot 237$

Urban. P.K. • 2: 50; 296; 344

Utechin. S.V. • 17;27;58; 344

Utenkov, A.Ja. 192

Uvarov, A.I. 1 191; 275; 331

\section{V}

Vaganov, F.M. • 199; 232; 331

Vajnštejn. O.L. ・105; 331

Vandalkovskaja, M.G. $\cdot 229 ; 230 ; 231 ; 233 ; 331$

Varga, E. 158

Varšavčik, M.A. $\cdot 199 ; 331$

Vasil'ev, A.F. • 189; 331

Vdovin, A.I. 189

Veen. H.-J. $\cdot 344$

Verbin, A.I. $1120 ; 123 ; 125 ; 146 ; 147 ; 151 ; 154$; $331 ; 332$

Veselovskij, S.B. 103

Viktorov, V.P. $\bullet 101$

Vilenskij, B.V. - 30; 32; 332

Vinogradov, V. $\bullet 43 ; 215 ; 229 ; 243 ; 244 ; 332$

Vitkin. M.A. 148

Vjatkin. M.P. - 42; 45; 46; 307

Vodolazov, G.G. $\cdot 291 ; 332$

Volgin. V.P. $\cdot 20 ; 60 ; 68 ; 307$

Volin. M.S. $\cdot 192 ; 332$

Volk. S.S. $\cdot 38$

Volkogonov, D.A. - 28; 241; 244; 250; 332

Volkov, F.D. $\bullet 238 ; 332$

Volkov, I.M. $・ 19 ; 20 ; 97 ; 189 ; 332$

Volobuev, O.V. $\bullet 250 ; 332$

Volobuev, P.V. • 7; 18: 19; 39; 41; 93; 98; 99; $100 ; 169 ; 175 ; 181 ; 183 ; 185 ; 203 ; 214 ; 215$; $229 ; 230 ; 233 ; 240 ; 245 ; 247 ; 259 ; 260 ; 261$; $263 ; 283 ; 285 ; 289 ; 290 ; 292 ; 332 ; 346$

Vorob'ev, Ju. V. • 93; 186

Vorošilov, K.E. $-53 ; 60$

Vorožejkin. I.E. • 189; 332

Vovelle. M. • 272: 344

Vvedenskij. A.A. $\cdot 38$

Vylcan, M.A. • 97: 333

\section{W}

Wach. J. $\cdot 4$

Wada, H. $\bullet 219 ; 222 ; 224 ; 225 ; 233 ; 237 ; 240$; $243 ; 262 ; 263 ; 264 ; 344$

Wagner, F. 158

Wallerstein. I. $\bullet 90$

Walter, K.-P. • 216

Watt, D.C. $\cdot 241$

Weber, M. $\cdot 293$

Weber, W. $\bullet 4$

Wehner, M. • 257; 262;264;291; 344

Weilemann. P.R. $\cdot 344$

Weiss, A. v. $\bullet 139 ; 344$

Werth. A. $\cdot 239$ 
Wheatcroft. S.G. $-2 ; 207 ; 219 ; 223 ; 224 ; 225$; $231 ; 238 ; 344$

Wilke, M. $・ 15 ; 28 ; 46 ; 72 ; 335$

Windelband. W. $\bullet 121 ; 131 ; 293$

Winger, H.W. -50

Winkel. J. $\bullet 252$

Winters. P.J. • 239; 344

Wittich, D. $\bullet 147$

Wittkau. A. $160 ; 344$

Wittram, R. $136 ; 345$

Wittstock, U. $\cdot 215 ; 216$

Wolfe, B.D. • 30; 345

\section{Z}

"elenina, I.A. - 134; 157; 158; 271; 282; 283; 333

Zibarev, P.B. • 78

Zigalov, I.I. 185

Zilin. P.A. - 51; 57; 84; 171; 172; 178; 179; $190 ; 206 ; 333$

7ukov, E.M. - 50; 56; 73; 75; 78; 81; 83; 92; 96; $111 ; 112 ; 122 ; 124 ; 171 ; 172 ; 173 ; 174 ; 179$ :
$182 ; 185 ; 191 ; 192 ; 193 ; 282: 283 ; 287 ; 290$; $297 ; 333 ; 346$

Zuravlev, V.V. $\cdot 229 ; 247$

Zajceva, E.A. 190

Zak, L.M. • 97; 190; 333

Zamčevskij, I. • 41; 42; 45; 307

Zamjatnin, V.N. $\bullet 35 ; 333$

Zaslavsky, V. ・163; 164; 214; 236; 299; 339; 345

Zastenker, N.E. - 157;160;333

Zelenin, I.E. • 97; 186; 189; 240; 241; 309; 333; 347

Zevelev, A.I. $・ 191 ; 244 ; 274 ; 333 ; 334$

Zevin. V.Ja. $\cdot 116$

Ziegler, G. $\bullet 216$

Ziemer, K. $252: 345$

Zinov'ev, A.A. 1116

Zinov'ev, G.E. 238

Zinov'ev, G.V. $・ 19 ; 45 ; 62$

Znamenskij, O.N. $\cdot 100$

Zubkova, E.Ju • 250

Zutis. Ja.Ja. 66 